


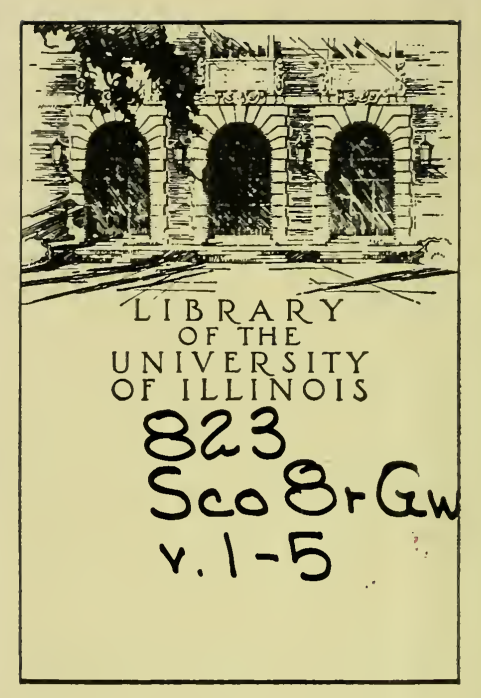


Digitized by the Internet Archive in 2011 with funding from

University of Illinois Urbana-Champaign 




\section{Watter Gétt's}

fámintflidae

S23

$f: \cdots$

e.

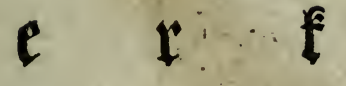

gien viberfegt.

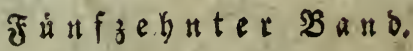

פi $\mathfrak{e} \mathfrak{g} a \mathfrak{u} \mathfrak{n} \mathfrak{t} \mathfrak{l} \in \mathfrak{t}$.

Eine Ergablung aus bem ady tzeften - sabrbundert.

$$
\text { Erfer }
$$

\section{St $\mathfrak{u t} t g a r t$,}

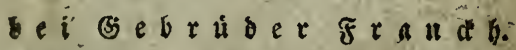

$$
1826 \text {. }
$$



$\mathfrak{A} \mathfrak{d} \mathfrak{d} \mathfrak{a} \mathfrak{u} \mathfrak{n} \mathfrak{t} \mathfrak{l} \mathfrak{e} \mathrm{t}_{+}$

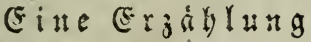

aub Dem adtaebuten Jabrbundert.

\section{Rom}

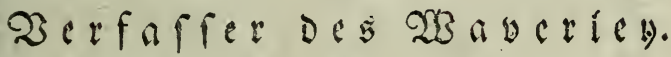

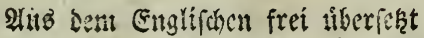
yon

\section{Carl $2 B$ cil.}

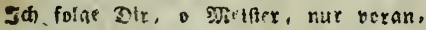
Dir bin th bis zuni zeo getreulith zugetban!

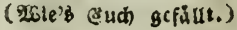

\section{Erftes $\mathfrak{B}$ ánd den.}

\section{St $u t t g a r, t$,}

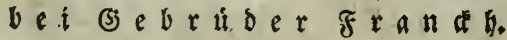

$$
1826 \text {. }
$$





\section{3 \\ Sco 8 rGw \\ v. $1-5$}

aedganntlet.

Exfter $\mathfrak{b} \mathfrak{x} \mathfrak{i}$ ef.

Darfie Latimer an $\mathfrak{A}$ lan Fairforb. Dumfrles...

Cur me exaninas querelis tuis? fu beutfifi, warum betábbit $\mathfrak{D}$ u midh nit Deinen Şmfereien? Şallt bod Hod immer in meinen Dheen ber betril bende $\mathfrak{T o n}$ wieser, mit weldsem $D \mathfrak{u}$ ju ?able = Syoufe

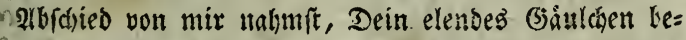
ftiegit, um zurúce zu fehren zur Ș̣laveré ber Suriž prubens. Er foien mir fagen ju unllen: ,D bu

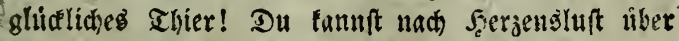
Berg und Thal laufen, fannit leben netten ssegen= franto, Der fid Deiner Rengierbe Darbietet, verfolgen, und bie Sagd aufgeten, went fie bas Jntereffe ver:

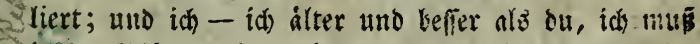
in ber 3 lüthenzeit zurudaffehren in meine entge Etule, Ju neinen ftaubigen Búdhern."

Dab war wobl fo ziemlid der Snkalt ser $R e=$

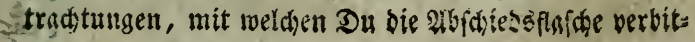
W. Gcott's מottr, XY. 
ferteft, und fo mus if nothmendiger siefife bie mes

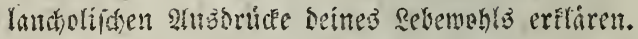

Itber warum mus es detin fo fenn, allan? warunt

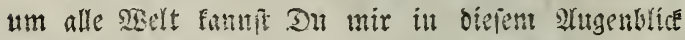
in eben biefer bebagliden *) Şerberge zum ?itter St. Beorg wicht gerabe gegentiber fitzen, sie fine on der Samintlyire, in Gesanten vertieft, indon Du deine jurififichen 2tugenbeannen wie eine Nisnie zufanment=

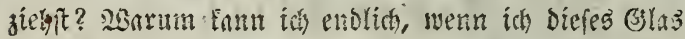

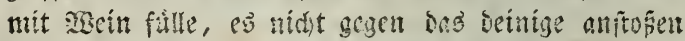
uno fagent: "Fairfors, iós trinfe Dir vor!" Nontum fanth bus silles tur onmm nicht foun, weil stlan Fairforo nich ien wabren greundforaftsfim! begen Darife Satimer best, uno meine Borfe niat mie nitue Enwfirontigen theileat will?

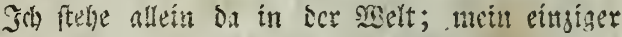

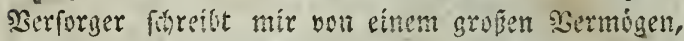
welches nit eingerintigt werben foil, wem $i$ ib bas 25 fte jalie wollig atreidt hale; mein genenuartiges

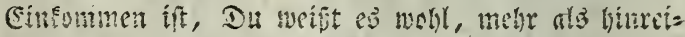

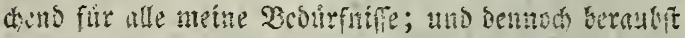

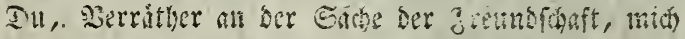

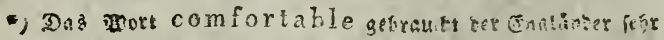

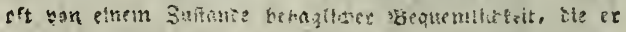

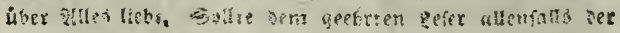

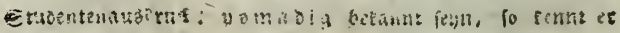
senkil den Einn de? Wartab.

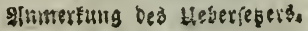




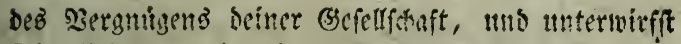
Dich lieter, onnit midh nut meine Meife nicit einige

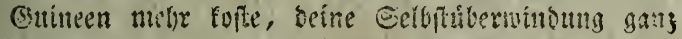
abgeredhet. Eage, gifchent bus nus Edonung fit meilie Burre, ober ift es eil Erifut, Deinm Etolje

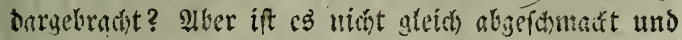
unveruinftíg, es fomme ltut, ntis welder Suelfe es

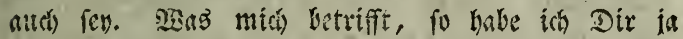

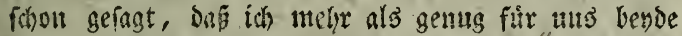

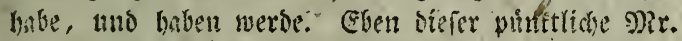

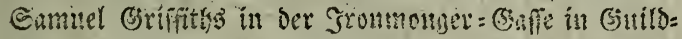
ball zu fombon, befien Sriefe elen fo ficter nie bas Dillartal antommen, hat mit, wie id Dir fagte, alf meinen 21 ften (seburtstag bie boupelte Summe ge=

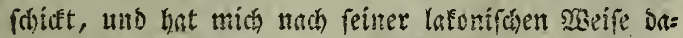
bei verifthert, baß fie bie zuturftigen Gabe now wer sopwelt merocn wurde, wto zwar fo lange, bis ish bie

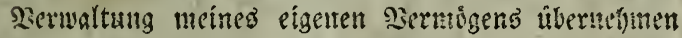
frim. Bis zu meinem zurtidgelegten 25iten sabre foll ih es vermeioen, Englandos boden zu betreten, uno ex empfieblt mir alt, alle sinchforid)ungen, meine Fomilie uno meine Serbaltuiffe betreffend, fur jeţt uoch zu unterlafien.

Erimerte id mith nidft meiner armen shutter in ibrem trantigen şittuengemanoe, nit einer Mie=

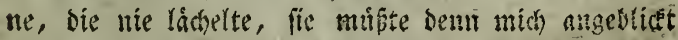
baben - uno felbit samn suifter und tribe, gleids ber Somie, wan fie burch alyritwolfen fojetut; entfernte 
nitht ihr milbes Matronenartiges 2lngefint und ifre Geftalt fold eituen Serdacht, fo witrde id mich fite ben Solnen eines Directoro der insifchen Sompagute, - dee irgeno eines reichen Bürgers balten, ber mekr

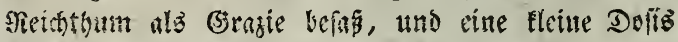
Sithingriligteit obentsin, mb ber iemanden, beffen

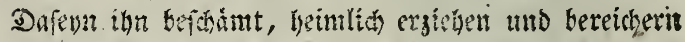
will. Drter wie geragt, id benke an meine Mutter, mo bin even fo feht libergengt, bas aldh nicht ber leffefte ficomte an Schmoe mis piner Sache entites ben finti, morin fie verwiclelt ift, wie ich es nom Das fesn neiner Seele bin. Snverten bin ich wollhabeno, bin allein, wab Enแm mm meinen cinzigen Freund gut

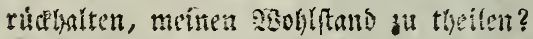

Bift Su benn nidht meit einziger Jreund? Shaft Du Dir benn nidyt ein $\Re$ ed t erworten, meinen 33oblftand fut theilen? Beautworte mir bas, mein

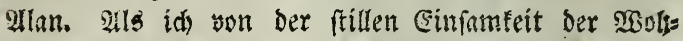
muth meiver Mutter, in den Tumult ber Slaffe auf bie kobe Sisille fam - als id meines englifonen Ifcrentes wegen - als̀ ein englif̧res Edywein mit Soneeballen semorfen - als ein fäbifiner plisoing it ber sintue berum gemaljt waro, wer war. Da ntit Exiftigen (s)rinden wno nuch friftigeren હtofen meit

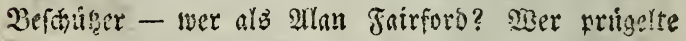
mick) aber auch wacker butih, wenu ib in unfer flei= nen siepubit die 2 tnmafumg eimes einzigen Snhtres, und patergin bie eines verzozenen Brben ourdtescen 
wolle? Wer anders alb 2llan? Ser legrte mid den Bnll zu fọlagen, ben Draden fteigen zu laffen, auf

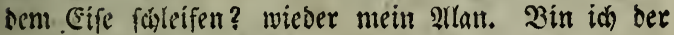
Stely bis Schullofes uns ber Schreden ber Trobler in ben ssangen ber joben Schule gemorien, fo gefönh'

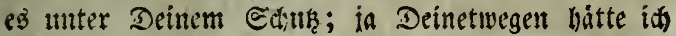
midt felbit besuigt, Durá) bie sisáfle des Sulfthors zu

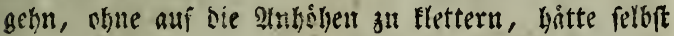
Kittle nine-sleps*) nie nilyer als von Bareforb's Park aus scfegen. Du lekrteft mín, meine zinger fem vou bem @dinachen zu balten, aber meinte fanth segen ben Starfin zu ballen - Yefreteit mich nicht aus ber Eatuk zu fanwsen - ba zu feln, wie ein

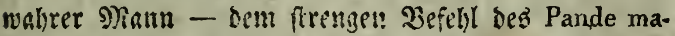

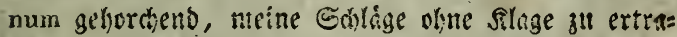
gen, gletd) cimem, ber entroloficn tif, fich bepiogen

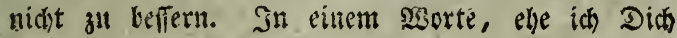
Pannte, Ennute idy nidhto.

Sill Eollege mar es eben fo. Sara íl po tràge, baf fein Selyrer miá beffern fonnte, Dein Bevfpiel, Seine Sufmutterungen fpornten mich) zul geiftigen the vungen all, zeigten mir berr $\mathfrak{B}_{\mathrm{eg}}$ zu geiptigen (Sentil=

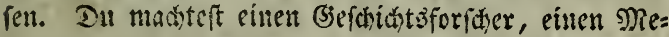
tapkyjifer aus mir (invita Minerva) - ja, beym

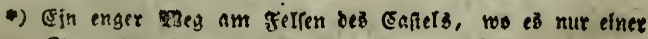
Blege obcr elnem Gatulbuben migrld If , ju gesen, obne

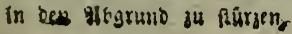


Simmel, Du bàtteft faît eiment srbvofuten auts ntir ge: macht, weil Du eg bijt. Hin mich nur nitst von

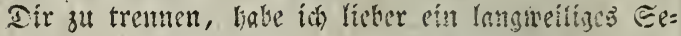

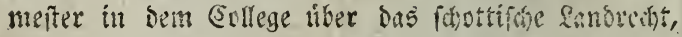
and eit nod) langweiligeres in sent ther bas birger= liche Siedyt gugebradt; und fann meill tod vorbanses nes uno Etudenten, mir nidgt nón jesct bezinzen, mit welchem Piuscu id fie borte?

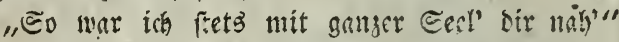

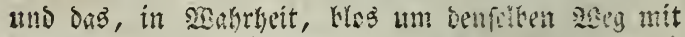

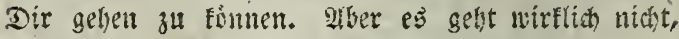

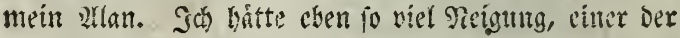

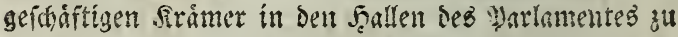
werten, welde ben fleinen Sinatun fireifel, 3âtle, Stỏe und hỏberne Degen veritufen, als ein Mits glied der langrobigen 3rtiberfant in Sunern, welde

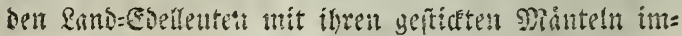

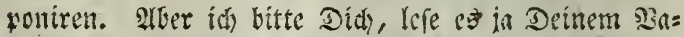
ter nicht vor, 2llan, benn fo viel id meis, mag er mich Sumitng atbends woll leisen; aber in den tibri-

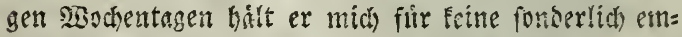

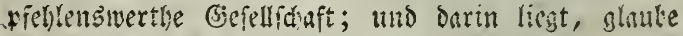

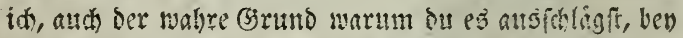
Siefem föftlichen sisfter einen Etreifjug mit mir durdh bie fitblidien (sorafichaften za machen. Ish glaube, der gute Niaun benft ufbel von mir, bas id) fo unrubigen (beiftes bill, Esinburg zu verlaffen, ehe noch die Bjes 


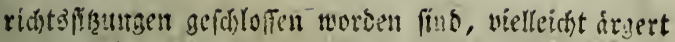

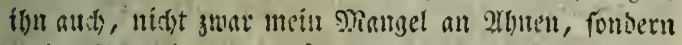
mein slangel an Befinutforiten. Er balt mich fur

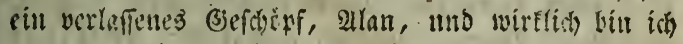

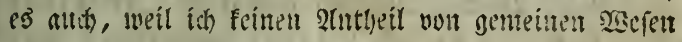
forbern kam, fo foseint ilym sas ein hinlinglicher (5runb зน fenแ, bas Du neinen umgang meioen follteft.

(3laub: nber nicht, bafich vergefle, was ich ibm

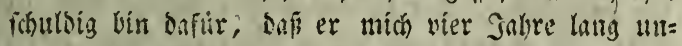
tor feitum Dabie beherbergte; liebt er mich nicht, fo mus meine Damkrarfeit bufix un fo viel griper ges

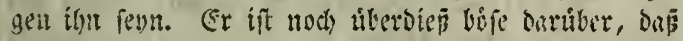
idf fein Surif merbea will ober Eam, mo betrachtet mid) alfo in Bejug allf Did) als eill pessimi exempli, wie er ficí) ausorticen wurbe.

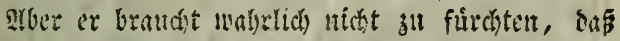

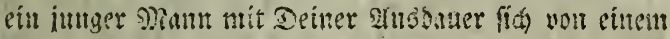

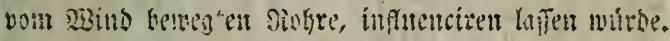
Du wirf Deinen Bang fortgehn, mit Dirleton swei= felt, mit Steward bieje şweifel lojen, bis eltolita you ber Eare ber 2ian more solito mit beberften

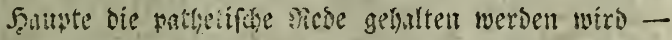

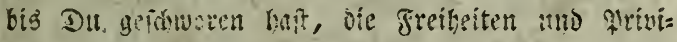

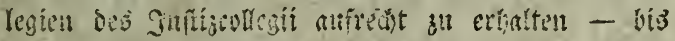
Der fowarje Mintel un Soite Schultern gehimbt

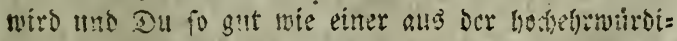

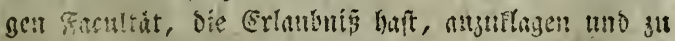
viotheioigut. Dann aber wifl ich vortreten, sllat, 
und zwar mit einem Sarafter, ben felbit Dein Sater nuikzlicher fitr Dids balten wirb, als batte ich ben elanzenten Befdhlup Deiner Nechtşfubien getheilt. In eillem Sorte, fann ich aud fein (oniulent fenn, fo will ich bod ein Elient werben, und zwar

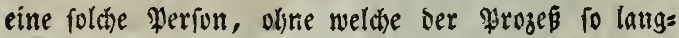
weilig ware wie eine aufgeftellte Nechtosinage. Sa, ich bir entichloffen, Dir bie exfen Sporteln zu lofen zu geben. Mian fant, id bin es uberzeugt, leidht in ei= nen Redhtsfitreit gerathen, nur nuifte man barauf bens fen, inn ein wenig verwickelt an machen. Dann fol len rowon einige Eeffonen meine Biebuld nidst ermu: ben, babe idy nur. Deinen lieben 23 ter sum Sadwal= ter, Did) zu meinem rechtsgelebrten (Sonfulenten, uns ben efrmitroigen $\mathfrak{M r}$. Eanuel (srifith im Nitchlalt. Sinrs und gut, idi merbe mobl foron cingang in bas cseridit befommen, follte es midh aud bie Mithe foften, eill delict noer menigftens ein quasi delict zu begelen. Du fiebrt, das nidat alles an mir verloren ging, was Erskine forritb und Sallace lelyrte.

Eo weit bitte ich nun geichergt, boch, slan, itt

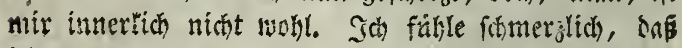

- ich allein ba ftebe, uno biefe sinfamfeit ift mir um fo viel orrickenter, ba fie nur mir allein cigen ift. In einem \&ande, wo jedermann einen Sirfel von Blutb3 verwanbten lat, ber fids bio anf ben fechisten Brab erftredt, bin ich ein einlames gnóvibuam, bab nue

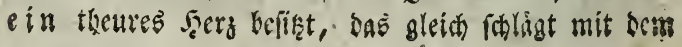




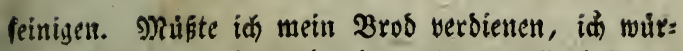
be, glaube id), biefe mir eigne 2 rt yon Entbehrung meniger frihlen. Die nothwendigen Serbittoutgen zni= fden Şerrn und Diener watroen wentigftens einen Sino= ten Emipfen, ber mids den úbrigen menfaliden (se= faledste náber bradbte - boch wie es ieçt ift, facint meine Unabbangigfeit felbit, bie Eigenbeit meiner $\mathfrak{L} a=$ ge ju vergrófern. Jo bin wie ein Frember in ei= nein befuctiten Eafféehaure, ex fómunt, verlangt irgeno cine Erfriftung, zablt feine গiectinung, und wird vergeffen, fobald ber 2 Hfwarter: "I\$ banke Shnen, meit seerr," fagt.

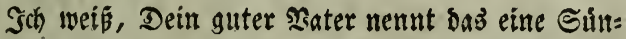
be gegen die Danfbarfeit uno fragt: wie es inir wrbl zu Mathe feyn wirte, wenn ich, ftatt baś id

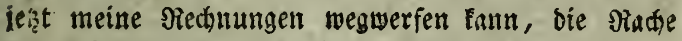

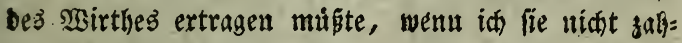

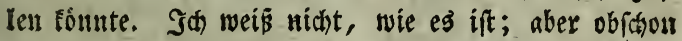
biefe gatz ridhtige Bemerkung meite Gebmefen burdy=

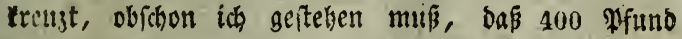

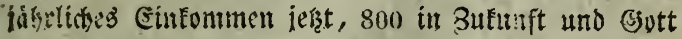
meif, wie viel Şunderte nod finftig eite gans htib:

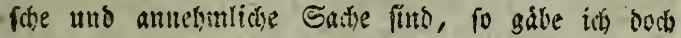
serne die Feilfte Dicjer Summe barum, Deinen Sater $\mathfrak{B}$ ater nenten jul formen, follte er mich altdy frtubo= lich) meiner $\mathfrak{T}$ rågheit wegen zanfen, uno Dith, mein

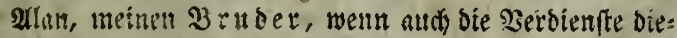

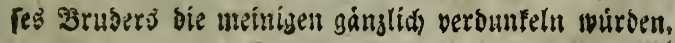


Dit fontut mir oir formatie, unvaridycinlide

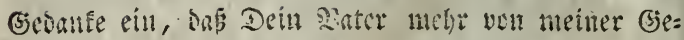

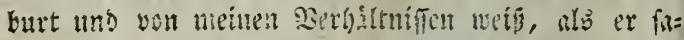

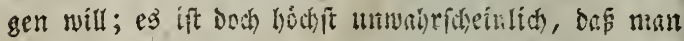
mich in eiment arter von 6 sakren in Ediuburg ge= loffen bithe, ohite andere Emffeb!utis, als bie regel=

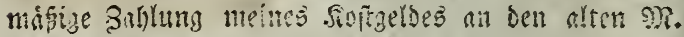
in ber boten Edute. Son bim, mas frutier geforb, erimtere iob mich nur, wie ich Dir fort fagte, ciner

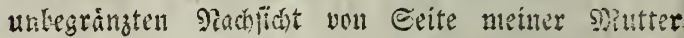

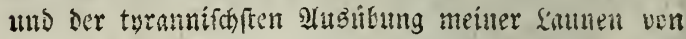
ber meitigen. Ich erinnere midh immer roch, wie bitterlid fie fenfate, wie vergcbens fie nith ju be= fanitigen fucte, wenu ión mit aller Energie bes De: frotismus wie zoln firler um eine Eate farte, oie

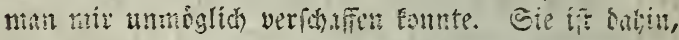

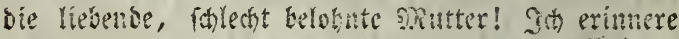
mid) der langen Giefidter - der fintersn Gitbe -

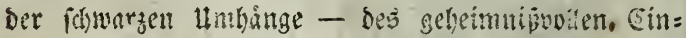

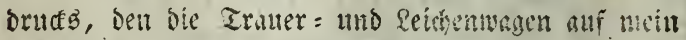

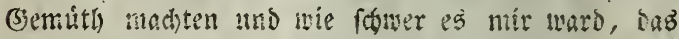

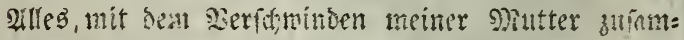

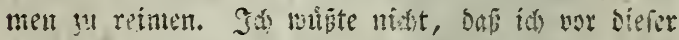

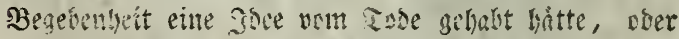
sus ich nur yon sem notimendigen ende aller leten=

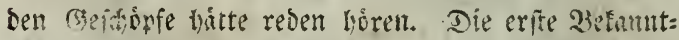
1dort, bie ith mit int matste, Heraubte mid neiner eimjigen. Sarwanoten. 


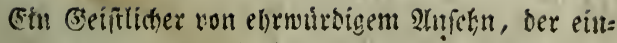

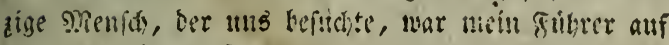

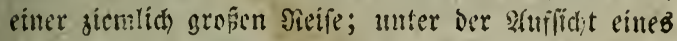
altoren altlichen s)lumes, ber feime Stelle eitunalm, wollentete id meiné Sieife nach Edyottlano, ord neis ich weber wie, noch wie fo - und bas ift alles, befien idt mitch erinncre.

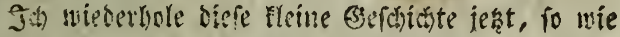
ids es fruiker foron bunbert Mial that, nur unt eimen Sufanmenbang sorin zu finten. SBende alfo Deinen

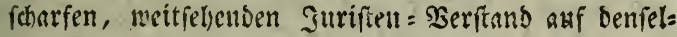
len Gegenirand - Vearkeite meine Befchidate, als protocollirteft Du bas télpelicht ausgebruabte Bengnis eines blau = benuigaten, bartfonfigen Elienten in ciner s'useinanderfesung ber Facta und umftunde, Dann frl!ft Du, nidt mein 2Ypollo - quid tibi cum lyra? - Fondern nisin sord Etair fern. Unterdeffen hake (c) mich alls meiner viblen Saune. herans geidrichen Ilos. Bnourd, Das idy Sartiver kritete, und mun will ich mich eine balbe Crambe mit bem gioan Nobin in Etalle unterbinten. Der Bureche fennt mich foron

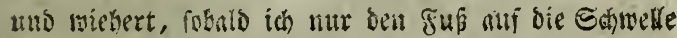
Troz Etrilles fethe.

Der Sappe, ten Du geîtern morecn rittft, vers furicht ein vortreffictier Siemmer ju werben, iekzt trabt er eben fo leicht mit San und dent felleifen, wie

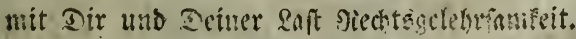
sisill fich ill meinen Besanfent alles ntm die arre Des grop̈en Gégeintuiffes meiner (seburt oreht; fo will 


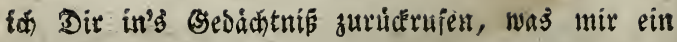
Mal Dein Bater fagte, als er mich mit Sam in vertrautem Seiprách 1iferrafote. "Es ziemt Jises פaters Soljn nicht, fo vertraut mit Sam's

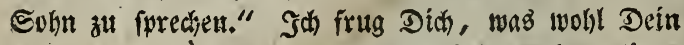

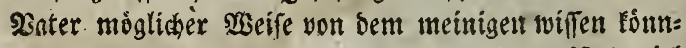
te; uno Du antworteteit: "Io denfe, er weís fo viel yan Deinem S3ater, alsె ex von Sam's నiater weís, es ift to ein fprichwortlicher 2 (uboruck." Das gentig= te mir nicht, ob id gleid nicht weis, warum. QIber ish Eomme auf einen fruchtlofen und erichosften (S)= senftand zurtid. Furtbte nidjt, baj id wieber auf diejes oft betretene und boch balunlofe geld von నer=

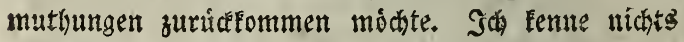
unk̨lojeres, faderes uno verabtlidjeres, als bas Dhr bes Freundes mit níthigen Silagen zu erfüllen.

Эa) will Dir gern verfwrechett, baf meine Briefe eben fo unterbaltend, als ragelmápíg uno von gebori= ser Linge fesn folletr. Wir babin efnen bedententen Dortheil voritus, vor jeglichem Paare. Der Freunde it Deil Tngen ber sorzeit. SBeder Davís und Jona= thich, weder Dreptes und Pithoes, noch Danton und \$ntbiaz - obzinar befonders ben leketeren ein Brief

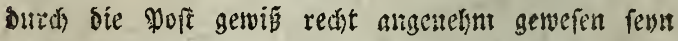

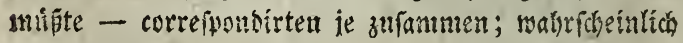
Fonmten fie nidht (a)reiben*), uns gewis batten fie

*) El, el git Darie satimer, foll wobl bex grofe Dralmens Dtciter nidht idretben getonnt baben? Sarteb ex 3.98 . midt ben Brief De्ड सriab?

भूnmerk bes Heberiegers, 
meder Poft now freichein, fich gegenfeitig igre fere zensergiefungen mitzutheilen. Dabing:gen Du, wenn

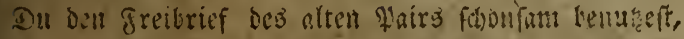

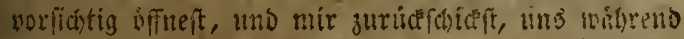

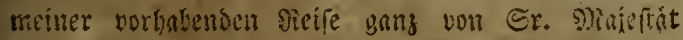

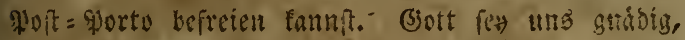
Alan, was fư 3ricfe berde hó Dir nicht mit $2 e=$ risten won alfen-sen. Dingen forden miffen, sie id auf mcinem wilben Streifung ofumbln Emut, fie

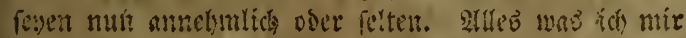

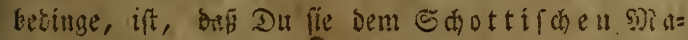

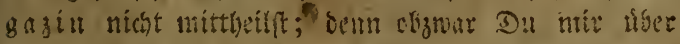

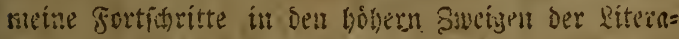
tur, Eomplintente machit, babei aber verblumt ju

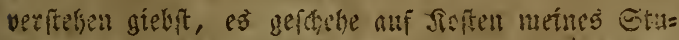

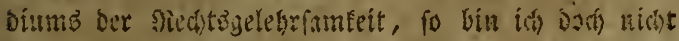

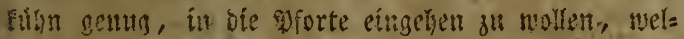

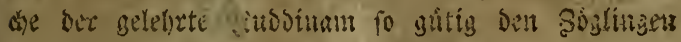
ber glituin iffitet. Vale, sis memor mei.

\section{D. $\stackrel{R}{ }$}

P. S.

Yorefire Deine Briefe an Sns Yoftant fier. Sd) werte es fo atoromen, oaf man mir fie nath= Sificheil wits. 


\section{3 to eiter zitef.}

Man Faitoro an saríte Satimer.

Negatur, mein theurer Darfie - Du haft ia $\mathcal{S}_{0}=$

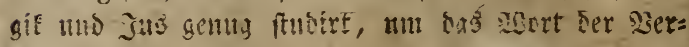

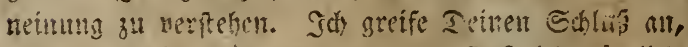

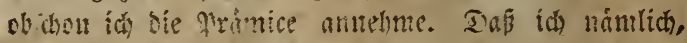

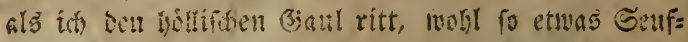

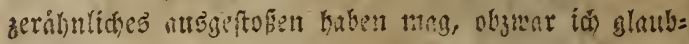
te, es mifipte fich unter bem Sifhuben und Schnat= dout bes nindbridtigen Tieles werloren halven, bas may fevn. Hebrigens mag woll bas Thier eimig it

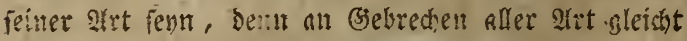
ihm vidlestat nut ses armen shannes Sarrengaul Der Da farb, Gerriefen in Seianze:

\section{"Einte Nielle weit von Ditndee."}

atber glaube mix, Darfie, oer Eenfser, welcher nit entidylinfte, galt melir Dir als mir, und betrif weder

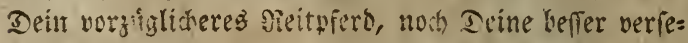

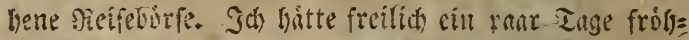
lich mit Dir in ?ante hermmitreiden finten; uno

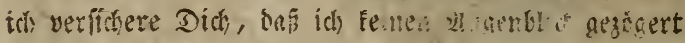
batte, Deinen volylweriehenen bieldhatel fur miere

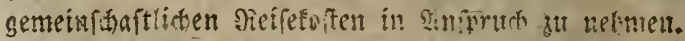

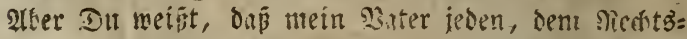

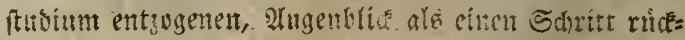

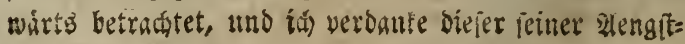


lidfeit gar viel, obswar fie mundbed Mal laftig ift. 3ิum 2icipiel:

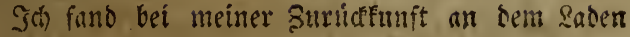

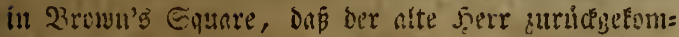
men fen, benturubt, cime Siadt auberbalb bes Eatu= kes feiner bỉuslichen Saren zuzubringetr. Da iá) von

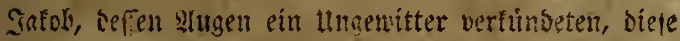
Siachridyt erbielt, foriçte id irgleich einen hodrlanbi=

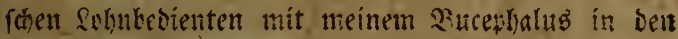
Ctall, falich mich fo geranthlos als moglich in mine fleine selle, uno fieng an, uber eine butb kegrifiene

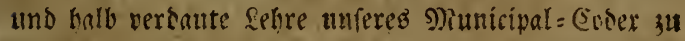
brummet. Id faf nod) nidt lange, als bas Bieficht meines sinters faft laufchens ourds bie halsoffene Thire

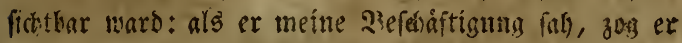
es mit einem halb =artifulirten "lim," meldoes einen

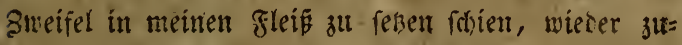

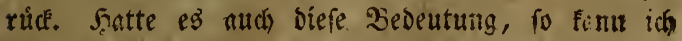
ibm bods nicht lturecht geben; Denn bie Situceriune= rung an Dich latte eine Etutide lang neine Eeele fo saur ergriffen, baf, obzwar Ctairs *) Sierfe yor mir lagen, uns ich zwei ober orei Blatter ummande, ber Einit nir boch ganglich entfalipfte, wenn foron feille ferrlichfeit einen flaren uno beuttidien Styl fatreibt;

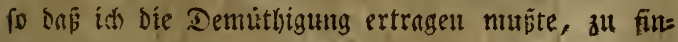
ben, saif meine 2 rbeit völlig nukles war.

-) Elair, cln berúbmeer fabotifacer jurtit.

2tnmert. จ. Uteberieb. 
- Thi wat nit meinen Saviren, um ben recten

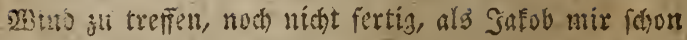
ins frugale alsendeten anfindigte. Da fanden Pia buxdyen, safe uno eine glaide alter alle's, ferner nur

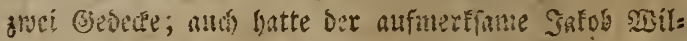
finfon feinen Etubl fúr 9). Darife búngeftert. Be= fanter satob, mit feinem longen (Beffitite, feiren ber= unterghingenoen Samen, feinen lamgen mit Reser un= wubente 3omfe, ftant, wie gewohalich, binter mei= nes Sinters Stuthl, fergengrade wie eine boljerne Euilbwadge vor cinem sjourionsten = Theater. "Du

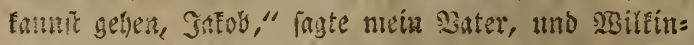

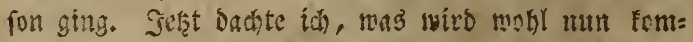
men, semod bat fich bas brohende Hugerwitter nidht an jourizont ber vaterlidien Ctirn verzegen.

Caine mipvergmigten 3 lidé trafen zuerft meine etiefelu uns or fritg mids, mit fpottifisem scideln, watir ich benu geriten mare. Er erwartete, Das ich "nirgends" antworten wirde, und bann bitte or fich

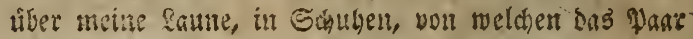

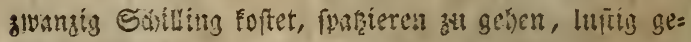

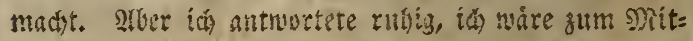
tigeffen bis nach Poble = 5̧onle geritten. Er frarte midi an (Dit Eamnit ia feime $2(r t)$, als bitte id ge=

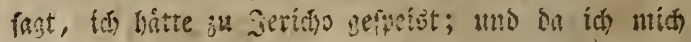
ftelts, als rumerfte id litu Eritnunent nicit, font

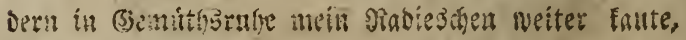

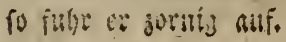




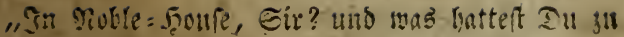
Soble = Sicufe зu thum, Eir? Denffi Du nicht darsil,

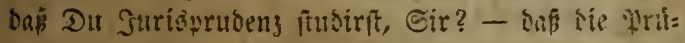
fung im edjottichen santrecht lieramtaht, eir? Do

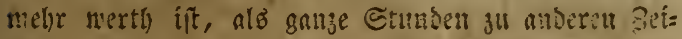

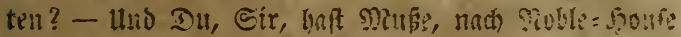
su getsen, und Deine suther fo tange zu wrtlaticu?

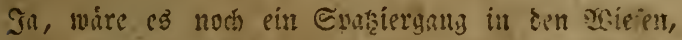

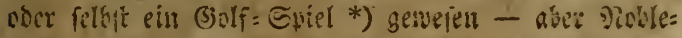
Şoufe, mas tentif Du, Eir?"

"Eir, iø) beyleitete dent Darfic Rutimer ein Etria

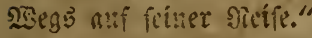

"Sorfie Satimer," erwieserte or in selinesecm

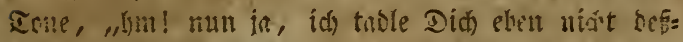

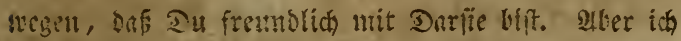

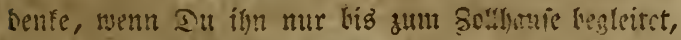

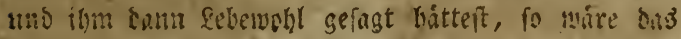

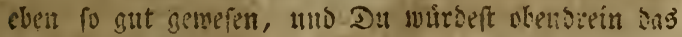

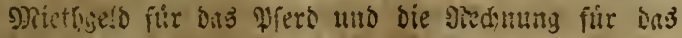
Mittagefien gefunt baben!"

"Das bizalyte Ratianer, Cir," antwortete id', benu id glrulte bie Eacte samit zu serbetern, aber id) bátte Eeffer fitill gefdewiesent.

"Sie niedutung, Sir! utno Du inerit fo riteoris,

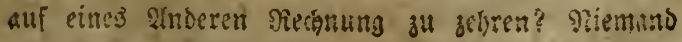

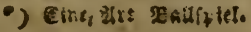

Enmak?. H. LatiticB. 
foute eit Baftratts betreten, ohne reine Schuldigfeit sabten su fonnen."

"Dns nelme id im arlyemeituen an, Bater, er=

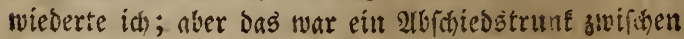
Darfíe uno mir, uno fo, meine idh, gelort es zu ben Slusitabmen Des Dochan dorroch."

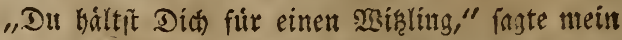
Sater unb láchelte babei grabe fo viel, als es ber Eruit feiner stige erlanbte; ,aler ich benfe, Du abeft Doá) Dein Mittngeffen uidit ftersento, wie bie Juben bas Dftertamm? Denn es exiftirt fin Beldyeid bom

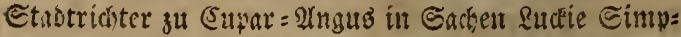
fou contra Ruckie Samiefou, safi, als bes Eriteren

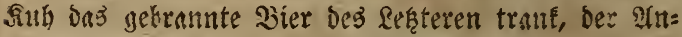

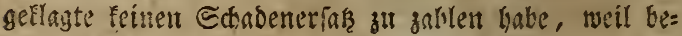
fagte fully es austrouf, okne lich babei nieserzuiekett. sitir cin fotser Umfind fant alfo eitten Dochan dorroch confituituren, D. i. ein ftebenbes Irinten, wofit

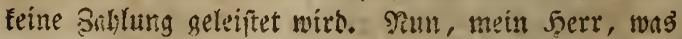

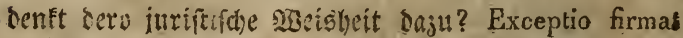

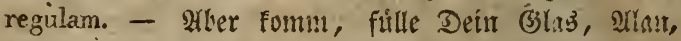

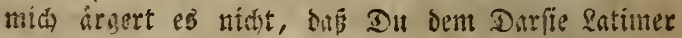

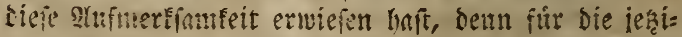
ge seit ift er boch ein guter Burche; und ba er la, feitseut er bie Echule verlié, unter meittem Dadse

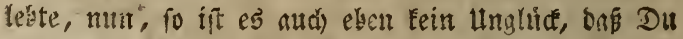
siue Eleitue 2iervindlicheit gegen ibn bait"

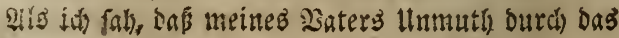


Besurtitfenn feiner Ueberlegentheit in iurifiticher 2 ele: fentheit fich gelegt batte, fo nakm id gerne peine sist sethumg melyr als éme Eache ber Bunde, als bor (bes rechtigfert anf, und antwoitete nur, wir wirben ut= fere libeibe gur viel langmeiliger jubringen muten,

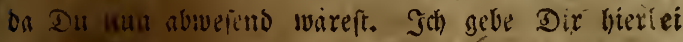

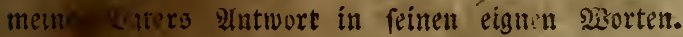

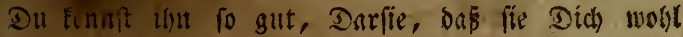
nicbt leleidigen wiro, auds weist Du, Das man bei bes guten Manmes (sennuigfeit und formlichtit,

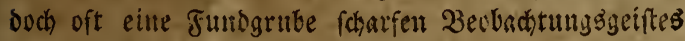
uno praftifden Deritandes entoectit.

"Es ift wahr" fagte er, "Darfie mar eill ange= nelmer Gejellichafter, aber zu nutbuillig, alan, fo ein Springinbfelo und leiditinnig bazu. - Pebentei

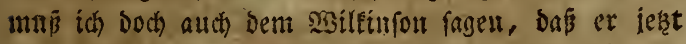

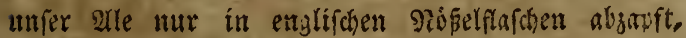
Dem eine Quart = Douteifle iebe Siadit ift bod fir nus beide, ohne feine feulfe zu vid. - Alber ber Darlie, wie id rage, Das ift ein burchtriebener Bsefell, ein we= nig leicht ba im obern Stodwerk - ich muinidge, eb modyte ím in oer walt woblergeh!t, aber allan, er. befigt weitig Solibitit, malyrlid, felbr wenig."

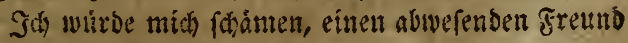

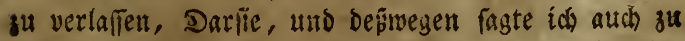
Deiner sertheibigung etwas melje, als es meill (Se= wiffen ftreng genonmen exlaubt batte; aber baf Du Der sied)togelebrambeit entlaufe!t bift, bas bat Bir

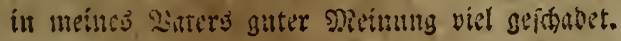




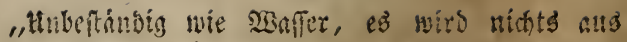
ifm," fagte mein 3 nater, soer wie bie Ecriuninta fagt: "Effusa est sicut aqua - non crescat." Ex githt in bie ミanthanfer und liest siovellet - sat est!

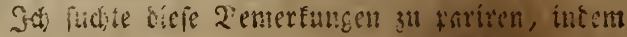

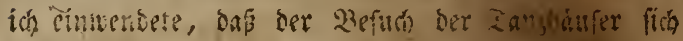
anf pir:e NaGit, anf la Pique's zall mo das Refen

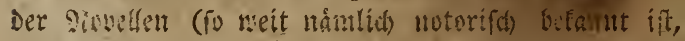
Darife) auf eiten eitizigen Bano bis Ton Jonez beforinte.

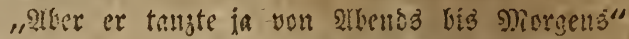

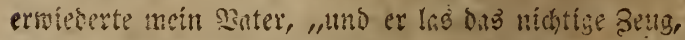
wofir ber serfafer geweitiet zu werben veritente, wohl jumitis Mal ourch. Es fan nic ous feinen Şinten."

Dam filgrte id) an, baf wabrfieinlich Deine Sermigenstumftád fo glomsent waren, oaf fie Did

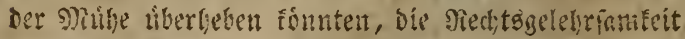
meiter zu finbiren, als Dit es bis jeşt ichou gethan

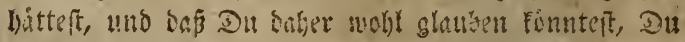

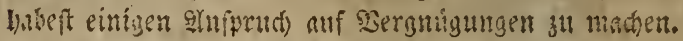

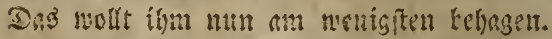

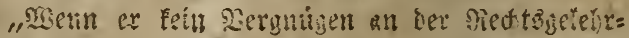
fomfeit. findet," fagte mein sitter auffabremo, "sefto

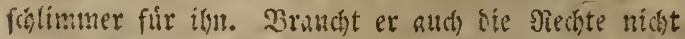

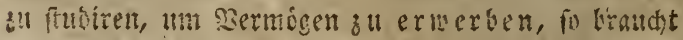

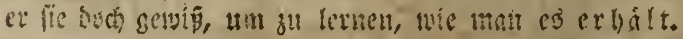
gicl befier wirbe ign diefes Etubium ziemen, alb, 


\section{5}

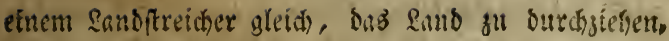

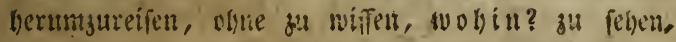

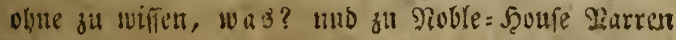
fémes sleidsen (Dabei warf er mir einen zurnigen

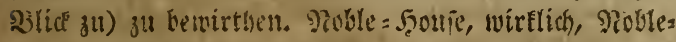
frourfe! witdergolte er nit erjobeter Etinun:e und frottifom Ione, als ob in bem sameri fetbit ctrag

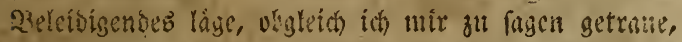

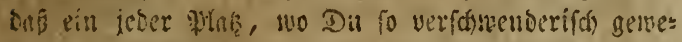

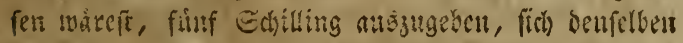
Enoel zugesogen hátie.

\$on beinem Gebanten eingenommen, bas mein

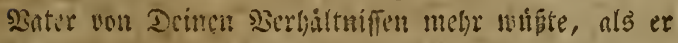

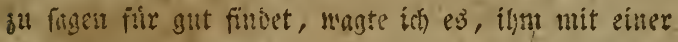
Dentefung alf sen sulyn zut fitilen. "Sch fefte nidat

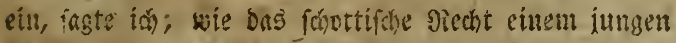

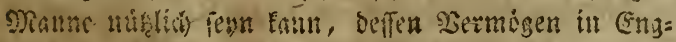
land flacirt zu ienn foteint!" - Id glatbte wirlich mein \$ater wolle mich fallagen.

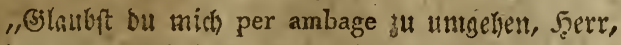

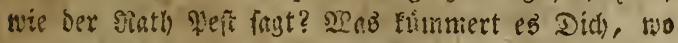
Darlie Satimers sermigen y racirt iff, of er weldses bat, nber rein's? Itnb was wirbe ilym bem bns fajot=

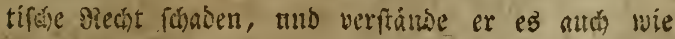
Etair ober Zantion? Sind niót dic Supitutionen

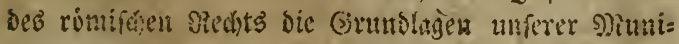
cipal = Beferse, uno wurben biefe Suftentionen nichet zu eitrer seit segebert, wo bas rimifale Sieid wegen 
feitter Bilbung und Belebrfamfeit berifbmt mar? (5ieht ill Euer Bett feerr, nad ber fojonen Expedition nach

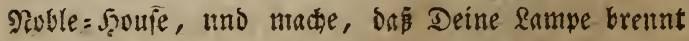
uno Dein Buds unr Dir liegt, ebe bie Conne anfgeht. Ars longa, vila brevis - wåre es nidht eine Cunde, bie gottliche wiffenfaft ber গiedtoggelelyrfamfeit nit Dem geringeren Samten: Siunit zu betiteln."

Eo brannte beun atch meitue sampe, theurer Darfie, ben náditen Miorgen, went foun ber Eigen= thimer bie (sefabr einer bauslichen Tachftudung mag= te, und beimliab im Bette liegen blieb, in ber Seoff= nutig, das̃ Der Echein, ohne weitere Interfuchung, als ein hinlanglidher ßemeis meiner Halten werden warse. Seķt, ben iritten Norgen nad) Deiner abretie, fteht bie Sabje nod immer nidjt befler; Deun obzwar soet tiber bie Panbecten, feime Saeisteit vor mir ausbreitet, fo gebrauche ich inn bod nur als ein Unterlegeblatt, worauf id̆ bieje Blatter, mit Ilorkeiten angefúllt, an Darfie Latimer idseibe;

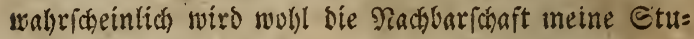
dien wenig fórbern.

llno nun, dintest es mir, bore id Did, wie Du,

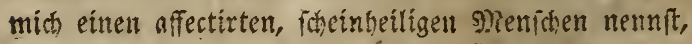
Der unter einem foldhen 3wangs = แn Einfdrantungs: Eyjrem lebend, nie mein 2ater fur gut finbet, es?

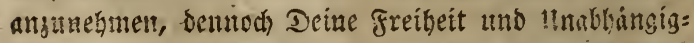

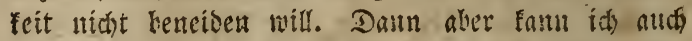
wicter fil meintem Jeerzen de Deweggrunde diefer 
Strenge nidit tabelu. Demn wo audi ibre suttle rev, fo fónnen fie mur in ciner ángftlidben, liebevollen uns unaufhorlidgen Peigung maines Soters entitelyen, in feinem Eifer fitr meine Bervolffommmut uns it einem lobensiwertben (Sefuil der Elyce des Stanbes, ou soldsem er midh beftimmte.

Da wir feine naben Serwandte baben, fo ift ber Inoten, weldier uns fnipft, wout ungewobnlicher feftig= feit, wenn er fdion an und fir fich einer ber fiarf: ften ift, welden bie Satur bilden Eann. Ja) bin und

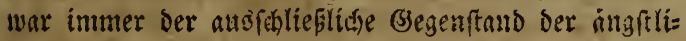
Gen froffnung, noch melir aier ber angitlichen furcht nteines Saters. WSelches Siadt babe ich alro, mid zu betlagen, wenn autif bie uno sa furcht uno şoff= nung ign bazu bemegen, laftig unb unaufíorlid alfe meine Ediritte zu beobidyten? Dabei fotte id Denfen, uno, Darfie, id thue es auds, baf nein sater mír foron bei verfáiebenen widstigen (3) ilegentheiten seigte,

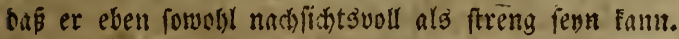

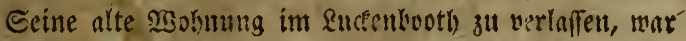
itm-mie eine Sdhetsung ber Seele vom fiorper; bod

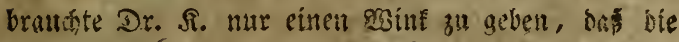
reinere Suft bes netten Stabtviertel. zutwiglicher fir meine Geinogrit wive, weil it) bamals an ben Pei=

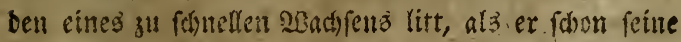
alte geliebte sisolinung, weldse gaits nabe ain fierzen von glit = ?othitu lag, gegen eires jener remen (Be=

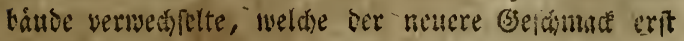




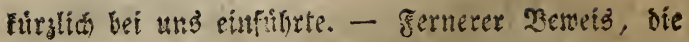

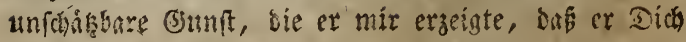

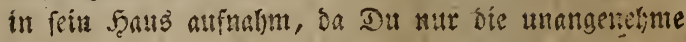
Mabl batteft, als eia erwadbenter Sungliug in ber (Sefelliciaft Fleiner Fitaben zu bleiben. Sas war onch

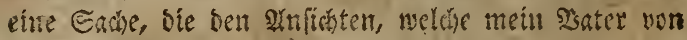

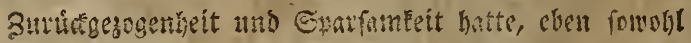
(c)murgerade entgegen lief, alz ben Mittelu, wolthe er. ơt Bepordertug meiner Soralitat uno meines

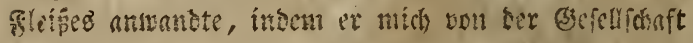
ancerer jumber fente entfernen wollte; fo bas ich, nuf

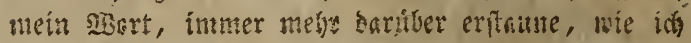

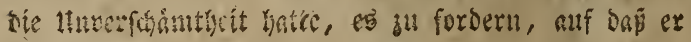
es gewirlyte.

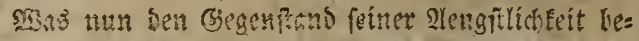

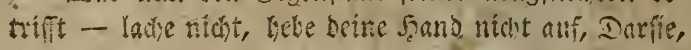

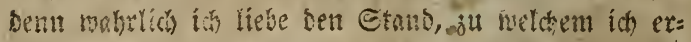
sogen merde, uno ernftich veriolge iá) meine norberei= tcuben Erubien. Die Siecté lind mein Bernf - in efter befontoren, in, idi modte fagen in einer erblioben

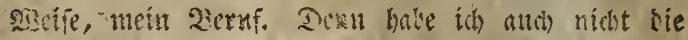
Eqre, zu cimer jerer gropien fomilien zu get)oren, weldhe in Edistthons, wite in sronfrcidy la noblesse de la robe

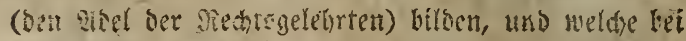

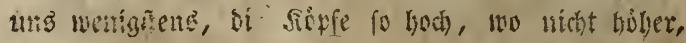
als or Eshuerotaid tragen - ba diefe maftens

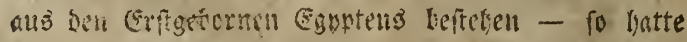

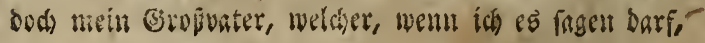


eill febr vorgliglidfer Miann war, bie (Egre, in bem eh:

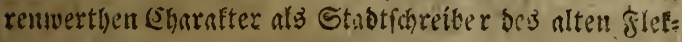
fens 23irlthegroat, eine bittere Proteftation gegin bie

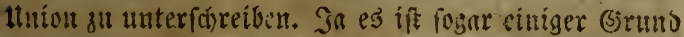
borlyanden, - foll idt frigen ju boffer, ober zu ver: nutben? - bafs er ber natuilitie Colnn eines naben Netters bes Fairforo war, weldyer Ju ben gertugern Baronen gerechnet ward. Siein 2ater nun ftieg auf ber Seiter bor Suriosrndenz eine Stufe biber binulf, Da er, wie Da fo glat wie ich sweist, erifer und ehren= werther Schreibe: Sr. Maleftits Suliegel murb, uno ich mieberum bin bazu beptimmt no(h) eille Stufe bo: her zu flinmen, die veregrte sirbe *) su tragen, von

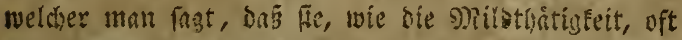

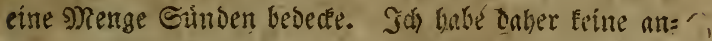
bere saly, als entweser entyor zul flimmen, ba wir

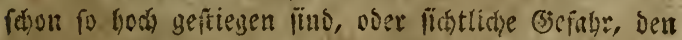
Feals za bredien, wenn ids herabfalle. So babe if mich benn mit meinem @dicepale susgefohnt, unb waik)=

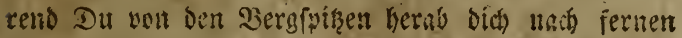
Geen mo meerbufen mathinit, trifte iós mich de apicibus juris mit ber 2rusfidt anf carmoinin rotbe

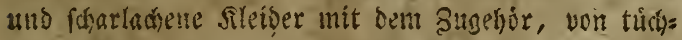
tiben Setiten mit Eparteln woil gefillt.

Du laryft Darie, more tuo und fiseinft fager zu

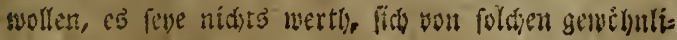


den Träumen énwiegen zu lafien. Die Deingen hit gegen von bober uns beldenmithiger Strt gleichen ben Jieinigen efen fo fehr, wie eine mit purpurnem ruche berd)!agene und mit aften befduerte Band, einem go= thischen, mit inoirchen Werlen uno mit Bold gefdumid"= tem Tirone. 2lber was willit su lialen? - sua quamque trahit voluptas - ano meine Siffonen non Befordes r!mg, obzwar fie nod vorerit alf nidits berulen, fins boch eljer zu erreicien moglich, als Dein Streben nach Gott weî́ - waš. Demn wie fast nieines হaterş Eprifwort? "Etrebe nad) eitrem goldenen Sleibe fo wirft Dn menigîtens cfme હaleife beron ertharchen!" Das if nun metn ârect, aber monath ftrebit Du? Das Dunfel, ivelches auf sem setheimniffe Deiter (Se= burt nno Deiner Sierwandthaft liegt, wie Du Dida

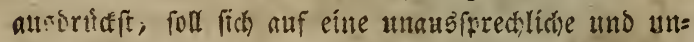

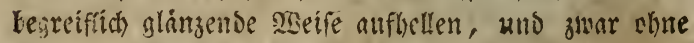
9)itite und Inttengung won Deiner Seite, Tesiglid

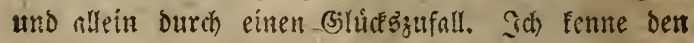

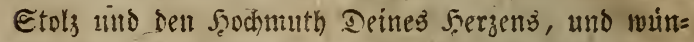
fare berzlith, bas Du mir nody alloere Sdulage zu banfell hattent, als bie, welche Su fo banfuar aner= Enmit. Denu hatte ich Dir bife Don Duirotifchen Erwartungen anjizeprigelt, fo glaubteft Du jeşt nicht ber seld irgento einer romantiphen Gerdichte zu fenn, uno vermandelteit Ban elyrlichen 3itirger mo Miafler, ber in fémen vierteliádrigen Epifteln nur bus. ftreng शethige fdreist, nidst in irgens einen weifen glean= 
Der noer gelehrten 2rlguife; ber mtyftifa und magif bein Edritefal lenft. Mlber id) weíp nicht mie es zat

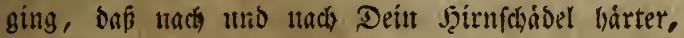
uno meine gáufte fanfter wurben, wenu $D \mathfrak{d}$ aud mit ber seit nidit ein sewiffermapen gefäbrlidses feu= er gezeigt batteft, melches ich, wenn auch nid)t fưrcb= ten, boch achten muste.

Da idh bod ecimmal bavon fwreche, fo ift es wohl nicht ungelegen, Dich zu ermahnen, biefe Deine úber: mitbige Siftulheit eill menig an mifigen. Sd furdhte

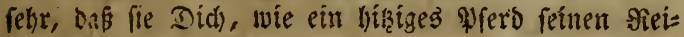
ter, in irgetto sinte gefályrlitie Inge bringe, aus wel= der es Dir fhwer werden wiro, Dids bera!ts zu reif: fen, befonders menn ber flibue Beifit, welcher Dich bineinbradjte, in bem gefihrlichen Miomente verichnoin: be. Bebenfe, Dorife, sap Du vou Siatur nicht utu= this bift, Du geftandeft mix in (s)egentlyeil fchon ein, bas fo rulig ich bin, ber sortheil in bicfent wichti= gen Dunfte auf meiner Seite fei. Sch glaube, ntein 9Ruth beiteht in meiner Pierwenitaife uno in meiner natirlichen (3)leidgailtigkeit gegen (S)cfabr; witcise, renn fie midy aldi) n.e zut qubenthenern treibt, mith

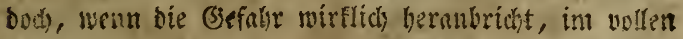

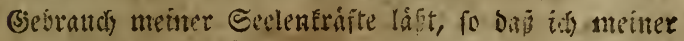
vilif michtig bin. Der Einige aber fojeint melye

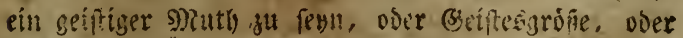
Etrelien nach ben 2 tuperordenthitgen; fie treiten Dich máditig jum Elurgitz al, madsu Did taub gegea 


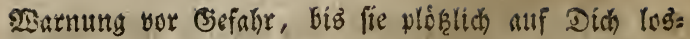

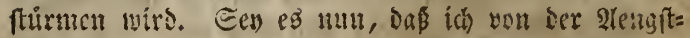
lick)feit meines saters angefteçt bin, ober sap eigene

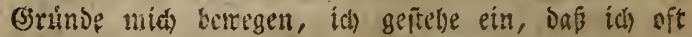
furchte, biefes wilbe Sagen und romantifden socrbát = niffen uno sibentheuern fonnte Didh in's thaltice ftur zen; uno wus wúroe bann aus Allai fairforo wer= Den? Dann mogen fie zun General = 2lovocaten nder zum Bieneral = \$rocurator nelymen, wen fie wollen, ich

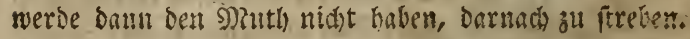
arfe meine Infrengungen gelsen barant bin, midh cinft in Deinen alugea zu reditfertigen, แmo gemís wurbe idh mich nicht einen Pfenning nelle um das gefticete

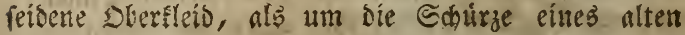

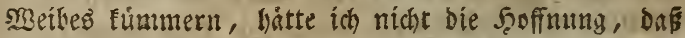
Du einit vor ben Echranfen fehen birft, um mia z" Conuntern, vielleidst gar un midh zu beneiden.

Domit siefis einf feun fonne, fo bitte ich Didh

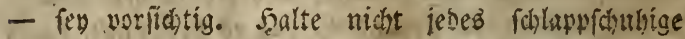

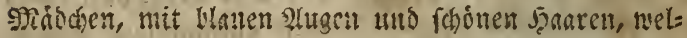
des in eitiem zerriffenen \$lats, mit eituer Siseibengerte beseafinet, bie silbe nuf bie siseide treibt, lalte fie

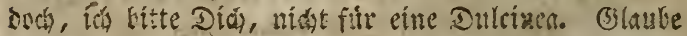

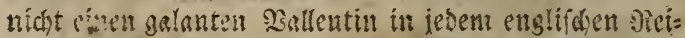

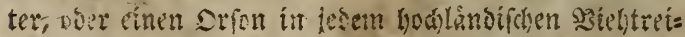

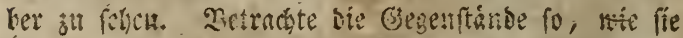
fins, uns sidst wie Drine frubthare Whantaple fie mas:

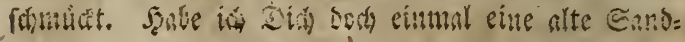


grube fo lauge betradten fehen, bis daf Du Sorgebirge,

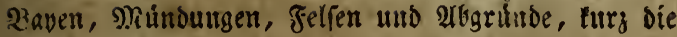
ganze bewutuberungsivurbige Lanbínaft ber Infel Ferro barin entbecteft, two profane 21ugen eine gewobutiche

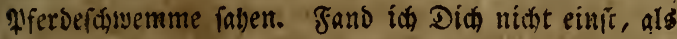
Du eine Eidedife mit eben fo groper 2 lattung anitaun= teft, wie iemano, ber ein Erocobil erblicat? Das wa=

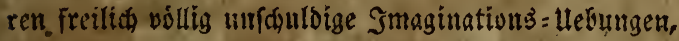
benu Du fonteit in ber Pfúke eben fo wenig ertritten,

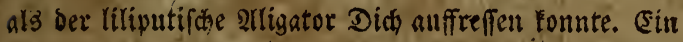
Atuberes aber, Darlie, ift es in ber menidsliden (s)e: fellichaft, wo Du Den (Sbarafter berer, mit welden Du umgelst; meder berfennen nod Deiner Einbil= sungstraft erlauben ourfit, ibre guten-ober bifen (Ei= genichaften zu tibertreiben, wenn Du Dich nicht lá =. çerlid) madien uno Did) nicts in ernite uno gefäbr= lidje Scándel verwidétn willt. Bemadie alio Deine Einbildungsfiaft, befter Darfie, uno glaube ber $\$$ fitherumg eines alten freunbes, baß es ber ounft in Deinen Charafter ift, ber feinen gutmutbigen uns

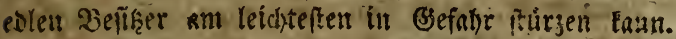
Recbe nonl, taffe bas Franco Des edlen Pairs nicht

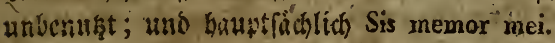

\section{5 .}




\section{D. it te: $\mathfrak{B}$ rief.}

Darfie Satimer an 2 tan Fairforo. Ehephero' Duid.

Tab labe Deine abgeiantiacte und boint anmaf

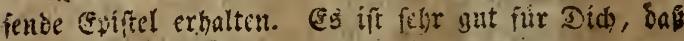
wir wie Soorlace uno belforb thercinatementen fins,

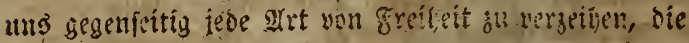

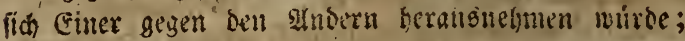

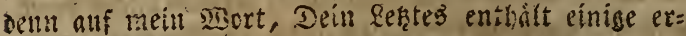
baulice 2 etrathtungen, welde midh fonft gestumgen.

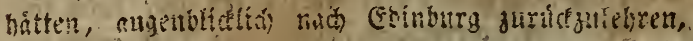

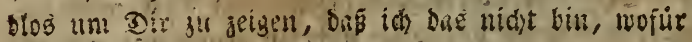
Bu mith bitst.

Dil hait uno beide fonberbar vorgeftellt! - Nith; indem in mich in Eifwierigfeiten verwidele, olns

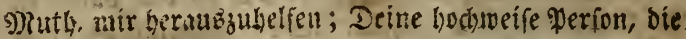
ed fausn wayk, cinen fur vor ben andern zu fellen,

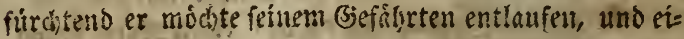

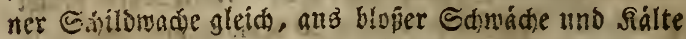
bes Syergens fitle ftehero, wábreno alle selt in voller Eile bi Dir vorbei eilt. Du bift mil ein lieber flor: traitmaler! Jah fage Dir, Illat, ich fali eimfit einen seffern nuf der vierten Sproffe einer Reiter fizzend, wel=

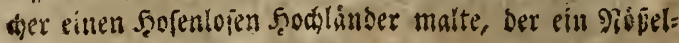


mane, fo bid wie cr lelbit, in ber sand trug; แแa einen geftiefelten sitcterlainber *) mit einer Etubpe=

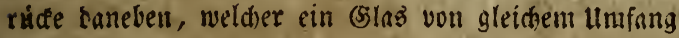

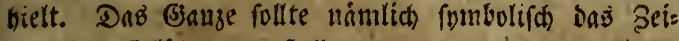
den ber Erlofing vorftellen.

SGie founteft Du nur aud, id bitte Dich, Deine eigene hodwerthe Perion, mit nllen Dethen 2 enezun: gen, welche benet eiter grofen bollintsiften Glicter: puspe gleidien, barftellen, welde Whó von ben Drua gewiffer Fevern, als 8. 23. Wfítht, Heberleglmis :c. ab: bangt. Michteit Du mid) wrbl glau!en matien, Du wưrbeft obue beren Intuls nicht weichen? 2lber babe ids-Díd, Eignor (Stavitàt, nicht (d)on um \$nitternacht auber bem kette gesplen? foll ich Bidh benn gerabezu an gewifie ziention tolle Etreiche er: innern? Da hatteft immar mit den ernfteften Senten:Jen in פitube uno ber frengften survickaltung in Dei= nen Ninieren cinen gewiffen soang zu bosbaften Etrei: dell, obzwar mit melyr sieigung fie in's giserf zil feken,

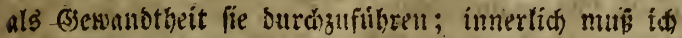

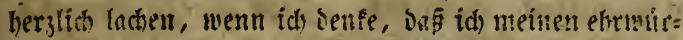
bigen Nentor, Praesident in spe, irgend eires bolien fabotticten (S)eriditshofs gefehen bake, wie cinen whut:

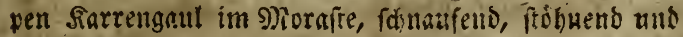

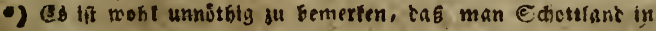

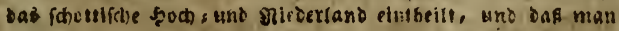
fír bas sebtere auch roobl furs weg die Nicheriande fagt. :

sumert. bes uebirf. 


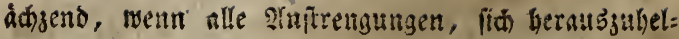

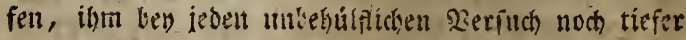
bineinjturien, bis ígeno iemans - ids felbit sum Beipiet - Mitteio mit Dem flagenden Hugeheuer

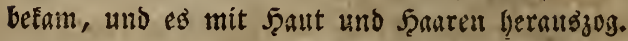

S23ab nich betrifft, to ift, wenn es móglich ware,

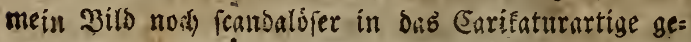

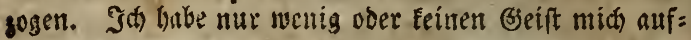
rect zu erbalten. Mo fonnft Du mir bas geritigite Nertmal des feigea (S) múths zeigen, mit weldsem Du miá), wie id glaube, blos desivegen begabit, um bie fichere uno gleidfformige S3tirbe Deiner eigenen thỏrids=

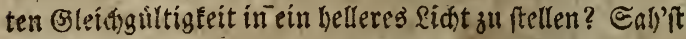
Du mich ie zittern, fo gieng es mir wie jentm alten fpanifaen (General, mein fiorper zitterte nur vor bee (3) fabr, in melche mein Beifit ign führen wollte. Sm Ermt, Ulan, Die Irmuth Des Beiftes, welche Du mic andittreft; ift eine niebrige 2 ntlage Deines Freunder. Sch bave mich fo fireng alo moglich geprift, intem idt mich wirflidy cill wenig gefrinft baruber fúble, das Du mid

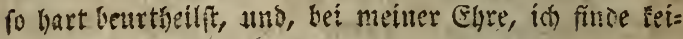

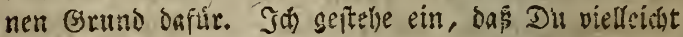
an Feftigfeit mo Gleingúltigleit bes Semuths einige

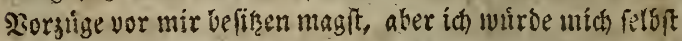

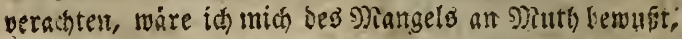
ben Du mir gar zu germe anoiditen móstefi. 2lber id benfe, ber unfreundfictie Şinf bat feitten Grumb nut in ber allzugropenen Sorforge meines Fretmoes fuir 
meine Sidherbeit, this da tas es fo betractite, fo ver: rablucte id es wie sie 2ranei eines woblmeinenoen

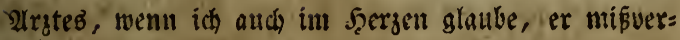
filge mein thebel.

Albftrabiren wir allex won biefer beletbigenden $\mathfrak{B e}$ merfung, fo banke id) Dir, 2flan, fur bas Utebrige Dei=

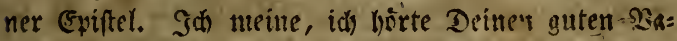
ter. Das SBort Noble-House, mit einer Mrichung von sicrndatung uno Mifbergutigen ausfyreden, als ware ber blofe Name bes armen fleinen \$geilers illm guwi: ber, ober als batteft Du von ganz Sthottano gerabe ben Drt ausgefudt, wo Bu an ş3enigften sk Nittag effen follteft. 2lber wenn ex eine befonbere abneigung gegen biefes unfdulbige Dorfden unb gegen bas unbe:

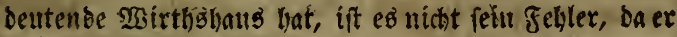
mich ia abhielt, bie Einlabung bes Lairo von (s)leniguls-

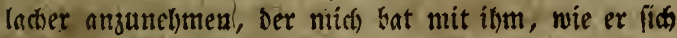
pathetifch auborlide,te, "auf feinen Sänorsien" eituen sieblod zu iagen? Eimen Tiebrock zu iagen! Denfe Dir, weld' eine glanzenbe Soee fir jemanben ber nie

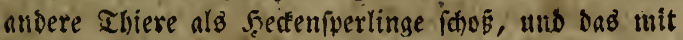
eitner Encspiffole, welthe er in einer Eriblerstube in ber Sulignffe Eaufte. - Du, ber Du Did nit Dei= nem Sutbe brifteft, magit Did erinuern, das id bie Gefabr, beragte yiftole loszufeuern, zuerft wagte, wálsreno Du zronzig Ealen weit bavon ftan= beft, uno bas, als Du ficher uberzengt marit, bas fie nicht zerfpringen wurbe, Dujalle গechte, auper bem beb-2tel= 
teren uno bes Etrirferen, vergajeft uno Diá) Der Di= fole, firr ben ganzen vieit bes geiertages, nusichlies:

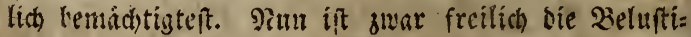
gaitig eines folden Tages feine volleommne- Sorfdyle

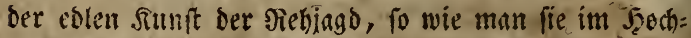
lanbe anşubt; Dentrod bitte id mir feine Bebentlid): Eeiten gemacht, Des elorliden (s)lengallachers cinlabung, feloft auf die (sefabr, zum exitenmal cinen felylid)us

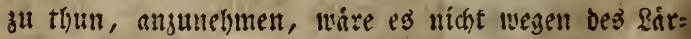

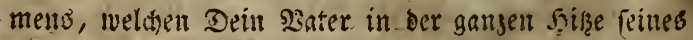

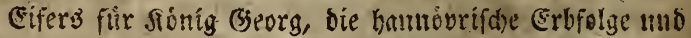

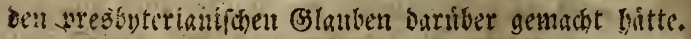
Seht wollte idh, ich batte barauf beftaitben, oa ich burd) meine unterwerfutg fo wenig in feimer guten \$iei=

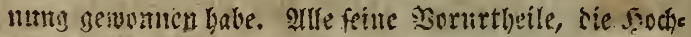

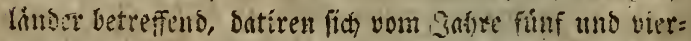
zig ber, als it uno bie anderen freinillizen wom seit: Port retirirte, ein jeder um fid in feiner cigenen s:ob:

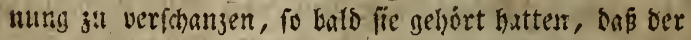
Qlbentbenter mit feinet Elans fich Sitritifon nabere. Dis flunt von Falkirk-parma non bene selecta - an weldser, wie ich glaube, Dein 2lbuber, religen 2lnden=

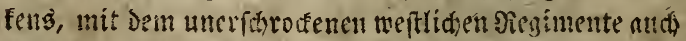
wobl artheil gebabt baben mag - fdeint feimen (s)e:

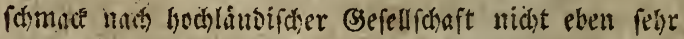
erbiht zu bulwen; (unterfube ood cimmal, allan, ob Sir wohl ber giuth, seffet Du Bidh rúbmit, und

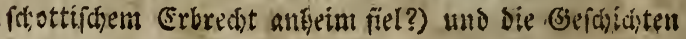


vom Nob Mog Macgregor uno voin Errgesuten MHan Nhthor Enmeron bienten feimer Cinlilbungstraft, fie

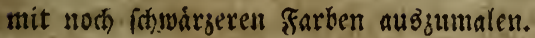

So viel id nim bavon verffehe, fino biefe gocen, wenn man fie auf ben gegenwártiben suftand Des san=

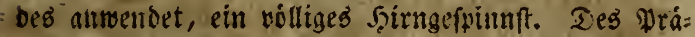

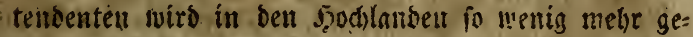
badt, als ware aud et fhon eingegat:gen zu feilten butbert und adjt 2lhuen, beren Bilber be alten Mauerir voll Solvroos zieren. Die breiten Edivero = ter fiud in andere Şätloe tibergangen, bie Tartfden werden baju gebraucht, bie Butterfäfer zujubeclen, ons (s)erthatit if gefunfeir uno finft tighlios weiter, von ftirmifdyen fralbwilden zu anbmen 2etriggern. Es

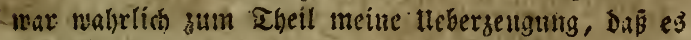
im sincocit nur nemig mebr zu felen giebt, welche,

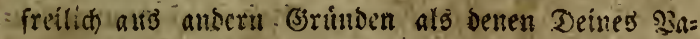
t:rs bervorgcheno, bods mit feinem Shlufe tiverein=

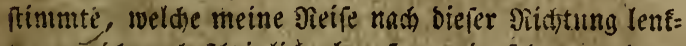
te, wo in wallicheinlial eben fo wentg felgen merde.

Eiris aber babe id) gcfelien; und es geidabl mit

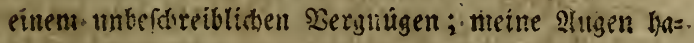
ben nimilids, wie oie oes fterbenten Wropheten, vom (3)ivfir des Misga das sand anjăauen durfen, Das

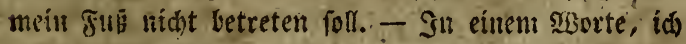
- fah sie ufer bes frobliden Englanos; bes fróbliden Englands! Deffen Erjewgter zu feun ich fold Fin, nno

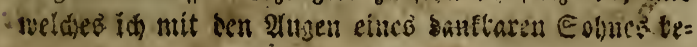


tracte, went faron bie tobenden flutben und ber be: weglidie Trieliand uns tremen.

Du fannft es nicht vergeifen baben, arlan - benu, mann vergaffeft Du je etmab, bas Deinen freund ke=

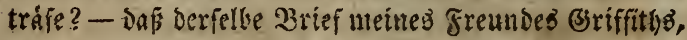
weldyer meine Einfunfte versoppelte uno meine Soans:

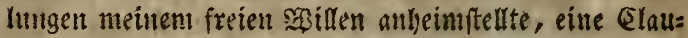
fel entbielt, nach weldyer mir es, bhe lirfacbe, verboe teu waid, falls ich meite tunftige Jiuhe uno mein funf: tiges (5)tice wunfdyte, England zu bercifen. Seber an= Dere Theil ber brittiriben Beîgungen, Terbit cine Sieife auf Den Sontineut, war meiner $\mathfrak{x}_{\mathrm{a} a b l}$ úberlaffen. Erimerit Da Dich des Mislyrchens, 2lan, yon einer

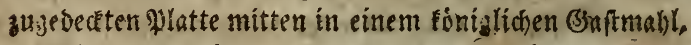
atif bie immerwábrent bie \&ugen ber Bsiffe gerichtet waren, welche alle Pectereien, mit weldhen ber Tifds be= lacen mar, vernahlafïgten? Diefe Serbannungs̆flau= pel uns Engleno - ans meinem Saterlande - aus Dem Ranbe dir Sapfern, Der 9 seifen und der Freien, betrúbt mid) mebr, a!s̀ midy die Freilbeit und unabbán= gigfeit, welde man mir in jeder andern seirfiat lápt,

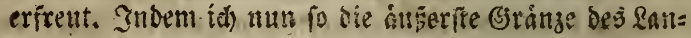
bes aufincte, das zu betreten mit unterfayt ift, gleiche ich bem armer angebunbenen Nerte, welches, wenn Du es bemert bait, immer am Pande bes Eirtels orabit, anf welwen eb, burds feinen saum, beforinft ift. Slage mid, nicht uber Siomantif an, weil ich bies

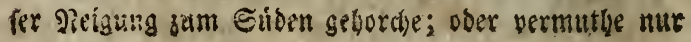


nicot, baß, um dem eingebilbeten Sdimactiten mach el: ner nithtigen Sengierbe Bentige zu leiften, idh mick

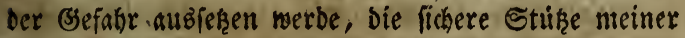

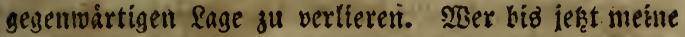
Edyritte leitete, hat mir buth rebende Beneife melie als bura's serficherungen, bie er (ich) erfarte, gezeigt, baj 'mein wirflider Sortheil Ssauptzmed swar. Sth wäre baber wobl árger alb ein 'arre, went id gegen ibre 2ritoritat Cinwuirfe machen wollte, felbit wenn biefe nach gaunen nusgcubt wore. Denn gewie in meinem arter - uńb wemu man mir nod' basu in

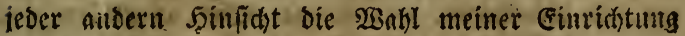
un bie Sorge fir mich tiberlabt - batte id wohl erwarten Eónnen, baß̈ man don ङruno, warum man mid aus Englano verbannt, frei und offen meines rigenen lieberlegung anb (sinficht úberliepe. Dennoch. will id) nicht bagegen muren. Id bermuthe, cines Tazes werbe if boch fiton ben sufunmengang ber ganzen (s)efoidate exfabreat; unto bann werbe ids viels leidit einfeken, wie Du zuneilen andenteft, dof an ber gauzent "Eache nidit viel Wsidbtiges ift.

Ich fann mict) nicht eutbalten, thich su vernumbern - aber, Gott weís es, menn id fo fortfabre, fo wiro mein 3rief fo voll $\mathfrak{3}$ !nnder werden, wie Satterfelto's *)

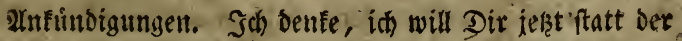
verzmeifelten ewigen \$Bieberbolungen vou Sermuthum

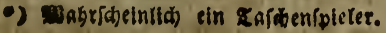

2nmert. bes Heber5 


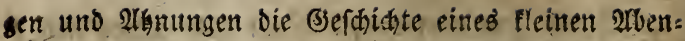
theuers erzálen, sas mir gektern zuftié; obzwat id

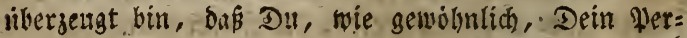
fpectio umwenden und riseine arme Ergáblung fur eine mbebeutende Begebenlyeit halten und für einen $\mathfrak{u n}=$ trono, von weldhem Du mid) wieber anflagen wirfi, faliche Sdhluffolgen gezogen zu haben. Sum Şenfer aber alth), Alau, Du bift fo wenig zum Shertrautsn eines jungen $\mathfrak{2}$ bentheurers, ber mit einiger Einbil= Dungbernft begabt ift, geeignet, wie ber alte einfilbije Sefretir bes Facarbie von Trebizonde. Dennoci muif: ren wir beide, jeber feinem befondern Shiafale folgen. Nicite 3eftimnung it es zu rehen, zu bandeln, zu erzáblen; - bie Deinige, wie ein alter frollander in Denife!ben Poltwagen nit einem Bsasconicr zu lișen, zu boren uno bie difiel zu zucken.

23!n Dunfries, ber f̧auptftast biefer Graffidaft,

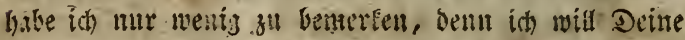

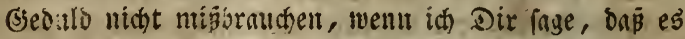
au seu Heen des lieklichen fluffes gith liegt uno bas man vom hoctiten StanopunEte ber Stabt, yom Sirds:

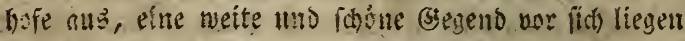

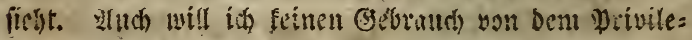

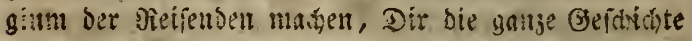
vom Bruce z: wicoergolen, welcher an biefent Drte in Der Dominituter sirche dea rothen (Somin erfitid, uno befwesen, weil er ben Bottesfrieden brad) uns ein Mitu=

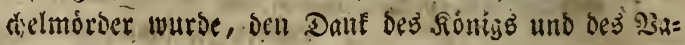


terlanbes einernotete. Die ießzigen Pewohner. von Dumfries erinnern fith beffen und vertheibigen bie Dhat, indem fie bemerfen, bas es nur eine papiffiche Sirche gewefen wate - benn zun Beweis fino bie Mauern ber Sirdie to vodíg uiedergeriffen, baf man

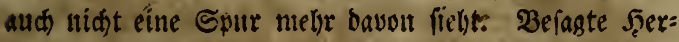
ren Burger vou Dumfries find eine Derbe Slaffe àd,t, blauer Presinterianer, Didnner nad sem Serzen Dei= nes Saters, uno um fo viel eifriger fur bie prote: fantifthe Erlifolg:, ia viele ber gropien Familien in ber thragegens im Sirtadit ariderer Sefinnungen fes: ben, uns, ferbit zum Eheil thatig, an ber Injurrec: tion im Sabre finfschi, andere fogar an ben neucren

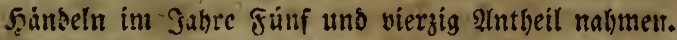
In bex leşteren Períobe litt bie @tast; Denu Sord

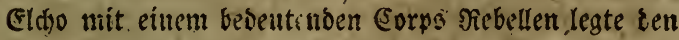
Burgern ber Etrot Dumiries eine ionere Sontrifution auf, weil fie ben 9iadtrabe bes (jhenalier*) alf feimem Suge nach England be'seutenden S.hnoen zugefigt batten. Siele diefer ttmitalide exfube id vom progoit $\mathbb{S}-$, weldser fiá, ba er mich auf bem siarft erblicte, erin: nerte, bas id eill Senusuenofie Deines Saters bin uns mica febr biflich zum Nittageften étulub. I(t) bitte Did, fage bod Deinem sisater, Das ich tiberall bie Ein=

-) Belname bes prastensenten. Doing cart bon Stuart, benn ble elnshinger bez-5aufés Sannober verwelgerten bem tas

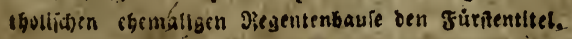

सumerf. bes Heberf. 
wirtungen feiner (s)ite gegen miá fühle. Nech bier uns zmanjig Etunten aber wurbe ich biefes, fonft gail

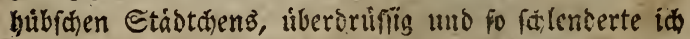
oftwarts ber Sifite entlang, inbem ich mich banit un= terbielt, arntiquitåten auföuruchen uno matidintal meine

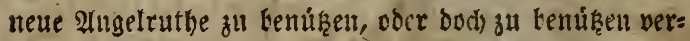
fudste. Fachben ias vier volle Etmeen gemartet hatte,

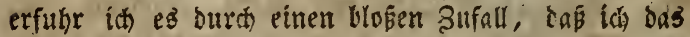

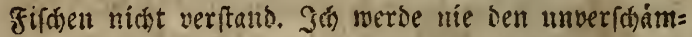
ten awolfiahrigen Buben, den sublirten vergeffen, der

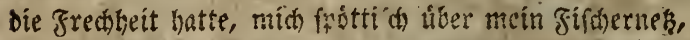

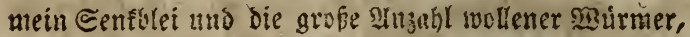
bie id mit gefammelt hatte, ?atş3uladen, er, ber we=

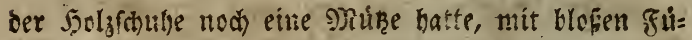

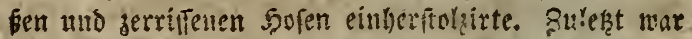
ich Dennoch gezwungen, bem potteiten Edhlingel bie Ingelruthe zu tiberlaffen, un su fehen, mos er bumit

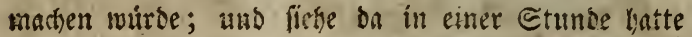
er nidit nur meinen Sorb bis zur Seâlite gefiult, fon= bern er legrte mín wirflid) mit meinen eigenen feän= ben swei Jorellen tioten. Das, uno weil Sam f̧eu

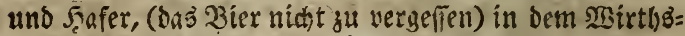
baus reast gut find, fiobte nír zuerit beu Bebanfen ein, einen ober ztwei Tage bier zu leiben; dem la= denden Epiąuven von fifhertuben babe id, mei! id) eitren andern firten fuir ín mictlete, bie (5r= laubnis verfdafft mich begleiten zu durfen.

Eine ordentlidye reinlide Englanderin ift (S)afs 
seberin diefes Eleinen Sirthsilnates, meine Shlaf: ftube wiro mit savendel geräthert, bat ein nettes ๔chitlfenfterchen und úberdiep fiub Die Mrauern nit Ballnoen von ber fóponen Sipamunbe und ber graufa= men Barbara allan kebect. . Bie unreil aud bie 2lusiprache ber 3 irthin fenn mag, meinem Dhre llingt fie hodaft lieblich; Dent uoch habe ich bie traurige wir: fung nidit vergetien, bie eure breite, langrame, nor:

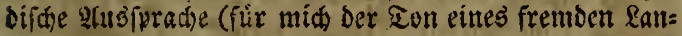
bes) auf imeine kindlichen Drgame hervorbradate. Id weis wohl, bas ith reitbem bas Edjottifale vollig ex=

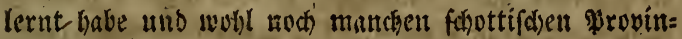
zialismus oaz!l. Inmmer aber noch faleint ber engli= fise Iccent meitum Dhre, wie eines Sreunbes @tim= nte, uno weun ich sim, felbft in Dem. Munbe eines manoernden Bettlers borte, fo verierlte er bod nie, mir ein 2lmofen zu entloden. Si)r E(j)otten, bie Jur auf Euere eigene sationalitat fo. ftols feob, mist fie audi) in 2 rnderen elrent.

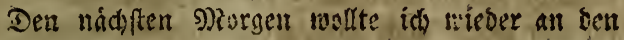
Strom grisen, wo idh bie vorige siacht su anzeln ange: furgen hatte, warb aver burch cithen gemaltigen gie: genfitauer, Der bear ganzen Sormitteg anbiclt, Daran

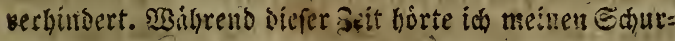
fen vou friber feine unzhidtigen Spabe fo laut in ber Silid)e, wie einen Besieuten auf bem 'Plarnbieje

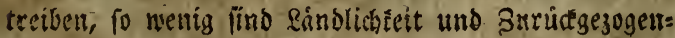
beit immer mit 2efdeibengeit und llufould gepaatt. 


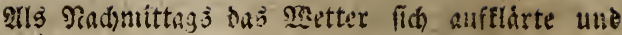

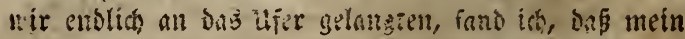

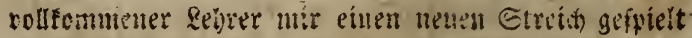

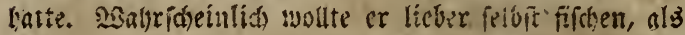

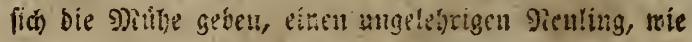

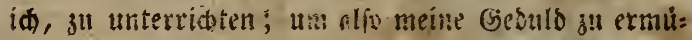

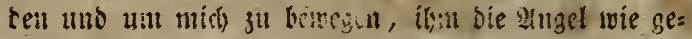
ftern, zu uberloffit, croache fid mein Jreund bie Qift, mich mebr als cine ङtunse nit riner 2 lngel of):

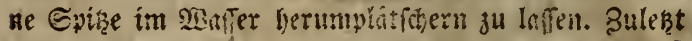

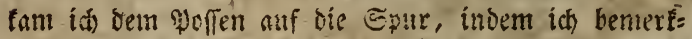
te, baj ber Sdjurfe immer vor Freube laut aufadte, wenn er eine forelle fich llatiern uno rubig bei ber Angel vorbeifdummen fah. Id galb ifhem einen ge= funoen steb, slluit; aber id) bereute es fojon im náditen 2rugenblice uno um ibn zu entrwisigen, lies ich ifn ben übrigen

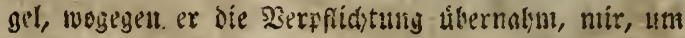
frime behisigutg wieder gut zu maden, éll Beridgt Forellen zun abendeffen heimaluringen.

Da id mich aif biere siefie ber Laft entledigt hat= te, mith alf eine au unterbalten, fo wenbeti idh meine Eabritte zum Nieere boer beffer geingt, zum Sieerbujen ron Gol= wes hin, welther bier bie beiben Echmefterfouigreide treunt lino der ungefábr ein Etúndçen entierut war.

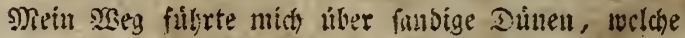
mit nicorigen hęeidefrảutern biwaćjen waren. 


\section{7}

Neine finger wirden ermiden, Dir ben fiot:

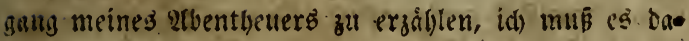
ber auf morgen aufikgieben, wo Du bie fortiekzung erfabren folft. IIm Did inteffen vor citrem ubereit: ten Sibluffe zu bewalyren, mus id Dir bencrien, dab Obiges nur ber Anfang Des sibentbeuers war, bas ich Dír erzáblen will.

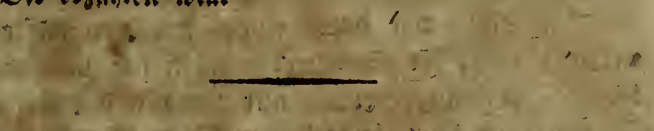

\section{$\mathfrak{B}$ ierter $\mathfrak{B}$ i i f.}

Dertelbe andenterben.

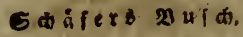

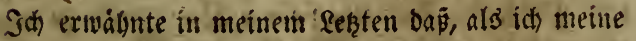
Inge!rutbe :als einen unnuken seitvertreib verlsffen bat::, td) úber bie offenen Ditriell, welche midh ron bein

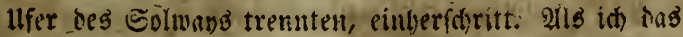

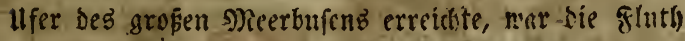
von einer breiten, fid meit erfirrecien:oin Eanbebene zu=

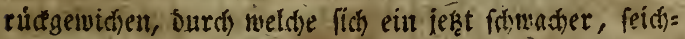
ter Strom einen Mieg zkm Drean gebalint hatte. Die eanze Sanofalt war von ben Gtrablen ber unterges benien Goune matt belendstet, melche wie ein Srieger, Der fich zur :

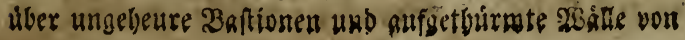




\section{8}

falarlachrothen unb fawarzen Solfen geigte, bie wie eine unermeflich grofe gotbifci, seftung focienen, in bie

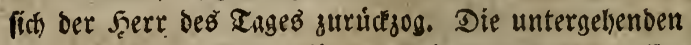
Strablen fómmerten glanzeno wieber auf ber naffen Dberfláche bes Gandes uno in ben unsábligen $13 a f f e r=$ gruben, mit benen fie bebeat war, weldhe die Ebbe in ben nngletaen Boben zurudigelafien batte.

Die Scene war burdh efue Stmahl.uon sieitern, welthe fich mit ber Salmiago bejóaftigten, noci melir belebt. Ia, 2llau, erbebe nux șand uno Irige wie Du willft, io fann biefer 2 (rt zu ficken letuen anderu Siamen geben; Denn fie eriagten bie fliche in vollen (5) slopp uno pacten fie mit ifren frumm gebogenen Spiefen, wie man auf alten Iapeten Jäger Bären toot: fied)en fiebt. Raturlid geht es mit bem Salmen leid)= ter, als mit bem Sáren; Doch find fie; fo fduell in ill: rem Elemente, Daßi, un fie auf biefe SBeife zu verfol= gen uno zu fangen, ein triditiger Reiter, ein fajarfes

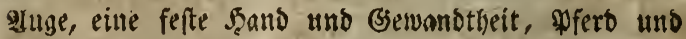

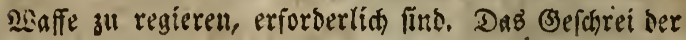
Burbe, nem fie bei ibrer lebbnften Ḋefóaftigung

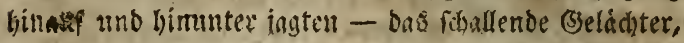
wenn' ciner vou innen fairzte - D.t5 laute Beifallru= fen, wenn einer einen gleifterfireid mit ber fanze ausfilyrte - saben ber Gcene fo viel \&even, bes math mich bie Begeifterung ber Jaşer ergriff, to Dafic ich mid) eine bebeutende Gtrecte in ben Cand hinein magte. Befoubers erregten bie Thaten eines Nieiters 


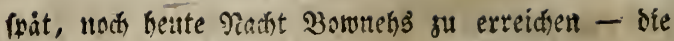
Fluth wiro figleito cintretett."

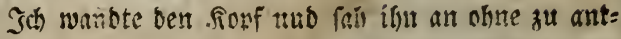
morten, benn fein wlobliches Ericheinen (beffer gefagt, fein nnermartetes Sermnahen) ini machfenten. Schat= ten uns im binmerenten Ridjte, batte fúr mich etwas soilses uns ๔danerlidies.

"Eend Glir tauls" frrrie er, "oder toll? - oder - Habt Jbr enft nach ber Eunfitigen giselt?"

"If bin ein fremoer, antivortete id, uno mollte

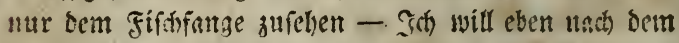
Drte zurtidgehn woher id fam."

"So cilt Euth bun: fo febr shr finnt!" fagte er. "Treer am Hfer bes Solwan's triumt, fanu in ber antoern Shalt ermacher. Der Simmel brobt mit ei=

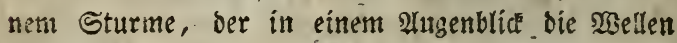
brei Fus hod treiben :airo."

Inden er es fagte, wandte er fein Pfird und ritt bayou, wályens ich, beumrubigt ufer bas was idh ge= hirt hatte, fdinell som fosttifhen lifer jueilte; ienn bie ghuth nimmt nuf biefem verzmeifelteit Eande fo reibento zu, das felsit moglkerittene Nieiter alle Sgoff= nung ouf Rettung anfgelien, wenn fie, felbit forson eine Strede von Ufer entfernt, bon Siseitem bie weipe Branourg fich uaben figen.

Dieine \&utgit fieg in iesem atugentelide, uno ftatt

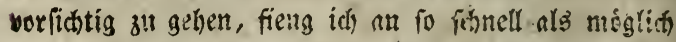
Iu laufen; ich fublte, ober glaulte bod wenigftens zu 
fiblet, saß jeber Safferffubl, burch hen id madete, immer tiefer uno tiefer murbe. Şuleşt fitien bie Dherfldite bes Eandes immer bintfiger mit Bruken

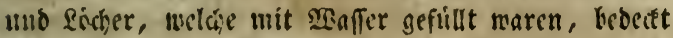
su fenn, fen es unn, dab bie gluth nirflid fich ber Budat náberte, ober lyatte id) nida, wie es eten fo leidt moglid ift, in ter cile uno Sernirrung meines sindzugs in Edwierigfeiten vermidelt, welde id) bei rulbigerer Uelerlegung batte vermetien finuen. Saie Dem auch fen, fiets verzmeifelter warb meine Sace, immer loderer warb ber Eand, faum batte id) mci=

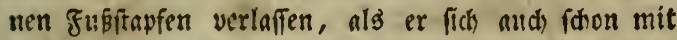
Sisaffer fullte. Da befielen mid munberlide Gebanten

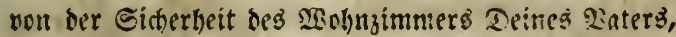
uio wou sem feften Tritt, but bas Iflafter von Brown's Equnre mo Ecott's Elofe geftattet, ails

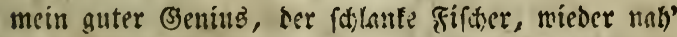
an nueiter Eeite erfotien; or und fein foumarges \$ferd gigantifa grof im Edratten ber Bammerung.

"Eevo Shr toll", fagte er mit bemfelben ticfen sole, ber fruiler in neinem Dhre tonte, "fevb She toll rier bes feches liberbriffig? Jlor werbet ben alugenblice in ben Triebrand gerathen." Id) befannte,

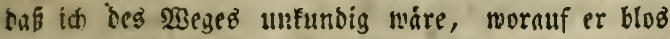

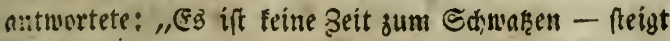
biuter nír auf.".

Er ermartete makrfacinlis, (i) nirse vom $\mathfrak{B}_{0}=$ ben aus bihauf foringen tönnen, eine Bewandtheit, 
weithe biefe (Srangbewoliner Surch ftete thebung in als len Neiterfiniten, erlangt baken; aber ba id un= fólüipig fteben blieb, ftrecte or feine Şand aus und indem or bie Meinige fapte, befabl er mir, meinen Fus auf bie Spikze feines Stiefels zu fekzen, unt po erlyob ex mid in einem su auf ben siúcen feines Pferbes. Saum fás ich lither, als er fdon bie suigel feines Pferdes fótuttelte, welches augenblicelich vor= warts fwrang, aber wabridheinlich burd bie ungewóbu=

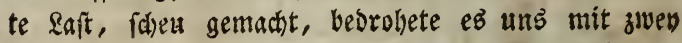
oder brei Eprúngen, wobei es eben fo oft mit ben

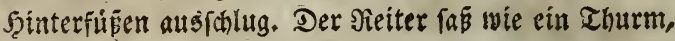
obgleich nití bie unerwartete Spruinge bes Pferdes auf iba geworfen hatten. Sporn und zaum bracten bas Pfers bald wteder in ben geborigen (sethor fam, fo bas ez in geitreaten Ballopy Davon eilte; finnell war ber

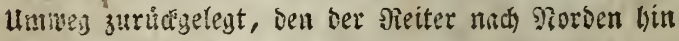

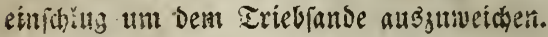

Mein Freuno, fait modite ich ifn meinen Erret= ter nenten; - beun fúr einen fremben mar meine Luge mit wirffidser (Gefabr verbunben - fubr fort it

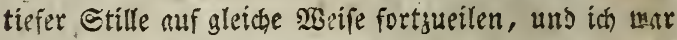
zu bejorgt, um în mit Fragen zu belåitigen. Baleşt famen wir an eize Stelle bes llfers, weldie nir vol= lig unbefanut war, wo id abities und ibm, fo g!tt

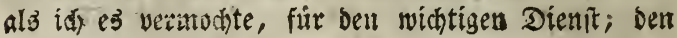
er nitir even geleiffet hatte, Danfte.

Der Frembe antwortete mir nur mit einem uns 
geduldigen: "Pah" und wolfte eben weiter reiten, mid) meinen eigenen f̧ưlfęquellen überlaffend, als iđ ibn bat, feine menfdenfreunblidbe Frandlung zu vollen=

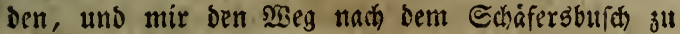
zeigen, weldeb, wie ich ibm fagte, mein gegenwárti= ger 2 (ufentbaltsort fep.

"भiach bem Sadifersbufa?" fagte ex, "find $\mathrm{es}$ zwar nur. Drut Stunden, fennt Shr aber ons santo niant beffer als ben Eano, to finnt Tyr ten fials brechen, ebe Jhb hinfommt, bas ift in ciner bunflen

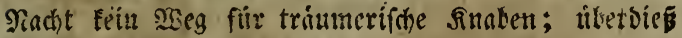
givt es Bäde und Climpfe zu burdwaben!"

Bei Der fiunbe fo vieler @disterigleiten, mit

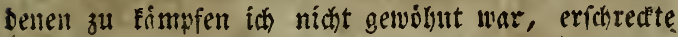
in) nidbt werig. Sdan wieder bachte id an Deflies soters traulidyen Enmin; uns serne batte ic mei=

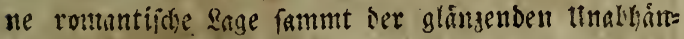
gigfeit, in welder id mid in biefem Slugenblict be= fallo, gegen bie gemithliche Behagliduleit bes Ectchenz beim Camine vertalldst, 'ware id andh genoithigt ge: mefen, meine arngen ouf Ersfine's Commentar cer Sufritutionen su befter.

Sdl frug meinen netien freund, ob er mich nidit fur bente Piacht in irgeno ein iffentlictes (Brithants

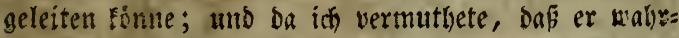
farcintich felbft ein armer siann ware, fo fighte ial, mit ber folbetbengten sisuse eines noht verioben 


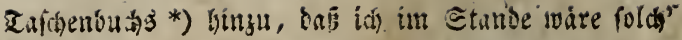

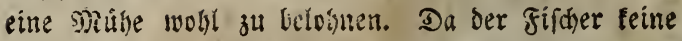

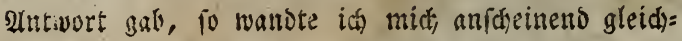
gúltig von ihm roeg uno fólug ben welchem ith glaubte, baş es ber ware den er mir ge=zeigt batte.

Seine tiefe Stimme tónte mir augenbliatid nad,

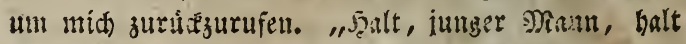
- Sar hast fason ben falichen Meg eingelólagen. -

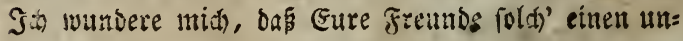

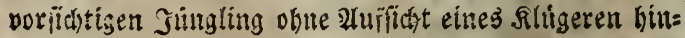

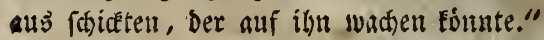

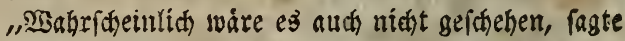

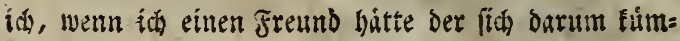
Querte."

"J̧ort, J̧err," fagte ex, "e’s ît nteine 2rrt nidat, gremben mein 5̧aus zu iffuten, aber Etre Lage iit

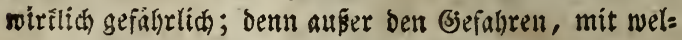

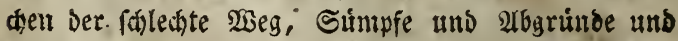
bie Pauat, welde formarz uno bifiter binein fieht, Euch bebrohen, gibt es zuweilen auds nod) boje CSeiellidiaft

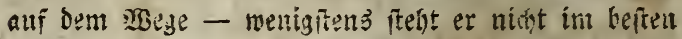

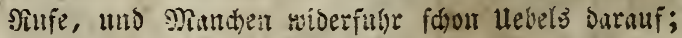
barun mug ia wogl meine Segal Curer Poth allfop: fern uns (Eat) in meiner ḩtitte Pachtherberge gebelt."

-) Detanntlli jablt man in Cnglano uno Edottlano fafi xuer mit Baninoien.

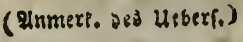


Soljer mag es̀ mohl getommen fesn, 2tlan, dak

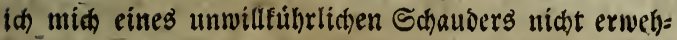
xell foutte, als idj eine Einladung empfieng, weldhe fo febr an ihrem Ylakge war und meinem naturticten Forínungşgeifte zufagent muste? Dod leidt unter=

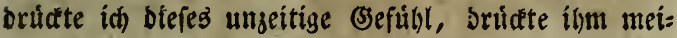

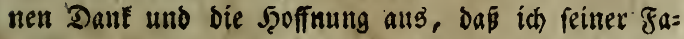
mille nidit zur saft fallen wuirbe; dabei liés ing wies

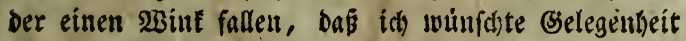
zu befommen, die thurube, die id itm verurfactsen módte wieder mit Etwas gut zu madtell. Baan falt erwiederte er mir: "Obne 3weifer wirb Eture Bjegen: wart, Sir, midh fróren, aber auf eine 2rtt bie Eure

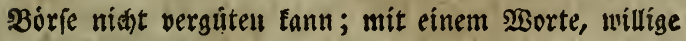
id) aud ein, Eudh als meinen (saft zu empfangen, fo bin í Dod kein 2 Sirth Der um's (selb beherbergt."

Shl bat inn wieber um rerseilsung und ferzte mid, auf rein Bitten, wieber binter iljm auf bas

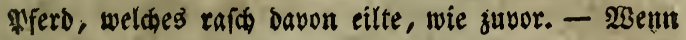

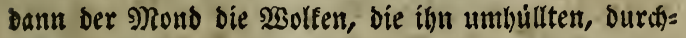
oringen fonnte, fo erfajien ber lange Sdjattent bes Thieres mit feiner boppelten 3 úrbe, fhanterlid auf Dem wilden, Eablen Boben wiber den wir eilten.

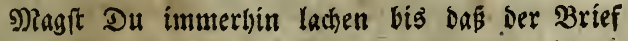
Dir aus den Sánden făllt, aber es erinnerte mida an Den sauberer 2ittantes auf féinem Seyupogriph, mit eí= nem Nitter binter fíd auf, fo wie atriofit iln unz bes

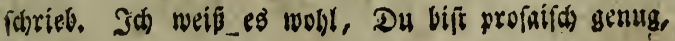


eine getvife : liche Biebicht zu beudgeln; aber glaube-nur nidht; baß idh, um Deinem fohlechten serdismade zu fameidheln, irgend eine paffende Sitation unterlaffen werde, die mir lie umb da baraus eimfallen módite.

Fort gings, inbem ber Şimmel fich fidwats unt:

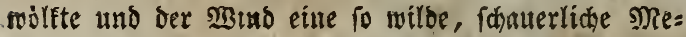
lobie bazu blies, bas fie trefflid mit ben tiefen $\mathfrak{T}$ D: nen ber hermulibenden gluth harmenirte, weldhe id in ber Ferne birte, gleid bem Brullen eines furdyt= baren ingehewers, sem man feine Bente raubt.

Endia) fúbrte uns unfer $\mathfrak{S}_{\text {eg }}$ ourch eine tiefe Sohlucht ober froklweg, weldyer bei bem oft verhillten Echeín bes SRondes abichuifig, fteil und von Baun= ftámmen unterbrochen idien, obgleid im artgemeinen 2åume ziemlich felten an biefen 1 fer zu finven find. Der $\mathfrak{3 e g}$, burch ben wir bur bie Ghlurht tamen, war iali', abrhuifig und holprig, man muste zwei ober oresmal, neben tiefen albgrtinden, ummenden. 2aber weber Befahr nod Finfternib founten bie rafben $B e=$ negurgen des Nappen hemmen, ber ben Engpás mebr auf feimen Sơften berunter zu gleiten als zu galopniren fisien, inben er mich wieserbolt gegen bie schule tern bes abtletifhen sieiters marf, welcher baburch feinerlev Beitwertidfeit leibens, bas Pferd mit ben

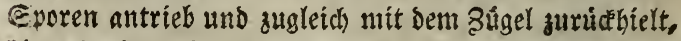

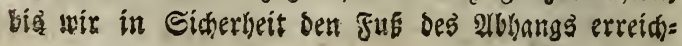


ten, mas midh, wie Du, Freund 2llan, leid)t bentent tannit, berzlid exfreute.

Surz nach biefer Galburedoendent sieiterei exreids: tell wir żwei ober brei Sclitten, von welden bie eine, wie ein abermaliger voribergebender Nonofucin mids belebrte, um ein Bebeutendes anfehnlidser fahien als bie in biefem aheile bes sandes gewoiknlichen fattit fchen Bauernháfier; betur bie Genfter maren verglast und in Dadie waren, fogenante Sturmfeniter ange: bracht, weldhe ein Beikhen ber \$racht eines zmeiten Stodwerfs fobionen. Die Lage foien rehr anjiehents, benu bié 230 hmung uno ber feof lagen allf einem

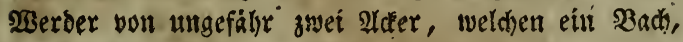
ber feimem Raufigen naw nidit unbebentens fitien, an ber linfen Seite bes fleinen Tlyals bildete; with= reno ex feinen Rauf nad) Der fernen Sneerestufte ritis= tete, weldier yon B̧aunten befchattet unb nerdunfalt sut werben fhien. - Der chene গaum Daneben exfrentete fich einiger Mronbblicte, fo wie bie ftitrmifhe Piacht fie gewälien fonnte.

(E) blieb mit welnig sait librig Betradtungen

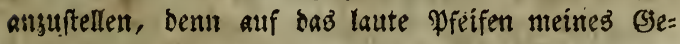
fährten, welchem ein eben fo lautes. Scallo! folgte, er= fdyien augenblidelid an ber Thyire bes onfebuliaften (Sebaubes ein s) sam unb eine Frau, benen zwei grošc

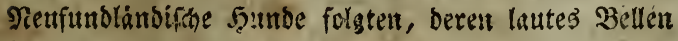
id (d)on eine Strecte weit gebort batte. (Fia oder

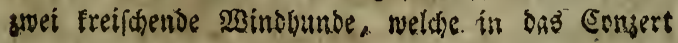


eingeftimmt batten, waren augenblidich fitle, fobald fie meinen fiulber faben, wedelten, winfelten utto fprangen auf ihn. Das Frauenzimmer entferute fich als fie cinen Fremben erbliete, Der Mianu aber, ber eime brennenbe Laterne trug, náberte fid, entpfieng obue weitere Bemerfung Das Pfero aus den Jeältoen mei= nes $\mathfrak{s i r t h e s , ~ u n o ~ i d ~ f o l g t e ~ m e i n e m ~ f r i l ) r e r ~ i n ~ b a s ~}$

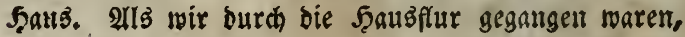
tràten wir in ein nett ausjeliendes Bimuner mit rein= lidem Boden von Baffeinel, wo in einem genodhn=

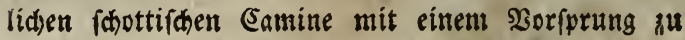
meiner groben Jreude, ein belles Jetter flacerte. গings herum waren fteinerne Bänfe angebradit, gz=

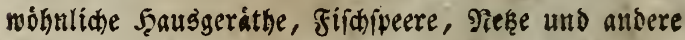

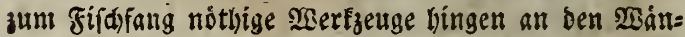
ben. Das Frauenzimmer, welches zuerit an ber Thú= re eridienen war, batte fich mun in ein siebenzimmer

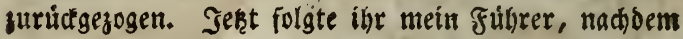
er mir zuvor ftillidweigend einen Sils bezeiduet batte; an ibrer Stelle eridien eime áltliche frau, in eimem grauen ftoffenen Sleide, mit bunter Saúrze uno Sa: furze, fidtlia eine Dienerinn, obzwar fie zierlicher gefleidet war als es in ibrem malyridjeinliden Stande gebrauchlid ift, - ein Siortheil bem ein bochit $a b=$

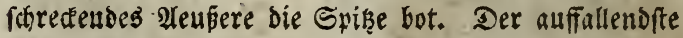
Theil ilbes alnzugs aber war, in biejer erzmroteitan= tifwen Bregend - ein Sidfentranz, an weldem bie flei= Heren Sinopfe vou fdwargem fololze, diejenigen aber, 
weldie bas pater - noster anjeigten, von Sillber waren, mit einem Erusifix von bemielben Retall.

Diefe פerfon madte Sorbereitungen zum abend: elien, indem fie anf einen gropenen eidenen rifळ, ein uwar grobes aber bod rciulides rifottud ausbreitete, Eededte uno Sals barmif ftellte, und bas feuer zu= redit legte, unt sinten $\mathfrak{B r a t r o f}$ barauf binftellen zu

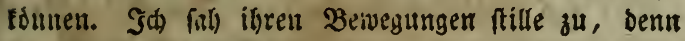
fie fdien weber mid bemerfen zu wollen, nod reif̧ten

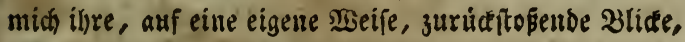
ein Bseiprád mit ibe anzutnupfen.

IIls bie Duenna alle biefe 2orfebrungen getroffen Gatte, nabm fie aus bee wohlgefúlten Iafale meines Begleiters, melde er úber bie Tlure gehaingt batte, einen ober zwei Salme ober Brillen, wie man bier iu Lanbe bie fleinere $\mathfrak{A n t}$ nemut, wablte bie beiten ber= aus, zeridinitt fie in Striden uno bratete fie auf Den Nioft; mid aber exgriff Der buftende (S)erud des (S)=

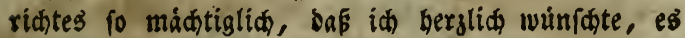
módte fein Şinberni zmifden ber Platte uno den Lippen entitebn.

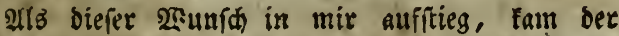
Naan, ber bas Mferb-in ben Etall gefilyrt batte, ill ba.s 3immer unb jeigte mir eitue nod unempfeblen= bere siene, als bie bes alten Wieibes war, weldse unit fo vieler sefdidelidfeit bie Serridtungen eines Siod)es úbernommen batte. Ex modite ungefáabr fedis: uis Jabre alt fegn; soch war feime Stirne nod nidt 
ftarE gefurdt, und fein noch fdwarges J̧aar war, burch bas grlter, mur ein menig ergraut, aber burchs= aus niकt gebleidit morden. Irle feine Bewegungen verfindeten eine nod) unverfebrte Ctárie; obzwar von mittlerer Etatur, hatte or bud breite હdultern, war regelmâpig gehaut, fallaut in ben f̧úften, uno ver=

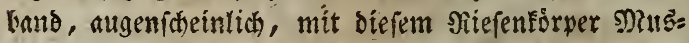
felfraft und Ihatigfeit; lektere ourch die Salje viel= leicht cin wenig geidswadt, boch bie erftere noch in voller 3ruthe. Sarte, fdiroffe şige - bie Ittgen tief liegend unter ben bervorftebenden Iltgenbratmen, bie sife fein saar ou ergranen, begannen - ein weiter Tiunt vou finem Dhy bis zum anderen mit zwei

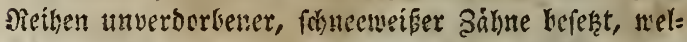
d)e io gros uno breit waren, Dafi fie in ser Sinnlabe

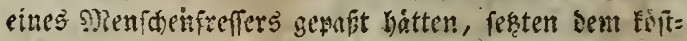
licten Bilse rie Srone anf. Er mar wie ein Findher gefleiset, in einer blatten Sadke und waiten frofen von

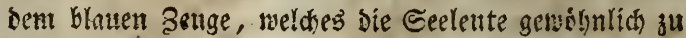

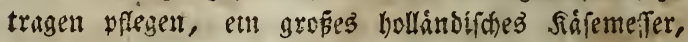
bem ber scamburger Echiffer allntich, ftal in eitrem breiten lebernen Gurtel, welder susfah, als fonnte er, bei Gelegerlyoit auth seaffen entbaltan, welde

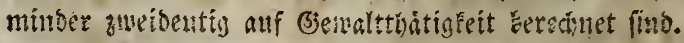

Diefer Diant morf mit einen forforenden, uns,

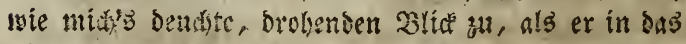
Simmer trat; aher oline weitere ?atiz yon mir za

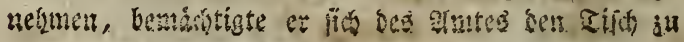


orduen, weldies bie alte Dane verlaffen batte um Fifche zu fochen, uno frellte, mit melyr Bemanotheit

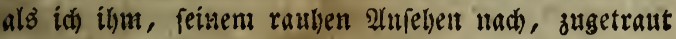
batte, zwei Seffel au bas obere Ende bes Tifoles und zwei Stuible an bas untere; Fereitete vor jebem Sire ein Eouvert, weldes ex mit Sserftenbrod uno einem

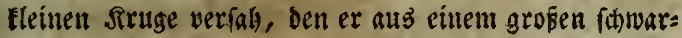
sen Sdlauch mit Bier fullte. Dren Sirtige waren

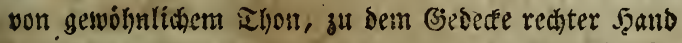
am ober:a Enbe des rifches, ftellte er aber ein fil:

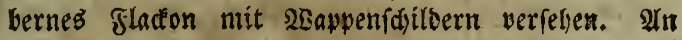
Dem oberen Ende bes Tifhes ftand ein Salzfap vor Silber, fabon gearbeitet, mit Salz you bleindender Wiseife, Pfeffer uno aldoeren Bsemuirzen. Cine zer: iduittene (Sitrone wars ebenfalls auf eiuer fleinen fit= bernen Platte yorgeftellt. Die ziven grofen szafar = butide, welche diefe Sorbeitungen volifonmen zu be: greifen foienen, feşten fich ieber auf einer Eeite bes. reifice, uno machten fich bereit, fure portion von ber

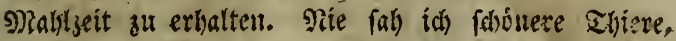
Die metur au eiu gewiffes (sefúbl bes anftands genofmt maren, nut wein ber Duft vom Eamín bís zu ibrer

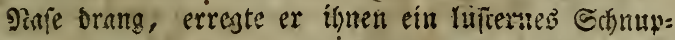
pern. Die fleituen f̧unde aber nabmen ikren Ylas unter sem Riface ein.

Scil fuble wabl, baf icf midi bey geringfigiger,

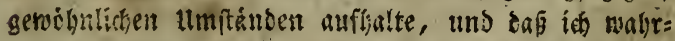

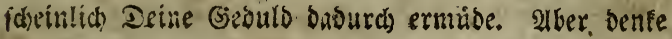


Did an meiner Stelle, allein an biefem ahgelegenen Srte ber nad bem allgeneinen Stilldmeigen zu ur: theilen, Der Tempel des Siarpocrates filbit fu fenn foricn - erimere Did baran, bafi es mein exfer 2rus̆fug von soufe war, vergif baten nidut, bas bie

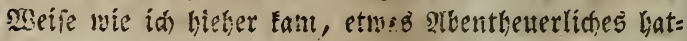
te, sas ein geheimnip̧suler Ealever alles bas zu um= geben fitien, wis id bieker gefehen hatte; und bann minit Du, glanbe ich, niăt melst liberrafict fenn, bas, an unb fir fich geringfigige ltmînabe, thir feiner Seit auffielen, uns meitum (Besádutuife aud fpater= hiu eingewright blieben.

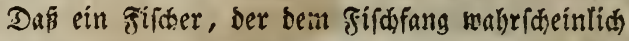

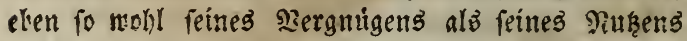
megen, nachgebt, beffer beritten ift, beguemer wohnt als die niesrere Slaffe der Rauern, nun, das ift frei=

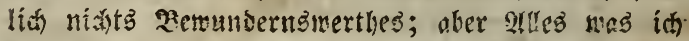
rah, fchtent anzubeuten, sas id mich eher in ber $R_{e}=$

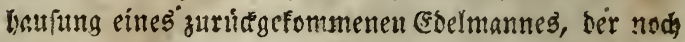

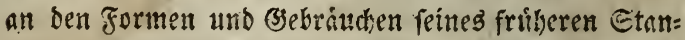
bes hing, befände, als in bem şaule eines gemolyn= lichen Zautern, ber fich won reinen Etantessentfen. nur durd verbáltnifimáfig gróperen - Sigblftano aus: seidinete.

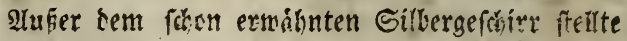
ser alte Maut nun eine filberne Sampe, Cruisie mie inr Estotten fie nenut, anf ben হifi, und zintete fie 11. Sie war nit gelåutertem se! sefullt, we!ctes. 
als man bie fampe anzimbete, einen lieblidien But verbreitcte; fie gatb mir (selegenheit; bie sisinde

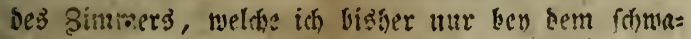
den Ridote bes feners gefehen hatte, gennuer zu be= traditen. Der Júdeintander nit feiner gemóbnlichen

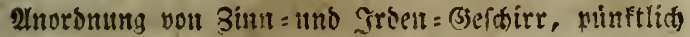
uno forgfältig gereinigt, frablte, nuf ber eiten Esite

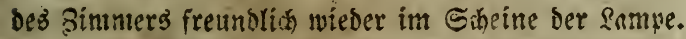
In eintm Erfer, ben bie ?itiche bes gemolbten Fen:

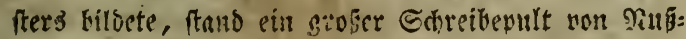
batimisols, feltiam cingelegt; uiber bentelben (Bsefädser

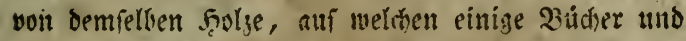
Papiere lagen. 2luf ber Seite welche bent Erfer ge: genuber war, waren, fo viel $i$ ith untericheiden fonnte, (benn fie lag im Sthatten, uno von meinem Flą̧̨e aus fonnte id $e^{b}$ nur unioffemmen betracoten) rine oder zwess flinten, Ginwerbter, Wiftolen uns anoere Maffen anfgeldatrf - eine Eammlnng, bie in einer armen foutte uns in einer fo friedlichen Begento nicht allein fonderbir, fontern fogar etmas verbaditig faten. Du fautit Dír mols voritellen, baf ít) alle dicfe Bemerfungen fohtller madite, als̈ crgiblte, oder als Du (renn Du fie uidst tiberfalageri buft) im. Etande marit, fie zu lefen. Swon imaren fie vepubigt, und ia) Sadite surauf mie id eine Itsiterbaltung mit hen ftummen Einuchuern bes (s)chotios anfmuinfen folte, als mein folityer, in ber Eeitenthure, burd) meldse er abgegangen war, wieber erfdien. 
Ex hatte ieķt feine grobe Nieitermủke, und fei=

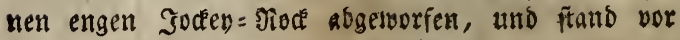
mix ba in ciuter gratten, enganliegeuden, fawars be: fercten Sacfe, welche feille breite, nervige Beftalt zeig= te, and feitte Beinfleiber von lichterer Farbe lagen to enge an bem fiorwer an, wie die spoctallaber fie zu tragen wiegen. Sein ganzer ânzug war vön feitierem Tuche als ber bes alten siantes, und feine \$záfhe, fo genau merfte in auf, refit uno unberdmutht. Sein Seento hatte feime Streifen und war am Scalfe mit einem falwarzen Bande befeftigt, úber bas fich fein

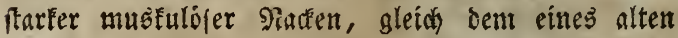
Serfiles, erbob. Der Sopf war flein, mit einer ho= Een હtirne uno gut gefornten şălnen. Ex trug we: ber Perafse nod) Scarpuder; uno die faftanienbraunen

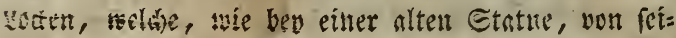
uem Soppe beral fielen, tritgen nidht bie geringite

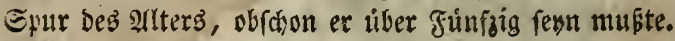

Seine alige waren fo eriaben uno fraftís, DaF man formante, ob man fie raub ober foton nennen follte. Doch gab bas funfelnoe ountle aluge, bie Mro= lerènare, Der woblgeformite Pruno, feinex Plbpíogno=

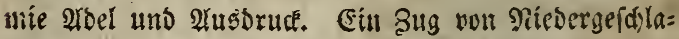
genheit voer vou Etrenge, oder vou beisen zugleid', fifienen ein melandolijd)es, bodiftrebendes (șemúth) zu verrathen. Iof fomite midh nicht enthaltell, bie fel= oen ber Sorwelt vor meinem Geifte rortisergehn zu

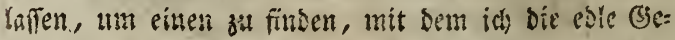


Falt uns boitums vor mit, vergleiden foonte. Ee

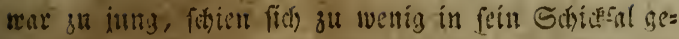
funden zu vitben, un dem Belifarius zu gletiten.

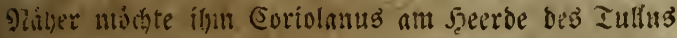
Qufioins foumen, aber ber biftete, bochmitbige 3lid bes frembest, war melsr ber bes siarills, fifzento auf ben Ruinen bes zeritorten Eartlingos.

9Gatbreno id $\mathrm{mun}$, verloren in meinen Trambil= bern, fasis, fand mein sisth am gener und betract)=

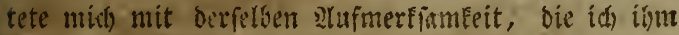

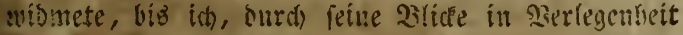

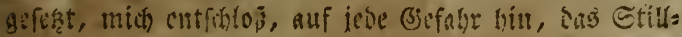

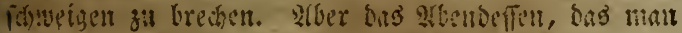
mun auftrug, erimerte midh an cin gewiffes (Scfubl,

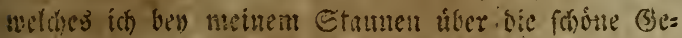
ftalt meines fribrers, fuit vergefferi batte. Entolich farath ex, mib faft exptarrte id) var bem tiefen, wallen Ton fititer Stimme, obgteids or mids nur cinlus, mids

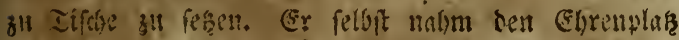

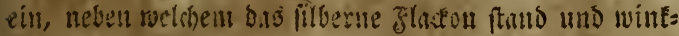
te mir mias nebsu ify an reicen.

Dit weigt, oaj Deines Saters genalte unb treff=

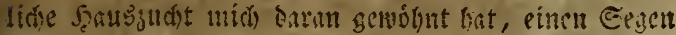
fpreben zu boren, elle wir b.

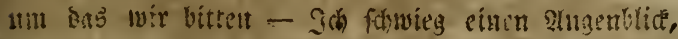
"ub ofichont ich es nicht faste fo vermuthe ids boch, minfen meine Bemenungen, meine Gebnten verntben biben. Die beiben Dience oder Hnteryebinest fapsen. 2B. Ecatru werre; XV. 
faron, wie id es bitte friber bemerfen follen, am utt: teren Ente Des Tídjes, als mein szirtis bem alten

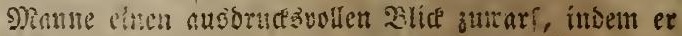

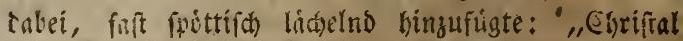
Ditron, firidis such bas (seket - ber sserr fdeint es zu erwarten." "Der lofe Feino merde Mieggelualfe uno fage Irtien, wenn ich siaplan werbe," bruminte bie angurebete gicrion in cinem Tone entisegen, ber cinem fteriensen Baren wohl geziemt batte; ,ifit ber Bsent=

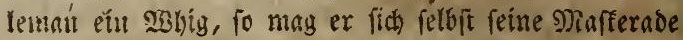

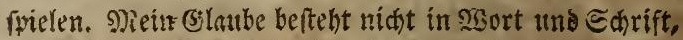
nobl aber in (serfenbrod und Braunbier."

"Mabel Moffat", fagte mein Jührer, indem ex

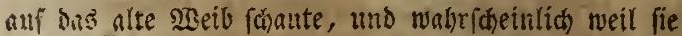
barthorig war, feime tönende Stimme erfiob, "fannft ou cinen Segen uber unfere Epeifen frrechen ?"

Die alte frau fouttelte ben fiopf, Eúpte bas Sireus bas an ibrem Niofentranze ling, uno fatwieg.

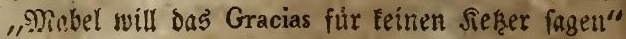
erwieserte der feerr vom f̧aufe mit demielben hóbni:

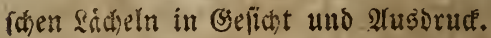

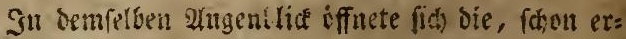
wihnte, Eeitenthitr, uno bus iunge Jrntiensinnier, weldhes id zuerit am Thore der siobnung erilicfte, trat eitige Sditte vor, baun abor blieb fie befdeiben fleten, als batte fie benurft, bas idh fie betrachte, unb frug den serrn des Sompis ,ob er gerufen labe?" "Ich ( fwrach nur fo laut, Damit bie alte Minlel 
mid) boren founte," erwieberte er, "mnb bod" pigte er linzu, als fie fid) umnanote um wieber zul gefien, "ed

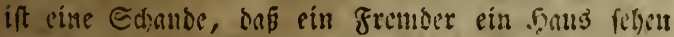
foll, wo midt einer ams ber Fanilie bas (Bsehet furedsen fonute ober mollte - fen ou unfer Sinplan!"

Dns sitidten, weldes wirlich fdion war, nalsete

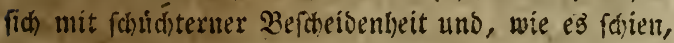
ohne zu wiffen bá lie eine, bier ungemólunlithe frand: lung verridte, fwrach fie den Eigen mit eituem Ioure gleidi) bem einer fitlernen stode, mit rilgrenser cin=

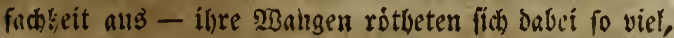
bas̄ fie anzubeuten fsicnen, ben minber fenerlicher (s) legenbeit wurbe fie verlegner geworden feyn.

Sisum Du nut cine fhome Beforreibung bicfes iungen Frautenjimmers erwartef́, Illan Fairford, un Dich) mit mir zu neden, bafi idg eine Dulcinea in ber Bewolnerinn einer Fifderbutte am Neerbufen von Eolway gefunden batte, fo folff Du fir biefes gial getaufdat werden; benn wenu id fage, bap fie ein redt

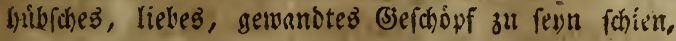
to ift bas alles, was id) fagen tann. Sie verfchwand, als ber Gegen gefprodien war.

)iein 2Sirth), brummte etwas von ber Silte un feres Sittes, uns vou ber rauben suft ber Eotway जiufie in einer Art, als wolle et es nicht beantwortet haven, und belub bam meinen Beller mit shatels Grillade, welche, nebft einer grofen liolzermen Edriffel voll Siartoffeli, แnjer ganges Minll susmadyte. Cini- 
ge Erowfen nus der Eitrone gaben ben Salim ei=

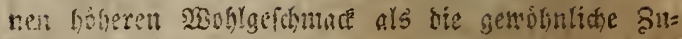
bereitung mit Eifits, und ifil verfigere Dir, bie

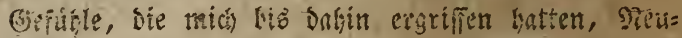

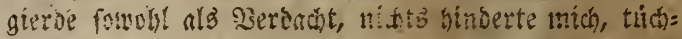

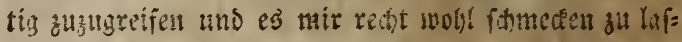

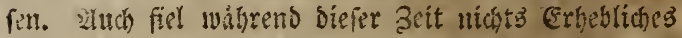
zruiften mir und meinem Gefellichafter vor, anfer baf er mir bie gemifulidgen Elyrentegergnngen des Tifhes (Die honneurs de la table) zwar mit 5̧dritgleeit, ioch nidyt mit jelter Gergliden Gaffireundichaft, erzeigte, welche Seute feines (anifineinenden) Standes bei fol= then Gizlegenthsiten gewsobnlid zeigen, fe!bit went fie fie niagt wirflich fiblen. Im (Ssegentheil, fétre sia: nieren frgienen sie eines bofliden ssirtfes gegen ei= nen unerwartetew, ia felbit anmidfommnen (Saft zu

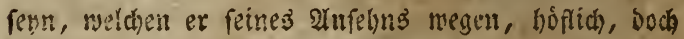
weter gut uodi beteitwillig empfängt.

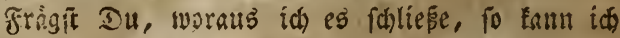
Dir es wabrlís níst fagen; ia went id Dir felbit

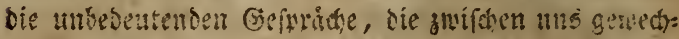

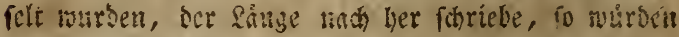

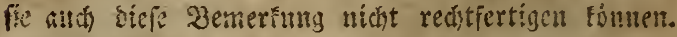
(5)enty, wenn er feime sombe futterte, neldies er won Seit zut seit mit gropser freigebigfeit that, fo forien

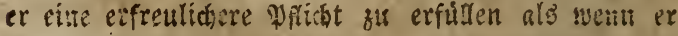

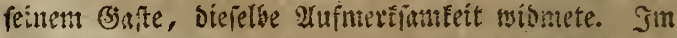
stllgemeinen madte er auf meinen Beift ben (a)ow er=

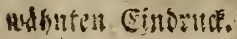




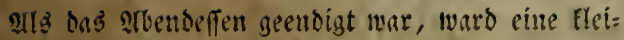
ne Imbahisflafhe nit Bramutwein in einem foltrmen Sieftell won gefochtenet Eilberarbeit ben Bsaiftent bar: gereitht. Sol) hatte fohou ein flemes (s)las Siquenr ge= trutifer, on fonnte ió midh, als siabel who (Shriftal fid beffen bebient batten- und bie Flafibe wieder her= auf gereiot wurbe, nicht enthalten, bas ssappen ge: uauer za betrachten, welehes auf Dem fitbernen Be: ftelle eingegraten war. Ұ/B̈ aber nteul Altge bem mei=

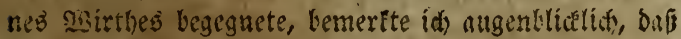

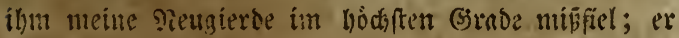
rumzlte die Etime, bíi fich in die Sippen, und zeigte

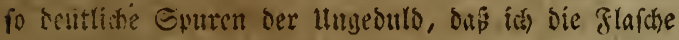
fouleich Gitufellte nub mid) zu entfouldoigen veriudste. Doch or wirbigte widh feiner Intwort, ia ex forien nicht simmal baranf zu bören nuto, auf ein Beichen von feinem Ger:n, entiernte Shrital sen Segentano mei= ner Fiengietie fomolyl als bie Schanle, worauf sas sisntwen geftudien war.

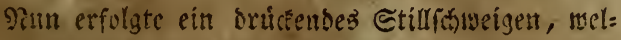

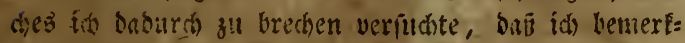
te: „itóf furchtete, meine Subringlidgeit bitte feiser Familie luanucbmlidesten vernrfacht."

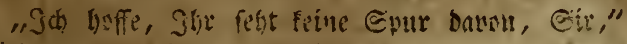
erwiederte or mit falter solfichfeit, ,iselde linats

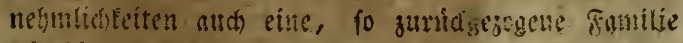
wie bie unferise burch cinen unersurteten buft, erleis

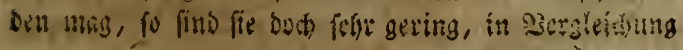


mit bem, was ber Gajt felbif burdh ben Nangel an

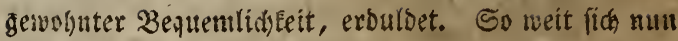

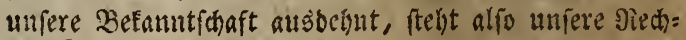
tuung gleich."

Diefer entmuthigeuten 2intwort ungeadstet, mach)= te ich, wie es in folden Fiflen gemoibnlich gest, eine

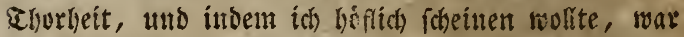

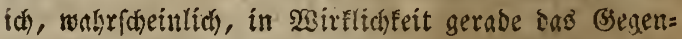
theil. "In furrotete," fagte ich eimen glice auf bie Geitenthure werfeno, "meine Siegenwart batte jemano von ser Familie von Tifshe versrangt."

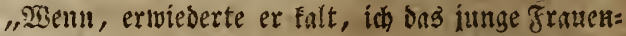
ginmer meinte, welties ich in Bimner gejelyen laitte,

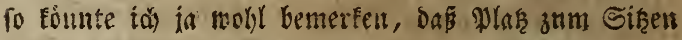

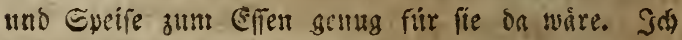
fontute bainer liberzeugt feun, baj fie mit gegefien bas ben wirbe, menn fie gè gemulufat hàtte."

Jeçt fonte id aber bei biefem doer einem andern

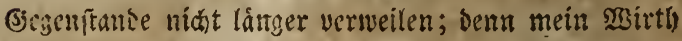

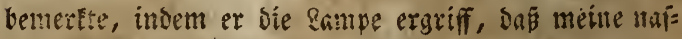
fat Slletor mid) nohl fur beute Fatht mit iber Citte aucirifnen wirdè, fruh zu Bette zu gehen; daf er ge:

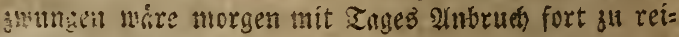

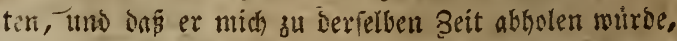

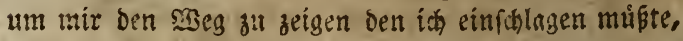
um uach bem Schófersbutch zurúa zu fommen.

Somit lis ex mir feitue Gelegenlyeit zu ferneren

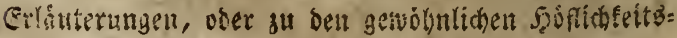


23eseugungen; benu ba ex weber nach meinem Namen frug, noch sen geringften यntbeil an meinen. Stand verrith, fo burfte aud id es nidjt wagen, ilgn mit folchen Jragen zu belaftigen.

Er ergriff bie lampe uno fithrte mich burch bie Eeitenthutr in ein felye enges Simmer, wo in ber Eile ein :iett für nich aufgefdhlagen worben war, uno ill= bem er bie Rampe binfellte, wies er mich ant, meine naffen Slleiser vor bie Thúre zu bángen, Danint fie, mákteren ber siadit, am Jetuer trodenen founten. Dann verließ er mich, inbent er etwas vor fich lis brunmte,

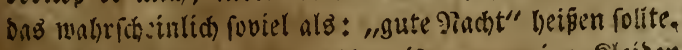

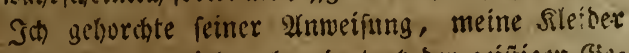
betreffent, un fo viel melve, ba trok ber geifítigen Bis= trinfe, weldise id zu mir genominen batte, meine sib)= we founatterten und id burch aingfliche Befinle ver:

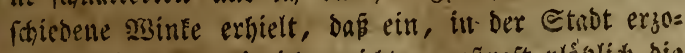
getter Gingling wie ich, nidht ungeftraft plofilid bie

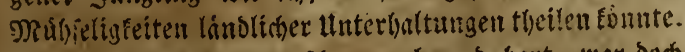
2lber meit Bett metm fofon grob und hart, war boch troceen uno reinlide, und bald bushte if fo wenig an

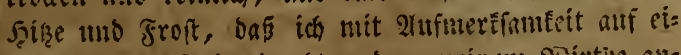
ben folweren Tritt bordite, ber meinem Sistive an=

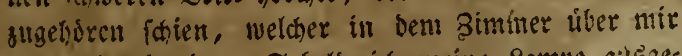
auf uno ab ging. Sobald id meine Rompe aubges

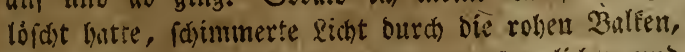

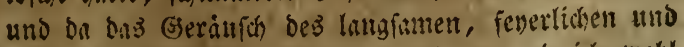

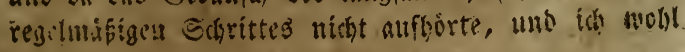




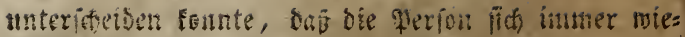

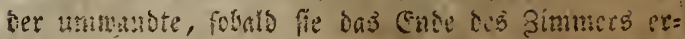

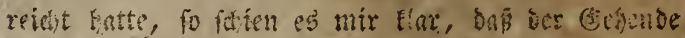

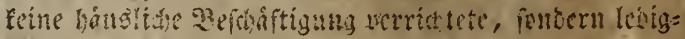

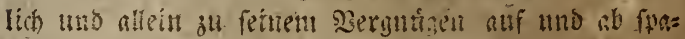

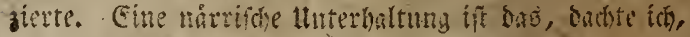

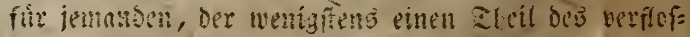

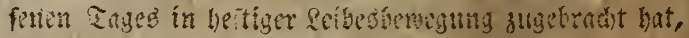
mid ber baven rebet, den nảdfen Jiurgen leim jĭn= bruक) bor Simmiertug aufathtilien.

Intersefien legant oor Eturm, ber foron ben gau=

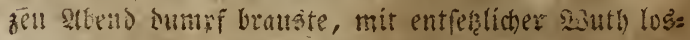
subrechen; ein Getofe, ifnlich bem in ber fertie rol:

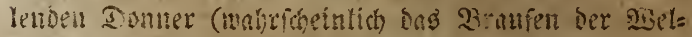
len, bie fich an ben llfer benthen) vernifiot mit bem

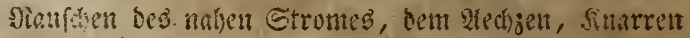

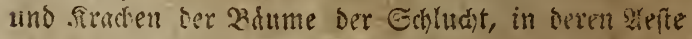

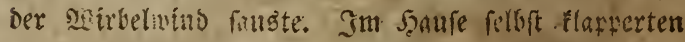
die gemiter, sie Thuren fielen

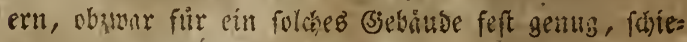
nen vim ๔urm zu zittern.

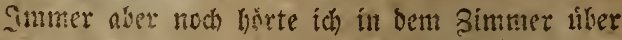

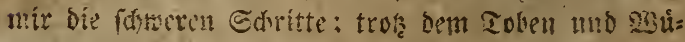
then ber elemente, gletchfornig anf unb nieter gelin.

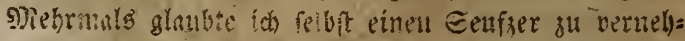
metr, boch seffele ich offen, bas in einer fo unhermli=

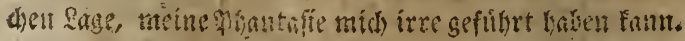

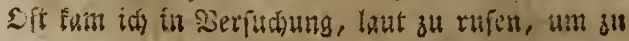




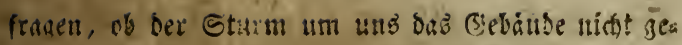
fälote; aíer wenn id boun an bett finfteren, tungefels

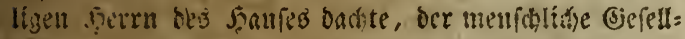

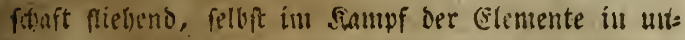

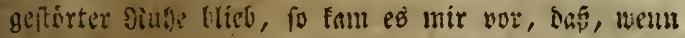

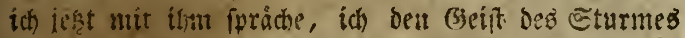
fellot bantete, ba es mir fobien, firn moeres sisefen foume fo rutsig uno getnffen blefben, wílyread um es Sibino uno sisafier fo cutresclid tobten.

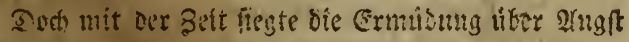
uno Siengicroe. Enttyeder der Cturn lię̃ nać), doee meine Eime ftunwyten fich gègen frime Edhreden ab, gentig, ich fallief eill, elye noch ber gebeimuifolle Sdyitt meines sirthes anfgebort hatte, bie Decie meines Simaters zu erítuttern.

9ion folte glatbon, bas siene meiner sage batte

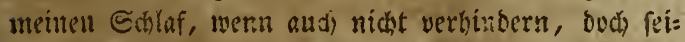
ne siube frotell, feime Dauer verfitzen follen. Dow

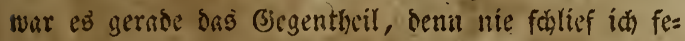
fter, unb erwadite แnu erft Dann, als beim 24ubrtid)

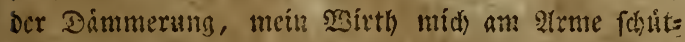
telte und cinca Tramat frorte, ben ich ou Deinem

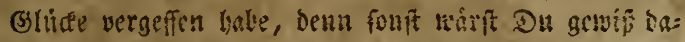
mit begltiat werben, in ber şoffnutg, onf Du bich Dabei als ein suciter Daniel zeigen witzieft.

"Ilor folaft gefuno," Fagte er mit tiefer Etim= me; "Doch else noch frinf Jalire liber Euer feampt ba= bin \{dowinden, wirb Euer Sallummer leichter feon - 


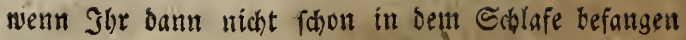
liegt, aus bem mat nie exmadyt!"

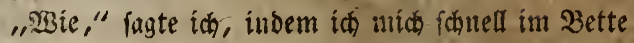
aufrichtete, "wist $J_{\text {hr }}$ etwas von mir, von neinen Derbáltmiffen, meinen 2lusifidten ?"

"sitidt bas. Beringfte," antwortete er mit bittes rem Rádyelu, "aber Shr tretet in bie Melt jung, un= erfahren und hoffiungsvall, barum proplezeitse ith

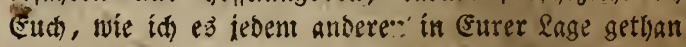
batte. - 2aber, fommt, bort liegen Eure slleider -

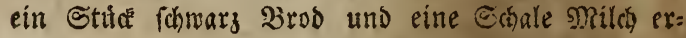

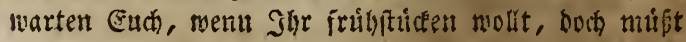
Sbr Euch eíleu."

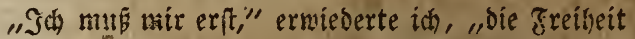
atblitten, einige Mimuten allein bubriugen zu birfen, ebe idh Die gewoihnlichen Tagegeidadfe beginne."

"Ia 10, ich bitte Eure 2 lndicht um \$erzeillung," antmortete er anto verlic

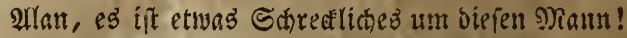

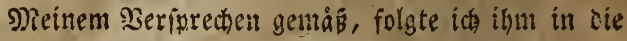
Siudie, wo wir geftern zu Fadit afien, und fano bort, mas er mir zun fruibftuce angebsten thatte, nicisto melir und nithts weniger.

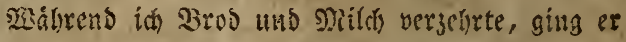
sweder auf uns ab; und ber langlame, aligentefiene,

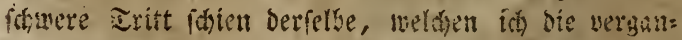
gene satht gebort gatte. Sein: Euritt, besidstig als

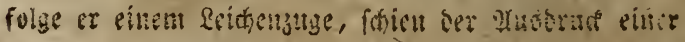


narh, einen Colon batte vorftellen fònten, gam talt biditig cines penzy gebet. Sd Hatte Deinen Mith nicht, shan, bot alfo nuct meinem getieimniprollen Dirthe nists an, obgleid trob bes Đrunfens mit fil:

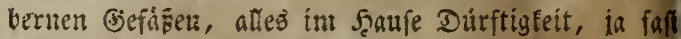
wirflice Sirmuth verrieth.

Mgir verliefert alfo ben sot zufammen. Ioch í

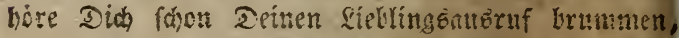

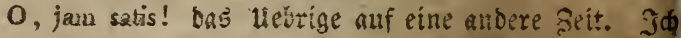
werise, iente id, meine Mittheilungen verichielen, bis id rebe, ob Du aud meine Gsute anerfenní,

\section{$\mathcal{F}$ ú $\mathfrak{x}$ ter $\mathfrak{B}$ r}

\section{Ilan Fairford an Darife satimer.}

Sth Gabe, mein theurer Sarfie, Deine amei Yerten Eviftel erialten, und bas sritte erwartens, war id

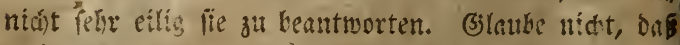
mein Etrffthweigen meitem shangel an intereffe sat: an, zuzurarreiten ware, Denn mabrlió fie itbertreffen

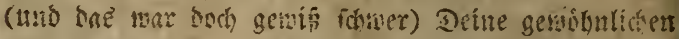
Dortreffichteiten. Seit ben erften 9lionbfalb, bis in

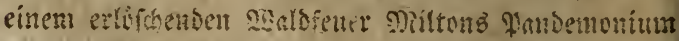
entbecte, - feit bem erften erfiudirifon subben ber

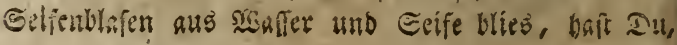


ein wixfliches Untheil genanut werben; aber was oen Sturm von Donnerftag (bcun on war es, glaub' ich) betraf, fo tobte, beulte, láminte uno fiólnte er éven To arg in ben alten Schormfteinfpizen ron Cadlemaker. Tow, als̀ er es̃ แulr an bell ufern bes Solway's foun= te, denu eben biefer Wrinb - teste me per totam noctem vigilante! - ja Télbfi nod den folgenden slor: gen, als - Bjott fiehe Dir in beiner fentimentalen Delifateffe bei - Du bem armen Sianme Rebenobl fagtefit, obue igm einen halben Sronentlyáer für grkend: effen uno Logis anzubieten.

Du lacifit mich aus, basi id einem alten Mianue einen penny gab (obgleich) Du genau genonmen fechs Fenze fagen múpteft) Den Du, im loben Echiutnge

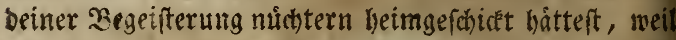
er bem Solon ober bem 2elifarinz gleich. Aflber Du vergapeit, bas die fogenannte 2ieleitoigung voin iem al=

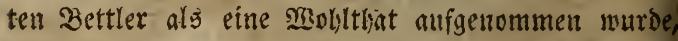

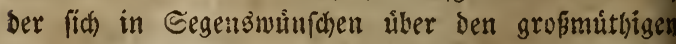
(3eber ergof, widrend er weit entfernt gewefen ware, Dir, Darfïe, fur Deine trodene Ebrfurcht vor feinem Barte in. .nftens zu sanfen. Serner ladjit Du liber meines guten sinters fludst won Falfirt, gerabe als wire es unziemend fuir einen Xiann, fich aus. Dem Staube зu marken, wenn bien oder vier Bergifalingel, nit getogenem flamberg und ferfen fo gewantot wie ihe Jinger, inm nachipringen, uno "furinisch" rufen. Du erinaefit Dich wobl nod, mas er fagte, als bet 
faird yon Buteflivat inm erflarte, Daß furinisch fo viel beist, als: "bleib boch einmal ftelyn."

"Ijas Teufel auds," fdrrie er, feine preskyteria: nifche Etrenge ob ber unverninftigen forberung bei foldhen umftiutton vergeffend, "baben die Spikbuben beun gcoactit, ids follte ftehen bleiben, um mir ben Soyf abrdineioen zu laffen?"

Denfe Dir fold' cin (s)efolge hinter Dir, Darfies uno frage Dich banu ferbit, ob Du alboann Deine Ed)enfel nicht eben fo in 2 (nf als Du es thateft zur seit, wo Du vor ber finth

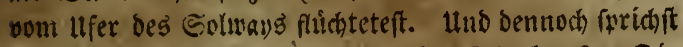
Dut meinem sater allen gruth ab. Sab aber fage Dir

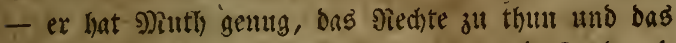
unredite zu verfolgen - Miutl) gemug, mit sano unb 2ive cine geredite Eatse su bertheidigen, und bie Cache des armen segen feiten Dranger zu fityren, olute bie folgen für fich fe(bit zu fürobten. Das ift Burgermutl, Darfic, mo wathrlich in unferem 3eit= alter, und in unferem Saterlande, ifit es fuir bie mei= ften siendien bochit unwichtig, ob fie miliabiachen 9) (utt) befif̧en ober nícht.

(3) ause aber nickt, bapi idh bofe auf Dids ware, obfdon iás es verfudse, Deine slieimung tiber meinen

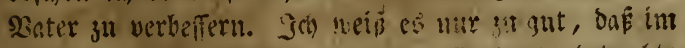

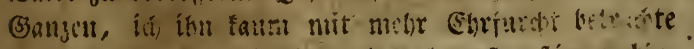
als Du. Uno, on id both einmal erñ̃ geffimm bit,

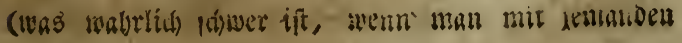




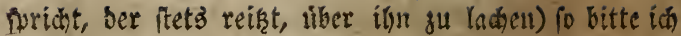
Dita, befter Darfie, la bi bith boch yon Deimem eifer nach abenthellern nidit mebr in ro gefabrliche sagen brit: getr, wis bie at den Dinten bes Solmar. Der tibei= ge Theil ber Erzáblung ift blofe Eintidoung; wobl sber batte bi fitirmifde giadst wersen Fonnen, wie ber gare sum Rear fayt: "eine bofe Tabt tarin zu folwimmen."

Dod) wem $D$ u itsrigens aus alten, quertopfigen Fifidern, gebeimnipholle, romantiche Şelden machea

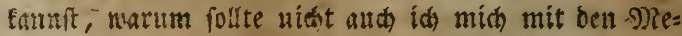
tanurpbofen unterkalten ourfen? Dods balt, felsit o.t, Da noth mu malt bediontig an werte gebn. Eben ber suciblicte Eaplan - Du furiafit fo wertig bon ilum, fo yél yon alfen anderen, baf einiger sweifel barob in meinem (s): mutthe entĩtegt.

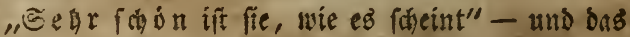

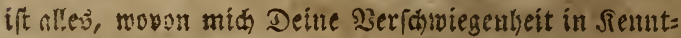

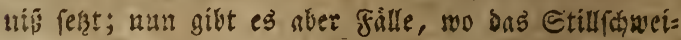
gen andere Dinge als eine Einmilligung bedcutet. Edanteit Du bí, oder marit Du erfáredt, Darile,

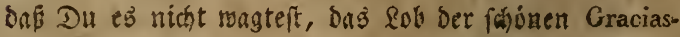
Sprecheriun zu verfunden? - Ẽo wahr ifh leve, Du

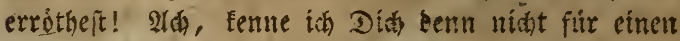
eingefeifoten Sivalier aller Damen? genoB ich nidht foun Dein Sutratlen? Ein jierlidier Ellenbogen ben Du fabit, wam felbit bie gange lubrige Geftak in ei=

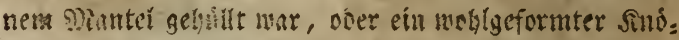
d)el, ben Du zufatfig erblifteft, nenn bie Jntraberian 
nad) Old Ahsembly Close gítg, fonten Dir auf actitEagen ben Sopf weroreben. Schon war, wenn id mid red)t erimnere, einft Dein feerz von eitnem Blicke ei= ne's unvergleichlichen, einzigen 2 แnges sefangen, uno

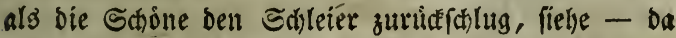

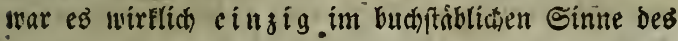
Siorts. Warfit Bu nidit zu eiter anderen Beit in ei= ne Stimme verliebt - in eine blofe Stimme, weldae fid in ber alten, grauen 3ridoerstirche in bic Pal= men gentifat hatte - bis Das Du entbedteft bas bie Befikzerinn bes füpen Drgans Miss Dolly Mac Izzard war, bie born uno hinten einen $\mathfrak{B u c}$ el batte.

Senn ich biefe facta wohl ervåge, und bagegen Deill feines Sd)weigen uiber Deine Piereibe vergleidse,

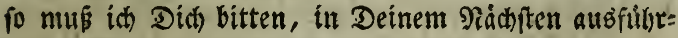

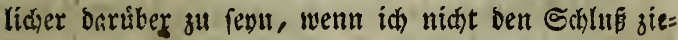

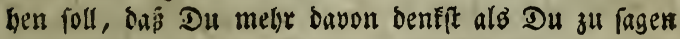
fur gut finoeft.

Du wirft feine grope शeuigfeiten von bier ermar= ten, ba Du die Sinformigfeit meines Rebens fennit uns wohl meift, bas es gegentwirtig uur einent un= unterbrodener. Stubium gerwiomet ift. Du baft es mir ia taufeno Mal gefagt, ich wurbe meinen Tegg nur Durá) ?iafigrublen madjen, alfo - nachgegribelt mus urerben!

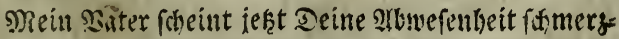
licher zu füllen als bas erite Mial. Er bemerft, wie es

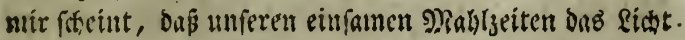

B. Ecots's werte. XV. 
feblt, mit nelthem Deine heitere soune fie erfielfe, ex empinitiot Echwermuth, fo wie fie manche Dreafiten

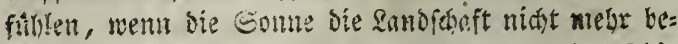

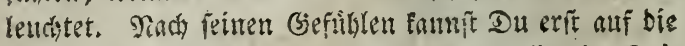
meinigen forliespen, und Eenten wie berglich ich Deis nen Streifzug beendigt, tut Didh wieber als unjern

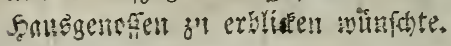

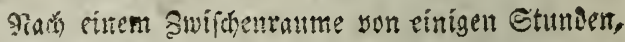
erigreffe ith vou Sienem bie feder, um Dich vou é= ner Degetentheit in Senntuif zu foren, allf wethe

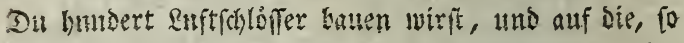

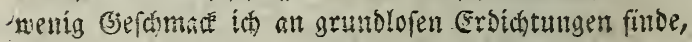
it) fotsi fonterbare sermuthungen grincen mus.

Nein şater bat mich feit. Surzen báutfig mitge= nommen, nenu er ill die (jerid)tsjif̧ung ging, um

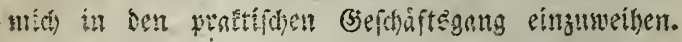

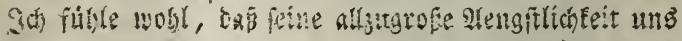

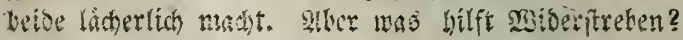

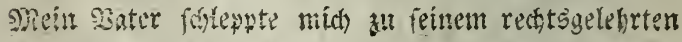
Sumait, - „Eino Sie berrit bente zu \&laibir, Mr, Mr. Eroffitie, - Das ift men Eoln, er if für bie Erranfen beftimmt - Só bit fo frey, ín bente mit in bie satatgoneriamnlung zu nelomen, blos Danit er fehe, wie man biefe Dinge lebandelt."

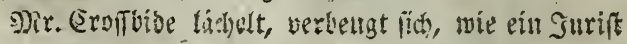

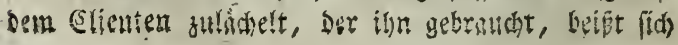


all bie Bunge, und fluftert Der erften beffen grofen

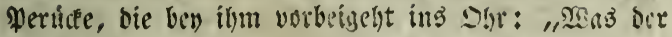

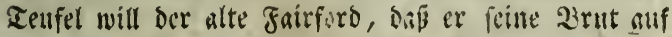
mid') losläbt ?"

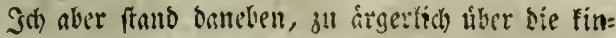
bifhe siolle, bie idly ficlen fillte, als bas idly ans ben trefflichen argumenten bes gir. Eroffbide grofien Pat=

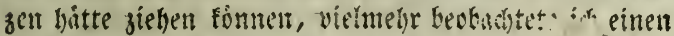
áttichen Mlan, ber meinen sater inme: leit im

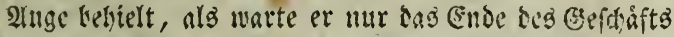
ab, in weldem er verwickelt war, nm inn nuzuredent.

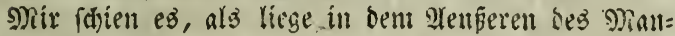
nes. etwas, das atufmerfanfecit erregte. Dodh war

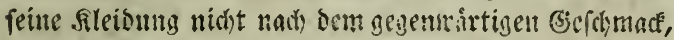
und obgleich einft pradituols, fotid fie mu vernltet uno umbafeno. Esin Sisce war von gefreiftem Eanmt, mit Eetoe gefittert, bie SBefe wour violetforbigem

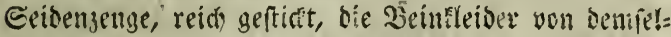

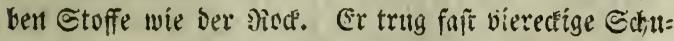
he mit bohen alb/ąent und feine feibene Strumbfe ma= ren an ten Sntieen zufonmengerolft, wie man $c^{3}$ nuf alten (Semálden voer hie uno ba an Erijistien fiebt, bie eitten Stolz barin fitcien, fich nadi ber Mivbe jul den Seiten Dietlutfalal'y zul Fleiber. Ein Chapeaubras unt

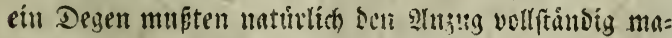

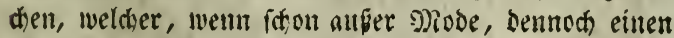
Ranu von @tande bejeitinete.

Siaum hatte Mir. Eroffbide feille Rebe geendigt, 6 . 


\section{4}

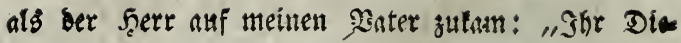
ner, Seerr Fairforo - ez ift lange ber, feitoem wir uns nicht faken!".

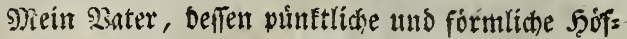
If(c)eit Du fennit, verbeugte fich, bufete, gerietl it

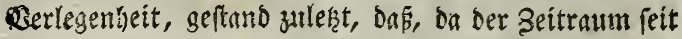
welchent er ind nidgt gejeben babe, fo grop fev - obs gleid) er fích des (seficítes volfommen erintere - bas

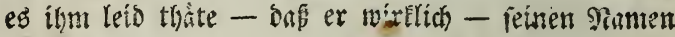
vergetren habe.

"SFabt Shr Den Serries von Birrenswork vergef fen?" fagte ber ferr; mein 2 ater verbeugte fid nod tiefer als zunor, went es mir gleidh fócen, als babe ber Empfang Des alten Freundes etwas von ber elir=

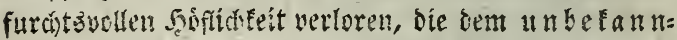
ten vergånut worden mar. Pan forien es mely- Pip=

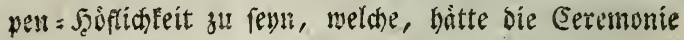

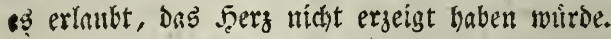

Indeffen verbengte fich mein sater ferbr tief, und boffle, er wirbe fith bod wobl befinden.

"So wolgl, mein fremb," fagte Mir. Jierries von

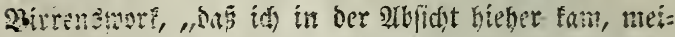

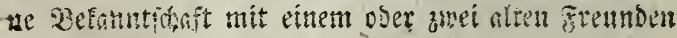
uns sorghiglich mit Grinen, zu ernetren. - Job logiere in meitien alten rbfteigenumtiek. Eis miffen bente mit mit bey Taterfon im percefopf effat - ea ift

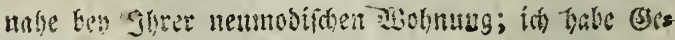
fiafte mit Jguen gu verbandeln." 
Mein Sater entictuldigte fich elirfurditsooll, boch nicht obne \$erlegenheit - "er wäre zu Şaufe úber: fdiftigt."

"Dann effe id mit Shne!n, mein guter $\Re$ ir. Fonir= ford; eill paar srinuten, welthe Cie mir nath Tifh fchenten, werben fir mein Bieschaft linlainglids genug feun, benn ich will Gie nidit von ben Ilyrigen abljal= ten. - 2luch bin ith. fein flaichenfreund."

Du baît oft bemerit, bas mein, Sater, ber die negeln ber Bonffrembidaft gemiffen!jaft beokatiter, fie boch mehr ber Yficht a!s bes 2 irgmigens ineaen, ausibt, uno wahrlid, biefie inn uidst fein biewiffen Den feungrigen za fweifen und ben fremben zu em= pfangen, fo whirbe fid feine Tlyure ben Fremben nod peltener offnen, als es ber grafl ift. Rie. fals idh ein ftärferes Beifpiel biefer Eigenleit, (bie'id) fonit Dei= ner Beichreibung nach fuir eine Enrricatur gelialten hatte) als in ber art, wie er bie Selffireinladung bes Nir. Seerries anfubm. Die verlegene Niene und bas erzmungene Sạcheln, welches bas: "wir werben bie Ehre baben, Sie um orei $\mathrm{tbr}$ in Brown's Square zu erwarten," begleitete, founte niemanden trügen, uno imponirten bem alten fairs bur(h) «us nicht.

Nit zornigem 3 lidée erwieberte er, "idi entlaffe Sie alfo bis babin, Nir. Fairforb," babei faien réu

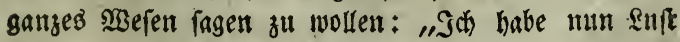
bei Dir zu effen, uno fúmmere míh nidt barum, ob ih Dir willfommen bin ober nidst." 
भils er fith wieg mante, frug id meinen 2 ater, wer bas mire.

"Ein unglicflidser Eselmann," antwortete er. "Er fielyt boch bey feinem unglủd ganz gut aus," erwie=

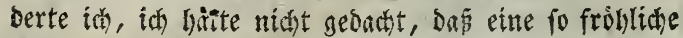
2upenfeite ein Mittageffen notritg batte."

"siser hat Dir benat gefagt, basi es fo ift," ver: ferte mein 2 ater, "Ci if omni suspicione major, fo

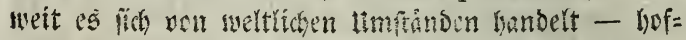

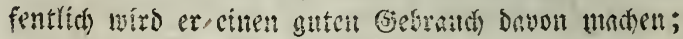

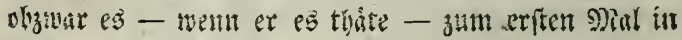
fituen \&eben wire."

"Si bat alfo unregelmapig geleft?" iagte ith. Meit Sater erwieberte mit fithem berichtigten Riebringsaus: Drute, mit nieldem er alle unspitigen Fragen, weldie

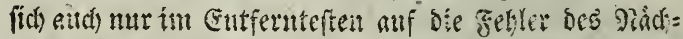

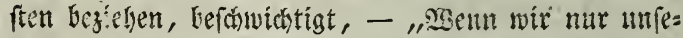
re eigene fehler verbeffern, sllat, fo baben mir gentug

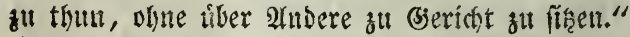

Da war ici alio wieder nicht redst angetomimen; aber $i(h)$ futipte von sieuem an uno liemerfte, or ba=

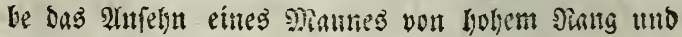
Goher gamilie.

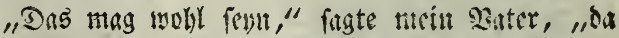

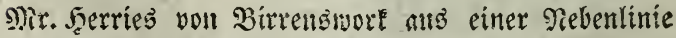
ber gropen, einft fo minchtigen Famille ber frerrics ab= ftammt, wovon bie âtere Brind: ill iem Semte 9it= thesente mit dem sode bes sorb siobia, bes whilofo: 
when Anno Domini-fedisgethi hunbert fieben und fechs:

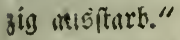

"Iit er benn nod in Befrize bes, diefem şare gelyirigent Miajorat's."

"Prein," erwicocrte meil 2 ater, benn fasn fut feitues Baters Beiten war es ein blofer Titel *) ba

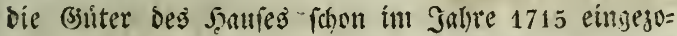
gen wurbon, als. Seerbirt Şerricg feinem Serwanoten,

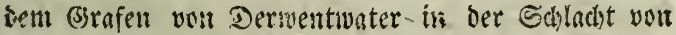
Dreston folgte. Smmer aber noch bebalten fie ben $\mathfrak{I}=$

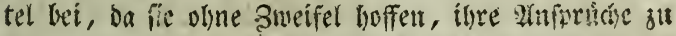

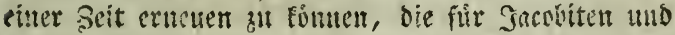

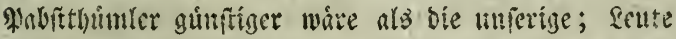
aber, welde teineswegs ilye thorigten samen uno sofftungen thoilen, laffen ilhnen bie Thorheit man= gefochten bingelu, ex comitate went nídt ex miseri-

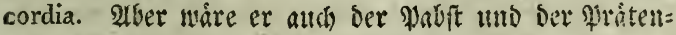

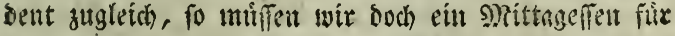
ín richten, ba er es fitr gut gefunoen bat, fid fersit

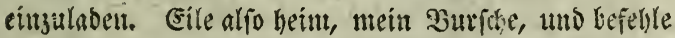

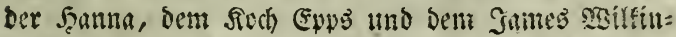

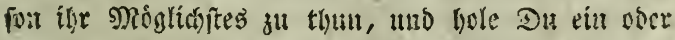
zneí Pioffel vom beiteat Macwell bernuf - er liegt in

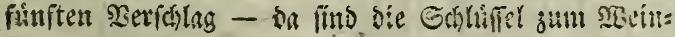

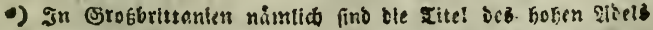
an bas Majorat geinupft. Der Beriupt beb sebterin jlegt aud ien bes Erfieten nach fich.

(Itumerf, Deb Heberfo). 
Peller, las fie aber nicht ftecken, Du tennit in bes az: men James forwadie Eeite, obgleich er bey jeber andern 2serfudumg, eill braver Serl ift - ich babe nur now etne Doer zwey Bonteiflen von bent alten Brantmein - wir muffen ín fur allenfallfige sirantheiten aufbe= ben, gllan."

Ici) ging weg - madte meine Sorbereitungen Die Mittrigeftunde fam, und fo guth פRr. Scerriez von Birretกรพwนrf.

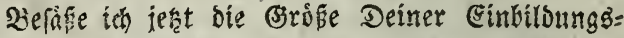
Traft, ober bie (Sabe zll foilloern mie Du, mein Dar= fie, ich wollte Dir von biefem Fremben ein fo fasines, bunfleb, mufteriftes, Nembranot = artíges Bemáloe ma= wen, bas ex fich zu Deinem Fifcher verbalten follte,

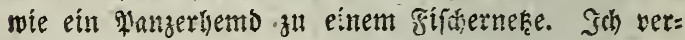
fidere es Dir, er bietet genug Stoff zu Beforeibungen Dar; aber ba ich meine Sdwaidse in ber Maleren fen= ne, fo fonn ich nur fagen, daj ich inn im hodften Srabe unangenelm finte, und fur fallecht ergngen bal= te. - গein, fallecht erzogen ift nidyt ber rechte 2 (us:

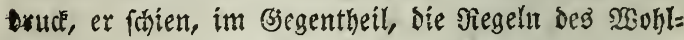
anftanses geneu zu femmen, aber zu glauben oer গang feinter Gefeilfonft enthebe ilyn ber snibe, fie anszu

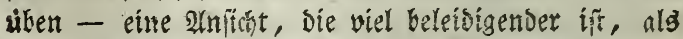
ware fein Betragen eite Fotge natrirlicher Siobheit ober

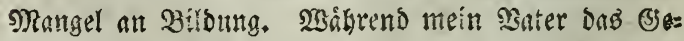
bet forach, piff ber Rairo, titio als ích, alif meines Maters 


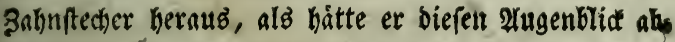
gelwartet, üm ilgn zu gebraudien.

So ging es. mit ber Sirche - mit bem Sobnige aber gings nod) folimmer. Du weift, Das̄ mein $2 a=$ ter voller Elyrerbietung gegen feine bsafte ift und im vorliegenden fall faien er mel)r alb gewoinnlich geneigt, iedem Intaffe zum Etreit altşzweichen. Er ging po gar fo weit, oas ex frine Siectitlichleit umging und

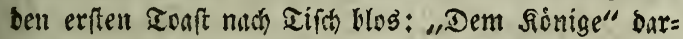
brachte, ifatt ber gemilnulichen pathetifhen Form "nem sionig Bjeorg." Unier (Sa)i marhte eime Bewegung mit dem (s)lafe, fo dafs es auf bie andere Seite des

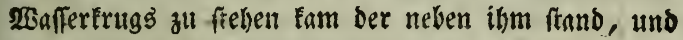
figte himu: ,jenfeits bes 2 Saffers !"

Nein Sater errottiete, boch ftellte er fich, als

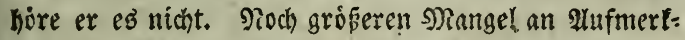
famfeit uno an gebufirenter Ebrfurdit zeigte ber frem= be in Feinen Nanieren und in bem Ton feiner untez= baltung, fo bas in faum meitten Sater entichuldigen gu fonnen glaube, baj er fo ftille bie Fredsheit bul= Dete-, mit welcher ber allfgebringliche (Saft ifn an fei= nem eigenen Tifche behanbelte; wenn idh folon feine Sorurtbeile fur şang tuto hole Bjeburt Eenne, und

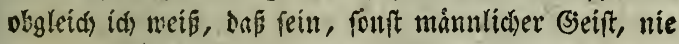

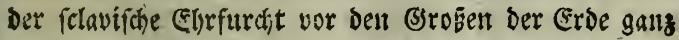
entragen fonnte, welde in feinen Sugendabren bas Niegiment fübrten.

- Du fankft es einem Neifenden in demfetten Sagen 
wohl verzeifn, wem er Dir zufally'z ober felbit alls

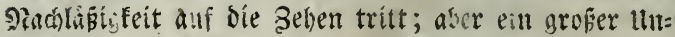

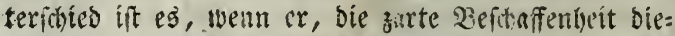

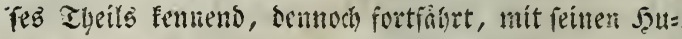
feu barauf herum zu tappen. Mieiner fdwathen Mei=

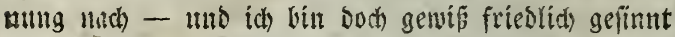
- fanmit Du, in biefem Falle, mur mit Múbe eine Siriegserthlintu vermeiden.

Ic) glanbe, mein siater las meine Ssesmten it

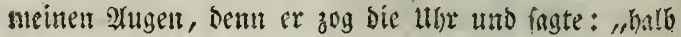
funf, sllan, - Du follteft zu biefer 3eit anf Deiner Stube fenn - Birrensworf wird Didt entiduldigen."

Injer (B)ait nicáte nathlifilig und id batte feinen

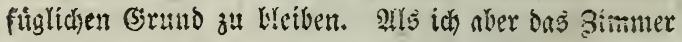

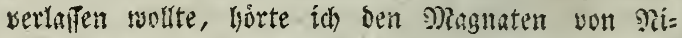
thesbale beutlith ben Panten satimer ausprecten. In

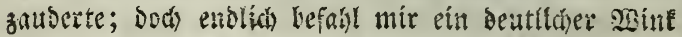
meines siaters, micli zurúa zu zieínen; als iá), eitle Stunbe fwiter zum ible gerufen wurbe, lyatte unjer Gutit uns verlaten. Ex hatte diefen abend in ber bo= hen Strafse (s)efhafte, uno fonte fich ferbft bie Beit nidht neimen Thee zu trinfen. Sol founte die $3 e=$

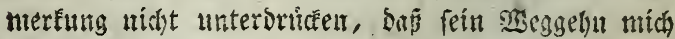

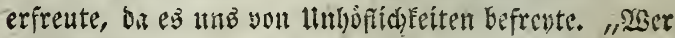
bat inn berufen," ingte i何, "uns bie Serinderung unfer 250 bnutg von einem unbequemen in ein beties

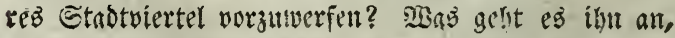
netun wir bie 2equemlidseit, ia firbit ben surus eis 


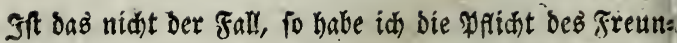

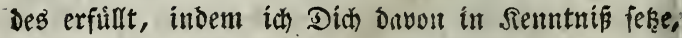

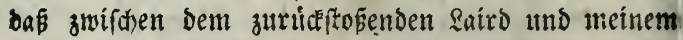
Sater etwas im \$્sert ift, bas Dich bochliá) interefiirt.

Lebe wohl! und obgleity ich Dir Stoff zu Iráu: mereien gab, fo baue bod fein zu idweres ミalofi auf

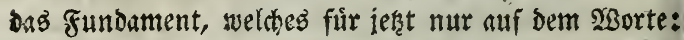
"Latimer" berubt, weldies im Sermache eines cbel= manns von Dumfries = Shire und eines Sontigl. Sanrei= bers auşgefwrodhen wurbe - Caetera prorsus ignoro.

\section{Se d)}

Darfie Latimer an $\mathfrak{A}$ lan fairforb. (Fsortfegung dez 3 ten und 4 ten grieiç.)

Эक) erzaiblte Dir, baj ith mit meinem erniten, finfern sirithe ins Freve trat. Siun fonnte id Deut: licher als in ber vergangenen গadit bas einfame Thal felsen, in weldhem zwei ober brei Schitten ftaliden, die

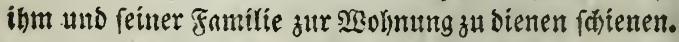

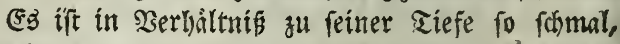
bapi Eein Strabl ber Miorgenfonue es erreidien fann, anto es wito nur Dann beleuditet wann bie Gonne Goch am frorizonte ftebt. Blidit Du in Das : Thál= den binab, fo fiebrt Du einen idjumenben Bad, ber in fluditiger Schnelle jenem Diaftig enteillt, wic ein sienter, ungeouldig das Biel zu exreis 


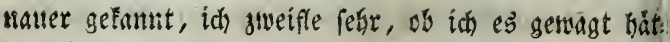
te, finab zu freigen; benn er verdiente eigenţlid nur Deir Pamen eines Sanals, welcher zum guten Theil

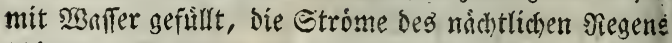
fariumeno und bratient in bas Thal leitete. S)it ei:

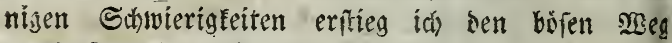
zu Fuse, aber mir forwilidelte, went ich aus ben Efuren, inelde. Der Niegen nícht-vertofdst batte, fab,

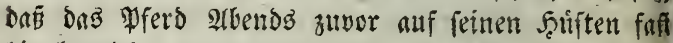
hinabgegleitet zut fenn ichien.

Mein Sirth) fowwang fich auf feines Pferbes Rut: fen, obme ben $F u b$ in ben Steightigel zu feł̨en-fam mir ben gefährlidyen șeg hinauf, jtwor, unb fpornte fein গố als fơne es wie eine wilbe Since flettern. waffer und Sdmus fprízte: beim wilben sauf von

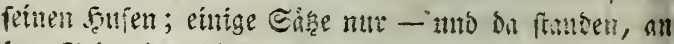
ber Epise ber Sluft wo id fie eintholte, -

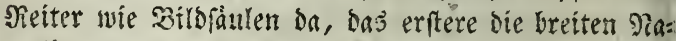
fenlidyer auffwerrend, ben Morgenuind anfoufangen,

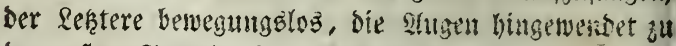
Den erfiten Strablen ber anfgehenden Sonne, nelfe im Difen empurfiteg und die entfernten siebirge son Eum= verland und siodestale verzolsete.

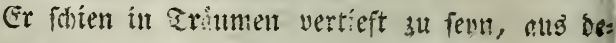

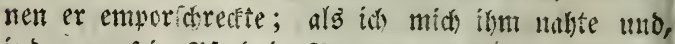

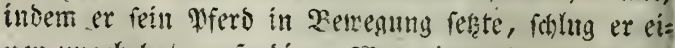

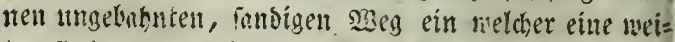

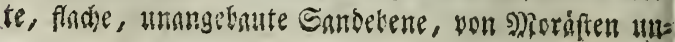




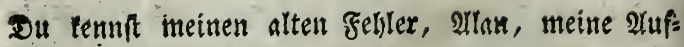
mertfantfeit lieber iebent anderen (segenfín:tbe zu wio=

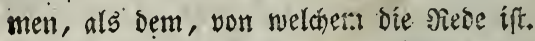

Diefer -liebenzwuiroigen Eigentheit zufolge úberleg=

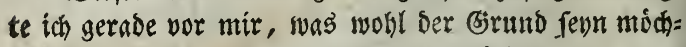

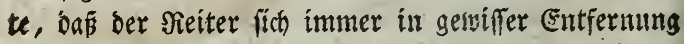
von uns bielt, als̀ mein Bsefathrte feine tiefe Etimme

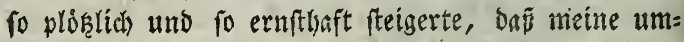
berirrendent . Gebanlen fíd mit einem Nale wieber

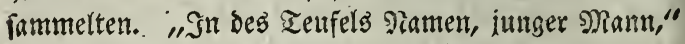
rief er, aub, "slaubt Shr, andere Reute founten ihre

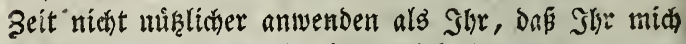

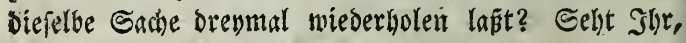

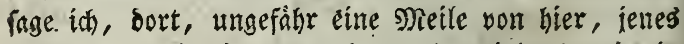

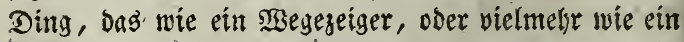
Galgen ausfeelts? - Sdf wollte, es hinge írgend ein

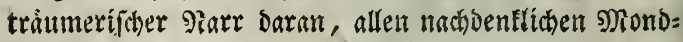
E⿱⺊口𧘇lbern zum warnenden tige Pfaht mirb Euth zur Brutue fulkren, Dort geht Sht alfo úber ben breiten Bach, immer grabaus, bis fid ben einem Sténthaufen melyre:-e 2 Sege frenzen Der beenfer such, ba triumet er fdon wieber!"

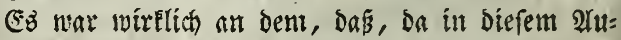

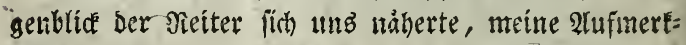

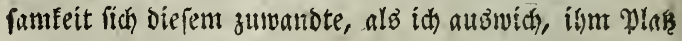

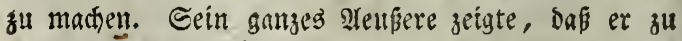
Der Gereüriftaft Der Freunte gehore, ober mie bie siselt

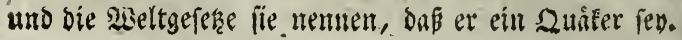


Cin ftarfer brattobarer, eifengrauer . Flepper seigte but ds

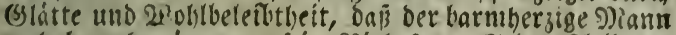
nuch larmberzin gegen feitu sieh fen. Seine Rleioung

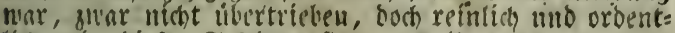
lich wie biefe Eeitirer fich su Eleiden pflegen. Eín langir tleberrod von angigescidinet feinem Itiche mel= d)er bis auf bie flife leernb fiel mar biơ ans simn zugefnopft, um ibn gezen bie Jiorgenluft Der Siano fémes nad) Dutfer $=2$ at , olme Snopf ober Ealeife herabhingende 2 iberlyuts, befhattete gutmú= thige, freundiche singe berill Ermft nit pitter Dofís Sountor's gentif(a)t nar, weldyer mit bem finfteren pu= ritanif(ben agefen weldses bie frómmlet bendela, nidbto gemein sul baben forien. Cine bobe Etime fres von ben Falten bes arlters ober ber 5euchelei, ein flares stuge, rubig und geferzt, forich boch einen 2 ftrich von 2 lengitlidifett, wenn nidht von Furcht zu ver: rathen; und als er ben gewónnlichen (3ruls: "Ît) wün= fhe Dir einen guten s)torgen, mein Fremb" alls= furach, oränte er fein Nof fo mabe an, bie eille Scite

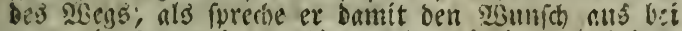
uns mit fo wenis tmifatioe als miglich, vorbei zu

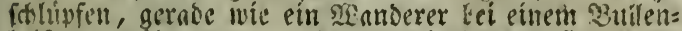
beiser voribergelt nuf beffen-friedidje Gefinmung:t er feinesivegs vertraut.

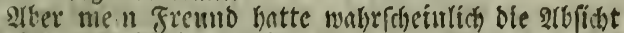
nicht ibn fo frieblich vortiberziehn zu lafien, benn ex

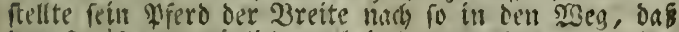

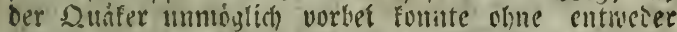

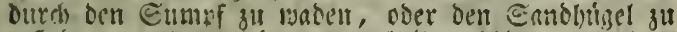
eritreigen ; unto zit leituem von beiben fotien er fonters

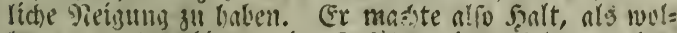

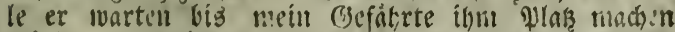
wurbe, und mibrend lie fo gegenuber franden, fonte

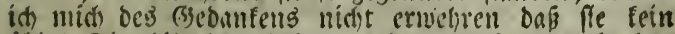
übles Sinnbilo des Siriego und des. Friebeng abgeben פB, Ecott's פierfe. XV: 


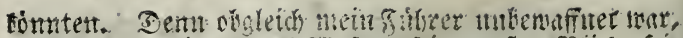

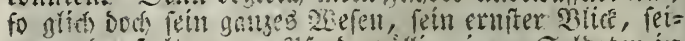
ne grabe Jaltung zu plfers, vôlíg einem Eolbaten it Cinilfetoung. Er redete ben Dutifer mit folgenden groorten all: "- Sen, ba Jreumo Solua - Dub bift bente ruthe auf bem gege, hat ber Geift Dial unb

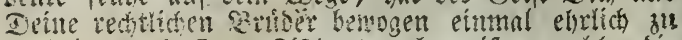

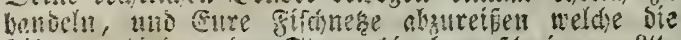
Jifthe verbinbern ben Etron bind zu fobutmen?"

"Beveif nide, mein Fround," antmortete Gofur

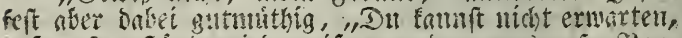

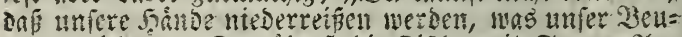
tel aufrichtete. In tootejt sie firche mit હpeer, In=

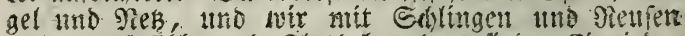
sielthe ouf Gbbe uno Fluth Eereciniet fint. Ein jeder thut, was in feinent थugen am beiten focint in fei= nen Bermaen fith einen Theil ses ङegens zu verfidern

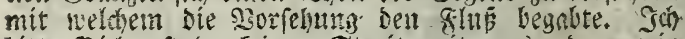
bitte Dich, fuche Eeinen Etreit mit mos, Denn wir werden Dir fein turerht zufingen!"

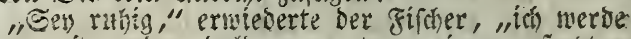

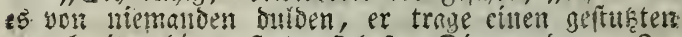

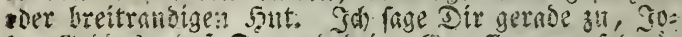

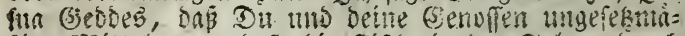
Eige Nittel antrendeit, bie Gifüe fn ber Solwan surds:

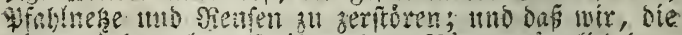

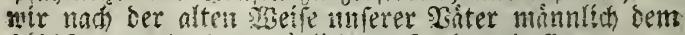

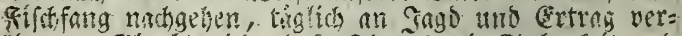
fieren. (Sthubt nidot bng She es mit Eghrbarfeit und bandielet ausfibren merbet mie bisher. Die sielt tind suir fenten Enth. Shr molt ben Ealmfang, ben lins serhalt finfoig armer Fontilien vernichten, und bant

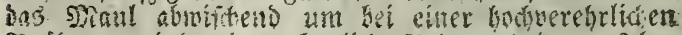

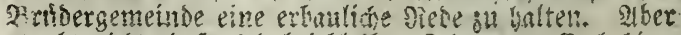

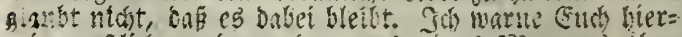

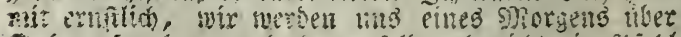

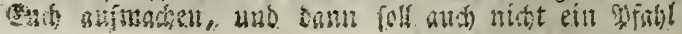


in bem Brunbe bes Sollwan felten bleiben, bie Fluth

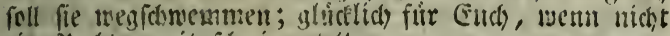
ein Madister mit fotmimme."

"Trenns," ervuiederte Sofura mit einesn ergmun=

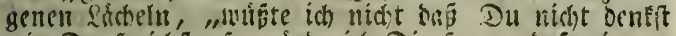
mie Du rurichft, fo wurbe id Dir fagen, bas wir un=

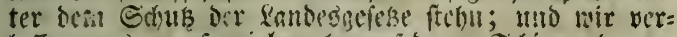
laffen uns unt fo viel mebr auf beren Echirn, ba m=

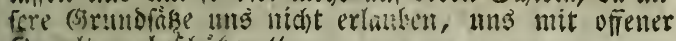
Benalt zu beithitsen."

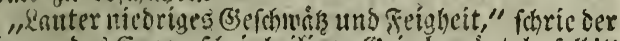

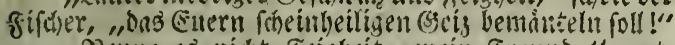
"Pienne eg nidst Feigheit, mein Freund," ant= wortete ber Sllafer, "Da Da wohl weist, bafi nenig= ftens cben fo viel sinth Dazu gebort za bulben wie zu hanbeln; diefer Stungling ober irgend ein anderer, urtbeile, ob nidit - felbit in ber mieinums der sielt, deren 2Infidten Du hulsigft - ob esi nicht feiger iit,

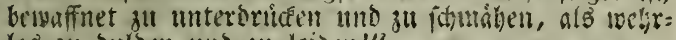
los ơ ouloen uns zu leiocn!"

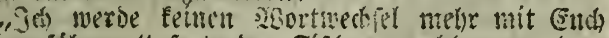
sartilier fuiben," fagte ber Fifber, welder bun bent leg̨ten (Srumb des Mir. Gsebdes ergriffen, iljm mun plab

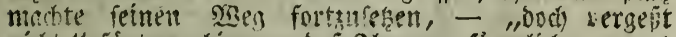

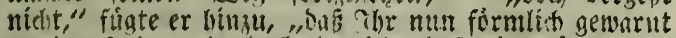

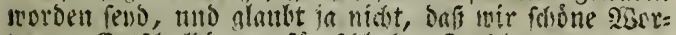

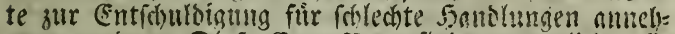

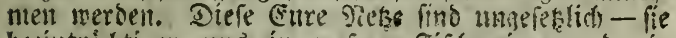
beeinträditigen ung - in unferer Fifererei - uno wix

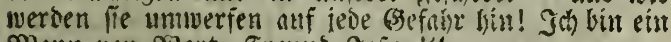
Dianu von Siort, Fremto Sojua!"

"Id) glambe eg gerne," fagte ber Dudafer; , abee um fo voriddriger follteft Du sann ald fenn, das zu fagen, wns Du nie nusfitigren nitrt. Denn ich fage Dir, freuno, objwar ein fo grober unterfaces givi= fden Dit uno einem unfres 20 lfes ift wie juifden 
einem Soiven und einem Schanfe, fo glaube id bod

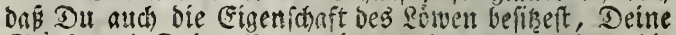
Etarfe und Deine Sisth niát an denen zat zeigen die feine Mittel zum Misideritano befiken. Der Sage nach foll o as (5ite an Dir fent, weun aud wenig mels."

"Die seit wirs es lehren," antwortete ber Fif her, "sod hore Solta, ehe wir uns trennea, wifl tó Dir "(selegenheit veridhaffen, eine gute That zu thun, wels

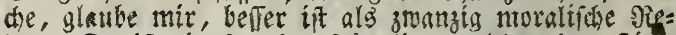
ten. Da ift ein frember Stugling welchen ber Sitm= nel to fwirlich mit (sjehirn verfehen hat, baper fith,

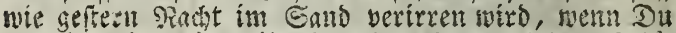

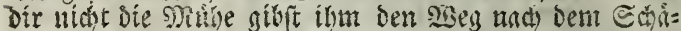

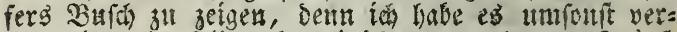

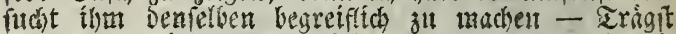
Du wohl fo viel Miendienlicbe unter sem Mantel Dei= ner Einfochleit, Quáer, Das gute \$BerE zu thun?" "Sieit, Dir Fremo," antwortete Jofua, ,mus es an sienfidenfreundich feit féblet weil Du me ver=

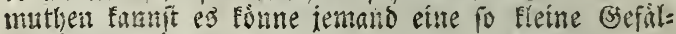
ligfeit veriveigern."

(3) hast Rient - id hatte kebenfen follen, bas es̉ Didn nichts foftet - innger Serr, biefes fromme

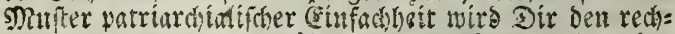

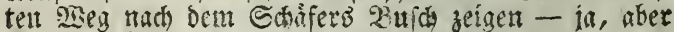
Dexnd wird er Dich faterea tvie ein Edhaf went Du allenfalls won ínm Eanfen oder ihn verfaufen widit."

Bant frug ex mith plisglich, wie lang id wobl

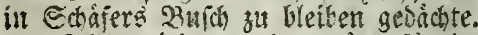

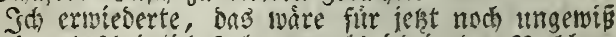

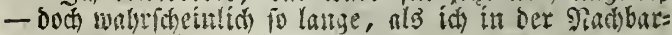
fijaft linterlyaltung finden wiros.

"Shr liebt bie Fifdiagd?" frigte er ín bemfelben furzen frageton bingu.

It) bejabte $e^{3}$, Doch bemerfte idh, Dafich vollig unerfabren barim ware.

"Sisen Slye vielleicht nod einige Tage bort wohnt." 


\section{1}

Fagte er, ,fo werden wir uns wieber begegnen, und id foumte (Eü) vielleicht Itnterriobt barin gelent."

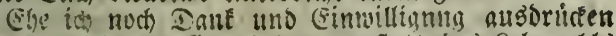

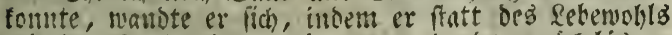
mit der sono winfte, hatmeg, und ritt zแrud bis an Den froblwen wou melchein wir antşegangen waren; als ex an siande ftille lielt, founte ith nod lange rei= ne Etimme horen, wie er ben Bewohnern bes Thalb surief.

linterdeffen ferten der Dotåfer und id) einige Beit unfere Peife ftitfónueigent fort; er zwang fein gehor= fames Dferd zu eineut Sajritt bem felbft eit minter

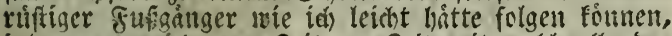
indem er mish von seit zul Seit nit mollwollender Neugierbe betrachtete. Эo meines Theill hatte fei:s Seigung die unterhaltung gu eroffuen. Jh war big=

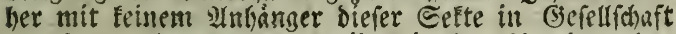
gestefer, und um zu vermeiben in ber 2 nrebe, ohte es zu wiffen, oegen eius Jhrer Sortrtheile ober (5i=

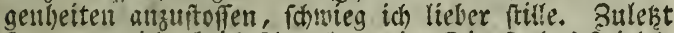
frug ex nitid ob ich foron lange im Diente bes Sairbs, wie man ihn nemte, ftánbe.

Scli) wieberholte bie \$Gorte: "iu feinem Dienfte?"

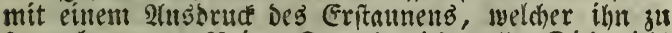
fagen berwog: "siein, Freuns, id) wollte Bich niat beleibigin, vermuthlich hitte ich mich leffer ansge= brtidt, weun idj geragt hatte, in feiner (sefelfifhaft ein Bewdohner feines Fanfes - meine ich?"

"Id feme ben Mrant, von bent ich midh dien trentite, gar nicht," fagte ich, "uno unfere zicfant= (d)aft nar mur vorulergelsub - Er war fo glitio, nír bett $\$ 3 e^{2}$ von ben Dinen zu zeigen, und mix eine giachtherberge gegen ben Sturn z"s-gewabres. Damit fing unfere Refanntfchaft an, unb walbricheinlich wird fie anth Damit enden, Denn Shr sueroet wohl bemer= fen baß uner freund feinessuego geneigt focint.

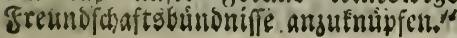


"Iin fo viel woniger," antwortete mein Befilurte,

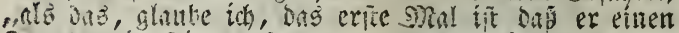

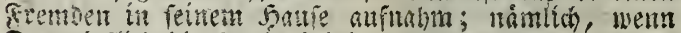

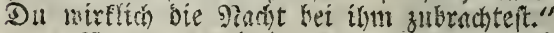

"PBaram zweifelt SGr Daran?" erwieberte ich,

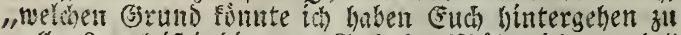
wollen? ath ift la bie ganze Gathe ber s) Rube nidht werth."

"Sen nitht bofe auf mích," fagte ber Dunfer, "aber Du weift, ocis. Dein égues Solf fith nicht an Die einfactie abalntheit bindet, wie wir es in ber $D e=$ nuth unferes serzens su thun freben, fonderi bas

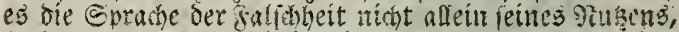
fondera auds ber jofidifeit, la mandhal fogar bes blofen seitwertreibs wegen, gebroudt. Jch habe man: berlei (siefhichten von meinem Pachbar gebort von denen ich freilids nur wenigen (Stauben farthe, boch fino anci) biefc fontwer in Eintlang zu britgen. Da ich aber jeist fum erfitn Shal horte, das er einen frem= ben in feine SBobnug aufnabin, io fonnte ich euten

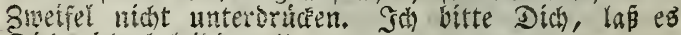
Dich nitht beleioigcu."

"sar fobeint," fagte ida, "nidst eben febr reidslich

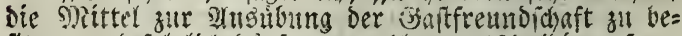
firen, uno folglich burfie er wohl zu entichulógen rebn, weun er fie in gewóbulidien fallen nidit mbietet." "Das beigt fo viel mein Freuno," erwiederte So: fua, "als Du bait fiblecht zu ?adbt gegeffen utio wabr=

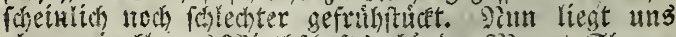

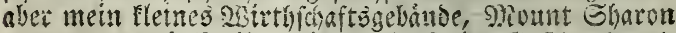

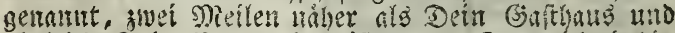
Disgleich Deil \$3eg weiter ift wenn Du mić) Dabin begleiteit, als ber gerabe sigeg mas Sheprers's Bufh, fo Denfe ith, wirs 23ewegung benen jungen (Sliedern fo wenig fhaben, wie eill volfitándiges gutes 9)Rahl

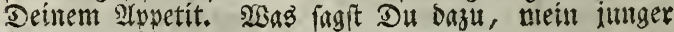
Befannter?"

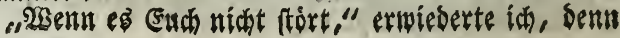




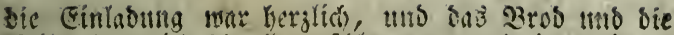

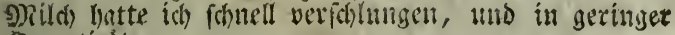
Qunutitát.

"9iein," fagte Softu, "getranche nidst die Surat the ber (somplimente nit betten weld)e Daranf vets

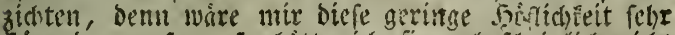

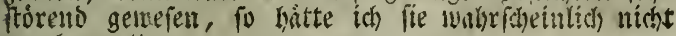
angevotelt."

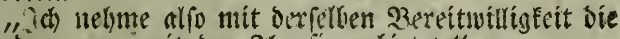
Eiulabung an, mit der Jhr lie mbietet."

Der Ouafer láchelte, retéte nir bie sano, ida

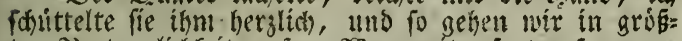
ter 2iertranlid)feit unfern 2 seg weiter fort fuf́mmen.

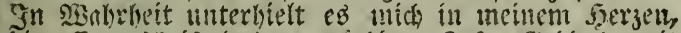

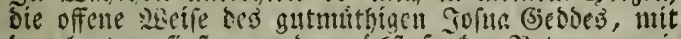
oent larten, finftern und zurueftofictoen 2ietringen mei=

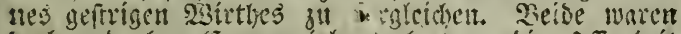

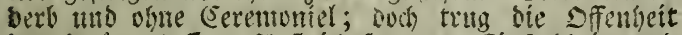
bes Duàcers einen Inftrich frommer Eitifachbeit, uno war ntit fo viel âchter șergensgute gepaart, alo wolls

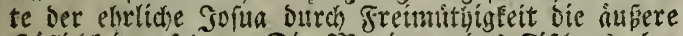

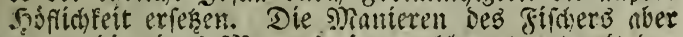
juaren bie eites 9)?annes, Der nohl vertrant mit bea Siegeln cintes feitten Betrngetis zn foun fóten, ber

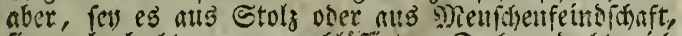
fie zut beobachten, vernachlalligte. Doch gebachte ich

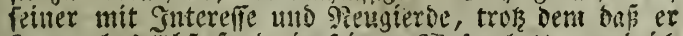
fo manches subtopente in feinem siseien hatte, und id

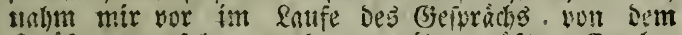
Sudfer zu crfabren was er von ín wipte. Fr aber

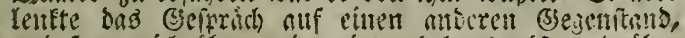
unto frug mich uber méne égente selensweife tnto ther

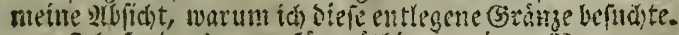

Jith fant es nun fir nithig, meinen simnen gut

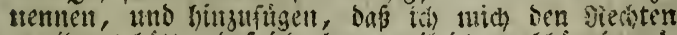
gemiomet hatte, bas ich aber, meil id utabhangig wa= re, wis cite Erbolung erlantht batte, mo sun in 
Elgepharo's Buch wohnte 1 m beffer das Sergnisen

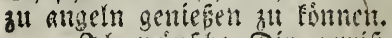

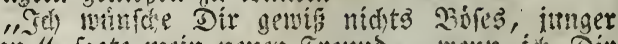
Minun" fagte mein neter fretmo, "menn id Dir für Deine ernfe Stmiben cine befere Befoiftigung uns ein nenfolideres sisernntgen (wenn Du bod) Ber: gnigen fudifi) fir Deine ("tholumgsitunden waniche."

"Shr fovs freng, Sir," ermieberte fín - "Denn

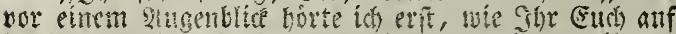

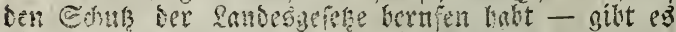
alfo Befece uns Nechte, fo mus es bosh aud Nechts=

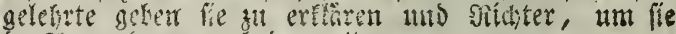

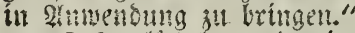

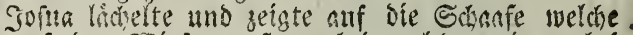
elen auf ber sciefe graften, bei weldher wir vorkei

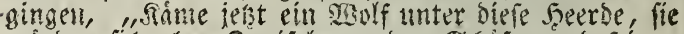
wirben firi obre Buchel ma ben Sdifer mo feinen

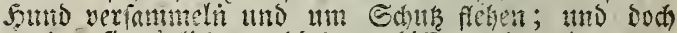
werben fie teiglich yon diefem gebiffen uno gewlagt, won iencan gefororen und zulest untgebracht. Dorh fage idh bas nidit um Didh zu beleibigen, benn obgleich fiechte und siechtogelebrte ein thebel finto, fo fino fie boch bey

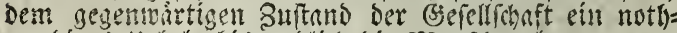

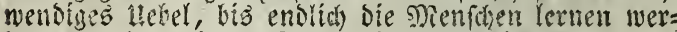

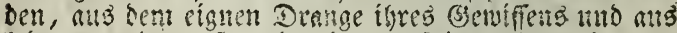

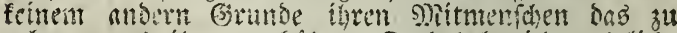

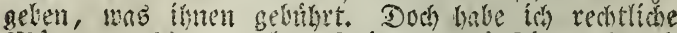
g) Tonner gefahnt weldie Deinen zuftuftigen Stano

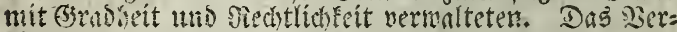
Dienft beffen ift thr ro viel gróser, ber aufrecht malt=

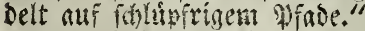

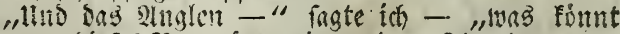
Shr gegen biefes saergnigen einwenden, Glik, der went

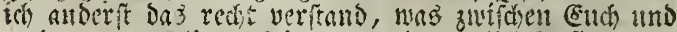

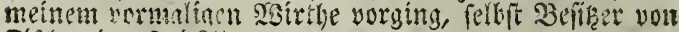
Fifchereich felso?"

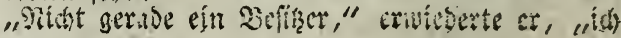


bin nur mit 'anderen Dabeí betbeiligt, ein Pachter, ment Du fo willit, eituer etwas bebentender Galm=

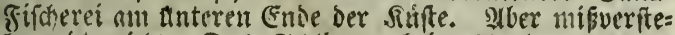
be mids nicht. Das Echlinnte beim \&nglen, morun= ter (ts) aud alfe Sirten ber Jagd wic man es nennt, veritebe, welche das Seiben Des Tlieres bezweckt, be: ftelit nicht im blósen Fangen mo Tosten ocr Thiere, mit meldien die (5) ite bor Dorfelsung bie Eroe zum Beften fer Sienichen bevolferte, fondern carin, Das nan aus ibren Leiben einen Eegenfinnt bes Şerguti=

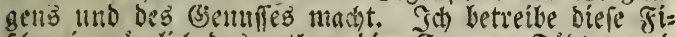

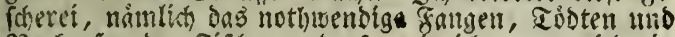
Serfanfen der fiffae grade fo wie id, ment id ein

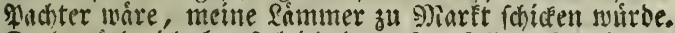
Dod whirde id eben fo leicht baranf verfallen, Frende am

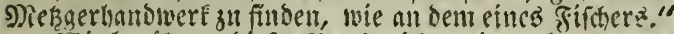

Sis beribrten diefen Wunft nidht meiter; Denn wenn (d) foon feimen (S)uno fiir allzu freng bielt, fo furech) mich bod) nein (senifien von jeber nitbern Freube, antifer ber an ber Theorie ber Feloingo frei, burmm friblte (id) alfo feitten 2oruf in mir eine 2ieiciafti= gung, weldhe mir nod) to wenig Freube gewaibrt bats te, zul vertheidigen.

Soir waren wibrend ber beit an ben Ueberbleib: feln bes alten sisegneifers vorbeigefommen, ben mein Sirth vorber als Marfifeit bezeidnet batte. Joh ging tiber eine verfallene bolizerne Bruice, welche anf lan= gen, frridétiobulichen Bfoften rubte, wábrens mein neuer Freuld Stron aufuarts eine fichere Furt zum ourdreiten fudte, Denut Der Strom war bebeuteno altgefortwollelt.

शtls ich ibn ant fenfeitigen 1 fer erwartete, beob= achtete ich einen 2 Ingler, weidser eine forelle nadh ber

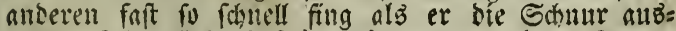
warf. Joh geftebse das ich ntich, trok meines freutu=

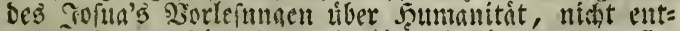

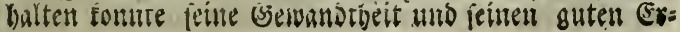


folg sut bencion, fo naticlid in unferem stemithe bie

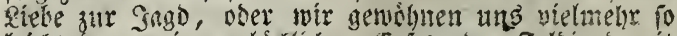
feicht baran einen glucklidhen Erfoig ber Felohago mit émer Joee on Sergnigen uno mit bem Lob, mel=

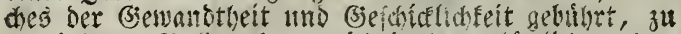
verbinoen. Bald exfaunte id in ben shictichen silng= ler belt fleinen Benjie ber, wie Du aus meinen fri= beren Priefen erfêten bait, ntein Rebrer uno unter= weifer in biefer eolen funit war.

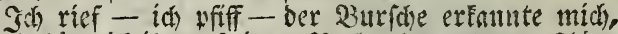
und als hatte ids inn allf einem serbrechen ertapt, fohien er zu jchwanken, ob er firth noberen ober fort lastfen follte; als er fich zu bent Eesteren entichtofis, befturm= te er mid) mit einem lauten, larmenden wnd tibertrie=

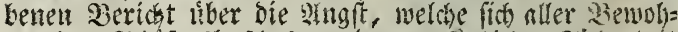

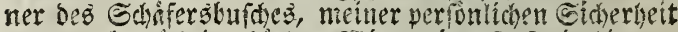

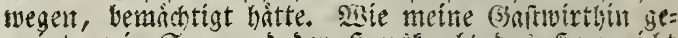

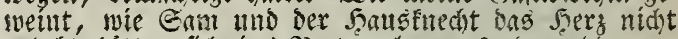
gehabt hátten fich ins 3ett zu legen, fondern bie gan=

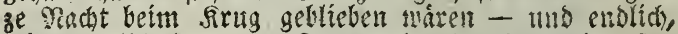
wie er fellit lange vor Tagesanlerud alt fgeftande!t fen, um Erfuttoigungen tiber midh einzuzlelien.

"sibabridseinlich pläticherteft Da tat sBaffer," pag=

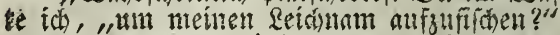

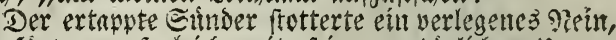
bod fugte er fogleid ont feituer natirlidisen linver=

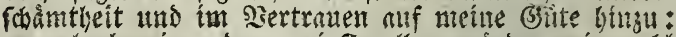
,er glanbe pille dere zwei frorelfen wirben mir tungl

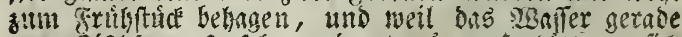

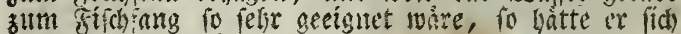
nidht entyalten formen bie strgel arşumerfen."

\$săbreno nir in biefem Niortwedhlel begriffen mo= ren, fam der wurdige Dotater ma alloren Ende ber

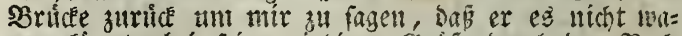

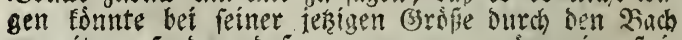
zu reiten, fonbern bafi er gezmungen wáre eine ftei= aterne 2 rúde sufuludben welche eime uno cine balbe 


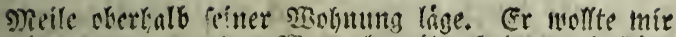

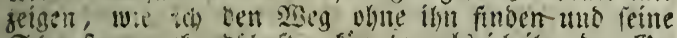
Eshmefter alsfunbichaften fónate, als ich ibm ben (je= donferi einflóste er folle, stenen er es fuir gut híelte, fein wero ben fleiten zienile altoertraten, ber és

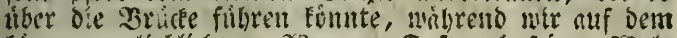

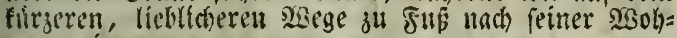
nutng gintigen.

Sofma fduttelte dent ropf, denn er fenue, fagte er, oen fleimen Denile als ben grösten Taugenteds in

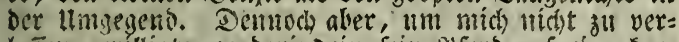
lafill, willigte er Darintecil fein wfero auf eque fur= ze 3eit feinter Sbint anjubertranen; Dod ermalnute er inn ermitich sas wiero ia nicht gub beiteigen, fondern

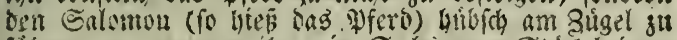
fübru, wosegen or ibm ein Eedygpente Sttice bei gu=

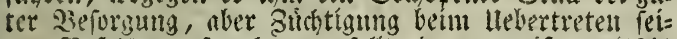
ner Befegle verfprads, "er foúte ban genis geveitidgt werben?."

sierfprechungen fofteten meinen Benié weníg, ex gelobte noch melyr ais man verlangte, bis ibm ber

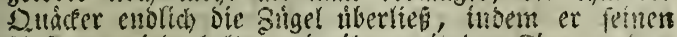
Anftritg wisoergolte uno ínm mit ben Fingern sro= hete. Sth, meiner Seits, trug bem Benile alif, bie

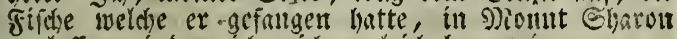
gu laffen, intom idh midh zugleich bey meinem netten Fremtude entfituloigte, oa ta nicht wiffen fumte ob

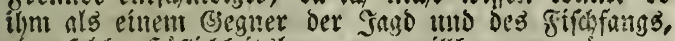
eute folche 5 biflidfétiobiesengung willfonmen ware.

Er veritand mich fogleid und rief mir fetme Defi=

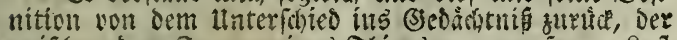
zmichen sin fanjen eines shiers zur granfamen \&uit

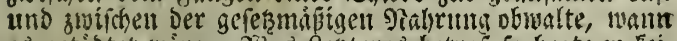
es getootet ware. Mias Reßteres butraf fo begte er Fei

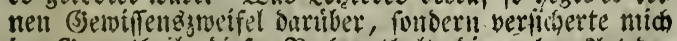

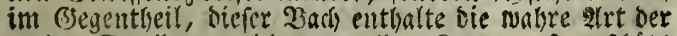
rothen forellen, welche von allen fiemern fo gefobaht 
wúrde und betten, (wetm fie nach einer Stutbe, nach= Dem fie gefangen murden, gegeffen werden) eitte eigne

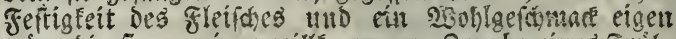

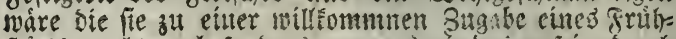

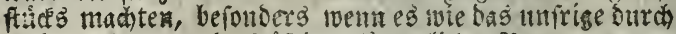

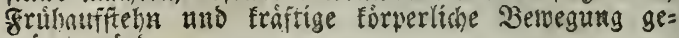
wúrst nurde.

Een nur rugig, allan, nod babent wir bie grifche

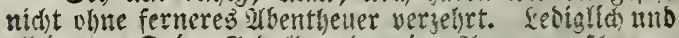
allein um Deine Bjebuld uno meine Ylngen zit fdonen,

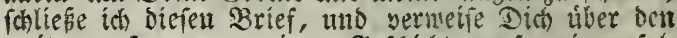

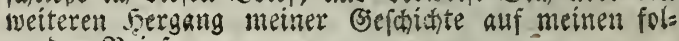
senden brief.

\section{Siebenter $\mathfrak{B} \mathfrak{i}$ f. \\ Derfelbe an Denfelbetr. (Fortfeţung.)}

Der fleine Benite mit sem Pferse manderte alio auf Der litufen Eeite Des Zinches, wáhrent oer Duáfer und íli auf ben ienfeitigen llfer fwazierten, wie $\mathrm{E}_{a}=$ vallerie uno Sinfanterie derfelben 2 trmee bie beiden llfer

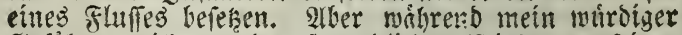
(s)efabrte midh von den freundichen Biefen un feiner 230bnung unterbielt, wid bet fléme Benite, obigleich ihm befohlen worben war in unierem (s)efichtśtreffe zu bleífen, von Dem vorgeichriebenen siese ab mo fílyr= te, indent er fich redbts iranste, ocn anvertranten $\Xi_{a=}$ lomon var unferen alugen fort.

"Der Elende will ifn reiten," fdrie Solua mit

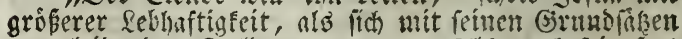
von leidenter Dulsung vertrug. anlb er beftig fort eilte uno fich bie fonlten van ber Etime zu verichen=

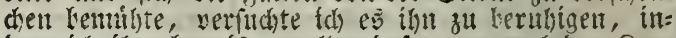

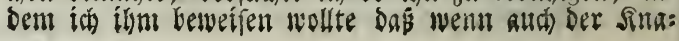




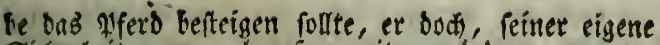
eidjerbeit wegen, langram reiten márbe.

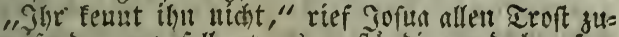
rúcliveliento, "er foll etwaz anftindig unto langian thun - tein er wiro anf sem Silomon galoppiren er wiro bie wabige Sedenlo dis armen Shieres, Das

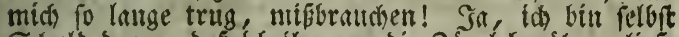

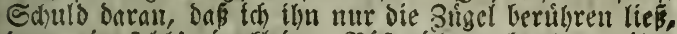
benu ein folch' cin fleiner 30 fervicht gab es vor ínm. utoch ntost im Eante."

Dant rednete er alle Sandfrevel ber, beren et Sentie befduldigte. Er ftand im serbadit, ben sieb= bifbuern Fallen su fteflen - war son Sofua felbit bar= auf ertapyt norben, alö er bent Singuigeh mit Reim= rutben uadgeftelit - ein fowerer sierbud laftete auf

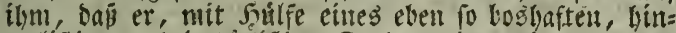
terliftigen, beimttudichen Dachshumbes wie er, meh= rere Faß̨en gequält uno geplagt bâtte, eltelich und Gaupt= fádich wurbe er angeflagt, cinte (Ente geftobien zul ba= ben fubem er fie mit eben biefent Dachslmuse eriag= te, welcher fo gebant im Siaffer wie auf bem Lanbe

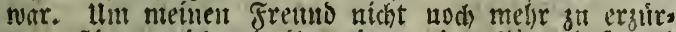
nen, ftimute id mit ilgm ein, uto erflirte bas aud id - aus eignter Erfalirung - ben 3 inbent sur Satalts: brut redonte. Sofun Eedoes aber tndelte bent susbrud als zil tibertrieben unto unzienend im ginnde eines

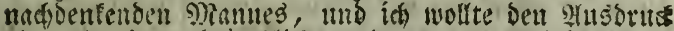
elen als eine gebriuchliche 9iebensart vertheibinen, als wir vom imfeitigen bórten weldies anzugeigen fofien, dos Salomon uno S3enite im Etreit begriffen waren. Die Enmorighel, binter meldyen er fich yerbarg, batten inn feiner sib= ficht gemás, unferen 23liáen entzogen, er hatte sen Salomen beftiegen und illn trichtig angetrieben, fo waren lie in guter freundfofoft fort galowyirt bis fie fich ber furt niberten, bey welcher bes Wferses gejes=: mápiger Eigentbutuer fdsou vorbét war. 
fier nter entitund eine Derforiedenteit in sen

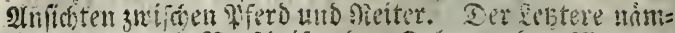
lid) wollte und soridhrift, ben Ealomou ben nis's aur fremernen Drufice an filgren, aber Ealomon glaubte

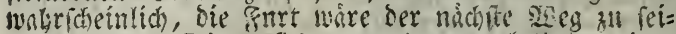
nem Etalle. Die âniditen nutoen von beiden Eeiten heftig befritten, tuno wir borten Deniies, "halloh -

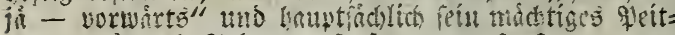

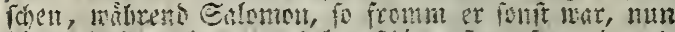

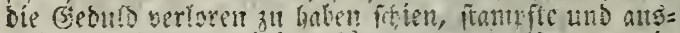
fá)lug. Siefer vereinigte corm mor es aljo, cen mir bórten, olyoron wír fie nicht feben funnten, und bef= fen Bimo Golua mobl vertmitgen fonte.

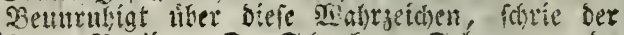
Dunfer: ,2ienjie - Du Ecturfe - Ealonion - Du

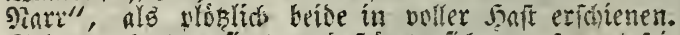
Ealomon batte gefiegt, uns fimste fich min iommit fei=

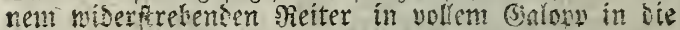
furt. She wedfelte mod Sorn fo idmell mit nenfon=

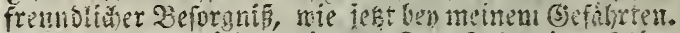

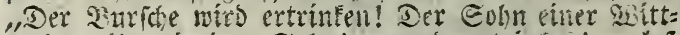
me! - ifr efniger Solnn! - uno ertrinten! - las

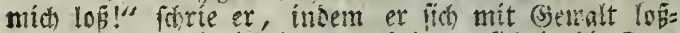
réf́cn wollte, als ich ín verbinderte fid in bie furt zu fitirzen.

(id) firchtete onrchaus nidsts firr Kienite, Ietin

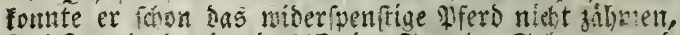
to fafi ex ooch mie ein offe im Eattel. Ealomou uno Beniie ourdichritten bie furt mit wenig shithe, uno fescten am diespeitigen llfer unafbaltfam ifren Ba= lonty fort.

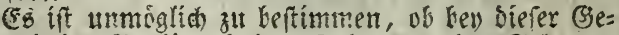
legenbet ber Benite mit dem Ealomon, ober Ealonon mit Penjie burchina, ood, Sharafter und Beweg=

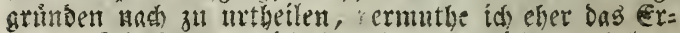
ftere. (g) fonnte nid) ies Ladens nidit entyalten als der Eburfe an mir porbei eilte, grimaend yor 2 ingit 
mo Şonne zu gleidfer Beit, wie er am @attelfironf

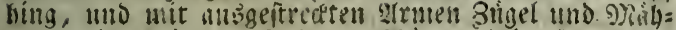

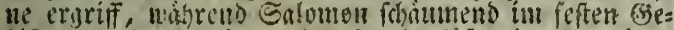

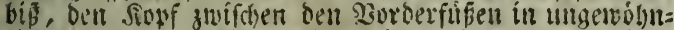

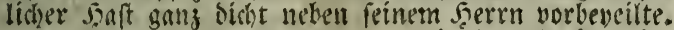
"Der liostinfte ziaprard" forrie ber Dudáfer im

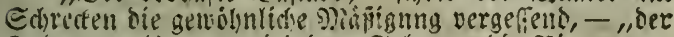
Esalgenngal! - ex wirb ben Enlomon die Sitwen zer=

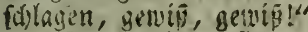

S(t) lat illn, lich zu froffen, verficherte illn, ein

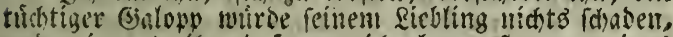
ullo erimerte illn onje er mids eben erfít wegen eines Durten Whosbucles yoil bem sinaben getabelt batte.

Gorm mat um sintmort nicht verlegen - "Ium= ger freuno, Du furadift von ber Scele bes" 3 ur= fichen won nuldher Dil belsmpteteit, fie ware tem bi=

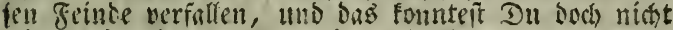
wifien; id) aber frrach von íly als Mienifh, mo went er reine febensart nibht andert wird or bem Etrice gesvís nicht entlaufent. Ja, man fagt fogar or getyore

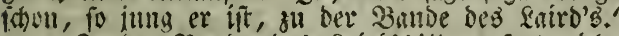

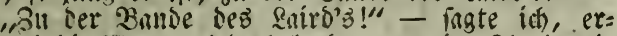
ftouneind bie scorte wiederbolend - "meint She Samit Deli Sinn, bei bem ich tibernachtete? - Jah borte,

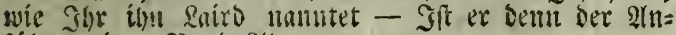
fúbrer eitter Banbe?"

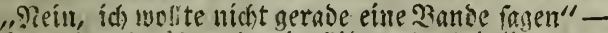

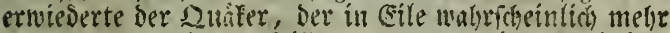
gefagt batte, alo or sgillens war - "eitre serbritie: rung, eine Whatei laitte ich fagen follent; aber, freuno entimer, fo gebt es felbit ben weifeften olännern, ment

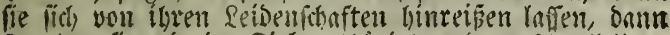
furechen fie nie im fieber thorigt mo borfcumell."

Das war alíp eine jeitátigun meines bistier ge=

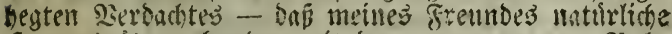
Sergenggate verbunen mit ber angenominellen Nabe

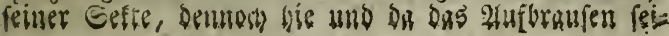


nes bout Tatur feurigen und beftigen Semuthes nidt gámzlich hatten veroraingen fonnen. Poun aber, als fúble er, Daf́ er bei biefer Gelegenbeit einen gróseren (5)rad von 23emeguting gezeigt hatte, als fids fitr feinen Sharafter ziemte, vermies Sofua alle fernere 2 Infpie= lungen atl Benice unb ミalomon, uno fudste meine

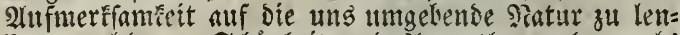

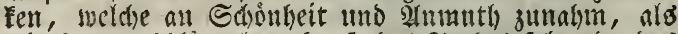

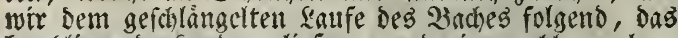
brad)liegende fand verliesen, uno ein wohl angebaut= tes von Såmen burchichnittenes sano betraten, wo 2leder uno Misiefengrund lieblich mit Báuntent uno Set= fen abwechielter. Siabe am Ștrome binabitéigent, fithr= te uns unfer siseg burch ein fleines. Thor fu cinem

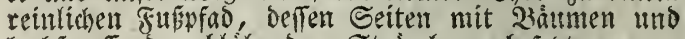
hochinroffenden blühenden Stränchern befeght waren; endich fihtrte eine liebliche Terrafle uns aus Dem Thale berans, und plóklich ftanten wir vor einem nieoriget,

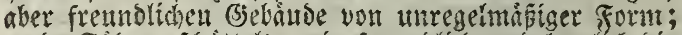

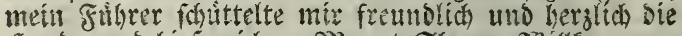

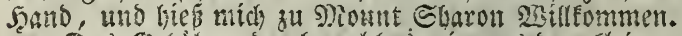

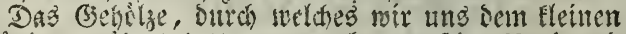
(sebsube genthert hatten, mingab es anf ser sioro und Porb = פiseft Seite; von ba aber zertheilte e's fid in verichiedene siciftungen, und waro von gut beswifer= ten und gut angefanten feldern interbrodhen. Das Salts gemabrte die Susficht nach Etid = Dit; liebliche

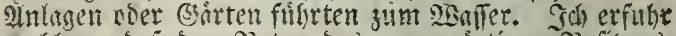

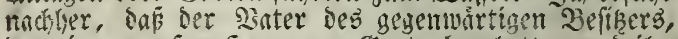

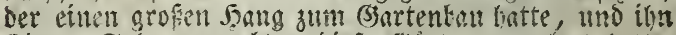
feinem Solnte vererbte, biefe Garten angelegt hatte,

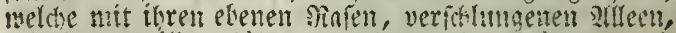
mit iben withen fibn emparfurofenden 23 anmen uno Eträuchern, alles gar fehr veroumfelten, was ntan it oiefer sirt in ber ungegeno verficht hatte.

\$̇ent auch ein wenig Eitelfeit in bem wohlgefäls 
lingen Sicheln verborgen lag, mit weldem mich Sorua

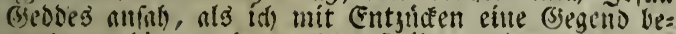
tratstete, die vou ocr: naften Seaibe, welche wir bente

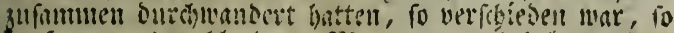
turf man es molil einem Sianne zul gut halten, ocr, wie er felbit fante, firperfiche (sefunobeit mo geifinge

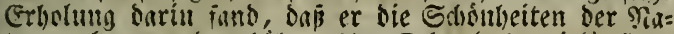
tur miknut mo erbiht. 2tm Ende des weitlónfigea (Bantenz bilbete ber Lach in einem jolfecirfel die na= t!̣rlide Granze. feine 2 efismugen mebr, bort maro bar 3nd von $a b=$

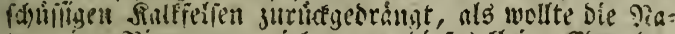

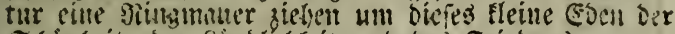

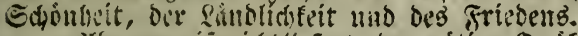

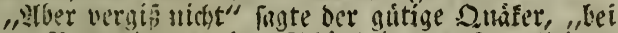
Deince Betmunterung oer Echinheiten unires fletuen

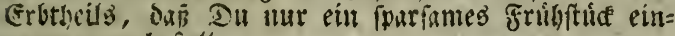
genowmen bait."

Jitben er biefes fagte, iffucte Gorta ein fleines

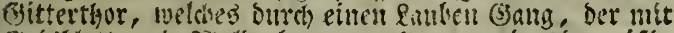
Geigblatt uno gialorelve untranft mar, in cill mifig

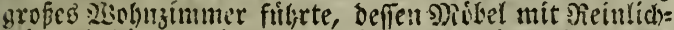
feit unb Einfathbeit tas bentliate fiennzeicisen ber Sefte truget, , z" sucldser ser (Figentllimer gehorte.

Deines 2anters fomma wirb aligemein alв cine

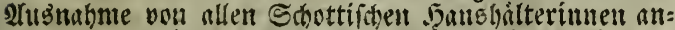

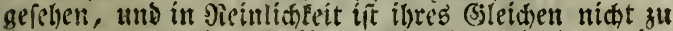

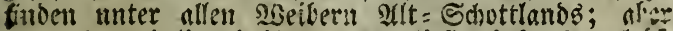

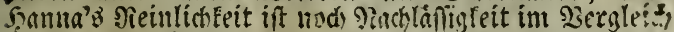
init bem forgfältigen Erhenren uno Pussen biefer Reute, melche anf bie geringiten Dinge bes febnis jene Strenge

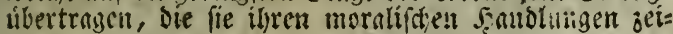
gen nollen.

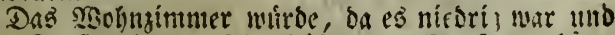

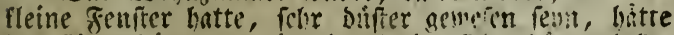

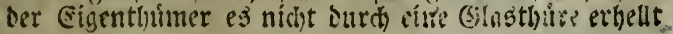

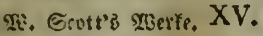




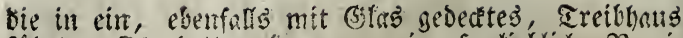
fithrte. Fich hatte nite jutor eine fo liebliche seret

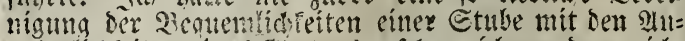

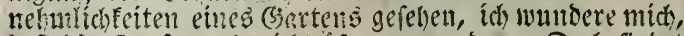

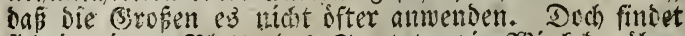

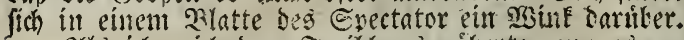

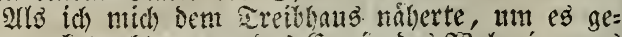
naner zu betrachten, fog tas Samin bes \$sobnzímmers meine Allfmerfinmeit nuf fich. Es war ein Pfoiler

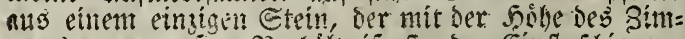

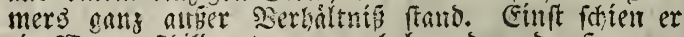
ein ssaypenfoild getragen, zu haben, bent ber Shammer oder ber s)ieffel, ber Echild und sifir zerfiorte, hatte ben Baldachin unverteget gelaffen, der bas fromnte siotto tritg: হaertran' anf (5) ot t! Sch hatte von je her, nie Dut wohl weipt, eine befondere freube an alt =ge=

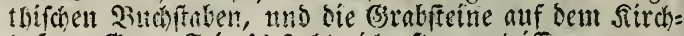

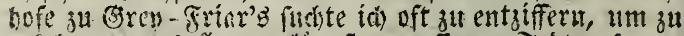
erfabren, was fie von lämif vergerienea sooten fagen.

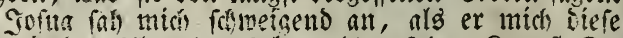
siclianie ses antertinums betrachten fab. "Sanmit Du es leien?" frug er endich.

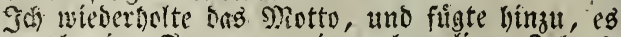
ware noth cine Epur von eituer elyemaligen Jabres= anbl vorliantent.

"s? folt woty 1537 be fent," fagte er, "benn fo lange ift es wentigfens, bas meine Soreltern, in - In Urinden 3eiten des Pabftlums biefe 20 obnung bateli."

,Tas ift ein alter 1trinruma," fagte id, indem ich

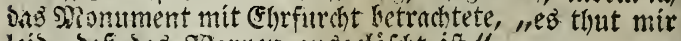

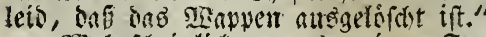

gisabricheinlich war es métiem freunde, oliwoht er pin Dutifer war, tnnmoglith, fo gant allen Siangel an

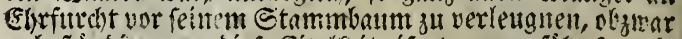
er beftandig gegen dief? Sitrificit eiferte, ungefäbr fo, wie Jack Zantes uns im Eollegium mit einer Shiene, in wel: 
der Sonermuth, Niene uno Gelbifecfibl vermifd la:

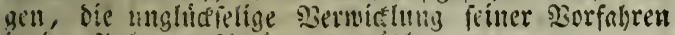
in ber Multerberfduorum? ergallte.

"I, Citelfeit ber Eitelfetten, fast ber Prebiger" - fing Gofun Sesoes von giount Eharon feine Siebe an - "neilil 11 ir fellif ein gichts find in ben 91 ugen (sot:

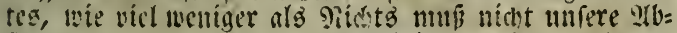

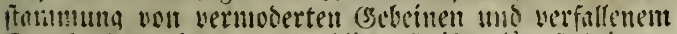
Etanbe fenn, Scren unferbliche Bietiter lingit loeimge= aangen find, Siechung alsulegen von ibrem Thun? Ga, frcuns Satimier, meine Sorfaliren waren beribmt unter ben rabuerifben uto blutouritigen siannern, welche diefes unterorickte uno geplagte Rano bewobnten, ia fo berichtigt uaren lít wegen ibrer glideliden sreibeuterei,

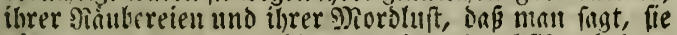
batten Den Tiamen Beboes von Dem Siaukfirdse befoin=

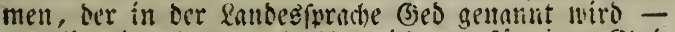

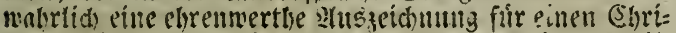
ften! Eie malylten tiefen flabbetwoliter nuf ibre Edil:

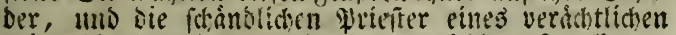

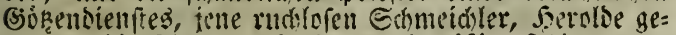
nanut, die Fifde, Siggel mo vierfiêpige Tliere ans=

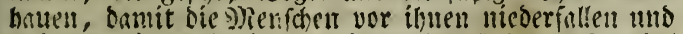
anbeten migen, beitiminten ibnca den Sied zum Enmóbl

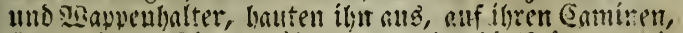

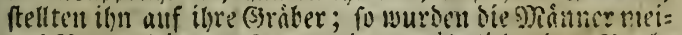

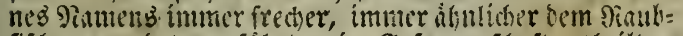
fifche, morbeten, fubrten in Biefangemichait, theilten

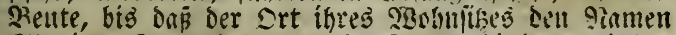
Elaring - Sinowe befam von oer Bente, Die oort juírden ifuell und ibren selfers selfern getfeilt wutse. Sine beffere Einficht wurbe erit meinem (s)robwater plílipp

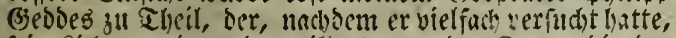
fein fidit an eintem ber willo fackerenoen itller, bie bn= mals in allen 2 tirgerverfammlumen loderten, a!tz!tjutu= ben, endid einen Funfen von der ?ante bis gejegneten 
(Goorg For auffing, welcher nach Schottlans fam, Das Pidit verbreiteno in tiefer finferniê, fo reichlich, wie er

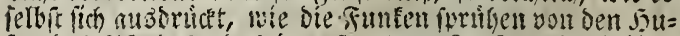
fen des plerbes, bas it gefredetem Raufe auf fieinigen Sisgen onbiti eilt." - Sier unterbrach fich ser gute

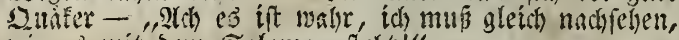
wie es mit bem Ealonton ftebr!"

Ein Diener, ebenfilis ein Duifer, trat jekt in ons Bimmer, neigte den Jopf gegen jeiten 5errn, aber nidht wie jemants, ber fich verbengt, und fagte gelaffen: "Sen wílfommen in Déusm santie, Freuns Sofun, wir er= warteten Didis nidst fo fribe, aber was ift benn Dei= nem sferbe Galonon ougeftopin?"

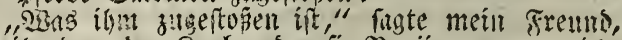
"hat ion benn ber Sintbe, ben fie Benite nennen, nidst loteber zurick gebracht?"

"freilich bat er bas," fagte ber Beotente, ,aber auf

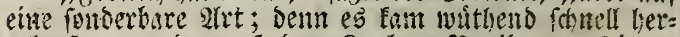
gelmufen, und marf Den Sinaben Renjie won fittem

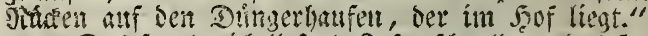

"3)as freut mich," fagte Sofun fonell - "Dos freut nitis won saltsan berzall! gher nein, or ift ber Eohn

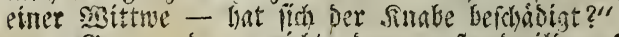

\section{lief onvoi!."

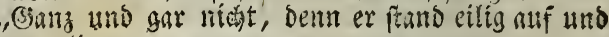

Sofin, numerte etwas vou dor Peiffice, danm

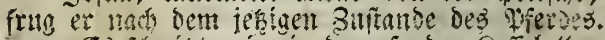

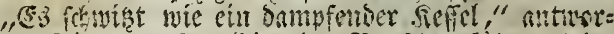
tete ber Diener, "Panloie, ber Burdahe, foint es im sofe an solfter "lminer, bafi es fich nidot erfiltet."

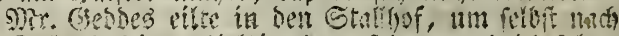

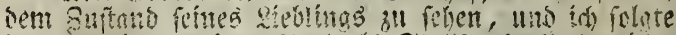

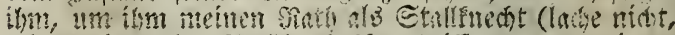

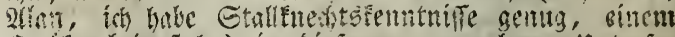
suafei beizufteln) in biefer unangenehanon ltuterfu dinng anzubicten.

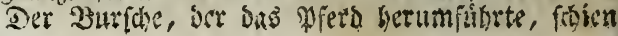


fein Quafer zu fern, bech batte ism fein limgan mit ber

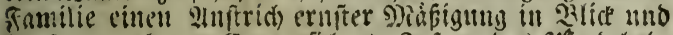
Sisefen gegelon. Er verfiderte gofu, bas affero habe

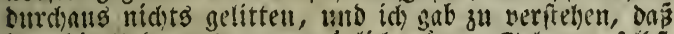
iljm die llebung fogar zutráglid) náre. Ealomon felbit neigte feinen Siouf gegen feinen Scerru, uto rieb ínn aut

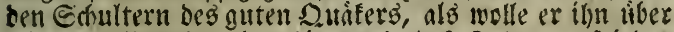
fein singlbefinden bermigen, fo das gofun, zufrieden

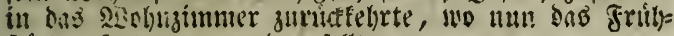
fride enfotringen werden follte.

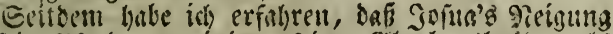
fir fein ungehorig betrad)tet wiro; und bap̈ er vielfad)em Tasel mterliegen muste, bas er ínm einen Pamen, tmo gar cincu bibliforen beílegte; dod) genos er einer fo gropen 2idstutg und eires to gropen Einfutfes unter innell, bấ lie siefe Ethwadte tiberiahen.

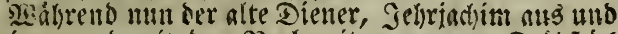

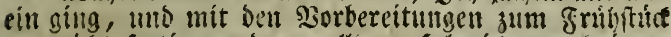
gar uidst fertig werben wollte, erfulle ici) von meincm

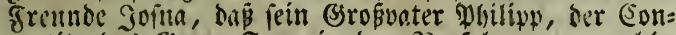
vertite ses 3scorg For, in ben 2 erfolgutigen, welche biefe unfchuldigen antoáchtigen in ienem unduldomen Seitalter von allen Geiten erduldeten, viel gelitten batte, uno baf: ein grofier Theil ibres wáterlichen Erbes zu (5rund gegangen war. Beffere Tnge waren bem 2 ater unferes Sofua vorbebalten, der, nadoem er fich nit ei= ner reichen Duaferfamilie in Sancoftire verfandizer hatte, verichiedene fandelszmeige mit Erfolg betribb, deat sieft des Bintes einlóste, uno inm ftatt bes siantens Charing - Sinowe, wie bie Granghewohner es natutell, bie ebangelíche 2ienennukg Nonnt - Eharon beilegte. Ermánter ybilipp Bjedoes Gatte, wie fdjon gefagt,

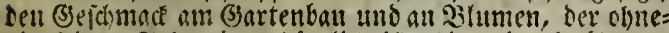

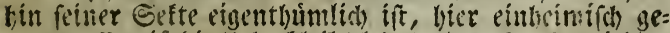
mant. Er rifs bie liekerbleiblel bez alten frufio nieder,

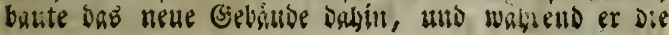




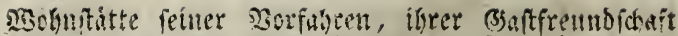
mesen, thid bas fromme siotto, bas fie zufülliz ang:= nonmen batten, verehrte, vernichtete er auf ber anoe=

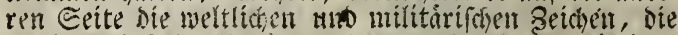

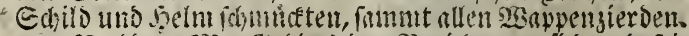

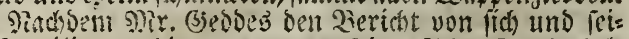
ner Familite geendigt hatte, trat feitie Echwefter Sinhel, Dus eingige nod levende sithlied derfelben in das sim=

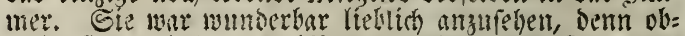
gleich fie wentgicens breisig Jals alt renn muste, hatte

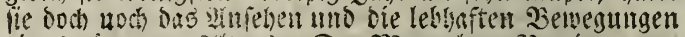

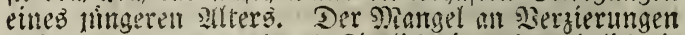

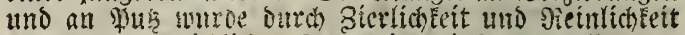

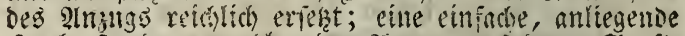

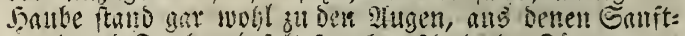
muth und Taubenteinfalt furads. IItudh thre Buige maren gar angenebm, boch batten lie eill wenig una dem erflär: ten Feitide aller Edyonbeit, vou ben Bhatterit, gelitten; ein Sinditheil, ber sunt Theil von cinent fion geform:

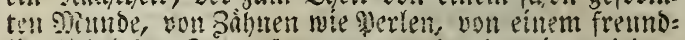
lich ledbelnoen sug anfgewogen warbe, ser einem jeden, mit sent fie jorith, jeitliche uns eavige sstudfeligfeit zu

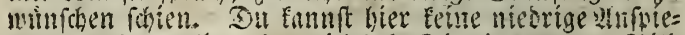
hung madien, glat, sent id habe Dir ein getreues zillo

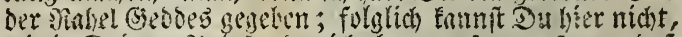

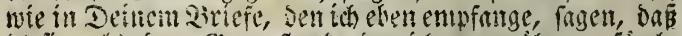

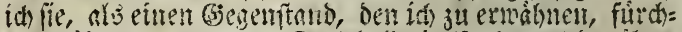
tete, uberizngen batte. Dod hald ein Dielyeres Dariber. Sisir begamen a!fo sas Jrhibitide nady étuem Es=

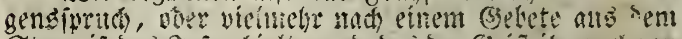

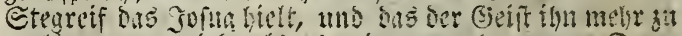

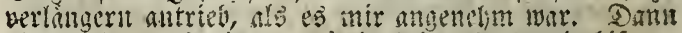

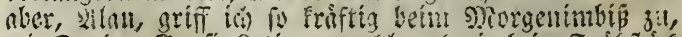

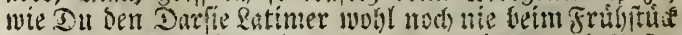

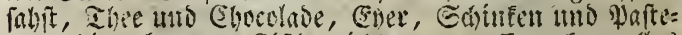

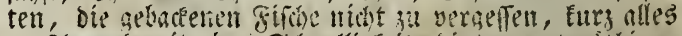

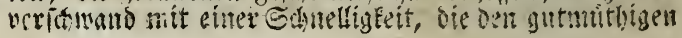


Quafer ftumen machte, ber nuinel Tefler immer won

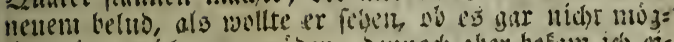

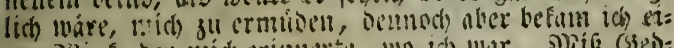

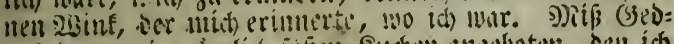

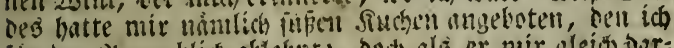

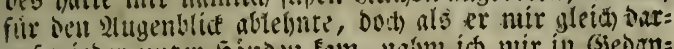

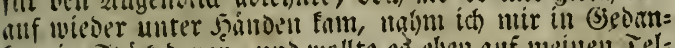

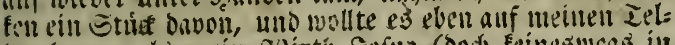
ler legen, alo mein Seirti) Jurna (ood) eeinesmegs in

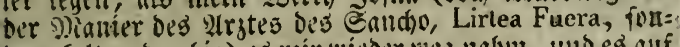
birn falt uno rulfig) es mír wiedor wey naf)แ, unb es allf den-zird) legte, indem er trocken fingte: "Du foblugit es eben aus̆, fremto Ratimer."

Diefe gutten Reute erfenutea das siedst nicht nh, fein

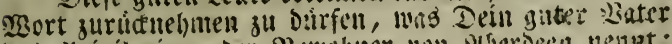

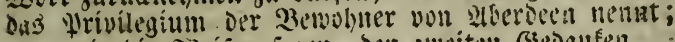
oder nie die sieffen fingen, den zueiten Bjedanfen.

Diefen fleinen $\mathfrak{B g}$ in nbgerechnet, Der nith bileht= te, D.is id mich unter felor punftlichen, eigentlyumlichea sienfichen befaud, war ill meinem Emnfang nichts ans: gezeidhutes - nur benterfte id bie ängitlide, gleidyor= mige Suvorfommenteit, vill wether nlle \&ufinerffans=

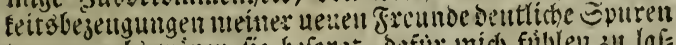
trugetl; als twaren fie beforst, buftir inidh fúllleu ju Laf=

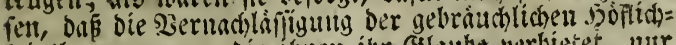
feitsbezengungen, Die thuen ibr (slaube verbitet, nur

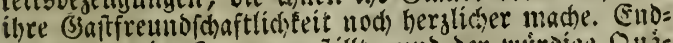

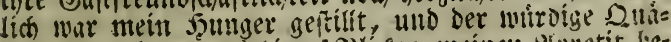

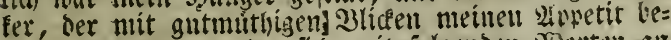
obachtet batte, wande fich mit folgenben wisorten an rille Ednueiter.

"Diefer iunge Manu, Sinfyel, bat in den Se!ten

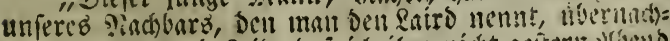

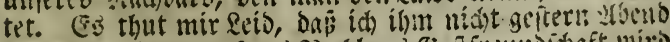

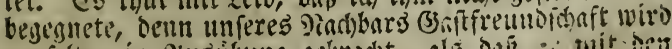

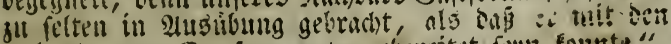
g) pitteln zum Empfamg gut vorbereitet fenn founte." 


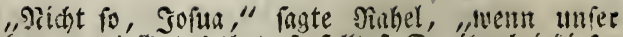

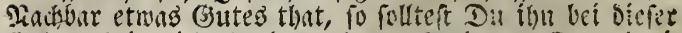

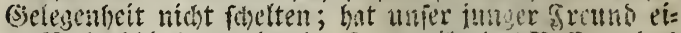

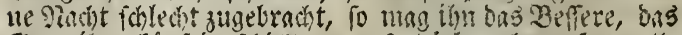

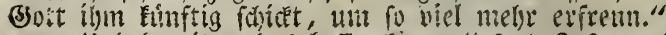

"thito bamit er bas beffer fomme," fagte Softa, , po wollen wir inn fitten, sinbel, ein ober zwel Tage bit uns zu verweilen: er ift jung, tritt eben in bie gadt,

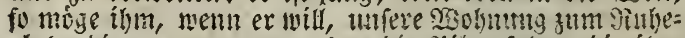

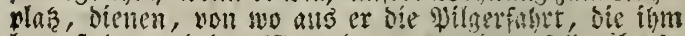

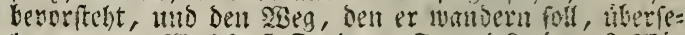

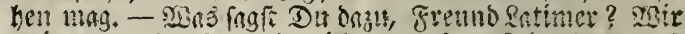

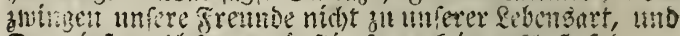

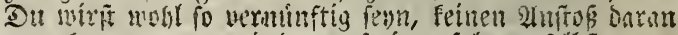
au nebnen, wenn wir ber unferigen folizen, felbit wenn

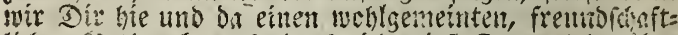
licien senty getien, fo benfe id wirft Du atud baritber nicht bofe werben."

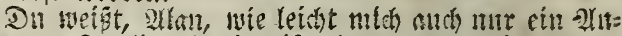

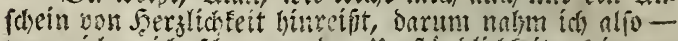
wenn ich midi fdon wor den unftandichfeiten ein we= nig firchtete - do Elidlaoming an, und bat nur, mat

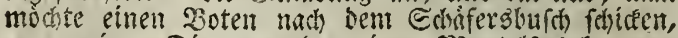
un meiner Dienter unb meinen s) iantelface fommen ju Inffen.

"Dli but recht, Freino," fagte Softa, "Dein gras=

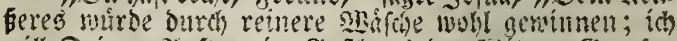

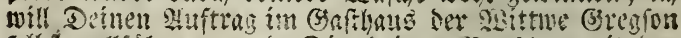

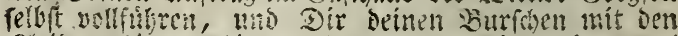

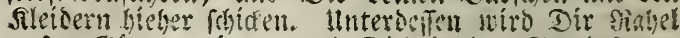

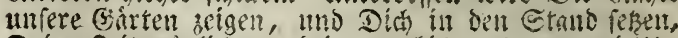

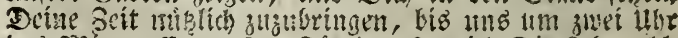

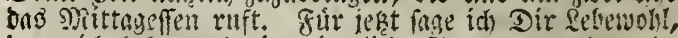

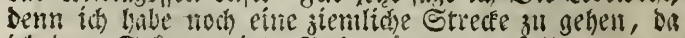

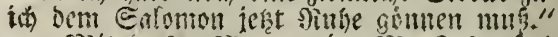

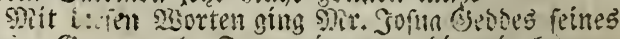

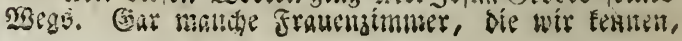


wuirden Serlegenheit gefuhlt ober alfectirt haben, weun man lie mit eiment - (frei herans gefayt, gllan) ar= tigen, jungen s)ianne, mit einent Seremben allein gelaf= fen batte, sie homents de la maison (bie gaftlichen Dffichten) zu mathen. Eie ging einige 9xinuten binanb, und fam baun wieber mit ibren énfachen (Bewuano, ib)= rer foube, und nit fomb fibille an bereit, mix mit eben fo eitrfacher ltutiefangentleit zum friber su biemen, als hitte e:3 Deintem sater gegolten sllan. Eo macite ich

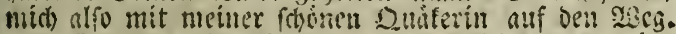

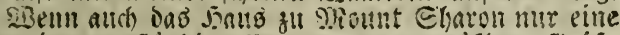

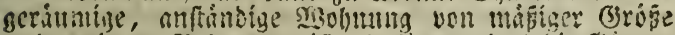
and geringer Bedentung iff, fo fonten boci) die (3).trten

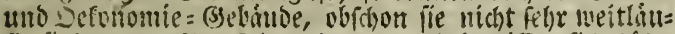
fig find, mas Eornfalt und Infwant betrift, fich flisn

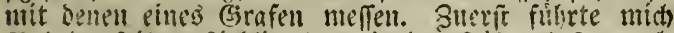
satbet auf ibren sieblingsort, in sen subneribof, wo al= lerle:) :ilrten Federviely, bas feltenite fowobl scie bas ge=

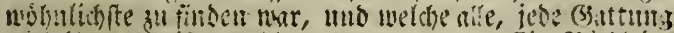

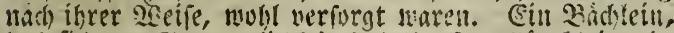

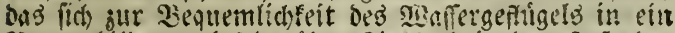
Siecten lifldete, riefelte tiber fiebfant in ben soof, ber bem (ssefligel befitinmt war, bas lïh) alf dem fande aufbilt, anto fo maren beibe (s)attungen wohl verfargt. Alte biefe Befdoufe fohienen ihre Bsebieterinn zu erfenten, und civige beionbers Bescintigte eilten ju ih:

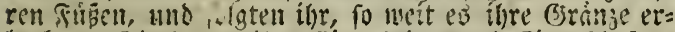
lanlte. Sie finnte ilgre Eigenbeiten ano Eigenidarten fo gentm, wie iemnnto, der fich dem Stubium ber Patur=

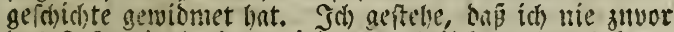
bas frofgertigel mit fo vielem is itlieil betrachtet babe -

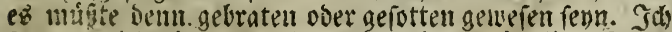

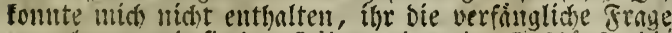
vorzulezen, me fie bas Tóden émes ber (s)efdónf?, die

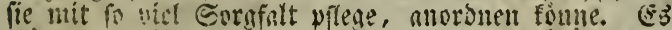

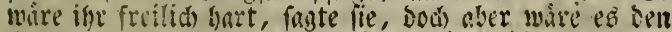
(B) fergen ifres Dafeuns gemíp. Sie múften fterben, 
boch muisten fie niht, wenn ber Tob heramnthe; mo

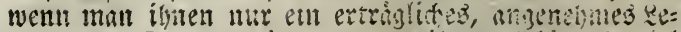

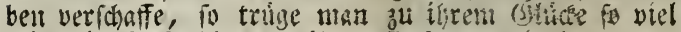

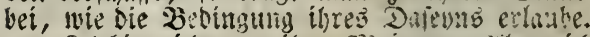

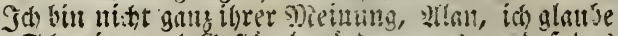

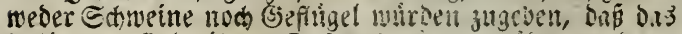

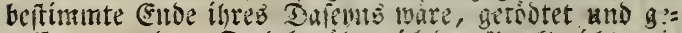
geflen zu werten. Ded berubrte ich sen phinft nicht twei=

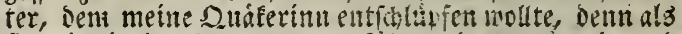

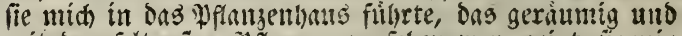
init ben felteniten oflunzen verjeben war, seigte fie mir

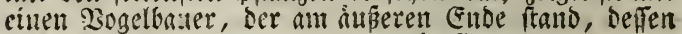
Bewolyer lie veriorgte, obne, wie lie faste, von den traurigen Gedanten an igre Sufunft geftort łu werden. Jo mifl Didh mit femem Berichte von ben verfichie=

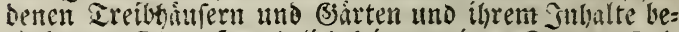

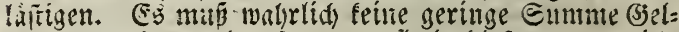
bes verwentet worben fent, tum je in biefem ausgezeitio=

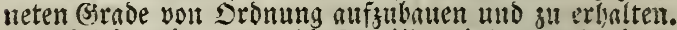

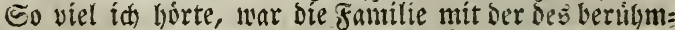
tell glillar befannt, unb hatte von biefer ben Sejamed am $\mathfrak{W}$ lumen = unt Ssarteubau angenommen. Statt aber botanifche Pamen zu rabebrechen, will id Dich lieber

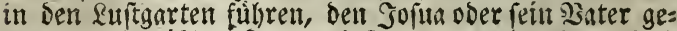

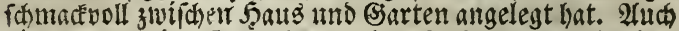
Diejer nar, im Gegentak zu ber fonit vorberridenden Einfatheit, ungenoibnlici) verziert. Sa gab es verichie: Dete Partien, welde aber fo gut vertundent twaren, Das Die ganze Fláche, die nicht grófer als $5-6$ 2róer fan=

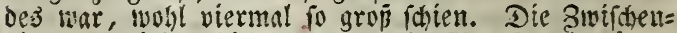
rimme enthielten didhte alteen und offene Epazierginge,

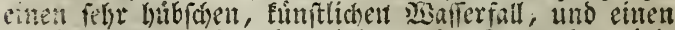
Euringbrumen, oer cines bedentenden Bogen beichrieb, und iu beffen ভtrome bie Sonnentitriblen einen beitin= digen glegenbogen bilbeten. Da fand man ferner ein Raube (Eabintet, wie es die Fratajofen nenten, um fids in

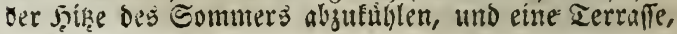


die geaen piorb = Dit von cincr secke von" Stechnalmen mit glänzenoen Dornut befihnizgt war, wo Da in heites ren, Eilten SBintertagen Dich Der erwiriatenden Eons

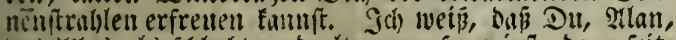

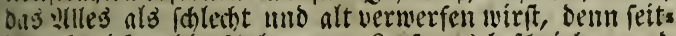

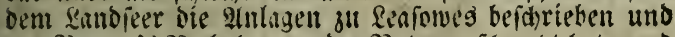

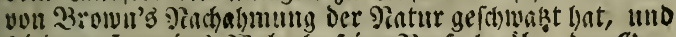
feitoem Jornitis sialpole feine serfude utber ben (Jar= tenbau befannt unadbe, bifít Du nur fưr einfacbe Patur= anlagen - verbanmit es, Terrafen in frever ?uft auf=

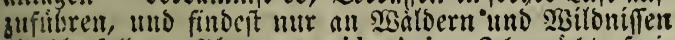

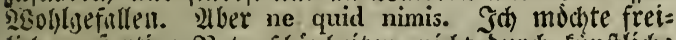

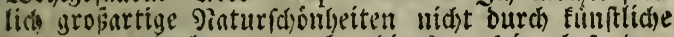
whlngen verberben, wo abur die Rnge félte befondere Edidulciten barbietet, on fino jie, glanbe ids, an ils: rim Ylaz̧e.

Scâtte ich alio cilt \&andhaus (mer weif, wie lang es bis dahin nod Dattert?) fo wirft Du (Strotten, 93affer: falle und Springbrunnen fehen, ja wenn Da midh mit aisioerfurud árgerteit, fo fountejt Du mid) fogar bazu bringen, einen Tempel bin zu bauen - reike midh alio

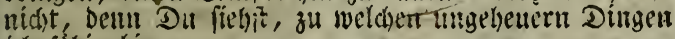
id) fốlìig bin.

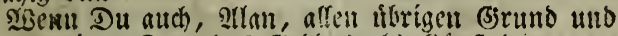

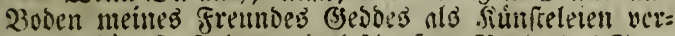
bammt batteit, fo bat er boch foharf am stande des Etro: mes einensisitoengang, fo difiter; io fenerlids, fo fiulle, Bas er Deine 23emunderming ergumingen hátte. Der

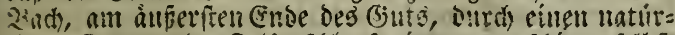

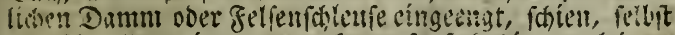
ansifidnollent mie er war, Eaum fanft babin zu gleiten,

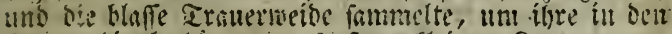
Etrom himab hingense glefte, fleine frronct von

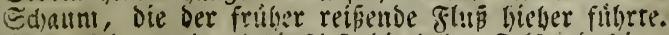
Santm foll man burdh bie grefte bie hohen felfen bes ien=

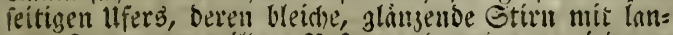
gen Jeeken yon wilden Nofen mo attoeren, nieberen 
Etråuthern befrätst, ein Schlagbaum fhien, der ben ruhigen Pfad, Den mir mandeiten, akfchied vun ber ge=

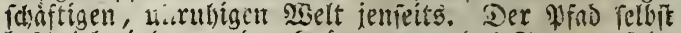
befdrieb, intem er Den Strinumungen deg Ctromes folg= te, einen fanft gebogenen f̧albcirfel, boch fo, baje er bas Ende des Siseges verbarg, bis man es erreicht batte. Cin

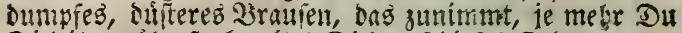

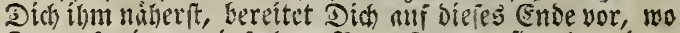

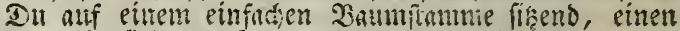
fechs bis fieben for holen siafferfall irbliceft, wo, wie

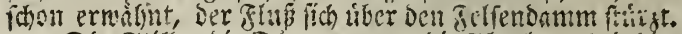
Die Etille, bie Dinntuerung, oie 2 bgelegenheit sie=

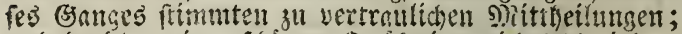

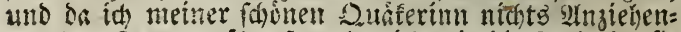
Deres zll fagen wuste, fo man ich mir bie freikeit, fie um bie Serbaltniffe des Rairso u fragen; benn Du

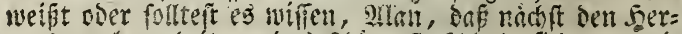

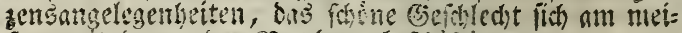

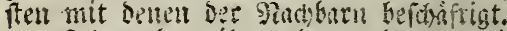

S(b) verbarb ing weder nteine situgierise, noch bie 2urt, wie Iofun fie zuruichewiefen hatte; meine Beglei= terinn antwortete veriegen: "Shl fam mar bie Saghr=

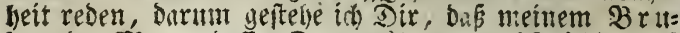
ber der Dinn, deffen Du ermänteft, mísfält, bas

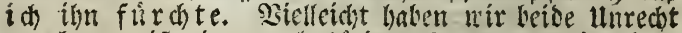
- aber er ift ein gennaltibátiger 9nonn, mo ubt úber

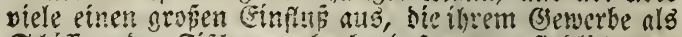

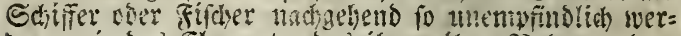
Den, wie saz Element, Das ibnen ibre sabrung bar=

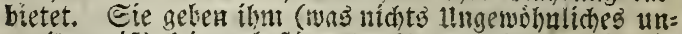
ter il)men ifi) Eeinen beftimmten ?anten?, senn es iît ein roher (Bsebraud) bei ínen, lid) segefoitig surd) Beina=

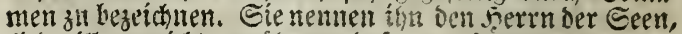

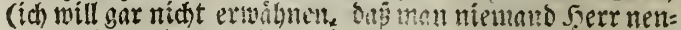

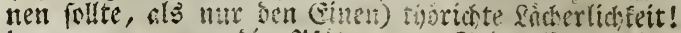

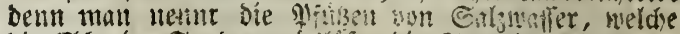

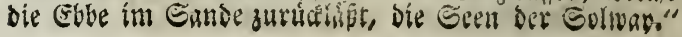


"f. Tat er Denn feine anbere Einfinfte, 'als bie, weldie er aus biefen Diuten gielst?"

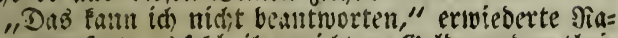
bel, "mant fagt, es felyle ilym nidat an (3)elo, und er thei= le beit Lirmen in fetner Hmgegeno freigebig von feinem Heberfuffe mit, obidgon er wie ein gewóbnlicher fifder lebt. Sie geben zu verifeben, basier ein Mam von Be= seutumg fen, ber in oer unglicelichen Emporungsge=

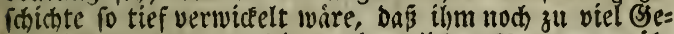
falbr brobe, weilu er feinen eigentlichen Tamen annáb= me. 2luch ift er manchmal agorben und gronden lang

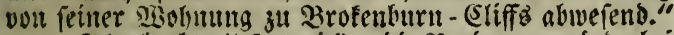
"Id) glaubte," Pagte ich, "bie Negierung wúrde bei iesiger Beit felfit ben bartunicéigften giebellen nidht in arnflagezuitatio verfetzen. Bar viele Jabre fino feit: bem veritridien."

"Das ift wobl wahr," ermieberte fie, "Dod begrei= fen Eente ber Irt wohl, bas ing \&eben nur gefichert ift, fo lange fie im Etilleat leben. Siant famm aber von bie=

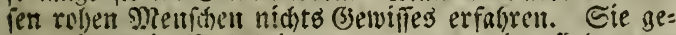

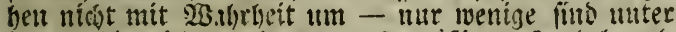

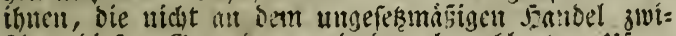

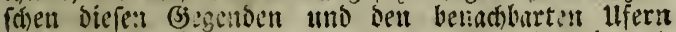
Englantos Sheil neimen; jese utrt von Jalfabeit uno Betruy ifi ínea wohl bofaunt."

"Eg it Jumneridabc," bemerfte id, "Das Stre Bruber folde siablarn hat, befonters ba idi) bemers= te, Das̄ er ilt einige Etreitigfeiten mit ibitell ver= witelt it."

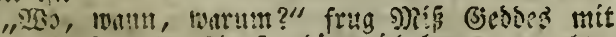

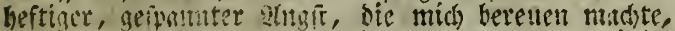

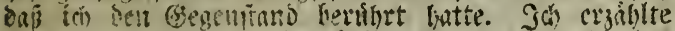

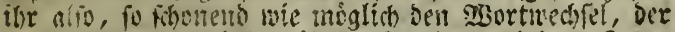

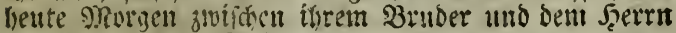
ber See Statt gefmben batte.

"Du erisistedit mich relor," antmortete fie, "eben

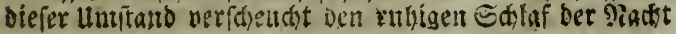


son mir. 2r!s mein Bruber Sofun fid) von ber Iheilnat:

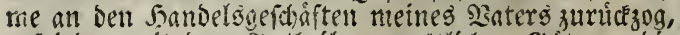
sufrieoen mit bem sintleil an weltliden Butern, bie íbm zugefallen maren, blieb er nur bei étem ober juei Unternebmungen letkeiligt, entweder, weil fein 3urtids=

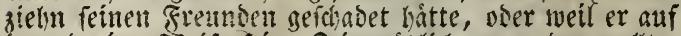
irgento eine siseife feine Seit ntiblich anwenben nollte. Unter ben wishtigern getiort eine fifcherei an ber Siufte, no burch eine verbefierte 2 (rt a)eufen fo zulegen, welche fid tein Jerannaben ber Ebbe ofiten, unto kei ber Flath foliefen, bei weitem melns fifde gefangen werben, nls wenn man ibrer, wie bie Seute von Brofen : Rurn mit Sek, Epeer und fifhengel, habbaft werden will. Sie beflagen fid ther bicfe Ebbe = ?eke als eine ?ieuerung, und alauben ein secht zu baben, fie mit Benalt nieder =

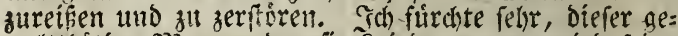
malthintige shann, ben fie Pairo nennen, wiro feine Srohung ausfityren, mos nidt obue \$erluft uno (je: fabr fur meinen Bruber aefitielden Eann."

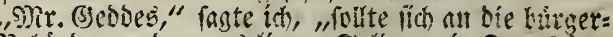
liche ßełorbe wenten; es liegen Eolbaten in Dumfries, bie man zu reinem Ghuls abienben finnte."

"Du fprichit," antwortete die Dame, "mie jemand, ber noh in ber (salle ber Ritterfeit in bem Serbanbe Der

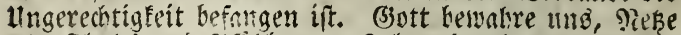

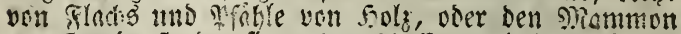
von (siem!nnit, ben fie uns verfchafen, mit sen founben ber firtenglente su bercháan, auf bie Ssefabr bin Sienforentut zut bigiefsen!"

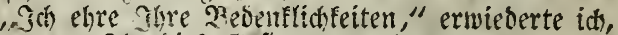

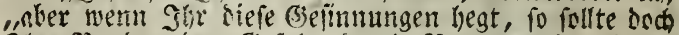
Shr Zirter ter sefabr butd Sertrag ober burd Sิadgek"u nusiveiche!r."

"Ias mare nobl auch das zieite," verfeste sturel, ,aber mes foum $i$ ch fagen? - Eerrift in sem forfocar=

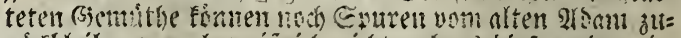

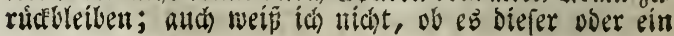


befferer (Beift ift, bir meinen 2 indoer Tofua bazu brinst, ba nill, Demmod fein silist nidbt lieren Drofyutgent nufoy= fern, ober fie surds fein sindogeben nicht crumuntern will, auth slnoern Echnoen 3!nufugen. Er fnat, feine Mit= gentifen kertranten auf feine Fentigfeit, uno er nofle fie

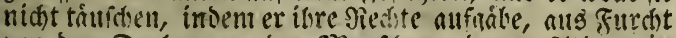
vor ben Drobungen Der Senfchen, Derent 2lthein it Der siafe-ift."

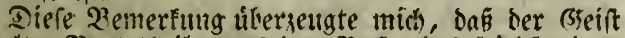
ber altent Reutetheiler ans bem Bufen bes friebfertigen Quáfers nod' nicht ginzlich verbanut war, uno in neci=

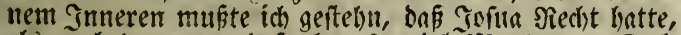

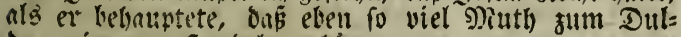
den mie zum frandeln achore.

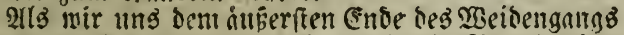
mahten, mard bas bumpfe und anbaltembe Branfen bes

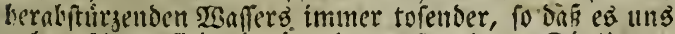
zuleşt fómer fiel mit einnitoer zu rurechen. Die linter: haltuntg freckte, Dod fafienen bie Bsebanfent meituer Bje: fábrtim inmerwábrento an bent trúben 2(knungen zu

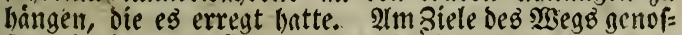
fen wir citter 2 (trsficht auf ben 3 sifferfall, wo ber anae:

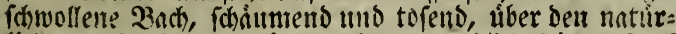
lichen felfenoamm ftúrzte, Der vergeblid) feimen \&nuf

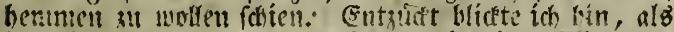
id) mich aber ummunote, meiner (s)efáhrtimu meine (sje=

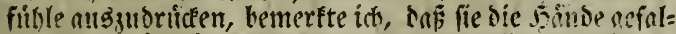
tet hatte, in eitror Stefluna fummerwoller crachung, nelche anieinte, dab inre Beomfen fern ron ber vor une liegenden saturfene maren. Da fie fart, bos iture Berfiretutua bemerft murse, ualm fie sie fruthere onthe in fliven Sisnicrent miebor an; und als fie mir binlong= lici' Oeit gelaffen hatte, bas Biel unferes ftiflen, einfinmen En:uterannas x"l beimtindern, fohlug fie mir uor, nuf ei=

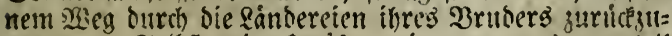
febren. "Selbit wir Duáfer wie man uns tennt," 
ragte fie, ,haben unferen fleitren Stols, und mein Bru=

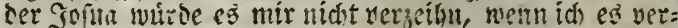

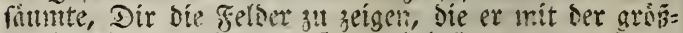
ten Freuse, mad ben neueften und beften arten subast;

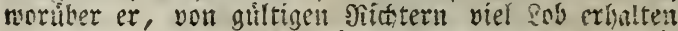
hat, aber auth won betten liaderlid gemadht surbe, die

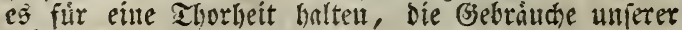
Báter verbeffern zu mollent."

Mályent fie furah, offmete fie ein niebriges Thor, bos burch eine mit Moos unt Enben bedecte Minuer,

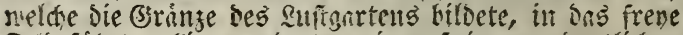
Feld fúlste; bier wanbertai wir anf einem: orbentlidien

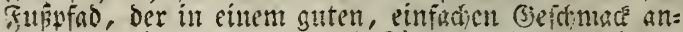

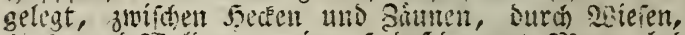

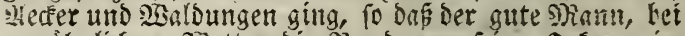

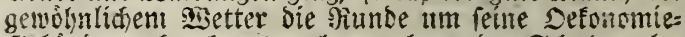

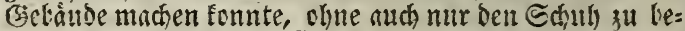

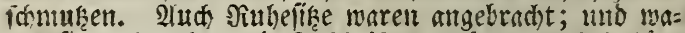
ren lie aud weber mit Infdurifren geziert, nod fo binu=

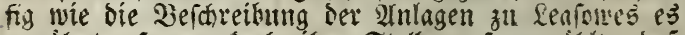
erwilynt, fo twar bods ibre Stellung fo gemsilyt, oas lie entweber eine ferme alugftht beherridgten, ober ei= nen Blice heimuirts gemaldeten.

शlber imas mir in Solua's Ssebiet am meiften auffiel,

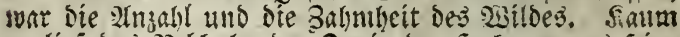

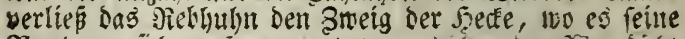

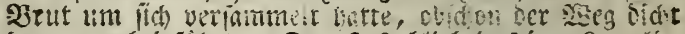
Deran vortei führte. Der Shafe klieb in feiner fnge lie: gen und fenatte uns, weim twir vorteigimaen, mit vol=

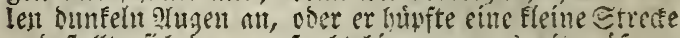
uno feffte fid sinn aufredt hin, um unz mit grobirer

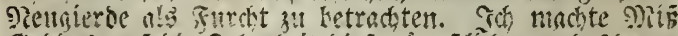

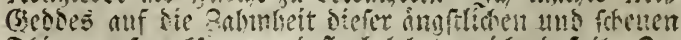

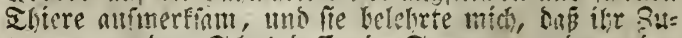

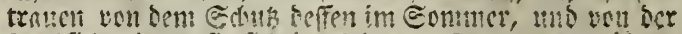

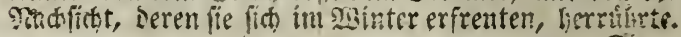
"Eir 


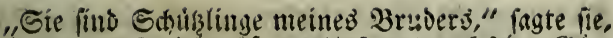

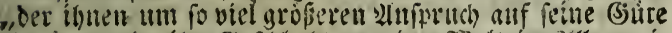

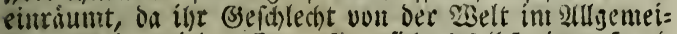

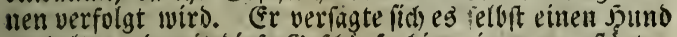
zu balten, banit diefe (sejchopfe hier einer ungeftorten Eidierbeit geniepen tommen. thito pelbit diefe harmlofe, menfihliche sieigung oder saune bat unfere yefäbrli= den Piachbarn beleidigt."

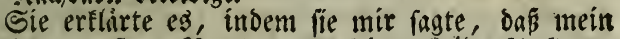
rsirth vout geitern Pacht weyen feiner Reidenichaft sur Jago bertidgtigt ware, ber er fich ohne sicucficht muf die הisminde berienigen, liber beren felber er jase, tibar=

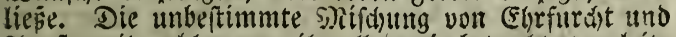
2(ngit, mit weldyer man ín allgenein betrachte, berleite

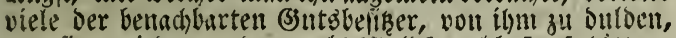
waz fie on jedem anderen als soaloirevel beitraft batten. 2lber Jofua Beobes erlaubte Eeinen Eingrifi in feine

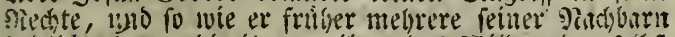
beleibigt hatte, die ilju, weil er bab sisild weber felgit jayte, nod jul ingen erlaubte, mit einem founde in ei= tier gleifherbube verglidgen batten; fo vermebrte er n!u bie stoncigung, oie ber Lairo fhon gegen igu gefäst batte, indem er ibm ein fur alle shal verbost, bem Mills

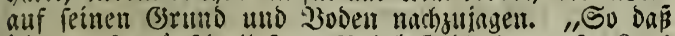

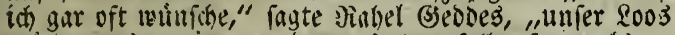
michte uns an einem anderen Drte gefallen fevin, alö an biefen lieblidhen llfern, wo wir, wenn auch wentiger

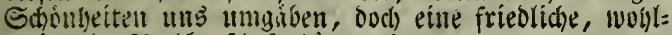
meitrende Fiadjbirichaft bätten."

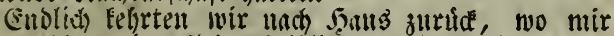

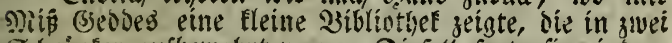

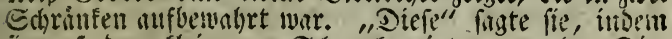
fie auf Den fleitheren Sdyrant zeigte, "werben Dir,

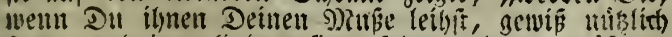

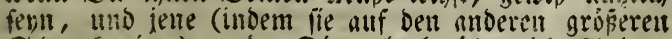

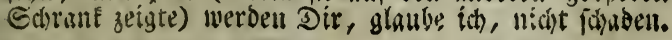
20. Crott' פ̇erti, XV. 
Cinige unferer sidfer glinben fieilid, ein jeder Erbrift= felfer, ber nicht fir ung ift, ware gegen uns, aher mein Sirnocr Sofua if gemáfigt in feituen Meinungen, no feht mit unferem Frembe John Ecott won 9lmmell, ser soch serfe gemacit hat, die felbit in ber sigelt

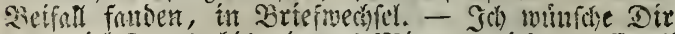

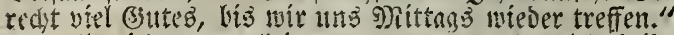

Irls ich lum allein war, interfuchte ich beibe Eammlungen; bie erite beitano blos aus theologifhen uno nolemifchen sybrandungin, bie zweite aler alts

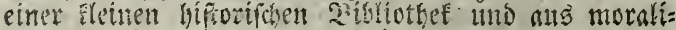
foren Edriften in \$rofa mo in serfen.

Sa ión mir hist biel linteribaltung bavon ver= furach, fo befikeft Du in biefen Blittern bie sruidste mei=

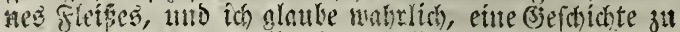
fáretten, mo mon felbft beat Sielden macht, ift eben fo unterinitend als bie eines fremben Randes in it = gent einer Eyoche zu lefeit.

San, ber immer noci) binfiget betrumfen als midch= tern ift, fom sut rechten seit mit meinem Orantel nack an, mo ferte mith alio in ben Stano, meine fileidutg io zit

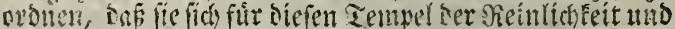

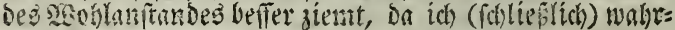

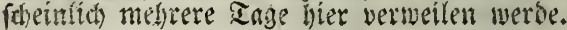

ఖ.

(1) hate mix bas arbenthener, wie ibr beimgezoge= nen schuglinge es. neuten nogt, von bent 2 efuch bes

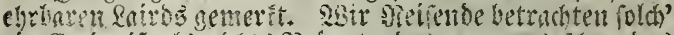

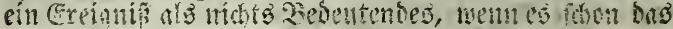

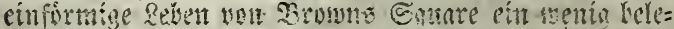

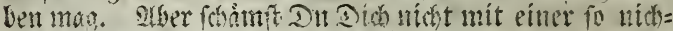

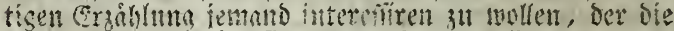

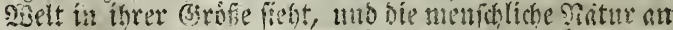

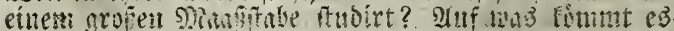

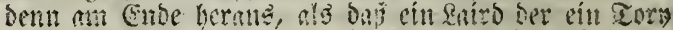

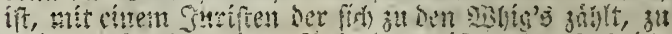

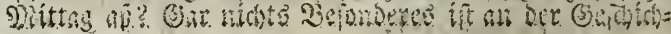


te, kefonters on Mr. Serries bus Mninat verterns

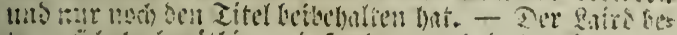

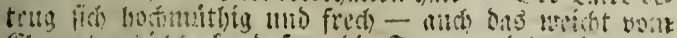

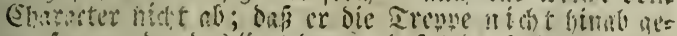

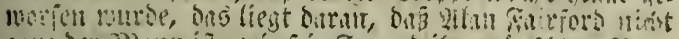

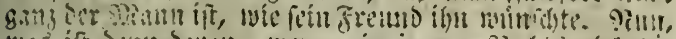

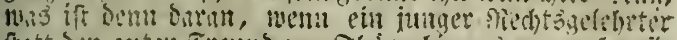

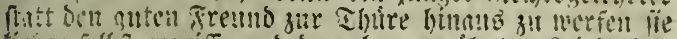

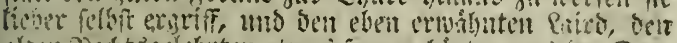

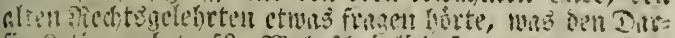

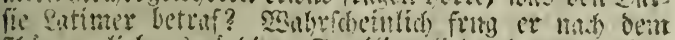

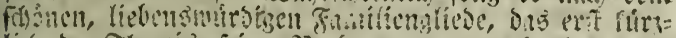

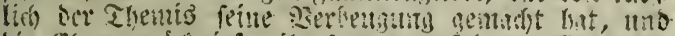

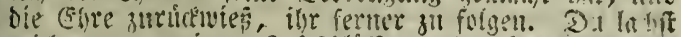

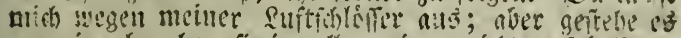

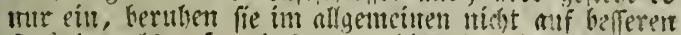

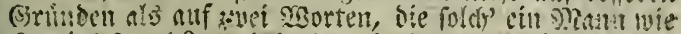

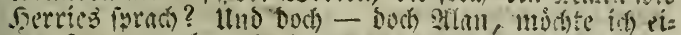

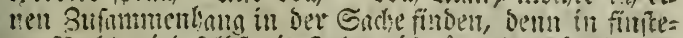

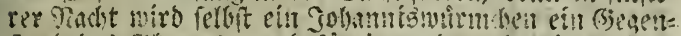

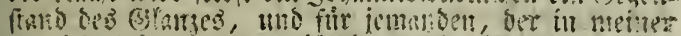

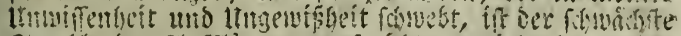

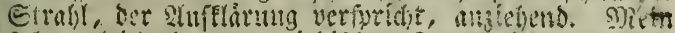

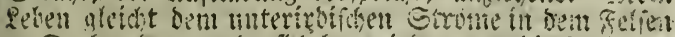

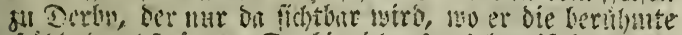

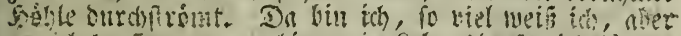

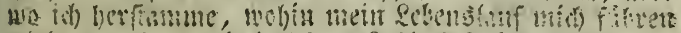

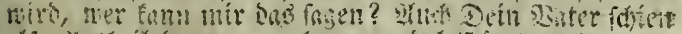

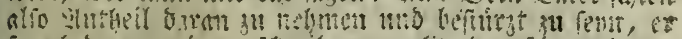

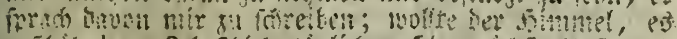

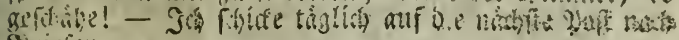
Briw? 


\section{If $t$ er $B$ r tef.}

- Ulan Fairforo an Darfie Latimer.

Du magit Deine flugel zuranmen fallagen tno friben fo viel Du willit. Du gebit auf 2rbentbeter aus, zu nír fommen fie ungefucht, ads uno wie lieblich fanten meine, da fie in form eines Elienten - einer

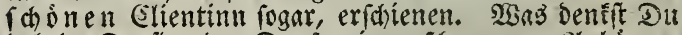
Dabei, Darlie, der Du fo ein gefoworener 2 Inbainger ber Sanen bift? Siann fiś das nicht nit Deinem yiben= theuer, Salme zu Wferd zu eriagen mefien, und bic Ge= frichte von einem ganzen Stamme Wreitrandiger ver= Dullfeln? - Doch idh mus methodifch verfahren,

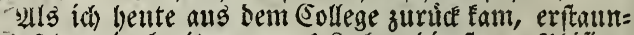
te ich felle, ein breitgezogenes \&achen bie ftarre phiffog= nomie des trenen James SGilfinfon ausbehnen! z" relien;

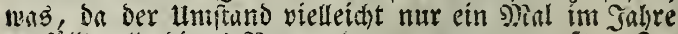

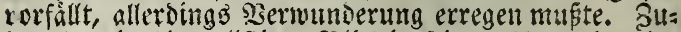

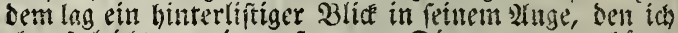
elen fo leisht yon einem finmmen Diener erwartet hâtte,

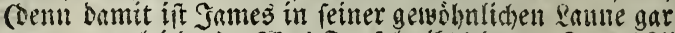
gut zu vergleichen), ภsas Teufel gibts Dent, Sontes?"

"Der Seufel mag wohl im Epiel fem, fo viel its

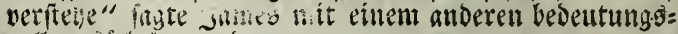

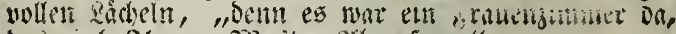

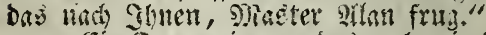

"Sin srattenginnuer sas una mir frug ?" fugte ich eritaunt; (benn Dul weift wohl, bas aliper det aiten Fante Teggie, oie Somntugs zun Dittagseffut foumt,

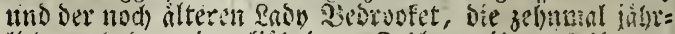

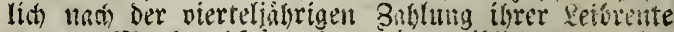
von 400 s) tun erer Thurichwelle nähert, ba mein sinter alle feitte

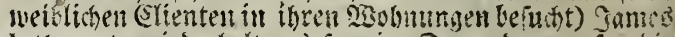
betbenerte wiedeholt, es feb rine Dane ba generen bie 


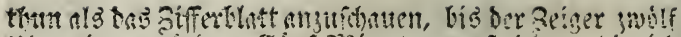

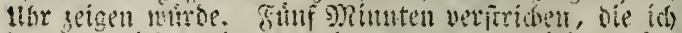

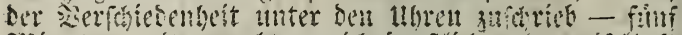

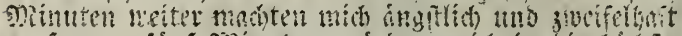
- fernce fuif gimuten wirdea nith in bie bodste Angentio letrest baben.

Pache nutr fo viel Du willf; alier erinuere Dis, Darfie, safich cin Jurift war, ber feilen eriten Elientea

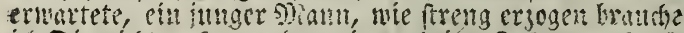

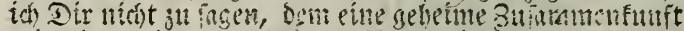

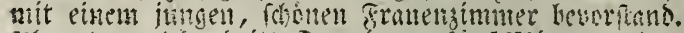

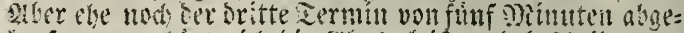

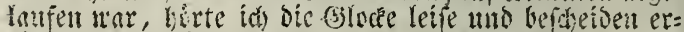

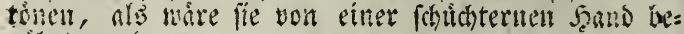
rullert worten.

Jatnes sisfinfon, in nidsts fonell, ift, wie Du

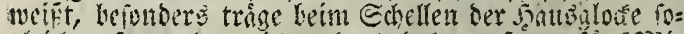

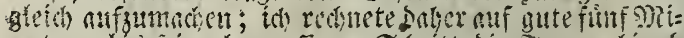

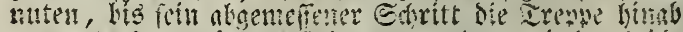

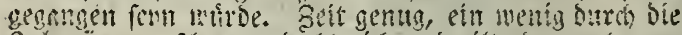

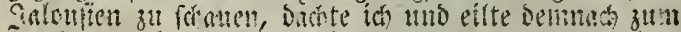
- Fenfer. grber ich lotte Die Siechntung obne ben gisirth

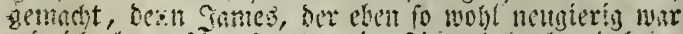
nite id), ling auf Eet Jausfur in seinterbalt, bereit beim erfen Edrlien fogleici) zu ofinch ; ich borte feute Etint=

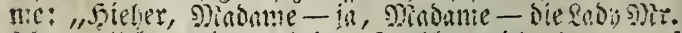

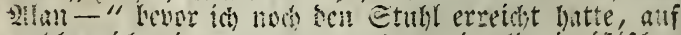

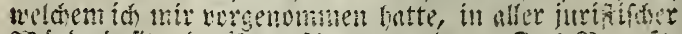

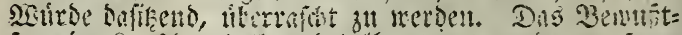

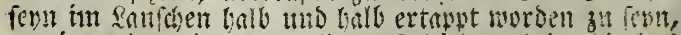
rereint mit nteiner natsilichen Edhubternbeit, bie bas iffentlidbe sertbeisigen nui abgewóbnen foll, madten,

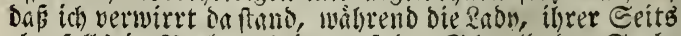
elenfalls in serlegentyeit, auf ber Sobuelle ber Stmbe

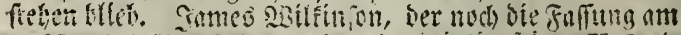

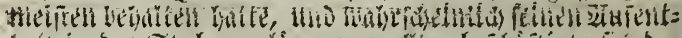

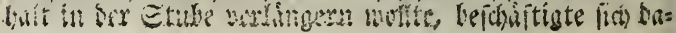


mit, der Dame cinen Stubl bin zu ftellen, und rief

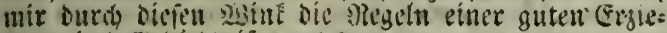

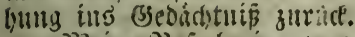

gheine Befinberimu war, obne Blyeifel efte Labo, unb wabricheinlich nicht geringen Sianges; felse befdhei=

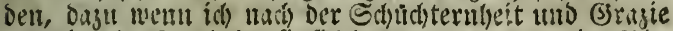
urtibeilen barf, mit ter fie fids bewegte uno auf meine 2 it =

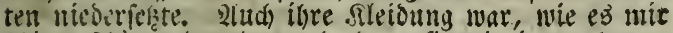
fohien, foch mo modern; boch war fie miténem phanta=

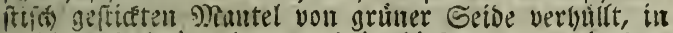

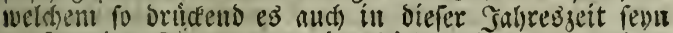
muste, ibe fiordir gam éngeluallt uno ber noch obeu= breut mit eiter (eupuse verfelsell war.

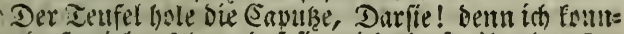
te grabe fo viel erfethen, baś fie nich, da fie tiber bas (s)e=

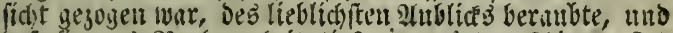

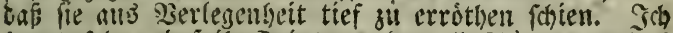

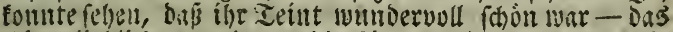
Rimn lieblich germbot - bie síppen wie (sorallen - die Bithne wetteiferno nit Glfenbein. arber weiter vermud)= te ser fithue 3 lid nidat zu bringen, beun ein goldenes

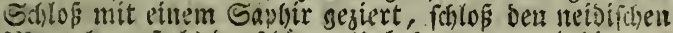

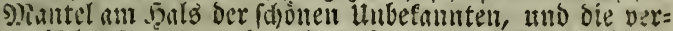

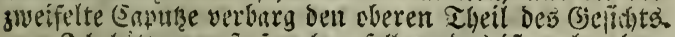

Ist) bitte ztherit ipredien follen, bas ift unlengbar;

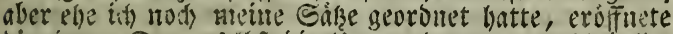

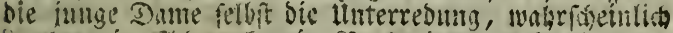

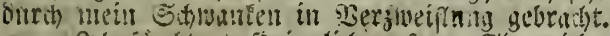

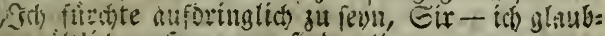
te cinten aitlichell seren zit findent."

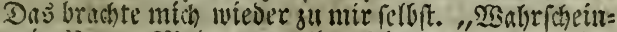

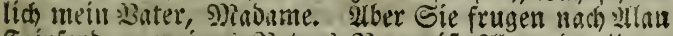

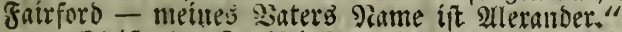

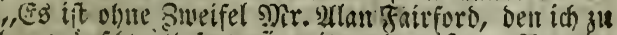

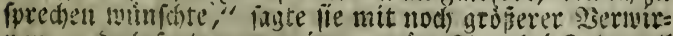

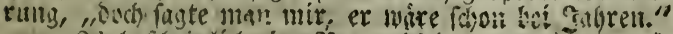

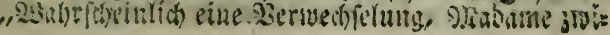


fchen meinem Bater und mir - unfere Tinfnamen haben

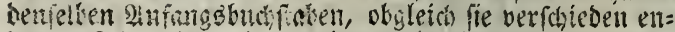
ben - Jei - ich - idt wirbe es fur ein febre gltichliches

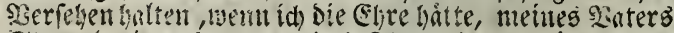
Etelle in irgend etmes, bas Jghen bienen founte, zu vertietet."

"Ete find febr gutíg, Sir!" Paufe in we'dher fie zroiffelbaft fotien, ob lie aufiteben ober liken bleiben fuite.

"Jith fin gerabe im 2 egriff, mente juriftifose \&auf= hobn zu beginnen, 9)indame," (hoffent busurd) ilire 3méfel ju belen, um ellolich zu boren mas fie wolfte, "founte Shten mein Siath oder meine s)einung non

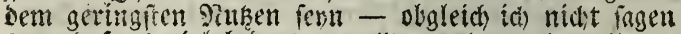
fann bas es viel beseuten wollte - bennody - "

Die Reis ftand auf. "Id bin Slnen walgelich fir

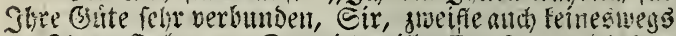
an Slyten Ealenten. Dod ich will offen fenn - id finn bieber um sie ju foredien, nun aber ba ids Eie treffe, halte ioh es fir beffer, Shnen meine gitttheilutben f(d)rifitiol zufommen zu laffen."

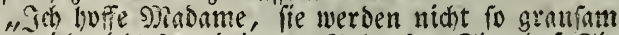
renn, mich nicht ro peinigen. Zerenten Sie, die Sie mein erfter Elient fino - Shr stefhaft meine erfte (5on= fultation - mad)en હie mir bas g)i isvergnugen nicht, mir Shr \$ertratten zu entzieljen, weíl ich einige Jalyre jinger

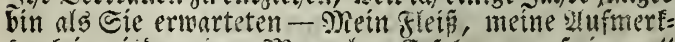
famfeit wird me nen \$) Jangel an Erfal)ring aufmígen."

"3ch zueiffe feineswegs baran," pagte síe subn in einem Zone, ber barauf berechnet fiten, die zunstiom= menbe siseife, mit ber ich es gewagt hatte fie anzureden,

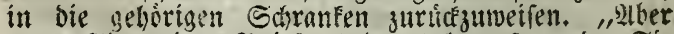
wann Sie meinen 2irief erinalten haben, fo meroen Sie relbit bie (S)ruinde billigen miffen, burum eine farriftliche

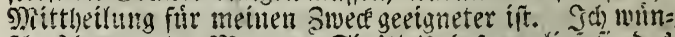

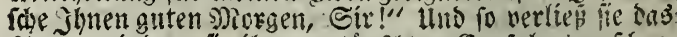

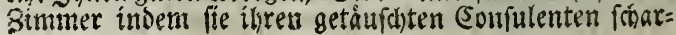




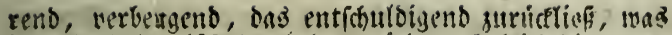
ihr allenfalls mísfallen haben módite, obgléch bie gamze Beleisigung barin zu befteben fotien baf fie nich iun= ger fauto als meinen Bater.

Sie offute bie Ibure - ging binats - eilte úber ben (5intty; Hanbte fich um bie Straffenecte, uno ftecte, glaub' id, die Sonne in bie Tanche indom lie veridument,

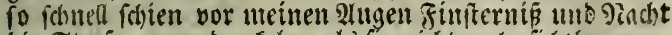

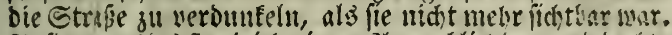
23: finmungslos ftant ich einen 2 lugenllick sa, umb baciste

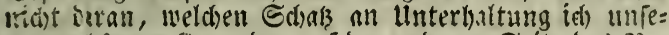
ren wagramen freunden nuf ber anteren Seite bes șin=

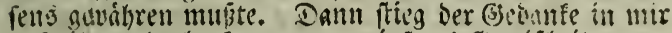

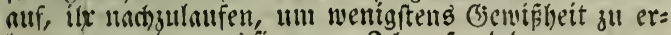
langen wer soer nuş fie war. Ich allf unb savon - ren= the dund ben eingejanten siafenplak, wo fie nicht melar zu feí) war und frug einen ber färbersburfchen, ob er

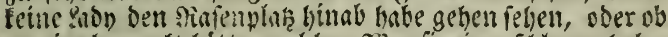

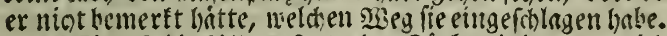
"Eine Rebdnf !" - fagte ber Färher indem er ittid mit ciner Diegenbogenmiene anfarrte, "Nir. Allan was

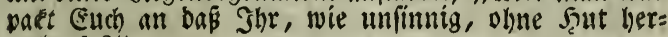
unlouft?"

"Ber Tellfel hole meinen fẹt!" antmortete idh, rann aber bod' jurúde ibn ju bolen, raffte ibn auf, und lief

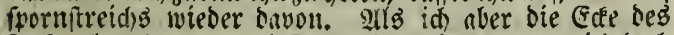

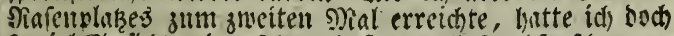

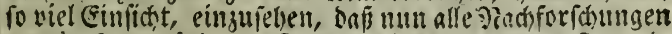
unnis fenn wirsen. Sann fab id) nuch meinen Freuns, Den Farbersgefellen in vertraulicher unterresung nit ei=

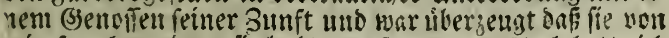

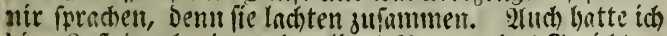
kine Qnit surch ein nochmaliges Netnen bag (S)eridt zu.

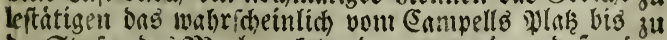

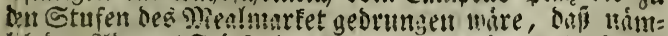

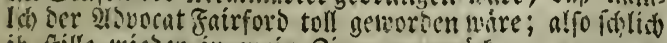
ib) frille wieber in nein Sinimer surtid. 
Meine erfe Befdiffigung war es num alle Epuren

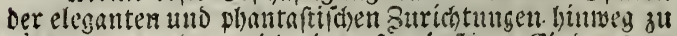
riunten, won benen í einen fo ginftigen Finorue cr: martet batte; Dent mutt inar id bejóamt mab irgerlich

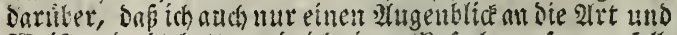
2Beife gesacht hatte, wie the einen Beftid emifangen foll= te, ber fo angerielsm besonmen, fo ungentigento gentid hat=

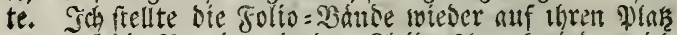
- narf die siappiere in ben Sleibiriesrant, insent ica nich babei immer mit fruchtlofen Sweifeln qualte ob eine (Gelegenbeit ungenuht vorbei gegangen, over ob ids $t i=$ ner fialle entgaligen fes, oser ob bie junge Same virflich

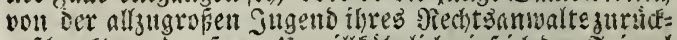

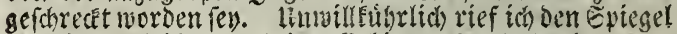

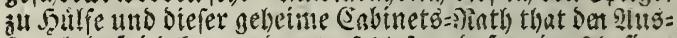

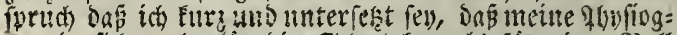

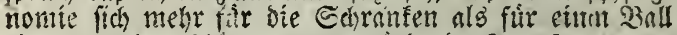
cigute - nidyt frgon gents crotbende Jungfrum zmm ¿chmaciten und mit zu bewegen, bier baffie gar sechts: fífle erounfen foltten unt in mein Bimmer zu gelangen -

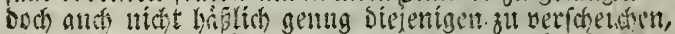

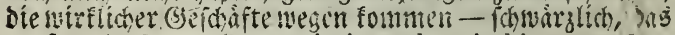
mus malyr feun, nber - nigri sunt hyacinthi - man fon

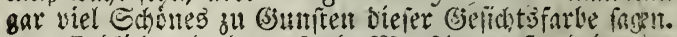
Enolid) - da der geinude sienfienvirftano imnier, wenn man nur will, sie sberbano bebalt - iberzengte ich

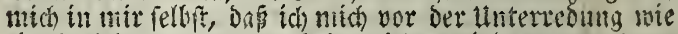
eil Efel betragen latte, inbent is zu viel erwartet latte - nie eit Efel wa brend ber Unterrevm: weil icb eg verfumit batte die wabre ploficht ber sabu bermus jo

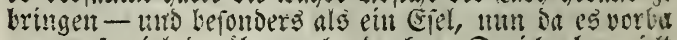
war - fo viel baruber nad)zudenfen $\mathfrak{D}_{a}$ ith aber nidt im Stande bin an etwas nnoeres zu Denfelt, fo bin ib entfoloffen, funftiger sorfifle wegen, batan zu benfer.

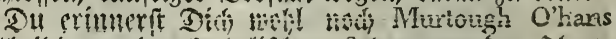

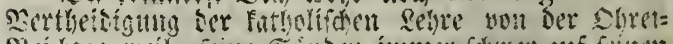

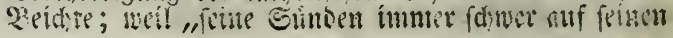




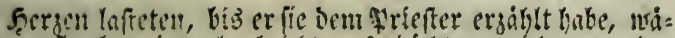

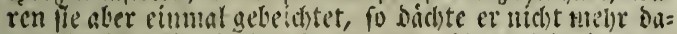
ran." Sch bate alfo bas s)iccept erprobt; und ba icls num meine aeleime Demithisulug Deinem vertronten Dhre mitgetheilt liale, fo will ién ands ferner nicht ntebren an

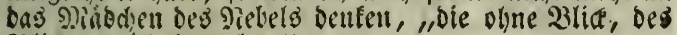
2lictes mich beraubte."

\section{- vier $1 \mathrm{Hhr}$.}

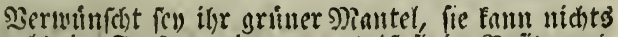
beffer alb éte see fenn; immer nod) ift fie int Befige mei=

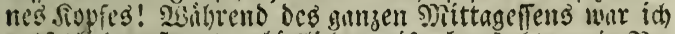

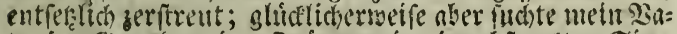

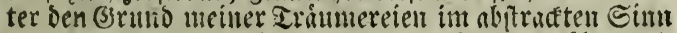
bes? ?chringes Vinco vincentem, ergo vinco te; liber wel: de jurioide febre ber \$rofefor liente Miorgen las. Eo minto irh frúljeitig entlaffen in mein eignes aimmer zu=

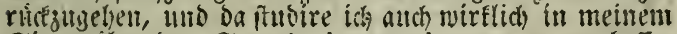
Eintiv uber ben Eprnch vincere vincentem, unt beffer bie thirigte Siengieroe zu unteroriden. - Sch benfe,

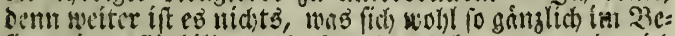

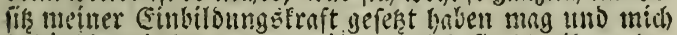
beftintig mit der Jrage qualt - wiro fie foreiben oder nid)t? Eie wirb nicht - fie miro nicht forreilen, fagt

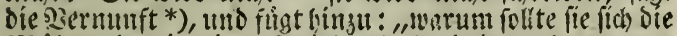
Mikge geten in einen 2 rifefwechfel mit iemanoen zu tre=

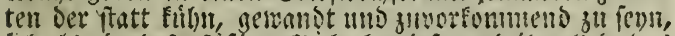

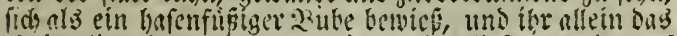

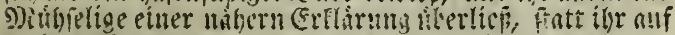

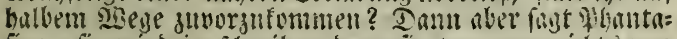
fie: "fie wiro in foreib an benn fie tring gar nichts vou einer plerfon an lich nie Shr, fert siernmit, in Eurer Dseisbeit fie (E)t voritellt. Sie war fdion wollig auper Fafing elye id ibren summer burd ein unveridisutes

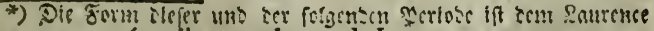
Etcul (yoriks sentimental lour.1eys 171\%. Fay. 44) nadigcabunt.

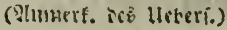


Betrigen meiner Eetts vermebrte. Sie wiro fareiben Denit

3eim simmel, fle bat gefdrieben, Darfie, meldse

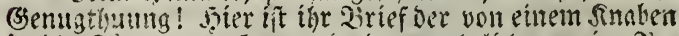

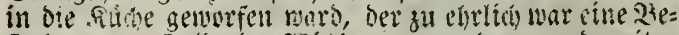

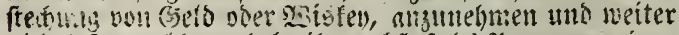
nidits fagte als, or habe ign nebin fechs dence von eimer getwónhlich ausichentos frau befommen, als er nabe ant Sirtube sefrielt kintte.

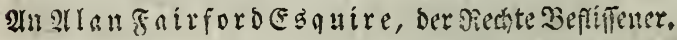
"Sir!

Derzethen Gie bns heutiae Mifperfantonip. Sch er=

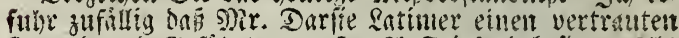

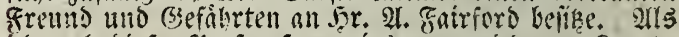
ich ntch biefer Perion frug wies. nan midh ätm Sircuke (nie man, glaule idh bie 3orfe Gorer Etrot nemt) mid bejeichnte mir einen egrwurbigen âttidgens sian - Sh)= ren 2 ater, wie id nun fehe. 2 (Is ith in ?zrowns Eanare

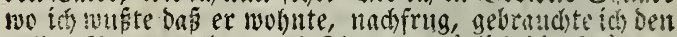

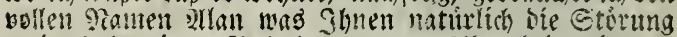

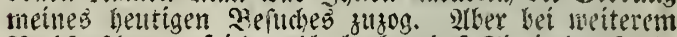

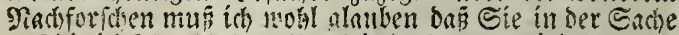

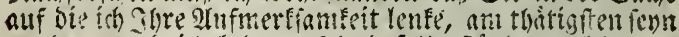

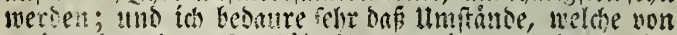

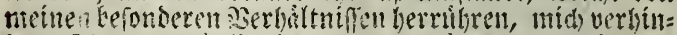

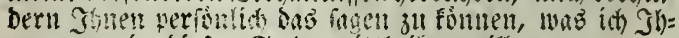
nen $n$ in in biefer Eacte mittheilen will.

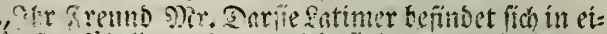

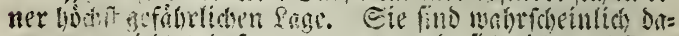

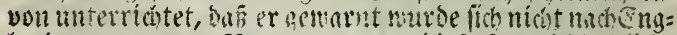

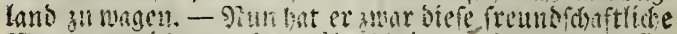

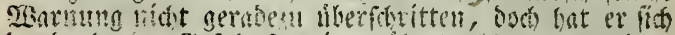

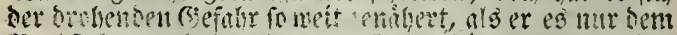

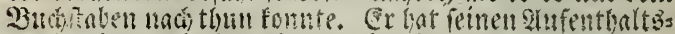

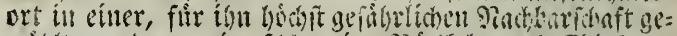

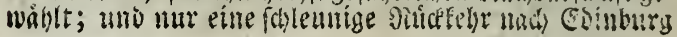


Doer wenigitens eine Reife mad entlegeneren Theilen

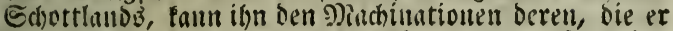

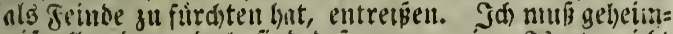
nipuoll reben, bods finto deb̈luegen meine siorte nidat minber gewís, und ich glaube, Sie werden foweit bie

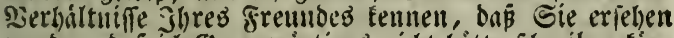

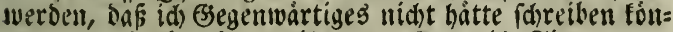
"ten obue barin eingeweihter zu fenn als Sie:

Sinn oder will er ben hiermit gegebenten Эiatl) uid) antelnmen, fo ift $e^{8}$ meine s)ieinung bas Sie ilsm nit

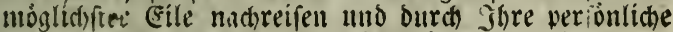

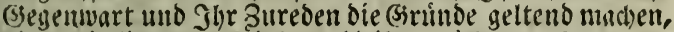

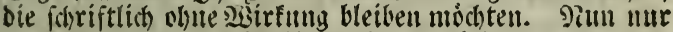
mod) ein 230 ort uno id bitte Sie, eg gutigit io aufzuteb)=

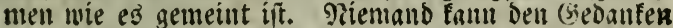
begen als fóme man গir. Trairford 8 Eifer fuir den Dienit

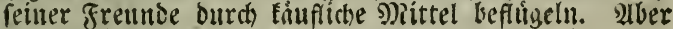

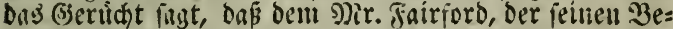
rufiftand nod hidht angetreten hat, int einten falle wie ber vorliegende, mohl bie!s)nittel fellen fontten, menn

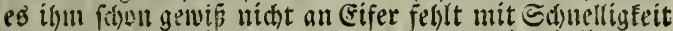
gu bandih. Misge Jjr. 2llan Fairford Die einliegente

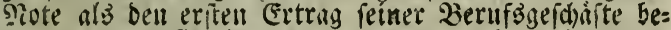
traditell, uno fie die es felldet, hoift, dá es eill Dmen

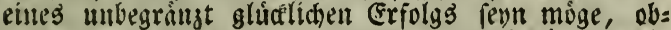

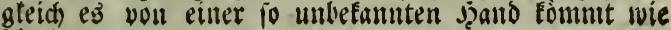
bie bes

\section{"(S)น̊n = Mantelo."}

Eine 2ianf = 9?

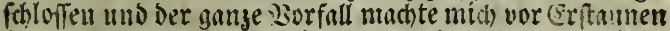
furaci)log. Sal bin nidht im Stande dell 2 (nifang meines 2iriefes, der bie Einleitung zu biefer auserocoentichen

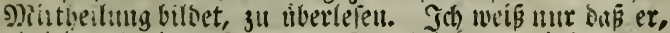
obyleid) mit einer Oienge von Thorheiten vernilat (Bsott weis wie veridhiesen lie bon meinen gegenmirtigen sese:

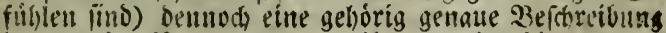
oer geiveintmipvollen Perion gibt, von Der Diefer Jrief 
forment, boch bake id neber zeit noch (s)eduld ben abges formaceten Eommentar von ben Texte jut tremen, ben Dit fo notíty mipen mupt.

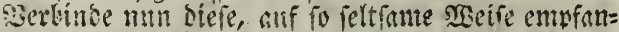

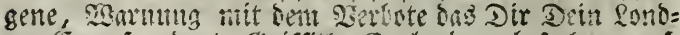

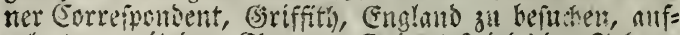

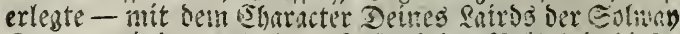
Eeen - mit dem geieklofen suftand dez @olfeg in siefer

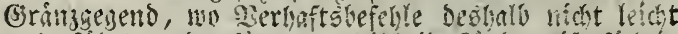

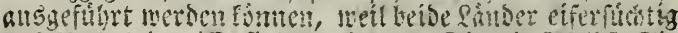

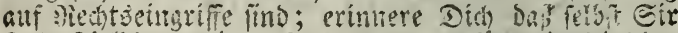

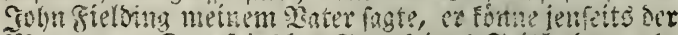

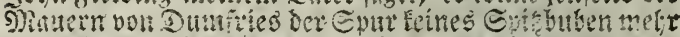
nachgehen - Senfe Daran dus die Emattung zunfen

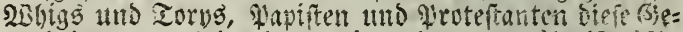

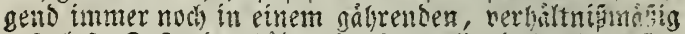

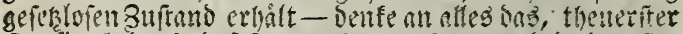

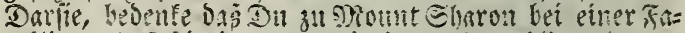

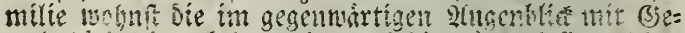

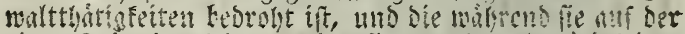

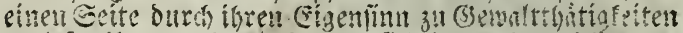

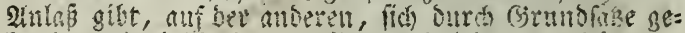

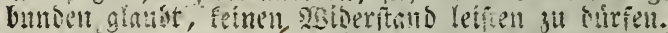

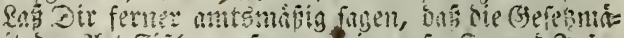

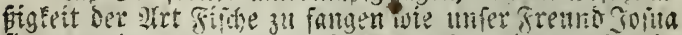

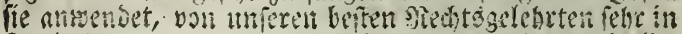

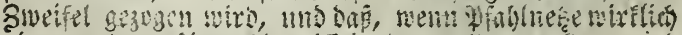

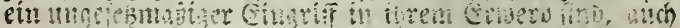
éte (sjefelfoda t tie via facti berfaint, fie nieserwist mo

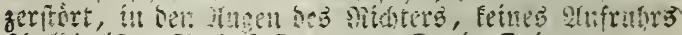

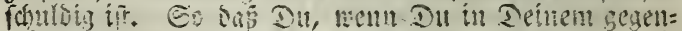

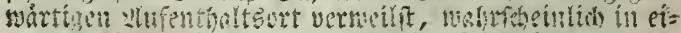

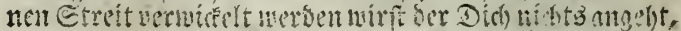
und fonte Deine fénse, wer fie and feys stonen, in sen

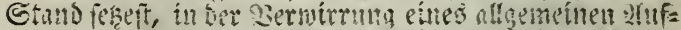

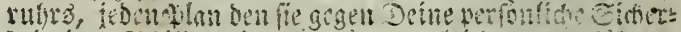

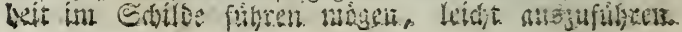




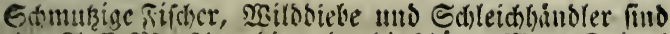

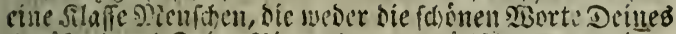
Qunfers nod Deine Pitterthaten zuricéchrefen werben.

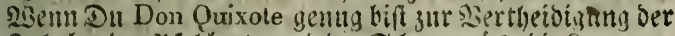

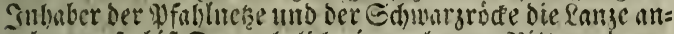
anligen, fo bift Du wallyrlid) sin verlorner Bitter; benn,

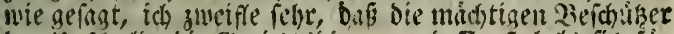

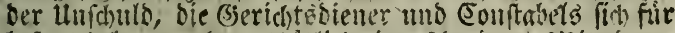
befugt halten werben, thittich einzudareiten. slit einem

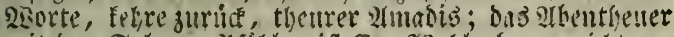

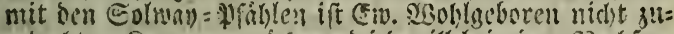

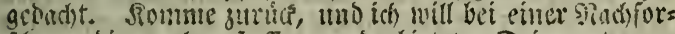

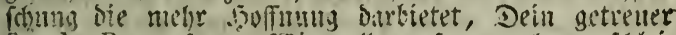

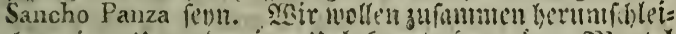

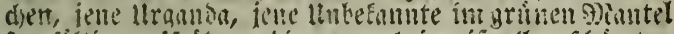

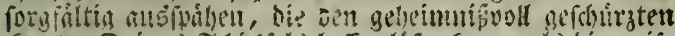

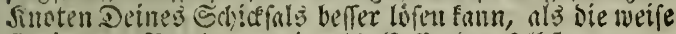

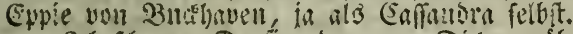

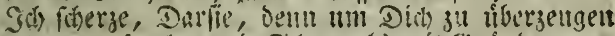
gelangt man oft eber nit Solyers als mit (Srunoen zum

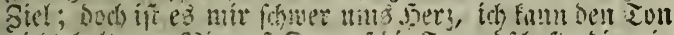

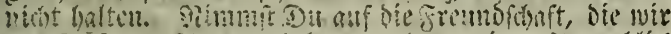

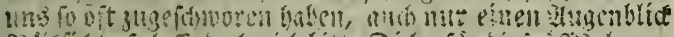

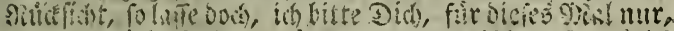

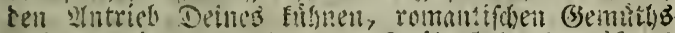

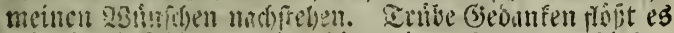

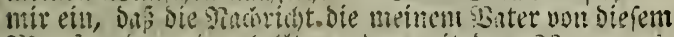

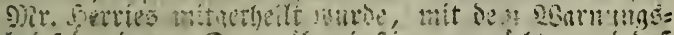
brief ber innger Dame thorin?

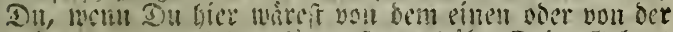

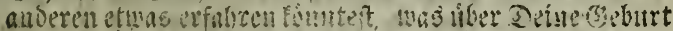

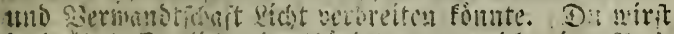

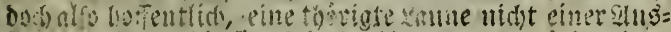

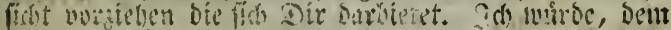

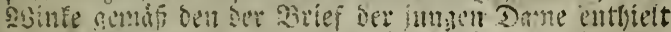

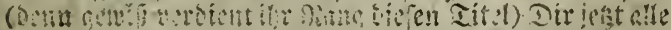

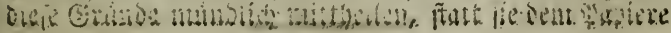


anzavertrautu. Doch weift $\mathfrak{D u}$, Daf ber Tag meitter Oluif:m:g feftgeferet ifit; fohon bin id ben Examinatoren vorgentellt norben, fatoil ift meine Thelis beitinimt. Freilich follte nuich bas sulles nidt zurita balten, aber

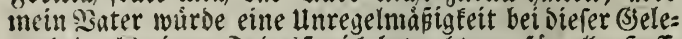
genleit als einen zodesitreid betrad)ten, für alle fecoff= muthen Denen er in feinem leben am meiften nadshing, námlid) Daś id) metn Examen mit cinigem (s)lanz beftehen

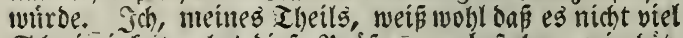
Edweierigfeiten hat biefe Drufung zu beitehen, wie hat= ten lie fonit mandhe aus unierer Befanntidjaft beiteben fönten? 2tber fúr meinen Sater find diefe Formalitaten eitue exhakene, ernfte feverlichfeit nad) welcher er fich fdon lange felunte, uno wenn ich mich in biefem 2 tugen= blick entfernte, fo fonnte es ihn nat' an siahnfinn bringen. Doch werden meitle bjedanfen fiets abwefent bon mir Fenn, went Du midh nidht umgeheno veriiderft baj $\mathfrak{D} u$ hieher ciliti. Ilnterbeffen habe ich die Shanna gebeten, Dein Ficines Bimmerdhen in ben mỏglichît beften Stano

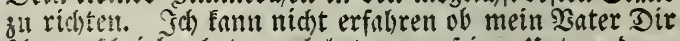
fofon gefdrifecen hat; aud hat er von feiner unterreoung mit Birrensubre nidht mehr geprochen; aher menn id ilg!t auci) tutr eine Epur von Der (3)efabr nterfen laffe, in weldser Du fáswebit, ro bin id hiberzeugt bas er meine

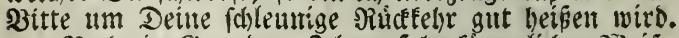

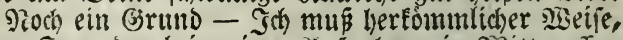
unfern Sremben bei meiner Mufnabue ein sittaneffen geben, umb mein sinter Der bei Diefer (5) elegenlyeit alle feine gemolgnliden givicelidgten auf Defonontie bereitigt, wúnidt bas es recht glälseno uerde. Somme alfo ber,

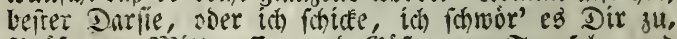

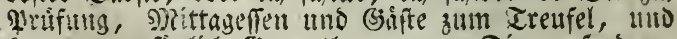
fonme, werionlicis Gemmothum vou Dir zu fordirn. Der Deititige, in srofer angit. 



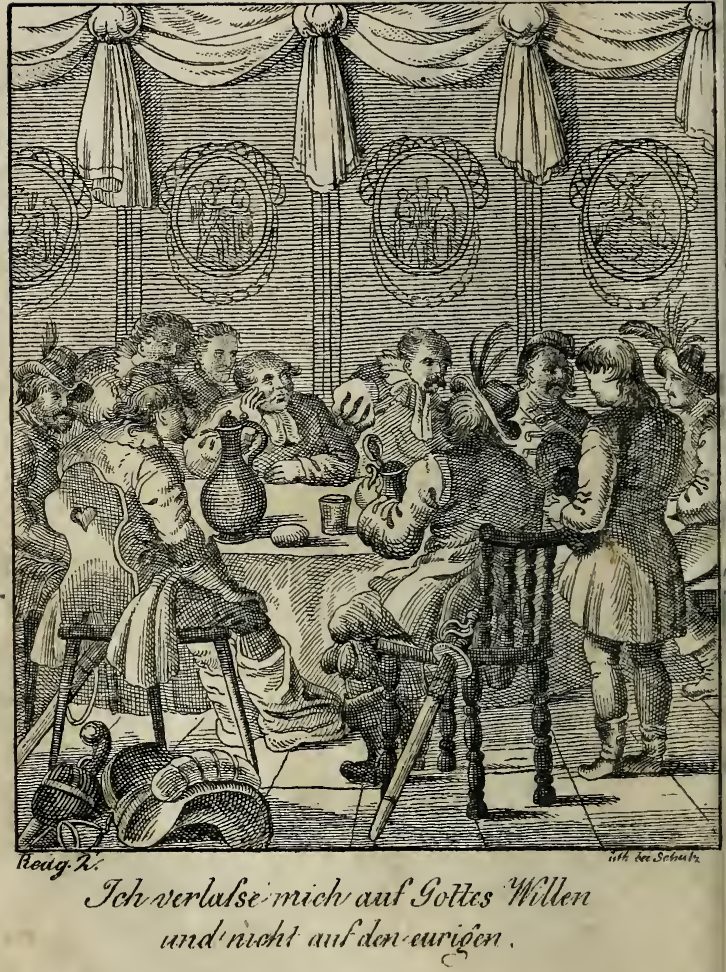




\section{Yalter Geott's}

fámmtriche
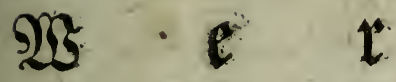

E.

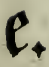

शeu ủberiegt.

Sechazefuter sand.

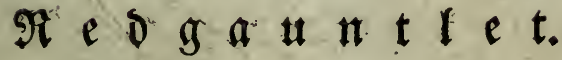

Eine 巨rádb satisunbert.

5 weter $\mathfrak{z}$ beil.

S $t$ แ $t \operatorname{tga} \mathfrak{a}$, be $i$ อ $1: 26$. 

$\mathfrak{A} \mathfrak{e} \mathfrak{d} \mathfrak{g} \mathfrak{a} \mathfrak{u} \mathfrak{n} \mathfrak{t} \mathfrak{l} \mathfrak{e} \mathfrak{t}$.

\section{Eine Erłágrung}

aus oem achtgelnten Sabrambert.

\section{నom}

$\mathfrak{e}$ efarfer deb arsactey.

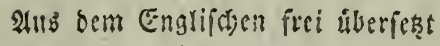

von

\section{carl 23 cil.}

St folge Dir, D Meiffer, nur voran,

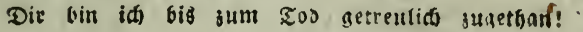
( 3 sie's (Eันd) gefältt.)

\section{Zweites Band ben.}

St $\mathfrak{t} t \operatorname{tg} \mathfrak{a}: t$,

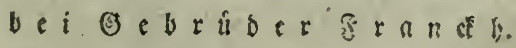

$$
1826 .
$$





\section{$\mathfrak{A} \mathfrak{C} \mathfrak{g} \mathfrak{a} \mathfrak{u} \mathfrak{t} \mathfrak{l} \mathfrak{t}$.}

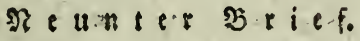

Alexander gaitoro, Eigneffcheiber, an mpr. Darfie Eatimer.

Theuerer Mr. Darfie!

Da ich bisher. She factor loco tatoris oder richtio

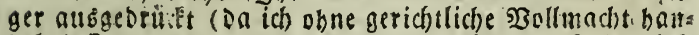
Delte) Int negotiorum gestor war, fo bertiffacht Diefe meine Stellung bแt Shnen, wein gegenmártiges Echreis

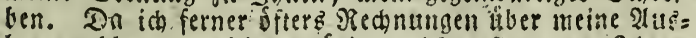
lagen ablegte, welche getorig, nicht allein von Sbren (Den ich nicht Dajls bringen Eonnte, imeh? als Die. Hes berichrift und die Totaliumma anjufehn) fondern attch von bem ehrenwerthen Mir. Samuel Brifith is Sons Don gutgeheifien wurben, fo fann ich aud gemifierma. Ben als Ist functus officio betrachtet rerbetr; - Doth beffe ic, anf ieden fall metoen sie miü nicht alb

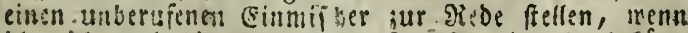
(id) mich auch hie uno Da twm She 230 blergeth befunt= mere. Die (5rtinde, meldac mici) fum Schreiben bems: gen, find Dermalen zmiefact).

I th babe einen gewilfen Mr. Serrieb arn Bitrent work, einen Edelmann at!s eirem fehr alten Saafe, be= 


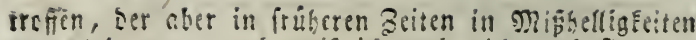

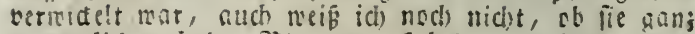

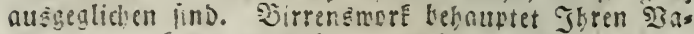
ter senset fefannt zut kaben, ton bem er lagt, er babe Sinlot fatimer ren eangeote $=5$ all gefeifien tmo in

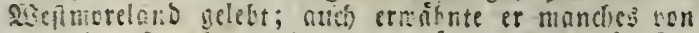

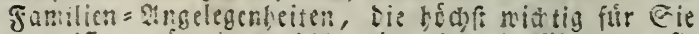

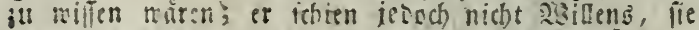

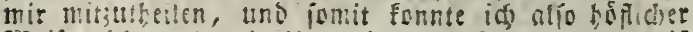
Nosife nicht meiter in isn iringen. Co riel ahir meif

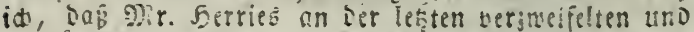

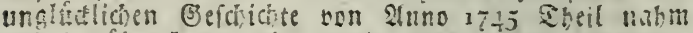

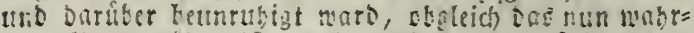

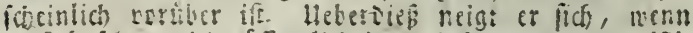
er fich ficen nicht offentlich Baj!t befennt, jut waniftis

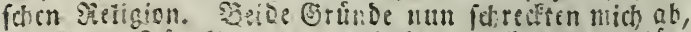

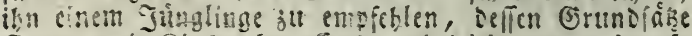
Etant limo Jirche betreffend, viellcicht nod nidt io

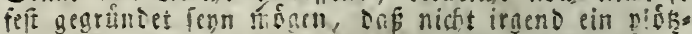

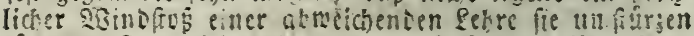

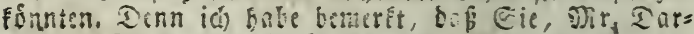
jie, nit Fbrer Frlanbnif, ein menig nm alten \&utuer= toig bes Girofentlumb finger, uno obidion ich, Gott bowahre, nicht hebaunten mill, bas Eic sut Moctefons

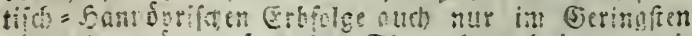
afgereegt ritreth, fo kabon Eie isch auth imurer mit gergnugen Dent trahleriforen, fibertricbenen zerichten

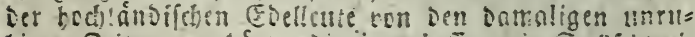

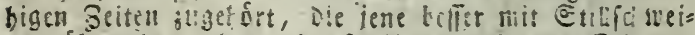

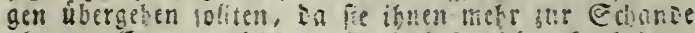
als. jur (Ehre gereichen. stueh tabe ich nebertei ge=

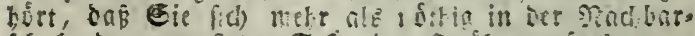

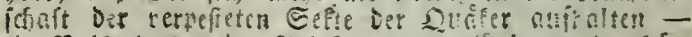

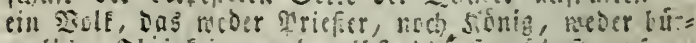
gerliche Dstigfeit, noch leltef Lie secrit aft trajerer Grietse ancifent, und reser in civilibus red crimi-

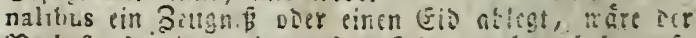

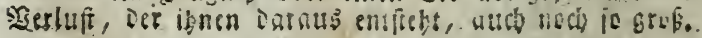


Es nåre gut, menn Eil Liber Diefe frezereien, bie

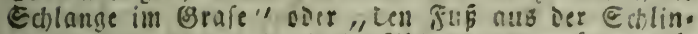
ge" leien molleen, ta beide albbandungen liber diefe Qebre mit bielem secifall aufnenenimen retrben.

giun, Fir. Dariie, missen Gie jeloft urtheilen, ob Sie, junt Rioghl ghrer Eecle, lánger unter biefé Plapiften und Suáern rerweilen isnnen, ia diére nb. weichen jut rediten fonnd und iene jur linEen abjallen. Joben Eie aber is riel Eelbifertratuen und glouben Gie ben bojen beipiclen Dieficr fehre miteriteten it fonnen, fo tádite ich. Ioanten Ele mot! in Jhrem gegenvärtigen Âtenibn!tcort bleiten, biร Eie Mir.

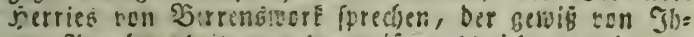
ren 2irgelegenbeiten mesr meí, nls ich.oon irbeno

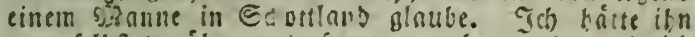
gern felbft cariber nutgeirngt, er aber noute, rrie iti) fichon bemerlte, nicht recht mit oer Eprache herans.

IIm nun con "elmaso sinderem ju recen, sate ićn

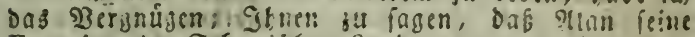

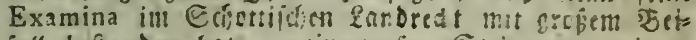
fall beftandon bat - ein grofer Etein ren treinem

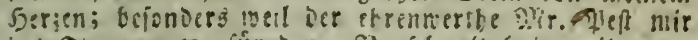
ins Dor raune, fur den "פuricten" (ris er itn ser tranlich vannte) brauche man Eeine siroft tu taben;

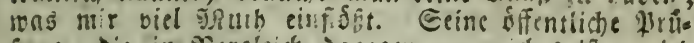
fing, bie in 2 ergleich iagegen gar nidsto int, mirb auf Befehl bes bodsu úrigen Eenict ber Facnltát, náhifen ojittwod fatt finjes, Freitan mins of mit Der Robe betleiset lind sibi, wie gebra and tich, feinen

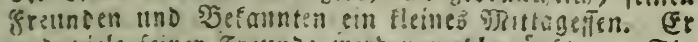
und biele feiner freunie izerien rabl nunften, Gie

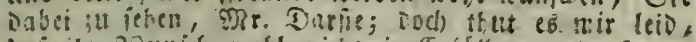

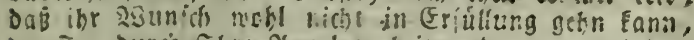
Da Eis Otirch Shre 21regelegenbeiten Daran terbindert

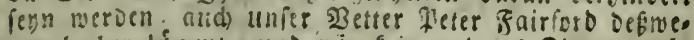
gen heteer lifime, und wir fein ar.2ereb simmer als ibre sosenenmer ibat arizubieten haben. Ferner mia

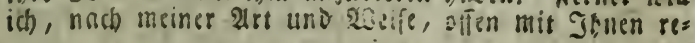


ben, פTr. Darfie; es ift mongethan, baf Eie nicht mit meinem dlan zttramenenfoumen, bis er bdllig an reinen neuen כjeruf geEettet ift. Eie find ein liebenss wirbiger iunger mann, pollet $23 i$ it uno Eehers, nas Gknen wobl anfeben mag, on Gie (nie ich hire) rier. mogen genug bejizen, Ghrer froflichen snume ein be nitge zu leifren. S\$enn Eie oie Erache reiflich úber= legten, to muiroen Sie mohl einfeben, Daß einem mohlbabenden s? anne ein rubiges, geferteg ziemt; aber weit entfernt, nit Der 3unahme Shres iab:= lichen (EinEommens altch eriffer 1trio besáchtiger ju mer Den, fcheinen Sie, wie es midh báudet, un fo furglofer, ie mekr es fich rermebrt. Ioch fálit ones, in fo ferm ez nur Eie. Jetrifft, sant Thren eignen 2 silfen aubeim. alan bingegen mis fich (meinen Nothpfennig nbgerech)=

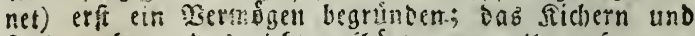
Eachen nher, bas nicht aufiert, wenn ikr jufammen feno, nurke bald ben gutier aus feiner glerricke und ben Mence aus feiner ₹nfche vertreiben. Dod boffe in, werbet ibe euch, wenn Sie Thre Etreifsuse vollen= bet haben, wieber fehen; Denn rate Der 2beife lagt: es

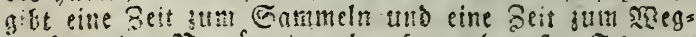

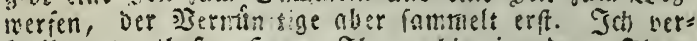
breibe, werthefier forr, She robluteinender, Jbren siefeblen ergebener fretmo

P. S.

Alerandergairford.

Alans Ibefis ift úler Den Punft: de periculo et commodo rei venditae, uno ift ein Miufer son Lati=

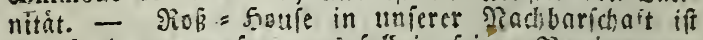
faft fertig, man fogt, eb foil in feinen serjierungen Duff. Şoufe felbit ubertreffer.

$$
\text { E. } 3 \text { ebnter } \mathfrak{z}_{\text {r }} \text { ief. }
$$

Darfie fatimer an Slan gairford.

Der finoten verwickelt fich, 2llan. Ifh habe einen

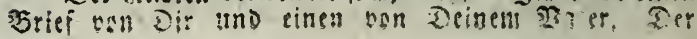


Diefer Foelmann nante ofn Nattign einer Famis lie in $2 B$ eftmore!aro, mit nelcher of ma fur bermand

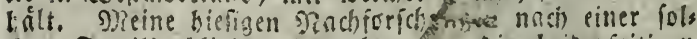
chen Familie blicben frubtlos og Die beiderfeitigen Ërnibewobner renig non einase miffen. Doch nill ich gemis noch cinen Enalánbe foben, Der itn Etande

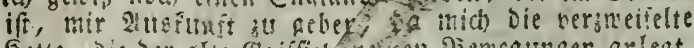

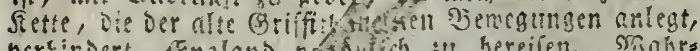

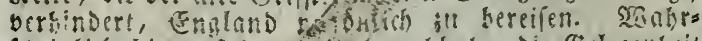

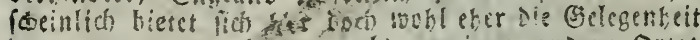
Dar, etmas. jtt sefarrem, als an eirsem andern Drte;

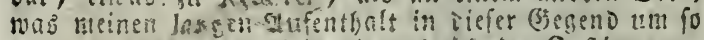

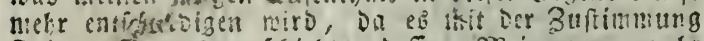
Drines driters Befáteht, Deflen gReintitgen nehe Grand baben meroen, als Die Deines mandernden Enmernden.

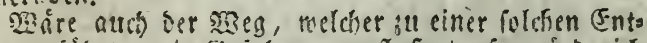
secung fibst, mit Gephren gepfoffert, io whire id Demnoc finen Ilugenbick naftehn, isn :u betreten. In

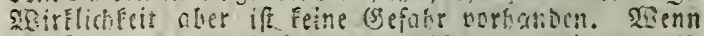
tie sritoren ber Eolman ble Ebecnépe meines etrlis hes Goins's fellf nicoerreifen follten, fo lin ich men

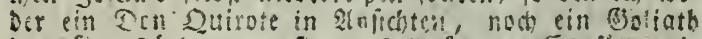

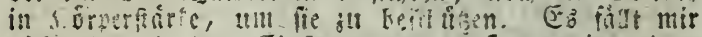
nichi cin, ein bem Einfurye nakcb, 5 nut mit meinen

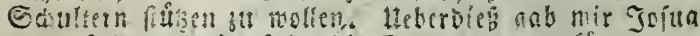

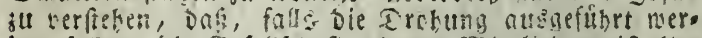
Den folle, bie Gelelfichoft, beren mitiglieb er iff (on einige baoon trofsien afuficten fuldigen) Die $2(u f=$ thiser geriatlich befolgen uno echaicnctfat forbern

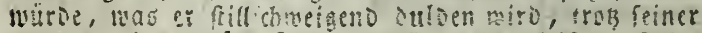

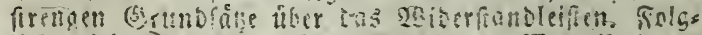

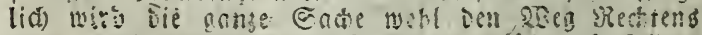
gebr, unt mesn ich mich in tarein mifche, fo foll es

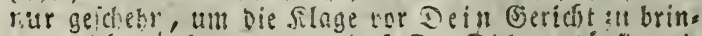

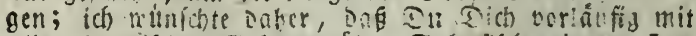
nll:n fattifisen Beictsen iller Enlmilicherei vom Lex aquarum abmartš, betannt machen ndótef. 
ibre-Tafchen geftecft - war fchon alfes umber famft uno

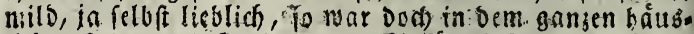
lichen Eeben und Treiben eine Einformigkeit, cin 50? an. gel on Intereffe, eine unveriónderliche, bofnungslofe Échláfrigfeit-, Die mir Dab̆ Leben Dort unausfteblich

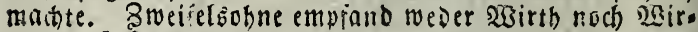
thin Diefe Leere, Diefan Rangel an Preiz, Der Dem Bafte fo läftig.war. Der Eleitu Sireis itrer sbécháftigunges, Mildbatigfeiten uno Erbolungen mar beftimmt; Rabel

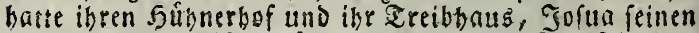

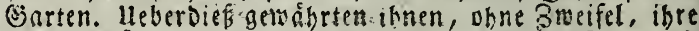
2(noad)taubungen manchen (B)enußs, fo.daß - bie Beit fanft und unmerflith whit isnen Dabin gleitete, twabrend fie

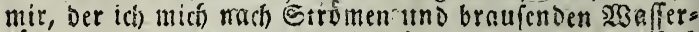
fállen fehre, ganz unbeiveglich ba zu frehn pien. Fen bachte Daran, ob idh nicht nach Schajers Eebren folle, und fing an, Den fleinen gjenite ulid die

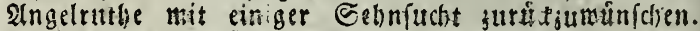
Der Schurfe bat fich her gerwagt 1 nilo latert, um mich bie und Da fll erblitten; ich vermutbe, Der fleine Fifrer anzelt nach einigen Eectionenceftutfen. Stber oas war

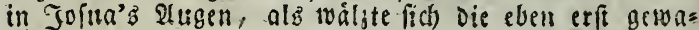
ichene Saut bon nettem im fioth bertm, und fo lange ich fein (s) aft bin, babe-ich mis feft vorjenommen, nicht fo beftig gegen feine Sgorurtheile anjuftofen. Dann molite ich Die beftimmte Zeit meines 2 afentbalts verfürsen, aber ach)! auch bas wat unmoglich. Sch batte eine W3och: beftimmt, uno mie voreilig autch mein 2 eripre= chen geleiftet worben war, To mubte es doch heilig, ia feloft buchfínblich gebnltein werben.

stlle Diefe Setrachtungen verietztent mich geftern atbend in eine geniffe llngeduid; fo Den ich meinen fyut ergriff uno mich fue einem Streifzts aliferbalb Der anges

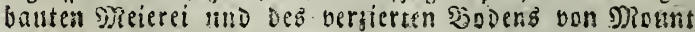
Eisaron vorbireitete, grabe alg ob ich Dem Sieiche Det

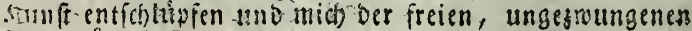
S?atur uberlaften nollte.

Jaum enpfand ich mebr פergnügen, als lich juerf 
Diefe frieslidbe 230 bnung betrat, als ietst - (fo unbes fándig, unbebarrlich ift diemenf(b)licl)e Natur!) - wo ich bon ihr ju Dell weiten I ünen zurádfebrte, Die mir fruber to sbe, fo traturig folenen. Die \&uft, , Die ich einatbmete, folien mirsciner und inoblouftender. Dis פBolfen, bod úber mir auf Eommerlúftchen bobin fobme: beno, tanjten frobliche Reigen uber meinent Sattpte; iusem fie bals die Eonne berinnfelten, bald ibren Gtrablen erlaubten, fied in ourchifchtigen @treifen uber nerfacoene Tbeile det $\&$ andidbaft zu erftiomen, beion: Ders über Den breiten Spiegel Deb fernen Jieerbufens oust Solman:.

Sch nabete mich oer @cene mit Dem leichten Gobritte eines befreiten Befangenen, tuns wie Sobn Bungan's gilgar; batte ich gebend, in meinem Saprzen. Stoff jum Singen gefunden. (Es war, als ob meine froblicheit Durch Das unterbraiten berfelben zatgencmmen baite, tmo als bitte. ich; in meiner-iekzigen frettoigen @simmung ein Recht, Die Erfwarniffe Der. SRoche ourchitturingen. Eben mollte id ein froblid)es ficb anfimmen, als ich tu meiner frelloigen lleberrafdiung, orei oder vier Stim. nen borte, bie reciot brav bas alte Irinflied fangen:

"Denn all uníre serute waren fetig und fröbtid,

"Ele farien juiammen beim frug :-

"BNei waren meits,

"Droi maren-Din,

"Itns- oreie apförten Sir \$hom - o' sune,

" Quls fie wafiten zur Strife, waren fie fröhtid uno fello, "Eie fafen:twammen beim Srup."

ents ber Ehoras envigte, folgte ein lantes, berili-

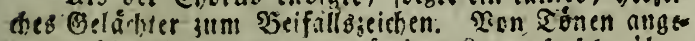
iogen, be mit meiner gegenwartigen enane fo fohr ibbe cinftimmten, nabete ich mid) Dem! Drte, bon Dem fie berfamen - Demnoch mit Morficht - Denn Die Dủnen batten; mie mir oft ju berfeben gegeben wurbe, Feinen guten Namen; uno Die Xnjiehungacinft Der Nutuf, obne grabe in Melindie mit fener-ber Evernen zut metteic fern, biutte-boch fî́ einen unvorlichtigen Liebbaber ábn. licbe unangenebme Solgen baben Énnen. 


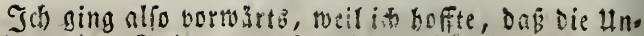
gleidibeit Des bobens, atti welchrm fübel uno sands grtben abwearfelten, mir geftatten wúrde, die glunifer

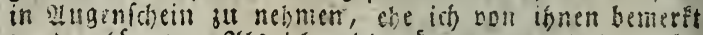

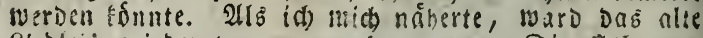
fieblein wieber von nettm begonnen. Die stimmen (ü)ienen die eines Mannes uns aneier finaben zu feral fie waren ralih, bieltell abor richtig Daf uno verries

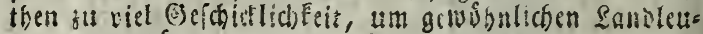
ten angugehoren.

"Iute iaf) in Die Conn' und ferrie Feure, ef brennt!

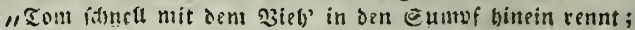

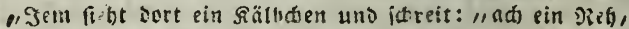

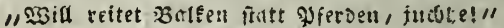

"Denn 2 If tuire \&eute waten felig und fröbllda,

"Sie infon bufammen baim frug;

"3wei waren mitin,

"Drei waren Dein,

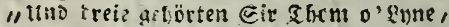

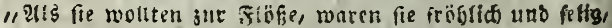
"Si̊ faß̧en julammen bein Grüg."

Die Etimmen, als fie fich bei berichiederen Etellen ner:inigten, andere fdnell thergingen, als fie Die (Slie= Der atts Der Jette Des alten, lufiagen Irinflied s bald

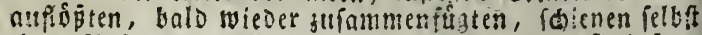
einen Infrich Des badanalíchen Eeiftes, ten fie beian.

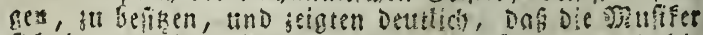
fich in iemielben fretudigen anumel befonden, roie bie

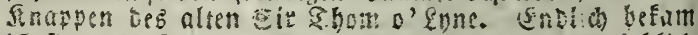

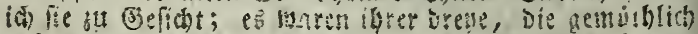

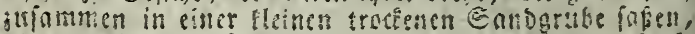
ois won einer naturlican Enabinnuer uno einer Secfe oon Etectralmen in voller פjltibe, ungeben wat.

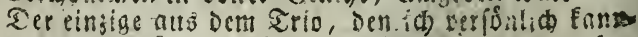
te, war ber berínsigte fleine sentie, Der, on er eben peinest Befana teenrigt batte, mit dar einen $5 a n d$ ein

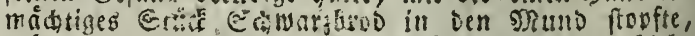
wábreno er in Der anberen elnen fhüumenben firtig biels. 
Datei irriben feine artegen yor fuff lei bem beimliden

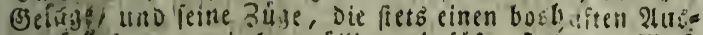

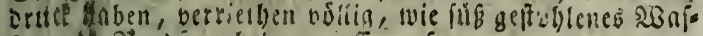
fer ung D̈roo, gebeim gegeffen, fen

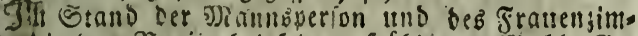

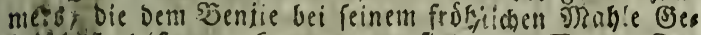

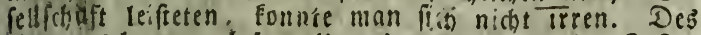
Jauseb langer, lofe anliezendir Heberrock, ber Saften Det (अ) elge mit Dem \$ragriensin, ber neben ibm lag, und ein Elether Edinosbfack, Der einige wenige noibwendige

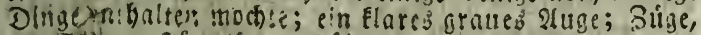

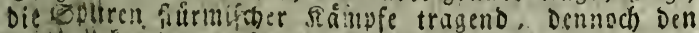

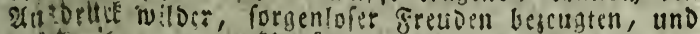

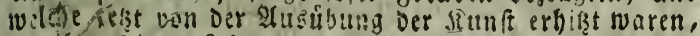
bie ista feinen febensunterbalt berich.iffe - alfes ver=

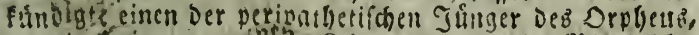
bie this in gemesnst Eeben wandernde sjerfiedler

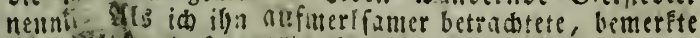

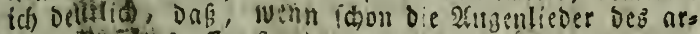

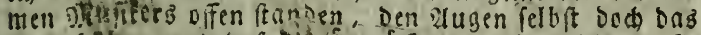

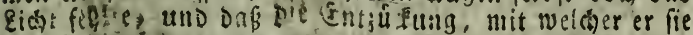

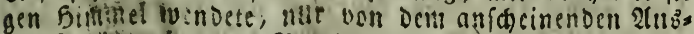
ortcef feilter Inneren jeswegung berfam. Dẩ aber die

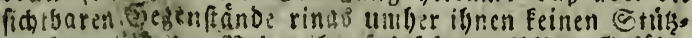
punit verlithan. Sieben inat fẩ feine weib!idse Bsejäbr. tin, getleste In einen Soannerhut, einen blauen

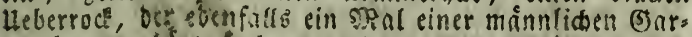
berobe angelyd it aben mochte, uno in einen rothen

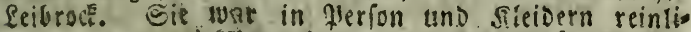

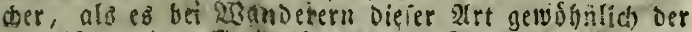
fall ift; und Da fis is ibren guten Tagen eine fastliche

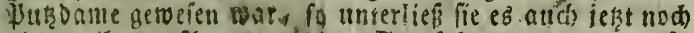

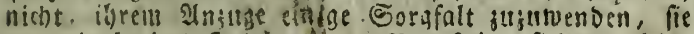
tritg ein breites 5 alsband oon 3 ernfein, filberne ObE: ringe, und ife fileio war tuber Der פ̧ruft mit einer Epange von temisiben metall befefrint.

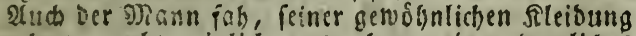
ungeaci)tet, recht reinlich aub, batte ein orbentlides. 


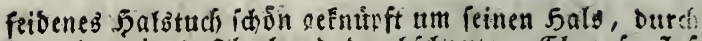
Dab ein reines Dberkemo ourdichaute. Eben fo fios fein Jart, fitatt einen fiadichten, melfere Tage bere

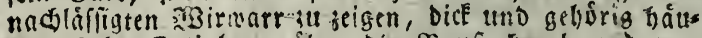

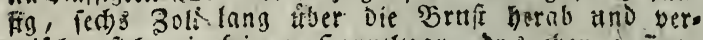

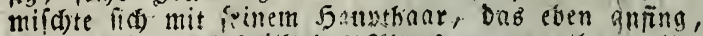

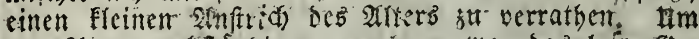

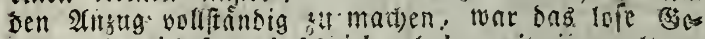
wans, sab ith fdon bejerteben havi, mit einem altmo

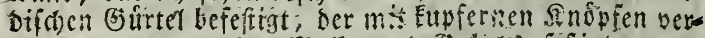
ziert wa: an werasen Meffer uno j̧abel befeftigt waren. Dow batte ser Manm etwas wilderes, abentheuerlides

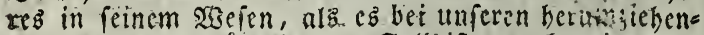
ben (steigern gewobnlid) ber Fall ift; nut seipte ber Etrid) feines Sogens, wenn er hie tuth ba mit feitier

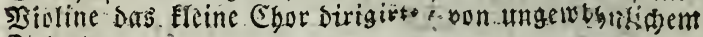
Ealente.

Du must wifen, baßs viele biefer Somerfungen bie Frudgt fịaterer Sesbactumgen maren; Senn Faum batte

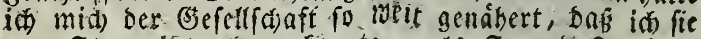
von Ferne betrachten Eonrte, Gits Frauno Seniie's iauternoer.5jegleiter, ben er jefr paffeno $55 \mathrm{emp} *$ ) nennt, bie Shren fpirte, und als er meine annefenbeit bes merfte, belleno mie cine Futie tem Drte zufprana, wo (id) verborgen bleiben wollte, biz idf einen anderen (B)es fang gehisit bátte. Faff was alfo gesmungen, fonell aufiufprimen, uno ben Jjemp; Der mid fonft gebifen

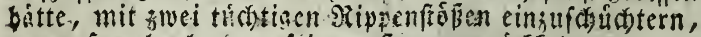

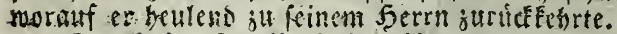

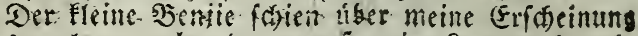
etmab. berlegen; aber ta er auf. meine fanamuth red.

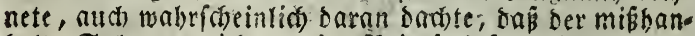

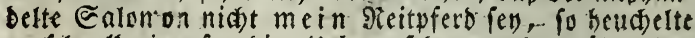
er. fentell ein: freusige laberrafoung uno ersáblte ben 23 anterern faft in eincm $24 \mathrm{tb} \mathrm{cm}$, id) wire: ",ein grofer ferr, bátce viet Betb, mo wáre febr gatig segen ar

*) Eulgentrixix. 
"Sgr babt ba tod eine Seige, mein Freund," fagte id - "babt Ibr einen Eameraben?" aber entwe"s Der wat sisilfie taub, ober frine 2ufmerffameit war noch Sen ₹onen zugewendet. Die Frau antmortete fur inn: "Ia, Sir, freilich baben wir einen Gefábrten, eit misgefarteter fert wie wir. SBobl fonnte es mein Siebfer befier baben, menn er wollte, Denn mand)es rus

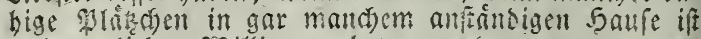
meinem lieben siblice angeboten morsen, menn or nur rubig alt cinem Drte bleiben who fen Edelletiten oors ipielen mollte."

"Still, ş3eib, frill!" fagte ser blinde Mann, in. bem ex argerlich feine Eoden fductelte; "betäube sen Serm nicht mit Deinen Shorbciten. Su Sauje fitien unis sen Eselleuten voripiclen! sttfitrcichen, wemn es Der fabl gefált und sen Sogen nieberlegen, menn SPD.

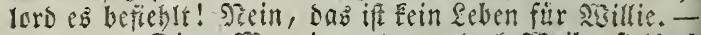

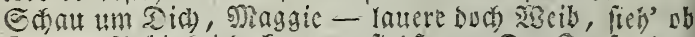
Du Den Sobin nicht tommen fiehf. - Der Seufer bole ifn, er treibt fith gemis mit vollen Gegeln bei Der punfdyowle eines E̋mugg!ers berum, und wird bie

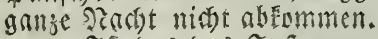

"Sif Das das Snfrument Eures Eefáprten, fagte (d), woll Gor mir erlauben, meine Fertigfeit barauf zu erproben?" ich (t)ob zugleid) ber frau cinen Sdyilling in Die 5 min.

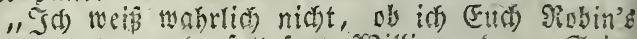
Ceige anwertraten Darf," fagte soille grabezt. Seine

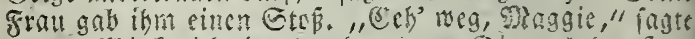

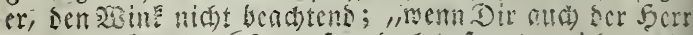
Gelo gegeben bat, fo mus er ood Defmegen nicht grave eine fand baben, sie ben segen ztl fithren werfebt,

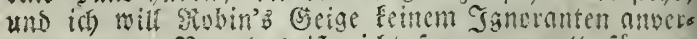
traute. - Patu ons ifi midt fo gar arg," frigte or

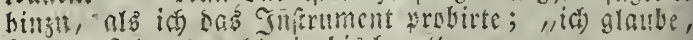
Thr verfebt es moly ein bisctich."

$1 \mathrm{~m}$ ibst nun in leiner ginfigen Decintng zu crbstl.

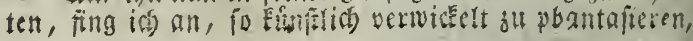




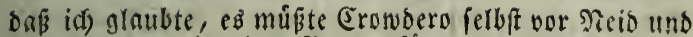
Эewunberung in cine Siarmorfäule verwandett baben.

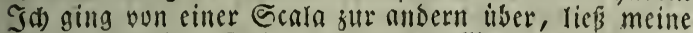
Finger von eiller Eatite zur alloeren fiegen, frielte 2 tr.

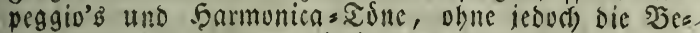
wunoerung zu erregen, bie id erwartet batte.

SGillic horte mir wirflich mit gefpannter 2fufmerts famecit ztt; aber Eaum batte ich geendigt, als er augen= blicflic) nuf feinem eignen Inftrumente bie phantaftiche כerbindung von Isnen, bie ich bervorgebrad)t batte,

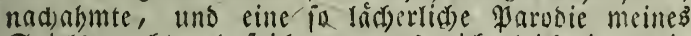
Epiels mad)te, dafi iđ, wenn cs mich gleid) ein wenig

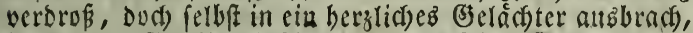
in weld)es Sonitie einftimmte, Den feine Ehrfurdbt vor mir burchat!z nicht baran verbinderte; wábrens bab

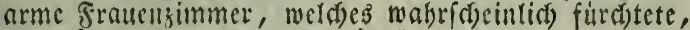
id) modste biefe Familiaritát libel nebmen, zmifd)en ihrer ebelidgen Ebrfurd)t vor ifrem soillie und Dem

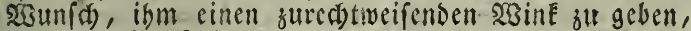
zll fdimanten f(bient.

Endrid) horte ber alte Rann von felbft auf, als båtte er mich jeţt burdh feine siad)abmung gentíglid zuredit gewiefen; und fagte: "Trot bem allen fonnt Jor mit ein wenig tlebung uns gutter 2011eitung rect)t gut

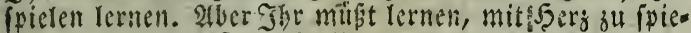
Ien, Freund - Serg binein zul legen."

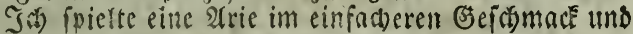
erbiêrt mun entfoicocheren Sacifall.

"Das if fton etwas, Sreuno, wahthaftig 5 hr fend ein gersander S3uriag!" Die Frau zupfe ibn wieber am Slotk. "Der Serr ift ein Bentleman, Sx̧ils rie - Dut must nicht fo mit ibm (pred)en, Sd)ăge (b)en!"

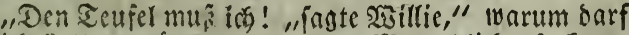

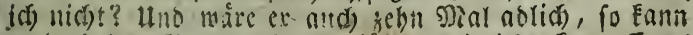

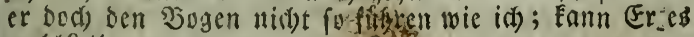
molis?

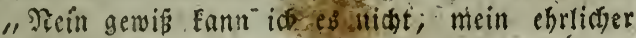




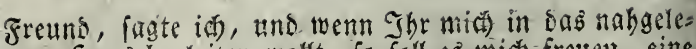

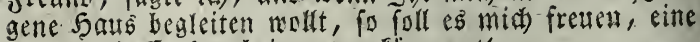

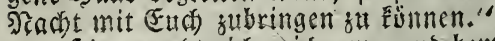

Shier wante ifi) midi um, und bemerfte, das ben=

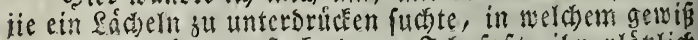

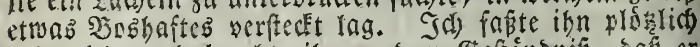

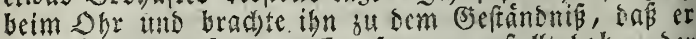
lade, weir er fict Den Empfang yorgeffellt babe, ser

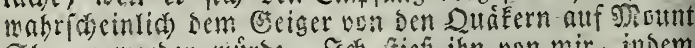

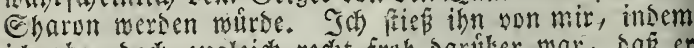

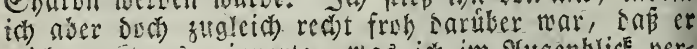

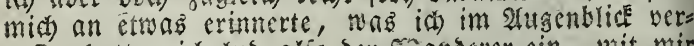
geffen batte; id' lato alfo den šsanserer ein, mit mir

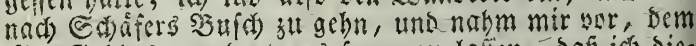

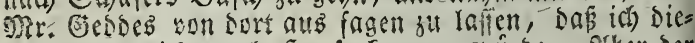
fen 2tbens nicht nach 5arufe fonmen murbe. Stber seer

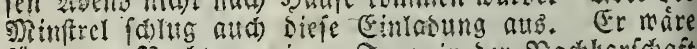

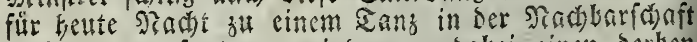
veriprschen, fagte er, insem er sabei cinen serben

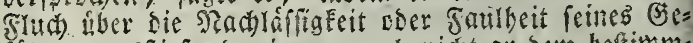
fábrten ausfifé, ber immer nod) nicht an Dem beftimm= ten Drt erfdyeinen wallte.

Эd) will ftatt feiner mit (Fud) gekn, " pagte id in einem 2infug toller \&aune, "uno Thr folft einen meraben sinfuibren nollt."

HIhr, fentt Sob Ben Sandrattfer, mich begleis

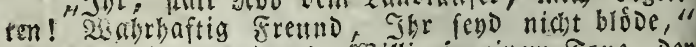
antmortete Der wandernde srsillie in cinem Eone, Der meiuem $\widetilde{E}$ (t)

2uler Singgie, Der Das Şieten cines Jironenthas lers nidut entgangen war, fing an úber Diefes Zahema

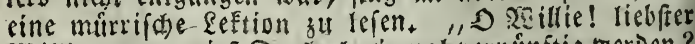
S23itfie, wann wirf $D$ it Dodj einmal vernünftig meroen?

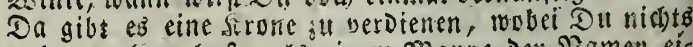
mebre zut than baft, als einem Naane Den Pamen eí

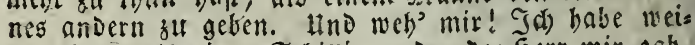

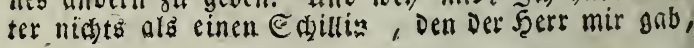


und eine Sheitemúnze; und Du willft Deinen Ei= genfiun nidit cinmal fo weit beugen, ons Eilber allf= zubeben, Das Dir zil Fiffen fállt. Du ininft wie ein SRarrengaul auf Dem Mift fierben! und was Eann ids Dann befieres thun, als mid) nicoertegen und mit

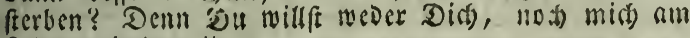
Qeben erbalten."

"Şalt" Deine unfinnige 3unge, 25 eib," fagte sill!:e, Dow weniger beftimmt, alis vorber, "ift er Deun ein wirflid)er (Jentleman, boer cin berfecllter?" "It) balte ilyn für einen refigten Eentreman," ragte Dic fralt.

"Uno i(t) balte, baf Fu wenis Bason verfebft,"

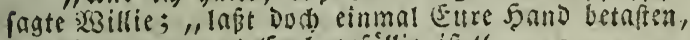
Rathar, memn ç (Elld) gefállig ift."

Id) reidhte ifm dic Stand. Er fagte sul fid felbft: "In, ia, oiefe Jinger baben nod, Feine barte 2rebcit getban." Daun fuibr er mir mit feiner 5 sno úler Das Sana, Das (j)efitst uno Das steid, uno fubr in fei= nem Selbftgefprácise fort: "Ia wobl, Duftendes Saar, gans riotig, Der Solok oum feinften ₹ud), renig= fens liebenjegn bundert Shntrlein auf Dcm skiteen, gan rictig. - stber wie, mein loderer 20 gel, wuth "Jbr fo fur einen reifenden Geiger gebalten werden" " "Neine sileioung if gans einfach," fagte id ,

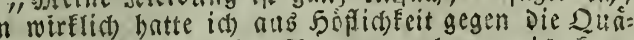

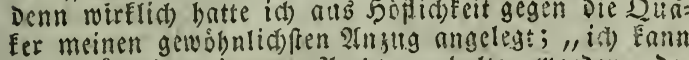
leicht fitt einen jungen gadter gchalten werden, Der

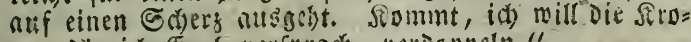
ne, Die ids Eud) verfprach, verooppeln."

"Der Seufel bole Eure seronen," jage De: un= eigennühige Spielmann. "Es if malr, auch id

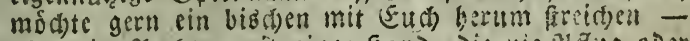
aber ein Pactiter mit einer $5 a n d$, die mie 1 fing oder Egge fúhrte, Das geht nicht! - Shr Eünnt cher für eluen Rndendiener atts Dumfrics, ooer fur cinen wandern= Den Ettidenten oder fo etwas gelten. S4ber bore \$Jurs Dae, wenn Du glaubft, Du Düifteft Dit) mit ben 
Dirmen Dort herumtreiben, fo irrft $\mathfrak{B}$ u Did, und wirft fhlimm wegfommen, fag? id Dir; Denm die Ti= fder fino milde Stą̧en, uno bertragen Eeinen Spap."

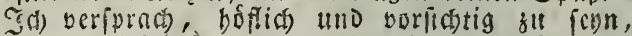
umb um mir Die gute Frau zll geminnen, Drtefte ids.

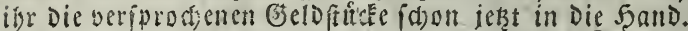
Die fatarfen Drgane Des brinden Mianneg entdecten Den Eleinen Sinftgriff.

Sogft Du es fdon wieder mit Dem Gerd zut thun, Du Siarrin? Id) fdwöre Daralt, Du borft lieber zwei grfenninge gegen cinander Elingen, als Die sone 9:cty) Dall's, und follte et altili) alls Dem Brabe allfo

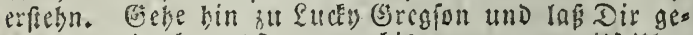
ben, was Du braubft, warte bis morgen um eilf thbr; uno wenn Du ben Sedoin tiehft, fo foticke isn mir."

"Sal) geke alio nicht mit fu Dem fefte?" fagte Nanggie im ₹one getóuichter foffinung.

Ni3ofur Denn?" fagte ibe Jecre und Neifter; „Dic Saacht Durdisutamien, Damit Du morgen Eeinen Eraritt geben Eannft, wáhrend wir Dod) jebn idgottif(t)e

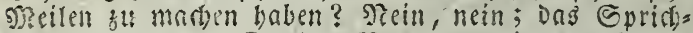
wort fagt: twetn Du Des Shachts arbeiten muft, io fibre Dein Wferd in Den Etall und Deine Frau in's Sett!"

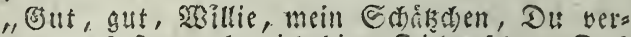

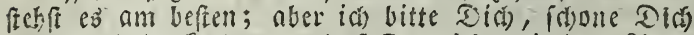

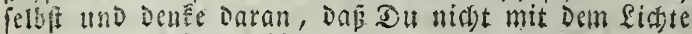
Der 2 ugen gefegnet biff."

"Deine Bunge lópt mich faft whinfon, aud Den

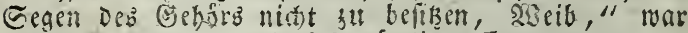

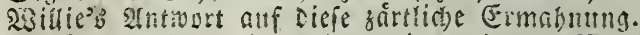

Setht mijote $i$ mid meines eigenen 230 itheils megen bincin. "Des ift afles gut, Shr lieber feute, beocuEt nber, ine (d) Dent 5 buben nad) 9)? ount Egaron foriden mufi, uns wern (Jbr, cbrlide Frau, nad)

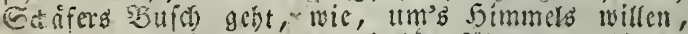
foll irs Den blinden smann Dabtn fübren, wobin er

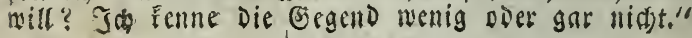


"IId), Sbb Eennt mein Mannd)en nod) weniger, Cir," criwiederte Maggie, donf Shr glaubt, er habe cinent fribrer notbig; er felbft ift ber befte fubter, Den Thr zmifden Eriffer und Earliste finden Énnt.

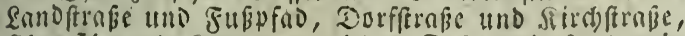
chauliée uno sircuzmeg, ieden Fus breit \&andes in Pithodale fonnt er."

"Ia, DIt Eannft fagen in ganj Sdjottlano, gus tes 23 eib," fügte Der (s)eiger binz". "stber ießzt,

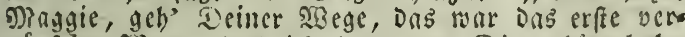
núnftige sisort, Das id) beute gon Dir gehort babe.

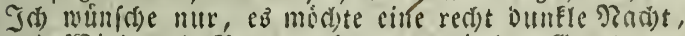
Ino 2 Sino uno Siegen geben, Damit Deb Eentleman feben Eann, Daßs es jumeilen beffer ift, brind zu fenn, als febeno; Denn id) bin in Durfeten cin cben to ficherer fribrer, wie bei Iage."

Sonerlic) erfreut, Daf mein (șefüfrte mir Diefen

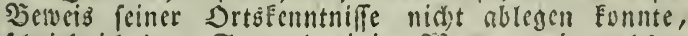
(d)ricb id) Dem Eamuel einige sionte, mit melchen id) itm befahl, meine Pferde gegen Pitternadts an Dell Dit kil bringen, Den thm vic Heberbringerin an zeigen múrde, uno fdjickte Den fleinen Seniie mit cis ner EntfGuloigung ful Dim wackeren Dutaker.

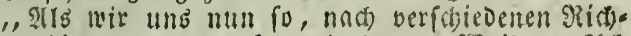
tunger hin, trennten, fagte Das gute $23 \mathrm{cib}:$ "2ia) Sir, littet ben Sistlie nur, er folle (E) eine bon feinen Esididiten erzáblen, um ben Siseg zu verÊtrs ten. Er fanm wie ein Miesiger nuf Der sentel res Den, er batte felbft cin plrobiger werden Eönnen, aber - "

"Salt Dein Nanl, Du Nirrin! - abor wart' cir SRa!, Meg - gib mir einen finß, wit rublth uns nid)t in 3anf trennen." So trennte fíd unjere ๒๋epellidgaft. 


\section{Eiffter $\mathfrak{x}$ r $i \in f$.}

\section{Derielbe an Denfelben.}

Stelle Dir null unfere Sieifen nuf Den Dunen nad) Den verfdiedenen siddturigen vor, Dout nad)

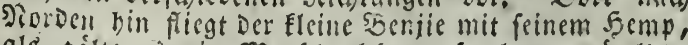
als gálte es ein Denrásenleben, fo lange nánilich, nlв er im Gefichtốtrife feines ab jenters ift, Denn fobars er meincul alugen cutfdrmunden ift, wiro er genifi fo bequcm, wie miglich, geben. Shiefituerts fiehft Du soggaie eimberforeitu, Deren Innge Oeftalt ourci Den aufgefrémpten Jुut unD Das Jinttern Deb

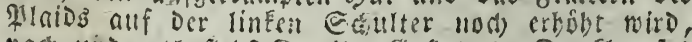
nac) tind naid) ficlift 2 th ibe Eeftalt im Dunflen fich ostefleinern und cnolich gand beridminden, fobalo Die lehten Eonnenftrablen fici) ins? Neer taucten. Jbre ruhige Sicife geht Dem Edáfers Dulfie zแ.

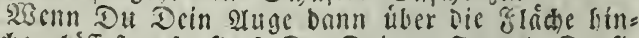
freidsen láffert, fo fiebr Du Deinen Freund Darfie Eatimer, mit f́inem netlen SocFanten, Dem manoern. Den 23 ílic cinberfobreiten. Del Eeţtere berubst bin UnD mieoer Den DoDen mit feincm Etale, Dod Nidet streifclino oder erforifacho, fondern mit oer Eidjer= heit eines erfablenen githen, oer oas SenEblei now auswirft, womn er foren Die ₹iffe votalls Eeunt; fo gebt er. feft und fulihn Dober, als bitte er Die sultgen

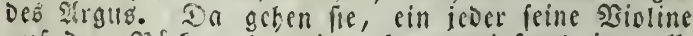
nuf Dem Silicken, ber cille aber wenigfens in solt= Fommener tinmiffenbeit, wobin es eigentlic) geht.

1" 11:0 nas berog (Eud), fo (d) nell in cine fo tolle T. ofie cinjugethen?" fagte mein meifer sintbgeber. -

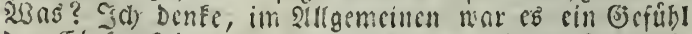
tor Einfomecit, eire Echnfucht nad) iener fretmolt:

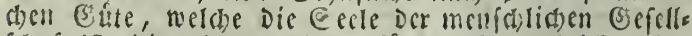
(d) aft iff, bie mid) serfeitete, firr oen siugenblick meine

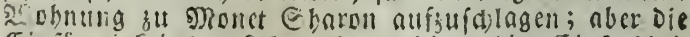
cinfirmigfeit Des febchs Dort, Die rubige Einfad)beit 
in Der Ilnterbaltung Der BeDdeffe, Die B̈leidformig= feit ibrer Defdíftigungen und unterba!tunge" ermú= Deten mein ungedurdiges (B)emútb, und fo beníkte id) Die erfie Eelegentseit, weldye oer Sullall mit Dare bot, ibr zul cutgeben.

$2 B a b$ bitte ich midyt Darum gegeben, wenn id im Etande gewefen wire, Das̉ ernfte frierliche (3) eficht nujunchmen, mit welchem Du fo oft Deinen 2(tsges laffenbeiten eine gewiffe 29 urde verricheft ! Du befikeft cine fo gluceliche grtt und siscife Die thoridleften Dinge

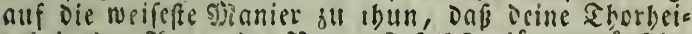
teii in sen 2tugen Der sernunft felbft, fúr vernúnftige Shandungen gelten fisnnten:

Als $i$ (h) Die sicitung brotadstete, weldse mein

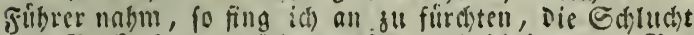

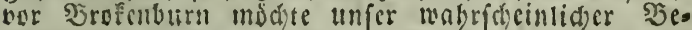

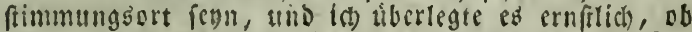
(di) mid) mit elnftand, in ob icli mid) fogar mit Si= d)erheit Der Bofffrelmofriaft meines fruberen 23 irtbes nuforangen fonnte. Jat frug alfo Den silllie, $n b$ mir sum Saird, wie Die Seute. ibn nenuen, befellt wåren.

"Siennt Shr Den faird?" fagte RBillie, indem er eine Duterture von Corelli unterbrad), von-melder er einen ₹beil mit grofer Bzenaulgfeit gepfiffen batte.

"Id) Eenne Den Enird cin wenig," foate ins,

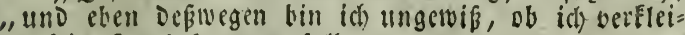
Dit fein 5alls betreten follte."

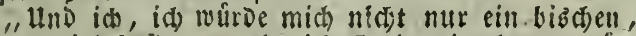
fondern viel befinnen, ebe ich Ench) mitnchmen wür De, Surrfchden," fagte Der wandernde, 23 illic, "Denn idt glaube faft, obne jerfchlagene sippen wirden nir fa, werlich Durdformmen, weber Ibr, nod id. Sirein, nein, mein Szuricoe, wir gehen nidst zum fairs, fon= sern zu einem luftigen fefte am Guße ses ßrofenburn,

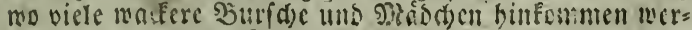

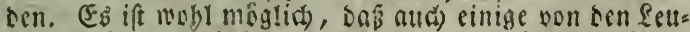
ten bes faits's binfummen, benn er ferblt geht nic ju 
forden (3elagen. Er hat nur nod) fir "bie 2̧Egeliags und das SaIntifitgen Ginn, feitbem Pile und Duskete rubt."

"Sif er arfo Eolbat gewefen?" fagte id.

"İh will es bocí glauben, Dap er Colbat war," antmortete $233 i l l i e ;$, aber folgt meinem Sathe und be= fimmert (Euth) fo renig um ign, roie er um (Euch.

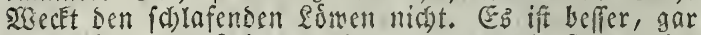
nidyt tiber ben Enird fu fagen, und mir fatt befien

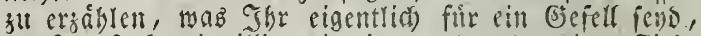
Der Shr fo bereitwillig mit einem alten hampigen fieds=

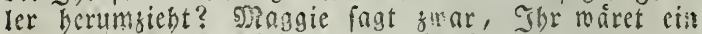
Esermann, aber bei ibr maít ein Schilling sen gano

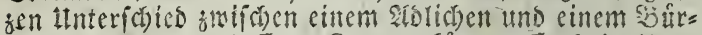
gerlichen aus, unt Eure sromen Esinnen (Eud) in ibren

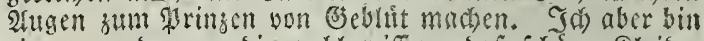
einer von benen, bie wohl wiffen, dafi fobine filcider

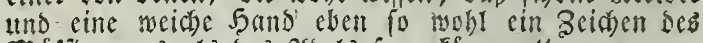

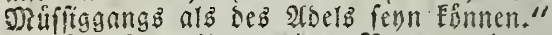

If) Fagte inm meinen siamell mit Demierben zus fat, sen id gegen Den Fir. Jofua (sedoes gebraucht

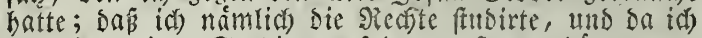
midh in meinen Etubien z"t fehr angeffrengt båtte, nun zu meinem Norgntigen umberftreifte.

"Ifit es Denn fo Eure 2trt, (Euć) mit allen Sands

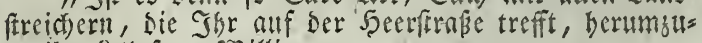
treiben?" frug soillic.

"Sh nein, nur mit ebrliden Senten wie Shr, Willie," war meine antwort.

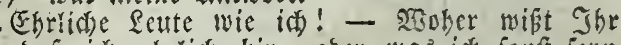

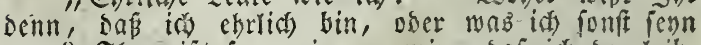
mag? Shr wiß̈t fo menig von mir, dás ich der leib= baftige Zeufer fern Esmute, Denn er bat sie mant,

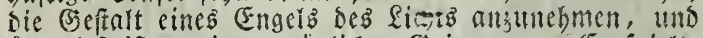
úberbiế if er ein vorgüglider Geiger. - Er pielte ia bent Eorelli eine Gonate yor, wenn Ihr es mint."

Es lag ctwa Soghaftes in biefer Siese fomobl als in bem Ion, in bem or es fagte. Es folon mir, 
als ob mein (stefáhrte nid)t immer bei gleidser Saune mare, woer a!s wollte er verfusbell, ob er mid) ers

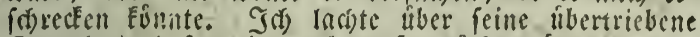
Epradje ind frug ihn, ob er fo thorig ware ju glaus beil, dof ber bofe feinto cine fo ládjerlidie Miasterabe treiben murbe.

"Ibr wift wenig bavon - febr menig," fagte ber alte Mann, insem cr Sopf uno Sart foúttelte

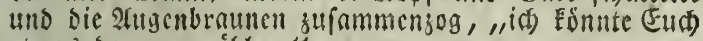
etwas davun ersáflen."

Natu ficl es mir cill, baß feine frau gefagt batte, er waire cin eben io guter Erzábler, als Neuifer; uno da Du meist, Daí id̆ abergláubifade Erzábluns gell gar gerne bore, fo bat id) ibn, in (5)chen, um cine Srobe feiner Fertigkeit.

"Es if wabr," fagte ber brime Mann, "Daf, menul ia) muse bin, auf Den Darmpaiten berumbuftrels

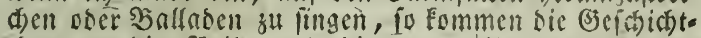
d)en an bie Reibe und biencn zur Unterbaltung bes

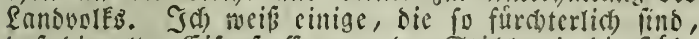
bẩ bie alten Eifenfreffer von ben Etuhlen in bie Sodbe fabren, unb bie sinder im Şette nad) ben Niuttern

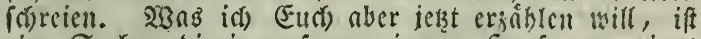
cine Gadje, bie in unjerem eigenen Shaule ju meines

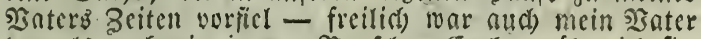

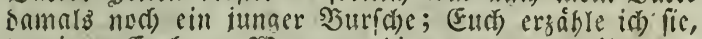
bamit es (End) fur $2 B$ arnung bienen mag, Da ibr nod) cin jungeb, forglofes 23 gegldsen fend unb (Eud) auf einfamen 2oegen mit icbem cinlaßjt, benn gar viel Jummer und Sorge entftand meinem Ërop̧uater Da. noll."

Er fing arpo feine Erzahlung mit Deutricher, Mobls tónender Etimme an, bie er mit grofer Fertigfeit bald erhob uns bald finfen licis; zuweilen fentete er fie bis zum fifpeln, und bann ridstete er bab flare, erlof́ć) 2luge gegen mein Ingcfid)t, als molle er sen EinorudE.

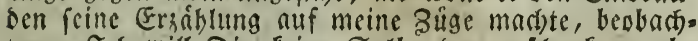

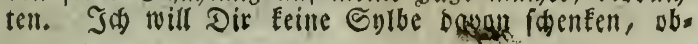




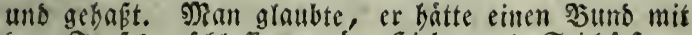

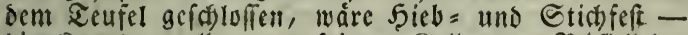
bie siugeln prallten von feinem stoller son $\mathfrak{b l i f f e l l e d e r}$ ab, wie ber Sagel yom siefel abjpringt - er babe

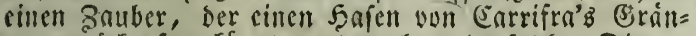
zen jutiderufen formte uno nod) mebr forcher Dinge, movon wir nuch fpredfen werden. Der befte Segen, ben man ifm gab, war: "ber Ietufer bole ben Ded = gaunt!et!" Dentwo'́) aber war er gegen feine unterge= bene nidst bart, feine Sebubleute modsten ibn wobl tei= Den; unb sie Diener und Truppen, bie mit ibm auf

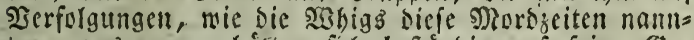
ten, aubsugen, batten fich beftandig auf feine bese funsbcit voll getrunEen.

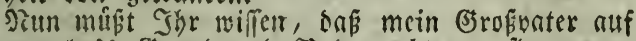
Redgauntlet's Srumb uno Sosen lebte - lie nenuen

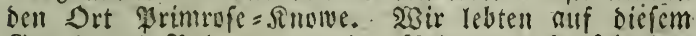

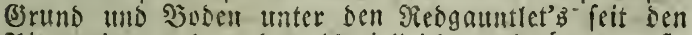

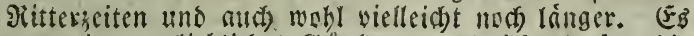
war ein gar liebliches Gifichen; und ia glantbe, bie, Suft if sort reiner unt anmutbiger, alb fouft irgents= tho im fande. Piun liegt es wuife; yor brei $\mathfrak{T}$ agen fas id auf sem zertummerten ₹borbalEen und war

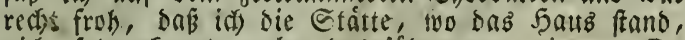
nicht feben Eunnte; aber bas fúhrt tuns ...

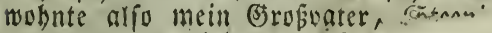

war ein berumbichender litfia

gen Iagen gewefen, verfan zu frielen, war wegen feir

rufbut, uns zwifden Socrmi

ner ben Duscliane fo fdd.

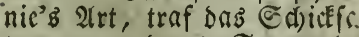
ten zu werben. Eo wurbe: namuten, wir nennen fie is

werfe. Siodi fieutiaen sans if. Der CEmanjipation Der fiatcoliff 
- wáre es̉ gar nicht anders móglich, oder als múpte man nuthwendiger 23 eife zu ber einen oder zu ber ans Deren Partei halten. Doch war er ben. ŞBhigg nicht abgeneigt, aud) gefiel ihm sas Slutvergiepen ganz tho gar niai)t, obgleich er, ba er dem Sir Robert in Ja= gen uno Seken, im suftautern und im Ergreifen. fols

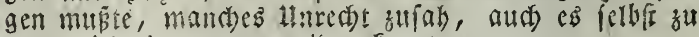
tbun nidst immer bermeiden Eonnte.

Steenie fant alfo in gewiffer bunft bei feinem Serrn, Eannte alle Settie, Die in ber Hngegend Des Šd)loffe wobnten, und warb oft fu ibren SYergnigen gertten, um auf Der pfeife zu- ipielen. Der Nellers meiffer, ber alte Dougal Mac Callum, Der ben Sir

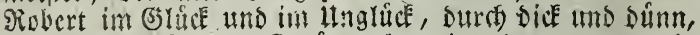
Durch Simpfe uno Etrome begleitet batte, war ein befonserer freund der Pfeife, mo legte mandes gute monrt fur meinen êtopsuster bei bem Saird ein, benn Dougal Eunnte feinen Serrn utm den Finger roikéln.

So weit war alles gut, bis bie \{levolution aus? brad), bie Dem Dougal tho feinem Serrn faft tas

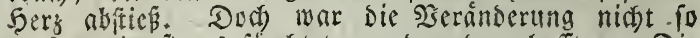
gros, wie fie es fürdsteten uno andere beffen. Die gre . . waton ein arges befeflerei, was fie num wobl - inbe, mit bem Sir Sabert Saeds - 2lber es waren zu viel grobe idieyt, als daí man cs bátie

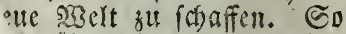
arifber binats, und Eir

Eovenanters jagen mutis 1, wie vorber. Eben is 1. eben fo bell erliudstet id)on bie Grafaelser ber in mup̃e, sie Sithe und viel ift cinmal gersifi, er ad) $\operatorname{tgels}$, als frtiber, tmo en Rairs nicit tnmillig mas plinetrich berichtigen. Suth or. D?enf́), dấ inn niemano 


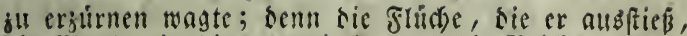
bie şuth, in bie er gericth, uno bic Shlicke, bie er

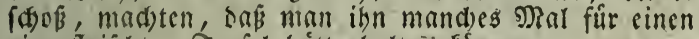
eingefleifden Ieufer bitte balteil Edmen.

Satun aber war mein B̈ropiunter Eein Saubharter

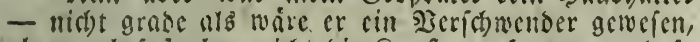
aber er befaj cben nidst bie Sunft, zu fparen, uno fo niar er zwei Sermine rifeffánbigen Sins fdulbig. Den

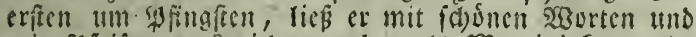
mit Pfeifen verfereidyell; aber al: Martini Eam, ta

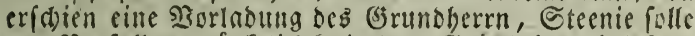
am Serfaltag punEerlia) mit bem (s)rundzing cinbalten oser Das (stitd)en ráumen. Eattere Mube fuftete es, Das Eilber zufammen zu bringen, aber er batte viel gute freunoe uno endrid) tricb er es bod) zufammen tallicho MiarE - Das Sieifite gab ein Nadbur ber, Enurie sapraik - cin feiner esejell. Saurie befas Beld und But - Eomnte mit ben Sunecn bellen und mit ben bafon Iaufen - Eonnte 23big ober Forn, Sciliger oder Eünder fenn, wie grabe der 2 sino bließ̈. Jekt alfo war er cin 2Anbánger Der SRevolution, Dod) riebte er aud cine tiadtige Etimme und cin Wfeifens frücketien in feituen Siebenftunden zut beren; und vor

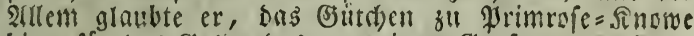

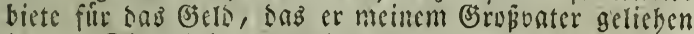
batte, Sidgerbeit aemug sar.

פit fdowerer $5 \delta$ rife uno Icichtem 50 crzen wanderte alio mein Gropuater Sem Sdillfe Resgauntlet's berzlid) froh, fem 3orn bes fairos entgangen zu fenn. (5); sas Erfe, bas cr auf bem Gd)lofie bort, ift,

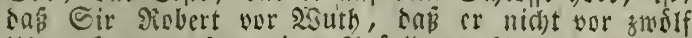

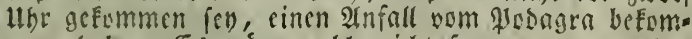
ment habe. Es mere mobl nicht fo gantj wegen bes ङelses, meinte Dougal, fondern meil er'meinen Brofos. bater nicht gern fortiagen modste. Dougar freute fich, meinen-Joropsater zu fehn uno fuhrte ihn in Das mitt

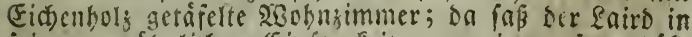

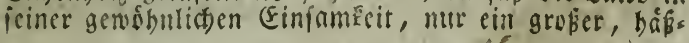


licher 2 fffe fü neben inm, der fein befonderer fiebling war; eine verzweifelte গ̧eftic war bas, die mand)sn bofen Etreich fpielte - fdimer war es, ifm zu gefal= len, reicht, intl zu erzúrnen; fobreiend uns beulend

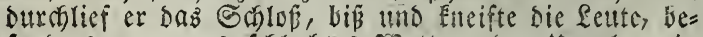

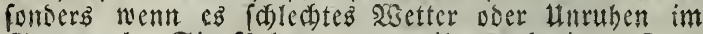
Etant gab. Eir Fubert namte ifn nad) einem zaut berer, Der berbrannt worden war, ggator şeir; nur wenige Funnten den Samen und bie Eigentheiten bes Ihieres leiben - man glaubte, es fáăe etroas linge=

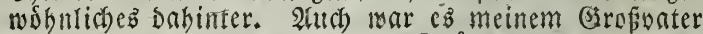

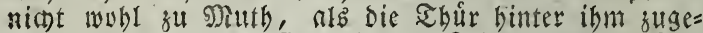
madst wurbe und er fid) mit Dem \&aird, Dougal s?ac Eallum und Dem Maivr allcin in Simmer [ah, was̉ ibm früher nie wieberfahren war.

Sir Mlobert alfo fafs, ober beffer gefagt, lag in einem gropent sarmitubl, mit reinem grüen Eammt=

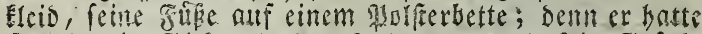
fomagl bie esicht als sas gotagra, uno feill Geficfs fah fo bleich und gefpcnferartig aus, wie daz bç ₹eu= fels ferbfit. Major 23 eir $f a \tilde{\beta}$ inm gegentiber in einem

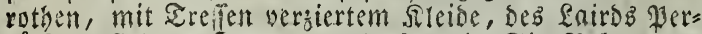
rúce auf bem 5aut; und io wie Cir Sobert por Somerzen grinzte, fo grinzte ber siffe auth, wie ein

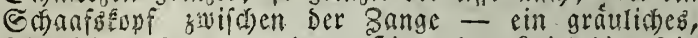
fintedeflide buffellebernes sullet an einem seagel, fein Schiverd uno feine piffolen alf 2rmbiveite; sem er bielt an ber

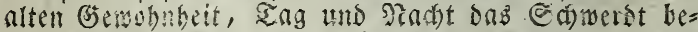
reit und ein Pferd gefattelt im Stall zu baben, grabe wie er es jut ber zeit madbte, als er nod) im Gtande war, fíd auf bas piers 3 werfen und bem Sandwole nactzutagen. Einige fagten, $e^{3}$ gefdrábe aus ânaft, bie șbigz modften fich an inm radsen, id) aber graube,

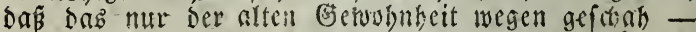

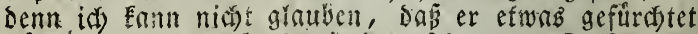
bátte. Daz Pachtbud) mit bem (d) warsen Deckel uns ben ftäblernen Syangen, lag neben ihm, ein unzúnti= 


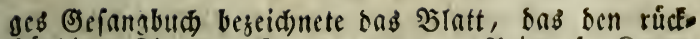

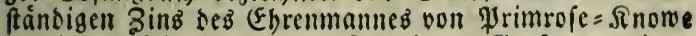

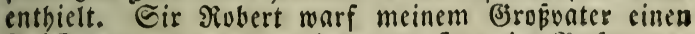

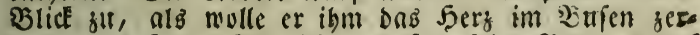
malmen. Igr mübt miffen, onß cr feine פ̇raunen auf eine 2 rt zufammentollte, baj man beutlid) bas Beiden cines Şufeifens auf feiner Etirn crblickte, tief einge= prágt, als wirre $\mathfrak{C B}$ bineingeftempelt.

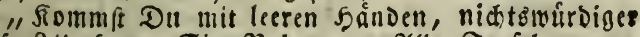
Pfeifer?" fagte Sir Robert. "Alle ₹eufel, wenn Du - "

Dein (5) refoater nabm eine fo beitere Miene an, als $\mathrm{CB}^{3} \mathrm{ibm}$ móslich war, machte eine $\mathfrak{B}$ crbeugung, und warf Den BelDfack auf Den ₹ifh, wie ein Miann, Det etwas freubiges thut. Der \&niro $30 \mathrm{~g}$ ifn baftig iu lich): "Ift allez Darin, Eteenie?"

"Ew. Enaden werden nlles in Oronung finden," fagte mein Esrob̄uater.

"Dougal," ragte der Eaird, "ninm ben Eteenie mit binab und gib ibm ein (s)as Jjranntmein, un= terbeffen will ich Das Seld jáblen und Die Quittung forreiben."

Saum aber batten fie bas Bimmer verlaffen, als

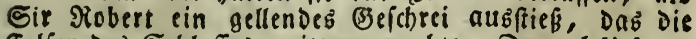
Felien Des Schlofies eryittern machte. Dounal tief jus rúf - Die bebienten fuurjten binein - ein freifchen= Des sefchrei nach Dem andern friç Der-Eairo aus, immer entięzlicter uno furchtbarer. Nein Erobuater maste nicht, ob er gebn ober bleiben follte, boch wagte er fich wieber in bas $260 h n_{j}$ immer - oa mar ein furchtbarer Titmult, niemand fagte geb' ober bleib. Entfeklich brülte ber Eairo nach. Ealtem $\mathfrak{B a f f e r}$ füe feine Süle, und nach $2 B$ ein um feine Butrgel zut lö. fden, und foile, jölle, foflle, uno ibre flammen! waren bie einjigen 230 orte, bie er berrorbringen fonnte.

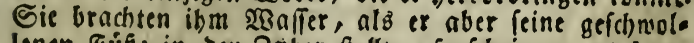
lenen Sufie in den 3aber ftellte, fo fchrie er, ez bren. ne; ia man fagt, Dấ to fiedend und fcháumend ges 
worben fey, wie ein braufender 230 fferfeffel. " Er warf Dem Dougal Den $\mathfrak{B e c t e r}$ an Den Siopf, fchreiend, er babe ibin vilut ftatt $\mathfrak{b}$ urgunder gebracht; uno man

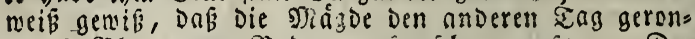

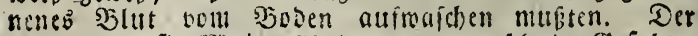
Affe, Den fie S)iaior wiscir namntell, fchnitt (3) fichter uno farie, als molle er fich mit feinem serrn necken;

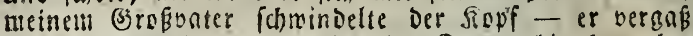
(3) elo und Dattung, er flog Die Sreppe binab; aber wie er fo rennt, wird bas freijebn immer- fdjwach und fdimather; enolich ein tief geathmetes, fdouter

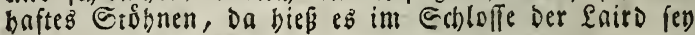
verichieden.

(3) ut alio, - mein Brrofuater ging meg, ben Finger im MRund, und reine belie foffnung beptand Darin, Dné Dougal ben Beloface gefehen uno den Enird yon Der Daittung batte fprechen boren. Der iunge Saird nun, Sir Sobn genannt, Fain bon EDinburg un nllez in Dronuny zu bringen. Eir Sobn uno fein 2 ater batten lich nie gat vertragen, er batte Die Slechte fitt. Dirt, uno fás im lek̨ten fatottichen Yarlament, wo er fúr Die union fimmte, weil er, mie man fagt, eine fabine Belobnung Daifur befommen batte - hatte fein

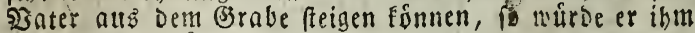

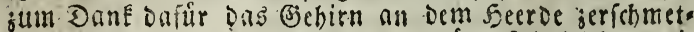
tert baben. Einige glaubten, es bátte fich leichter mit Dem siten ranben Ritter, als mit Dent jierlich reben. Den iungen serrn abrecbnen laffen - aber Davon nach, ber ein siseitereb.

Dougal פ)rac Eallum, Der arme פurfche, meinte uno fchludh) ste nicht, fondern (chlich, einer leiche ábnlich, im 5aus unber und machte, wie eg feine Pfficht ges bot, Sorbereitungen ju Dem groben Seichenbegangniß. Dounal fat mit cinbrechenier sincht immer fohlimmer

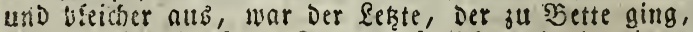
tund ber fich in feine Siammer fohlich, bie in einem Thurme dem Bimmer gesenúber lag, das fein forr bei Sebjeiten berafnte, und wo er ntm in Todess 


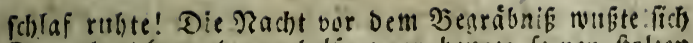
Doubal nidit mebr at helfen; er beinze feunen foljen (3)eift, und bat Den alten Futtheon boflichf, eine Etunie bei ilgn in feinem Simmer jujubristuen. 'Gm Iburm anbefoumen, nimat Dougal ein (\$slis @ranntrsein ju its, aibt Dem futbeon cin anderes, múnf(l)t ihin sseriunoheit und ean lan3es Seben; was inn bes trápe, faxte or, er nuirde nicht mehr lang am Seben bleiben, Denn leit Sir Siuberts zod erElinge iede Dardst

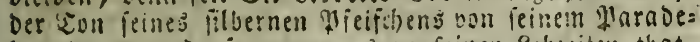
bett ber, gerno is wee er e.s zull reinen Sebjeiten that, wenn er im bett untzewend at werbin mollte. Dougal fazte feraer, Das er lich, weil -er nllein mit oem $\mathfrak{I}_{0 D}=$ ten nuf Diefen Echlobifüsel wohne (Denn niemano trug

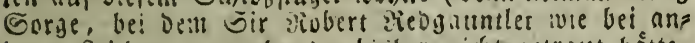
beren Eeithen ju radben), bisher nicht getraut taitte,

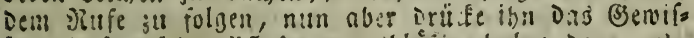

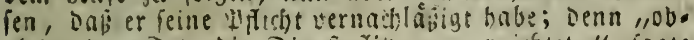
gleits Der Soo Die Dienftprititen vernichtet," pingte g)?ac Ealtum, "io foll er Duch nie meine Dlenfte ge=

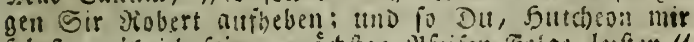
folgft, wil ids feinem nathiten wfeifen fouge leiften." Jutcheon batte gerade kene londerliche Jrende Daran, aber er batte Dem Doutsal in Sd)lacht und Etrcit ;ur Eeite geftanden, uno ivollte ibn nun in Der bíblften

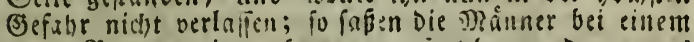

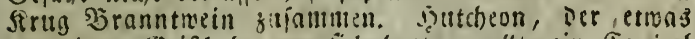
bon einem Besefflicben an lich batie, wollte ein Eayitel in Der भjibel lefen; aber Doungal molite id thenb ein Qied dez David Eindjay horen, - preilidh cine fälecinte Norbereitung.

2lls Die sin?tternadftsftunde herbei Enom, uno allez in Sanz rubig war, wie im Brabe, oa artonte richs tig Das filberne pieificen fo fonrf uno. fchneidend, als ob Sir Robert es blieie; Die beiden alten Diener madb= ten lich auf und nabten fing jitternd Dem Oesmactje. Sutcheon ah bei'm eriten Silice fhon genuty; Fiersen branulen im (ङentadje, bei Deren Edbein er Denl bojen 
Feins in vollem Ornat auf Dem Earge des Sairds fiken fab! Er fiúrite bin, nlb hátte er den Beift allfo gegeben. Er Frnnte nicht beftimmen, wie lnnge er be mustlos an Der Iture Ins, als er aber mieber ju fich fam, rief er feinem (sefábrten zu, und oa er feine 2Antwort erbielt, fo medfte er Die Sette im STnufe, melo d)e Den Dougal iwei Ediritte nan Der פartre feines Serrn todt am $\mathfrak{B o d e n}$ liegen fanden. $\mathcal{T}$ ag gyfeifden war verid wunden; icch ward es noch oft bem Esiebel Des Sonufes und zmifchen den alten Eaminen uno St úr. men, no bie Enlen bauren, getort. Eir Sohn fuchte

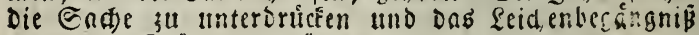
ging obne Erórung voräber.

$\mathfrak{A l B}$ aber nilles borúber wat, und ber faird ans fing feine Gefe áfte zu oronen, Da ward jeder \$jachter

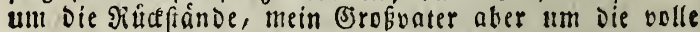
Eumme gemabnt, Die in glachtbuch begen isn jeugte. Eat, er fchlendert a! fo bem @chloffe zu, um benlicr= fall zu ersáblen; er wird jut Bem Eir Sohn gefúbrt, Der in tiefer Trauer, mit Finr und Đinde nuf Dem

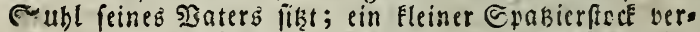
tritt an feiner Eeite Die Etelle ieg alten Echlachts fchwerdts feines $\mathfrak{B a t e r s , ~ D a s ~ m o h l ~ b u n d e r t m a l ~ f o ~ f c h ~ w e r ~}$ gemefen fenn mochte. Tab babe ibre unterreoung io oft eriáblen buren, on ich zugegen geirefen, wenn ich for on Domals nech nicht geboren feon Fonnte. (20irflich, 2tan, abmte mein Esefábrte mit recht bielem fumer Den einf́ch neidhelns Den, befánftigenien כan Des Plnchters uno ien 2Aแs= Druck Der fcheinteiligen Edmermuth in Der 2 Antmort Des Lairds nach. Eein Grofipater látte náhreno Der unterreoung Die antmen beftándig attf Dng Zing่buch

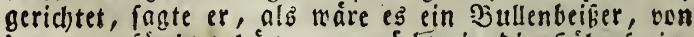

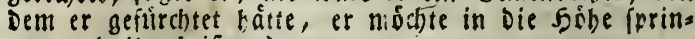
Ben und ibn beiken.)

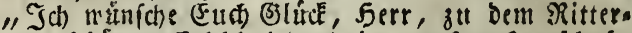
fik, "Der fófonen Erbichnft uno ber grófen Serrichaft.

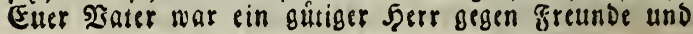




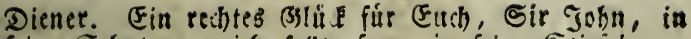
feine Échune - id follte fagen in feine Etiejeln ju tretell; Denn er trug felten Sdbube, nuB̈er wenn Das Pooagra ith plagte."

"ICh, Steenie, "rief Der Sairo, indem ex tief

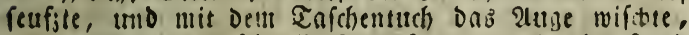
"er mars gar jtl fobnell abgerufen mind wird itt frend febr vermight werben; feine Seit blieb ihm, fein Saus zul beftellen - ond) ift eg obne 3meifel in gottlidben Dingen mobl bei ibull beftellt gervefen, und Das ift ia Die 28 urjel von nllem. - 2lber einell verworrenen Ináuel bat er uns altamuinoen hinterlaffen, Eteenie.

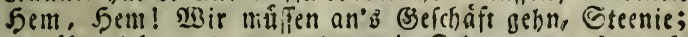

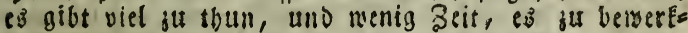
ftelligen."

Sier dffnete er ben unglidefelisen Эुant; ich bale

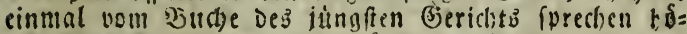
ren, getriß ift es Das Djuch âber Die Şrundfteuer vers armiter Pachter.

"Stephen," fagte Sir John immer in semfelben zarten weichlictgen Sone, "Stepben Stevenfon, ober

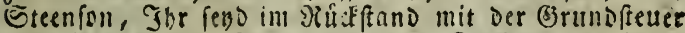
von einem ganjen Jabr; Der lep̧te Zallungstermin if fobon verftriden."

Stephen. "Pierzeiken Ew. Braben. Sir Jobn, ich jable inn (Eturein siater."

Sir Soba. "Jor habt Dann obne 3 meifel eine Quittung, Stefgen, und tount fie "orjeigen."

Etephen. "Daju blieb nir wirflich efeine Zeit úsrig, wenn (Em Enaben verieibn; Denn Eaum batte id) Das Silber hingelegt, Enum hatte ez Se. (3nnden Gir Robert empiangen, IIM $e^{3}$ zu jáblen und Die Quittung zth fobreiten, als inn bie Sibmergen ergrifien, an benen er farb.".

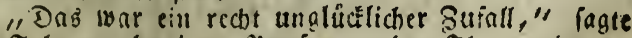
Eir Tobn nach einter Misufe, "aber Shr merbet es mobl vor seinen bezoblt batien. Th will nur enen

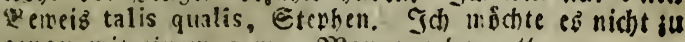
Benau nit einem armen MRanne nehmen。" 
Gtephen. 2utf mein wart Gir Sohn, eb mat niemand im Simmer als 3angal Dore Enlium, ber Sellermeifier. Saber wie Em. (S)nnen mobl wifien, iff er feinem alten foerrn "nachgefolgt."

"Das ift nieber fehr t!nglútelich, Etenken, ,fagte Eir John. ohne reine Etimitte nuth nut uni eiben Ton 3t verámbers. "Ier Sj) ans, welchem bie Sablung ge= leiffet maro, ift toot, tho Der, Der es jufab, ift auth toot - auch ift Das bselo nirgendos gefeben oier ges bort morben. Sisie foll id nun ias alles glauben?"

(E tepben. "Id) Fonn es nicht fagen, (5m. (5nas

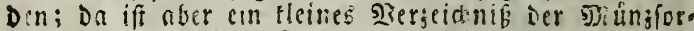
ten, atts Denen CE beftand; Denn, (E) ftt fief' Mir bei,

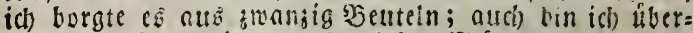
gellgt, Dá ein jeier uon Diefen Mánnern mit cinen heiligen Eib befchndren wird, zu welchem ebebraucbe ich Das Eelo gelergt habe."

Sir Jobn. Sd zweiffe gar nicht, Dấ Shr Das Eels geborgt Fnlut, Eteenie, fúr Die Bablung abor muf ich) \$beneife haben."

Etepben. इas Geld muß im franfe fern, Eir Sohn. Detin in Em. Enaden es nidt befommen bat, uno Eiw. Enaidiger J5err 20 ater es nicht mitgenommen baben fonn, fo muí es boch einer im sontte gefeben baben."

Sir Sobn. "Mir mol"en bie Sette audfragen; Das ift nidht mebr n's getorig."

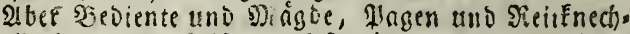
te, alle Ietigneten fteif und teft, ie einen (B)elofack ges febn zu baben, mie mein Bsrofuater ibn befarieben batte. Zu allem llnglits batte er feinem von isnen geiagt, Dafe er Den Brungzing zablen mollte. Eine Mago nut batie benerkt, Dafi er etwas tmiter Dem Arme trus, batte es nler fur feine pifeife bebalten.

Gir John Reignuntlet beforl Don Dienern, bin= attiugebn, und fagte iann ill meinem (j)rufunter: "Etcenie, Str febt, es gebt alles in Form Rect tens; Da Jbr nker beffer als ein anderer willen müft, wo 
Das (s)lb ift, fo bitte idf (Ench) biermit hoflichft, Dem! BartEclipiel ein Enve ju mochen; Denn Sterbin, Jbe uníbt entweder jablen, ober attomandern." "Bsatt vergeb" (Eud) Eure Mcinung," fagte Stees nie, Dem nun der 2 erftand ftia ftand. - "ICh bin cin ebrlicher Dinnn."

"2luch ich bin $\mathrm{ez}^{3}$, Etephen," Pagte $E_{e}$. Enaben; "tuno hoffentlich nuch alle leute in meinem 5aule. aber wenn ein Schurfe ttnter uns ift, fo nutuß es notbs nendiger $\mathfrak{B}$ elfe Der fenn, Der eine (s)ef́chichte erjáblt; bie er nicht bemeifen fonn." (E. fchmien einen 2 angen= blick uno fekzte Dann ernfter binjta: ", 23ienn id) Euere Streicle recht berftebe, Etephen, fo mollt Shr wan einizen boobbafren Gjerúchten liber bie 2ngelegenteiten meiner familie, uno befonders von. Dem plóstichen Eode meines 2 nters, ?iuken ziehn; Shr wollt mich)

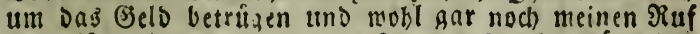
angreifen, indem 5 br zut verftehen gebt, $f(d)$ baitte ben Grundzins, Dent ich ietzt fordere, fchon erbalten. WOO glaubt Ifor, Dafí Dng Ëeld ift? - ich verlange eร fu wiffen!"

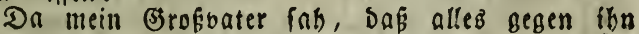
setugte, gerteth er faft in Sersiveifung - er Drehte fich bon eineıt Fuß altf Den anderen, warf feine Slicke in alle Ecken ber Etrbe umber tno formieg.

"Seraus mit Der Eurache, Serr!" rief Der Enird,

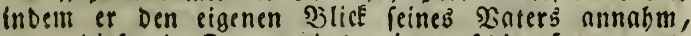
wenn biefer in ârn gerieth, in eg fethen fognt, als bildeten Die Falten feiner Etirn baffelbe furchtbare geiden Des Sufeirens. - ,Feraus Dnmit, Ferr! ich will wiffen, was Sbe benft; - slaubt Ibr, idb batte Das (3)elD?"

"Jern fen es oon mir, bas ju fagen," erwiederte Steplen.

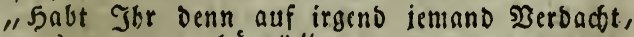
Daß̉ er é genommen hátte?"

"Ich mótite $e^{b}$, frinem Infchnldigen jur Saft leo gen, fagte mein (frobiuater; und iit nuch einer (chulDig, to babe ich Doch feine Đerweife." 


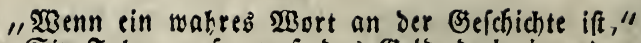
pagte Gir Tohn, "fo muß Das Belo boch irgendwo

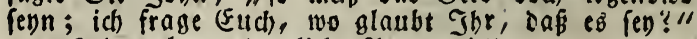
"Sch berlange Dettliche Antmort!"

"In Der follle, wenn Glor Doch meine Bedanfen miffen mollt, "fchrie mein Brrobuater, allfs A gebracht, - "in Der Şoflle bei Euerem $\mathfrak{D a t e r}$ und feis nem filbernen "Wfeifchen."

Schnell lief er jeß̨t Die Treppe binab (Denn nach

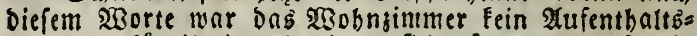
ort mebr fur ibn) und binter fich borte et Den \&airo, fo arg wie nur ie Sir Robert es that, Bift und Solle fucben uno nach amtmann und fáicher brúger.

Mein Srob̂ater eilte su feinem Sauptgläubiger Saurie Sapraif, um fu verfuchen, ob er etmas mit ibm anfangen fonnte; aber ols er ihm feine (s)eforichte erjáblte, befam er noch Scheltworte in Den Fiauf Dieb, כettler, Sd)urEe, waren Die gelindeften 2 uss briffe; auch bie alten (Sefchichten rúbrte \&aurie mies Der allf, oń er feine 5ånde mit bem Slut ber fei= ligen sottes beflect-babe, gerabe als fonne ein $11 n=$ tertban fich bent Mufgebote feines Sairbs ent;iebn, und noch Dafut eineb Sairds, mie Sir Robert Rebgatuntlet.

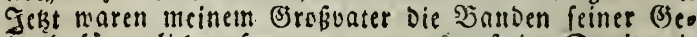
Dulb fämmtlich gefprungen, er vergafi im Gtreit mit Dent Raurie unglifellicher Weife alles, was er Bott und Menichen fouldoig mar, ftiế Redensatten atso, Die Die Butorer fclaubern machten - Eurg; eg war nicht mebr Derielbe Sienjd); toll und wild verbradite er ben ฐกg.

Enolich trenntell fie fich und mein (S) rofuater ritt Durd) Den finfteren Eannenwald bon Sitmurfie nach Banfe. Sd) Fenne ben SBBald, ob er aber finfter ober bell ift, Das fann id) llidht fagen. - 2 m Eingang Des Betolges ift ein brachliegelloes alment und am Fnde Des 2 Iments ein Fleines einfames Wirthshäแลs क)en; Eteenie verlangte oon Der $2 B$ irtbin (Sibbie Fats war ihe 2aame) ein (Slas כ̧ranntwein, benn er batte 
Den lieben lansen $\mathfrak{T} a g$ nicht Das (5eringfte ju fich gee nommen. Tibbie ging ith ernftlich nn, etmas ju fich zunebmen, er aber vermeigerte es, jog Den fur nicht nus rem Ereighúgel, leerte sas oslns in jmei 3 úgen und brachte bei iedem einen Esaft. Der Erfte biê: "Dem 2Andenfen Dez Eir Robert Niedzauntlet, nicht

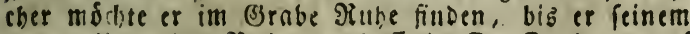

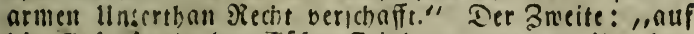

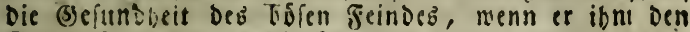
Gelofack mieder berichaffen oder fagen mollte, to es bingefoumen fen, Benn er fábe, Daß Die siselt ibn Dod fút einen Dieb uno einen פestüzer halten murbe, und

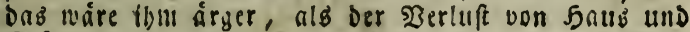
5.0F."

Fort ritt er, mogin? Darum befummerte er fich

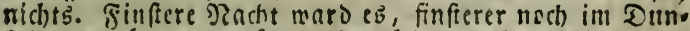

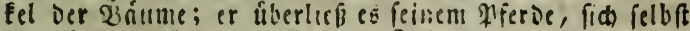
Den 23 es zu fuchen, als baz shier, fo ermattet nno mudoe es vorber war, plsalich fo furchibar anfing fic fu batumen, um lide zu fchlagen tno ju toben, dak meil Eorobuater fich fallm im Satfel balten fonnte.

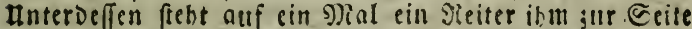

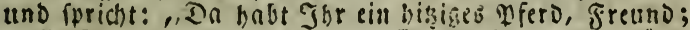
mollt Shr es berfaujen ?" - Er frrichts uno betifibri mit Der B̈erte Den Jonls Des siferbes, und liebe, Da geht es wieder feinen alten, fchlárrigen Scbritt. "थaber es fcheint ia, als verrauche ons Feuer bald," fube Der frembe fort, 1, fo gest eq attch mit dem muth gar viee ler gRenfonen, Die Da glauben, fie fónnten grofe Dinge verrichten, biz es Dnjul fótimt."

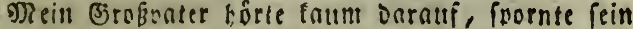
Pferb uno rief: "ङusen alliend, Freund." Der הrembe aber fefien nech nicht nbbred)en it mollen; ienn Etees nie mochte reiten mie er mollse, Der frembe bielt int. mer gleichen Eabritt. Enolich ward mein Brofuater, Eteenie Eteenfon balb airgerlich, uno (um Die 20 abrs beit su fagen) attch balb und balb furchtiam. "2sas wollt Sor von mir, Frcund?" fagle es 
"fend Thr ein Rauber, in babe fein Beld ; fend Tir ein ebrlither Mann, bem es an (s)efelfichaft feblt, ich bin weder zum Siber; nod) zum Eprechen selaunt; babt Jhr ben sieg verfeblt, ich fenne ibn felbft Eam." "Erisíblt mir Doch Die liriache Eutres summers," fagte Der Frembe, "zuar geniege ich nicht Den beften Ruf in Der 2selt, nber ich bin einjig in meiner Art, wenn es gilt, meinen Fretnden beizufteben."

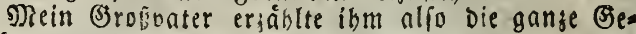
(chich)te oom Infana bis zum Ende, iedoch mehr, um

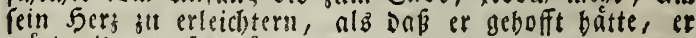
wurbe itm belfen ionaten.

"Es ift freilich ein fdmieriger Foll," fagte bet Grembe, "Dodh glaube ich, Euch belien iu fónnen."

" $25 \mathrm{enn}$ Sbr mir Das Bjeld auf lange Beit binaus borgen molit, Eir - Tonft gibt eb nuf Erben Éene Şulfe für midh."

"I Aleer unter Der Erbe Fann es geben," ernies Derte Der Fremoe. "fiommt ber, in will offell mit

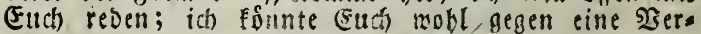
f(b) reibung bns geto leiben, aber ich glaube, Jbr mers

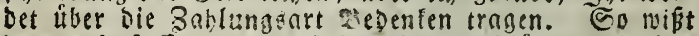

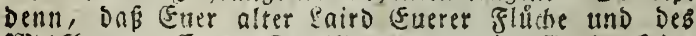

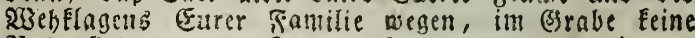
Olube findet; wenn Sibe es aber wagen wollt, ibn zu befuchen, fo mird er (Eud) Die Quittung geben."

Eei bem Sorid)!aze fanden meinem (3rsinater Die Saare za Serge, aber er Dadte, fein Besábrte ware wobl ein lasmiget Sburfiche, ber ibn nur erfares ceen wallte und ihm am Ende ooch Das J5eld leiben müroe. Uleberdieß war er oom Branntwein erbik̨t, oor

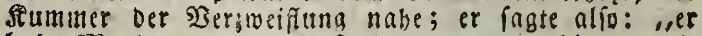
babe gRuth genug, Der Datitung, wegen bis an Die Wforten Der Jjolle - mo noch einen Echritt darúber fu gebn." - Der Frembe lachte laut nuf.

Fort ginas alio Durdi) das Dichtefte' (B)

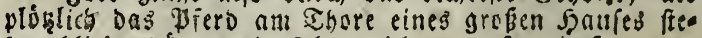
ben blieb; batte mein 2 bne nicht Benubt, Daß er wea 
risftens zelin Meilen baron entfernt mare, fo mutbe

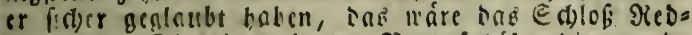

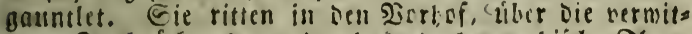
terte Sugbruffe, Darn imd) ias nlle grthiid)e Ifor;

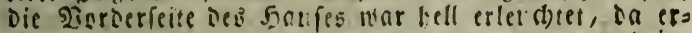
tóntes glfeifen und (b)cisen, in murbe getnngt und iu. bilirt, inie in Sanfe ieg Eir Siobcrt am 2licibnadots. abend und an Tubilate, Dier all anieren feften. Eie fiegcn ab uno mein srefionter bnns, nie es ibm ichien, fein giferd an benfelben Simg, an Den et ez Denfelben gicrien bcfeftigt batte, als or ju iem jun gen Eir Jobn ging.

"Sont," fngle mein Afbne, "wenn Cir Roberts goo nut cin Traum rére!"

Er llaffie an Bas Stor Der fande, mie ex es ges mofnlict, that, und liebe Da, wie gendsulich, offnet inm auch) fein alter Defannter Ioutal Dac Eatum

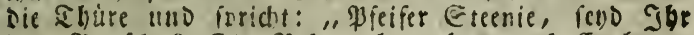
ba, Jurfbe? Eir Sicbert bat eben nach (Fud) bes fragt."

Ojein $\mathfrak{A}$ hue glaubt gu tráumen - er fieht fich nad Dem jrculien um, Der war meg. (Enolicb, magt

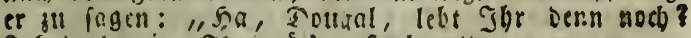
Sch Dachte in, Shr war't geftorben."

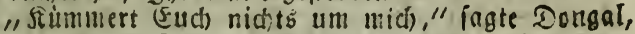
fonbern nebat (Fud) in 2icht; nebmt rop niestionien etmas an, meier (Effen noch IrinEen, nuch Eein Belo; nur eben Euere Duitung."

Tindem er ins fagt, fúhrt er ifn burch seallen

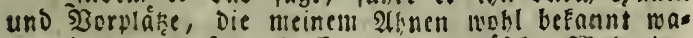
ren, in Das grefe, mit Eidienkol; geláfelte Wobntim= mer. Da erfdaliten nujuchtige Gefánge, on funfelte Der rothe 2 Beill, ba torte Han Botteglifiermigen uno

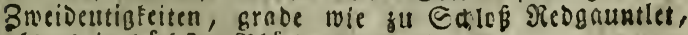
als $e^{2}$ in tóchfer Silutbe frand.

aber, Bott baite uns in feinem beiligen Echuth, melce fobrectlidie Gefpenftergeftalten faben un Den Eifd! - Decin 2ibne tannte viele von ibuen, Die 
långft fchon beimgegangen maren. $\mathfrak{D a}$ fap ber ftolice Midoleton, Der aubfchireifende Rottes, Der geigige Eaubercale, autch Dalgell mit feinem Sableopf uno

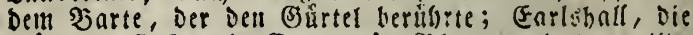
Sánde befieckt mit Cameron's Solltt, und Dar wilde

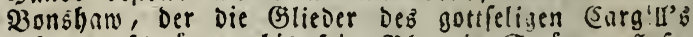
sufammenfonnurte, bis fein פlut in Soromen flob. Dumbarton Dougals Daju, Der zwiefache Berräiber

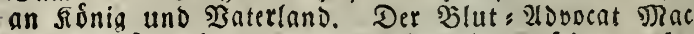
Renvie fẩ auth $D a$, er, Den die anderen feines melts lichen $\mathfrak{B}$ erftandez und feiner Einficht megen ju einem

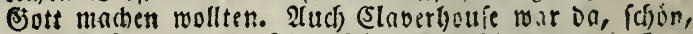
wie im Seben, mit reinen langen, fchmargen Locten, Die gefráufelt berabielen nuf Das planjerbemd; Die Itmke jand lag auf Dem rechten Schulterblatte, Die

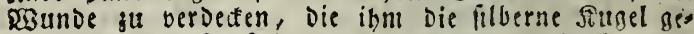
macht hatte. Er fá̧ von Den Ânoeren abgeionoert, uno foaute fie mit fiswermú:hizen, ftolien Sblicfen an, Die aber lármten uno fangen uno lachten, Dnß́ Daz Bitmmer miederballte. Alber entífţlich verjog ficb zuweilen Dos fácheln, und dag fachen aing in fo mils

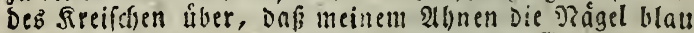

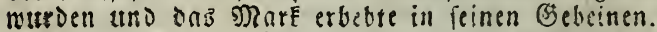

2luch Die am ₹ifche nufwarteten, maren grade eben Diefelben verrutiten Diener und Edoaten, Die auf Ërben ith rublofes হbun uno Treitien beendigt batten. Da mar ber lange Serl von gethertown, Der Den alrable fangen balf, - oa Der (J)er detzoience

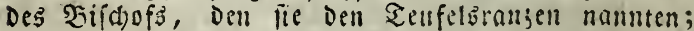

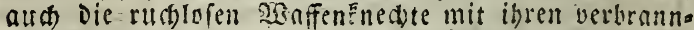
ten Rocéth, und bie wilden hocblándifiben 2lmoritce, Die SIlut sergoffen, wie $\mathfrak{B}$ alfer; autb mand)er folje Diener, mit bodimuthigem Serjell uno mit hlutigen

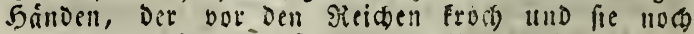

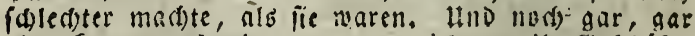

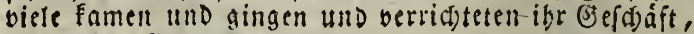
als rebter fie nod).

DRitten in bem furd)tbaren IUmult gebot ploblin 
Der Sir Robert Redgauntlet mit ciner Donnerftimme

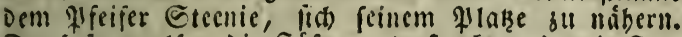
Ia faß̉ er alfo, die súfie allóacfirectit uno mit Flae nell umbunden, die 5 alfer = Yiftolen neben ibm, Dns grope Ed)lad)tfanerot am Etubl angelebnt, gerade fo wie mein (s)rofinater ibn sulekst allf ErDen fab.

Iud) ins Jififen fúr oen 2 ffen lag ibm sur Eeite,

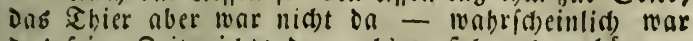
Das feille seit nid)t; ienn als er fid) nabte, borte ex fie fagen: "Sft Dor S) injor nod) nid)t gefommen?" uno ein $\mathfrak{A}$ neerer nutmorfete: "Der 2 ffe twiro Eommen, menn ber Iag anbrid)t." Hind nls mein (5rofsenter binjutrat, Da (prad) Eir Nidbert, oder fein (3) eift, over alld Der $\mathfrak{E}$ eu el in feiner Eefralt: "Siun Pfeí fer, baft $D$ u mit meinem Eobne wegen" Der Brund. freuer nigerectenet?"

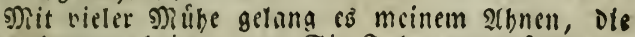
seorte beroorgubringen: "Sir John wolie fid) obne Die Quittung Єr. (3) nocul nid)t zufrieden ftellen."

"Du follft lie fúr cin Etticḱd)en allf Der $\mathfrak{P}$ feife

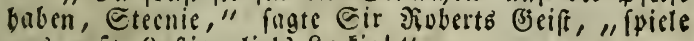
ung auf: \&uftig, lieb' Euckie!"

Das war nun gerade eille Nelodie, die mein (5rofuater son einem antuberer lernte, Der fie gebort batte, alo fie bei ibren 3llfommentúnften ben Zeufel anbetetill. Sulucilen batte es mein Ģrofinater mobl

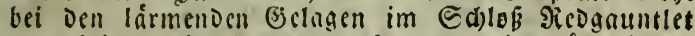
onrgefpielt, nie that er es aber gern; jeķt úberlief es ibn eisfalt, als er es untr nennen borte uno oarum fagte er fur Austrede, er bátte feine 1 feife nidt bel iid.

" Diac Eallum, Du Sellfetsbrut, " fagte Der ent. perslidbe Eir Fobert, "bringe Dod Dem Eteenie Die Prfeifen, bie id) fúr ibn aufgebolien babe."

Mac Enllum brad)te ein panr ilfeifs", Die mobl Dem Donnlo boul den Sinfeln gebsit baben mócten. 2 IIs er fie ilbm aber cinbálldigte, gab er ibm einen खBoinf; Eteenie blicfte verftoblen nber yenaul Darauf, 
Da bemerfte er, Daß Die Sidfren yon Etabl mo glits beno beí maren; fo war er idson newarnt, reine frin. ger jern bavon ju laffen. Fr entíchubigte fich ates= mala, indent er fagte, "er wáre zll febr erfobrcefen, aud) fehle ễ ibm an 2 (th)em."

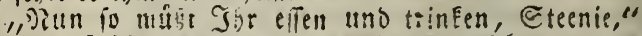
fagte Die Ericheinung; "Denn wir thun felten etmas

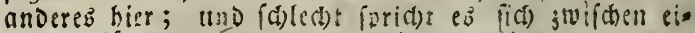
nem (B) fíttigten und einem spathiternen!"

Diun waren aber bas eben bie wiocte, welche ber

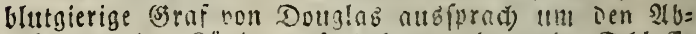
gefanden des Sönias atijubalten, als er in Echlofie

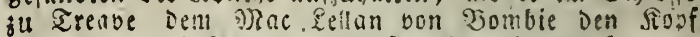

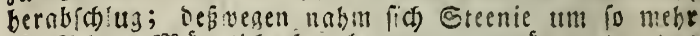

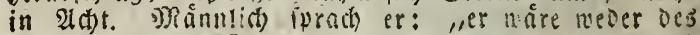
Elleng nod bes irinfens wegen bergefommen, aud) nidit um norillipielen, condern um zu exfakren, waz nus sem soeloe gevorden máre, ons er ibm bejalst

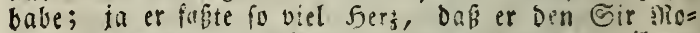
bert bei feinem (sjewiffen befduwor (Denn Den heiligen

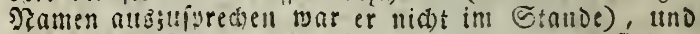
fo er hoffe Frieden uno Nuge itit (e)rabe ju finden, ibm feine Tatale zu lezen, und nun zu Dem Ecinizen ou verbelfin."

Die Erfolinung fletfdte Die Safhne uno Intte, Dann nabm fie Die Suttung nuts einer groken Briefs tafbe und bandigte fie Derm Steenie ein: "Da if Deine Quttuna, Du erbarmlider sisids, und ivas Das Eelo betrifft, fo wird ez mein Sunvefobn in Det Sinkenmiege fincen."

Dein Erofuater ftammelte feinen DanF, und mollte eben geben, als Eir fiobert laut auf briflte: „Falt, Du factiduelnder Sureniobn! wir fino nod nid)t fertig! bier sibt man nid)ts umionft; to milfe Denn, beute uber's Jabr muft Da nieder fommen, Deinem geifter fur feinen Eshut zu kuldigen!"

Da losice fid ploslich meines Ahnheren Bungh

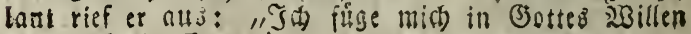
und nif̆t in Euren!" 
Saum batte er Dab Siort gefprosten, Da ward es problid) ganj finfter uno er fiel mit cinem io befo

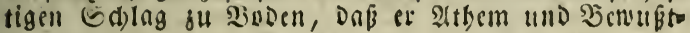
(e)n verlor.

28ic lang: Etcenie in gclegen fenn mod)te, Das.

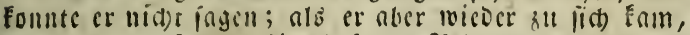
Da lng or auf Dem Jiirdstof bon sieognumtet, gernde am Eingange Der Tamiliengruft, icis 2isppen Deb al= ten Sitters, હir Siobert, bing úber feinem saupte. Ein idwerer szorgennebel lag anf Dem Grafe und auf Den esrabfrinen rings umber, fein 91 ferd aber weis Dete ganj rubig neben ven beisen situben Des Plarrerg. Greenie bátte alles futr eincn Iraum gebalten, aber er biilt bie 2)uittung in Der $5 a n d$, fden sefdrieben

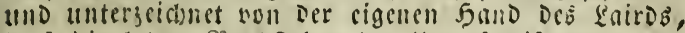

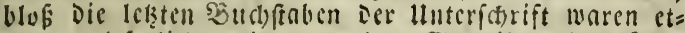
toas unlefentich, wie wenn Den Gabreiber ein ploklls d)er Ecd)merz eifapit bátte.

Smuerlid sou beftiger lunrube bewegt, berlick ex Den f(d)aurigen Ort, ritt im s)iorgenucher ocm હd)loffe

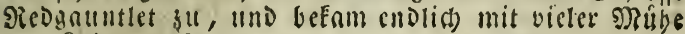
ben Sairo zu fipredien.

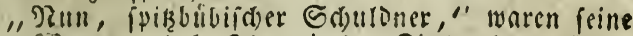
erfen 230 orte, "babt 9 br mir Den Bins gebracht?"

"Piein," antwortete mein (3rofuater, "Das nicst;

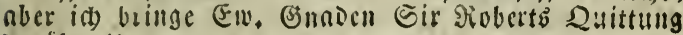
Darúber."

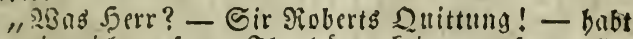
Jor mir nicht gefagt, Shr beittet feine empiangen?" 1, 23eflen En. Gnnoen nid)t febch, ob es mit Die= fer fleinen St,rift feine Sid tigkeit hat?"

Gir Sokn betractete icoe seile, ieden judfte

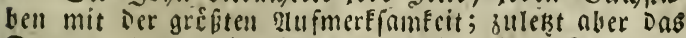
Datum, Das mein Greß̧onter nid)t bemerft batte: "Si on Dem mir nugewiefenen orte,"laser, "Den funf uno z wanjigften Rovember." รูธกร! - Dnछ mar in seftern! - Elender, Du mußt Desnegen in Der J̧ille getuefen feyn!" 


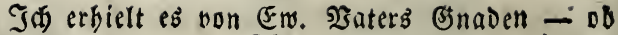

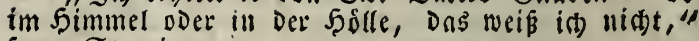
fagte Steenie.

Id) . will (Eud) als cinen Bauberer Dem gebelo

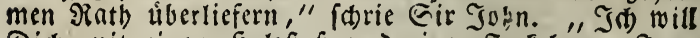

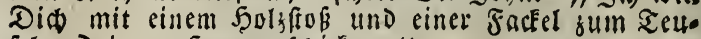
fel, Deinem 5errn, fdicken!"

"Id babe die allifidt, mid) felbft Dem Presud. terium zut elltoecken, "fagte Eteenie, ,uno ibnen alo leż zu erzáblen, was id) Die vergangene शaddt fab. Dhnebin find Das Gegenftánde, viber Die ibnen eber, als einem Laven ein $\mathfrak{u}$ rtbeil jufteht."

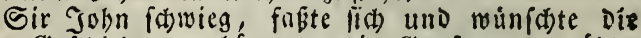

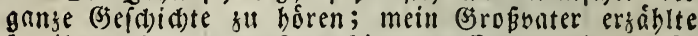
fie ibm alfo vom 2nnfang bis bum Ende, wie in) fis Eud erzáblt babe - 230rt für 230rt, Eeing mebr und Eeins weniger.

33ieder fdurieg Gir Jobn eine ziemlidje Dann fagte er enolia) febr rubig: "Jort Eteenie, Eutere Esefdidste betrifft aufer Der meinigen nod) viele edle Famitien in Sende; habt Ibr fie sum zeettoer. treib erfinden, oDer um (5) aus Der उెefobr zu bleben, to ift ein glübendes (Eifen Durch Dis Zunge nod) Das (B) eringfte, wab (Eu) erwartet, und Das wáre nod fdilimmer, alb wenn Sbr Eutd sie Finger an Den glúbenden Fidbren verbrannt báttet. Dod Eann fie auth wabr fenn; findet fid alio bas (J)eld vor, Daun freilid) weif́ ids felbft nicht, was id) Danon Denfen foll. - aber wo follen wir Die Rakenmiege finden? Sakzen gibt es freilid) genug in Dem alten Gaule, aber id) Denfe die werfen wobl ihre Jungen,

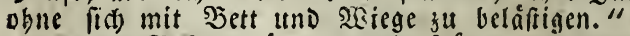

2Im Jefte: wäre es, wir frugen den 5utdeon Darúber," fogte mein Grofionter, "er Eennt Die alo ten rainé alle fo gut, wie - ein anderer Diener, Der geftorben i, unis Den ids nid)t nennen mó(t)te."

QUts man nun ben feutcheon fruts, fo fagte er, Daß man yor 2itters einen nun jertrummerten $\mathfrak{T}$ burm 
Ben bosbaften Eejळjpf, Dem כRajor 23 eir zutr faft, uno verfalgiegen Euren Sraum im $23 a l d e$ ron Pit =

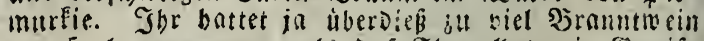

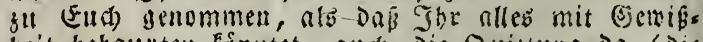
beit bebaupten Eonntet, aud) Die Duttung Da (Die Sallo fitterte ibm, als er lie in bie sabre hob) - ons

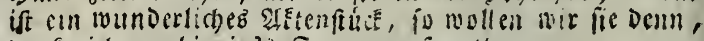
Denfe ish, rubig in's Jeuter mesfen."

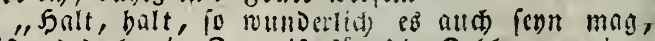
io ift eg tod cin Becugniß fir sic Bnblung meince

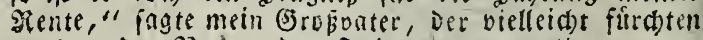
mod)te, Den Pitticn Der Suittung ju verlieren.

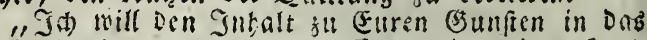
Binsobuá) eintragen, und es (E) mit meiner fand quittirell, "ingte (Eir John, "unD zwar pogleió). Hno Eannft Du, Ëteinte, úber Die Endje Teine Bunge im Baume hniten, fo folff Du funftig meniger Sing zablen."

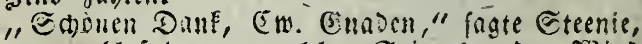
Der nun wobl fab, ven nelder Eeite ber Der Saino blieb, "Dibe Bweifel meroe ia genall dent befeble Ero. Gnaden gehorden; Dod modte id gern fiter

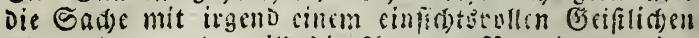

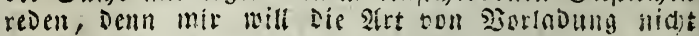
ionderlia) behagen, Dic Der siater (Ear. Binnien - -"

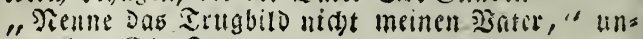
terbrach inn Ei: Sohn.

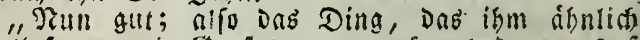
inh, " Fogte mein Erobuater; "cr fprad ineon, onf isb nath einem Iabre wieder Fommen follte, und das laftet nun auf meinem setriffen."

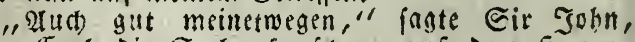

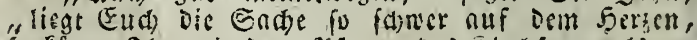

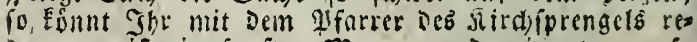
Den; er ift ein fonfter Mann. uno nimmt um to

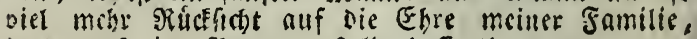
Da er auf cine Fatronatsftelle bofft."

Jun willigte mein Dater getn Darin cin, Dn 
Peinen guten Namen zu erbarten, peinen Freunben bie

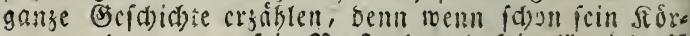

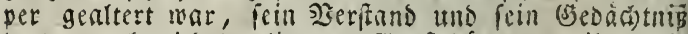

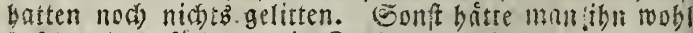
befdurdigen Evinen, ein anuberer fu fey?r.

Ber alsengibatten batte fild foron bebeuteno ser, finfert, als mein fribrer feine lange Ergsiflutug mit folgender sjogral holeb: "Siebit Du man, men: sojs gelchen, Dais es in einem tmbetannten Eande fein flei=

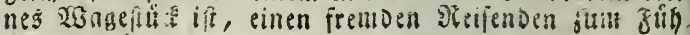
ter fut nelymen."

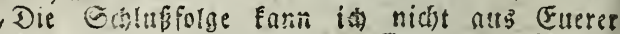

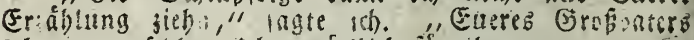

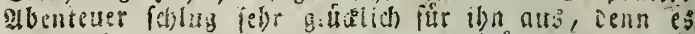
rettete inn nom untergang wno von sontfrigseit; auch

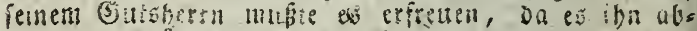
bielt, eine bo bit ungerchte bunjlang ju begeten."

"Ju, jecins, fritist soir ipaier muBien boch

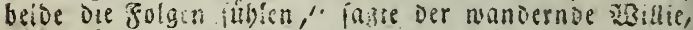

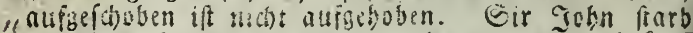
nach einer furjen sirantheit, ebz er now viel fiter

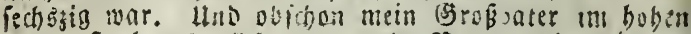
æalter farb, fo ficl $O D(i)$ meill 2 anter, ein rujtiger

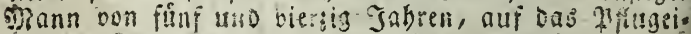

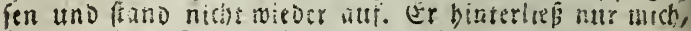
fein einjiges sins, eine arne, blinde, sater = und mutteriofe shoife, we meder an atroeit noch an man.

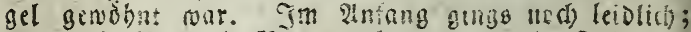
benn Eit Jesisalo Kiesonanntlet, Der einzize Sobn Des

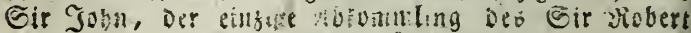
und, webe mir! Der lezite Eprobling Des ebrenmertben Sanujes, mabat mith bon menem glaci)terbauechen in fein echlof und forgte fur nich. Er war ein Freuno

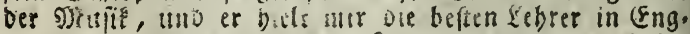
lano uno Eögottano. Sieli Sabre brachte ich bei ibm zu, aber, ach Eot, in ven unf und sierziger Jabren ieg er n.bft anüeren EDelleuten aus - ioo mag nicht 
fabren, meinen einformigen 2 benteuern fo viel Tutes refie unterzuídieben, als id) nur Eann, uno follte sicies

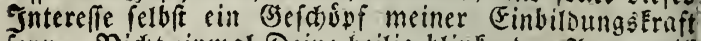
feon. Naid)t einmal Deine beilig blinfenten 2 ugen will

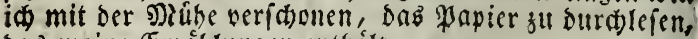
baร meine Erzåblungen entbált.

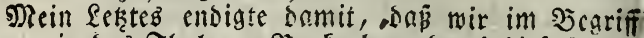

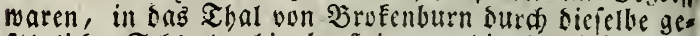

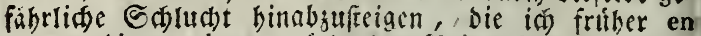
croupe binter einem whitbenten Seiter fennen lernte, und Deren (șefabre!l id) jekzt wieser, unter ser unfids. ren Leitung eineš Şlinoen, Irot bieten woíte.

(Es wars sunkel; sod) war bas fir meinen filbres

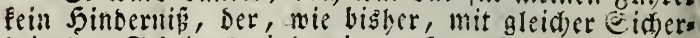
beit bes $\subseteq$ dritteb einberging, fo baßs wir balb tas. Ende ber fluft erreideten, ivo iá) in meinem fruberen

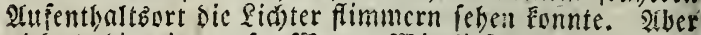

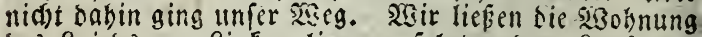
des Sairbz zur Sinén licgen, folgten bem Eanfe fes כadaes uno erreidsten bald einen Eleinen siseiler, melo der an ber gltunsung bes frluffes (wahridjeinlia) ber

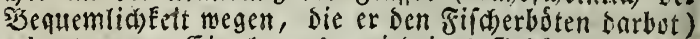
erbaut roar. Ein langes, niebriges (sebátube, nefien Fronte grabe vor uns lag, war bell erlettdete und sas.

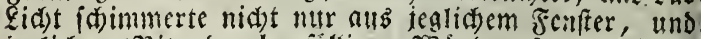
ieglidem Fike ber banfalligen soante, fonbern iogar

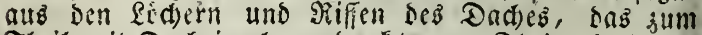
Eheil mit Dadziegeln gebed t, zum Ibeil mit Etrob und Mogs be D C $\mathfrak{E}^{\mathrm{t}} \mathrm{t}$ war.

MBabrens sicfe Erideinung meine AufmerEfamEeit in $\mathfrak{A}$ (n) geImásig folgendem funftampfen, vermifat mit cinem

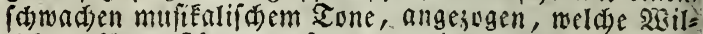

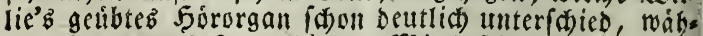
reno id̄ es nod faum birte. Mit beftiger Leidenidgaft fiế ber alte Diann Den Stod auf bie Erbe. "Die luberlide Fifdersbrut! Eie baben mir einen anderen

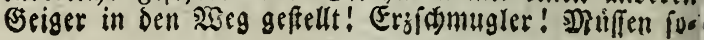


gar in ber Mufit ihren Sd)leidhandel treiben; aber bei mir follen fie fablinmer megkummen, als bei allen Mrautbbeamiten in ber Braffd)aft. Still - bord) - (B

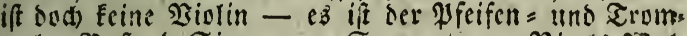

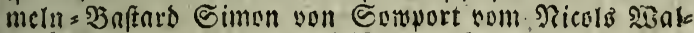
se; aber ids mill ithn bepfeifen uno betrommeln! Pafst mid) nur erfit bie linfé Sand an feinem Salbtu(t) baben, fo rollt Ibr fdoon febn, was bie Sled)te thun wirs. Fommt nur - פtirfdaden, - Eommt nur - rebes

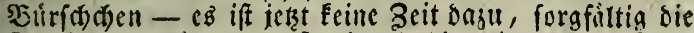
Sofritte fu wiblen." (Er cilte Dabin init grofen, fiches ren Edsritten, utro zog midh nad).

Mir war es nidst gan' wobl in feiner (3ejellid)aft; Denn nun, on fein SReifferfingerfols beleibigt wat, ver=

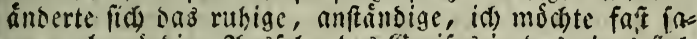
gen, chrwirsige 2 (usfebn bes Greifes in bas eines fol

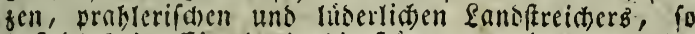

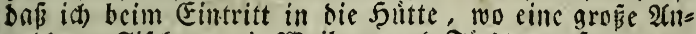

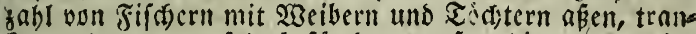
Een uno tanzten, febr befurd)ten murize, bie ungesuldige

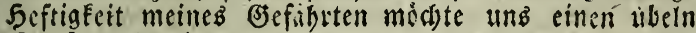
Empfang bereiten.

Zlber bas allgemeine, Inute şßillésmmen, mit wel= dem ber wanternoe $23 i$ illie empfangen waro - bas

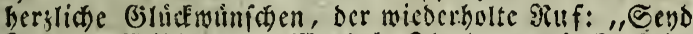

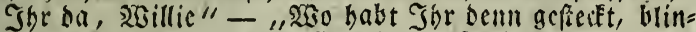

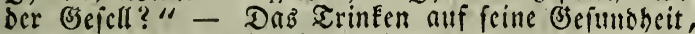
endlid) vorzuglid) dic Eile, mit weld)er man bie miber=

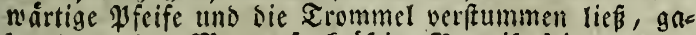
ben bem alten Dianne fo Eráftize Şeroeife feiner unver=

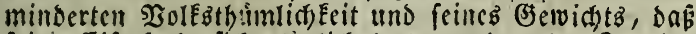

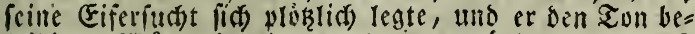
Icisigter sourbe in einen anderen umánderte, ber paj= fenter war, einen berzfichen Empfang zul ermiedern. Die iungen meánter und Frouen verfanmelten fids, um ihm ju fagen, wie febr fie gefürdytet bátsen, es módste inm ein unfall begegnet fenn unb baß̧ fie zmei ober brei junge feute aubgef́didst bátten, um ibn- ill puden. 


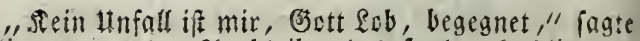

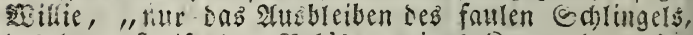

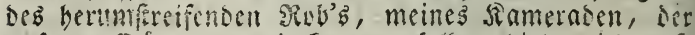
auf ben sinen zu mir fammen iollte, bielt mirg auf.

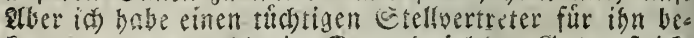
Esmmen, ber wobl ein Dusend forker esalgenferife verth iff."

"şen baft Du benn aufgetriebch, alter 2Biflie?" fragten cin ba!b Duscend Etimmen, wabrend fith aller Trtigen auf 3 einen gehurfamen Diener ridgteten, Der fo gut nie moglich die ônifung zu behalten fuchte, ob=

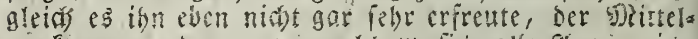
punet zu terden, naid weldem fidi) alle siligen rich= teter.

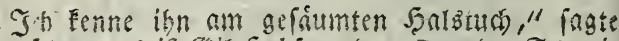

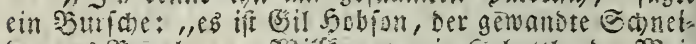

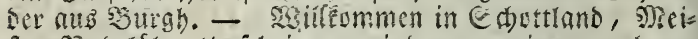
fer Padelobr," forie or, indem er eine ungeboure

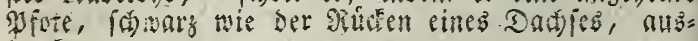
fircute.

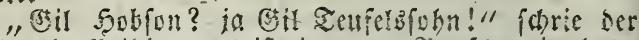
manternoc stillie; "es if ein netter Duride, it bale

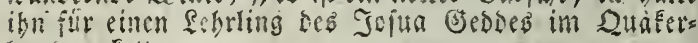
batomerE."

"NSas mag tes fúr ein Sandwert feun, freund?" fragte ber Daciblinan Fanfige.

"Eeten und @ingen" - pagte șillie, mas cin Domerndes fachen hervorbrachte; "id aber will dell

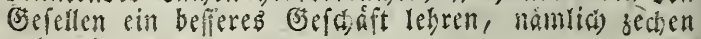
uno geigen."

Ing : berrieth, war eigentlid gegen bie 2 ibrese; sod freute

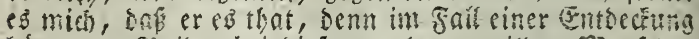

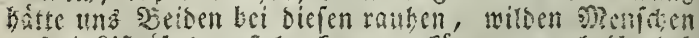

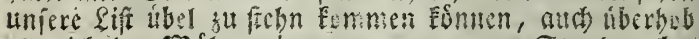

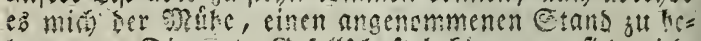

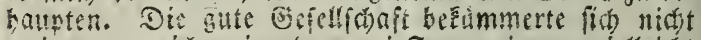
weiter um mid, ein doer smei Frnuenzinmet vielleiót 


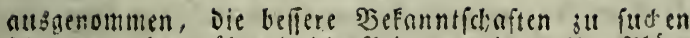
fobienen; aber nábreno Die adelteren mieder ibre

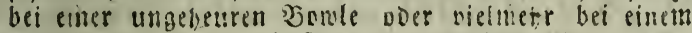
Dampienden sieffel mit 5 ranntmeinpunich eimahmen, oroneten fith Die Güngeren, uno riefen ben sisillie, ionen aufistefreiches.

Siad) einer mir gegebenen (Entaknung: "meinem Pilfe (5bre su bringen, Desn bie fifter batten gute Dbren, wenn auti) : se gifole fe tle batten, ". fing Wuillie froftig sll geigen on, und ith nciompngnirte

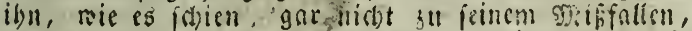
Denn er gnb mir bie uno da einen beiffillinen watine.

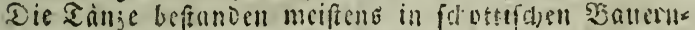

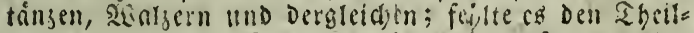

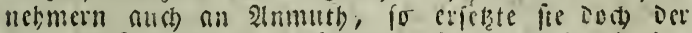

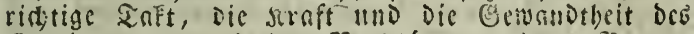
(a)rittes, uno die Den ?iordindern eigene siemeg.

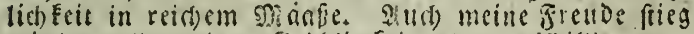
mit Der allgemeinen froblit feit, bureh zivilltes mus fterbaftes epicl und ousct) fein háufig wicoerbultes: "bray gemacht, litier Edbats, redit bias." - Ia,

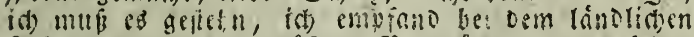
Eefte cin bedetteno groberes Stregntigen, nls nuf oen

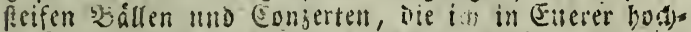
beribmten Etnot befudite. SBicllciaft fam es nut Daber, Dab ia) Der Ion angebenden Dome oon SErs=

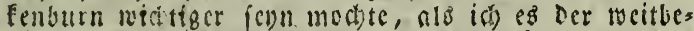

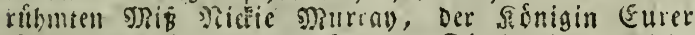

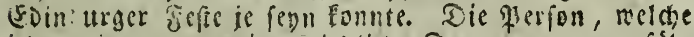

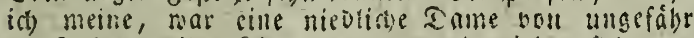
3o Sabren, ibre \{inger maren mit riten litbernen unD 3 - - golocten Singen gesiert; unter ibren viclen blaten, excifon uno fóalndirethen Huterriden

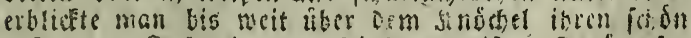

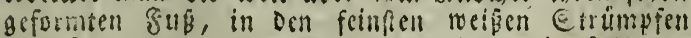
non fammmo"s und Eorduanfotuken mit filkernen Ganallen. Eie fitien mir in Enaden getrosen, uno

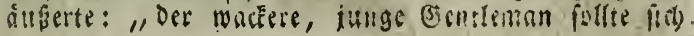




\section{. 58}

nitht fll toot geigen, fondern aud ein paar Mal mit berum tanjen."

tin ?:" fingte sisillic.

Uno tex foll Demn alts mir werden, frall Mar-

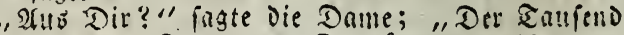
hole Difl, alter Sirausbart! Dul Es nnteft wubl juan bis Stunden lang in eincm fort ipielen, uno Die gange Eanditaft mit Eanjen crmitoen, the Du Deis uen Tyogen niederlegit, einen fabetrunE oder fo etras nttigenomitan

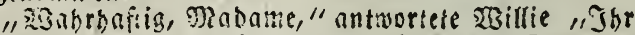
babt nicht gan; tmrecitt; wenn alio mein famerad tansen ioll, io fanffe mir nut meinen Schoupen, und Dam! geht meinesilenen mit ibm auf und Davon, wic Dingsa midolebie.

Der Siane waro balo herbei gefthaft; aber mibe

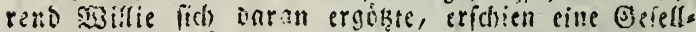

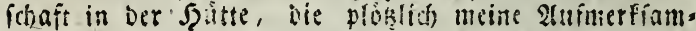
Feit auf fich zog, uno Den Gedanfen an bie galante Irtigfeit verorangt?, mit welcher ich mir vorgenommen latte, ber rothwangigen, nobigebildeten, neibfinigen Thetie, die mir bie Enthafimg bon meinem mufieal:s Ghen birufe nutegentrit bntte, meine 5 and ju reicien.

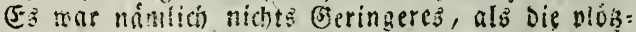

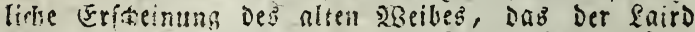

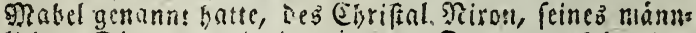
lichen Dieners uno ber iungen Dame, melábe bas

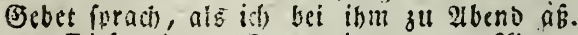

Diefes junge frauenjimmer - 2flan, Du bifít in Deiner 2frt ein Sejemmeiffer - Diefes iunge Frateen= simmer, ons ich nicht befchrieb tmo bas Du eben Defs wegen firt einen mit nicht gleichgúltigen (Segenftand bielteft - ift $e g$ natd), ich fage es ungern, nicht fo notig, wie die Silugheit es gebielen murbe. Ia fann es biefes onal nicht fietie nennen, denn zu dft ge. brauchte ich Das wort bi vorülergebenden faunen und Einbiloungen, albु Dấ ich) Deinem Epotte entges ben fónnte, wenn ich Das befribl fo nenne, Das mich 
jekt befeelt. Denn ich mus es geftehen, nadh Den Jahren jut rechnen, die an mir vorúber flegen, habe id) Den 2tusbrutek ein menig jtl oft gebrattcht (ein Pomantifer mitroe fogen entmeibt). Bater in ernft, Der fchóne Sinplan son Srofenburn bat meinem forfe oft Befuche nbgettattet, menn et ganj und gat nichts onrin ju fuchen hatse. Tindeft In onrin Den Échlü: fel ju ben Erimoen, Die mich hervigen ponnten, im

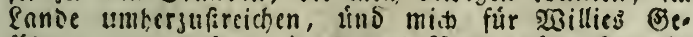

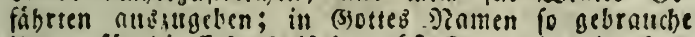
isn - fúr die Erlatlunif bratteft ₹u nidit jl: Danfen, Denn in ieoem falle hintteft Dut es Doch gethan, erlatilit ober-nicat. $\Theta_{0}$ frund es mit meinen Eefúblen, tuno nun benfe Dir, wes mich surchortingen baben mas, als, gleich wie Die Etrablen Der Eonne bie 230 olfen

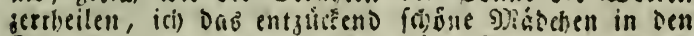
Salljfanl treten fah, nicht alo Fume lie ju if reb Blcio chen, fondern einer bebieterin sleich, Die mit ihere Eegenmart Dab frendenfeft der lintergebenen verberrlis chen will. Der nlte grann und die Fratl folgren its mit eben io finferen Sjlicêen, ala Die ibrigen liebreich maren; es fehien, alz ob zmei rauhe sginiermonate

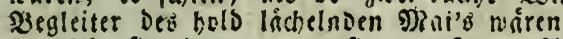

$\mathfrak{A l B}$ fie eintrat, trub fie - erftntme $\mathfrak{A} ! n n-c i s$ nen grúnen Miantel, genau fo nie Du die Sulte Deincr idjonen Elientin beichriebft, mas meine sBernu.

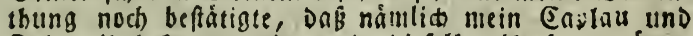
Deine Unbefannte cin und Diefelte Herfon méren. Sonum erfonnute fie midh, alb ibre Stirne fich aud idsn fichtlich verfinfterte. Sie gab ber meiblichen Die. nerin ibren Mantel, uno nach einem slugenblicf, in welchem fie zu ictewanken fchien, ob fie bor s oder ridi. marts gehen follte " trat fie mit murbiger Bube in bas Bimmer. 2allez wich ehrerbietig auf bie Eeite, Die Syánner zogen die Múken ab, die fratten rerbeusgen fich tief, bis fie fich auff einen Gtubl niederließ̈, Der achlungoswoll, fern vou ben úbrigen gefiellt morden mar.

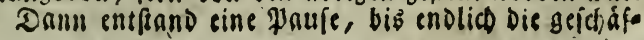




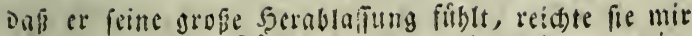

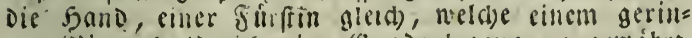
gen siitter buloreid) cise esneoenbejeugung gerábrt.

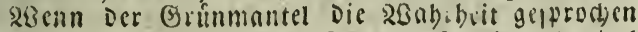

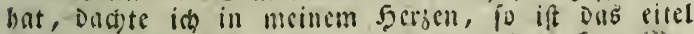
3iererei. Denn iunge Damen madyen boú fente bes

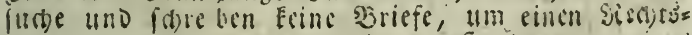
gelebrten zu bearegen, fid) in Die Samolungen cines

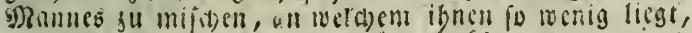

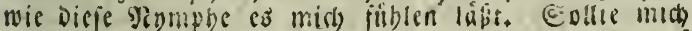

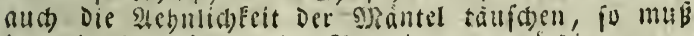

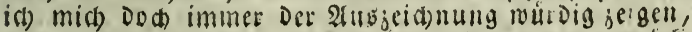

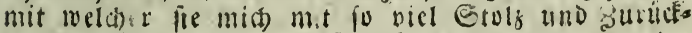
baltung begnadigt hat. Der Zanj, welder clen bes

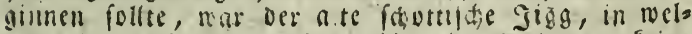

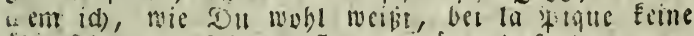

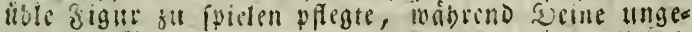

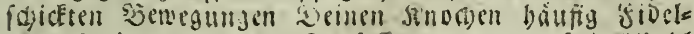

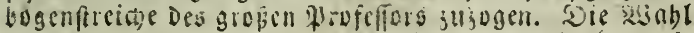

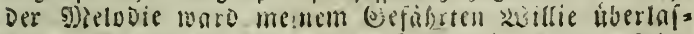
fen, Der, als er finen isune bechoigt batte, fpikz=

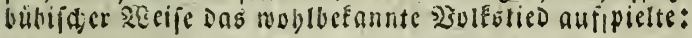

" Eultig tanjte Dis sunters giseib,

"Ino luptg tanste Der suafer."

Ein fdallenies (B) lád)ter brad) altf meine Sioften aub, uno ia) ruide mich vernidstet gefüblt baben,

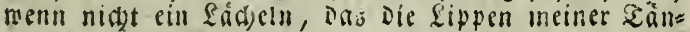
zerin umfer webte, fern pon Gpott mil fagen ju wole len filjen: "nimm Dir uns nid)t zu Şerjen." 2illd

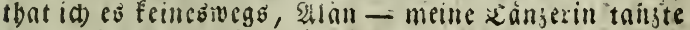
munderbar, tho id wie einer, Der, wenn er fajon weís, Das er úbertiofen wird, Do由 niont gan; bers DunEelt werden modjte.

Sicher verdienten unfere Reiftungen fowohl, als

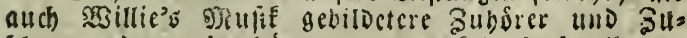

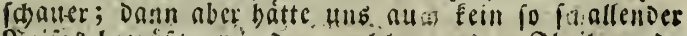
beifan begrüt, wie Der, welder.uns su হbeil mard, 
als ich meine sánjerin allf ifren Plat jurudefubrte, und einen Eik neben ifr einnabm, wie icmand, Des ein $x_{i c d) t}$ Daku bejikt, Dic bei folden (Selegenbeiten

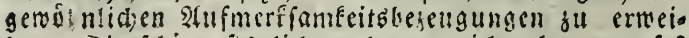
fen. Eie folien liwtlib verlegen, id) aber war feft

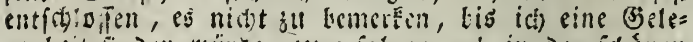
genbeit finden murve, 3ut erfabren, ob in Der fodsen sorm nush cine fitone Eeele mobne.

Doch alier, io Elibit aud Der Entich!ul gefapt

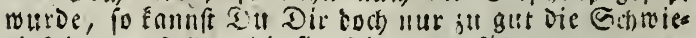
rigkeiten worfellen, Die lid) feialer antubübruing entgegen frellten; Da $\mathfrak{c}$ mir ftets an 1 mgang mit Den Sicijent

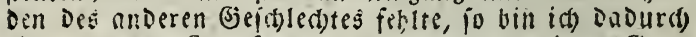
ein alberner Zrotf gemorden, Der nur einen Bran

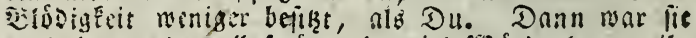

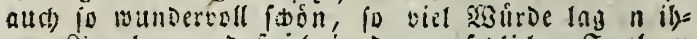

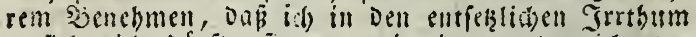
verfiel, id Durfte lite nut mit einer ausesejeidjneten ElrtigEeit anreden; aber boi allem Jin = uno STerfin nell wolle mir attd nicht eine cinjige IDse einfallen, Die Der Jerftallo nidbt entweder als Eriewente Echmei= d)elei, oder als fiadjen uno fnoen saits beroammen muŝte. Eg war mir, nla wíle mein Denfvermogen nidbt mibr mein Eigenthum, fondern fánde bald unter Det Serrid)ap̧t Dea 2ubiborontapfoscophornio, balo unter Det feines nárifa) Jen felndes Rigoum Gunnions. IIth wie veneioete $i$ (b) in Diefem slitgens blies unjern freund Jacé Dliver, Der mit roblgefälli

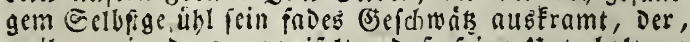
weil cr nie Daran zweifelt, Daßs feine Unterbaltung Jergnigen gewábrt, ein icoes fobne 2seib, oas ibm in oen sieg figmmt, fúbn anredet, uno Der Die pons

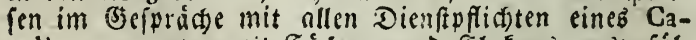
valiere servente, mit fáchern uno fInfons nubjufúl.

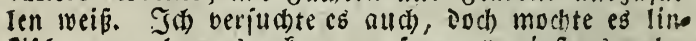
fift genug beratts gefommen feyn, wentgftens nabm fie \&ady (3) rummantel, wie cine Furffin Die Suldigund sines feibeignen auf. 
einjugeftehen; irfe idj aber nidt fo rede it mit Serrn Darjie Earimer."

"Darjie Latimer ift Der Dame Des Nannes, Def

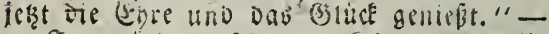

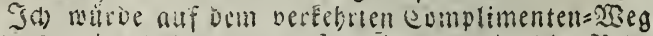

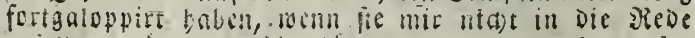

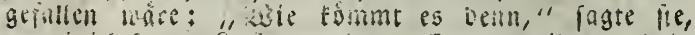

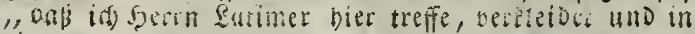

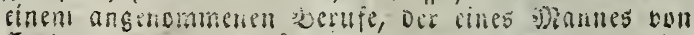

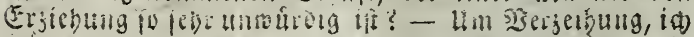

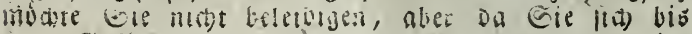

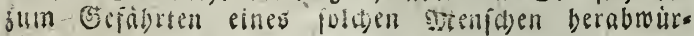
Digen - - "

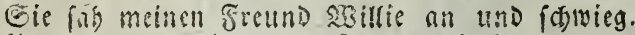

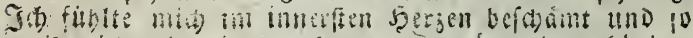

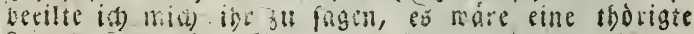
faune, welate ber sifanget an sefandigung mir eins

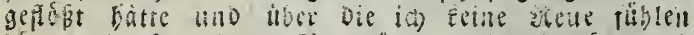

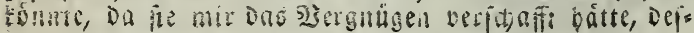

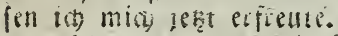

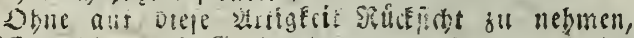

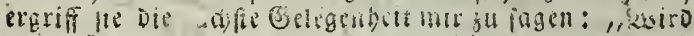

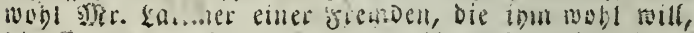

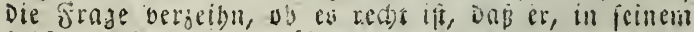

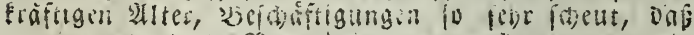

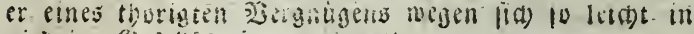

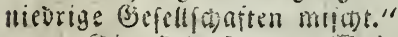

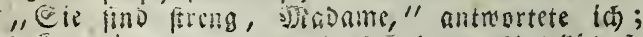

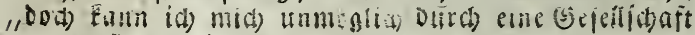
entegrt finden, in roisger (it) - - "

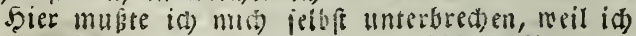

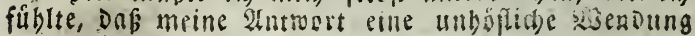
nabm. Das Argumentum ạd hminem, vie lę̧te Bu=

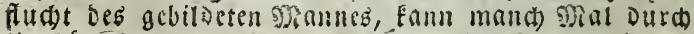
Hmftande entfajuldigt weroen, aber felten oder nie Da Argumentum ad fueminam.

Eie fúllte die füde meiner iede felbft nus. "In melder Sie mid trefren, wollten Eie wabrfideinliळ 
Fagen? 2(ber ber Fall ift febr verfabieden. Fail uns

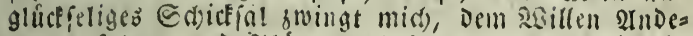

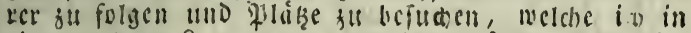
eincr andern Sage, gern vermeiden würde. Lieverdéb

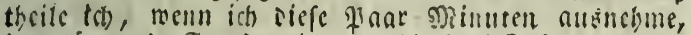
icne lermende Frende nicht - bin blok Bufonater uns merbe non. meinen Dienern begleitet. There Snge ift

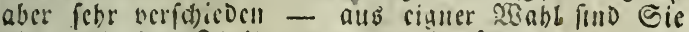

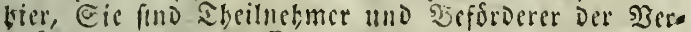

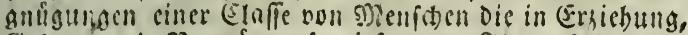
Gecburt uno 3 ermogen fo tief unter Sonen fechen. sisenn id) ctwos hart rebe, Mir. Entimer," fligte fie mit Der fúfefien Etimme binzl, ,10 meine in es Dod won Jerjen gut."

Shre Siede braidte mid in Sierwirrung, benn frreng war fie in iugendid)er seisheit, " alles ??as

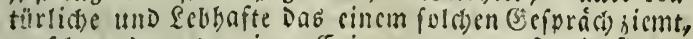
oerfotmano aแb meiner Erinnerung, ernft wie fie ges than, ermieberte id): "(5s ift wabr, id) babe midi) eincr befiern Ergichung zu erfreuch-gebabt, alo Dicfe armen Leute; aber. Eie N?aDame, Deren gútige fours forge id) Danfonr anerferinc, Sie miffen bon meinem

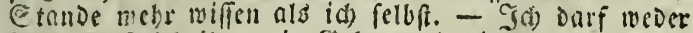

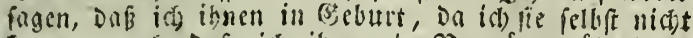

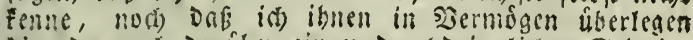
bin, Da aud) Daruber cin undurdoringlider Edyeier liegt.

Uno warum follte Eie Denn Shre llufentní Dies

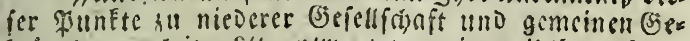
briuben verleiten ?" antwortete mein weiblid)er s? ?ello

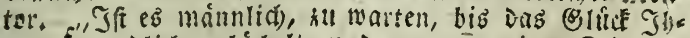
uen freundich zuládelt, "lnd zmar ju einer Beit, ws Ghre cigene Shat Elaft Eie emuorhelen Eahn? Risgt

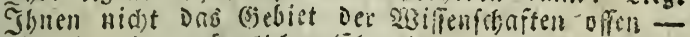

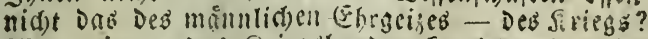
2! ter nein - Das SiricgshonowerE ni(j)t, Das pasen Gie füon sut theter zablen miffen."

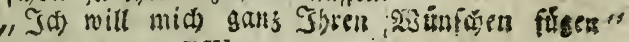
on Eioti'b şarf. XVI. 
antwortete id eifrig - "Sie Dúrfen mir mur Den $20 \mathrm{eg}$ ansigen, und Sic werben felhen, ob id ibm nidst willig jolge, wóre $e^{3}$ auch nur, weil Eie mik $e^{3}$ befeblen."

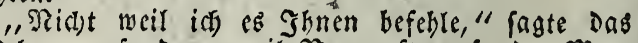
Mádecn, "fondern weil Dernunft, gefunder MRen=

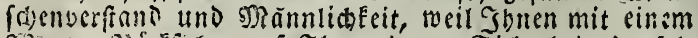

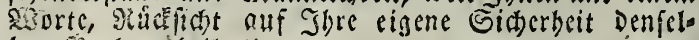
ben siath eribcilt,"

"s sie Dem atich fen, gewifí nabm secift und 2 er nunit nie cine ifisnere Form - Der Heberzengung an" fitgte id bafig binzu, Denn lie manote fich von mir ab uns gab mir Erine eelegenbeit meinen angefan= genen Eak zu beendigen, bis id entichloffen, unjer

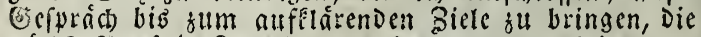

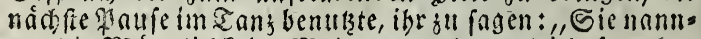
ten oie Mánntidfeit, Madame, uno zugleidh (prad)en Eic uon perfonliber Ejefobr. Nun aber fagt mir

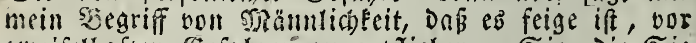
3neifulsaften Ëcfobren zut entflichen. Sir, Die Eie

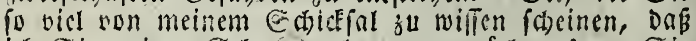
iá) Gie meinen @dutiengel nennen mod)te, fagen Gie mir, welct)e Gefathen mid) beoroben, Damit id ur= theilen Ennn, ob mir Die Noannlidbêt gebietet, fie zu erwartell oder fie zu fiebn."

icicfe 2ufforberung bradte Cie in grofie 2 ser. legenbeit.

"Eie Inffen es mid) theller entgelten, Dabi id Shren menfobenfreundian meinen Sintb anbot," er: wiederte Eie entid): "Iof geffthe es ein, Dá in an shrem Edidfiale Sbeil mehme, mober Diefe sheil nalime aber entfebt, Das Darf id) Sbnell eben fo wes nig fogell, als wober und ron tocm Eie gefábidet find; Dow ift eg nict)t minder wahr, das die (s)efabr fehe nohe, unenolid) grố ift. Frngen Eie mish nichts methe Daruber, um Sbrer fclbft willen verlnffen Sie

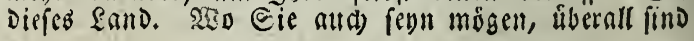


Sie fiderer. - Sier ziehen Sie fid felbft 9 hr $4 n=$ glicte fil! !"

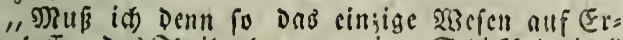
Den verlalfen, Das Sheilnabme an meinen Edjiefial jeiat? - 2ad), lagen Gie es nid)t - fagell (cic mir, wir werben uns wiederieben, onmn foll Die Soffnung mir ein lieber Leitftern fein, Der ntir Die SBnhn zeigt, Die idi) wandeln full."

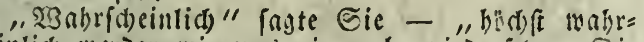
(d) einlich rerden wir ung nic mehr micoerjetn. Die Jublfe, die id) Ihnen iekt geveibre, ift allib, was in meinen Siráften fteht ; $i$ id) that Ibnen uicht mebr, als

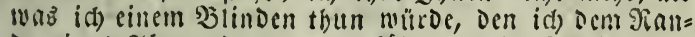
de cines 2lbgrunos zugeben fábe; ez Darf હie nidat in Erftaunen verickin, uno gebietst Eeine DanEbar= Eeit.

Sicicoer manote fie fich fonell $\mathrm{um}$, alb fie $\mathrm{e}$ gefprodicn batte, fprach auti) Eein si3ort, bis Das Der Tains fid), fcinem (Ende nabte, Dann fagte fie, "oer=

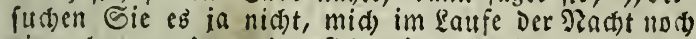
simmal anfureden, oder lid) mir zu naben; verlaffen Eie die (sefellinaft fo bald alz miglid), aber ia nidgt auffalleno und - Gott idúke Sic."

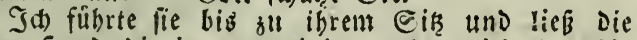
f̧dne Sand, Die in Der meinigen rubte, nicht los, bis id) mit cinem leifen Druk meine (Befíble ju erEett= nen gegeben batte. Eie errotbete fiuditig uno jog

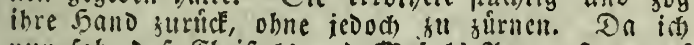
IIIn fab, onj Ebriftals :tnd Trabels Rugen ftarr auf mid) gcheftet maren, fo nerbettgte id mid tief und

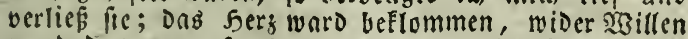
ward Das auge feudt, als Die rogende Nenge uns trennte.

Deine 2afidt war, wieder zu meinem Sameras Den willie binjuf(t)leiden und fo gut wie indglid) Den Sogen ;u fúbren, ob gleid id in Dem 2 fugenblice gern mein balbes Bermoggen fúr eille Dinute in Der Ein:

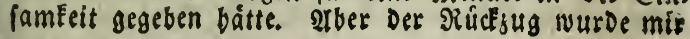


von Frau Martin abgefidnitten, mit Der Dffenbeit (ich) glanbe Der alusoruce ift nicht unpaffend) ránoli= d)er (s)efallfutht, die grade auf Daz siel losgebt.

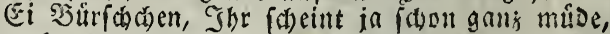
da Shb eben noch ro leidit Daber gehifft fend? Fin Pferd, Das Den ganjen $\mathfrak{T} a g$ líuft, ift Doch beffer alb ein Renner, Der eine Meile weit rennt, Dann aber nies Der liegt."

Das war nun freilid eine ziemlid Dettline 2 tufs forderung, Die ich nidjt gar mobl zurúctweifen fonnte.

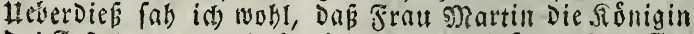
Dos zeftes twar; und fo viele raube und fonderbare Ees ftalten umgaben mids, Das id Feineswegs ficher war,

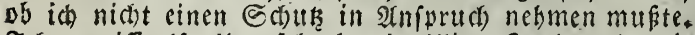
Id) ergriff alfo ibre febr bereitwillige Sano uno wir fiellen tns in Die Reihe, wo idi), wenn autio meine Fritte und Serwegungen nidjt fo ganj genau waren wie zuoor, Doch) Den Erwartungea meiner $\mathfrak{Z}$ änserit

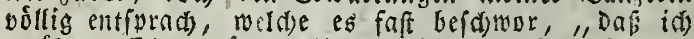
unúbertrefficis wåre - "Sie, ibrer Seits", ftrengte (iic) entfesclich an, büfte wie ein (Seislein, fduappte mit ibren Fingern wie mit Enftngnetten, inudeste roie eine 3 adjantin und bopste mie ein Federball, bis baf

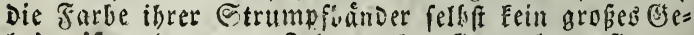
beimnis melgr war. I Gh glaube, fie verbarg fic um fo viet meniger, da fie oon himmelbtauer Seide uno mit Frangen befetgt waren.

(Es gab wohl falon seiten wo mir Das einen Gauptfpás gemarit baben tourde, ooer beffer gefagt, in nier Sahren war Die vergangene Nad)t biẹ einzige

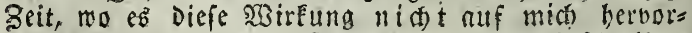
brachte; Denn id) Eann Dir nod) iest niast beforeiben, wie grof meine Selnufucht war, midg non frau 9)?ar=

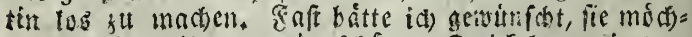

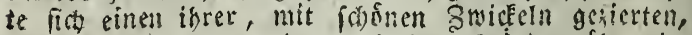
Rndibel terforingen; Dem als $i(b)$, bei ten úbertrico

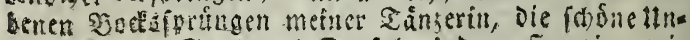
Eecannte Den Gant berlafien [ah, inven fie mir, wie 


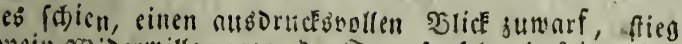

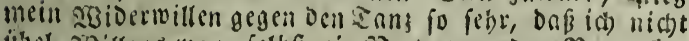

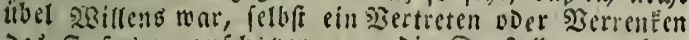

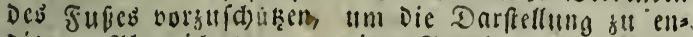
Digen. 2aber id wat van ciner 2 nanbl nlter siseciber umgeben, Die mir allsjaben, alb wüste eitle iede von ibnen irgend ein Ilniverfalignitte! für einen fold)en Sufall, und on mir (sil silas mit feiner angeblistien

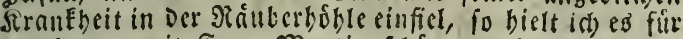
rathfamer, mit Srall Martin (d)on fut thun uno fort all tanzen, bis fie es fü gut finden wirroe, mist zu entraffen. Da eb nlfo cimmal gefdeben muste, fo

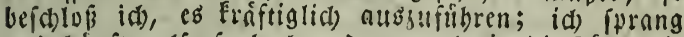
und bripte nlfo fo bod und wagred, in Die 5obe wie Frau DRartin feldft, und ermaib mir Doudurd) Donnern=

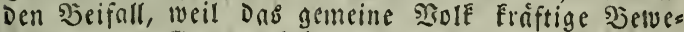
gungen UnD (3) ewand theit fets Der summuth vorzusies ben pflegt. (Endidi) ward es ferbft Der frall MRars tin lomoglids), weiter zu tanzen; id freute michy, oas

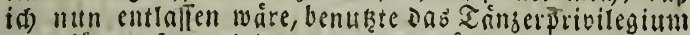
uno fibbrte fie ati ifsen Plat surúck.

"Pok taujend, meine 5crrn, "rief Frau Martin ลแร, , id) Eaun foum mebr (d)ualfen! subabraftig, junger Diann, idt) giaube, ibr babt mid) zu toot tan= zen wollen." Id Eannte oas fugefingte Hebel nur mit einigen Erfrifdungen wieder gut mad)en, Die is berbcifolte uno Die lie willig genoß́.

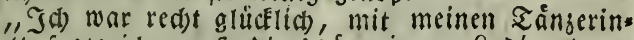
nen," fagte id, ,erfit bie fadone iunge Ladý, Dann (Eแd), fratl D?artin."

"(S)bt mir weg, mit Euren Schmeideleien," fagte Srau Martin. "Bjebt nur-gebt; füftert mir

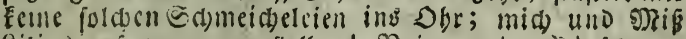

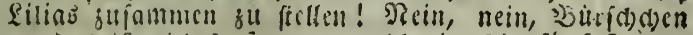
- Das ift nirista, lie mag wobl vier bis fünf Tabre,

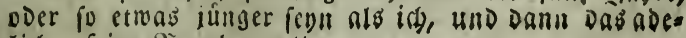
lid)e, feine \$ènebmen." 
"Ift fie Die Todter Des SairDs?" fragte id,

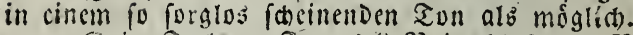

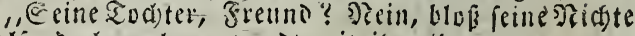
- alio bodi) noci) vermanot mit ism."

Ia freilich, " erwiederte id), "Doch glaubte id, fie führe feinen siamen?"

Lilin"s.".

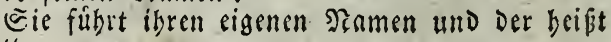

"Shat fie feinen andern Samen?" frutg iat.

, of ofll brattibt fie einen andern, bis fie ciumal ei nen Minn bat?"' nutwortete meine Thetis, viclletd)t (um

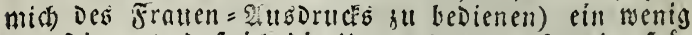
verftimmt, Das id bie Interreoung auf meine frú bere Fanzerin und niđt auf fie lenfte.

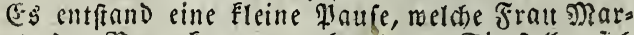
tin-mit ber Sbemerifung unterbrad): "Eie freflen fić) f(t)on wieder sum Bans."

(Es if wabr, " fagte ich), Da id) Eeine \&uft batte,

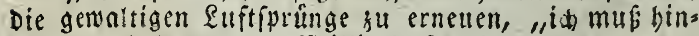
geben und Dem alten sisilfie belfen."

(E)e id) mid) nod) losireifien Eonnte, borte id, wie bie arme ₹hetis fid) an einen Eecmann, mit ei= ner blaucn Tacfe und weiten Matrofen= Ṡeinfleidern wendete - (fie bátte, beiláufig aefagt, im Sorabend

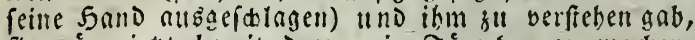
fie ware ietht bereit Dazu, ein ₹ánzdien zu madien.

"Ianz nutr zu, mein Ed ákzhell," fagte Der rachs fudtige $2 \mathfrak{B a f f e r m a n n}$, obne die Sand ;u bewegen; "Dort" alf Den ₹anzboden zeigeno, ,ift łhaks genug fût (ङ)

Da id) mir nun gemín einen, vielleid)t gar zmei Feinde gemactit batte, fo eilte id meinem fruberen Gize neben scillie zu und fing rvieder an, Den jogen zut fúbren. Ieutlich Fonnte id nber bemerFen, Daß mein Setragen einen ungtuftigen Einoruck berborges

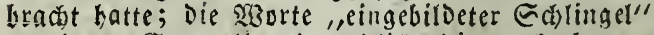
"sesterter Etuke" und endiä die nod) beunrubi= genvere sjenenung "Epion" gingen balblaut von 


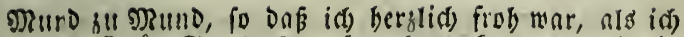
an icr Shur Eam's 2tngefid)t bemerfte, was mid) in fofern bertuhigte, $D a$ id) nun (id) cr war, cin Siettungo

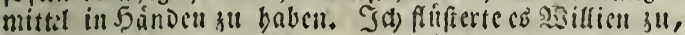
Der, feinen SEorten nad) zu urtbeilen, no(t) mebr son

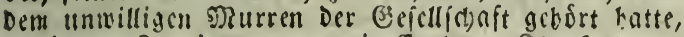
als id): "Ja, ia - weg mit (Eud) - Sbl ferd nut cason su lang bier - fd)liuft un!emarft hinaus Inß̈t es nicht leben, Daß Jhr nuf Dem Eprung fteht." Sd) Drficte $\mathrm{sem}$ alten Doun eine balbe 3 minee in die Saild, morallf er alitwortete: "2: w) was! Sborbeit - ood) mill id) es nid)t nbld)lagen, weil id boffe, Ibr werbet es entbebren fúmen. - Iekzt fort mit (Eud) - und menn Semand (Eud) etwag anbas ben will, fo ruft mil mid)."

Ja) ging nlro, fcinem S?ntbe gemáí, Durd) Das simmer, nls fudte id) eine Ecinjerin, trat zu Eam, Den id) mit einiger Endwierigent bon. feiller Somle Iosrif, und fo verlieben nir, fo unbemerft als mogs lid, bie Fitte. Die Pferde waren in eittem nabe liegenden Berfdjlag angebunoen, und Da Der Mono (d)ien und i(t) un binlanglich vertraut mit bem zivar unebenen und ungleichformigen 23 ege mar, fo erreicte ten wir Gadafersburb febr bald, wo bie alte झुirtbin uns ángftlia) ermartete, weil (wie fie fid) autsorúckte): (d)on mandier nus ifrem Saufe und aus den benards. barten Stáoten nad) Srockenburn gegangen wáre,

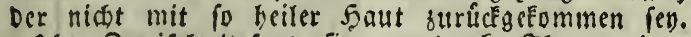

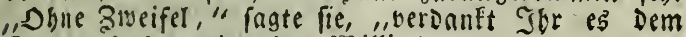

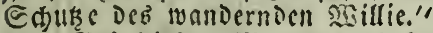

Sjei biefen 2iorten erbob fich Sillies Frall,

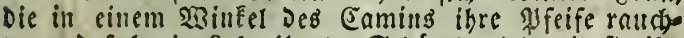

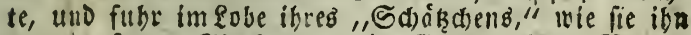
nannte, fort. Sie fuchts meine Eropimuth bon sieuta su erwecken, indern fie cingebildete Ba efabren befarieb,

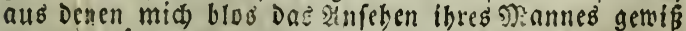
gerettet baite. I (b) war aber nidt in Der faune, mir nod) m.br (s) 
alfo, befturmt bon son verfoticoenartigften sefiblen, zu bett?.

Eeitoen babe id cin paar Eage bald zit Mount Ebaron baro bier zugebradist, indent it bard las, balo Dir Diefe autsfubrlide (Erján!ung idrieb. Dann

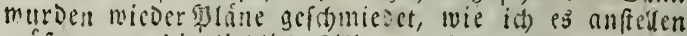

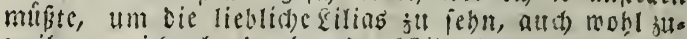
seilen - idi alaube eben Des dBiseriprubis wegen troß̉ Jofun? Sorurtheile, ein wsnig geangelt, Da ich, feitdem ich fortforitte in Diejer Stunft gemad)t babe, auk) megr freude Daran fince.

Itno nun, mein thetterfter $\mathscr{A}$ Ian, Da Du mein gan=

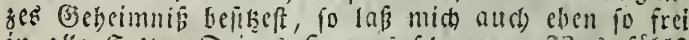

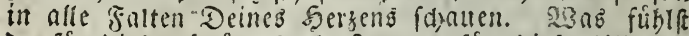

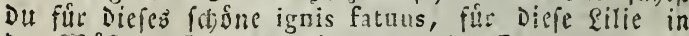
Der 2 suffe? Sag' es mir trell und offen, Denn wie lebhaft fid) au(t) ibr şilo meinem (Eemuthe eingepright baben mag, meine siebe zu 2alan Fairforo ibertrift

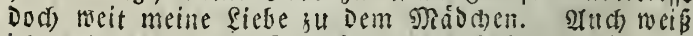
id wohl, Dafs menn D u liebft, ev gefoliebt: "Einmal sul lieben und nidyt megr."

23Benn fich einmal eine tief veriebrende Reident fornft in ener Fraftigen $\mathfrak{B r t i f t}$, wie Die De nige, ent=

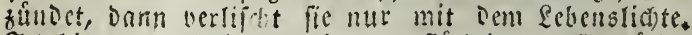
I.t) bin von serichiedenartigerem, fuidstigerem Ge enuthe,

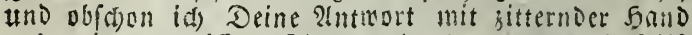
und mit ungewifiem Serzen erbedsen merde, fo pollfit Du febn, Dafi inenn fie mir ein Lffenes Eeftátionié bringt, Daß Diefe fordne Itnbetamnte einen tieferen Einorute nuf Did gemad)t hat, als id noth Deiner ErnftbaftigEcit ermartete, Dafe ich Den Bffil fammt feinem subertinfen mit eigenen Sánocn aus meiner sginnde reiken Enn. Unterdeffen werde id, serlafie

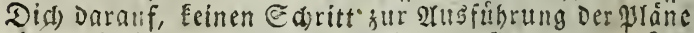
thun, die ia mir entroafen babe, um lie zu iehn. Ia babe es bis iest unterlaffen, und ids gebe Dir mein Egrenmort Darauf, id werde es ferner thun. Do(i) 
tell, nber, Gott fath' nit bei! Gie Fam ia in Be=

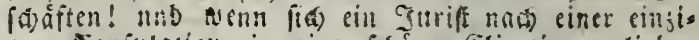

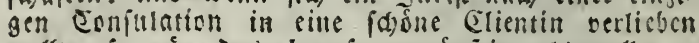
mollie, fo mare ons cben fo bermunfig, als molite er ita) in einen befonoers frofnen Eomnenfrakl vergafa fen, Der augentidelid feine 2 mts= J4) bese Dir meill Sisort Daralif, mein Serz ift tins sermunoet; uno berfichere Did) noc uberoies, sas, else fid ein sieib in mein $5 \mathrm{crg}$ einjoleidt, id bors

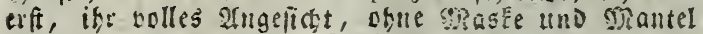
fehen, uno einen guten ¿beil ifrer Eeele fennen ges lernt faben mús. Eeg alfo meinetwegen unblorgt, meitl gutiger, groburtbiger Dalfie; aber un Ieinets millen - bab 20: allf Did), Damit Did Ecine foncll aufgepangene, tboridgte Seidenfidaft in einfts lide Eicrabren nerfeţe.

Diefer Gegenfand beunrukigt mich fo febr, Daß (d), Da id nun mit Der ebrenbollen Robe befleidet bin, neine Paufbabn glcict bei ibrem Sieginnen ter. laffen baber murbe, um zu Rir du cilen, retn es nidt meinem $3 a t e r$ gelungen ware, meine finge mit

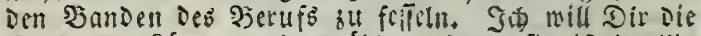
Gade Der Eánge nad) erjablen, Denn fie ift orollig genug; und marum follteft Du meinen jurificion abenteuern nidat eben fo gern ein geneigtes Dor leiben, wie id Denen, bie Dir auf Deiner irrenden (5)igerritterfanaft sufiefen?

Das golttngefien twar orruber, und ids uberlegte eben, mie id meinem Dater meiuen Entid)lü, nad Dumfriesibire zu reifen, am beften beifringen Eonns te, oder of es nidt vielleidst beffer ware, allf und Davon ju gehn, uno ming foriftliti zu entfdu! sigen,

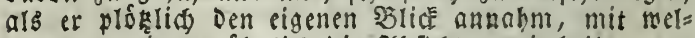

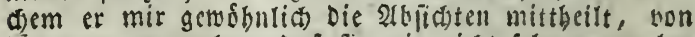
benen ef bermutbet, Das fie mir nidt febr angenebm fein múrben.

", Slan," iagte er, ,Du trágf nun Die Sobe-

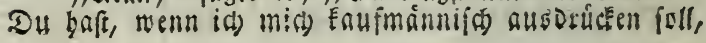


Deinen Saben ersfinct; Tu glaubft nun, obne Bimeifol, Der SoDen Der (šcrid)tebdfe wáre mit Buineen bes ftreut, und Du Dürteft Dir nur Die gitube eeben, Did) hu búcten, um fie su fammeln."

"Id) fuble mobl, 2 ater," fagte $i$ đ), "Daß̂ es mir now an 2 Riffen uno an Licbung feblt uno Daß́ id) bor 2allem frebell muls, fie z"l crlangen."

"Mobl gefprod)en," antwortete mein sater; Doda "weil cr fieto fifrd)tet, su febr aufsumuntern, fo fuigte cr binsu, "wobl gciprocisen, Allan, wenn Du nàmlid) aud Danad) bandelft. Siad Sénntmif uno Helung fireben, Das ift Der reste $2 B$ ahlipruas. Du weifit abcr, saran, Daf in Der andern Facultát, wo man Die Ars. medendi frudirt, Die iungen Doctores, che fie vor Dem siranfenbette, in Palláftén ftebn, wie

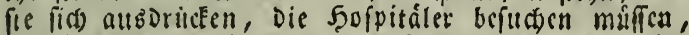

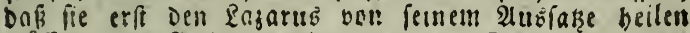
mififen, ebe fie baju gelangen, Dent Dives etwas nes

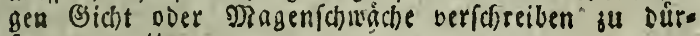
fen. - - "

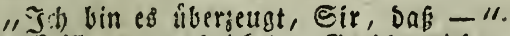

"Etill - unterbrich ons ङeridt nicht - Oat fo baben autf Die 23 untárite Den loblichen Oebrauch, Daßj fie ihre febrlinge und Brehúlien fich an emprin. Dungslofen, toden seorvern lubin laffen, Denen fie, menn nuth nichts (5)utes, Doch auch Feinen Echaden anfiisen fonnen. 2auf ber aniern Eeite aber erlangt Der Bethulfe oder Der febrling eine geiwiffe Fertigfeit uns Hebung, und lernt nací und nach eincts lebenden

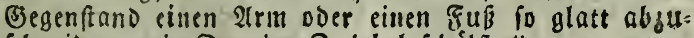
fobneiben, mie Du eine 3wiebel fohálft."

"Ich glaube Eie zu berftehen, Sir," errwieberte ick, "uno máre nicht eine befondere Nerbindlich feit -." "Eprid) mir nichtỏ von serbinolichEeiten, fondern (er) ffil"e - Du bift cin guter Eobn - unterbrich alfo Das (E)ericht nicht."

gRein $\mathfrak{B a t e r}$ pflegt, wie Du weift - mit aifep Findlichen Egrfurcht fey es sefagt - etwas weitfóneis 
fig in feinen Reoen fu fern. Ich Fonnte alfo weiter nichts thus, als mich nnlehnen und jukdren,

- Prielleidt Denffi Du, 2ulan, weil icis bon meinen murbigen Elienten mit Der F̧eforgung einiger ङefidiáfie beauttragt bin, fo suirde i $i($ Dir fie nuch antenblick: lich tibertragen, uno Dir auf biefe Weife, fo meit námlich meine Eltcinen Befdáfte und mein Einfü reichen, fogleich eine nicht unbedeutende Praxis berichafs fen; tho (reilich, 2a!nn, bolfe ich attith Den $\mathfrak{x} n g$ nod) zll erieben, an welchem es efcheben foll. 2aber ebe ich, mie ons Earichnort fagt, meine eigenen fiiche meinen eigeren Ecemvoen sormerfe, numb ich meines eis

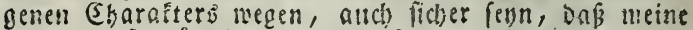

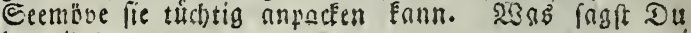
Daju?"

"Icb) bin to weit bavon entfernt," anture tete

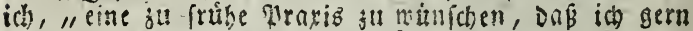
einige Zage baju beftimmen móćte - "

"Bu meiterem Etudio, willft Du fagen, 2tan. 2uber Das if iekt nuch nicht bet rechte $2 \mathrm{eeg}-$ Du muBt Die fofpitâler befuchen - must Den \&azarus beilen - Du muft einen abgeftorbenen seorver zer. fchneiden nno jerlegen, um Daburd) Deine (J)efchict. lich Feit ju besettgen."

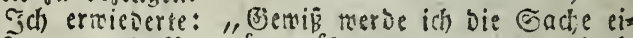
nes 2 rmen mit Sergnugen libernebmen, uno mix fo viel ojúbe safür geben, als gálte es̉, eincn Sorjog ju vertbeidigen; aber Die náchften jmei ober Drei Sage - "

" Diuffer ernfem Etudio gemidnict werien, 2alna - Pehr ernffem Etmoid; Denn Du muft Dich rorbe= rciten, nád)iten Dienftag in praesentia Dominorum einen offentlichen $\mathfrak{D}$ ortrag ju balten."

"Jch, Sir!" ermiederte icb ooll Erftannen, ich bale la meinen situno noch nicht in Der sorballe aufgethen."

11 Siumare Dich nichts utm bite unteren Tnftanjen,

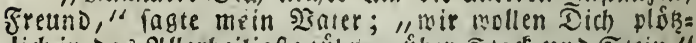
lid) in Das allerbsiligfte lúbren, uber હtock und Etein." 


\section{7}

"2lber, Cir, wie lcicht finnte ich nicht sine Sache verberben, die mir fo pldslich nufgetragen nird?"

"It-tannft fie nid)t verderben, 2Han," fagte

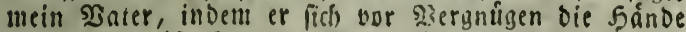
rieb; "Dns ift eben bie Gade, Treund. Eso ift, wie id) vorher fagte, ein (Begenftano, an welchem feit fünfs gebn Iabren alle Bchulfien ibre girobeftuteden abgelegt

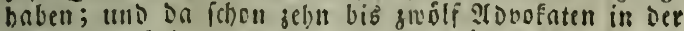
Sache gearbeitct baben, von benen icber feinen eiges nen $2 B$ eg einichlutg, fo ift fie in einen foldien Buftand gerathen, bnf weder Etnir noch Irnifion fie berteffern Ednnen; fo fannft nut Du, 2 lnn, fie nicht verfolitto mern - Du fonnft Dir eiren Diuf Danit erwerben, aber Eeinen verlieren."

"Itnd, ich bitte Sie, wie heift benn mein glúct. lider Elient?" fagte ich ziemlich unfein, wie mir's Deucht.

"ISoblbefonnt ift fein S?athe im Parlamentsbatle,"

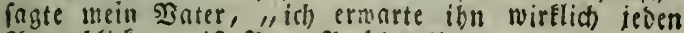
alugenblick; ;

"Meter Dleelles!" rief ich mit Erftaunen nub, "Onz ift ia ber mahnfiunige Mettler - fo arm mie Siob, und fo toll wie ein פ)ierr; = Jaje."

"Ëchon fünfisebn gabre fábrt er bei Den (Gerichs.

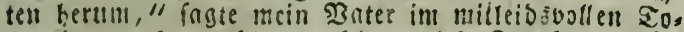
ne, ber zu fanen fdien, fchon Dieje Ehatiache máre

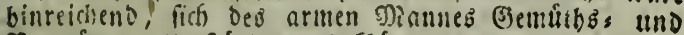

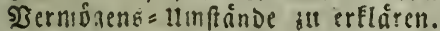

"Hebcrier, Eir," fügte ich binju, "fteht er anf Der ârmenlifte, und Sie riffen, Dnß es beftimmte 2lo. bofaten gibt, oie mit Der Beforatng itrer 2 ngelegen= beiteit beauftragt find; mie follte ich mich nun binein milchen.

"Etill, STan! - unterbrich Das Biericht nicht Das ift alles feton vorbereitet, wie cin Federball (mein sinter enilchnt manchmal feine bifcifiniffe tmo bilder aus Dent, von ibin fraher fehr getichten (Brolfiniel) -

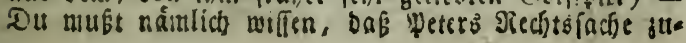


erft Dem iungen Dumtonfite úbertragen merben follte - Du cennft vielleidjt sen iunnen Mienfchen, es ift ein Ertin bes gleichnanigen Dutumeurte, welcher im Parlamente Die Eraffehnaf * * vertritt, und eine गeffe vom iúngeren 5 rabor bez Lairos, Des eljenmertben

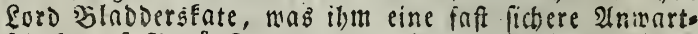
fchaft attf Degunftigung und bielleicht aut eine She. rifpiftelle gibt, fo gemis wie alts einem fleinen Eieb ein grobeg werden Eamn. Seute Morren Eam alfo Eaunders Drusgeit, Des Eairds Echreiber, in Der Parlaments 5alle zu mir, als tatte er ben serfiono berloren; Denn es fdecint mir, onf ber junge Dums tonftir zum armenaboriaten ernsunt ift, tmo baf ibm

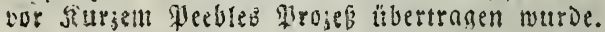

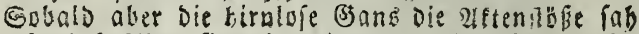
(uno freilich 2lan find fie nicht von Den Eleinften),

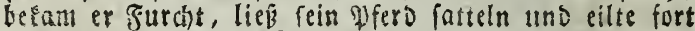
nut's Sand; Daher finmt eş; fagte Eaunders, Daf Miy!ro vor Echam tmo Herger faft bergeht, ba er fieht, wie fein গieffe bei'm! Feginnen feiner Laufbahn ait und bayon gebt. "Ith will Fuch etmas lagen, Gaunders," fagte ich, "ware ich Finglord, und ein

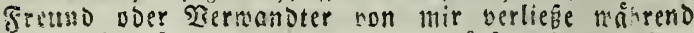

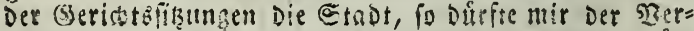
wande, boer mas er auth fey, nie weber meine sture betreten." Dann verittchte ich es, 2tan, den ballen

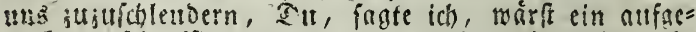

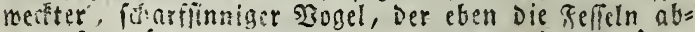

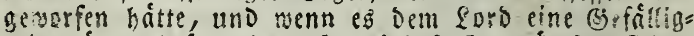
teit máre uno fo reiter, fo mirbeft It nách ften Dien=

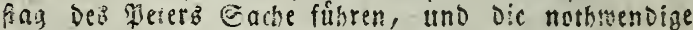
Mbuefenteit Teines Treundea mit iraend einer finn=

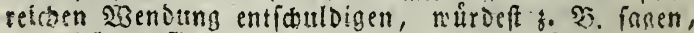
wie viel Der (J)crichtsh of fomohl, als Dein Crient Durch Die Entfernung eines fo tief gelehrten Garhmalters ver= liere. Saunders fchnappte ben risorichlag allf, mie Det 5ahn ein Berftenforn, Denn er fagte, ons einjige f̧ilfšmittel, Das noch übrig bliebe, máre, eine unges 
tibte fand in bie Sache jut bringen, Welche bie nufs gebưroete faft nidut ju beurtbeilen verfánie; benn ez. gáve Eeinen iungen 2 lobofnten, Der, roenn er auch nut jwei Siçungen beigetoobnt bátte, nicht tobterané dibet Peter Peebles Projeß werden wúrde. Ee rieth mir Das ber, Dir die Sache fchon vorjultellen; id) aber fagte ibm, Du márft ein guter Eobn, Allan, und bátteft in polchen Dinzen feinen andern sisillen und fein ande. rev̉ Tiergntizen, als twas mir gut Dünée."

Sisas fonte id wohl, Darfic, gegen eine fo woble gemcinte, sabei nber fo laffige HebereinEunft fagen? Den Febler uno bie Flud)t bes iungen Dumtouftic nacts: afmen, bießs nit einem Dale bie Foffnungen meines

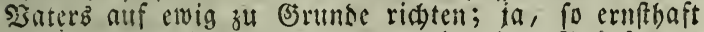

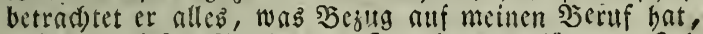

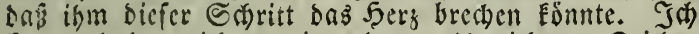
founte baber nidbta weiter thun, alb midh zum achaten einer Eummtervollen Eintwilligung zu verbengen, nor

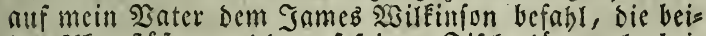

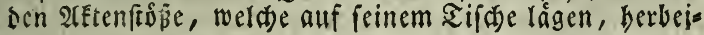
jubolent.

Iames geht ab und Fommt bald barauf zurilet, ges beugt unter ser \&aft zweier gropen lebermen Sáfle, sie bis an ben Sans mit papieren gefúflt fins, auf seren

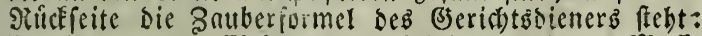
Peebles contra Plainstanes. Diefe ungebeure Niafe ward auf ben ₹ifa) bingelegt, uno mein 2 ater mit un= gewobnlider freute im sefeficte, fing an, bie veridsie? Demen afEtenftópe herworzusiehen, die nidt) etwa mit ros ther Echnur ober bunnem Ecil, fonsern mit bidken the rigten Stricken zugebunien waren, sie foson cin

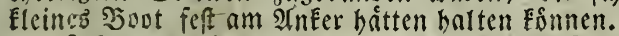

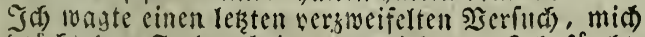

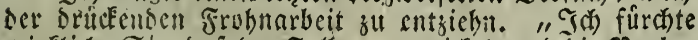
mirEli(i), Sir, sais ber Fall zu vernidelt und bie siorbe

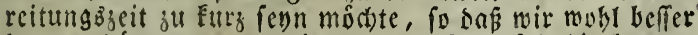
saran thaten, wenn wir Den Gseriát tobof Sabin bewegs ten, ez bis auf bie náchfte Geffion aufaufabieben." 


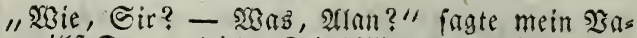
ter, ",willft Du ju gleicher Beit billigen uns mişbilligen, Eir? - Du baft nun cimmal bie Eache bes armen MRannes angenummen, unb baft Du aud Die Grorteln

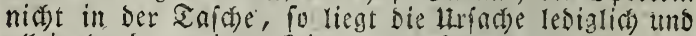
allein Darin, weif er Eeine zablen Eami ; uno mun millf Dut fie in einem sithem annebuen und zuridtueifen?

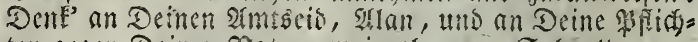
ten gegen Deinen sater, mein thetterer @okn."

Nod) cinmal, was Eonnte id) fagen? - Idb fah an

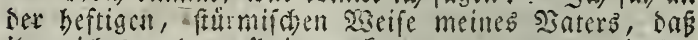

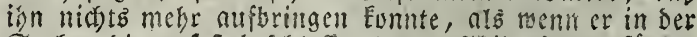

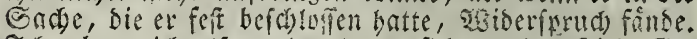

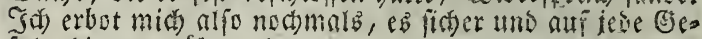
fahr bin, zu ubernebmen.

"Srav, brav, mein Sino," fagte mein Şater, "Sort gebe Dir alth Iongez Seben ant ber Eroc, neit Du die grauen 5aare Deines şaters ehrit. Du Eannft vielfeicht einen verminfrigeren SRathyeber fimben, aber gemî́ Eeinen, Der ez beffer meint."

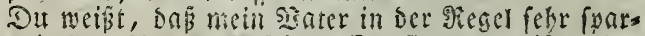

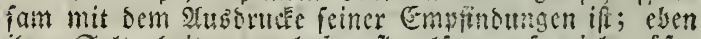
ihrer Eeltentsit wegen baben fie alfo um fo viel grópes

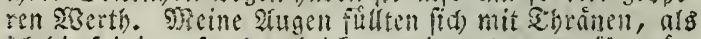
ich) sie feinisen feutst erblictere; rein uno ungetrübt wáre

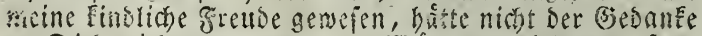

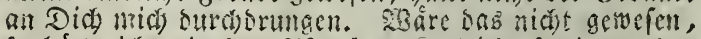
fo batte ich mit ben Sletenbetteln leid)t feriig merben wollen, ths môren fie fo grofie wie Sornfácke gewefen.

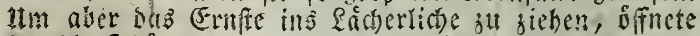
fii) Dic इture und binein.

Du must sicfes Sriginal foran gefehen baban, Dars fie, bas, gleith anderen in serferben Enge, immerfort

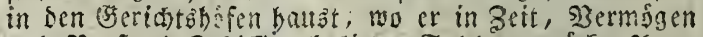

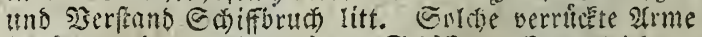
forenten mir zumeilen einem Edifibirrace zu g?cián, ber auf Sen Ganbbanken bon efrobivin ober an ben 


\section{2}

yorgeffeflt morsen maten, mobei idi beutlici bemerête,

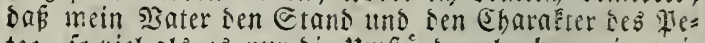
tec, io vier als es nur die tImfténde erlaubien, in mei= nen stugen zut crbjhen fuden molite, fagte er: "2tian, Das ift Der (s) entleman, Der Didn fitntt bes jungen Dums touficie jum 2lovofaten anmebmen wifl."

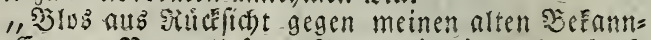
ten, Etteren Sater," fagte Peter mit einch berablaf=

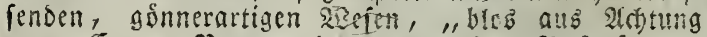
gegen Eueren 2 ater uno megen meiner 2 uienfreund:

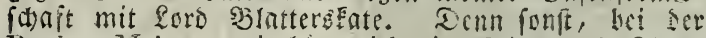
liegiam Majestatem! bitte id eine sEitt = uno Jitsg = Edhrift eingereid)t gegen ben Daniel Dumtouftie, sis:

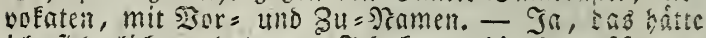

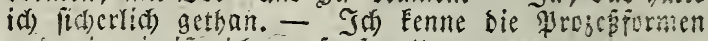

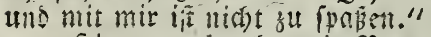

5ier unterbrad mein $23 a t e r$ meinen (Elientent tus erimerte ibn soran, wie viele (E) Wareil, ba er lia) vorgenommen batte, Dem iungen Cont=

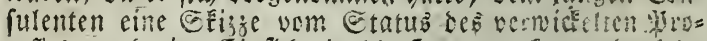

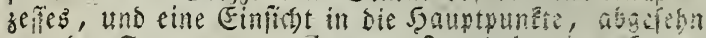
von ben formen, zu geben. "Sit babe einen Eurzen

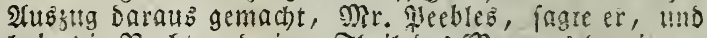

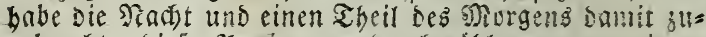
gebradut, bieie Hapiese zu Durchwihlen, um meinem

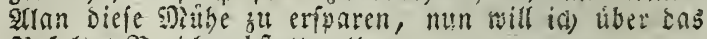
Sicfitlat Siericht abfatten."

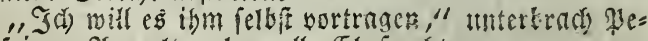
ter feinen alnmalt, obne alle Eyrfurbt.

"stein, feinesivegb," fagte mein šater, "für itht bin id) (Euer Ead)walter."

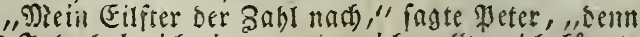
jebeb" Jabr babe id einen netten; ich melle, id tonnte eben fo fid)er teoesmal auf einen neuen Sto te rechnen."

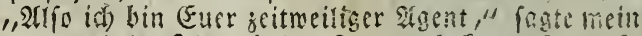

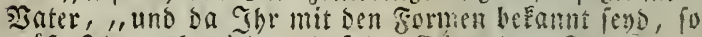

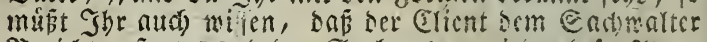
Berint erfattet und ber Eadjualter wieder bem siruo Eaten." 


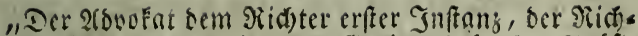

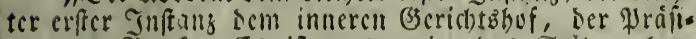

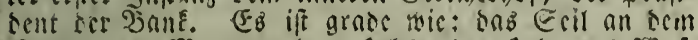

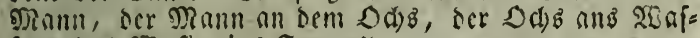
fer, tas ginfler ing Feuer."

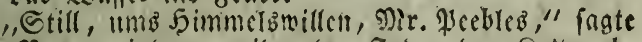
mein Nater, insem or ibm ben Fnocn ber fiette nb= (d)nitt; "Die Seit oringt, wir milien an bie strbit

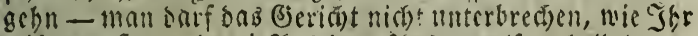
wipt. - $5 \mathrm{~cm}$, bem! 2118 bcm 24183 thy a!fo erkellt" Ebe I6r aufangt," fagte Peter Yechleb, "whire Det Ğbr mir cine Sefálligéteit thun, menn $\Im b r$ mir ein

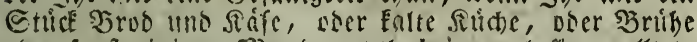
oder fonft cinigen g)?unouorrath bringen lofien molltet; id) habe midh fo febr gecilt, Euren Evobn ju fpredsen, Sถ

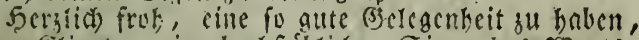

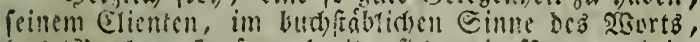

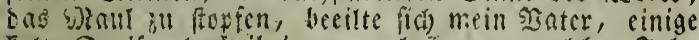
Falte Eveifen berbcibringen z"l roilen, zu melden John 2sitfinfon, Der 5aubebre regen, cine slafae $\mathfrak{b}$ :annt= mein binjufigen mollte, bie er nber, allf cinen ssint

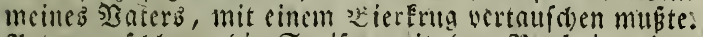
Peter verifblang sic Epeifen mit ber Raubgier cines ausgchungerten- Soiren. Sa mabl aber nabm feine

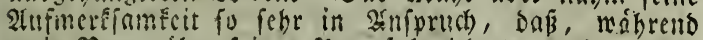

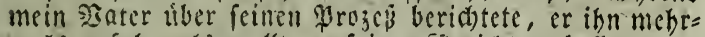
mals anfah, nls wollte er feincen seriot verbeffern, es aber nie uber ficis vermotite, feinem Mitunde bie ange=

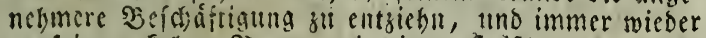

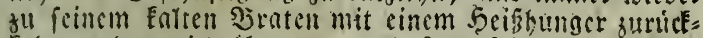
Eebrte, ber mid) tiberzengte, ons er feit vielen כagen feinc fold)e Gelegenheit gefunten baben muste, feinen

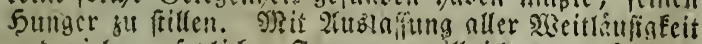
und vicler acfehlictica gormen, will id) es verfudten,

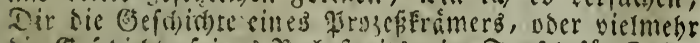

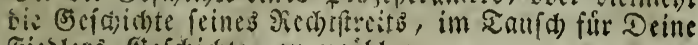

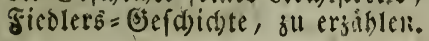




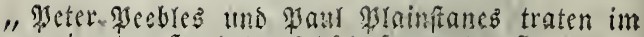

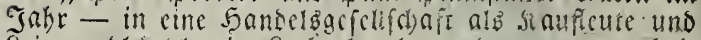

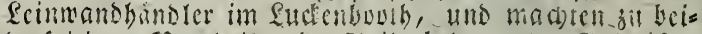

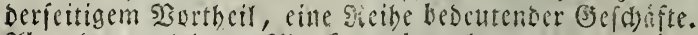

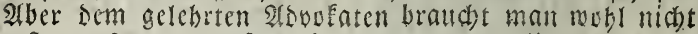
erff zu fagen, bafs societas est maier discordiarum, "affociren fibnt zum prozeffiren." 2(rs fid) nimlidi in Jabr - Dic Sendelegefellowaft mit beiserfeitiger Ein= willigung aupiffete, brod) ber @treif aub, tutb nad mebreren vergebsidyen şerfuben, sie Enche auferge= richtrich beizulegen, warb fie enolids, in mebreren tins

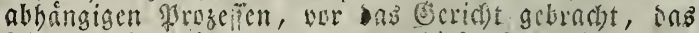

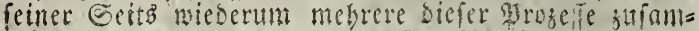

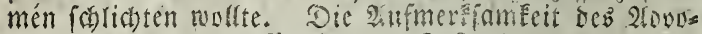
Eaten nut

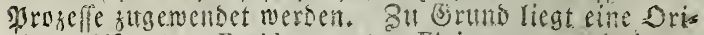
ginal = 2ffte des Pechles contra Flainstanes, wurin $\mathrm{ct}$ siefen wegen der sabung einer Eumme ton 3000 Wfund

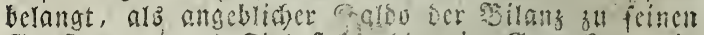

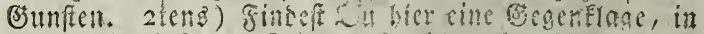

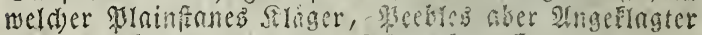

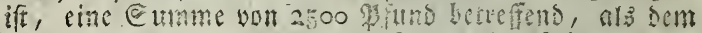

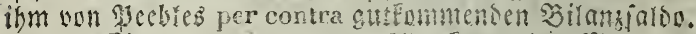

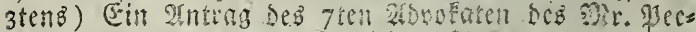

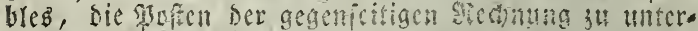
fucten uns bie fur richtig befmocnen spofen genau

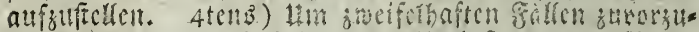

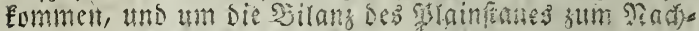

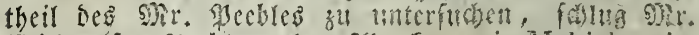

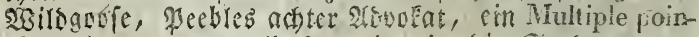
ding *) por, th alle yarteien in die Cacte zu ver wivifeln.

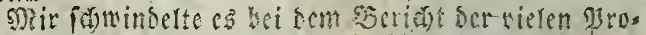

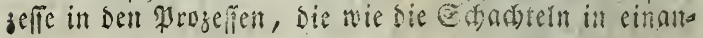

*). Şม פroratorium nenmen. 
Der feeften uns mit selten ich mich) fimmutriă) be Éannt mad)en follte.

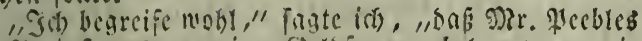
scir piantentes um cine Gelsfonme betangt - wie

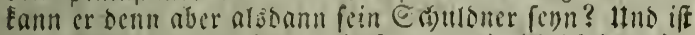

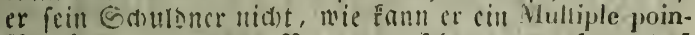
ding forsern, sa bas sicrlangen foun voraubfebt, bap.

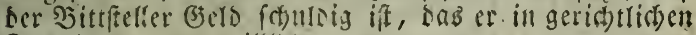
Eerminen jablen twill?"

"Id) glaube, Jor verfteht wenig von ser Eadile, mein Freund," Pagte פRr. Jecbles, i,cin Multiple poin-

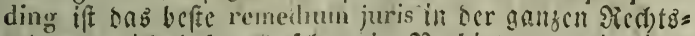
orsmung, id) habe cs ichon in Sicrbinsung mit ciner

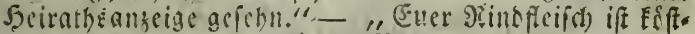
lici), " fagte or zul manem siater, ber unfonft ben

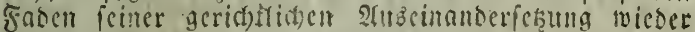
anjuEn!ipfen fudte: " Mur etwas zull frare gefarjen -

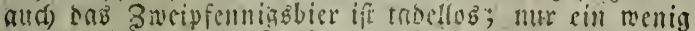

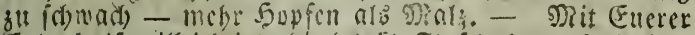

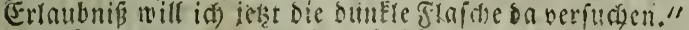

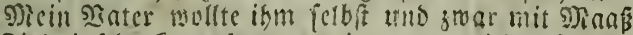
unt Bicl cinf(benten, aber zu meiner unchorichen frente

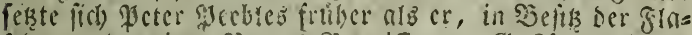

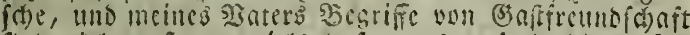

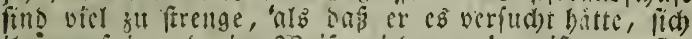

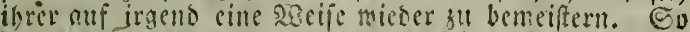
Fehrte Peter tritmphirend wieder zu feincm sif (t) zurtide, sie Seute in ben silauen.

, Es wire befer, ein şeinglas zu nebmen, Mir. Mecbles," lagte mein sater in einem ztreed, tureifensen

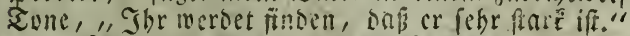

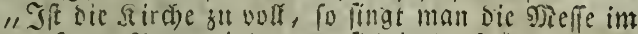

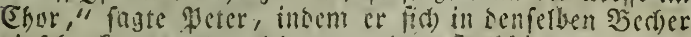

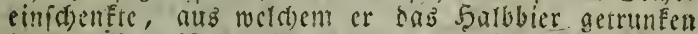
batte. "i2sas if sab, usquebaugh? - \$ranntwein,

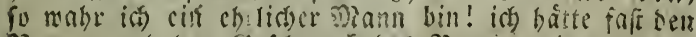
siamen uno ben Geichmad bes Sranntweing vergejs

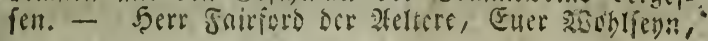




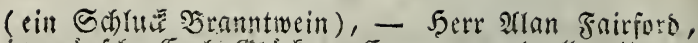

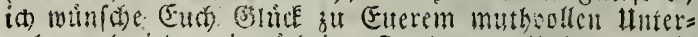
nebmen (nicher ein thidtiger altg). - uno mun, abs

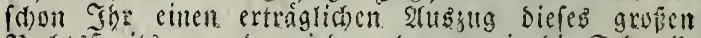
Red)taftrcits, von sem icsar, ber nur ie die Eswefle Der Slüenhalle betrnt, gebont haten muf́, gegeben habt (wieber alif Eucre Eefundbeit als zwifasenbefaseio), fo

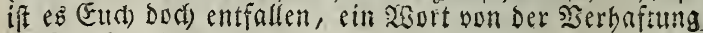
zu fprectien."

"Id walle cben diefengunEt berifhren, Nir. Peebles."

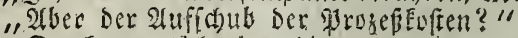

"Da Eomme id eben bin."

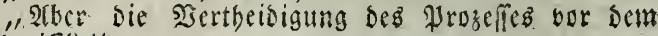
Ed)erif?"

"Da Eomme ich eben bran."

"Ina, wie bie Swees nady Merrofe Esmmt, glaube

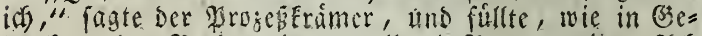

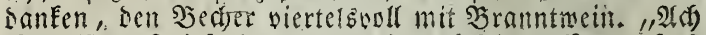
Mr. Stan fairforo, welds' ein glticelidyer Mann fend The Dod), greid beim Seginnen Eutrer Eatiflohn einen sroxen we sen Meinigen, zu fuhren. Er if gewifer=

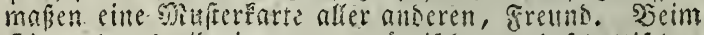

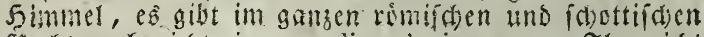
Sied) attch nicht ein remecium juris, toogun Ilyr nicht

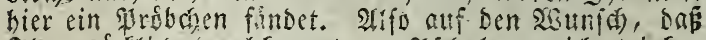

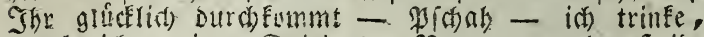
glaube id, reinen Epiritus. Situn, wenn Der Steide allyuftare ift, fo bullen mir inn mit Sier taufen (bier

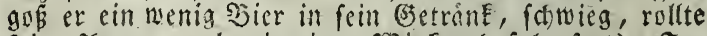
feine 2rugen, gab mir cinen खinể und fuhr fort). Ia, Mr. Fairford - Der Eturm uno 2tngriff, Mir. Fairs ford, als ith oen clenden plainfanes fo lange reizte, biz ex mir faum zwei E chritte wen Jinig Jarls E tos

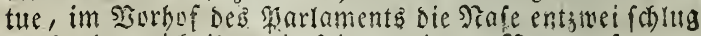
- Da katte iós ibn mit feinem eignen secke gefangen. Denn niemans fonnte mir fagen, wie id) Sen Prozes

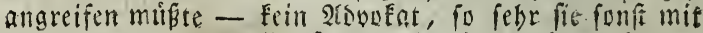
sogins, handeli, mollte lich berablafien, mir zu fagen, 
ob es beffer wire, cine গjitte oner cine Srag = Estrift

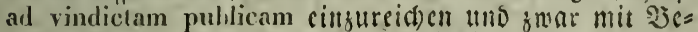
williaung bes Adow faten Er. Miaicfăt, ober mid) nuf sie Etatuten viluer Ed)lágercien pendente lite fut ftutbett, mas mich meinen grozef batte mit einem gine genith

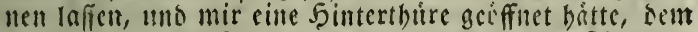
gerichtlid)en Siscraibren zu entgebn. S3cim Simnel,

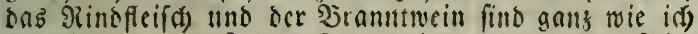

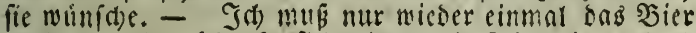
veriud)en (er fochet fid cin menig Sicr cin); tod)

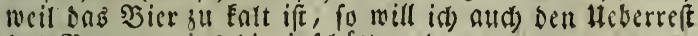

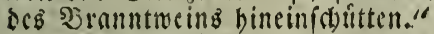

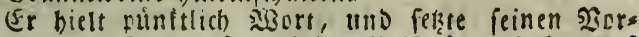
trag attf eine fo lebhafte, hiţige siseife fort, fohtug auf Dell Sich, trank tuno fchnapfte abrechielno, fo Daß

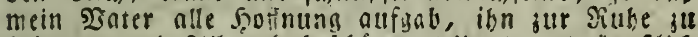
bringen, und frill und befchimt, leideno und ängftlich

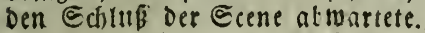

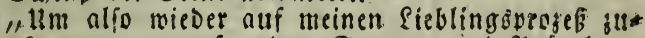

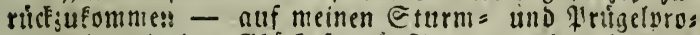
jế, als mir oas (s)tice fo guinftig war, inn fo weit ju reizen, Daf er mir bie vale an Der Ech welle bes serichts entimei fchlug, mas mir gerade fehr gelegen Eam - Mor lieft - Ghe Eennt ibn Dod, Fairfordchen? - Dir alte joje. Peft fagte, ez confftutire eine sers.

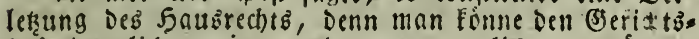
bof eigentlid - in - ei - gent - lich - ware ct mein SEohnhaus. (G) wohne Dort mebr, als fonft an einem Drte, und Der wefentlidfre Thunft einer Jgaws: rechtéberleţung ift, einen s)?ann in feinem 230 ohathate

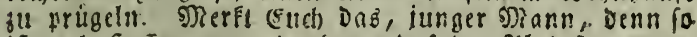
ift noch fyotinting norbanten, Dop ber sillainftanez ges rángt werden fonn, wie fchon niancher andere um ein. Ejeringeres baumlen mutute. Denn glylords - wird Weft zu Den Sidutern ingen, - Miplorss, Die Marlns menteblalle ift '́cebles 2iobnort, fingt er. - Da fie conimune forum ift, uno commune forum est commune

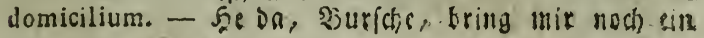




\section{8}

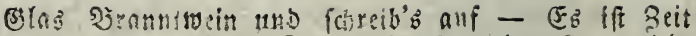

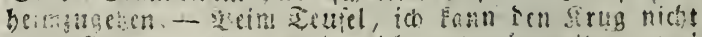

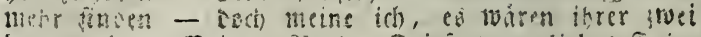

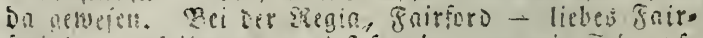

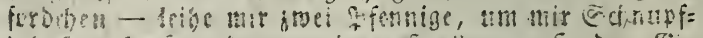

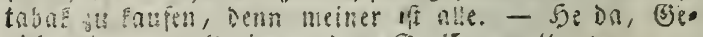
ricitsoiener, ruf cine nnoere Eache nor. "

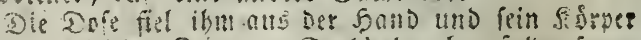

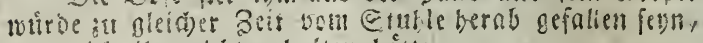
menn ich isn nich t gethalten taitte.

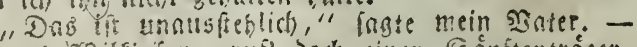

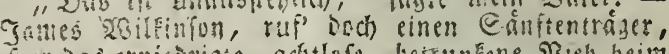

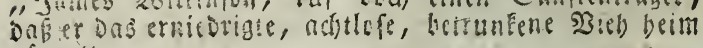
trẩวt.

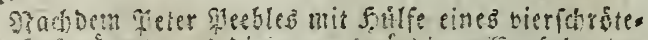

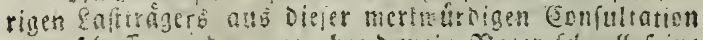

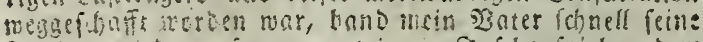
mantere wicese gunmmen, gie ein Safdenftieler, sem

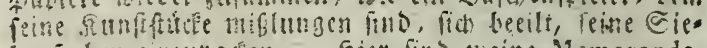
tenfachen eimiapacis. "Jier find Heine Memoranda, gllan," facte et eiliger soseife; , fieh fie forgfáltig Durch, vergleiche fie mit Den stêten, uno arbeite es bis Dien. frang forgfaltig in Deinem ficpfe atrs. Echon manche gute Frede bard fir cin sich oun einem (Elienten gehats

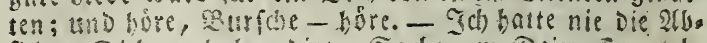
ficht, Dith nach beenvigter Eache um Eeine Exorteln

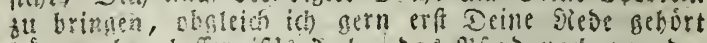

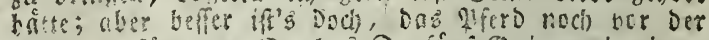
Sieife ot hittern. Sa baft Da funf ettrineen in cinem feibenen Senteldien - es if now eine 2rebeit Feiner

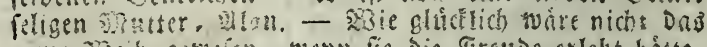
arme siseib gemeren, wern fie die Grende erfebt bonte, ibren ithmfter Gohn Die sumbiteitung tragen zu fehn.

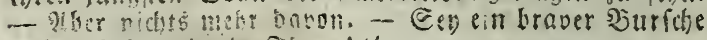

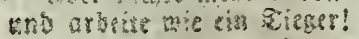

T(i) macite mal on rie atrocit, Farjẹc; benn

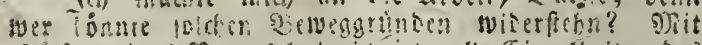

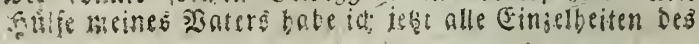


Rechtsftreits inne, fo sersvicfelt fie anth find; und

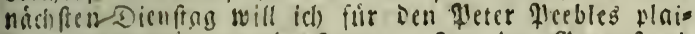
Diren, alb ware or ein 5erjeg. Ta, Der Gegenfiand

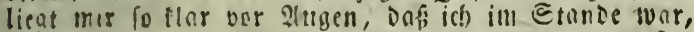
Dir Diefen ersfen jrief jut febreiben, in welchent lich ieineb ber gleser und fein siechteftreit fo fehr einaefchlichen raben, baf in roub! baraus erfeben Eannft, twie fehr fie gegsnuartin meine Beonnfen befdráftigen. 2ulfo noch einmal, bab'2(i)t nuf Dich, Bedente meiner, Der ftets mit gleicher Sreunofchaft ift

\section{Dein \\ Aran Saitforb.}

Einiger llufiante wegen, weldie in ber Tolge e: joihlt werben follen, beritrich eine gernume Beit, ebe iiefer Sorief an Die Alerion gelangen fonnte, fúr bie er beffimut war.

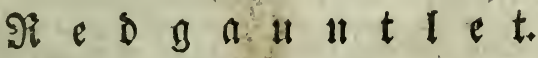

\section{$\longrightarrow$ \\ Exftes sitapitel.}

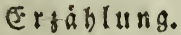

Der Sortheil, ien eš gewabrt, wenn man Dem ecfer vie 2 benthetuer, welche w:r liatten erjihblen muifs fers, in sen 2Sortch ber handelnden glerfonen feloft bor= legt, bat bei nmieren NBerfen sie ה̃riefferm, fo wie fie ron meitraren srofien ectrítfeliern und nuch ron ung in oen rorgeterisen Eanschen angewand wurde, fely in stufnaltise getracht. Sech aber tonn eine folche

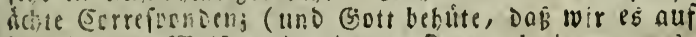
irgend eine SBgeife mit eigenen Smerpolaticuen auss

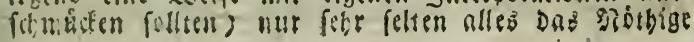


enthalten, baz erforberlich ift, um ben fefer som gen= jen Lattf Der seffohichte ju unterrichten. 2Attch mus oft vorfommen, Das 23 eit(d) weifigfeiten uno 23 iederhos lungen itm 23 echfel Der Briffe Den Lauf Der Erjählung bemmen. Hit Diefes Hebel zu bernteiden, baben einige Siontaphen Die briefe Der betheiligten fierionen, oder

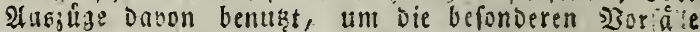
Doer bie Beftible, welche fie begten, zu beritreiben; mábrend fie Diefe gelegentlid) fo mit ihrer (Erjábiung verbanden, Dafi fie den \&auf Der (s)efchichte beforderten.

Eo bewegt fich Der muthige Reifende, Der Den Bji= yfer Deß Mentblane befteigt, leket langfain fort nuf Der tiefen, uneienen Eaneematte, fo Das man fein Fort

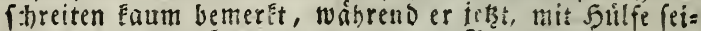
nez 2Alvenftocfes tiber Den trennenden Sergftrom iprinnt, bie bindernde Jiluft tiberfareitet und fo feine Reife be ichleunigt.

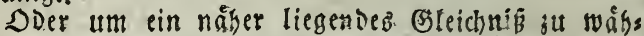

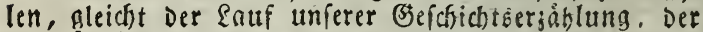
urfprüglichen $\mathfrak{B}$ eftimmang Der Dragoner, Die zu. Wferd

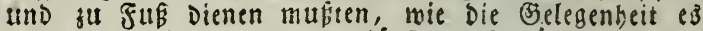
erbeifd)te. Fiach Diefer vorláufifigen Erelárung molten wir es verfuchen, einige $\mathfrak{H}$ mfiánde náber bu belettchten, welche allan Fairford feinem Freunde nicht fchrieb uno nicht fobreiben Fonnte.

2oir glauben, unfer fefer wird fits einen jiemlidi genalten Degriff von Den SauptcharaEteren Der Mleríos nen gebildet baben, welche in Den früberen Bánden bandelnd auftraten. 2Aber im Snall, Daß unfere gtite Deinung voni feiner Beichicélichfeit etras itbertrieben máre, und um Denienigen Esentige z̆u leifien, bie fich

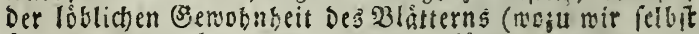
ribrigens fuweilen grobe Neinung ftiblen) ergeben bas ben, indsen Die folgenden náberen Er Élärungen vielo leicht nicht tiberfuiffig renn.

Mr. Gaumbers Fairford, mie man ifn gemofnlich

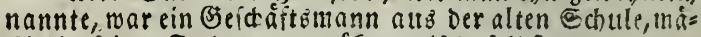
big in feinen Sorderungen, deonomifh). felbfit etwas genalt 
in feitten 2 (usgaben freng rechtlich in Der 2 fusfuthrung feiner eigenen bift áfte tmo Der feiner Elienten, nber burd) eine lange (5: fohrung lelehrt, war er nuch nufo merfiam uno misernuisch bei ben fynolungen feiner Mitmenichen. Z'únftlid, fo nie die (Slocke onn Enint (5) les - cun ubr follug, fab man die runde, reinliche (Bieftalt Des ehrenmerthen alten Syerrn an Der Eed)welle Der (serichtaballe, sDer Dodh mindeftens am fufie ier ich warjen Erepte reinlich) gefleider, in einem rollfom. menen 2 njug oon fitnupftabnfibraunem iach, mit feidenen oder nollenen Eirlimpen, wie Das sisetter eb erlnubte; mit einer Sopfuerricte uno einem fleinen Dreiecḱtgen Soutchen, uit (schuhen, bie fo reinlich ges pukst maren, als rátten sisnrren fellift fie gefchmarst, nit fillernen @d)ubfdnallen mnd einem Etock mit goldenem Jinopfe. Ein פJlmiinfirnup im Eommer, ein 3meig ron. Immergrin im 2 sinter vollendete feine woblbefonnte Sileisung und Öeftalt. Eeine D?anieren ftinmten mit feiner Rleioung ciberein: freng bóntich ano nicht wenig umftánolit. Er war sirdenálteffer

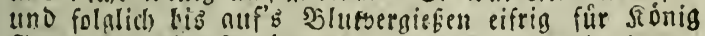
(5) corg und feine Regierung, waE er auch gejeigt batte, on er zu ibrer Ṡertbcisigung Die 230 ffen ergriffen batte. Ater sa er unter ben fartilien beider folitis fchen parteien (slicuten uno Eechajtroerbintungen bat. te, fo mar er febs forgfom, alle Eonbenienz=2usbrtide iu gebrauthen, welrhe Die Griflichfeit feiner Beit fum Eprad)gebrauch fmifchen beiden \$arteien, erfunden bate te. Eg fprato tr mohl jutweilen rom Eheyalier, nie ater vom gr rinjen, wemit er feine eigenen Ertino. fréze nufigeorfert, nuch nicht voin Prátendenten, womit or Die Der 2 nbern beleisigt hatte 2 siederum bejeichnete er die SRebellion mit Der (B) efroide te im 9 abre 1745 , und (prach or von einct glerion, melche darin vermicfelt war, fo war fie ju eines geniffen Perido im feld. Eo war Nir. Fnir. foro im gllgemeinen ein Mann, Der von beiden Sel= ten wohlgelitten uno geachtet war, fo wie eb aucb fer" 


\section{2}

nen Freunber vielleicht feinen firmmer verttrfacht ba=

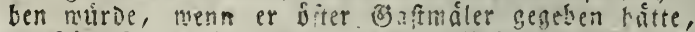
Da fein siefle eine 2tuswabl alser syeine entriclt, mit benen er, jesodi) nur bei feltenen B̈eleaenbeiten, nid) geijin.

Das einjige Sisergnủgen, Das Der gutmúthigenltmo.

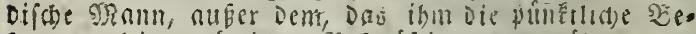
forgung feiner tiggliduch Şefá)áftigung gewábrte. ge.

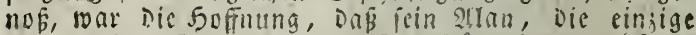

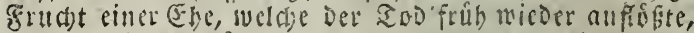

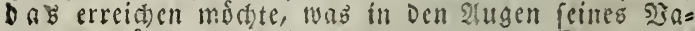

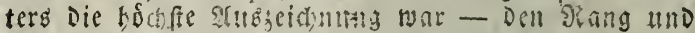
Den Rubm cines praftifan Guriften.

Geder Etand bat feine eigenen כegriffe uon Ehre; (o Gatte nud ter nlte Jairford Die stuficten Des feinigen fo fehr eingejogen, Da: er Dutrd)aus nidts anders in siserth hie!t, nls Das Biel, weldes Der (Ehr= geif feines cigenen Sectlfo ifm Dartot. Fr baitte

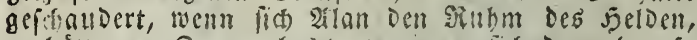
er bitte vor Sorn gefacis, wenit er fich Den elen fo

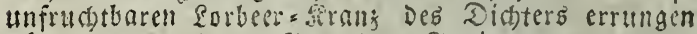

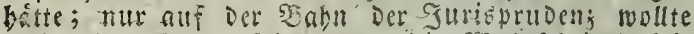

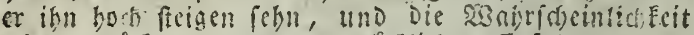
feines glicklition woer ungliteflidien Erfolgs waren

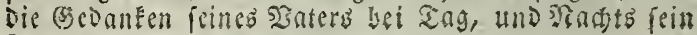
errum.

2tlan Gairforo's s!nlngen und Falente muBten

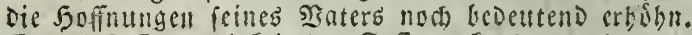
Er befaß - Echnelligreit Der faflungsernft, berbunden mit Der Sermohnbeit eincs anbaltenden, unermúbeten Studiumb, Die vurch Die firenge 3uat im 5aufe feines siaters now erboht ward, Der cr fid , im allige. meinen, mit Dear befen sibilfen unterwarf; er fublte Eeinen aenicifen, nto folde, die mit feines sonters ángfticher Etrenge, mobl befteken Eonnten. $28 \mathrm{enn}$ er nber ia bin athd wiever cinmal an ithgendidjen susgetallen=

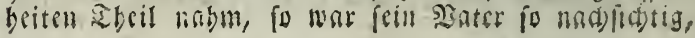


es ift alio nicht sut berwundern, Daf nidst allein ibre

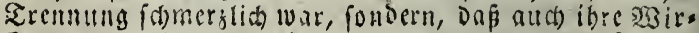
Eungen, verbunven mit ber $\mathfrak{A}$ (ngft, weld)e Dir Snbalt

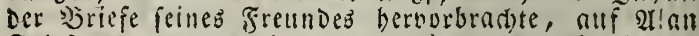
Fairfuro grede Den Eindrute vergriberte, Dem 5j?. Seuns Ders-zuvorfonemen wollte. Der iunge Mrann ging 3 war feinen gewobnlichen Mffichten, feinen Etudien und Den Prufungen Denen er untermoifen warb, nad), aler

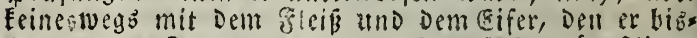
ber an Den Tag gelegt batte, fo Dá fein ángftlicher und nufmerffamer sonter bald mur zu Deulid) fah, baß feil 5er' bei fein ill abwefenden Freunde vertweile.

Ein Philofo h wároe, alf Das pringip bin, Dak ein Extrem fid) felbft auñobt, Und Daß allo ibre vers

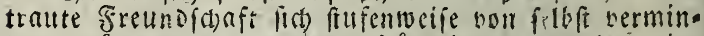
Dern wirbe, wenn man oen Silnglingen erlaubte, eine Seit lang zuflammen zull libeit, Dem Etrom foiner (ses fible Panm gageben baben; Mar. Fairforo aber fals

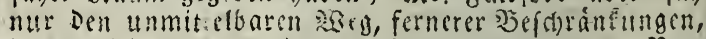
Dear er jebora uner irgend einem antehmuaren פiss wande zu verfollegern fuchen wollte. In Der orngft, Die er onbei entpfano, unterredete er fied mit cinent nlten ĐeE annten, Meter Ertudogrit, mit Dem Der \&efer

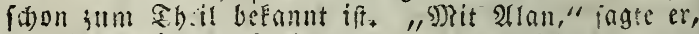
, werbe is immer follimmer; er ermarte deden arugen=

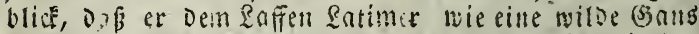

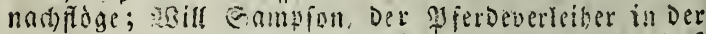

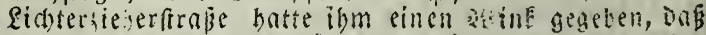

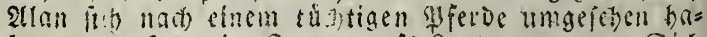
be, un allf wenige Sagen alfiz Lant zll gen. Eid

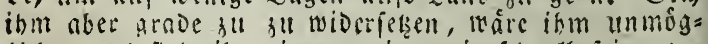
li.t) - es ficle ibm immer ein, wie folnell peine ar= me metter weggerafft worden wáre. - wablte bott $i \cdot h$ fonte ifn in iggens ein Gef aft servidfeln, es

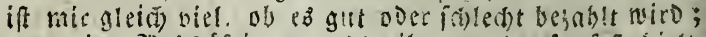

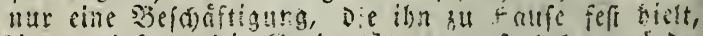

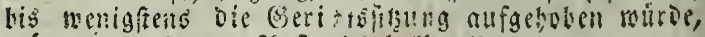

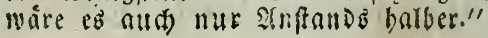


Feter Drulogeit frimunte volffommen mit ifm úber=

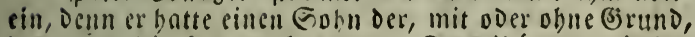
Durdaü Die Eurßen, bard)enten E(t)rcibámel mit Der blauen Iacke, mit sucißßn du uff triagen vertnufchen wollte; er gab ibm alio Den (s)edanfell eill, unferell Freund

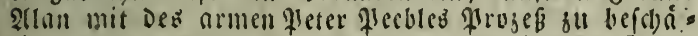

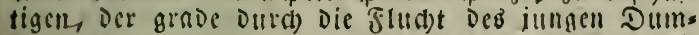
touftie z"t bergeben war, nubsi man zu gleicher Beit

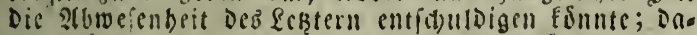
mit witroe man, wie DrHogrit fich nแsorickte, 1, 3wet DrúcËn mit einem Echlng toot fohlagen."

mit Dicfer Erefartung wiro Der Sefer mohl cincn Mann, Ber wie Der nlte Fairford, mit $\mathfrak{B}$ erfano uno Erfabrung begabt tuar, yon oer gewngten, Ingeduls o gen semalerbe frifpreshen, mit welcher cin sinnbe eineh jungen 5ुund in einen tiefen Şrunnen wirft,

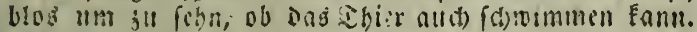
Eo riel 3utraucn er aud in Die, wir filit) bedeltenden,

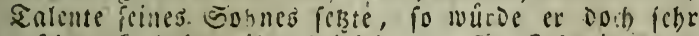
gefidwanft haben, ibm bei feinem-erften Erjtheinen ror Den ËbranEen, Die Pflitht anfuerlegen, einen vars micelten und f(t)wierigen Recttoftecit ill vertbcioigen, wenn es ibm nid)t Das witfinale MRittel geidienen baitte, Den iungeit Deann von cinem Sa)ritt abjubals ten, der ihm, beim exfen sintritt feines sohnes im Eeben, nad) feiner Denteart, alo bodjif verderblici) fite nen muEte.

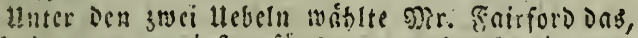
weldes cr am nenigften fürdtete; uno we ein taps

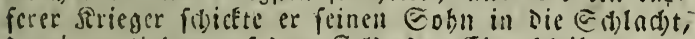
Damit er lieber auf Dem Felo Der Ebere bleiben, aló ebrlog feine fabne verlaffen mochte. alber er libers lię ibn aucb) feineswegs feiner eigenen ₹hatfraft, ohne

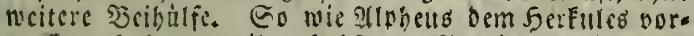

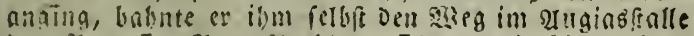

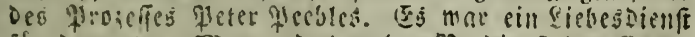

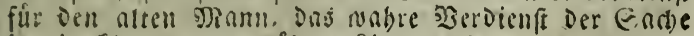
in sin Elates, ungetrubtes Lid)t fu f(r)en, Da es Durd) 


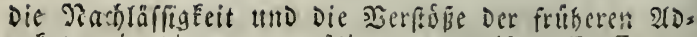
voEnten in eine unermeñlidue, (b)atifache gande un= verfándidaer siunfausoride vermiart worden mar.

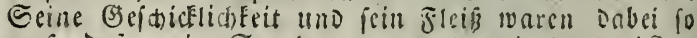

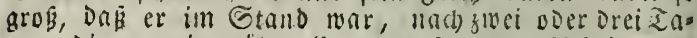
gen, Die er mit mübevoller, engeffrengter sirbeit ver. bracht batte, Dem jungen 200voFaten De Souptfacta

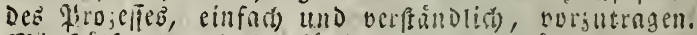

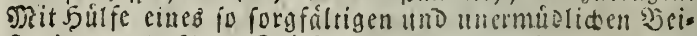

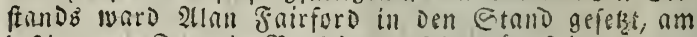

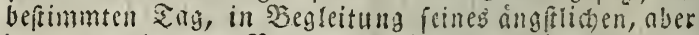

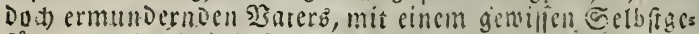

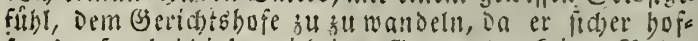
fen Durfe, bei Diefer widtigen Eselegenbent Eeinen Sinbm sll verlievert.

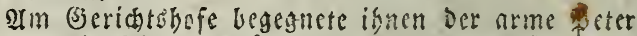
Pcebles mit feiner gewdontidfen Diden pletrüde und feinem beroorragenven Sylt. Er ergriff finen jungen

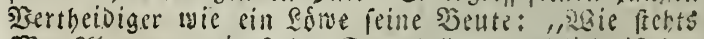

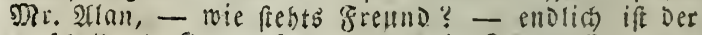
entfocidende ₹ag gefontmen - ein ₹ng, ocfen lange nod) gevadyt werden wird in Diefem Saufe. - Der arme geter greebles gegen gilainfanes - alle pros zeffe zuframmen - in Plenum zu entid)eiden - po beist

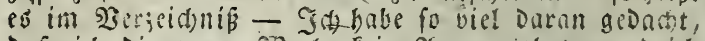
bos ich Die ganje saspd) Eein stuge zuthat, tuno ing tyette Darnuf, es ift Dem Lord 3 ráfidenten eben fo ge

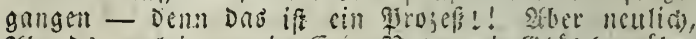

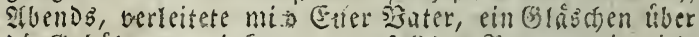
Die Gebubr zu trinEen; man foll Den Šramenein nidit

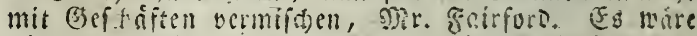

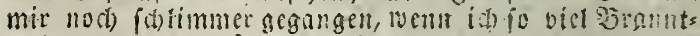

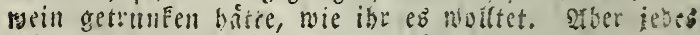
Fing bat feine seit, und shr follt mit mir ju गुits

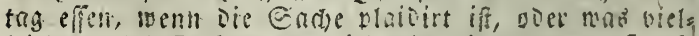
Ieidit nod) beffer fenn mag, id will mit End nad) Eanfe beben uno Dann babe id) nidsts gegen cin (O) láscben 


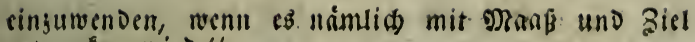
oetrunfen wird."

Der alte Snirford sudfte bie Gdultern, cilte bi feinem Elienten roriber, fab fänen Eobu nit Dem fd) wars fen Mantel hefleiden, Dir in feinen 2ingen ebraursis ger war, als Der Chotrock Des Ersbiftiofs, mind Eonnte fid nimt enthalten, ibm freundida anf Die. Edulter sul Flopfits, inocm or ibm ins obr fuifierte: "Fafie

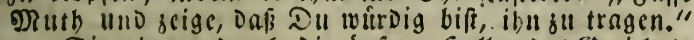

Eie gingen Durd) Die áubern fallest Des Gerintses bof $\$$ (wo einft sie $\mathfrak{B}$ erfanmilungen Des alten ictottifasen Parlanenteb waren) Das wie 23 eftminfter= Sall in Eng= tand, sugleich) fum 20 orplate Deb innern 5aufes, wie

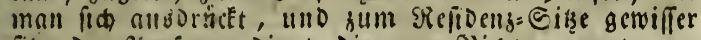
fikendocn getfonen Dient, Die man Siicterer nennt.

Dent erfen Theil Des Diorgenz. benukge Der alte Faiiforo Daju Dcm Alan feine Infruftionen fut wies Deibolen und von Eincm jum sindern zu ranfen, um,

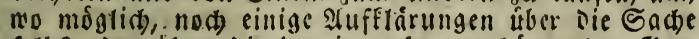
felbft oder itber die Damit jufammenhangenoen Pros selie zut erkalten. 2ánbreno Dieier 3 cit bielt fich Der arme Peter \$eebles, DefTen olnehin fduad)es Esebirn nun ganz unfábig war, Dic 2Bidgtigéeit Deś Nomente gil ertrngen, fa nabe an frinen iungell arowo Faten, wie Der Gedatten am fiorper ; bafo foien er istit zu fpres ben, balo ibm ins Dbr zu fúftern, iek̨t $1 \mathrm{~m}$ seg ein

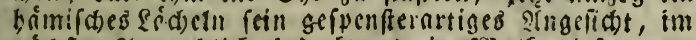

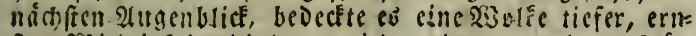
fter $233 i d b l i g f e i t$, Die Dann wied cr einem ;ornigen, fpdts

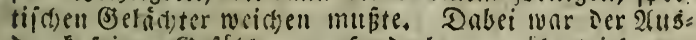

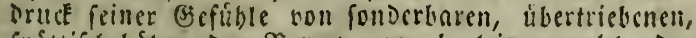

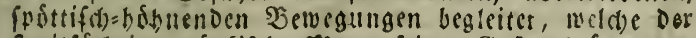

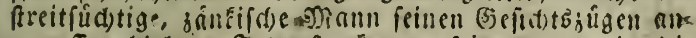

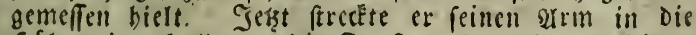
Sobe, ictit ballte er Die zallft, alo mollte er feinen હicgner jul Boden werfen. Sndiefem siugenblick legte

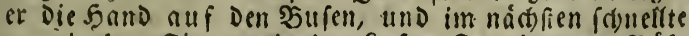
er mit Den Singern in ser \&uft. Den iungen গúf: m. Ecot's $23 \mathrm{erk}, \mathrm{XV}$ i. 
figgingern in Der 5alle, entginaen weder Dicie Eräf=

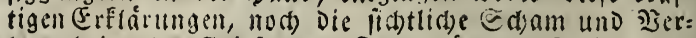
legenbsit Drlan zatrfords. Zlwar naberten fie lich Dem

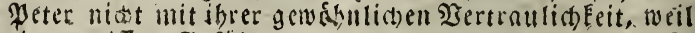
ein getwilfez Befithl Der aldtung - gegen Fairford fie

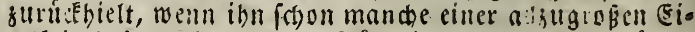

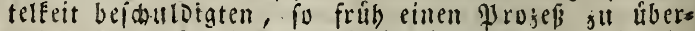
nehmen, Der fo viele @dtwierigfeiten Darbot, wie Dies

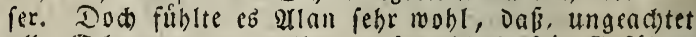
aller şbonung gegen ibn, er fowohl als fein (Sefabrte Die Bielfọcibe der 3ibizivolte und ves bieláchters fen,

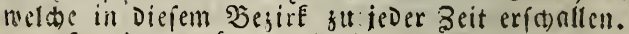

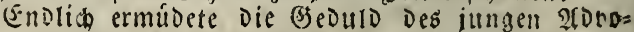

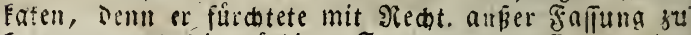
Fommen, uns Die nothigen Facta zu vergelien. Wilan fagte alfo feinem $\mathfrak{B a t e r}$ grade zu, Dake, ivenn er nidat von Der perfüntiden Segenmart uno von Den Einflis: ftertungen feines Elienten erlogigt wolirde, or Eur; ab feon múte und auber Stand fer, Den Prozeß̄ zu fúbren. "Still, fitll, mein theuerfter alan," fagte Der ab te Bientleman, Dem bei Der $33 a b l$ Der Serftand fill frono, "befúmmere Did) nitht um die milifigen $2 a u g e=$

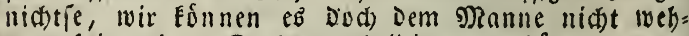
ren, feine eigene Gade vertbeidigen zu horen, went es foon nidft ganj ridtig in feinem sopfe ift."

"Bei meinem Qeben, Gir," erwiederte arlan, "in bin unfáhig hervorzutreten - er veríd)euds)t alle (Ers

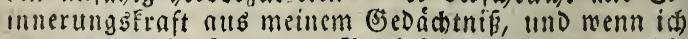
es wage, ernfthaft bon oen פeleidigungen zu reben, bie er erouldete thid von ber Lage, in Die ex berferst iff, Eann iá) Dann etwaz anderes ermarten, als baí die. (5) eftalt Dicfes Sobolts alles in's fácherlide zieben wiro."

"5: ift etwab গạhres Daran," fagte Gnunderg. Fintrord, indem er cinen Sblick auf Den armen lleter warf, lno Dann forglich feinen Finger unter Die Borf

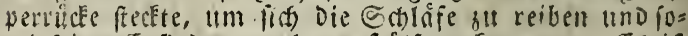

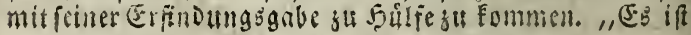


freilid) Eeine (5eralt, Die man obne fadth vor Den Edjranfen fieben febra Eann; aber wie foll man ihn los iwer= Den? Jhm verninftig zujurcoen, swiro am wisenigften

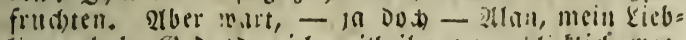
ling, babe Esedulo, id will ibll augenblidfidj $1 \mathrm{reg}=$ (d) afin.".

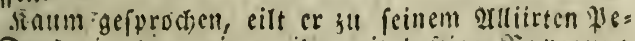
ter Drudgeit, Der, mie er inu mit beftiger bejechung uno mit jorglidsen glienen nuf fich jufummin lebt, die Fedir binter das Obr fteckt, und frágt: "213as treibt Eud ju mir, Mir. Saunders" - Jeblt's ir gento mo:?"

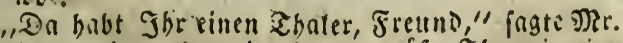
Enunders, ickęt ooer nie, Heter, múst Sor mir eine (S)éálligFeit erjeigen. Da, Euer Dzamenşuctter Deter

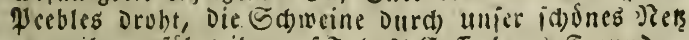
zut treiben; fitb)t ibn auf Jobn's Eaffichaus, Jreund lejt ifm Dort ein Drittagoldnápschen geben uno bals tet ibn Dort, betrunfen oocr nitdtern, fo lange auf, biz oie (3)erict)tolikung vorúber ift."

"(Senus Bgefagt," ipred) Deter Drugeit, Dem Der Intheil, Den or an Dem (sefodifte nebmen follte, nidat miffiel. "Id) will thun mie Shr gefagt babt."

Der "2Abrede gemáß, fab man balo onrauf den

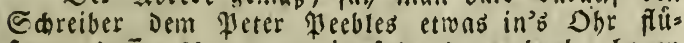
ftern, Deiten almiworten in folgenden, abgebrochenen Ēáţen horbar wuroen:

,Den B̈erid)tahof an Diefem gropen Urtheilstag berlaffen? - nein, iđ gewiß̈ nid)t - Ei, was iagt

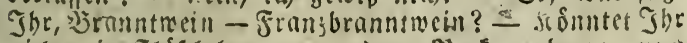

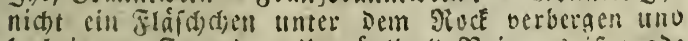

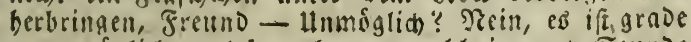
ou unmiglich, aud) braudft man wohr eine gute Stunde Daju bis die yeten und Die Bejerate alie abxelefen lino; id gehe alio in botte Namen mit, freitiog

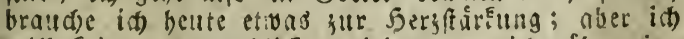
mill Eeinen Qutgenbrick berjieben - nidist aber eine 
Ninute - will nidt mobr alb cin Gadppden trint= Een."

Einige Minuten Darauf fah man Die beiden Peter

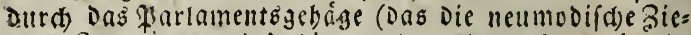
rerci Square nennt), Dahin wradoern, Der triumphirende ₹ruogeit, inoem er ben willenloien peebleg gefangen fout fübrte; fo Dase feine Süpe firt Dem Sornuntmein= Inocn naberten, wábreno feille stugen auf Dem (j)erichts" hof verweitten. Eie. veridyanden im (jemuble son John's (saffechaus, Das frúher Der Lieblingsaufentbalt Des claffifden und genialen Lir. Platenirn war, uno für ifkt wurien lie nidht mebre gefebn.

allan Sarford Eonnte num, Da er van feinem $P l a=$

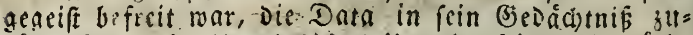
rúcérufen., Die ibm bei oer Unrube feines Đemutba

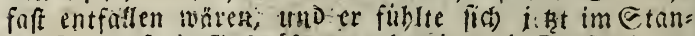
D.e, fid) nuf cin ङefthaft bor Doer פRíblingen einenbebentenden Einfluí nuf fein

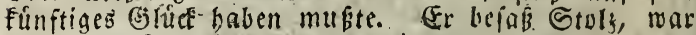

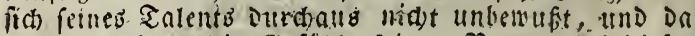
er nod) zudem Die (5)efüble feines Finters bei bicfer (S)elegenbeit Fonnte, fo pornte es inn jum bod)fen (Fi= fer an. Itno úber sttes, beiaß er icte Eelbftbeterr=

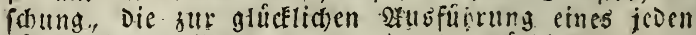
Eúbnen unte:nebmens unumganglid) nơthig iff, war won iener fieberbaften. Serijbarket frei, Durd) mel=

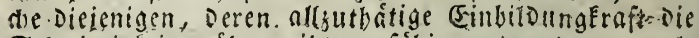
(Sd) wierig eiten úbertreibt, unfribig neten, Demen, wel=

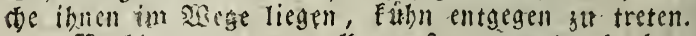
Fingoem er mun nafe jeaftrette uno algebro= dene gegenftanie nieder griamment tho verbunden

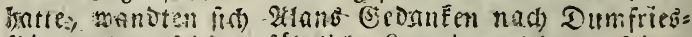
fhite und aup Die gefábrlibe enge in melcter er feinen

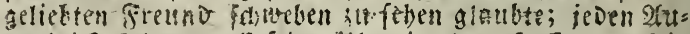

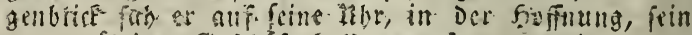

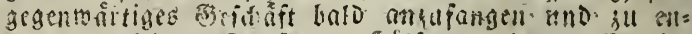

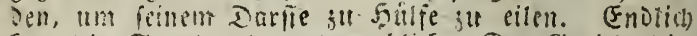

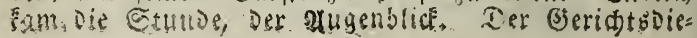


ther faric aus wollem Salfe: "Ter arme Peler Peebles contra Plainstanes, per Dumtoustive ef Tough: - Serr Danier Dumtoufric!" alber Dumtouftie reiftete Dent शrufur Eeine folge, benn fo laut und figallend er aud ertonte, fo Eonnte er ond nid)t úber bie Queensferry (bie furt ber fionigin) oringen; aber an feiner Etelle trat tnier Soer Alan Fairfurd vor.

De: (Scrisht3bof war georingt noll mit 3ufd)auen. alfer 2 rt ; benn bei friberen BJelegenbeiten batte es al= len viel Bergnugen gewahhrt, wenn. Peter neben feinem Nertbeioiger ftebeno, belien Borte mit Mrienen uno 2tublcgungen begleitete, uno, indem cr ben Ernft ber

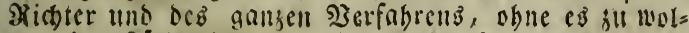

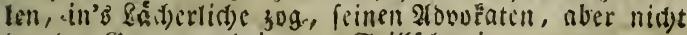
den ber (3) aenpartbei, zum Etillid)wcigen jivang.

Die Silit)ter uns Subjorer fibienen von ser jugenos liden B̈efta!t des iungen Mannes fehr uiberiajd)t, ber an Dumtoulisie's Etelle erid)ien, um cinen verwidelten, feit langen Jabren anbingigen Prozep za ereffuen; ier Pobel aber fand fid) in feinen (Erwartungen getauld)t, ta Peter ber Elient, ber Folidinell ber erwarteten Unterbaltung, feblte. SRit fretunlidsen Slicken faben

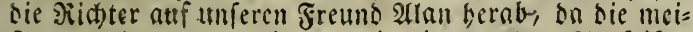
ften, mebr ober weniger, mit eincm alten Praftifus 'vie fein Sater, befannt toaren, uno meil fie fämmt=

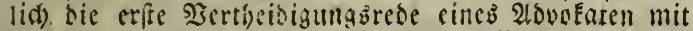
derfelben Jemogenbeit aufmebmen mollten, bie sas Unterbatis ber Sungferntese feiner netten Mitglieber

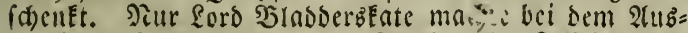

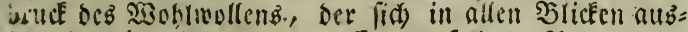
(wrad), eine Ausnabme. (Er warf bem allan unter feinen langen, sliftern, grauen 2lugenbraunen Slitfe ju, als bitte lid) ber iunge Red)togelebrte bic (Ebre, sie feinem s?effen jugebacht mar, angemafit, fritt jeis nen Fibler zu bededen; unt, aus sefublen, die Er. Serrlid)Eeit nid)t eben febr zur (5hre gereid)ten, wtinjote er, bá̄ bem iungen glanne bie Sad)e nid)t gelingen módte, bic fein Serwanster im Etiog gelajicn batte. 
2ber Sorb Slaborbate felbft Fonnte ber verninf=

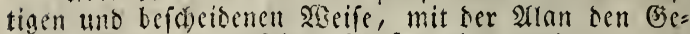
rid)tbbof antcoete, feinen SEeifall nidht verjagen; ier junge sovofat fing romit an, fein fúbnes unternebmen nit tem wlö!chen ErEranfen feines gelebrten Eollegen su entfouloigen, fur sen, mie er fagte, bie Einleitung cinc fo fajwierigen uno widtigen SRedbrgftreitb viel an= geme fener genefen wáre. Son fid) felb(t (prad) er, nie er war, won ocm jungen Dumturftie, wie er britte fenn folfu, serweilte aber bei feinem diejer begenfance langer, als es freng neithig wur. Co mic er rescte, nurest nath uno nad) die blicke deb alten Richters noblwollender; fcincm familienforls mar ein Benfige geleifiet worden, und on ifm bie Şefdeibenbeit und bie Giffichfeit tes jungen Nannes, ben er fur jubringlich ino anmasend gebalten batte, gleidi) moblgefiel, fo bers mantelte fid ser linwille, ber fid in feinen Stigen ausgefpredien batte, in Den afusoruck ber vollfommers

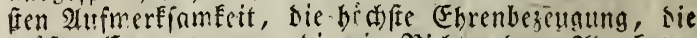
grifte (Ermunterung, bie ein Richter Dem ADopenten erzeigen Fann, ser inn anrebet.

Sradjecm es arfo fem jungen Rechtsagelebrten geo

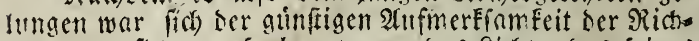

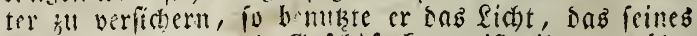
Sinters Helung und उefwaftäenntnife ibm-aewihrt katte, uno fing mit einer, von einem manne feines ars ters unermarteten, Gemand theit uns s? larbeit an, tem Tedhtsfereit fel! nlle perwidelten formlid feiten $a b=$ zllfoneren, mit senen er liberlasen nar; fo wie ein sounsars ben sicrbent berunterreibt, ber in File urn eine silune gelegt wurbe, $1 \mathrm{~m}$ num secundum artem feine focilung anzuftelen. Entblobt won sen serwickels ten Siedtiburmen, meld)e ber fartnáckige (Figenfinn te? Elienten, bie unbefonnene Eile ober sie Unmiffenbeit

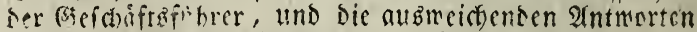
cines binter!iftigen (jegners angeboiuft batten, nar on und fur firh sie ead)e des armen Peter Peebles aar

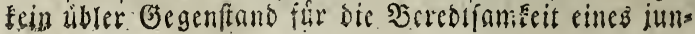


gen 2ronofaten, und fo serfeblte nud unier frcund âran nid)t, bei fen Ettikzpuften fein Desmertalcut ju zeigen..

Er ficllte feinen Glienten-alB einen einfad)en, chrs lidjen, woblmeinenten giann bar; ser wibrend ciner

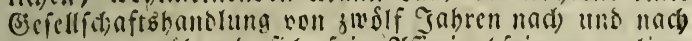

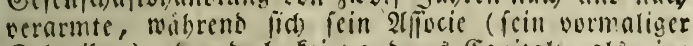
(edreiber), ser sod) Ecin anseres. (Espital, als eine

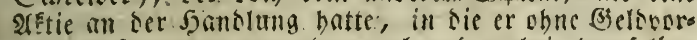

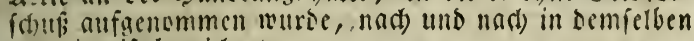
Sicibituis bereidyerte.

"Thre Sierbinding " pagte 2tan, unt sas Bilb maro" mit einigem Seifall nufgenonmen, "glid) ter alten (sefdsid)te non bem $\mathfrak{A}(p f e l$, Der mit cincm Diefier zerid)nitten wurde, tas nur auf ciner Ecite vergiftet wor, fo Daß ber, dem ter vergiftete Theil angeboten

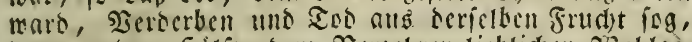

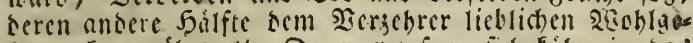
(d) maté gewabrte.". Dann waf er lid) Eubn in tas mare mignum ier ftreitigen Pied)nungen; perfelgte je=

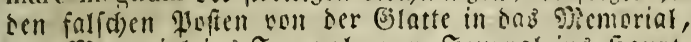
rom Memerial ins glurnal, vom Gournal ins 5aupto buá); veralid bie Eunftrich eingejdobenen uno linters

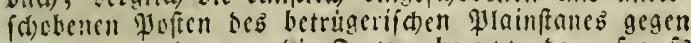
cimanber, uno gegen rie Jacta; benupite sarallf aufs

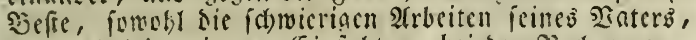
als aud feine eigenen (Eimid)ten, bei ben Riedrnungen,

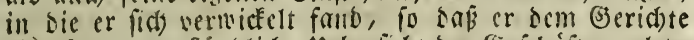

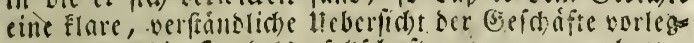

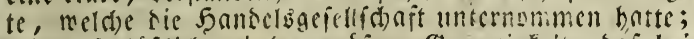

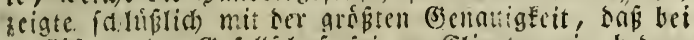

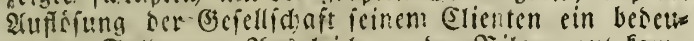

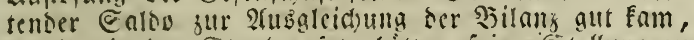
ber inn in sen Etant mejebt hitte, leine Eteflung zu ber hiraerlichen (s) efellid)aft a!s ein unabbingiaer, bes

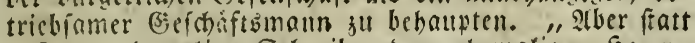

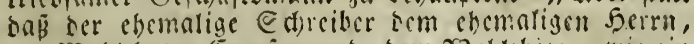
Der wobltbaten Empfangente bem Sobblthiter, wie cin 
chrlid)er 5ann bem antoren freiwillig bas bitte geben iolfen, was ikm aebribrte, marb fein unglucklider Elient in sie TotbmendizEeit werfert, feinen gegentwar = tigen Edursner, feinen vormaligen E(t)reiber, von einem (berid)te zum auteren zll verfolgen; feinen gered)= teften 2nipriaden murben fadin erondite, aber unge= grindete (segenaniprliose entgegengefełt, fo fonelf uno oft wie cin Sarlefin feine ummanolungen bewerffel= ligt, fah man feinen begenpart bals flagend, bals ber= theitigent. Golange, io vielfad berumgezugen, ber=

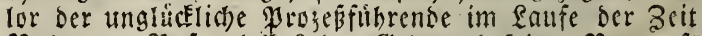

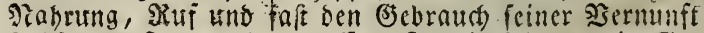

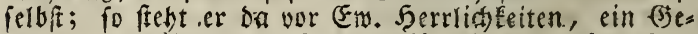
gentans uniberlegten Eputtes für bie Gebanfentufen,

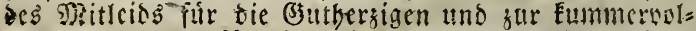
Ien betrad)tung fuir einen teden, ber bedenft, dẫ in

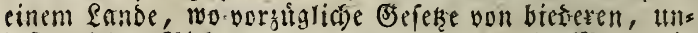

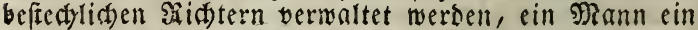
fait unbeftreitbarez stutbaben burch alle formen und

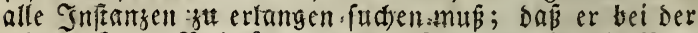

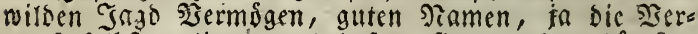
nunft felbif verliert, und bne er fid) nun tem bodfiten

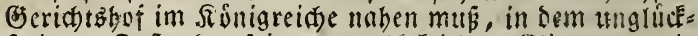
ferigen Surfanse feines unglúcklid)en Elienten, cin Opfer verweigerter ofer verzogetter Bered)tigeit, tmo mit bem Esfúble ber fd)wantenden fyofinung, bie tas Serz zu פoben srúckt."

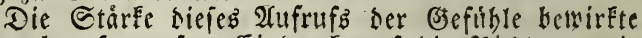
cimen eben fo gropen Einstude auf bie Richter, reie bie Jlarbeit det weife war yeters abgefamadte Eeftalt mit feimer

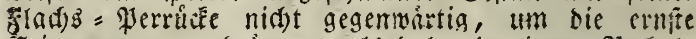

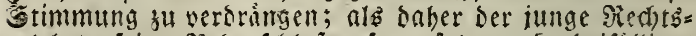

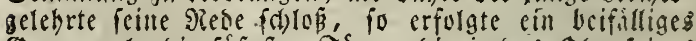

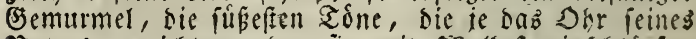
3aters erreidten, Der ite mit sisollufit cinidyltirfte.

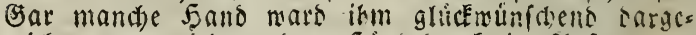

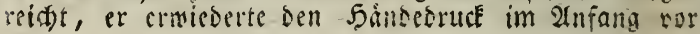




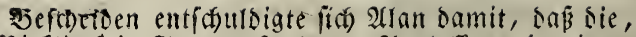

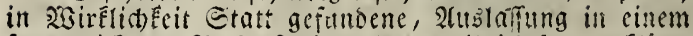

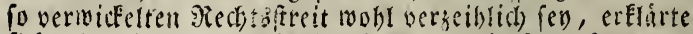
fick aber im $\mathfrak{A} u g e n b l i c k$ bereit bazu, sie Eurreiponben; zu unterfuchen uns zu beveifen, báp lie ber form und bem Tnbalte nad), vollig mit ben S(nfid)ten von ber

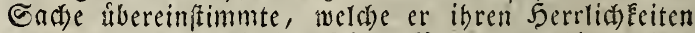
vorgclegt babe. Er bat feinen sater, ber hinter ihm \{ẩ, inm von Beit zu. Beit Die \$riefe in Der Reibenfoise einzlthandigen, in ber er fie vorlefen und erflaren wolfte:

श3abrfdeinlid) war es bie 2!bfid)t des alten 2(ones Eaten ₹ough, bie soirtung ber Jebe Des jungen Suri=

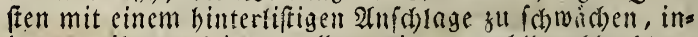
bem er ifn verleiten wollte, einem wohldurboditen, Elaren und vollfunoigen Jortrag einen eiligen 2anbang

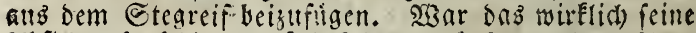

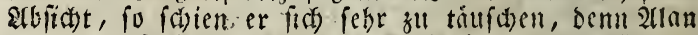
war barauf eben fo gut, wie auf bie anderen Geaens ftinde des Prozejes vorbereitet und begann feine sers theibigungarebe bon sieucm mit fo viel febhaftigfeit,

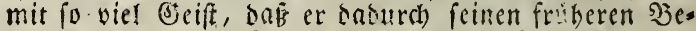
bauptungen nod) grofieres (sevid)t gab; io Daf ber alte (5entleman es mabrfacinlich bereut baben wittoe, ifm

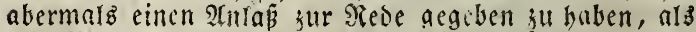

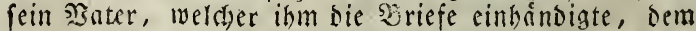
jungen Siertbeisiger eill Sareiben in sie Sanb gab, bas einen fonderbaren Einorud auf ben abvokaten zu mad)en (d)ien.

Er fab nuf ben erften Şrick, bafi ber Şrief fich in feine: Sinfiat auf Meter Peebles Prozes bezog, aber

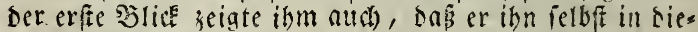
fem $\mathfrak{A}$ ugenblide uns in Eesenwart ber saititer lefen muife; bei Şeendigung befferben fojen er aanz autier

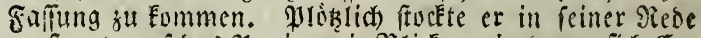
- farrte auf das \$papier mit Şliden, in Denen fid (Ers ftaunen und Enticken fpiegelte - ftiế ein B̈eidicei nus, warf Den Srief, ben er it Sanden bielt, fur Erbe und 
entfoh aus bem Eanle, ohne ein einjiges 230 rt auf Die Frasen zu asitmorten, mit benen man ihn von al.

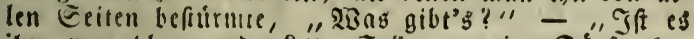
ibm unmobl aemoroen?" "Eoll man eine Eánfte bos len?" t1. r. m.

Der álsere gairford, ber fiken blieb, uno bemufits los vor lich bin frarrte, alo - máre er von. Etrin, fam endlich Durch Die ángftlichen Rachfragen ber sRichter uni Der Adnofaten nach. Der Befunohest feine Enbe nes, wieder itl fich felbft. Da-erhob er lich mit eis ner niene, in relcher fich die tiefe fechachtung frie= gelte, bie er beun (sieridate ju erjeigen gemohnt war,

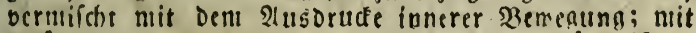

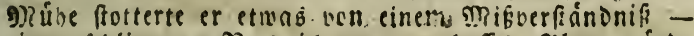
ciner fchlimmen शadrict) - er boffe, 2lan múrde fich mo:aen-mieder moll befinden. Dann ner, unfá. bia fortiufatren, fallug er-sie fránbe zufammen, und mit Dem Itusrufe: " Mein Eohn, mein Eohn!" ver-

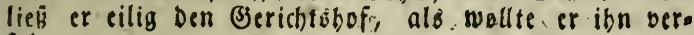
folgen.

" $28 \cap$ gibt' ছutrichen," fagte ein fecharfïnniger, metapbyilicher Richter. "Eg ift Doch eine verimeifelte Eadse, Blabe

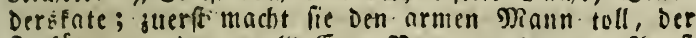
fie fúbrt - Dann gekt Euer $\mathfrak{B}$ etter nus purer 2 angft allf und bavan - Darauf bringt fie den iunaen, hoff nunašnollen Mann vor lauter Etmbinm an'z llebers f́chnarven, mie-ich alaube - turin nun miro gar oes nlte Saundars finirforo fo mondiuthtia, mie einer von Qullen. 2Bas fagt The itl ber faubern. (Seirhichte?"

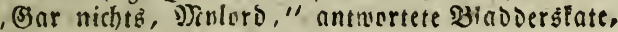
Der biel zu iehr on Den formen bing; als bâk er Dell poetifchen Echmung, Den rein Eollege manchmal nahm, bemundert háte - "Sch fage gar nichts, und bitte nur ten Simmel, Daß́ er unż den eigenen Derftano lâs fen mige.

"2lmen, amen," antmortete fein gelebrter Mits bruber; Denn einige von uns baben obnebin wenis zu berlieren:" 
Det Gerichtoritof bob Die Siking auf, und Dia Subirer zerfitetten ficb, Das. Salent betwunderns, Das Alan Fairford hei feinent erfien Erfecheinen in einer io fchnierigen und vernickelten Eadie an Den Fag gelegt hatte, aber illoem fie jugleich) bundert verfechiedenartige

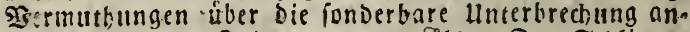
frellten, Die fenen Eriumphtng ammolfte. Daz. Schliamfte bei Der Sache aber nar, one fechs girsjefítrende, die

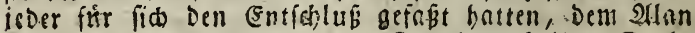
beim Sernug̈geben nus Dem Berichtibgf ibre Eache enjubertrauten, Fopffscuttelnd Das Eselo mieder in Die

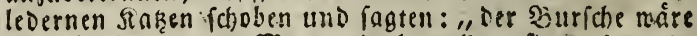
freilich ein ganjer Mann, roch wollten fie noch mehs von-ibst pebell, ege: fie fich in Beideáftsoerbinoungen mit ibm einlief́en - ithnen gefiele Das Sortipringen, wie ein Glob oom Settuch, nicht."

ริ weite. Siapite?.

פ্Benn unfer Freund, alexander Fairford, bie Folgen norausigefeben bätte, melche Die plobliche Flluest reines Eohnesy die wir am Ente des rerigen statitels ermáhnten, nach fich $30 \mathrm{~g}$, fo biatte leicht die 9hrophes jelung Des nexfrándigen alten Richter in Erfúllung geben, und er um feinen Serftand fommen finnen. Dech atth fo war es ibm fehon arg genug jtl Nutb. Eein Eohn, Der um zehen Erad in feiner Meinang DnDurd geffiegen war, onj er ein juriffifcheb :alent gejeigt halte, melstes ihm Den Seifall Der Slicter uno Der Rechtsigelehrten rerfichaffte, melcher feiner $21 n=$ iicht uach 'o viel 2 serth hatie, a!s ber ber ganjen útris gen siselt: iein Enhn alfo gnb ihm iekzt ein rolies jecht iu iem hoken Echáçungsmeribe, Den felloft feine ráters

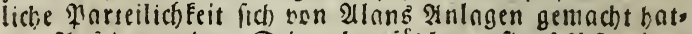
te. 2huf Der andern Eeite aber publte er fid felbit, einer 
Berheimficfung tregen, die er gegen den Cobn feiner Soffunugen tund feiner 2 sirufche angewand batte, et. ติล ge gemútbigt.

Au Morgen bez ncthingnifroflen $\mathfrak{Z}$ anes batte remlich Mir. 2lleknoer Fnirforo van feinem Eurrefpon. Denten uno Fretmde, dent Frovoft (srosbie von Dam= fries, einen Strief fo!genten. Inbalts erbalten:

\section{Mein wertber feerr!"}

"Ihre-gethrte 3uffhrift nom 25: v: פRts. Durc! (8) tite" Des Scrrn Darlie Ratimer, ward mir richtig jot = beftellt, tuno icl erwies betti inngen sentlemtan fo viel QuffmerffamEeiten, als er anjunchmen fír. gut fano. 'Der 3riect meines negenmärtigen Schreibens ift jweis

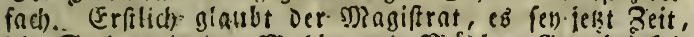
Die Eacle- mit oer Mabl = und Miúblen = Bérechtigfeit

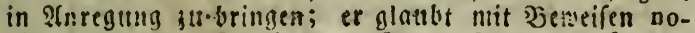
viter repertum Sie in Den Etano. Feßzen zu fônnen, Den Dechten uno bem Brauth Der Etndr Winfichtlic Der grana invecta et illata eine grüsere Sftrs dehnutug ver.

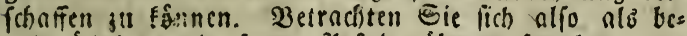

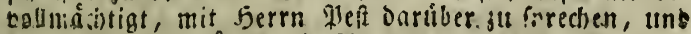
legen Ele irm autitigft Die sfften vor, ivelche Eie ourch Den ginftuagen erhalten werben. Der gangiftrat glaubt, zjoei Gisineell für Grorteln trürben binteichen, on

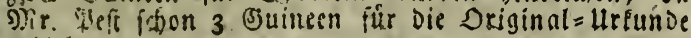
erbiclt.

Jeh benuke bieje Bfelegentheit, Eiz: ju benachrichs

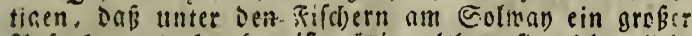
Stufuhr a!tzgchrorfen ift, bei melifem fie nicht allein auf eine hól)fe eiacnmirchtige seseife Dis 21 fablnetze an Der Neündung Deg Bftufies zerfideten, fondern noth

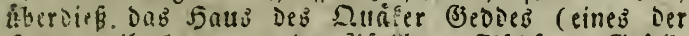

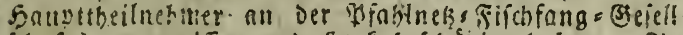

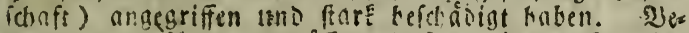

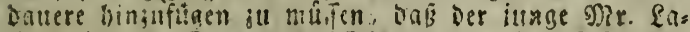
timer in ien Etrcut verwiffelt isar, tho bas feit Der 3eit alle fersteren Jiad) richten über inn mangeln. IJtan 
(pricht bon einem Morie, Dorh mag bas nur fo geiant fesn. Da Det iunge (Jentleman ziemlich unregelmáfig lebte, fo lange er fich in Diefar Begend aupibielt, io mie er 3. 3. mehr als einmal meine Finfaoung jum Mittageien ausíhlug, um init mandernden bierfied Iern uno folchem Bulfe im Sande berum ju ftreifen, fo mollen mir boffen, dof feine gegenmartige abimejenbeit abermnls Die Tolge eines Sugendfreich) s ift ; weil aber fein Diener fich bei mir nach feinem berrn er. fundigt bat, fo bielt ith es fur woblgetban, Eie

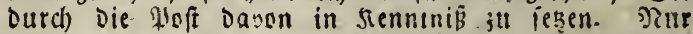
noc) is viel, Daj unfer Eberiff eine llnteriuchung angeftell bat, uno einen soer zivei bon den 2 tufriths rern in Serbaft nebmen ließ̧. Rann ich Shnen in Dep Eache bienlich fenn, indem ich entweoer ben Mr. Sas timer als vermin̈t angeige uno eine velobnung fúr den ienigen beftimme, ser Jiachrichten von ifm geben Eann, oder fonft nuf eine siseife, fo werbe ich ghren mers then befenlen geborchen, oa ich ftets zu Sbren Dien= ften bereit, mich achtungsooll nenne

\section{Bollliam cros̉bie."}

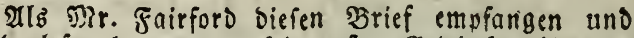
Durchgelefen batte, mar fein erfter Bedanfe, inn aus genblictlich feinem Sobne mit;ttheilen - Itno fogleich eine Efftaffette oder einen fonniglicien Bererchtäboten

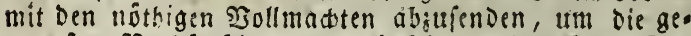

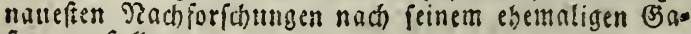
fte anthfillen.

Et munte mohl, Dab bie Eitten Der filicher imar eath, abes boch nicht gerabe will und blutgieriz find:

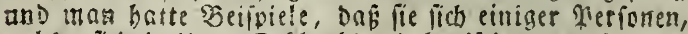
welche fict) in ibren Ecfleichbandel milichen molltan, bes máchtigt, uno fie nad ber Infel Man, ober uach eis neiti Orte gefdlepyt batten, mo fie einige $\mathfrak{S S}_{0}$ chen ges fangen gehalten wurben. SRatúrlichermeife mufite alio פTr. Fairferd liter daz Echicial reines ebemaliaen Satagenafien febr beunrubigt feyn, uno náre ber 2 us genblick minber nichtig gemejen, fo bảtte er fich ge:viế 
felbit all bie Sieife gemacbt, oder nuirbe feinem Engne erlaubt baben, auf ग?achforfdoungell nach feinem freun: De nutritugesen.

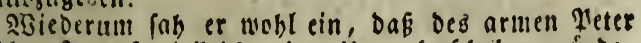
Peebles Zrojeß bielleicht sine die nufgefchoben murbe, wenn Der 2 rief in sie Sand feines Sobnes fáme. Er Eunnte die gegenfeitige. fchmármerifde Zumeigung Der iungen feute, tund mufte wohl einfehen, Dab bie

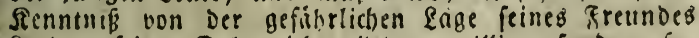
entimer feinell Eobn nich) allein tmwilltg, fondern fo. gar unfátig machen mürbe, lich Der Pflichten, welche ithm biefen Tag oblagen, zu entlebigen, worauf boch Der alte Bentleman cinen fo groß̧ell Skertb legte.

Obfonon mit niderfrebendem Beiúble, beichlob er ooch nach reiflicher Ueberlegung, mit ber Mittbeilung Der unangenchnen Fachricht, Die er erhalten lotte,

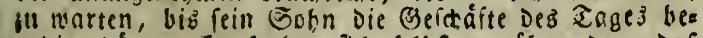
endigt há:te. Er fuchte lich felbft zulliberreden, Daf

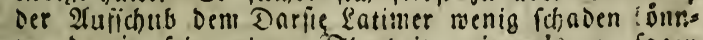
te, ba in feine eigene Thorbeit, wie er'b zu fagen mage, ihn in bie Schlinge geführt babe, wo er ourch eine augenblictliche Jeranbung feiner Freibeit, Die auf Diefe viscife nur nut einige Ettmoen verlángert kurbe, febr angemeffen lieftraft ware. Uleberdief nürse er ondurd) Zeit 3ewwinnen, mit Dem @eneriff Der (Grafichaft - ia nelleicht rogar mit bem Edniglichen Eeno ral=2tnmald, ju furechen, um Die Sache regellitápig zu betreiben.

כुun ₹heil gelnang ber Plan, mie nir gefeben bro ben, and maro nur julekt surch feiren, wie er fellof

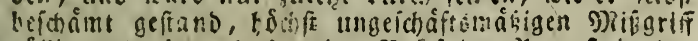
néllig bernorben, dá ar Den Brief ies llrowoft in Eer

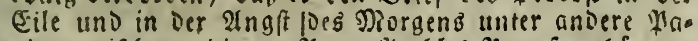
piere mifdite, die ;ll Peter Weeblez Mrojeß gefiórien, und ibn, obne sas Ferfehen ju bemerfen, ieinem sorne

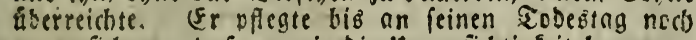
tII verfichern, Dap er nie bie ltnoorfichtigfeit begangen bátte, ein Mavier ants ben Fánben iu gehen, obne die Ueberichrift julefen, aufer bei Diefer unglidtlichen \&̈ele: 
genbeit, mo er, mehr als fonft, urfache batte, feine SRachláfiigécit jot bereuten.

Bun Diefen betrabtungen beunruhigt, empfand Der alte DRann jum erfien Mal in feinem Qeben, yor

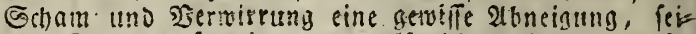
nen Eobn jt: fprecken; um slfo Die Surammentunft, Die iba peinlich ortiote, etwas ju ver;ôern, ging er ant Eberifi, fand aber, baf et in grojer (Eile nach Dumfries abisereift war, Imu in Derion Die. gerichtlithe 2lufnalyme, meidte fein Ete!'veriteter an Drt mino Etelle gemacht batte, ja unteriutes. Der-Echreber Des Eberiff fonnte wenig liber Den afuftano fagen, ex batte nut getrirt, oag er ernfthaft gemeien und laß viel Echnoen an Eigenthum uno ferreilidie Eemalts trátigeeiten an mefionen ausgeftyt morden fenen; - aber fo. viel er niffe, wáre ven-Feinem Morde bie Siebe.

N?r. Fairford mairserte alfo mit feiner ?eugfeit

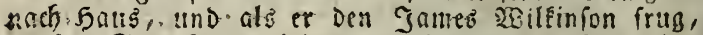
no fein Sohn fey, erhielt er int 2Intmert: ", Gerr 2llnn mầre auf feiner Erube uno fehr beict aitigt.".

"Şir múfen uatb merfándizen," fpricht Saun= Ders: Fairforo zu fich Felbet. "Beffer einen Finger, als die ganje Sand verlieren," geht dann bis an bie Thure Der Etube feimes Eotnes, flopft erft leife, dann

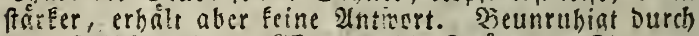

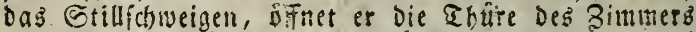
- es. mar leer - cunorbentlicf lagen die fileider bei

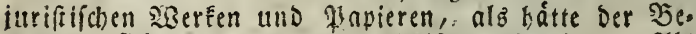
mobner fich (ch)tiell jut einer Reife vorbereitet. 21 b MR. Foriforo in grober פenegung um fich fah, fiel

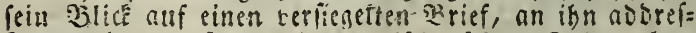
firt, malcher auf Dem Echrestif(be feines Sobnes lag. Er enthielt folgende NBorte:

14 Mriat theterfez Dater!"

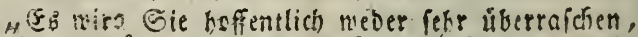
noch fetir betraten, ment Gie ksen, Dof id) munmehr a uf bem 23 ege nach Dumfriez, 巨hire bin, Durch eigne Erfundigungen Esemińbeit úber bie Lage meines thentes 
ren freundes zu erbalten, uno um ihm wo moglich al. len beiftand zul leiften, Der in meinen sirajten ftebt, und ber boffentlich nie gewunfohte wSirfung nicht ver:

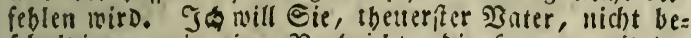
(thuloigen, mir eine Nad)ridht, bie fo eng mit ser Rube meines Gemútbes und ntit meinell (B)litat ver = bunben ift, verbeimliat gu baben; Doch boffe ich, wird Diefe Jore fandung meine gegenwartige כeleibigung, wenn aud nid)t ganj entfchuloigen, Dod wenigitens Den widtigen Echritt mildern, Den ich unternommen babe, obne Sie Darum ja fragen, uno Der, mie ich ferner befteben mus, unter ben gegenmártigen umftán. ben, meinem ganjen. Unternehmen gbre פrib́billigung gusteben Eann. 3 u neiner weiteren Entichuloigung Eann (id) nur nod) binjufugen, Dab, wenll Der Plerfon, die mir nach Jonen am theuerfen altf (Erben ift, ein Un: gluef, (was Eott berbuten wolle) wioerfafrell ift, elvige

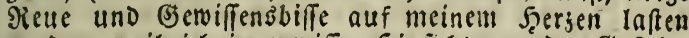
werben, weil ids in gewiffer Sinfid)t vor Der (J)efabr, melose ibin Drobte, getoarnt uno, mit Den Netteln ver. feben, fie abiurenden, Dod nid)t augenblidflich of fei. ner 5 filfe eilte, fonoern meine $\mathfrak{A}$ (ufmelffamfeit bor

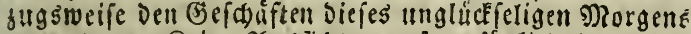

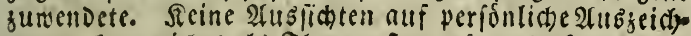
nung, Eurs nidyto als Shre ernften, oit altogefprochenen sounfac founten mid bio beute furidebalten; und da

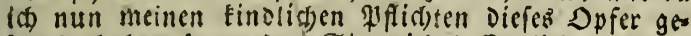
lradit babe, fo werden Sie mid boffentlid entiduls

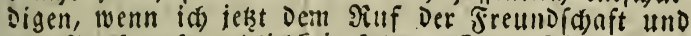
Der Menfdenfreundlid)Eeit folge. Seyn Sie meinets wegen gant nuffer Бorge; ich toerde mida bei allen ror. Eommenden Norfállen mit Der geborigen refimen, Denn fonft batten mibi meine vicliabrigen iu. riftifden Etudia wenig genukt. Ta bin, für Den Noth, fall, mit (5) nell fid nber Darauf verlaffen, Das ich), nubee im bódfen Rotbfall, eine iede Gelegenbeit vermeiden werde, nis జ. Scutt' 


\section{4}

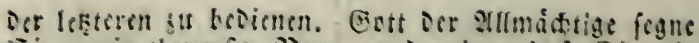

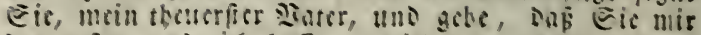

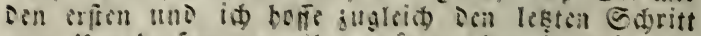
jum Inngeboriam scrjciscn mogen, Bon idj mir ick̨t

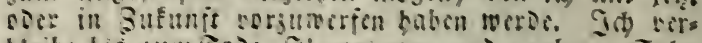

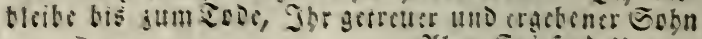

\section{P. S.}

"शlan Jnirporo."

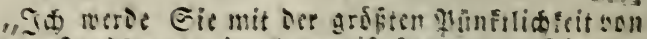

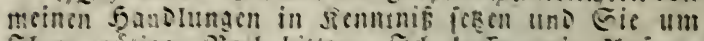

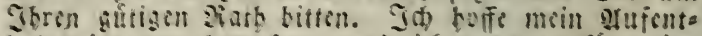
halt miro nar lurj fonn, tino id palte cs fur mog. liw, Darfien mit iurdefubringer."

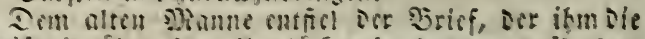

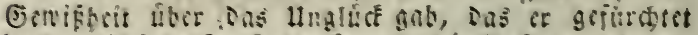
parte. Eein crfor Gobanfe war, Sic lioft ju nchmen, tum ben Fludtling ju verfolgen; Sam abcr ficl ihm

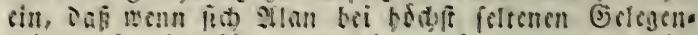
friten miderincnitit gegen bic patria potestas gcjrigt

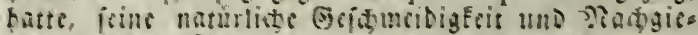

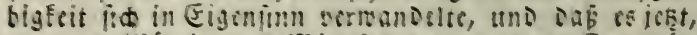

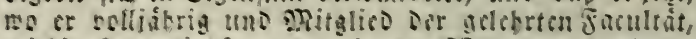

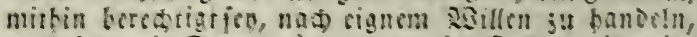
naw ithe bis frrage wate, ob cr, im Talle or ikn cins

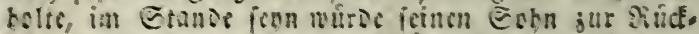

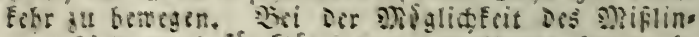
gens biclt or os fúr Eluger ron icm Unternchmen ab.

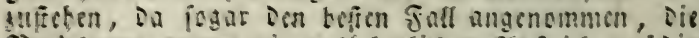

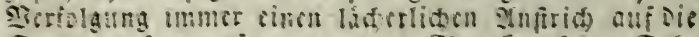

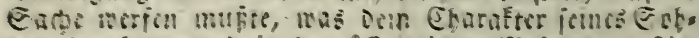

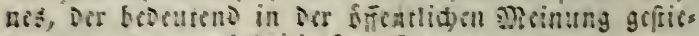
gen mar, mur natitcilig jom Ennte.

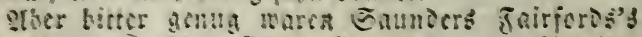
Betradotungen, als of lid in AIan's Icternen Mrbeits. foukl mar, Bea unicligen Srici micser cultob und ris aen th

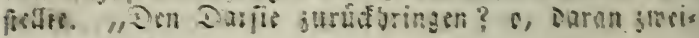




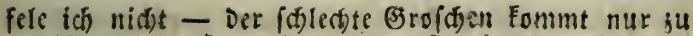

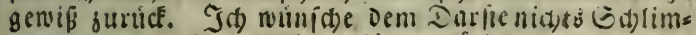
meres, als baß er Dabin gefuibrt wuirde, wo Der eins. fáltige Rare, oer 2 lan, ibn nie wieder sll feben bes Eáme. Sur bojen Etunde betrat er mcine Echirclle, Denn feit Der Seit bat allan feinen eigenen frúberen

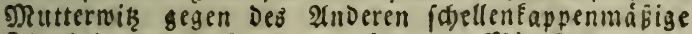
Shorbeit uno unfinn vertauidt. - Mit Besdo verfes ben? Da múfiteft ou mebr baben, als id) weiß̄, mein Freuns, Denn ids bielt Did in Dem PunEt ju Deincm

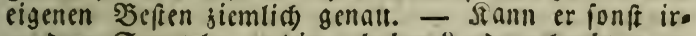
gendro Eporteln verdient baben? orer glaubt er ets

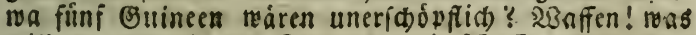
will er, oder irgeno Jemand, mit $23 a$ fen thun, ies Eein Goldat im Dienft oder Eein Diebsháfther if? Id) babe vie $23 a$ ffen fatt, wenn id) lie (d)en fúr stos nig secorg und feine siegicrung fubrte. 2tber Das ift nod ein idsl:mmerer Sandel als ber bei Faffirf. (3att fief) uns bei, wir fino arme unbeftándige (J)es

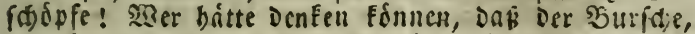
Der eben erft fo biel 2Anlagell jeigte, ię̧t fchen einem

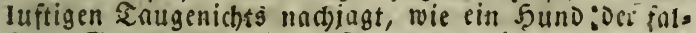
fdep Spur! 2(d), licber Simmel, ę iff Doch gar sa traurig, wenn eine brummige গ̂th, Den idáumenoen, vollen פeild)eimer umfisfit. - $2\left(b e r\right.$, bei $2 A l^{3}$ bem, zers

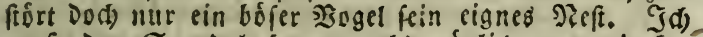
mú oell Ecandal to nut als moglid bull serdecéen fuden. - 23as gibts, Tames?"

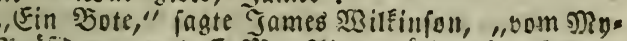

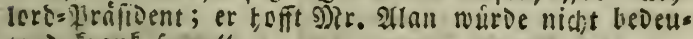
teno franE fern."

"Wom Sord= Práfidenten? Gott fteh? uns bei!"-

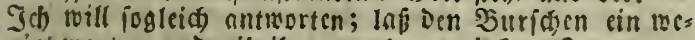
nig! warten und gib ihm etros su trinfen, James. 2 sir wollen felsen," fagte er, indemer ein अaricr mit Jolbrano herborjeg, "wie wir Dic Afntwort eintibten Edrnen.", 
Ehe aber nod feine feder Das Papier berúbrte, war James fchon mieder oa.

"s3å gibts fdon nieber, James?"

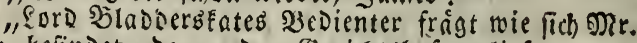
Allan befindet, ba er Den Ecridtebbof verliép - - " "ग2lun ia, ia" antroortete Saunders bitter; "er bat auch einen Epaziergang. bei Diondíbein gemacht, wie M?ylords Neffe."

,Eoll it Dils ausridten, Gir," fagte James, Der als ein alter Goldat alle Dienffiad)en budfftáb: (id) nahm.

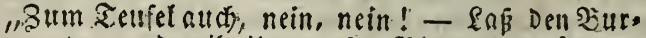
fall warten und gib ibm unjer bier ztt berfuden. Ja) rill Sr. Serrlich Feit 2(ntroot fidreiben."

2Sicoer mard: Das Esoldrapier ergriffen, und nod= mals iffinete Jamez Die Ihưre.

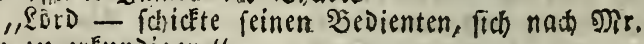
Alan zu erEunoigen."

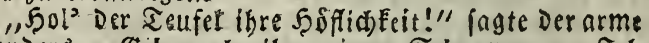
Caunderb. "(Bib aud) ibm einen Scbopken - Ja will Er. Ferrlid Eeit (chreiben。"

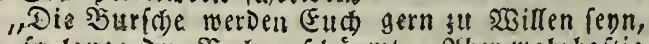

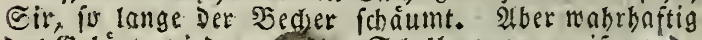
Das (selátute wiro no ift ichon mieber Jemiand,"

Er eilte alfo san Nieuem Die Zblire zu Dfinen, und Earn zurúce Dem $\mathfrak{M r}$. Fairford ju fagen, Der Decan Der facultat fer Da, fict) nach $\mathrm{Mr}$. 2llan ju erEundigen. - "Eoll ich itsm auch cinen Edopken geben?" fagte James.

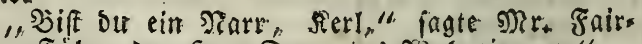
forb, "Fithre Den STrn. Decan ins Sisobnimmer." InDen er nun Etufe fír Etufe, gan' gemádich

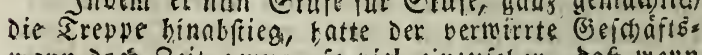
mann Dof Beit genug, fo viel einjuicken, baf Iwenn

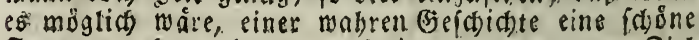
Form ju geben, Die zigahrheit inmer leidter zum Biel

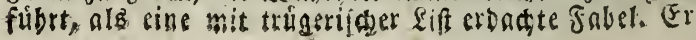


fagte alfo feinem gelebrten Freunde, Daß obfaron fein

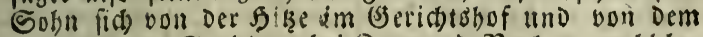

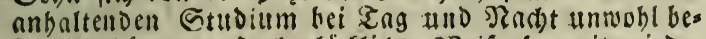
funden bátte, er Dods glütlider 23 eife fo neit wieder bergeffellt fen, onß er im ङtande gaweren wáre, eintem problicten Ollif nufs Lano jolge su Jeiften, seld)er eine Snche nuf Eeben uno Iod betrife.

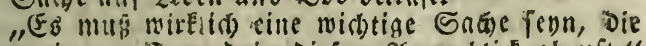
meinen iangen Jreund in Dicjem $\mathfrak{A}$ tugenblick nbruft," fagte Der gutmutbige Decan, "Id) baitte getwunfot,

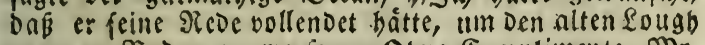
ganj zu $200 \mathrm{ch}$ zu werfen. Ohne Eomplimente, DP. Sairford, es war cine fo fadne Afntrittserede als ich nur ie borte, nur thut es mir leid, Daßj ISbr Golin

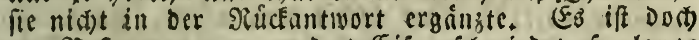
am Šeften ivenn man Das Eifen fámiedet, fo lange es no() beis ifte"

Mit bitterer Miente fiinmte Mr. Gaunders Jairs ford einer Micinung bei, Die nur zu (ehr aud) bie reis

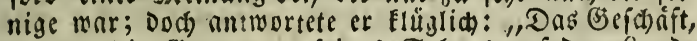
weldeb Die Begenmart feinez Sobnes auf Dem Lambe unumgainglid) ndthig madbe; betráfe bie angelegen beiten eines lebr reichen jungen Szerrn, Der cin vero trauter Jremo 2alland fey, und Der nie einen widtio gen Ed)ritt unternábme, Dbne feinen red)tв̈belebrten jeuno zu ?ath zu ziebul."

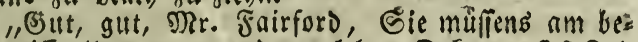
ften "wiffen" antwortete Der gelebrte Defan. "Ift $20 D$ oder Scirath im Epiele, fo mún man freilid) vor einem Ieftament doer vor Ebepaften alleg andere liegen Iaf,

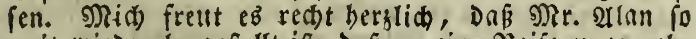
weit wieder bergeftellt ift, onßß er eine Seife unterneho men Eann, uno wüld)e Sbuen sinen freundidgen gut ten Drorgen."

Da er mit Dem Decan ber Facultăt fo gut Durdje gefommen war, fo farieb Dr. Fairford Den Drei Rridse tern fonell Antwort tno ersáblte Alanb Abreife auf 


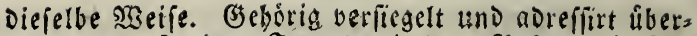
lieferte er fie Dem Jameà mit Dem Vefehl, Die כe: Dienten zu entlafien, weld)e unter $\mathrm{ter}$ Beit cinige Maa 3meipfennings=:3ier ausgetrunEen batten, mobei fie über einige Stellen im Corpus juris frritten, indem lie iid) mit Den ₹iteln ibrer Serrent anredeten.

Die arbeit, welde inm Das verurfacite und die Sheilnabme, die fo viele \$erfonen von 2 nfeben im Geriate an-dem sioblbefinden fines Eobnes áußer= ten, ermuthigten Den niedergebeugten Escift unferes Gaunders fehr bedeutend, und unter dent Eeflecer Des

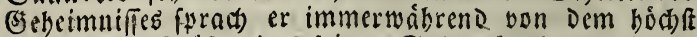
micutigen Eseráafte, Das feinen Sobn abgebalten batte, Den wenigen @ikntungen beizumobnen, weld)e Das $3 e=$ ridit in Diefer Sefinon nod) balten warde. Sa er ver=

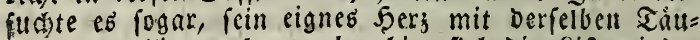
(d) ung zu bintergeben; aber bier fiel Die Sift minder glúcklich aus, Denn fein eignes (J) ewifien fagte ihm, Daßs,

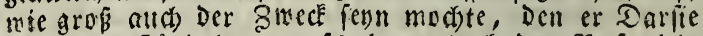

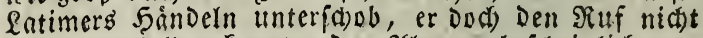
raieder berftellen Eonnte, Den artan wabrideinlich ber= for, invem er Die Eafbe Des armen peter peebles im Etich) lies.

Ob finon fid) num cinftweilen Der Dunft, welcher

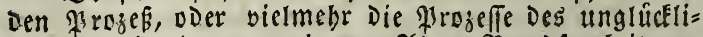
den Etreitenden umgab, vor 2rans Soered fame eit zer= theilt batte, wie Der Nebel bor Dem Donner Des ङe $=$

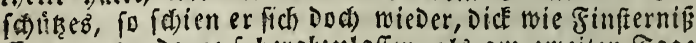
Egyptenz, Darauf berabzmlaffen, als am zweiten Tage nac) 2llans 2 breife, $\mathfrak{M r}$. Tougb alb 2 lobofat Der (S) $=$ genpartei Dab Naort nabm. Mit hobler Etimme, mit lang gezogenem 2 (t)

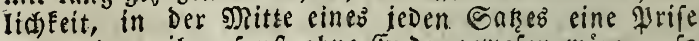
nebmeno, weil er fonft obne Ende getwefell wåre - fo ermiederte ber alte, ausgediente 2lovofat alle Punfte, welde 2 fran in ein fo belles fiaht gefert batte, uno fo gelang eb ibm Den Sdleier Der Duntelbeit und Der 
Itnoerftinolidfeit wieder vorzusiebn, Der fo lange Beit Peebles Trojés gegen Pluninftenea verdunEsl: batte, fo waro die Ead)e zur nect)maligen Seratbung uno zu abermaligem Siortrage aufgéd)oben. Da Der $2116=$ gang Der Sadje Den Ermartungen Dez glublifums bei Qlans ReDe nicht entiprad, fo gab Der Urtheilófprud su Den beridjiedenartigften $\mathfrak{B}$ ermuthungen 2 Anlaß.

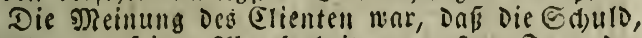
erftenz, an feiner 2unejenbeit ani ceften ₹age Der S3erbandrung lége, on er, wie er fid) Gusbrúd te, mit Sranntmein, Hżuebnugb, uno anderen bikigen (3)e=

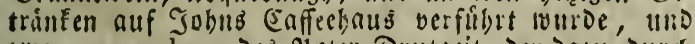
zloar per ambage Des ?̧eter Drutgeit, Der Dazu Durth Den Siath, Den 2nishlag unD Durd) Die Sinterlift Des Eaunoers Fairfuro, feines Eríd)walters, oder vorgeb= lisien Endjwalters, aufgemuntert worden fen. 3meis tens, an Der fluát und oem freimilligen Entlaufen Des jüngern Fairford, Des 2Lonofaten; alloieweil uno Desiregen molle er Sater und Eobn zugieió) mit ciner

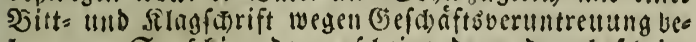
langen. ๔o fatien ber anforbeinende und wabrideins lid)e $\mathfrak{A}$ uggang Der Gate Dentublinnigen Gaunders Fairforo mit neuen Esegenftânden Des summers und Der Demútbigung zu berrobell, was ihn um to viel mebr EránEte, Da fein cigenes ङ̈eniffen ihm fagte, Dẩ

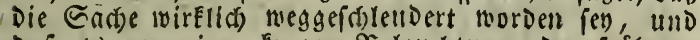

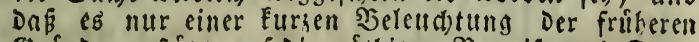
Brunde, gefrüt auf Die notbiaen Demeife mo facta

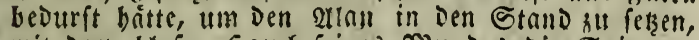
mit dem blofen fauth) frines Fiundes Die Epinnens getwebe zut zerreifen, mit weldien 9)? Fough Den Pros zeßs rieder ungarnt batte. 2(ber es gebt tonnit mie mit cinem 2 Uแ $\{$ prud ill contumaciam, man verliert, weil man nidjt wiberiprechen fann.

Unterbeffen serging faft eine 230 dise, obne Dak $m$ r. Tairford allf Direftem $233 \mathrm{cge}$ etwas von feinem Eokne hirte. Siwar erfab er aus einem Striefe Des Dr. Erovibie, 


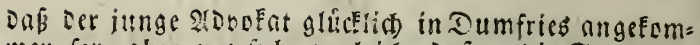
men (ev), aber er erfubr zuglei(b), Daßs er Die @tndt rer= laffen batte, um einige शiacbforidungen anjuffellen, De= ren 3 Weck nicht befannt war. Der alte DRann, welder nuf Diefe sEcife peinlid)en (Erwartungen uno quálen. Den Siúcerinnerungen viberlnffen und bes bátslichen ulmgang bernult mar, an melcten er fich gemshnt batte, fing an Eorperlich fowoht als geiftg jul leioen. Er batte ben Entidup gefaft, felbet naw Iumpriesfbire zut teifen, alt nacisem er ungemobnlic und faft un= ertráglids aufiabrend, verbrieflich und múrrifit gegen Ed)reitier uno beoiente mar, fo fekzte fich Die bittere

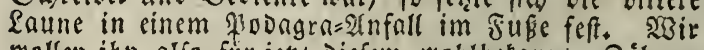
mollen ihn alfo fur iebt Dicfem moblbekannten $3 a ́ b m e r$ Der bod)anffrebenden beifter liberlafen, on die fort=

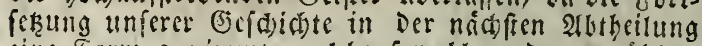
cine form annimmt, welche fowobl won Dem erzablen= Den als som Brieffinl nbiveicht, Dennod) aber Dag Ei= gentbülidge beiser årten bat.

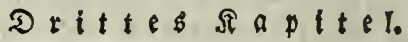

\section{Darfie Latimer' $\mathfrak{Z}$ agebud.}

(Die folgense anrete freft nuf oer innern Geite sez um(d)lags, welder ias zagebuct entbielt.)

2 In weffen Sánde auch Diefe פllátter fallen mos gen, fo merden fie Dod immerbin Den sinder in Jennto

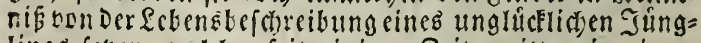
lings feken, welder feit einiger acit, mitten in einem freiem Ennde, und obne Dafi man inm ein Sierbreden jur faft legen fónte, einem ungefeşlichen, gemaltfas men awang unternorfen tourse uno no d) untermor= fell iff. Siser alfo diefen Brief eriffnet, wird biemit 
befchmoren, fict an bie nád)fie richterliche Perfon ju men= Den, und indem er Die 2 tngaben benukzt, melthe Diefe

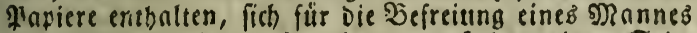
iu sermenden, ber, to wie et auf ber einen Eeite

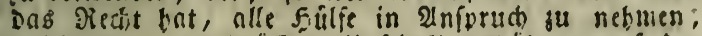
melclise ier unserdticften Unfchuld gebubrt, auf Der andern zugieich Den 2 silten und Die Fititel bat, fich feinent Siefreicr DanEbar ju bejengen. Eollte es aber

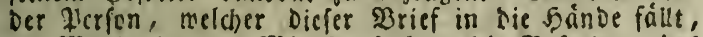
an Diaib ober nu Mittein feblen, Die Wefreiung Deg Echreiber -gu bemerffelligen, fo wiro fie biermit bei

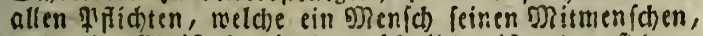
und ein (Shrift Demienigen (d)uldig ift, Der fich jut Demifalken beilinen (3)lauben befennt, befchmoren, Die fcbleunlaten g)inabireseln iu trefien, Diefe Blättep ichnell und ficker Dein Ilopolaten 2llan Jairfors, Eegr.,

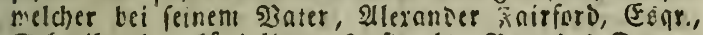
Echrciber bes fonigliden Infiegels, jorow'ns Equare

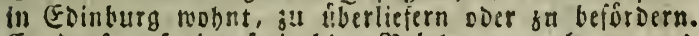
Er Darf auf eine freigebige Solohnung rechnen, und fein eigenes Bsemifien Fann ibm fagen, Daß̧ er Der Sgenichbeit einen mabren Dienft geleiftet bat.

\section{"D?ein theuerfier Allan!"}

"Da ids in Ungewifbcit und im unglice now eben fo warm fure Did) fuble, wie ie in Den fch onften 'sengen unferer innigen freundfhaft, to trende ich Die Erroibs lung einer (s)efchid)te an Dich. Dbgleid) fie wabrfateins lids in-Banj andere foinde follen mitb. Ein Sbeil meines sorigen Eeifes befeelt meine Jeber, rábrend ich Deinen s?amen nieberid)reibe; ith will midh in Dem Bedanfen olidclich trátumen, Dnß Du mein Şefreiet aus meiner ickigen unglitcklichen uns beunrubigenden Eage fenn mirft, wie Du bei frúberen, glüctliçeren (Selegenbetten mein Subres und mein Sinibgeber warff; fo will id) Den Iribfinn veríchetichen, Der mich fonft

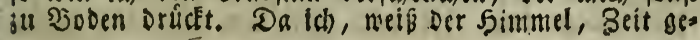


nutg jum Streiben babe, fo mill ich es verfuchen,

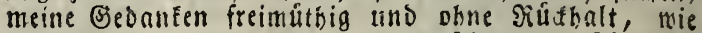

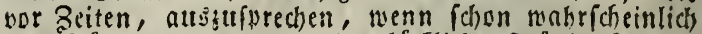
Die frútere muntere und gläcliche Fröblich feit fie nicht mehr wuirst.

Sollte Diefez Papier andere Sånde alz die Deis nigen erreichen, fo merbe ich auch bann noch ben 2 us: bruck meiner Esefiftle nicht bereuen. Fenn menn idh

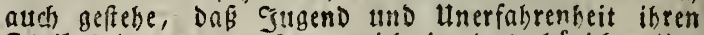
Theil beigetragsu baben, mich in Das thirichte uns ternegmen gu jieben, fo furchte ich boch nicht, Das meine Errálthig mich felbft befchámen miro. Ta ich bofie rogar, Dấ Die einfache Offenheit, mit welcher ich icoen befondern unglifellichen (B) egenftand erjählen werde, felbef einen gremben, fu meinen \&unfen ftim. men wirb; und Dấ unter Der Nenge Der anféceinend unbedelttenoen limfánde, melche ich Der Sánge nach erjáhlen mill, fich Doch ein Schlüffel finben wirb, Der mir Die Ihbre meines Befángniffes dffnen Eann.

Noch ein anderer Fall if Der marrycheirlichfte -

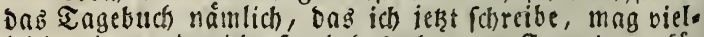
leidst nie, weder die jand des theueren Freundes, fü Den es beftimmt iff, nod) bie eines gleichgultigen frem= Den erreichen, fondern eg wird Die 2 ente Der mens fchen merben, Die mids iek̨t gefangen balten. Mag es fenn - fie merben menig daraus erfénen, mas

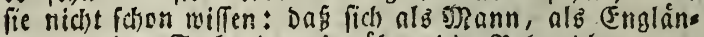
Der, meine Eeele in mir úber die $\mathfrak{b e h a n d l u n g} e m$ rort, Die ich erdulden mufs; dak ich entf(s)loffen, ies Des Mrittel, Das mir ju Esebote fReht, du benuken, um meine Freibeit mieder zu erlangen; onß Die Ẻes fangenichaft meinen Ëeift nicht bettgte, und Dak ich,

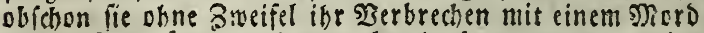
bejwliefen fornnen, immer bereit fenn werde, meine

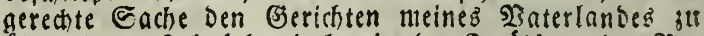
übergeben. Ich fabre Daber in Der Erijåblung Der פes sebenbeiten fort, Die mich feit Dem Echluffe meines 
lez̧ten Ђriefes an meinen thetteren Alan Faitforo, be= trafen, uno Diefer war, wenn ich nidt irre, bom 5 ten Des noch laufenden F?onats 2huguit Dntirt. SRicht

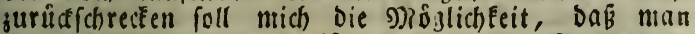
mir meine gapiere entreißen uno einem Manne jur Durchficht vorlegen Eann, welchor, ba er iekzt fchon obue allen (s)rund mein feind ift, nod) beftiger gegen mich aufgebracht werben wird, wenn er Die Eriáblung Des̉ Unrechts liest, bas er mir jufúgte.

Die Fadit zunor, ehe idf ienen $B$ rief f(hrieb, war

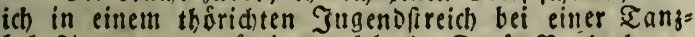
beluftigung gegenmartig, melche im Dorfe Brofenburn, Das etwa fechs Meilen von Dumfries entfernt ift, ftatt fano; viele Perfonen miffen mich Dort gefebell baben, menn allenfalls oas gactum fo wid)tig fitseinen follte, Daḱ eine gerichtliche unterfuchiung Dariiber angeftellt muirbe. $\Im$ d) tanite, fpielte $\mathfrak{B}$ iolin, und nahm an dem Sefte bis gegen Mritternacht Dheil, mo mein Diener $\subseteq a=$ muel Smen meine $\mathfrak{Y}$ ferde bradite, tno idi) nads einem fleinen (Snfthofe, Scháferşbuch genannt, zurúckfehrte, Da ich in Diefem fatre, mo eine betwifie Mrs. Nixoa

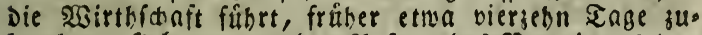
brachte. Sjch menbete Den 2 nfang Des 2 ormittags Da= zu an, ben fchon ermáhnten Sjrief zu fechreiben, Den Du, thetuerfter $\mathfrak{A l a n}$, wobl richtig erbalten baben wirft. W3arum befolgte ich ben Rath nicht, Den Du mir fo oft gabft? 93 artun berzogerte ich meinen 2Aufenthnlt in einir gefáhrlichen $\mathfrak{R}$ achbarfchaft, nor melcher mici) eine gâtige Stimme marnte? Dod bas find ieķt uns nithe Fragen; mein Echidefal bat mich berblendet, mie eine motte fatterte ich $4 \mathrm{~m}$ Daz Sid)t, bis ich mir Die flúgel verbrannte.

Gchon war Der oräbte Theil Deß Eages verfinfien und fablver laftete bie כeit auf mir. Freilid) follte ich errotben, wenn ich bebenfe, wie oft mir ber theutre Treund, fúr ben Diefer פrief beftimmt ift, $\mathfrak{S o r m u r f e}$ uber Die feichtigkeit machte, mit meldher ich in múffi. 


\section{4}

gen 2uttgenblicken meine Sandlungen von Perionen lel= ten loffe, bie zufállig in meiner Niáge find, ftatt mit Die Mughe zoll geben, fur midl felbft'zu Denfen und stt entícheiben. Eeit einiger Zeit balte ith einen Diener

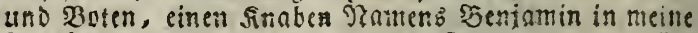
Dienfte genommen; - er war Der Eobn einer geirifïn 2Bittme Eoltherd, melde in Der Siabe Des Echaperbus iches trobnt. Ich geffebe eint, bas in Ber lethten Zeit Der

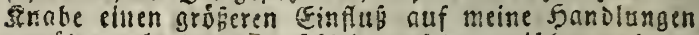

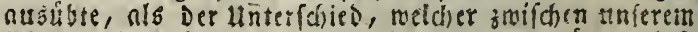
alter und anferem Entande obnaltete, eg baitte jutlafs fen follen. Jekt mandte er alle Heberredungatúnfe an,

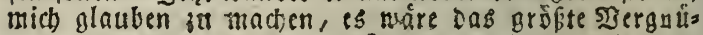
Ben, Das man fic DenEen fonne, zugujeben, wie man bei Det Ebbe bie Fifche alls Den sieufen bolé, melche in Der Eolmay alafgeftellt fino, er trang fo febr bars anf, Dấ ich Dodh Diejen zbend bingeben follte, Daj ich, menn id es mit ten úbrigen thinfánden sergleide, nicht anders glauben fann, als Daf er einen befonses ren Betveggrano Daju batre. Sch ermábne Diefe aleis nigiciten, Damit, itm ralle Diefe gapiere in Freundes Eande fallen, ief finabe aufgefutht uns tertort merbe.

Da alle feine Bercitfamfeit mi nicht überzettgen

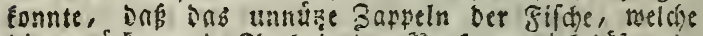
Die zuritctrtetende glutb in Den Reuren zurtude lápt, ein

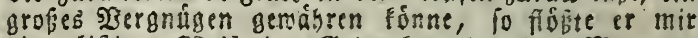

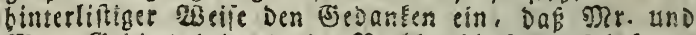

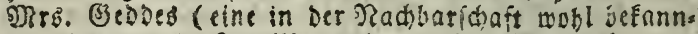
te, ebrentertbe somilie, mit melcher it in fretmis

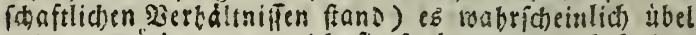
nefmen murben, wenn ich fie fo lange nicht befuchte. Seise, faste er, bátten lï eifríg nad ber lurinche erEundigt, Die mich berogen bátte, geftern fo plokglich ibr 5aus zu verlnfien. Sch befwlob alí, nach srount Sharen fut manoern und mich ob entichtiloigen, eps laubse zugleid) Dem sinaben, mich) ju tegleiten uns meine Situffebr aus Dent Şaufe abzumarten, Damit 
3wifden adit und neun $115 \mathrm{t}$, els es anfing Dun= Eel zu werden, gingen wir allf Der Terraffe fpanzieren, um Den 2Anblick des firmamentes zu geniesen, mo Dlillionen Sterne Durd) Den Ieid)ten 2nftrid) eines Sommerfrofteb, in zehnfad)em Estanze fdimmerten. $2 l^{3}$ wir Das erbabene Edjauipiel betrad)teten, mar,

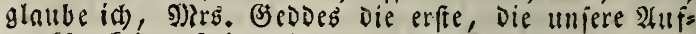
merffamét auf einen fallenden Stern oder Sternfdü lenfte, Der, wie fie lagte, einen langen Sd)weif binter

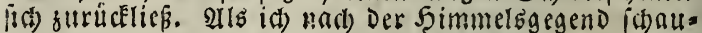

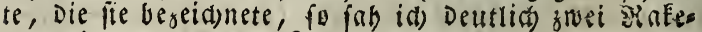
ten feigen und in Der \&uft zerplasell.

"Dieje \&ufterideinungen," fagte NOr. BedDes, antwortend auf die Semerfung (einer Garefter, "find nicit im foimmel entfanden, aud fino fie Eein gutes Deichen far bie SEemsbner der Erde."

$\mathfrak{a t}$ er eg $(\mathfrak{r a d}$ ), (ab id) nnd einer anderen Sims melsgegend, unD Da frieg, als wáre eb ein Signal fur Intmert auf Die fỉon gefebenen, rine Siakete bun Der (5roe bod) in Die \&uft uno fojien erft unter Den Eters nen zll zerplaken.

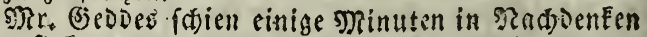
su verinfen uno ipras) Dann zu feiner Sdjwefter:

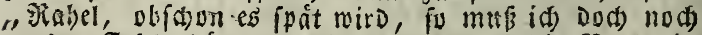

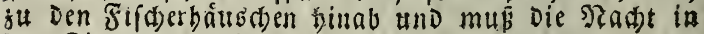
Dem Simner Des Sberauff́ber bubringen."

"ild), nicht Dod)," antmortete Das Srauenzimmer, "Denu íd bin nur zu geniß̄, Dáp Diefe Sinder Эes fials die Pfahlnetre und Féfen bedroben. Sofur,

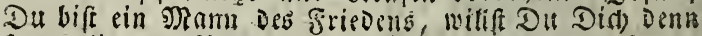
frebentild) Der sierfubbung nusfezen, ben aiten sham

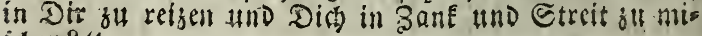
iftent?

"23obr bin id ein Mann Des griedens," anfmoro

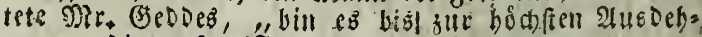
nung, Die unfere ifreunie som sitenitsen verlangen;

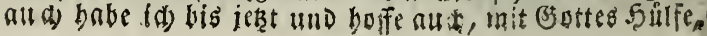


Sgr glaubt. Golfte das Biel meines \&ebents am beus tigen arbens fenn, fo werden nur sisenige wiffen, Dnß

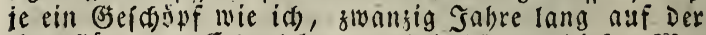

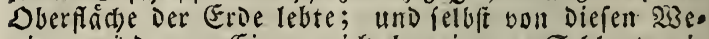
nigen wird nur (Finer mide beneinen. Ed)lagt mir

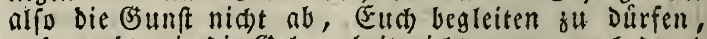
und raubt mir Die ङselegenbeit nid)t, wenn nud Durd - eine unbedeutende Sandiung, zu zeigen, Dafi wenn ih

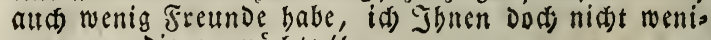
ger gerne dienen mod)te."

" 23:abrlid, Du baft ein edles Sers," fagte Sos fua "ङedDé, Den Druck meiner Sand errwiedernd. "Rabel, Der iunge Diann foll mit mit gebu. $23 a r u m$ collte er nidft Fubn Der Jefabr entgegen geben, um Redtet und Frieden zu erbalten?" "פir fngt eine in. nere Ctimme," fügte er, indem or Die 2Augen gen

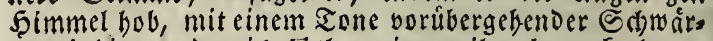
merei bingu, Den i由 biober nie an ibm bemerkt batte, und Die wobl aud mehr auf Red)nung feiner Secte, als feines perfonliden Eharafters zut foreiben ift. "Id) fage Dir, mir verfindet es eine Etimme in meinem Snnern, wenn audi) Der Bottlofe toben mag, wie Der Eturm auf Dem Reere, fo wirD er Dod) nidet ob. fiegen."

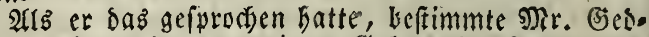

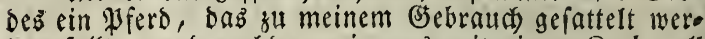
ben follte; und nađjoem wir uns mit cinem Sorb voll Diunboorrath berfehen und einen Diener beauftragt batten, bie $\mathfrak{P}$ ferbe abzubolen, oa in Der Sifderei Eein geeigneter Plak fur jie war, ritten. wir um ungefăbr neun 1 he bes 2abends yon Mount Gharon weg, uns ers reiditen nad Sierlauf von brei Siertelfunden unferen $\mathfrak{B e f t i m m u n g}$ gort.

Die Einriutung befteht, ober beftand Damals aus

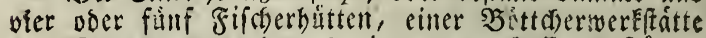
and Schoppen, und aus einer etwas befieren Sưtte,

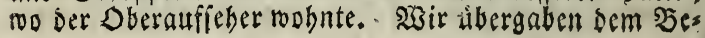


Dienten Die Pferde, um fie nad) Mlount Ebaron juruic. fufubren - (mein (jofinbrte fd)ien jebr menfabenfreund.

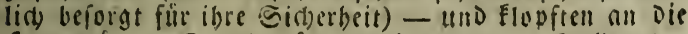
Soustbutie. Suerft horten mir nur Das Sjellen oer Sunde, aber bald berubigten fid) Die 2biere, alo fie, an Der Ibute fdumpyerno, Die giáthe ibres Treundes merften. Damn flug cinc laube Etimme in ciuem un= freundidaen sone, ner wir máen 11 no was wir wolk ten; uno nur als Sofun feinen Sianen nannte uno Deni Dberauffeher zul offnen befabl, erfolen Der feß̨tere an Der Ibuice, begleitet von orei gropen Sumben, ?zetk foundándifdjer अince. Er trug eine Fadel in Der Sano uno znei grobe, fomere Gdififpifrolen im (3) intel. एs mar ein Eroftiger, beinbrter Distun, Der, wie id) borte, in feinen frifberen Lebengiabren Matrofe war, nun aber

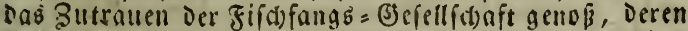

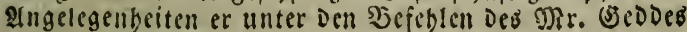
bejurgte.

"Su baft mia mobl beute $\mathfrak{2}$ (beno nict erroartet, greund Dasies?" fagte mein freund fll Dem alten g)anne, Der uns Ctúble an Das Geuer ftellte.

"Prein, Mr. (Sedies," nutwortete cr, ,uno wenn id Die sBabrbeit fagen foll, fo münfdite id es aud nid)t."

D)r. (3) CODES.

"Das ift berfindict, Sobn Davies," antmortete ven licbt."

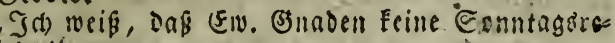

"Du mirft ç wobl vermuthen, was tuns nod fo fpat bierber fubrt, gobn Davies"?" fagte S) "Ja) rermutbe, Sir," antwortcte ier Oberauffe=

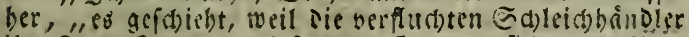
ibre feuchtEugelu an Ufer loglaffen, "Im lich su verfiom= meln, wie fie es in Der शRat)t oor Dem Tage madsten, an veldem fie Sdjettien tino Dasmme nicserrififen uno bas fano liberfromten. Sff saz aber wieder Der Fall,

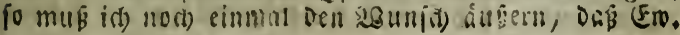

203. Esott'b șist'it. XVI. 


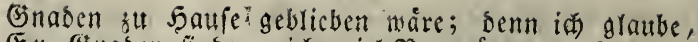
Eiv. (Snaben finden nid)t vicl כiergurigen am fecliten,

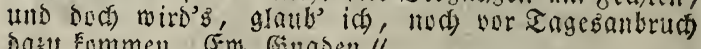
Daju Eummen, Em. Ënasen."

"s?ur ber Stimmel if gnidoig, John Davies," fagte

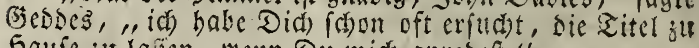
5aufe su laflen, wenn Du mifh anrebeft."

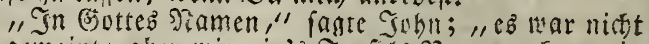
bós gemeint: aber wie, in's Tetfelb siamen, Eann cin

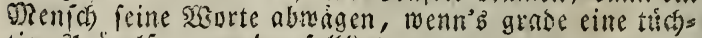
tige profigelfuppe geben foll?"

"Igh byfe es nicht, Iolyn Davics," fagte Sofua (3)esses. "Ouf" mir bie tibrigen \&eute, id) will ibnen Werbntungsbefehle geben."

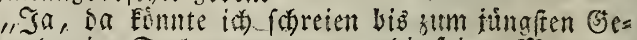
ridt), ehe cine Eeele antwurtete - Die feigen Diemmen

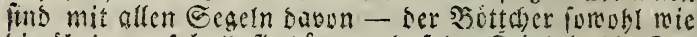
bie librigen, pobald lie borten, ons ber fecino in bie Eee fichdie. Gie baben Das lanae Sbot ausgerebt uns bas Echiff ser Sranbung überlalien, auß̈es bem Eleinen Phil uns id felbri - baben fie beim - !"

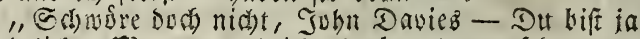

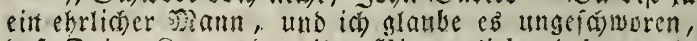

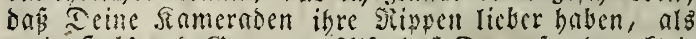

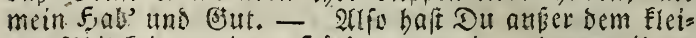
nen Phil Eeine weitere Stiffe gegen ein = oder zweihun= Dert Mann?"

"lim siserzifung, da find bie beisen frunbe şep= tun und Thetis - auch. ber Stmige ift fdyon zu gebratl=

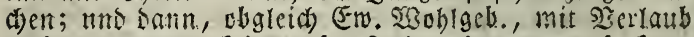
zat fagen - wohl Eein grofer fed)ter fenn mag, fo fann ood) Der iunge feerr da bulfreide forno leiften.

"soun ia, und mie idf fehe, hât Du Didi ia aud

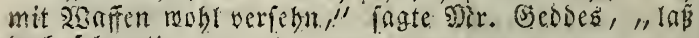
bock ichen.".

"In, ia Gir; Sa die beisen Piftolen beiper uns

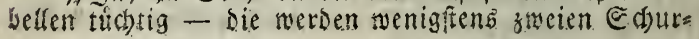




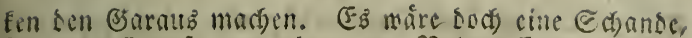

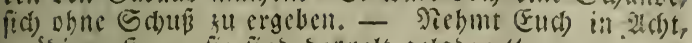
ginabiger 5err, fie find soypelt gelasen."

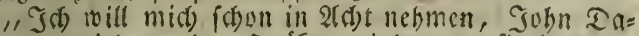
riç," croviederte Der Duáer, insem or fie in eincr sisafferbebáter marf, ser neben ibm frand, "tho in

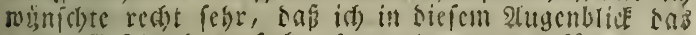
ganje (sefd)ledst scrielben fo matslos mad)en Eunnte."

Ein Ed)atten tiefon Misucrgnigens verinfterte fir cinen 2fugenblick tie obnebin merandyulifgen 3rige LCB Iubn Davies. "Es foheint alfo, Em. Esmasen

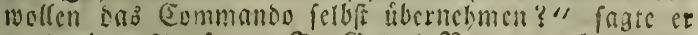
nact) einer gaute. "Sn Eontes Siamen, aber samn

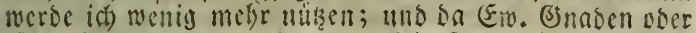
Ew. 280hlgeburen, ober was Gie fenn mögen, es im

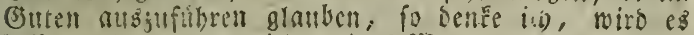
befer geben, wenn id meines şiseges mandere, benn

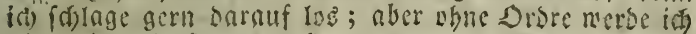
nie meinen \$ofen verlafen."

"Die will ich Dir geben, Sohn Dasiesz; gche aljo

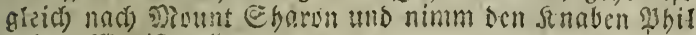
mit. 230 if $\mathrm{cr}$ ?"

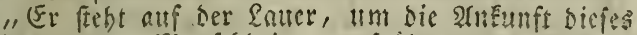
2rbichaumb fer solenfobeit zit erfputhen," sntwortete

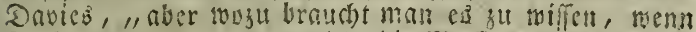
fie Eob:men, wern man nicht sie Sizaffen ergreift." (c)n.'

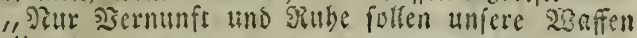

Es mirbe ebin fo viel nitşen, wem Cie Extctie

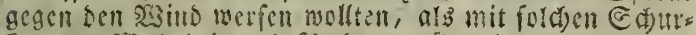
Een won 230 nhibeit uno SRecht tu resen."

"(S)tt, gut, es fey fo, "fagte Sofur ; , "tho nut

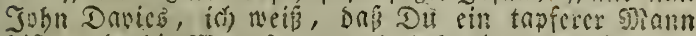
bifi, wie bie 23 clt fogt, uno babe itrmer gefunoen,

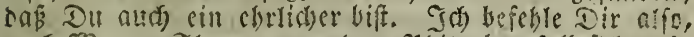

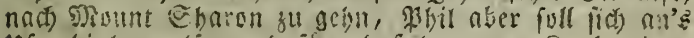
Hfer binlegen (jorge bafur, bap ber arme Sinabe cinen 
Manter unbat) und Dir fagen, tons es Nelles gibt; follte a:ifí) Das (5)tht Dort gemaltiam angegriffen mer= Den, fo vertratte ió auf Desine arcue, Daß Du meine

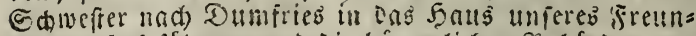

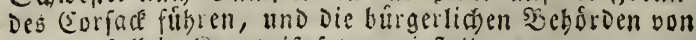
Dem unfall in Senntniß̧ fersen wirft."

Der alte Eeemanu fitimieg cinen augenblide, "Es ift cine barte g(ufgate fur mich)," fagte er Dann, , Em. Enaden in Der sfoth fu verhafen; uno Dennod) miro meine (o)egenwart bie Eadje nodi reridilimmern, and muß man freilia fur En. Bnaden Edmefter, Mi

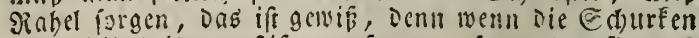
einmal unbeil anjufriften anfangen, fo weroen fie aus" nady Nount Gbaron fummen, nachoem fie biefes Eleine Phede = \$1 thischen zerfidut haben-werden, wo id lebeng= reingliơ vor suner zil licgen boffte."

"Stedit fo, Tohn Davise, gans redt," ingte Jos fua Ǵedoes; "es ware am biften, wenn Du aud) Die Funde mituabmefi."

"Ia, ia, 5err," fagte Der \$્oteran, "fie baben ohnehin meine (s) big unbeil anftiften feben; fo founte fie leitbt felbft ein unglüe treffen, Die armen gutmethbigen Zhiere.

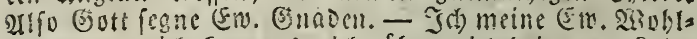
geboren - ich Eann c3 nid)t ther mich bringen, febes wohl zll ingen. - Se Da, Sicptun, Ihetis; fonmt, ife Surde, forment."

Indem er bas fagte, verlief Jofn Dasies mit ges beugtera (3) emuitbe die Syutte.

"S?un Da geht eines Der befien uns getretten Gies iofopie, Das ie geboren ward," fagte Mit. Geodeg, als Der Sberauffeher Die Sblire jumadite. "Die Natur

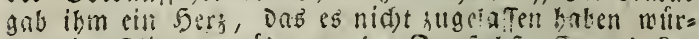

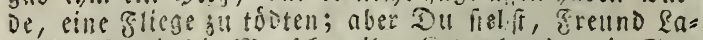
timer, fo wie vie stenfigen ibre fiettenbutioe mit Etas

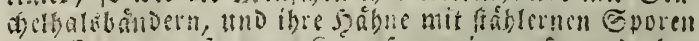

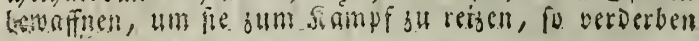


(ie aud) mit ifrer Ersichung bie beften, miloeffen 2?a. turen, bis sbarafterfarke und bsift in Starrfinn und 2isilobeit nusartet. Stanbe mir, Freund Latimer, eben fo gut wirde id) meincu getreuten 5 ofbund einem unแú. ken sinmufe mit ciner focerde $28 d f e$ ausfezen, als jentes

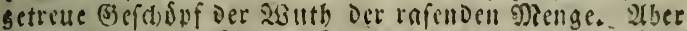
id) braudse Dir, Freutio fatimer, wobl wenig Dartiber bu fagen, Da Du nabrfacinlicí) auth fu glauben geneigt

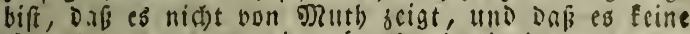
Ebre bringt, menn twit mánnlicl) Dabienige erragen,

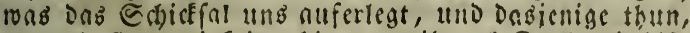
mas Die (S)erectigfeit gebietet, weil auch) Dull bereit bift, Esemalt mit Senalt zil vertreiven, und Die Eleinfte 5 be

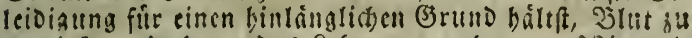
nergieben, ia fogar Das feben zu rallben. - sair mol. len aber Diefen ftreitigen glunft nuf eine gelegenere zeit

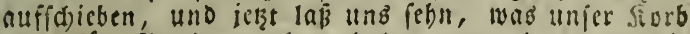
nobl fúr munonorrath enthniten mag, Denn um rie Sabbrbeit bu effethen, Freund Satimer, fo muf ict) Dir fagen, Daß id) einer son Denen bin, Denen meder Surcist nod) Ingft ibren gerodhnliden arppetit raubt."

23ir fanden Den Jiorb mit gltten હprifen woht ber-

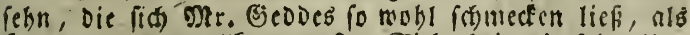

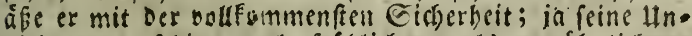
terbaltung fitien no(b) próblid)er, als geroobnlidis zu fern. P2adsen wit unfer albendeffen versebrt batten, verlieben wir gemeinf(d)aftlid bie Șütte, uno singen einise 2 tugenblicfe ain $l l f e r$ Des SReeres iparzieren. Siolf uno flar friegelte fid ber Diono allf Der ebenten

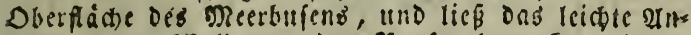
(d)lagen Der sieflen an Den Rellfen bemerfen, beren áuberfte Evižen ein menig alts Den sgagen beruorrigs

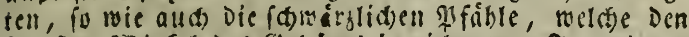

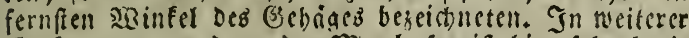
Entfernung, - Denn Der meerbuien ift bier febr breit

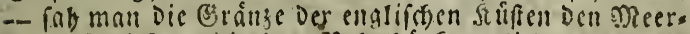
bujen faliefen, Die ben siebelbanfen glidgen, ton bes 
nen man fagt, saś sie Seefabrer nidft wihen, ob es wirfliches Sano ober eite armospbirifde sauid)ung if. "Eie wersen uns nad eimige Stunden in Rube

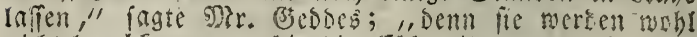
nidgt berabenmmen, bis bie (Ebbe ibnen crlaubt, sie

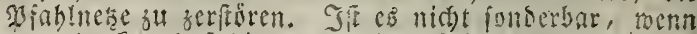

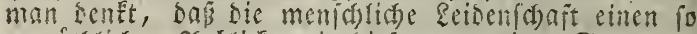

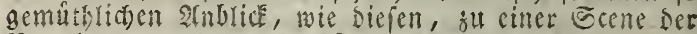
Sermirung und ber aerfirung umfdaffen wirs?"

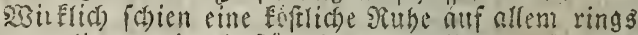
umber zu liegen, ta sie frumíflyen sosellen der Eolman pogar (bjenen, went aud nidst grabe fu folafen, sub

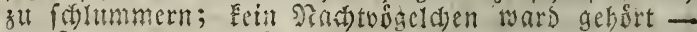

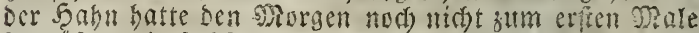
begritist, wic felifitraten leifer auj, nls bei sag, als wolfen wir es bermeioen, mit bem (beritu unjeres Sritte bie beitese sube um uns zu firen. Enorich un

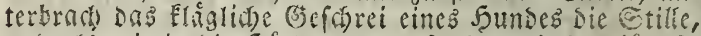
unb a!s wir in bie Soutte traten, fanden wir sas iungfte ber Drei Shiere, bie mit Sohn Davies gegangen waren,

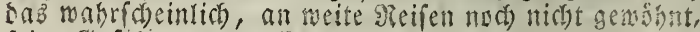
feine sefubrten veryafien batte und zu feinem Geburis. orte zurlicigefebrt war.

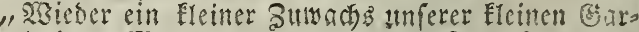

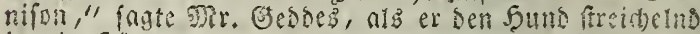

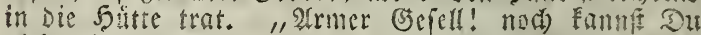
nichts Uebles thun, boffentlich wird Dir aut nidbto Ucbles miderfabren. sisenigfens fantif Du uns sid als Eatronadie gute Dienfe thun, und fo Ennen mir uns tubig sem Ed)lafe fiberlafen, ia mir fiber fenn Esnnen, safis Du uns erweden wirft, wenn Der feins nabt:."

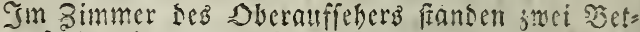
ten, auf bie wir uns warfen. פ)

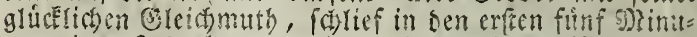
ton ein. Sch aber lag cime Beitrang in zmetfirhaftest,

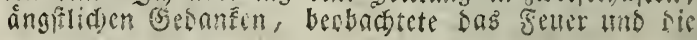




\section{35}

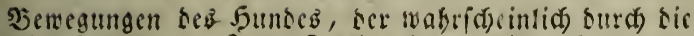
Abmejenheit SCB John Davics beuminbigt, bals bem Seero jur इhưte, balo wieser jurudflicf, sann nabete

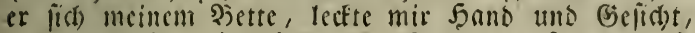

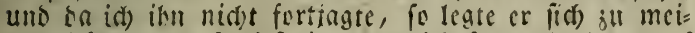

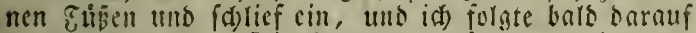

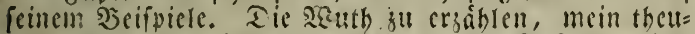
erfer 2 ran (benu id) gebe ned) immer rie Soffmung nid)t

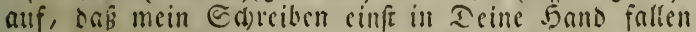
wiit), bat midi nod) immer, bat mid) ferbft in meiner

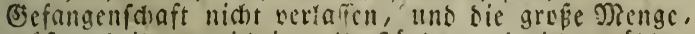
gréstentbeils unmidtiget lumfánse, sic id erzéblte,

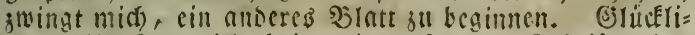
d)erncife Ennn id) bei meincr Elcincn Edrift vicle Dogrte in wenig Siaum jmángen. 



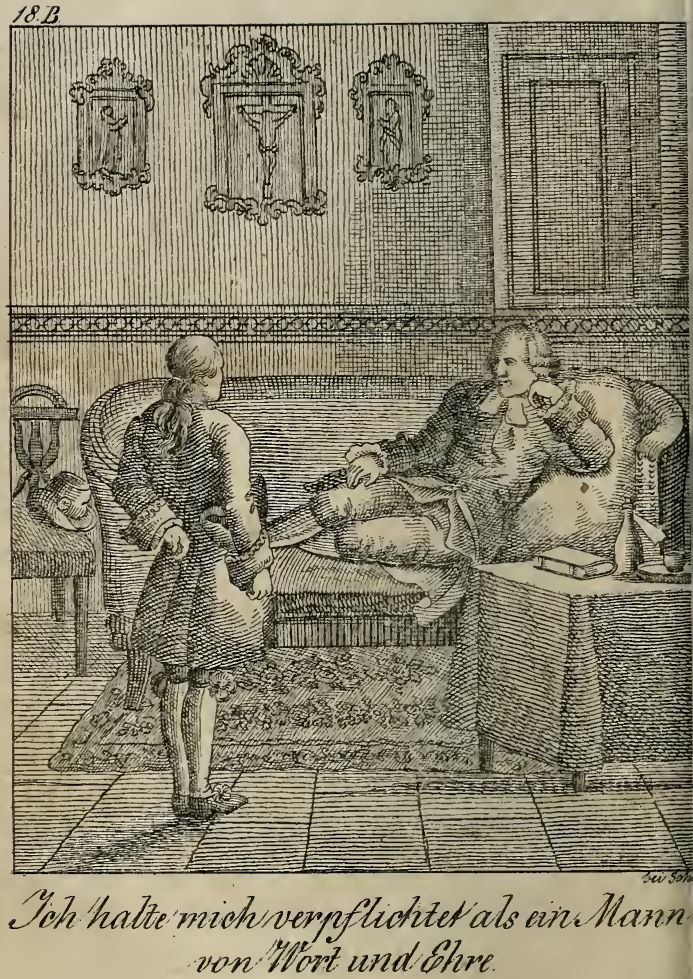


NBalter Scott'B

fåm mtlidae

$\mathfrak{S}$

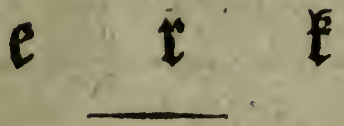

e.

Rea táberfę̧t.

Siebenzernter" Baub.

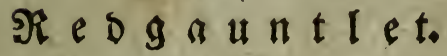

Eine E:zåglung aน̉ Dem ad)tzehnten รalibundert.

Dritter zheit.

St $t \mathrm{t} t g a r t$,

bei (s)

1826 . 


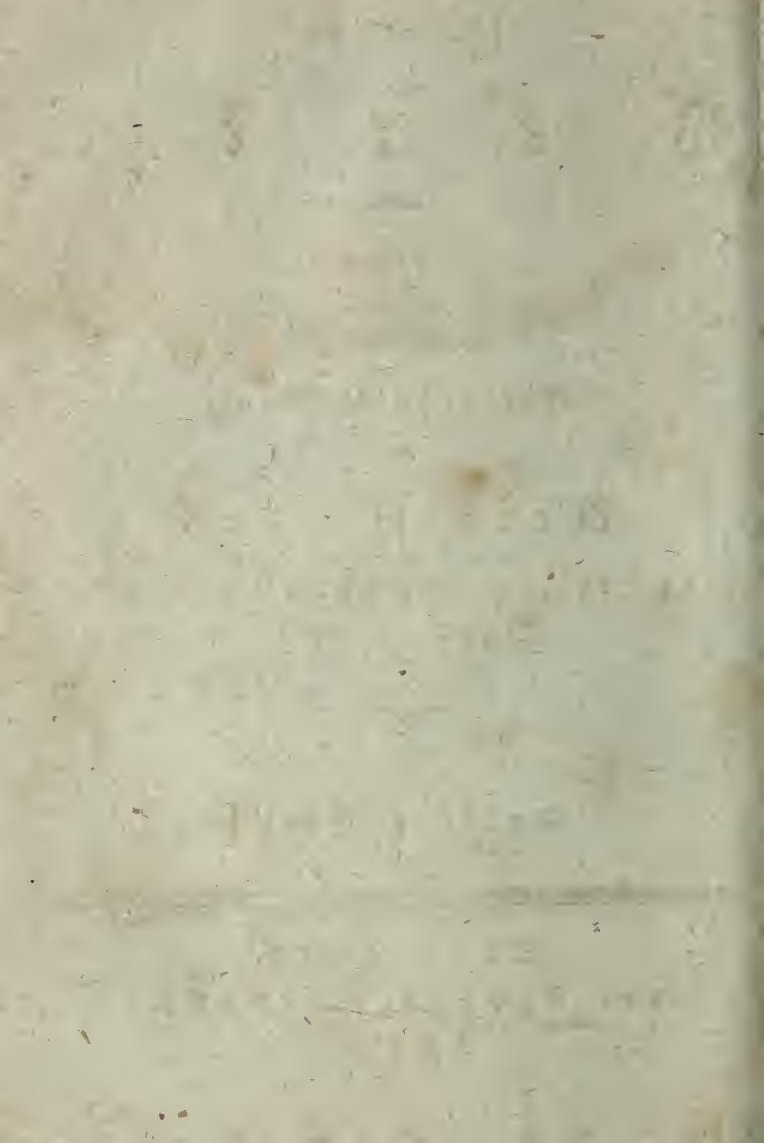




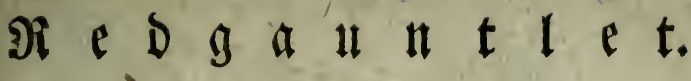

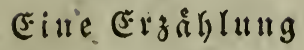

a

\section{- $\mathfrak{B o m}$ -}

\section{Derfaffer dez 2 a a e rey.}

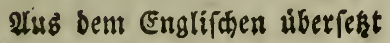

von.

(5 a $\mathfrak{x} \mathfrak{I B}$ eil.

S由 folge Dir, o Meiffer, nur voran,

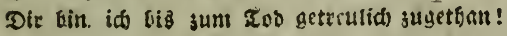

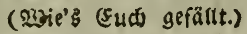

Dritteb $\mathfrak{B}$ ånd den.

St tat $\mathfrak{g} a \mathfrak{r t}$,

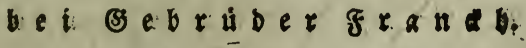

$$
\text { I } \overline{8} 26 \text {. }
$$





\section{Re}

\section{Erfe Sapitel.}

Sabon graute der Morgen und noch lag Mr. (3) CDes und ich in tiefem Scblafe als mein hündis fcher Bettgenofie ung erwectle, indem er !onfing son

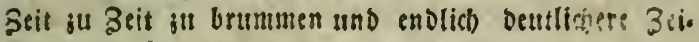
cben, gab, bak ter feind fich nabe.

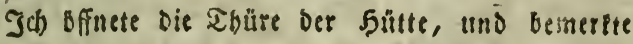
in einer Entfernung won ungefäbr 200 Ellen eine fChmale aber fefe gefthlofiene Colonne von Da annern, bie ich für eine Dunfele fecte gebalten baben wartie,

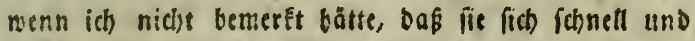
fabreigend näberte.

Der Sund fubr ibnen entgegen, lam aber nurgen.

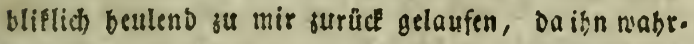
(d)einlich ein Stof ober ein Stein getroffen batte. Itngetwis ob MRr. Sedoes fich bertbeibigen doer unser. banbein woßte, war if im Begriff ebent mieber in

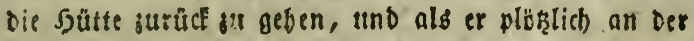
Eolite ju mir fam uno feinen $240 \mathrm{rm}$ in ben meinigen 23. Ecost' 23:rt: XVII. 
legend, fagte: „\{aß̧ uns ignen månnlich entgegen gelin, mit baben nichts gethan norülice mir befabsumt fevn müsten. - "freund," fagte er, indem er feine Ctimme erbob als wir uns ibnen nabeten, "wer tmo mas feys Sbr, und in welcher 2Alficht feyd Jis bier auf meinem Eigent? um?"

Fin lautes 5abngeläbter mar die antwort, uno eine Feike Eefiger melche vor Der Fronte bermarfbirts ftimmte fogleich bie befaimpfende Dielodie Des fiebes an, Das mit ben 230 oten arfangt:

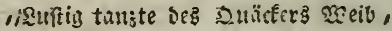

Juno luftis tante Der suifer."

Ealbft in siefen 2ungenblice bes Echredeng granbs te id) Den Ctrī Des blinden Beigers $23 i l l$ ill er: foumen, der man feiner umberftreifenien Lebenentst megen ben twandernden Sillin nent. Gie naberten fich fofnell und mit groper Drinums, bornus: "Dis ftoljen Beiget, Striegsgefänge fpielend;"

a्Alz fie bans nab bei unz maren, umsingelten fie uns mit einer einjisen 23 enoung, und erfoben ein

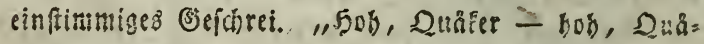
Fer - Da baben wir fie ia Beide, Den naffrn QubEer und Den trockenen Daju."

"f fengt ben naffen Duafer sum trocinen auf, tub macht Den Frocienen Durch Itnertauchen naí," sintwortete cine andere Ctinme.

„2030 if Denn Die Eecotter, Soln Dnvies, Der mes: Fifhe raubte als ein Ceenalb auf Dem Miian: 
gelfen?" rief cine britte Stimme aub. "Ich babe nod) cinen alten Straus mit ifm, und bringe eine ₹ajche mit un bie federn binein fu thun."

25ir ftanden in ruhiger Erwartung Da; benn ges gen mebr als bundert פonnn Die mit Flinten, Sifchs. [peren, eifernen Etangen und \$rügeln bewaffnet wa. ren, \$Biberfand ju leiften, würbe eine wabre $\mathfrak{D e r}$ rüclbeit geiseren feyn. SMr. Besbeb, beantwortete bie Grage nad) Dem Sberaufieber, mit ftarEer, volttonen= Der Estume, uno mit einer thannnlichen obletcl)gültig= feit, bic fie zmans, nuf ihn zu acosen.

"Iobr Druiez," fagte er, "wirb, boffe ich, bald in Dumfriç feyn."

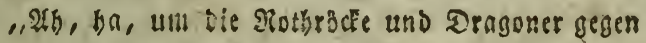
uns zu febicken, Du fdjeinbeiliger, alter Schurfe!"

In bemfellien 2azenblick warb ein Echlag auf meinen freund aefubrt, Den (d) mit bem Stoc pas tirte sea icf in ber Sand batse. Sinbenbliatids ward ich zur (Frie betworfen, und ici) glaube nich noch er. innern zu fünnen baf einer rief: "Solslagt ben iun= gen Spion todt," und baß andere fich für mich ver= wendeten. Saber ein gweiter Schlog auf bem Sopfe Der ben Gebadel traf, bernubte nich meiner Einne

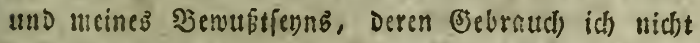
fo bald mieber erlangte. anls id) wieder zu mir fam, lag id auf rem sette, vou weldbem ich mich vor bem Etreit erboben batte, uno mein armer Gefäbrte, Der iurse 2ieufondläner, Defien Niutb bei Dem Lärm 
Deb 2Allfrubris ganj gefchwunden war, batte fid fo nab als mäglid) an meine Ceite gebrängt, zitterno uno mimmerno, wie in Der furchtbarfen Tobesangft. Tch) wat im 2(nfans nicht ficher ob nicht Det ganze 2tuffano cin Traum fen, aber als ich es berfuchte mic) iu erbeben, fo fublte ich Schmerien und 2 eflems twing, bie mich) nur zu febr überieugten, nie wabr bie כeichäbigungen fercn, bie ith crlitten batte. Эक fam. melte meine Ecclentråfte, lauldite - und börte in Der Jerne Dns Jauchsen bir sufrübrer, roclate, obne

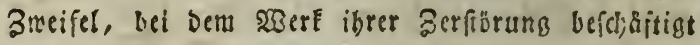

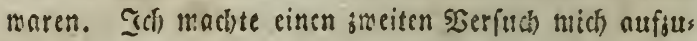
ticjeten, nocr mich menigfetis umjumenden; iens ich lag mit Dem (Geficjt gegen bie 23 wnd Der Shütte, aber ich fand Daf meine Gelente feft sufammen gebunben,

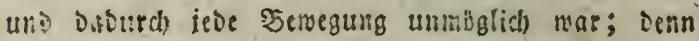
gtrate uno Süpe waren, swar nicht mit etricken, aber mit leinenen und rollenen Iudbfreifin, feft jufan. men seiántirt. 216 idf meinen Suftand bemerfte, feupjte ici) ticf sebeugt von Ërperlicien seiben uno. non Geelculdomers.

Dèrubigend lipelte eine Stimme an Der Eeite

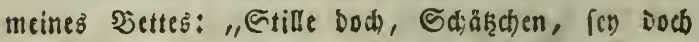
rubis, balt bein Daul, wie ein gutes fint - Du bift uns fchon thetret genug iu fieben geiommen. Dein Manncien ift faiber Dralif gegangen,"

"Dr ich Die Diedensarten Der frau Des wanierns ben sjufifoncen ju erEennen slaubte, fo frug id lie 


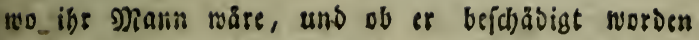
wåre.

"Berichlagen," antirortete Das Weib, "gans in Etadten zerfchlagen; ju nichts mehr zu gebraucisen als 3ttnobb!jchen Daraus ju machen - Das befte slut in Echottlano."

"Erichlagen? - Slut? - Ift Euer Nann ber. wundet? Ift $\mathfrak{B l u t}$ vergofien - Sind Elieder jers fclagen worben?"

"ङSlieber gerfalchgen? - Id) mollte lieber," ante

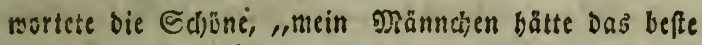
Blied an feinem Siörper zerbrochen, als feine Beige, Die Das befe פ̇lut in Schottland mar - es ma: eine Eremonejer, fo viel ich) meifs."

"Pab - nur feine Ëeige?"

"Ich) meiß nicht was (Ew. Gnaben meb̆r bätten berlangen Eürnen, wenn er nicht gar ben Şals ges brodsen båtte; Denn das ift für mein Diänncoen $2 B$ il. lin und für mich ein eben fo grobes Itnglück. Etill boch, ift leicht gefagt, aber wo befïmmt man etros Den funger fu ftillen? Der Broterwerber ift fort mun fünnen wir fikzen und bungern."

"Nein, nein," (agte ich, "ich) will Euch zwantis folcher Beigen zablen."

"3mansig foldter! wift- She mab bab beift? Im banisen Lanbe gibt's feine foldhe mebt. 2aber menn alich Ew. (s)aden fic uns iablen wolte, was (Euch freilich) 
bier tand ienfeits zut grösten Ebre sereicfen můrbe, mo wollt Jar Das Eeld bernebmen?"

"Sch) babe (j)eld gentts," fagte ich, inoem ich es eerfuchte meine Sand in Die Voruftafche zu fiecten; "löbt biefe Banden-uns ich will (Euch fogleid) zablen."

Dor wing fobien fie zu beivegen uno fdion näbise te fie fich meinem Jette un mich, wie id) boffte, bon meinen รanden zu befreien, alb ein näbereb, vers

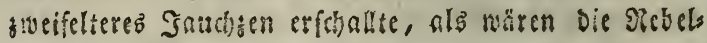
len Det Sgälte naí.

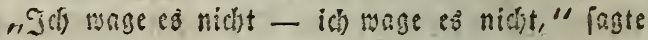

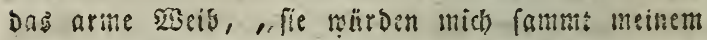
Dianndign sillin ermorben, fie baben uns folyon foblimm gentis traftipt; - aber wenn es noch etwas attf Er. Den gibt, nusper Dem fo. foll es gern gefcheben."

Das erinnerte mich an mein Eüperlit)ez Seiden. Die Deregung meinç Femiths, uno Dis folsen Der Sorhandung Die ich eiduldete, Eatten einen beens nenten Durf in mir erweut. Saf forderte einen Erune গุaffer.

„3er allmåchtige Simmel behtite Epps ainslic einem EranEen Serrn Ealteb $923 a f$ fer ju geben, wenn et

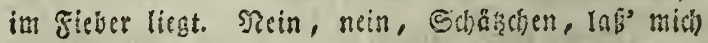

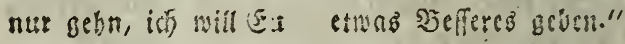

"ङebt mit was 9hr wollt," erwiederte ich, "nur Ealt uno fitffig mus es feyn."

Die frou refchte mir alfo einen grofen Selcs mit Branntwein und 20 ffer, ben ich vine mich viel um 
war bas Erfte, bas ich wieber vernafm; Dann bemerls

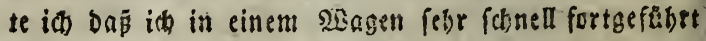
ward, Deffen ungleiche Bewegung mit beftige Echmer.

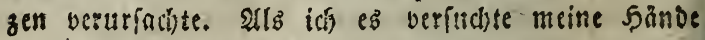
ausiuftrecfen, um ein mittel zu finben mich biefsm Seiden zat entziebn, fo fand ich), bas ich nod immer wie früber gebunden war; on trat mir bie (d)rectichle

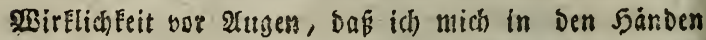
Der Menfchen befänoe, bie fich erft vor êurem fo fcherer an frembem (Eigentbum vergriffin und mich nun rauben ober gat emorden mollten. Sh) Dffinte bic Alugen - umfonfi - alled umber wat in Dum fel gehtullt, benn ein valfer Iag wat feit meiner Ees fangennabme vetfricícn. Eime entmutbigende Sirane. beit laftete atof meinem Sante - mein Serts glibte, wabreud meine füfe umo Saänce wegen Des gebinders

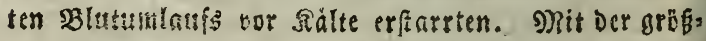

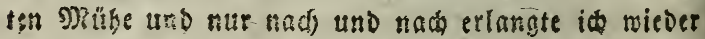
Die firnft, Die åuferen Ione und umfrande zu beobs acitin; aber als ich es wieber vermodyte, ba fiellte fich wenig Struftiches bat.

Mit ber Samb umbertappeno fo weit die Ban. Den es etclatben, und mit Sülfe cines zufäligen Donishinmers, bemerfite ich, Daß Das FubrwerE, in welclect ich fortgejchleppt wurbe eins vou Den leiditen Jaaternuagelein war, wie fie im Sande thblich fino; Doci) batte man mit einiger 2 (tufmertafamleit für mich epirgt, benn ich las auf einigen Etrobfälen, bie mit 
Iaffen warbe, Dafi man mich ungeffraft eruorben ober gefangen-balien fönnte; aut ibre Sgabfucht fuchte idi) Durch eine Şelohnung ju reiz̨en, bie ich ibnen veridrach, wenn fie mich los laffen wollten. Ein zors niges (s)läb)ter war bie 2ntmort, die mir nuf meine Drobungen marb; meine Nerfyrecjurgen (cbienen metbr Eindrud zat machen, Denn fie füfterten zufammen als fobrwanten fie, fo Daß ich meine Inerbietungen wie.

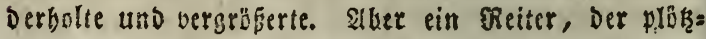

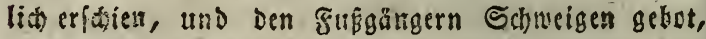
neferte fio bem Fithruerfe und fagte mit ftarfer ent (d)loffener Stimue: "Iunger פiann, eB̉ foll (Fuch) serisulich nich)ts zu Seid gefackn. Wollt Jbr Eucb fill tmo rubig be:balten, fo Funnt Shr auf gute Res benblung zăblen; verfuclyt Shr es aber, diefe feute oon Sbrer Pfficht abmendis zu machen, fo will ich fols che M?aapregeln ergreifon, um (Ench) sur Etille zu bes

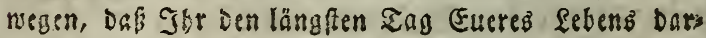
an benfen follt."

It) glaubte die Stimme zu fennen, welæe diefe Frobungen atsoffief; aber in meiner sage fonnte mein

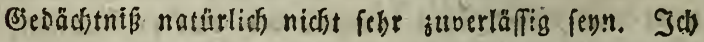

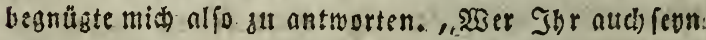
méget, Der mit mir frricht, fo nebme ich ia nur bas SRedt des niebrigfen Eefangenen in sinfpruch, ben man gefeţlich Eeinem gröperen 3mange unterwerfen I.n als Der jur Sicierung feiner Perfon nöthig iff.

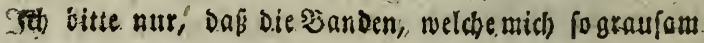


mofnt, und die von den fifáern Des Dörfdens Der Eairs Der Golmay Seen genannt wird. Doch fann

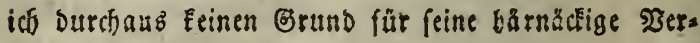
folgung gegen mich finden.

Unterdeffen ward Das SubrwerE fchlafrig und lange fam fortgegogen, bis bas näber beranrolende Don. nern ber Situth eine andere Befabr befürchten liefi. Sch Eonnte mich in Den Iönen nicht täuitien, Denn einft batte ich fie bei einer Belegenbeit gebött, mo

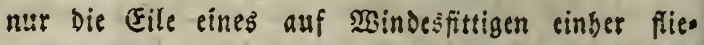
genoen Foffes, mich von Der \&efabr rettete, im ₹rieb. fano unizuEnmmen. $\mathfrak{D} u$, mein theuerfter Sinn, muft Dich Deffen noch erinncrn; aber, 0 , Des munderbas ren 23iberipruchs! Derielbe Mann, fo viel id) mich erinnerte, bir mich Damals errettete, war nun Det gübrer Dor Befes!lofen zande bie mich meiner freiheit beraubte. Die Sefabr ward oringeno, wie ich ver. mutbete; 30 otte wurden gewechflt und Zeichen geges

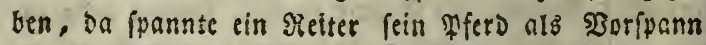
wor Den şagen, um Den erfchipften Ihieren ju Sülfs ju fommen Die inn jogen; ief̧t mard Die Mafchine fcheller in Dewegung gefert, und Die Pferde mit Slücben und Etüfen iutm $\mathfrak{A}_{n}$ icbn angebalten. Doch

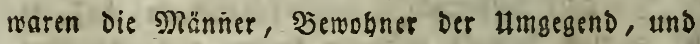
ic) batte perfünliche Srünbe jut glauben, Daßj twenigftens einer van ibnen, mit Den 2 bgründen und Sdbluchtes:

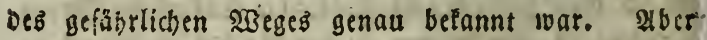
auch lie fefwebten in Sefabr; und wat Dem alfo, mic: 
18: Fliffern uns ibre 2Anftrengungen Das Fubrwert funnell von Drt uno Etelle ju bringen fürtsten laffen mubten, io war ez Eeinem 3meifel unterworfen, Daß

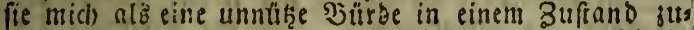
rituflafien witrden, ber eine iede פg̈̈lichfeit Der flucht undentoar macbie. Das war ein gratenuollsangfti. d)er Buftund Der bangizfeit; aber eb gefiel ber \$or. fchung inn bis auf einen punft ju fteigern, wo ibn mein Seift foum ertragen Eonnte.

AlB nit แแn einer fdomarsen sinie näberten, die ich, fo febr fie nuth in Pebel gebüllt war, für bas Hfer erpannte, burten wir einige Jlintenfwitfe. Da

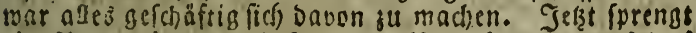
ein Dieiter einber and (c)reit : "Tुorgefelsn, vorge(ebn!. Die Eandreiter fino ausgejogen, allonby zom nutb frime faomng verlieren, wenn Shr nicht beift."

Bei Diefer Madicht cilten Die Meiften Dem Mtfer

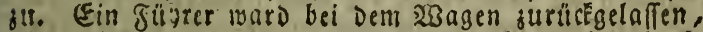
alb er ign aber nach allem פJemühen Eaum Foarbreit son Der setclle brachte, als bas Subtwerl tief in Den

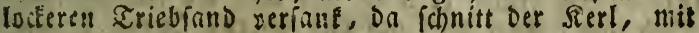
furchtbaren. Flüchen bie (E)tränge entjivei, unb eilte mit ben Mferden Davon, Die ich noch lange im feachs. ten Gande und in bea Wiellen platfchern biote, wie [ie in rollen esallop bintweg eilten.

शoci) immer börse icf cinjelne frlintenfchülfe, bats aber verlor fidt) Der Schall in Dem Douner Der naben.

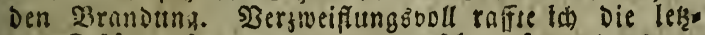
ten sirâte zufammen, ridatete mich auf, und es ges lang mir eine fizzenbe Stellung anzunebmen, Die mix

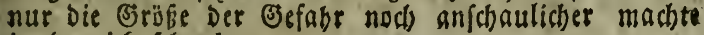
in ber icf) ichmebte.

Dort lag mein 2 aterlano - mein liebe s Entgs Iano - Das Laris mo i id juerft Das ficht er blickte, wobin fith feit meinem frübeften alter alse meine

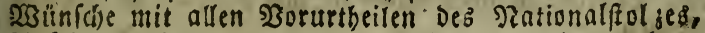
binfebnten, Dort lag es - eine Epanne meit van bem Drte wo ich mich befand; und boch war Diefe Spanne, 
Die eit Sind in einem 2 ungenblice uberichritten bstte cin Echlagbaum, Der mich auf emig von Englano trennen folte, uno som feben. Bald börte ich nicht blos Die furchtbare Siransung fich nahn, fonderm ich fab alich, bei fchmanendem lichte bes Monder,, die fchäumenoen Nisegen Der serfeblingenden MBgellen, Die

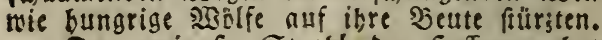

Der geringfe Etrukl Der Soffnung batte mich verlafien, Eeine ßiettung (chien mebr méglid); Da über: mannte bas Semútétena meines sutftandes bie fee frigfeit, mit Der ich nlles bisber ertrug. Dreine 2tugen wurben feucht - ichwindelno und berjweifelt ont Furcht mein Sopf - ich fehnatterte uno beulte wie bie beulende, tobende Eee. Echon batten juei grose Bietlen ben $23 a g e n$ erreidit, Da erichien, mie Durd Sauber, Der oft ermáhnte 2anfïhrer Der Siebellen an meiner Eeite. Er ffrang som Wferbe in Den 28 agen, ierichnitt bie Seinemant, die mich fefielte, befabl mir

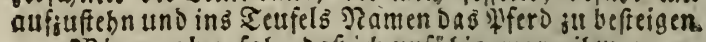
Qsie er aber (ab), Das ich unfäbig mar, ibm jtl ges torchen, da ergriff er mich, mie man ein balbiabriges Sino fast, marf mid alff bas Dfero, frrang binten cutf, bielt mid mit Der einen 5ano, mäbrend er mis Der 2tnderent ias Pierd lenfte. Süflos und enn Echmerien gepeinigt mie id mat, wat mir ber Grab Der Eefists tmbefannt in Der mir fchwebten; cinmal aber glaubie ich, mufte bas giferd fobrsimmen oder mat des nabe baran, uso nur mit Delibe gelang es neinem ernfen, gewalsigen föbrer, meinen Jiopf

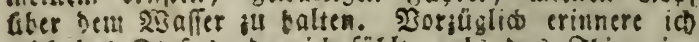

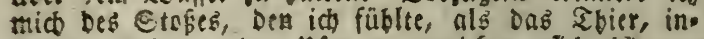
sem es veriudte Dag llfer iu erreichen, fich täumte

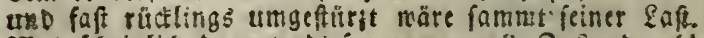
R3abricheinlid rauerte Diejer grauenvolle Suftan wobl nicht mebe als jmei Doer orei grinuten, Entię̧en tmo codesangf aber fabien fie mir fürchterlich ju vet. tongern.

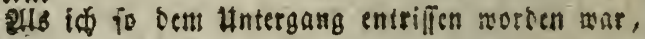


fonnte idb zu meinen Befbatzer obet ju meinem un teroräder (Denn er verdiente beide 3 enennungen) nat Die 230 rte fazen: "Ior wollt mich allo nidat ermor. Den?"

Gnoem er mir antwortete, ladjte et, asoer ez mar ein Eseláchter, Das ich nie wieber bören möchte: „Tbr glaubt mobl, fonft batte ith ben 23 ellen die 2rrbelt uberlaffen? Áber wenn ber Sdh zer reine Sdarfe als dean $23 a f f e r$ siebt, geidielst es wolgl um ihnen Das Reben su retten? - Sdweige aber mit Frazen uns

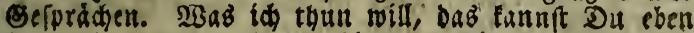
fo wenig errathen oder verbindern, wie ein Masn mit

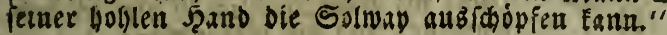

In war zu febr eridoipft, als baj in batite ant worten fonnen; und ba ia an allen (Sliedern gelihar uno erftarert war, fo muste fid es ohne wiberitaus Dalben, bas man anid auf- eiti Pferd fehte, Das mat

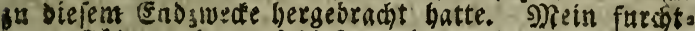
bares funter ritt auf biefer, eine andere perion auf iener seite, uns of bielten fie mich aufredfs in Sat.

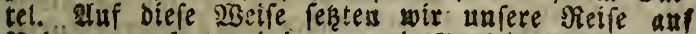
R:Sentyegen fort, mit benen nein begleiter eben fo ves trat wie mit bea gefábrlichen Pfaden am Solway wat.

Eablid, nachjem wir ein Eabyrinth, Dunflex, ens gec sesenwege dardipandert, uno meír als eine rau.

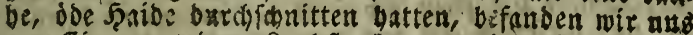
a Equipage uniere 24 (alunft zu erwarten folien. 3is me uer gropen (5eleid)terung ánberten wir nun unfer

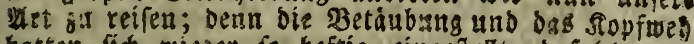
batter (iक wiejer fo beftig eiugeiftell, bafs ic sam

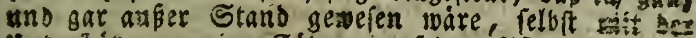
Uateritúnum meiner Fubrer, auf oem Pferbe zu firen.

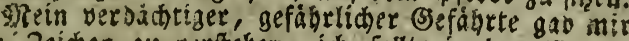

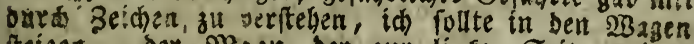
iteigea - ber Rasn ber zur linfen Seite meines pferbes geritten war, ftieg uad mir ein, und $30 \mathrm{~s}$ 


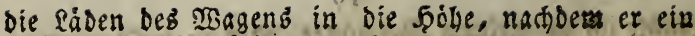
geichen Jum fortfabren gegeben hatte.

213 ber Sutforer den : th. beim Echimmer einer Blendlaterne die Săge nete nes neuen Begleiters, uno war fait gang fitser, baß id) tn ihm Dell Diener DeB Bantenanfäbrer vor mit bobe, den ifich fruber in frinem eigenen soule an scofenburn gefetien batte. um ficher zu gehn, frug ich iln, ober nidht Shriftal Sirun biese.

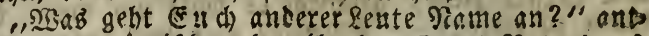

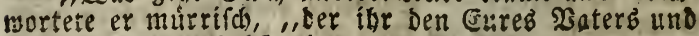
(5uezer Nutter felbft nict fennt?"

"Ibr aber pennt fie, wabricheinlion" rief itb bes. tis lekt erdulbe, fteht mit biefem (3ebeimuis in sirbirs

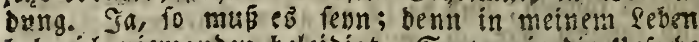
babe id niemanden beleidigt. Sagt nir tie llrfade

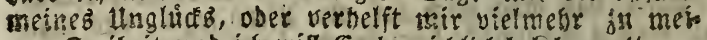
net Jreibeit und ich will Eut reidilch Helobnen."

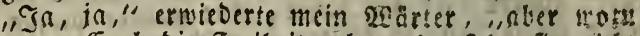
forte inan (Euch bie freibeit geben, Da she fie nidut mie ein Gentleman zu gebrauchen mift, iondern Evers Seit mit Duäfern und Beigern uno folchem flimien gefindel attbringt? $23 a$ are ich Euter - bm, bm, $\mathrm{km}$."

Sier bielt Ebriftal plöblid inne, wie es fchien. reil ihm eine Sacheicht entichlunpen mollte. Sch bat itn nochmalg fich freunofhaftlich gegen mich zut betra: gen, und verfarad ibin bas annze Eavital, bas ith bet mit batte, $D a b$ aat nicht itnbedenteno war, wenn es mir ztt meiner flucht bebillfich feyn molfe.

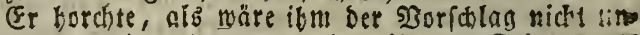
angenchm, und ontwortete mit milberer Etimme ntg

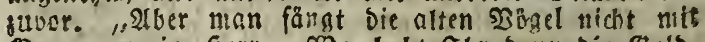

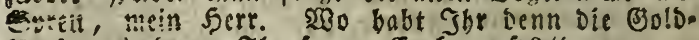
füdre, mit benen gife fo um Ench merft?"

"Ich will (Euch Das (Sels gleich geben, und sneas in bianfnoten," fagte ich; aber indem ich "mit meines Sand in Der Bruftafde mublte, fo fand ich, Daf mein 
Eajchenbuds meg war. Sth hätte geglaubt, Daß blos die Steifbeit meiner Sände mid berbinderte, es zแl fin. Den, wenn Ebrifal Niron, Deffen Züge Epuren Der Brobbeit trasen, weiche Frentie an uienfichlidsen Elend

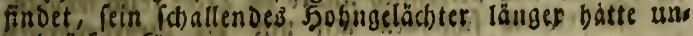
terorficken fönnen.

"O bo! tilein iunger sert", fagte er ; "wir bas ber Sorbe getragen, (Eirch die Mittel ju nebmen arme

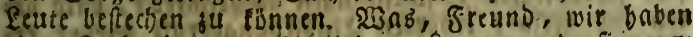
etme Eecle To sut mie andere feute, Ind fie juat Ereubruch berleiten zu nollen, ift eine Iodtrunde.

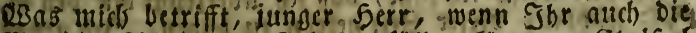
Marien= Sirde Init (Sals anfüllen Ë̈nutet, Egrifal giron wútbe es eben fo wenig reikzen, als wären es dien lo viele, stierelfteine.

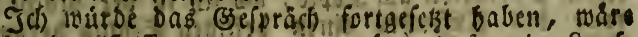

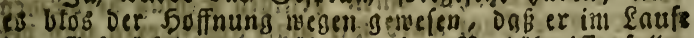
bes. (seipräc)s etwas uber meine Serbältnifie fallen taffen warbe; er aber fohnitt alle fermere ssittbeilum gen ab, indens er mich bat, mich in bie Ecke in lesen und zu (c) tafen.

"Dir sifi fobon ermattet genag," fügte er binju,

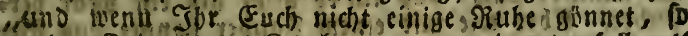
berben Deine Iunge Jirochen gan suseinanderfallen." sizirffich bedurfte ich Der Rqube, upenn auteh nicbt Des Schlafs, Der Frane, ben ich su nit senommen Batte, nirite hods inimer fort ich berabigte inich alfo bantit, $D a B_{B}$ man feinen 2lugriff nuf tmein Eeben beabs fiefitigte, Die Furcht bor cinem ploblichen ₹obte rang

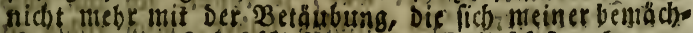

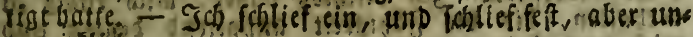
erfuicticlici.

2t

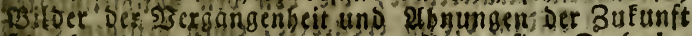
Torrebten vernitrt bor meiner phantafies Doch bes therfte ith, oaß fich meine Eage, uno grwar bedeutens su meinen Gounften, verändert batte. Jah lag in eis nem guten Sette, Deffen Hmbånge jugesogen waren; 


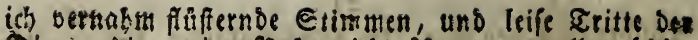
Diencr, die neine Finte nicht fibren zu mollen fohis nch; $e^{3}$ Pam mir tor als̉ befände ich mich in Den buntoen meiner Fretunde, ofer in Denen ron DReme foten, Die mir perfönlich nichts ju Seibe tbun mollen. undeutlid. (d)meben mir nur tie Begebenbeiten Det twei oder Drei ₹age vor, bie ich in abmechfelndes

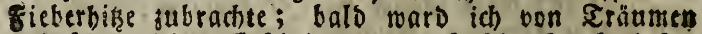

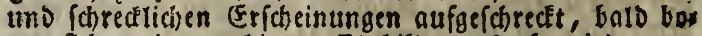
ten fich meiner erbikzten Einbildungstraft wieder ers frenltedere Gegenftände Dat. 22lan Fairforo roiro mid perfeben menn ich fage, oas ich tiberjettgt bin ben B. alor. mäbrend Diefer Seit gefebn zu baben. Jch genof sistlicher 2 ebienung uno mebr als ein פRar ließ maB

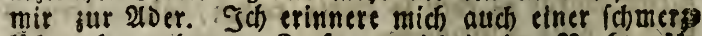
lichen Operation am Ropfe, wo ich in Der Nacht wabs

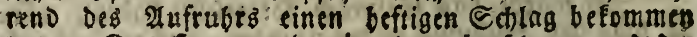
batte. Das 5aar maro mir glatt abgejétoren und dee bitnichăbel unterfutt, um zu leben of bas Eebirn nidet gelitien bate.

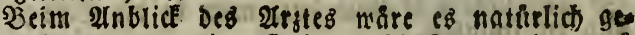
mefen, ign megen meiner (Sefangen [d] aft anjureben, uns

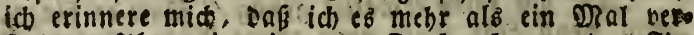
fachte. 2lber wie mit einem Sauber bannte Das fie bet meine Sunge, tund wenn ich Den Doctor um Saülfe bitten mollte, fo phantafitte icf Darüber, uns (prado id) meiß nid)t veldjen unfinn. "Eine unmiberfteblide Bes. roalt fchien Das Ëefpräch auf einen andern ols Den bes abfichtigten (segenftand ju leiten, uno obgleich ich mich Des Irrtbums betwuft war, fo fonnte ich ibn oDed vicht serbeffern. Ich befalós oabet, mich rubig in berbalten, bis die fäbigteit anbaltend benten und mich ausorüden fu Eonnen, mit meiner gemöbnliden Befunobeit jurüctéefrte, Die von Den Diubjeligfeite: and Den feiben, Die icb erduldete, einen beftigen Etop exlitten batte. 


\section{3 weites statite.}

Sortiesung Des gasebuds Dacite a atimers.

शandbem ich strei ober Drei ఇage, vielleicht mebr, vieflecht weniget, im Şet!e stigebracht batte, wo icb forsfaltig verpflegt, uns wie ids slanbe mit fo vieles Borficht bebandelt murde, als nar meine Eage es ers beifate, rard mir enslich erlatubt Das Siett, abes nicht die Stube zu berlaffen. Nun roar ich fobon eber im Stande, einige sBenierEtungen über Den Drt ja macben, wo ich gefangen gebalten warbe.

Dem 2(nebn uno Den Mäbeln nach, glich Das? gimmer Der beften Stube in einem Pachters 5atts ble genfter gemäbrten, vom zmeiten Stocfwerf berab, Die Uusfict)t in Den Sof, Der mit allerlei Bseflugel bes.

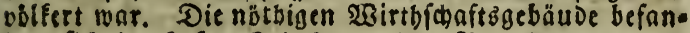
bent fich im 5ofe. Sch Eonnte Das $\mathfrak{T r a u b a u s}$ uno Die Echeune tuterfcheiden, auch börte ich von einem ento fernteren Bebäube ber Das Brillen Des פiebs uns andere Iandiche Sobne, die ein grofes , wobloerfebenes Pachterbaus berrietben. Der Anblict fowobl als dis ¿öne waren geeignet, Dic furdbt bor einer periouli

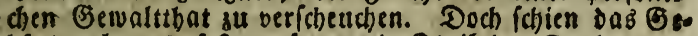
bårse nlt und feft ut fenn, ciu Ibeil Des Daches twat mit binnen verfehn, und Die Nenuern maren unges beuer Dicf; enolich merfte (ch noch zu meinem 2 sers Drufie, Dafi-Die fenfter Des Bimmers, erft oo surs rem mit eifernen Stangen verwabrt morben maren, uno Dá die Diener, welche mir Eveisen brachten - dee andere băusliche Dienfte leifteten, immer Dis sgure wieder zufdoloffen wenn fie weggingen.

Die Ṡequemlichteit und Reinlich Eeit meiner Stu be war ädt englifber ast, fo wie ich fie nie auf Dem 
andern $\mathfrak{t f e r}$ ber Tweete fäb, bas febr alte (5)tafel, mornub der Fubboden und das Befimfe beftnno, wat mit enem fleíre gefdenert, ben cine Gchottlánoerinn Eaum ibrem Eofturifen möbel fobents.

Die Bimmer, melche su meinem Bsebrauch beftimm waren, beftandent in einer Schlafítube, einem anftoffen: Dent Eleinen $30 b$ raimmer, mit weldjem ein nod) fleineres fiabinet in $\mathfrak{2}$ erbindung fand, welcheß ein ichma.

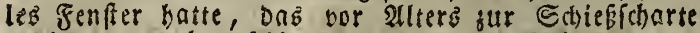
genient jut baben fajien uno nun ber Luft und Deta (ic)t einen freyen Durchbang gemäbrte; nber außess Dem lounte man unmöglich etwos anberes alg Den blatten finntrel feben, und felbf den nur, menn man

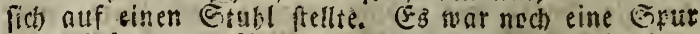
eines beronderen Eingangs in Das Jinbinet vorbanden, nuser bem Der in DกB 280 bnzimmer fübrte, Der nbet erfit fïrslich jugentauert worden war, wie ich entoedkte, inbent ith einen Sheil Der: apeten megriß, bie Das frifche Materwere bedecte. Ich fand dafelbft meine

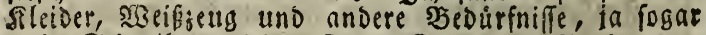
mein Edareibjetts, Das zeder, Dinte uno papier ent: bielt, fo Daß id) im Stande bin, Diefest bericht von

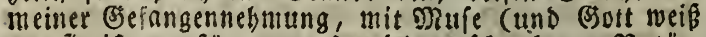
e3, lie ift ungeftört genug) nieberjufchreiben. Nature (id) bertraule ich fie meinem Dulte nicht an, fondern ich trage bie gefchriebenen Blätter bei mir, fo Daßs

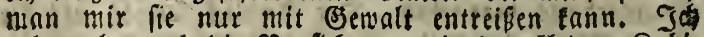
gebrauche nuch bie Sorficht, nur in Dem fleinen Sabis net zil fehreiben, fo Daßj.ich, wenn fich iemand Dem anderen Bimmer nåbert, Beit genug babe, mein ¿as gebuh bei Eeite zul legen; ebe man fommt.

Die Dienftboten, ein Fräftiger Eandburiche und ein zierliches Ennomäbchen, Dab einem Mildsmádchen nicht unäbnlich fiebt, fcheinen von bem åcbten હchlag englifher Bnuesn ju feyn, benfen wenig, wünfeben faft gar nichtb, Das aukier bem bef́rhränEten Sireife ibs

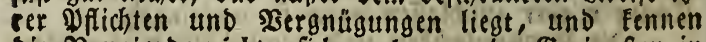
bie शseubierde nicht, fich auch nut im Eeringften in 
Die 2(ngelegenbeit anderer $\mathfrak{L e u t e}$; tragen g:gen mich ift sugleich febr gütig und febr sigerlicis. Mein Tifch ift reichlid verfehn, fie foms

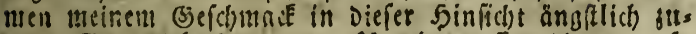
bor. Frage ich aber ermas tiber bas Effen binntrs, fo bringt mich Der Dummosif mit feinem "Sef," "nno

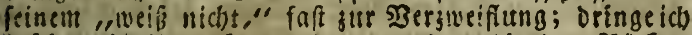

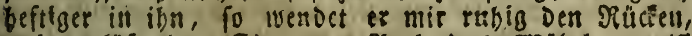

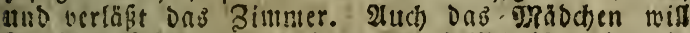
fir to einfältis gelten wie er eg wirflich ift; aber ein (chalfbafte 3 Lä(j)ln, Daв fie nicht immer unterorüden

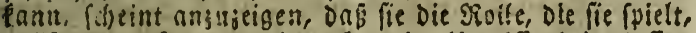
roiffommen Fennt, this aber in linmiffenbeit laffen

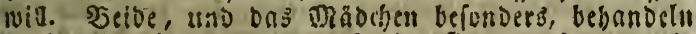
mich wie ein verzogenes frind; fie berweigerent mit nie etruaz geradeztt, aber fie rorgen zugleid Dafür,

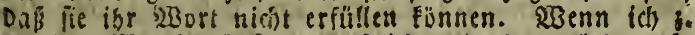

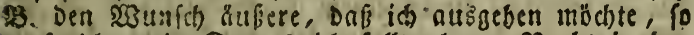
perfpridet mir Dorcas ids follte beure giacht in Den \$urE fpajieren geba und jufeben wie man die frub melft, grnde nie man einem Sinde ein folches $\mathfrak{B}$ er. gatizen verfuricits. Dabei aber forgte fie dafü, Daf fie, wenn es nut imuner miglid) ift, nie 230 rt bält. unterbeffen hat fich eine (s)leidhgültigleit gegen greibeit, eine Gorglofigfeit wegen meiner enge bei mir eingefdlichen, fïr Die id) Durchauts Eeinen Ëruns antitseben weif, wenn fie nicht folgen meiner torpers lichen Schrasche uno Des bäufizen vlutoerluftes find. Jib) babe von Mannnern gelefen, Die, eingemattert wie ic), Die $233 e l t$ Dutrh Die Bewandtheit in Erfteunen fezenten, yermige beren es ibnen sclang Die furchtbar. ftell Schwierigfeiten, bie fich ibrer glucit entgegen

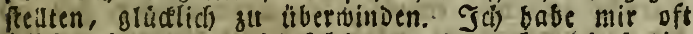
feloft gefngt, wenn id folche alnecooten las, baj nies mano, ber auch nutr ein Gtüdél)en von einem Luaterftein ober einen roftigen Nagel befig̨t, um flamnern attşubeben, oder. Sdblöfer ju bffnen, und ber volle Dufe bat fich Damit ju befchäftigen, gejwunsen if in 


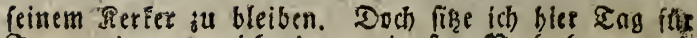
ing, unb wage nicft ben geringften $\mathfrak{B}$ eríuch um meb ne icefreinng jth berberffellitgen.

\&uber die Duelle meiner unthatigfeit entiptingt nidut in ber Erfchlafftung neines Beiftes, pondern in Beffibien gans nuberer art. Meine Lebenegefchidutes Die lange 3 eit in ein tlefes Bebeimniß gebülut nas,

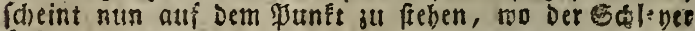
faien nird; ein inneres Beftibl gebietet mir ben \&nuf Der כegebenteizen abjuwarten, wogegen zu Fimplen, meine fotraci) (n Jrăfte Dem 233 illen Des Echicétals ents

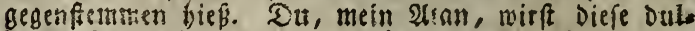
bente Sinbe für zeigbeit nniebn, bie mich rie eine

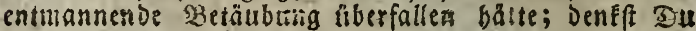
aber an Die Ericheinang, Die mein stranéenbett tum

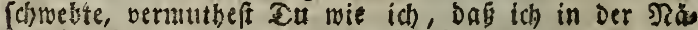
be, ia vielleicht unter einem Dacise mit Dem B. DN

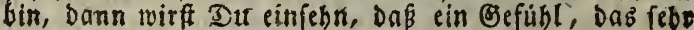
verichieden von Matblofigéeit ift, mich Dazu bemegt, mich gemiffermafen mit meinem @chicffal ausjurübnen. Doci) geffebe ich ein, $D a \hat{B}$ es unmánnlich ift, mich geduldis einer gewaltibitigen Eefangenichaft zu unter werfen. DRein Sers empört fich Dagegen, befonders wenn ich mids nieberfere, um in meinem Eagebuche mein Reiden za erjäblen; ich bin entfolofien den evo ften Echritt ju meiner Befreiung zu thun, and wo

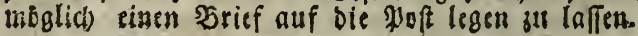

Ict) bin getänjcht. Mls Das Mabchen Dorenв, Das tch mit zum $20 t e n$ ausierieba batte, non Det Sejore gung eines 5zriefes bürte, bot fie mir roldig ibre Dienfte an, und ampfing ben fironenthaler, ben ids ii) gab (benn meine 2 b̈ríe mar mit meinem inbaltş (c) mereren इaícísnbuch nict entifolnn) mit einem \&a cheln, Das Die ganje Reibe ibret weif́en Säbne jeigte. 2lls ich fie aber, um einige 2ufliarungen tibe meinen gegenmärtigen 2lufentbaltsort ju erinngen frugs nach welcyer poftetation fie meinen Sorief tragen oper 


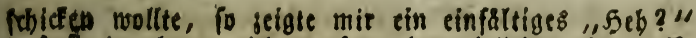

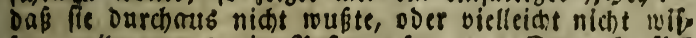
fen rollte, tons cin Poftams (et). - "DummEopf! rief tch beftig aus.

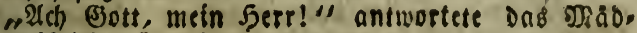
ben erbleicheno, wie es ibr immer ju beben pplegte, wenn td) Seftigkelt zeige, - "werben Sie nicht bets tlg - Sch will ia Den Drief' auff Die Poft legen."

"Sisas! und lemnit Doch Den গRamen Der Plofiftre

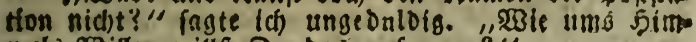

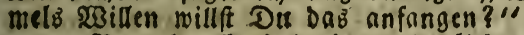

"Serubigt Euch Doch, mein lieber Sert. Fुas brattdit Sbr ein armes Jiabchen za erforecten, Die nid)t selabrt ift, Damit fie nusframt, nas fie in ofr Armenichule it Saint sees lernte?.'

"Sft Eaint Bees weit von biet, Dorcas? Scjicts She Cuere Viriefe Dortbin?" fagte ich, (o cinfdumeids leno tno forglos als imogliob.

„Eaint Bees! - Da muifte ciner ia verrüct fenn - So bitte Em. Bnaben um Detjeibung - es if num fdjon eine B̈efchidtte oon zmanjis Sabren, Dabi Des 2Batet fll Saint כeç robnte, Das 20 oder 40 obts, Eott meib roie viel, gReilen von bier liegt, Dort in Dften, - in Nortbumberland; and bätte itb Eaint Fees nie verlaffen, wenn nidt Der Sater" -

"Ulef), bol' Det Ieufel Deinen Dater !" ermieverts (d): Sie aber entgegnete: „250abrbaftig nenn nidit Em. Snnden ein bischen wirt wären, fo würden Sit nicht Den $23 a t e r$ anderet Leute berDanmen; and litt icb ez̉, auf mein Bort, ron Eeitrem AnDeren."

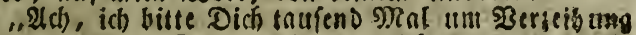

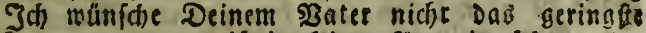
2Bofe - er toar gemís in feiner art cin febr restito fcbaffener Mrann."

¿Er wa r ein rechtichaffener s)ánn!" rief fie aus (Denn die fumberlander find eben fo tik̨lich in - Sin.

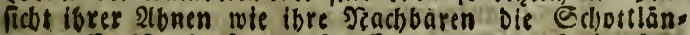
Der) "(5) if ein fo recht/chaffener Mnann als is einer 
einen Gaul mit Dem Solfter über dem Siouf auf Die

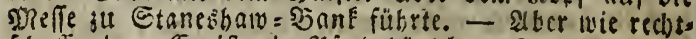
foselien! - Er ift ein Pferdehinder, Serr:".

"Recht to, in Du baft gnat recht," crubieberte id);

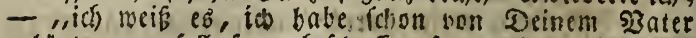
getourt - er foll to reflithaffen feon wie nut irgento

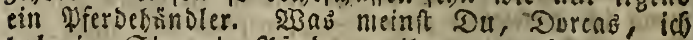
babe in Ginn ein Bjerd won ihm zu énfen."

"2Ah, Ew. Enades," feufste Doreaz, "Da ift et

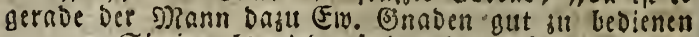
- wemn Eie jenta!s wieber frei werbes, (fichadet nichts, wenn's aud rodis ein bischen ith oberfübehen feblt.) Er wirb fie um nicht viel überietzen, bëchftens un - "

"Eust, gits, wis merbetl folon finig werben, nein Sino, verla Dich Darauf. SBillf Du, mit nun nbet mol fagen, wie Du Den Sief ju befordern gedenffi, ben ich Dir geben nill?"

"Irgie? Ei Den lege id in ben Beutel bea Gquire

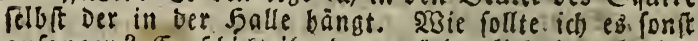
anfangen? Er fáidłt ițn Dann müdhentlich einmal, ober twie eß ibm einfäilt, entweder nach Jirampton doet nadh Earlible, ober mobin er fonft mia."

"22(d)!" fagte ich - "nicht wabr Dein Siebftet gobn bringt fie bin?"

STein - Der nicht - audb ift Det Gan mein Eiebfiet nicht mebr, feitbem er auf Den Geburtötag feiner Tante mit ber Jitty ßutlege getanjt bat uns mich fitzen liéb; ia, Das bat er serban."

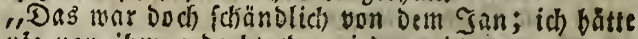
Das nie von ibm gebacht,' ermiederte id.

"Ia, es ift aber Doch ein ojal fo - er bat nich grabe - iu fiken laffen, ia, Dab hat er gethan."

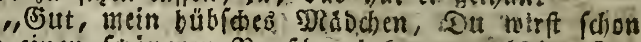
no

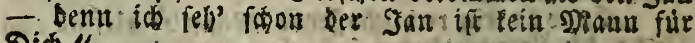
Diథ."

"Rein," antwortete bas Snagfercben; ",aber ein

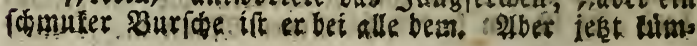


mere id midh nickts melje un tbu. Ser Mituers Sobn, ber mit auf Dem lekzten Sabrmarft ju 2upleby

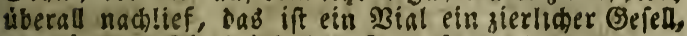
bas fönnen Sie bei bellem rase feben."

"Ta, beg if ein fobuer, riftiger Burfae (s)aubit Du er wirbe den 2rief nad Earlible tragen."

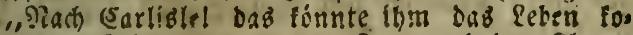
fen; ir mup immer nach bem Eros und ber Silappe fehen, wie man fagt. Yor $\mathfrak{B l i}$, fein $\mathfrak{S}$ ster würde

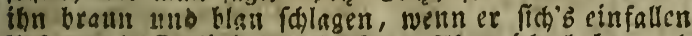
liefe nach Earlible zu laufen. 2tber ith babe noch mehr frever alb ibn, Daift z. B. Der Shulmeiftes, ber farreibt faft fo gut, wie Du, ?reunb."

"Non ber ift ja ber redate Nann sazu an eimen 2rief zu beforgen; ber weís audi wie viel gribe es foftet biz man einen gefdriebent bat."

Ia nenn Du Davon fpricift, Freand, Nubs coftet $6 \bar{b}$ ifm wahrhaftig senus; blob vier Stunden brastht er sul vies Beilen. Dastn aber fón rêtbe ex aud

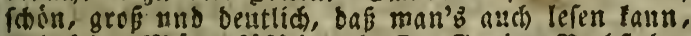

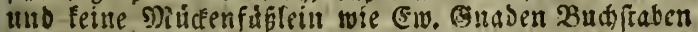
masten. - Iber nach Earlible fann er uícht gebu, benn

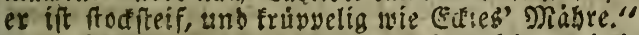

Tian in Bosteg Fiamen," fagte id, "wie bentl Du alfo meinen Brief zur Nôt zu befórsern?"

"Tं bab's ja faron gefart. in lege itsu in ben Mortbentel res Eguire, ben fádét er bann burd ben Ebriftal Siron zur Poft, wie er inn mobl zwweilen zu nennen beliebt."

Bon meiner Ituterbaltung 308 id alfo ieinen at

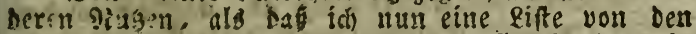
frenern ber Doreas batte; aber hinfichtlich bes, in Frase ftehenden (3)egentendos, ftand ich gerabe vieber auf bem vunft you bem ich ausging. Dod wat $e$ b mir widtig bas Nábden au ein vertrauliches (s) forads su gewobnen. Dent wenn es mir selang, fo

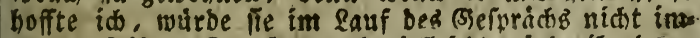

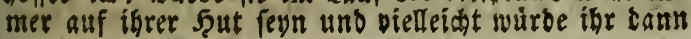




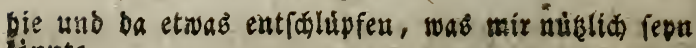
tonnte.

"Plegt der Squire gewobnlich Die Brieftafde burdiguebu, Dorcab?" fragte ich anịgeinend gleids gâltig.

"Ja freilid", fagte Dorcas, "neulid warf er mitr einen Brief an ben פ)tüllex Raff beraas, weil et fagte - "

"Schom gut, ich will ibn mit bem Drein!gen n'ät belâfigen," faste i由, "Dorcas, id will aberbafur an ibn relbft fareiben, aber wie foll id iba an: reden?"

"Sheh." war Dorcarent Bafludt. me 谁?

if Id) meine, wie man ibn nemt? wie fein Ra:

"Dás miffen Ew. Braben wobl am beften wirs fers, " faste Dorcas.

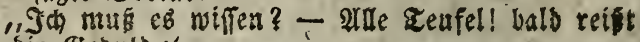
mir bie Seduld."

"Riat bud; bleiben Em. Sinaben in ben Saran.

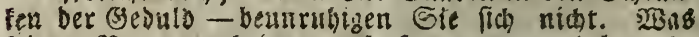
feimen geamen allbelangt, fo jagt man, es habe mebe

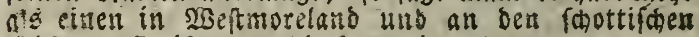

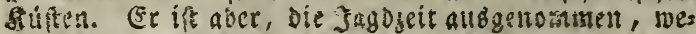
nig bier, uno oann nennen wir in Squire f́decht

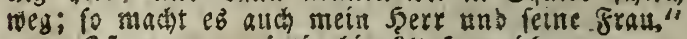
"Iit er gegenwartig bier?" fagte ich.

"Iekt grabe nicht; er ift auf ber நirenago, wie th gebort base, nach satterbab zH, aber ex fommo unb gelt we ber Sturatwind."

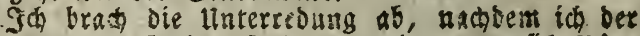
Dorca etroas Eels aufgeorungen batte um fich :Bän:

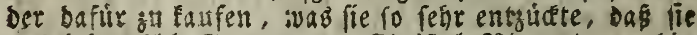
ausrief: "IAd (5ott, mag Egriftal Prixon immerbiu Stulimnes you Dir fasen, Da bift bow ein hoflicber Sertteman, urts auch anfandis bei ben fratlen."

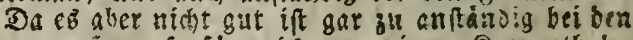

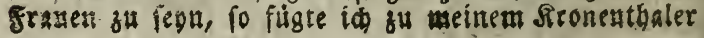


genchaft, Die id auf feinen Befeh! exduldate, gewis

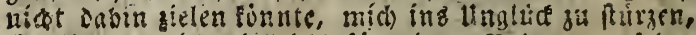
Er linute midh vielleidt fitr einen 2inderen anfebu, tno be

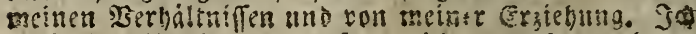

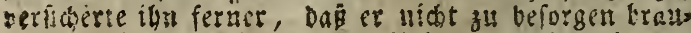

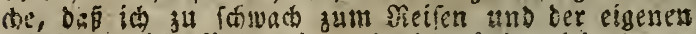

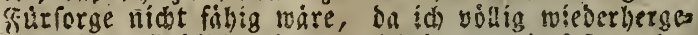

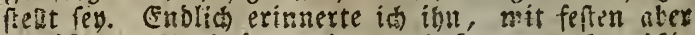

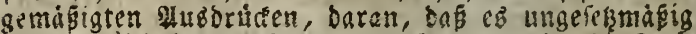
mire, mich Den (3efeben zum Trọ, welse bie grets

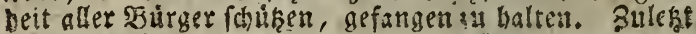
berlangte ich vor einen sionter geffellt fll werben,

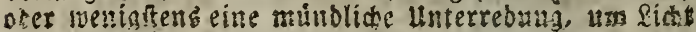

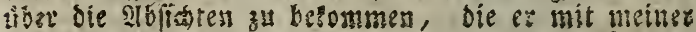
Befangenichnft bezwedte.

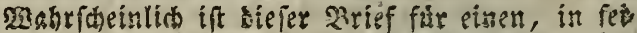
nen Pedten gefrintten, Menn fu Dertithig. 2lbe mab Ponte íti tbrn? Ja war in der genalt einez sidenfden, Deffen Leibersictaften eben fo brftíg, al feine mittel ihnen zu frobnen ausgebebat fchienen 2lud batte id) (srumbe zas glasben (bas if fur Did, Ilan) bar nicht reine gange Familte die (jemaltthis tigicit billigte, die er gegen midh gebrancite. (Enolís unto hantfäblich war Freibeit mein Streben, uno wer wirbe nídt gern alleb aufopferen um lie zu ex langen.

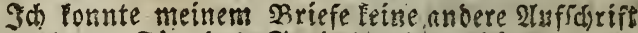

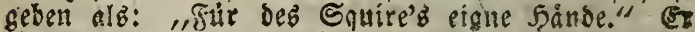
founte nicht fern feon, benn nod an bemielben Tace emping it bie 2 intwort. Der Brief war an Darlis Latimer geristet und entbielt folgende 20 orte.

"Sie haben eine Unterresuna mit mir aesvinfot, Sie verlangen vor einer richterlicten yer gu werben. Die erfte Bitte foll Shnetl gewabrt wers ben - vielleídt aud die zweite."

"Sepn Sie fo lange tibergengt baf Sie natis 
wen Rewtbformen gefangen find, und baf eine s:re

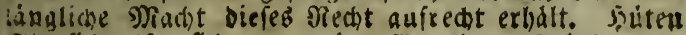

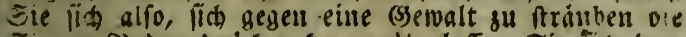
Sie su Boden orideen fann; tiberlaffen Sie fido brua saufe ber 5 egebenbeiten die uns Beibe nit fort reip fen, uno benen feiner pon uns wiberfteben fann."

Diefe geheimnifoollen $\mathfrak{3}$ orte waren obne llnters farift und ließen mir nid)t alb mid auf ben veriprodenen

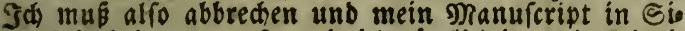
derbeit bringen - fo weit id nåmlid it meiner jekzis gen Lage etwas ficher nennen tann - indem id es

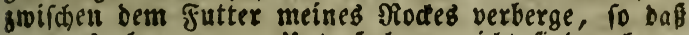
man es ohne genaue Interfudung nidt finden fann.

\section{Drittes Ratiel.'}

Sortięung oes Tagebuts Darfie Eatimers. :

Friber albition es erwartete, fand bie widitige llu: terrebung Statt; nod an bemfelben rage an welchem (d) Deu 23rief cmpfing, gleid nad beendigtem 9jit tegeffen, trat ber Equire, ober wie man ibn fonft

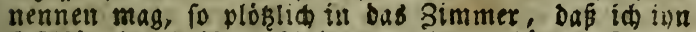
faftifir eine (seifterericheinung gebalten bitte. In oet (Seftalt diefes (S) Ranties liegt ein eigener अibel und ein eigentbumlidser 21 bo bud ser geftigfeit; feine Stim, me hat lene tiefe falle bes Ilccents, bie unwiberftebs

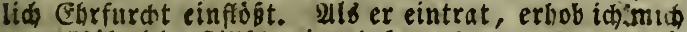

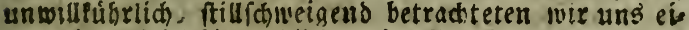
uen Ungenblid bis enolid mein Baft bas Stillfoneis sen brecto.

"Sie winfaten mid zu fpridjen," fagte er, , bist פ. Ecctrs siertc. XVII. 


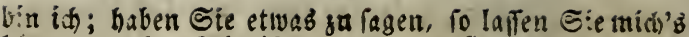
boren, meine Beit ift ju lurs um fie mit fins:iden Guitarren zu verlieren."

"Ich wolte Sie fragen auf weff:n Befehl uno su we!d)en (5nozwed id bier gefangen gebalten werde."

"Id) babe Gonen foron geiagt," erviederte er, "Daßs mein Niecht unbeitreitbar ift uns $D a \dot{B}$ meine

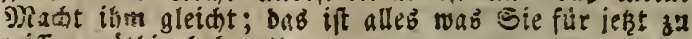
wiffen nothig haben."

"Ieber Britte," antwortete ich, "l)at bab ఇecht bazu, Den sruns su wiffen warum man ibn ia gefánss liter 5aft bált, aud Eann ian niemand obne geiebs naibigen 2 serhaftabefebl feiner Freiheit beraaben. setigen Sie mir den, ber Sie daja beredtigt."

,. Sie follen nod mebr fellen," fagte er, , id win Sie fogar vor ben gichter ftellen ber ilgn aubéfirtigte, unb zuar fogleis."

Diefer uterrafdenbe Rorichlag beangftigte und bes unrabigte mid; aber ba id midh einer geredten $S_{a s}$ de beroust war, fo beidlos ids lie fúbn zu vertheibio gex, menn ich fion einige Seit zur Sorbereitung ges misifst batte. Er aber wanbte fid $\mathrm{tm}$, rí bie Ibure des 3:m ners auf und befahl mir ihm zu fo!gen. AlB

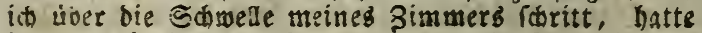
id nitst divel Ruft alf und bavon zu laufrn, aber wo rolle ich bie Trepde finden, wabrideinlios war bie

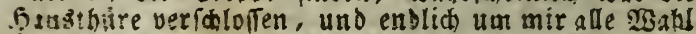

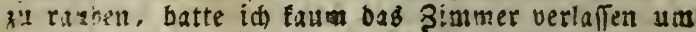

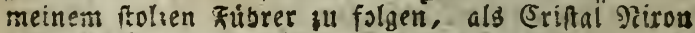
laum knei Stritte binter mir tand uno mir aads?

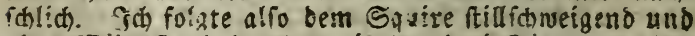

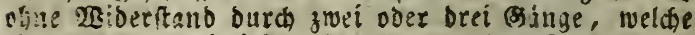

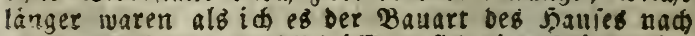

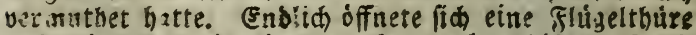
und wir traten in einen grofen, altmobificen Saal. Die Fentir waren voa gefärbtem (5)laż, eidenes (ses táfel a: ơn 23 inden, ein ungebeuerer Roft beozd

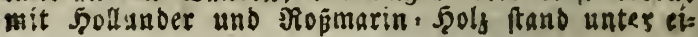




\section{6}

Qub Der Pfeife unterbrach, und bann ben Tampf in

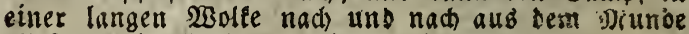
blief. Bei alle bem, Hilan, modate eb inobl feinem 3neifel unterliegen, Daß́ Der ermähnte Nichter ein zie:ns

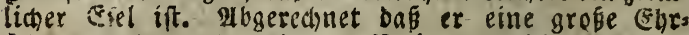
furcht bor sen rechtogelehrten Deinungen feines Eđrei: bers hat, was̆ in ber Patur ber Dinge liegen mag, foreint er aud nod wunderbar unter ben Befeblen feizes 3itilgenoffen bes Squire's jul ftebn, (wenn ei. ner von beinen ben $\mathcal{T}$ itel verdient) ia fogar noch mebr als es tich teit feiter angebliaten 23 tirbe ziemte.

"s 50 - ba - ia - fo fo - bam - bam bab ift alfo wohl ber junge mann - bum, ja, ja - er

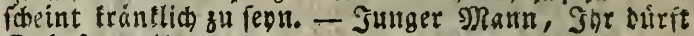
Euch Peken.".

Sक machte Bjebraud von ber gegebenen Erlasts nis, benn meine frantheit hatte mid mebr geidawad alb id) es geglaubt batte, und ich fúbite midi yon ben wenigen Schritten uno von ber innerliden Bewegung felor ermidet.

"Euer Fame, junger \$amn, ift - bum - ia, nuก, wie beift er?"

"Darfie Eatimer."

Fiedt - ia, bum, ganz redit. Dariie Eatimer 10-ift's - ei, bum, moher lommt Shr?"

"2ub Swottlanb, Sir," erwiederte id. fo ? $^{\prime \prime}$.

"Ein seborner Shottlámber - ah, bum, - ift's

"T⿱宀 bin ein Englanter yon Sipburt, Sir."

"seded - ei - ia, fo ift'b. 2lber fagt mir bodo

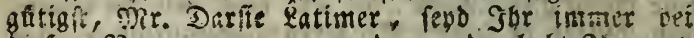
biefem Pamen genannt worden, oder habt Jar roch

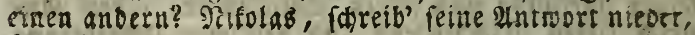

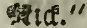

"SO viel ich weí, trug id nie einer anders," rar metne 2 (ntwort.

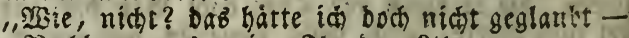
feb), शiadbar, mas meint Shr bazu?" 
STier lab er ben andern Equire an, her fich uad. láfiig in einen Stubl geworfen batte, inderm or bie

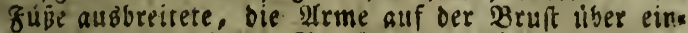
anoer (c)lug uno bem 2 Serbor nur wentg glufmertiams teit wibmete. 24uf bie Frage beg Ri由ters antwortete ex, bas Gebadtuif bes fungen Mannes whiroe fich nobl nidet bis auf feine eriten Rebenbjabre exfireder. "2lb - eb - ba - Jar bort was ber Bseniles man ipsidt - fagt mir bod id bitte, wie weit mag fid wobl Euex Bsedichtnif erftreden? bum."

"Bib. bun 2llter von ungefáhr brei 'Jabren."

"Und Sie twagen eg bu bebaupten, Sir," rief Der "Squire, indem er fid plözlid erbob, unb feine Erimme bis zu einer furdtbaren Şobe fteigerte, ,Daß Gie bamals Jaren jeģigen Samen trugen?".

Die Suverfidht mit welcher diefe frage vorgelegt warb, erfolitterte mich, und umionft wriblte id in meinem (Sebúdtnis nad eimer 2 nntwort. ftens," fagte id. "erinnert i申 mid bas man mid immer Darlie biefi; in fo fruhem elter nennt man Sinder gewohnlid nur beim Tauf = S?amen.

"Sa fo benfe ial audi " erwieberte er, uno ftreds te fit wieber in feinem Stubl.

-2Hlfo uannte man euch Darfie in Euerer Rínds beit " fagte ber ^ichter; ,uno - bum, ei - wann nabint Jar zuerft ben ?amen Ratimer an?" geben."

"Jథ nabm ign nidht an, Sir, er warb mir go

"Эक frage Sie," fagte ber Ferr bes Şaureg bod mit minber ftrengem Tone als zuvor, "ob fie fich exinnern lónnen, ie satimer genannt worben zu fevn,

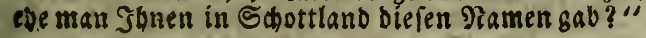

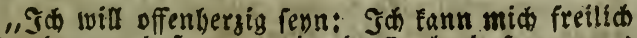
ntdit srinnern baj man mito in England fo genannt bátte, aber id weif aud nidht wann mir ber Rame guerft gegeben wurbe. Rann man alfo aus biefen fras Ben uno Intwort leine genugente Salubfolge gielln; 
To winche id, dafi man meine zarte Sindbeit berud fichtige."

"frum - ei ja," fagte ber Richter; "alleb mas Bierticfichtigung verbient foll berticefichtigt werden.

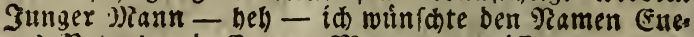
reb ㄱaters und Euerer Nutter zu wiffen."

Da berúbrte er eine 23 unde an der id idjon reit vielen Jabren litt, Darum ertrug id aud bie Frage nicht to geduldig wie die frúberen, fondern erwieder: te. "ISd) aber wünfte meiner Seits zu wiffen ob i由 vor einem englifhen Friebenbridter ftele?"

„Sr. SEeftrengen Squire Forley non Forlen F̧all, reit jwanzig Jabren woblbeftallter Ribter," lagte $\Re$ r. Pitolas.

Dann follte er wiffen, ober Sie, Sir, alg fein Schreiber follten ihm fagen, Das id in diejer Sache sláger bin, und da che man mid einem Freus = und Duer = Serbor tn, termirft."

,5ुนm, boi - wab, ef - es ift etwas baran, Nacbur," fagte ber Pichter, ber vor iedem Saublea ber Rechtäge!ebramfeit erbebend, die Einftimmung bes andern Equires zu erlangen wuinidte.

"Id wanbere mich tiber Euch, Forley," Pagte rein entichloffener Freund; ,wie lonnt The denu dem

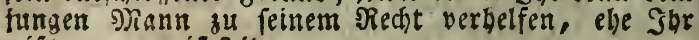
wift, wer ex ift?"

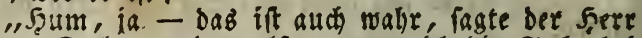
Nichter Forlen; ,jekt alfo, wenn id bie Sache bet náherem Sidht betradite - fo ift - hum - im Esan, zen, gar nidhtz bamit gejagt - aljo Sir, Jar múse

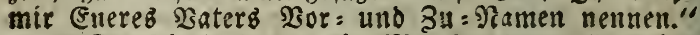
,Da Síe bod nun ein Mal burchaub alle meine

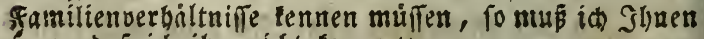

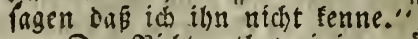

Der gitdster that einige makthtige Biflze uns birlt

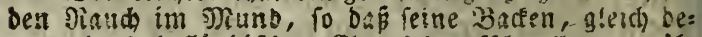
nen eineb lollándichen Sberubs aufiaswollen, wảhs 
rend feime Augen bon ber anfrengung berbortraten, bie er anwenden mnîte um feinen 2utbem anzubatten. Danu buiç er ihu von - ba, fiine Eltern nidit zu fennen, junger Mann. - Dann mú̃ id Esch alb einen Lanoftreider eins

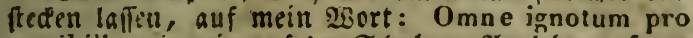
semibili, wie nir auf Der Esule zu Ioplebo su fagen pilegtell, D. i. jeber, ben ber Eandriater nidat ternt

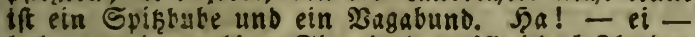
ladt nur immerbin, Eir, Dod zweifle id ob Jor ben Sinn bes lateinifocn Sakes veritanben bättet, wenn iđ ibn niđt úberfę̧t bátte."

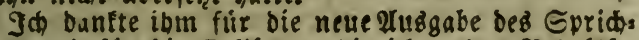
wort und fúr bie Erflárung bie ich, obne Beibúlfe, mir nie bátte tráumen laffen. Damn fubr id fort meine Silage mit gró̄erer âuerfiat aug einanber zu feken. Der Ridter war ein Efel, Dab war connen. Elar; io unwiffend aber fonnte er boc unmóglim fent, baf ex dab grothmendigite in einer fo flaren $\subseteq a=$ we n'd)t einfeben follte. Io ferite ibn alfo von bem

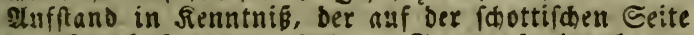
beg speerbufens von Eolway Statt gefunben baste; ert!arte innt wie id in meine gegenwartige gage ges reetb uno bath follifilic, or modate mid in Jreibeit fesen laffir. Sh vertheroigte meine Eade fo gut als

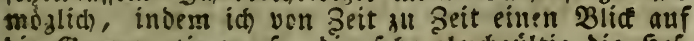
bie (Beyenpartie marf, rie fehr gleidgúltig die J̧ef= tigleit anborte, mit ser ic tlagte.

$2(1 \vec{B}$ iक enotid aufborte, weil id in einer fo $\mathrm{fla}$ ren Eacte nichtb mebr zu fagen waste, fo erwirderte ber siditer: ,bum, el - ia ond twanterbar! alfo das

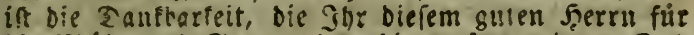
bie Mitibe und Sorge zeigt, bie er fur uno um हuक batte?"

"Id geftethe ein, Sir, bas ex mir bas Pelien ein Mal, vielleidht zwei Mal gerettet bat, aber biefe What gibt ibm nod fein Redt luber meine perfon. Den= nod aber verlange id weder Beftrafung ned sindẹ 
in will friedlid mit dierem (S)entleman fheiben, bef: fen Beweggrưne ich nidst gerne als bofe annenmen móchte, twenn foun feine Sandlungšweife gegen mid

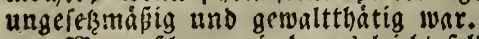

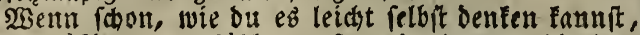
Diefer miäsigung (s)efúble zu Srunbe lagen, bie ben Angellagten nidht bertibrten; fo foien boch bie Milloe, mit ber id meine Sadhe fúbrte, tieferen (Eindrud auf ibn zu machen als alleg bisher Befagte. Er waro fo gertibrt, oas er fajt aufer faffung fam, und nahm oft jeine suthutht zul feiner Dofe, um nur einiger Ra. $^{2}$ ben feine iumere Bewegung zu verbergen.

Minder gunitig war Der Einbruck meiner fiede auf ben sitchter For!ev, auf ben fie bock hauntfáchlich berechnet mar. Ex flifterte mit feinem Echreifer șeifter Riclab, ráufperte fíd, huftete und runselte bie 2 ugenbraunen, ald ware er úber meine 3 itte er: sirnt. Enblich nadbem er fich anfdeinend berabigt butte, lehnte ex fíd an feinem Stuhle, Ianpite mit geoser feftiateit und gab mir einen brolienden wink, bes mir zeigte, baf alle meine Brunbe an ing verlos ret ginzetr.

MlB ich endidi, mehe aus Nangel an 2 them als Gub Mangel an Brimben, einhielt, erófnete ex feine

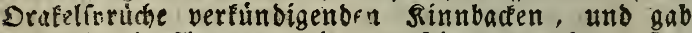
mir folgende arntwort, die ion feinen gewohnten $\mathfrak{T n}=$ terieftionen, und von langen, diffen Raudowolfen bes gleitet waren; glaubt Jhr, mein Junge, Jhr tonntet den Nathias Sorley, ber feit oreisig Jabren wohlbeftallter. Fries benserister ift, mit foldem (s)ewaidhe bintergebn, wo: mit man faum ein f̧odjermeib anfúbren fann? pub, puf - wie, Freund - beb - weist Dut nicht, ba man in ber Sache feine Burgichaft annehmen lann, ano bafi - bm, ei - ber aróbte Nann - nuf, oer Baron von (srayitock felbft fich einer gerichtlichen $D b=$ bust unterwerfen muÉ ? lno bod behauptet Gar von

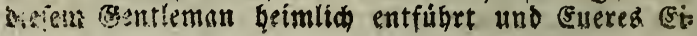


gentbumb berabt morden su fevn, und Bots meib,

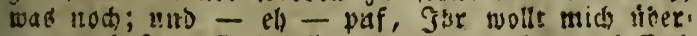
resin, bafi ex Eud alleb genommen hat rab Eud fablte - ef - id glaube wohl, bas (Es!d) vieteb feblt. 3a, ja Sbr fens fo ein Sunite, ber bern aller $\mathfrak{x}^{2} a$ : ben los uns lebia feon módte, und - ei - hum fo ein muibiger Stubent, ein biBiten verwirrt im Dierftubchen Dasu, wie mir bie elrtichen feute im Jaafe fauen. - Sor muft alfo unter ber Afufíd Eseres $230 r m u n d s$ bleiben, bis Ghr majorenn mets Det, ober bib ein Warrant beb Porb (s)roblanglerb (Eub) oie fubrung Euerer eigenen (s)ęáfte úbertrágt, bie ghr felbit banu, wenn's wieber rubig im sovfe fteht ei - bem - zu beforgen, End nidh febr beeilen wertet.

Die Sivifhentame, bie Sr. Seftrengen hems uno bumb, uno bie stige aus ber rabafofyeife, in finer siede liefen, benubte ich basu, meine (sebans fit s" fammeln, welche ber unewmartete Inhalt der - Fiede lebr exfdúttert, batte.

"Iक fann ourdaus nidt begreifen, Gir," $\mathrm{er}$, meberte idh, "aub welders fonberbaren (3rand diefe Derion (Schoriam bon mir als feinen maindel fors bert; es ift eime foamlofe Rúge. - Ja fab ign nie in meitem Leben, bis oor vier wodren, wo id un glidalicher Beife in biefe Gegend tam.

(si Sir - wir eh - wiffen, uns find barauf oorbereitet, - baf - puf - Shr gewiffer Leute gia nen nist aern horen módt; uno bas - eb - \$br verftebt míb fhou - eb Dinqe, Tóne, getriffe (s) senftinde, Unterhaltungen tiber Ramen utub mes. rere bergleitien Gegenftande gibt, Die Eud aus bem finkfinen bringen - mas ic leine fonberlicte Euft anzuiebr babe. Doch aber פTr. Darfie - oder paf - Dir. Darile Patimer - ober - pub, puf ef - ei, Dir. Darlie obne ben Latimer - Sbr babt berte fo viel einacitanden. bas ict einfebe, wie feht wobl verwabrt $34 \mathrm{r}$ uater ber Sorge meinet bier an: 
meienben, ebrenwerthen greunbes febo - alfe Euere Eseftándniffe - uno nods sazu bas - puf, eh - id ton als eine abthare Perfon tenne--a - ia boch, ia als eine bómit achtbare uno ebrenwerthe perion Sount Shr tab leugnen?"

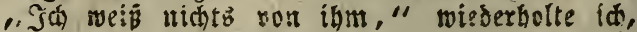
, nicht einmal reinen ramen, uns idi babe ibn, wite

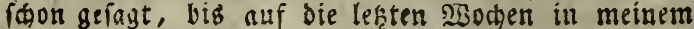
ganjen Reben niøt gefehn."

"Trollt Jin sarauf fhinoren?" fagte der fonbers

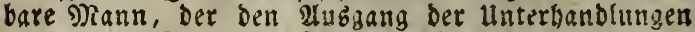
gu erwartell fohien, fo ficher wie eine filapperiolinge ibrer Beate ift, wenn fie fie einmal in ibrem zallbers treife gebannt hat. Und wäbrend ex biefe Morte mit tiefen :onen aubiprach, ricete er feinen Stmbl, fo

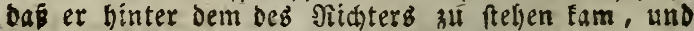
weber biefer noch fein ভdareiber iln bemerten founte.

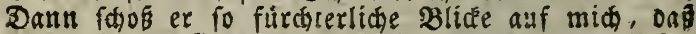
niemand, der lie erblickte, fie je vergeffen tann. Lleber

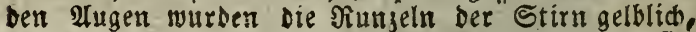
fa fait fówars, uns ba wo bie Alugenbraunen fíd vereinigen, bildeten Sie einen Falbcirtel, oder viels mebr eine elliptifale form. Ith hatte einen folden Blid in einer alten Teufe' छgerchidte beidreiben hö. ren, bie ich) zufálig vor nidht langer seit ergánlt bes Eam, wo biefe trefen, finfteren sergudungen ber Stirmmableln, nidht gang obne (sisus, mit ber Form einez lleinen ḩufeifeng verfinnlicht worben waren.

Seiner seit erwecte jente Ergäblung eine grauent volle Sifion meiner frubeften findheit, und ieste, on ber eritarrente, furdstbare Blice auf mich geristet war, fo oranate fie lit nod leobafter meitler Erinnes rang attf. Die unbertimmten, fawantenten steen, die lenes furcbtbare Seichen in meinem Bemuthe er, weat batten, erichreutten mide fo fehr, tas id ftarr

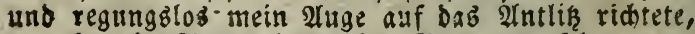
wo es , ein fhreckenorobender sote, fu fehen war; bis ber geheimnifuolle Rann, indem er einen Angen: 
blid mit feinem Tafchentud tiber fein Befidt fuble, ben 2 lice aufbeiterte, ber mir fo faredenoou gewefen war. "oiun wiro mosl ber junge shann es nidit mebs

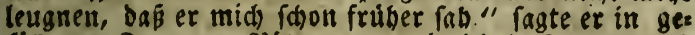
filligem con zum Siidter; "unb id holfe, er wirb

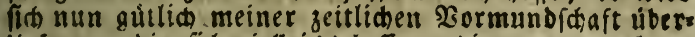
liefern, ,bie fïh vielleidt beffer endigen mag, alb ex eb erwartet."

"İas aud meine Erwartungen fenn mogen, "ernieberte ich, indem ia mich wiever fammelte, ,fo fele ids) Dod, bas id von Diefem Feerrn, Deffen 2 (mt ez igum jur yalicht machi, weder S̄duk noch (B)ereds tigleit erwarten fantr. Sie aber, Sir, wie conderbar

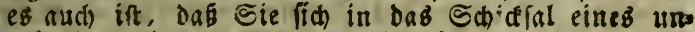
gludididen jungen M) Mannes. eittorátgen, ober welden Unfpruch Sie aud allf midh zu mathen vorgehen, Sis

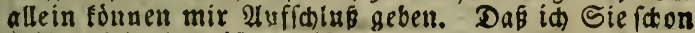
friber fab r bas ift gewis ; benu niemand lann ben Blick vergeffen, mit welchem Sie bie Madat zul baben follten, diejenigen zu vernidten, auf welde Sis inn merfen."

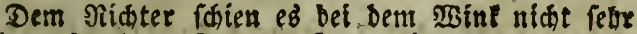
wobl zu Nath su reyn. "J5a - ei," fagte er, ,eb ift Beit zum fortgebu, - Rachbar. Th muв now mekrere greilen reiten, uns modhte fie in biefer Bsegend nidt bei Padt gurúdilegen. - Mr. Ricolab, wir múf fen uns fortmachen."

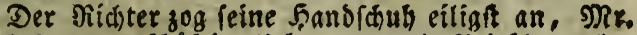
Nicolas war gefdáftig lleberrod uns Peitide zu hos len. Jor 2 irth wollte fie zurudibalten, und bot $99=$ nen ein 2rbendeffen und ein Nachtlager an. Weibo banlten ibia bóflichif für feime Einladung, boch foien es als hatten fie leine fonberlide \&uft sas bleiben. Der Jichter Forles enticuldigte fich bunbert gral, als bab sta sochen Dorcss in bie Stube trat, undeinen Ssent: leman anlünorgte, Der ibn uber Beriकts facken su fpres dent wưnçte. 
(preds)n?"

„ISsg fut ein Bentleman? - uno wea will er

"Er fommt eben auf feinen eigenen వิeinn bier

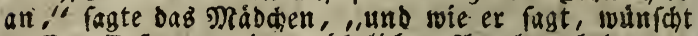
ex (5w. Beitrengen in gerichtlichen alngelesenbeiten su forecten. Ich balte inn fur einen (sentleman, denn ex foridst eben fo fertig Latein wie ein Sdulmeifter, ater, ou liebe Beit, er bat eine brollige \$erúce auf."

Der eben. angefundigte und befarcéene (sent: l:man, fturite ungeftum in bas Bimmer. Hoer Da fd fhon mein Blatt Papier voll gefdrieben babe, uns mein fonderbareb Befdicé fo faber auf mir lafter, fo mus ich wobl ein neues mit bem bollforeiben mas erfolgte, als ich in bas Bimmer treten (al) - mein theurer $\mathfrak{a l a n}$ - Deineu verruden Elienten-ben araten Peter peebles.

\section{Si ebe-ute a a bitel.}

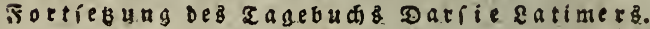

\section{Sweites Blatt.}

Bis auf bie firglid verfloffenen, fummerbollen Tase, habe id in meinem Reben aud nidt wabrend

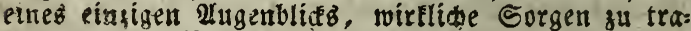
gen Gehabt. Bab ich to nannte, war, wie the test wobl weif, bloz ein seiftegúberbrus, ber, weil ex in Demelben Hagenblide leinen Brund zur Flage hatte, dingitlic in die rergangenkeit und in bie Sufunft faast. Diefe Perioden ftebn mit bem eigentliden leben bez Nenidhen aber fo wenig in Serbindus, aab bie beitige Sarift felbft fagt: "ein jeber gag bat feine eigene. Plage." 
ben, 2llan, als id, mebr um Dir Bjefellfibaft su Leiften, als meiner eigenen ?ietigung folgeno, häufís

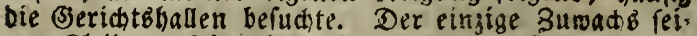
nter Sileidungsftucte beitanb, (in feinem Ebarafter als

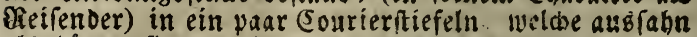
alb bâtten fie bas Schlachtfelo von Scheriff - moor gefehn; fo breit, fo fitwer, Das. obgleid fie mit breio ten vielfarbigen wollenen 3 ándern ant feinen ermúbeo ten Shenfeln feftgebunden waren, lïe bod bå̆ $2 \mathfrak{n}$. febn hatten, nlä wären fie einer siette wegen, ober sur 3 use angelegt worben.

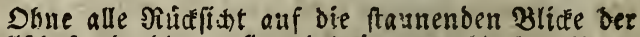
Sefellínaft, in bie er fich einoringte, tólvelte Peter mitten in bas Simmer; Den fopf vorgebeugt wie ein ftoffender waiboer grübre er fo!gendermaß̈ent:

"Buten $\mathfrak{Z} a g$, Shr Reute, guten Tag, Ew. Snas ben - Serfauft man bier Stectbriefe?"

St) bemerfte, dás fith mein Freund (ober mein Feind) bei feinem Eintritt zurviossog, und fitch fo Rellte

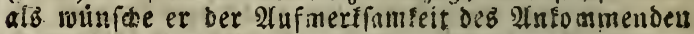
su entgehn. So weit ich eb vermodhte, that idh bars iel:e, benn idh vernutbete Daß Mr. Peebles mid ers

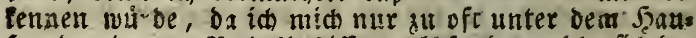
fen ser jungen Recht bbefiffienen b. fand, welche fich Das

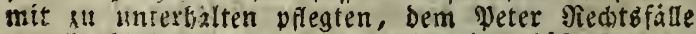

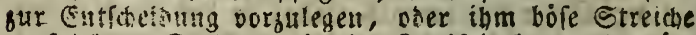

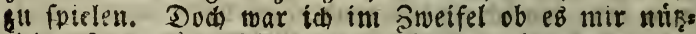
licher feen murde feine Befmuntichaft zubenuken, um wo móglidh ein geridttliches aengnís von ibm zu erlan gen, oder ob eg beffer ware, ibmeinen Sirief anzul vertrauen, Der mir fitherer ful meiner freibeit verbels

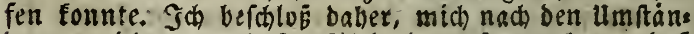

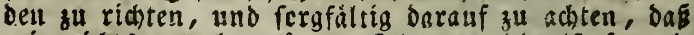
mir nidts entgehn wurise. Shb zog mich alfo fo weit

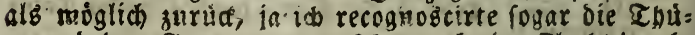

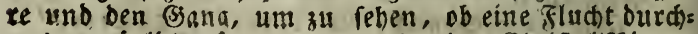

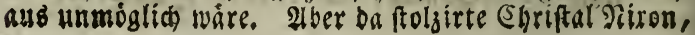


Deffet Eleine, formarie Bafilialen: 2 ugen angenbltcts lidh mie!n Sorbaben in ben meiniaen su lefen f́chienen. Sc) liep̃ mich alio, fo weit wie móglid bon allen parteien entfernt niever, und hrohte auf sab Befpradd, bab viel anjiebender war alb ich eb ermartete, und in weltem Peter Peebleb eine frauntrolle foielte.

IIf $e^{3}$ bier wo man 2 erbaft befeble berlanft Stederipfe, meine idh, Shr verfteht mich fdon," pagte Pleter.

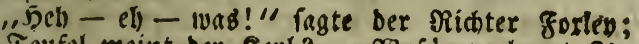
was Teufel meint ber Serl? - Mofur verlangt Str einen Sierbaftbefebt?

, Um einen jungen abrofaten feft fisen zu lafo fen cer in meditatione fugae ift; benn er hat meime flage angenommen, uno bat meine Sadbe vertbe bist; batei habe id ifm nod wader Eporteln gesablt, unb und ohenorein to viel Siranntwein als er an jenem Sase in bem Shaufe feines bent fur ein fo innges Jsefwsif liebt er ben Drannto wein unmásig.":

"Und was bat Eua benn der betrunlene grovo. lat zu qeib gethan, baf Sbr gis mir fommt - beb -

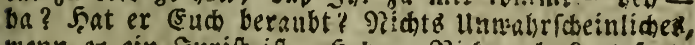
wenn er ein Surift ift. Seb - 9lide - ba? " jagte Der Nicoter forley.

"Er mich feiner felóf beranbt, Sir," antwots tete Peter; "usmlich feiner frtilie, feineb Troftes,

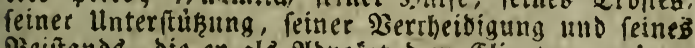
2iecitandB, bie er alB 2 boofiat bem Elienten, ratione officii zu leiften fauldig - feht, bas ift cie ganse Sate. Ex bat meine Sporteln in ben Sad gefdo ben, lat einige Niaaß Branntwein getrunfen und nuts madat er fich auf und bason und lágt meine Sade balb gemonnen, balb berloren zurude. San baben mir einige foarffinnige Bur be, mit senen ith str weilen in ber Parlamentbiblle von inriftifhen Dingen vlaubere, geratben, nur in (Sottes Namen ein fers au faffer, uno ibm nadjufeken; alío babe id mit 
meinen beinen bie Poit genomaxen, mobei íf fretlid bier unb ba einsal aud ouf einem Keitermagen: ober fonft eintw Fubrwerk aufftieg. Sn Dumfrics

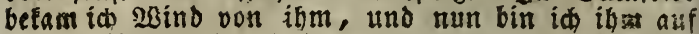

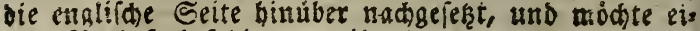
nen $\mathfrak{T}$ erhaftsbefenl gegen ign."

Mein thenerfter Mlan, twie hod follug mir bas $J_{\text {fer }}$ bei biefer Siadridet! Da bift mis nabe; und

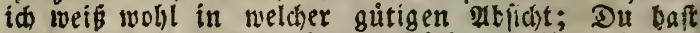
äles berknfen, um mir zu sülfe zu cillen; ba id Deine Freunbitaft, Deine Ireure, Deine gefunde Bernunft, Deine als̈banernde unermúblidfeit Perne, fo ift éc fein 2eunter megr, wenn ,tmeines soufcus

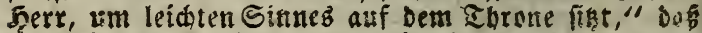

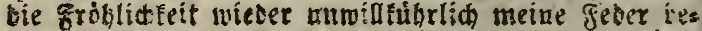

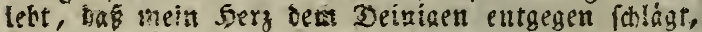

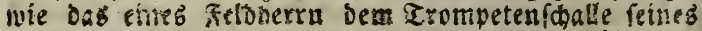

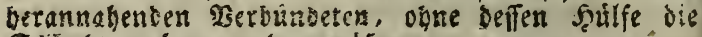
Exilant verlorent seben

Э由 lief mich von biefer freubigen Heberrafchuras nidt allfer faffing kringen, fondern fubr fort mit

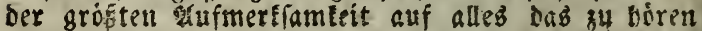
was bei siefer fonterbaren Eache gefagt murbe. Dof ber arme Yeter Peebles von eintem feiner jungen Siatts:

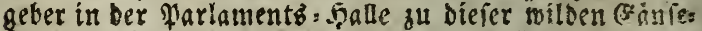
Jajo gereigt morben war, hatte er felbft zut verfechent

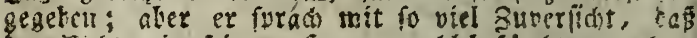
ber fichter in feinem fergen nohl befurchten mochip, einen Geligriff in ber Ence zu thun. Unto da let ben bekjorden an ber englishen Grenten febr pft bie

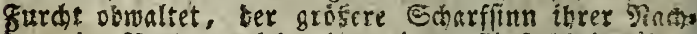
barn im Siorben modte iyre eigene Einfadbeit üher, liften, fo wandte fï M. Forley mit forgliden 'Vlis dea zu feinem હareiber.

"ES - oh - Tita, bel Díd ber - Tannfe Da bena nidt fpredoen? Da hantelt eb fich mefir sut

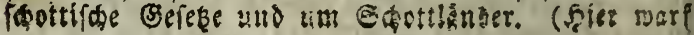




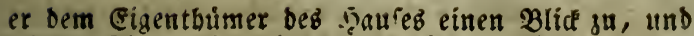

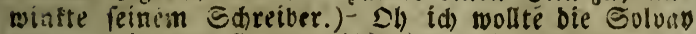
ware fo tief me fie brest ift, denn lómten wir ood boffen, Daś fie ung in siule liffen wurben."

Sitelas fprach einige Ulugenblide mit Dem 2 itt: fteller allein, unb ftattete dann Beridit ab; "rer

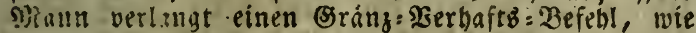
eb fareint, bie ftellt mau aber nut gegen Shu!dner $a 38$, er aber braudbt einell, um einen sovolaten feit nebmen zu laffen."

"llnd warum bafư nidat?" fiel ifm Peter Pees bles "fred in bie Rebe; "warum nicht, bab midht' id bod gern wiffen? Weigert fid ein Tagelobner feine Irbeit zu vollenden, gleids zwingt Shr ibn oas su, - láuft eine lieberliche Dirne aus bem Dienft, gefanind faidt Shr fie wteber beim, - macht fid ein Sioblenbrenner oder ein Salzbánoler bei Mono: fhein aub bem Staube, im Alugenblict padt Shr ihn wieder an ben Sinterpfoten; und bod betrágt ber Schaden niat melor alb ein paar soblen ober ein paar Desen Salz. Sier aber. lauft mir ein Burftoe mir nidits bir nidats weg, briat feime serbindlichs: feiten, und bringt mix einen Sdyben pon 6000 \%f. Sterling, nám!ich 3000 bie id gewiunen wirbe unb 3000 die ich wobl verlieren werbe, und $5 \mathrm{br}$, ber Sor Eud nad ber Beredtigleit nennt, fonnt einem armen פann niat belfen, einen zu fangen. Eine fojoue (Serechtigleit finbe id ba bei (5uक)!

ber.

"Der fierl mus betrunlen fepn," fagte ber Sarei:

"Nuaftern von allem, auber ber Sưnde," er: wieberte ber Supplifant; "feitbem ía Das bieffeitige ther betrat, babe ich uidat mebr alb einen Solud fa!t walfer su mir genommen, und sott mets of einer von Gud su mir fagen wirb: „,5ुub, millt Dit trinten?" 
Der Nichter fhien von diefert 2 orten gertibrt.

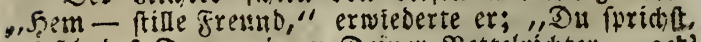
aib̉ fiănbeft Du vor einem Deiner Bettelriohter - geh' butinter - lás' Dir etwas zu effen geben, Jreund (ant Der Erlaubnif meines Ereundeb, feiner (sajts frellnofhaft zuvorgutommen) aud einen Edhlud zu trinlen, und ich gebe Dir mein $\mathfrak{B}$ ort, bann findeft Du fo viel (s)eremtigfeit bei unb, wie Du wünfकeft."

"Id will Euer nadbarliches 2lnerbieten nitht auscctlagen," fagte ber arme Deter Peebles, inbemer fich

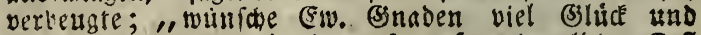
\$geisbeit, um Eadi ill einem fo auperordentliden fall rimtig zu leiten."

ald Peter Peebleb eben bas simmer vērlaffén wollte; fo wollte ic bow einen zeugen, ber mich dew siciter guinftig barftellen founte, nidat io weggeba

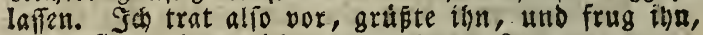
ob er. fid meiner nicht mebr erinnere?

(5r ftarrte mid an, betractete inid yon allen Seiten, nahm einige prifen Sabace, Dann hoien es plöklích, alb lebe eine alte sưcécrinnerung in ibm auf. "Do id mich Euerer erinnere!" fagte er, "mets ner Brell, id will'b wohl glauben. - Ergreift ibu Gentlemen - Sonftabler, baltet inn feft - wo ber lieberlide Salgenvogel ift, oa ift gewis alan faits forb nicht weit. - Jealtet ign nur feft, Reifter son ftable; id trage es (5uch allf, benn ich múste mich febr irren, oder er ift Edulo an ber ganzen $\mathfrak{2}$ seg= lauf=(Gejhidite. Der ift's ja, ber ben Sarren Mlan mit wagen und Pferden und all' bem Teufe!bzeng,

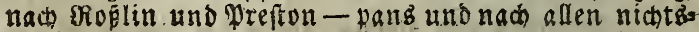
nusigen Drten; die er auffindent tonnte mitichleppte. Er ift ein weggelaufener @tubent, er ift'b."

"Mir. Peebles," fagte: idh, thut mir nicht ths

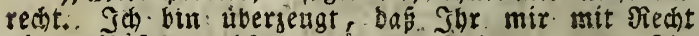
nimts : woll, , biefen: Sperren : beweifen Esunt, Das, id ein 
Student Der Redite zu Edirburgb bin - Darfie fa: timer mit Ramen.

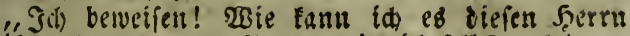
beweifen," antwortete Nieter, , oa id felbft nod lange

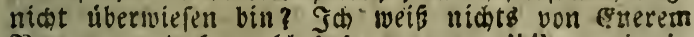
SRamen, แnd funu blog beseugen, nihil novit in causa."

"Einen forinen Beugen habt Sly ba zu Eueren Banften wrooucirt," fagte opr. Forley. "alber ba - ei - id wia ibm boch eine oder zwei fragen vorlegen. - Sadrt, Freano, wollt Jhr eimen Eis barauf ablegen, Das biejer Jungling ein weggelaufes net Strbent ift."

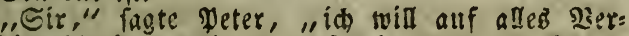
ntuftige fáwworen; ein projef, ber zum Eisablegen fortme, ift ein gewonnener Proxes: aber ith bin febr begieriy En. Bimaden Dittagstafel z! beriudsen;" Denn feitdem Peter etwas vom-s) sittageffen gehórt batte, war fein Vetragen gegen ben Dichter viel ebr: furbitguoller geworden.

"Shs follt - eb - bum - den 3aud geftopft betommen, wenn's moglich ît, iln zu füllen. Engt moir aber boch erem, ob biefer junge smann wirflit

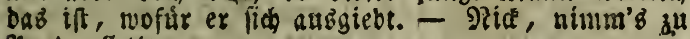
Protocoll."

"Ib, er if to ein junger Epringinbfeld, oer nie ernftich an fein Studium badte - rappelig, fert, gang xappelig." -

Sor bamit - beh?" " "

"Pun, eben verbreht," erwiederte Peter, raps Itat, - bat einen Sparren zu viel ober zu wenig; es ift aber was ganz (semolinliđez - bie balke $23 e l t$ balt bie andere Shilfte fur rappelig. Id bake bin nud wieder sienichen gefunden, bie mid fellot fur rappelig bielten; und id, id balte wieter bas sber: tribunal fur. rappelig, neil eb feit swamig Jabren 


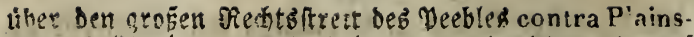

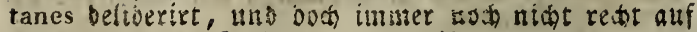
Den (Serand der Sache gefominen ift."

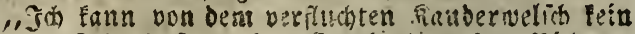

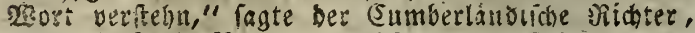

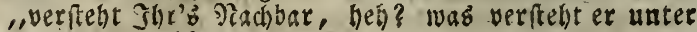
bem rappelig?"

"Er meint verrictet," lagte ber Irmgeredete, ber aub Itureduld tiber bie verlangerte Sighung feine bibs berige sorlicht vergar.

"Shr babt'z, Sar, babt'b," fayte Deter, „Dab eben meine ich; nicht gerode wabnfinmig, aber bod." Sjier bielt ex inne, uno betractete bie Derion, welche er anredere, mit einer Mitene bes freabigen

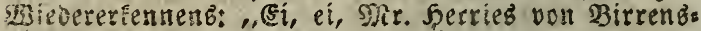

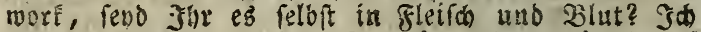
habe sobrbaftig gemeint, Gar battet fwon langet auf Der Gesteinzeniefe zu Semnington ober zu F̧airiebie ober fonft irgenswo, baumeln muffen, noc detn fous berat (Somplott, Dab Ji) Anno 45 angezettelt habt."

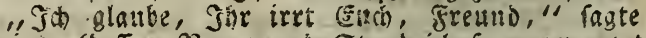
fyerries, (beffen Fame unb Stanb ich fo unerwartet erfutbr) mit Ernft.

"Deu Seufel alsh," erwieberte ber meriळro: cene peter Meeblez, ,id lenne Eud recht wohl, senn Shr babt is in bem grofen Sabre 1745 in mets nem Soufe gewohnt, wabruaftig ein widitiges Jabr war es; Die gros̃e Rebellion bract alts, wat alth meine Eache - Die grob̈e Sache - Peebles contra Plainstanes et per contra folite bein IInfanty der Minteribsung vorgetragen werben, alä megen हैuerer Dlaibs, Eucrer pfeifen und Eures unimnes bie ङef: fion nerigaben nurbe."

Ith fage Dir, Rerl, " entgegnete Sherries, now heftiger, ,Du verwechelif mi由 mit einem 2rnoeren aus De-net fomurigen "Ilaffe."

Sprecht boch wie ein (s)entleman, Sir," nar

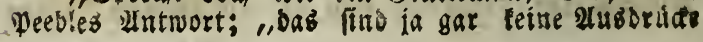


die fid vor einem Nichter sienien, Mr. Sgerriç von Birrentwors. Sprect in form fiectens, ober is

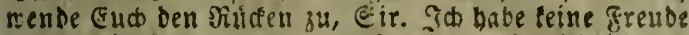

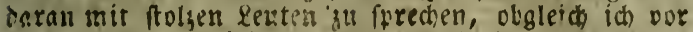

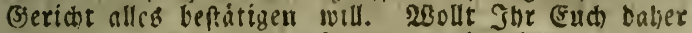
nitt alten Bsefolidten erfreuen, und mit ben tollen Streiden, Die Sir und Der Eapitain Niedgatutlet in meinem Faufe ausgelruiet babt, prablen, oter mit ben madtigen Bectern mit Branntnein, bie stor trantt, obne an tag Sablen zu Denten (zroar actete ich es bamals nicht viel, obichon ict unterdeffen fetbit Nangel Daran litt) in (Botteg Namen, fo bin ich z"s jeder Seit ein Ettinoden ful Eneren Dienften. - Mber wo ift benn iebrt ber Eapitain গiedgauntlet? Dag mar ein toller Saus, grab' ruie Thr Birrenkworf. Id hoffe Shr babt Serzeibung erbalten, oegleit fie feit einigen Jabren Euch armen Eetrelu nibt meht fo nac) fpuren; bas Söpfen uns feăngen ift nun ziomlid bar: bei - eine bofe (seidjidite - eine bitter bofe Beo finichte. - "

शreine Thfmerlanteit ward ourd biefen aujer: orbentlichen, unerivarteten Sorfall im höchftet (5ras ve gefpant. Nit fo vieler Alufmerfínteit, als nur meine eisente (s) muthbunrube zu meinen (seboten felin

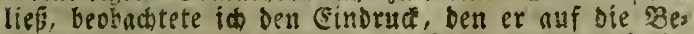
tbeiligten Derionen zu machen fdien. 2fugenióeinlich batte unfer Freuno pleter Deebleb, ofne es sut molder. eine Entbeckung veranlast, welche die Esefíble bes viidter frorlep und feines Streibers gegen den DR. fierries fel)r veránberten, mit sem fie, ehe ibnen fein giame befannt war, fo bertraut zu fenn fábenen. Sie fititerten beimlid zufammen, fouten in ein Yapier,

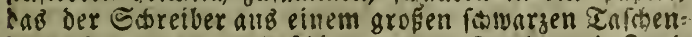
buche bervorsog, uno folenen, von Furdt unb Bwet= fel benest, fobuanend wiber bas was zu than feve.

Ferrieg war eine anbere, intereitantere figur. Base wenig auch Meter Deeblez bem Ensel Sthuriel

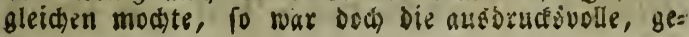




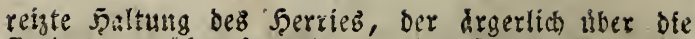
Entbeçuth, aher furdtlog yor den Folgen, den flù fternsen friebenstidter unb feinen Énretler mit ets nem 3licte betrachtete, ill weldem die 2 seractung fich beutligher fpirgelte, als 3orn uno singft, furz

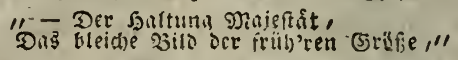

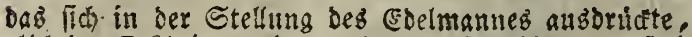
glid) Der Ericheinung bes entbeckten Jeerrichers der (Se) fiter ber Quifte.

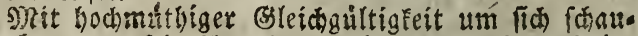
eno, begegnete feit भuge dem meintien, und do fóten es mir, alb fhlthge ex eg nieber. 2uber im slugenblic.

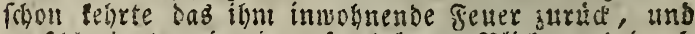
et fchleuberte mir einen furchtbaren $B$ lide 3 ts, lei wels wem ex bie Gurchen feimer Stirne feltfam zufammen 30g. (Erfátedet, aber zulgleid) mich meiner eigenen

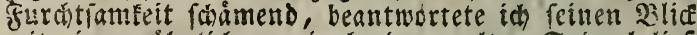
mit einem ábntiden; ein breiter, alter Epiegel lieg min meine eigenen. Sulge fêten, - ich fubr zurices, Den in bieferm alugenblicke glaubte ich bie trithend.

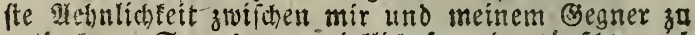
entbeden. Sey ez nun wirflich fo, ober thillíte mid meiate Einoiloung हf

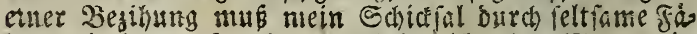

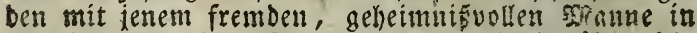
Berbiubung ftekn. Seşt aber fonnte id Daraiber nich weiter nachgrublen, Denn bie darauf folsube Huterre Dung nabm meine ganze 2ufnerffamfeit in 21nfweth. Fać einer allgemeinen Paufe von ungefăbr fün Dinuten, in welcher Eeiner von 2rilen wuÉte was ba

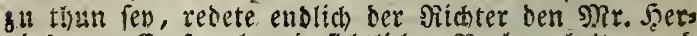

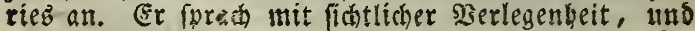
feine zitternde Stimme, und die langen swifchenráu= me, bie feine Seben.palteten, zeigten Furdht vor bem angerebeten.

"Jeerr Tachbar," fagte er, "Das båtte id nicht gebacht; oder wenn ich auch - hum - eg wirflid 


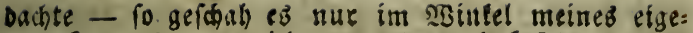
nen STersens - wo í vermutbete, Dasagbr - was

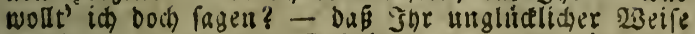
in die - be, buin - Beịidite von anno fúltf und piersig verividelt wadet - boch wollte id eg felbft gern vergelien."

ii)?nu, ift es benn fo etwas Seltfames, baj ein Mamt im Jabre finf und vierzig aubsog?" fagte jers

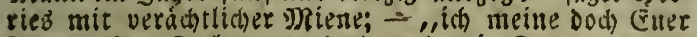
Bater, NR. Forley, fog Doch auch mit Derweattwater im Jabr funfyelgn aแb."

"Ilno verlor bie f̧álfte feines Bermógans," ant, wortete Jopley mit ungervobnlicher Shnelligfeit; ",uแb war nabe oarall, ham - gebängt zu werden, oben=

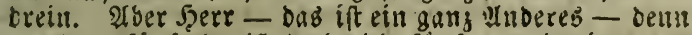
- eq - fúnfselun ift bod nidht fiuf uno vierzig; auth batte mein water serseibung erbalten, She aber, wie ich glaube, habt fie sto: nicht erlangt:"

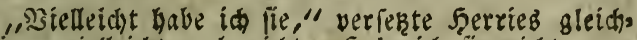

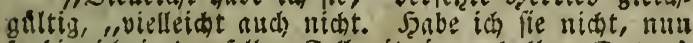
io bin in in Demielben fall mit einem halben Dukens anberer Reate, melche bie Regierung ber s)rúle nicht werth balt lie jekt noch fu verfolgen, wenn lie nut nies manden ulergernis und unftó geben, und feime un, raben Fiftel."

r.ther, Sir, Sie baben fowohl bas Eine als

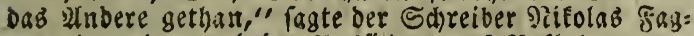
got, ber, ba ex einige $\mathfrak{M}$ uziichten auf Beforberungen batte, ben eifrigen 2lnbánger bee liegierung fpielte; „ano Sie fonmen von feimem Ridhter verlangen, DaB er Sie frei siebn laffe, Da nun Sar \$sor = und suna=

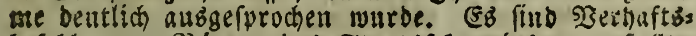
befehle vom 2üreau des Staatsfetretairs ausgeiketlt, segen Sie vorbanben."

"Eine fonderbare Bebauptung, Jerr Staatbant walt, Das nach Derlauf fo vieler Sabre Der Stantb. refretair liid um bie unglitulliden lueberbleiblel einer 
vodfommen zu Grunde geridteten Sache, bemiben follte," antworteke Mr. Serries.

"Trenn bem aber ood io ift," war die Antwort

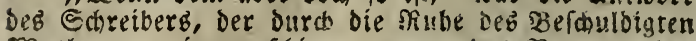
s)utb fu gewinnen faien; ,wenn bas Betragen des Edotmannes felbft 2unlafi baz" gab, der, wie man be, hanptet, bie alte Beichichte wieber aufgeruibr und lie mit neuen miśfádizen Ssegetutánden paarte. (f) fage, wenn Dem fo ift, fo wurbe ich jenem Esels manne rathen, fich wohlweislich feltep, dem geiet:má

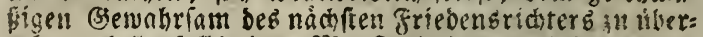
geben, (allenfallb̈-Dem Mir. Forley) wo uno Durch mels dien bie Eache gehóríg eingeleitet murbe. Sá fez̧e tur ein Mal ben Fall yoraus," fingte ef binzu, in= Dent ex furchtíam die 2 irfung abwartete, die moht feine Morte alf ben, an ben lie gerid)ret warea, ber= borbringen wirben.

"Sclite zum Beifpiel der Nath mir gelten," fagte serrieg, mit eben fo ungeftorter siube. - ,Sch fege tuir den fall voraug, wie Sie zu fagen belieben, mix. Faggot - io wunichte ich boch ben Serhaftshes fegl zu rebn, ber ein fo emporendez verfahren bered, tigt."

Statt ber 2 ntwort bandigte ifm Rilolas ein $\mathfrak{P a}$ wier ein, unb fhien ångftich bie barelub entfelienten Folgen zu beobadten. Eben fo gleichmithig als vor: ber, lab eg Nir. Ferrieb burch, und fubr dal' alro

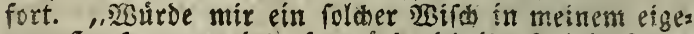
nen fhaufe vorgezeigt, fo wirbe ich ith fo in's geuer (c)leubern und Sieisholz obendrauf. *)"

23ie gefagt, fo gethan; denn indem er mit der einen Sand Den $\mathfrak{B}$ erbaftzbefehl ing Fenter warf, fafite er mit der anderen oen ofnmalt fo maichtiglich an ber Sreteft, bua biefer, ber fich weder in torperlider Stór, fe nod) in (Betiftesfeftigfeit mit thm meffen tonnte,

") Fraan ier Mame dez Eabreiberz beift ju irutíc: ein Bun Del Dietífols. 2. D. U. 
sitterte wie ein $\mathfrak{B}$ igelein in ben Slauen eine Raub: bogels. Dod fam ex fúr biefes oral, mit bem blofen

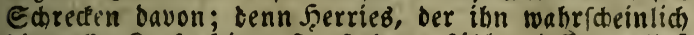
bie volle Jiraft reiner frauft batte fublen lajen, lieb ihn mit einem bóbnifhen selád)ter wieder l08.:

"Scmalt - Raub - Mord - zu Şúlfe!" farie Peter Peebles, ben bie Beleidigung die bab (5) ber Perfon deś gititolas faggot erbulbete, aufz fidd)= fe emporte. Alter fein, gellenbeg (sefarei warb von Der Donnernden Stimme des̉ Ferrię úbertáubt, ber bem Ehriftal Pixon befabl, ben beulenden Parren bie Ireps pe hinab zu werfen, inm ben Bauch su fullen, eine

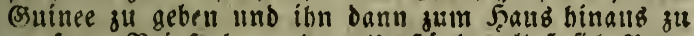
werfen. Bei fo kewanden umitinden liép fic peter gerne von binnen treiben.

Dann wanbte fic STerriez zu bem Ricter, beffen (3)efich bie purpurne $\mathfrak{i o t h e}$ ganglich verloren hatte bie now ror furzem Darauf ftrahlte, unb ber mun bie bleide fivree feines Edreibers angenommen hatte. "Mein alter freund und Refannter," fagte er, "Ihe famt auf meit Bitten, mir zu Bsefallen hieber, um biefell flatterhaften jungen Nann von bem Recht sul thergeugen, Das id für jekt úber feine perion aubs iben barf. Sh benfe, Sbr werbet mobl bie albicht

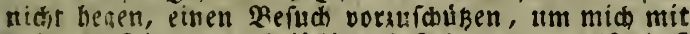
anberen Dingen zu beláftigen? Jebermann wein, Das ich SRontate und Sabre lang offentlich in ben nordin chen Brafichaften lebte, und bas man meiner zu jeber seit batte habhaft werben lonnen, wenn bie Sidber, beit bes Staates ober mein eigenes Betragen eb er:

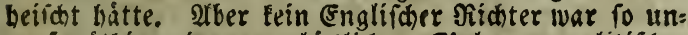
grofimitbig, einen ungludilicten Edelmann politifíd)er Meinungen und Streitigfeiten wegen su beunrubigen; bie fich fchen lángft bolfommen ju (s)unften ber herrs fonenten Dunaftie geendigt haben. Ith hoffe clfo auds,

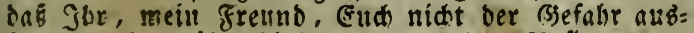
feken werbet, uiber biefen Punft andere 2infidten an: 
gunehmen, als Die, welche She feit bem 2 tnfang un: Ferer Befanntichaft an ben "ag gelegt habt."

Edneller uno geiftreicher a!b genólnulich, erwie. berte ber Ridter: "Piachuar Ingoldsby - was Shr ba fagt, ift - els - ift geviffermaffen wabr; und wenn Ibr zu einem Pferderennen, fu einem Feabnets Eampf, zar פReffe, zur Jago ober zu bergleichen Din gen tamt, - war es - eh - weder mein (5e fobåft now mein $\mathfrak{B u n f h , ~ e i n z u g r e i f e n , ~ - ~ i c h ~ m e i n e ~}$ - die Beheimniffe, bie um Euere 2Ingelegenbeiten fámebten, zu unterfuchen, uno aufzulláren; benn albु Jge nue bie mo ba ein guter Jagos und Erines Gefầbrte gewefen fevo, - hielt ich eb - eb- nicht eben fưr nothig, mich in Euere 2ungelegenlyeiten zu iniránen.

Unbsent id fhon bachte, Jbr wåret - a bem in fruberen Unternebmungen, Sisagftuden uno Sers

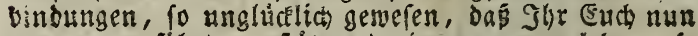
gesmungen fábet, unftát uno eingezogen su leken, fo fomte id bod - eh - wenig Sergntigen baran finden, - Euere Sadhe Durch 2lufbringlichteit zu ers rchoren, oder (Eud) Sied und gintwort abjuforbern, bie man leid)ter gibt, als erlangt. atber wenn a mentlide serbaftäbefeble uno zeugniffe vorliegen uno biefer Pame, Tauf. und Familien = Pane einer - els - gegenwartigen Perion angebort, wels che, wie ich boffe fälichlid, - befouldigt wiro - a bent - Die Bentither zu abermaligen Reibungesi uno Hnruben zu entflammen, um bie eben erft erlofchene flamme bes 3 ürgerfriegs wieber anjufacten, Dann Seerr ifit eB eine ganz andere Sadbe, und id bin genotbigt, - hum - méne Pflict su thun."

als ber Richter feine Rede (d)lö́, ftand ex anf

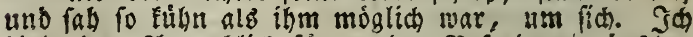
bielt den 2Uugenblia fur meine Befreiung gunfris,

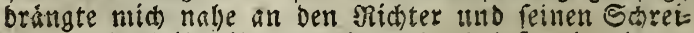
bet, uns theilte ilinen meinea Entichlus mit, ilgnen beisufrelg. Ater Sperries lachte nur tiber die oro= 
bor Edreiber auf den Friebenzricter, ber fortfubr,

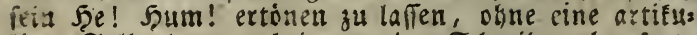
lirte Salbe hergorubringen; ber હchreiber aber fagte

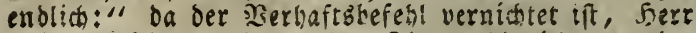
friebengridter, fo werder Jgr wohl nidht gemeint rega; bie serbaftung Dennod vorjuneloment."

„5Tum! - ey! warum níbt" - aber - Nitolas es roúrbe boc nicht gans ráthlich feyn, uno ta die (Sefdidite von 1745 fobon ziemltch a!t ift, "tnb (er buftet) Da mein freund hier hoffentlid feinen Srrs thum einfehen, bas heibt, ibn foon eingefehen haben, - uno Dem Papit, dem Teufel und dem Diárenbens ten entiagen wirs, - ich meine es nitht bós Piacts bar, - po dente ía mir, - ba wir sab polie, oder bie Sonftabler ober bergleiden nidit haben, wir laf: ien ung die Pferbe bringen, - unb betrachten, mit einem Mort, Die Sache als abgethan."

Sluger EntfoluE, fagte- Der Mann, den bie Enticheibung betraf, boct bevor ibr gebt, wollen wir cins auf uniere Fremo ichaft trinfen."

Ja, fagte ber Friebenbrichter, fid bir Stirne reibend, bei unferer 2 rbeit, (er huftet) hat man mols foituen surftig werden.

"Shriftel giron, fagte Mr. Ferrieb, , bring uns fogleid eine rect friche Sanne. grö́ genug, Den Durft Der ganzen Sommifiton gu frifles."

Tábrend Ehriftel negen bez ermunternien $24 f_{3}$

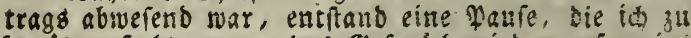
bentigen fudte, um bas Bseforád mieder anf meine eigenen 2Angelegenbeiten zu bringen. "Sir," fongte í su dem Friedenzridter Forlev, ,mid gelit (Fure lezte Serhandlung mit Mr. Serrieb eigentliố nídt: an, aber ibr laf́t mid, einen lovalen unterthanen beb

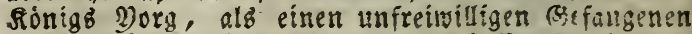

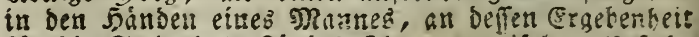

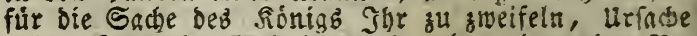

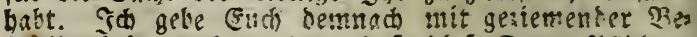

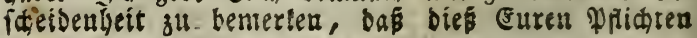




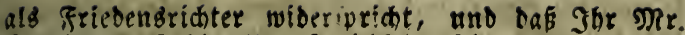
jerries alff oie lingefeblichlett feines Benebmens aufmertiam maden, und hur meine Befreiung Soritte thun folltet, entweser auf ber Stelle ooer bod fobald als ilar diefe Sadue

"Sunuer D\}anu," fagte ber Serr friebenbrichter fortev, "shr folltet Eud exinnern, bas ibr unter ber (sewalt, ber gefeslidien (s) walt (er huftet) Eures 2 or, mundes fendo"

(Er nenntifich freilid) fo," erwieberte ich, ,aber ex bat Eecten Vemeis leigetracht, um einen fo wioerinniBen Inipruds su begrunoen, und wenn nuch, fo wits De der Umftand, Daß er, als ein überwiefener $\mathfrak{B}$ erräs ther von Der 2 mmeftie nusgefchloffen ift, ein folches Recht bernichten, menn es ie beftanden bätte. Sch bes gebre Daber von (Euch, Serr Friebensrichter, uno (Euch), feinem Gchreiber, meine Lage in ફ̉etracht ju bieben, uno mit Eurer eigenen Befabr mir beizufteben."

"Das if mir eill junger \$̧urfche," fagte ber fries Denzriduter mit zicmlich verlegenen Blicken, ,Der glaubt, (ch) fübrie Das ganje ftatutarifche Recht Englands im Sopfe bei mir, uno ein (3ratíchaftzaufaebot in Der $\mathbb{E} a$.

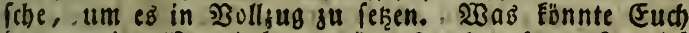
benn meine Dermittlung nüBen? aber (er bufiet) ich will mit Eurem $\mathfrak{2 0 r m u n d}$ sul (Euren (S) uniten fprechen." Er nabm ferrn Jerrieg auf die Seite, und (chien in ber Ibat megen irsend etwas mit grofem Ernft in ibn ju bringen, uno vielleicht mar eine folche 2 rt oon $\mathfrak{B} e r$ menoung alles, was ich unter den vorliegenden Lumftän= ben bon ibm itu ermarten berechtigt war.

Cie blickten bei ibrem Ëefpräche oft anf mich bin, und als Shriftel Nikon mit einer mächtigen Raune bereintrat, bie Den befoblenen. Trane entbielt, wanote Serriez iich ein menig ungetuldig bon ferrn forlan ab, und fagte mit )?achoruck: ,ich gebe (Fuch me:n Ebrenmort, Dabibr in Diefer Jinficht nidst oas geringfte stl fürchien habt." Er nabm cann Die Janne uno lagte laut auf gälifch: "5ei Dent Sionig!" Er nippte 
fooann ein menig, und reichte ferru foulen Die Sinnne, Der, um nicht vielleicht nuf Deg Prátendenten Eefund: beit $\mathfrak{B}$ eicheid ou thun, auf Des Serrn Serries eigene mit grofer feererlichfeit trane, aber niclst blos nippte. Der Schreiber folyte Dem Beifpiel feines Serrn und Deifters, und millig that ich ein gleicheg̉, Denn 2ngft uno Furcht madjen menigftens eben fo ourfig,

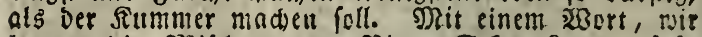
leerten Die 9rifchung von Bier, Eeft, Emonenfaft, MugE at und andern guten Sachen, bie nuf Dem filbernen Boden Des ङsefäfles ftrandetell, uno machten Dr. Burens berübmte Zeilen lesbar, bie Daralif eingegraben maren:

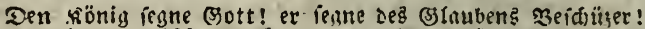
(3ote feune - iffs linred)t denn - Den Wrätendenten aud!

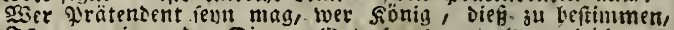

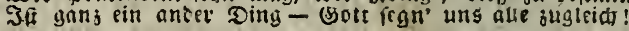

Thh batte Beit genug, Diefen Erguß Der iafobitis

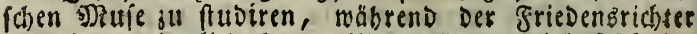
mit einem ziemlich langmeiligen (Eeremoniel 2abichied nabm. Der von Serrn Faggot nar meniger ceretnoni= bab, aber ich vermuthe, es gieng allber Den leeren (5om. plimenten noch etwas anberes jwifchen ing und ferrn Serries vor; Denn ich bemertte, Daß̧ Der lek̨tere ein

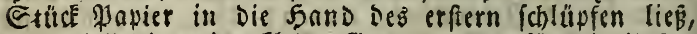
mas vielleicht eine fleine (3)enugtbunng für Die Unbes Dad,jamfeit war, mit Der er. ien 2jerbaftsbefebl ber: brannt, und feine STand siemlich unfanft an pen ach. tungswertben Ë̈nfling Des Befetres gelegt batte, Der iun borgeigte; auch entgieng mir nicht, $D a k$ er biefe כefänftigung auf eine Sieife vornabm, Daß fie vor Dem Serrn Des metroigen @ehteibers berborgen bleiben mafs= te. 2Als dief in Dronung war, nahm man gegenfeitig bon einanoer $2 A b$ fhied, mit bicler förtmlichfeit von Eeite Des Serrn Forley, unter Defien abichiebazbraien mir folgende befonders merfntirdig war: ,ich vermu tbe, Jbr werbet ettch nicht lange mebs in siefen bes. Bsuben aufbaltetl?"

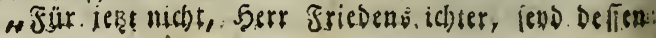


gemadt su baben, nnd bie lekten ibre rbaten bei \$roiton, (slifton uno Faltirt wioerfauten.

Dá ) Ríbergnugen folder Werionen war allzabe. Deutungblob, um die Ulufmerffamfeit ber Regierung su erregen. $($ d batte aber von einer funnern und

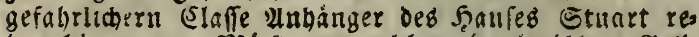
ben boren, von oránithern, welde mit romiduem (3)lo verfeben, hermlid und verlarot fich in oen vericties benen Slaffen ber Sefellfwaft umbertrieben, wno Dea erloidsenden Eifer ibrer Martbei lebenbig zu exbalteu frebten.

Unter biefen Menfकen, beren Birlfamleit uns Streben nur von oberiátliden Menichen in 3weifel gejojen werbin fonnte, wiés ids obne weiteres dern Dir: Jeerrieb, beffen geiftige siraft nicht weniger, als feine perionlidbe Stáxle und sbátigleit ibn zis eiser ro gefábrtichen Rolle zu eignen foien, einen be:

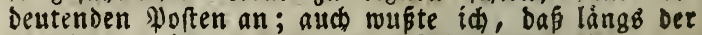
weftliden Rúfte Englanob uno Søottlanob eine folde Menge Unbanger ber Stuarts wohnten, baś fo tin Dann mit vollfommener Sidherbeit fid bier aufbal: ten modste, wenn nicht ber Negierung ganz befon: Derb Daran gelegen war, fíd feiner Perion zu verit. dern; und felbit bieß Borbaben tonnte leidat oereis telt werben, entweder ourch eine fribietiue Berach: richtigung, over, wie im ffalle bes Mr. Forlav, burch die geringe Bereitwilligleit ber Wrovinzial: Dbrigleis ten in einer Sabe einjuftoreiten, die man jek̨t als

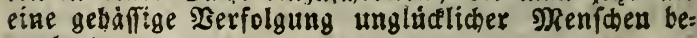
tracitete.

Indeffen baben fich furglid (s)ridte verbreitet, als of ber gegenwartige 3uftano ber 9tation, ober wenigftenz einiger misvergnugten Provingen, erseugt ourch eine Jjenge Uriawen, befonders aber burch bie unpopularitát ber gegenwártigen Ninifter, diejen ofufitiftern als ein gunftiger Beitpunft ericheirse, um ibre Sntriguen oon newem zu beginnen; auf ber aus bern 
meines pigenen (solitits in bem Epiegel, in sinem

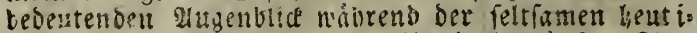
gett zlifommentunft, uno ich eilte in bas âtsere sim: mer, unt ben Eplegel zu befragen, ob er moglich fen,

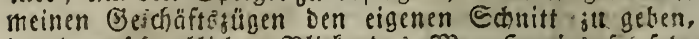
Der Dem fchrectlichen Blicke des Mar. Serries fo fet? glicis. selber ich faltete meine Etirne vergeblich auf taufenderlei s3eife, und muste endlich ben Echlus mas dien, Inf entmeder bas vermuthete Beichen nuf meirer Etirne nur eingebilbet, ober Durch millfubrliche yn. firengung nicht heruorgertten toerden tönne. 23 ährend ich io mein bifficht gleich einem toflen Epieler in atse

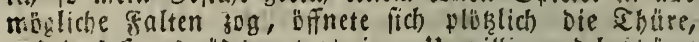

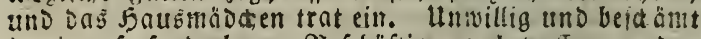
in einer fo fonserbaren befchäftigung tetroffen morien zu fenn, wander ich mich raich um, uno vermuthlich

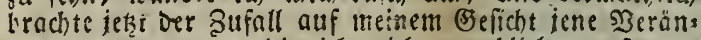
Derung hervor, itm bie-ich mich vergeblich angeftengt batte.

Das Mäochen bebte surüc, tino fagte: ,tt:m Gottesmillen, ientt feht Shr ia atts, leibrajig mie Ber alte Equire - nber Da formmt er felbft." InDem fie

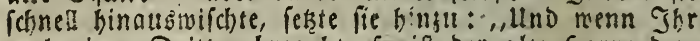
nech einen Dritten braucht, fo ift ber alte Sarry Ders ienige, Der am beften Die Etirne runjeln Eann."

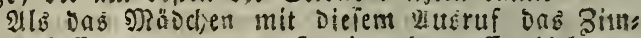
mer verlaffen hatte, trat Jerriez ein. Er bielt an, alb er bemerlte, Daß ich wieber in ben @piegel ge= fohast hatte, un bas (seficht zu mechen, - wobarch bas elufiltige Ding stueifelsogne erichreft worben war. Ex friten meine Sebanten z"serrathen, dent er be, merfte, ala id mich sut ilsm wattote: "3wweifelt nicht,

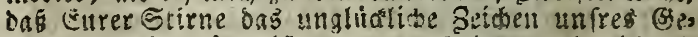
folect)tb aufgestidet in, wenu aud iefst nod nidht 10 fenntlid, alb bann, wenn Sabre unb Summer, wenn. bie Spuren fturmijher Seidenidaften Eure Stirne gefurcht haben werden."

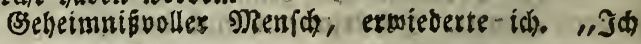




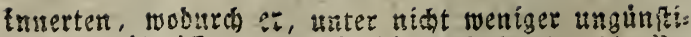

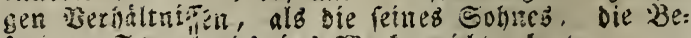

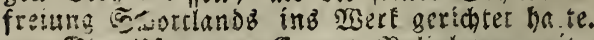

Wor lliryator Esaars Ballol war mit wenigea

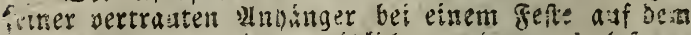

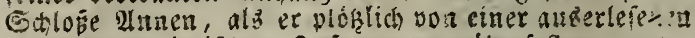
Swat patriotifder salurgenten tiberfallen warse.

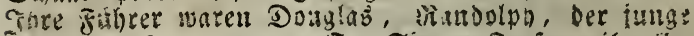
(sarl bou )Roras, m.s Sir Simon frafer; iftr to: foly mar fo vollánolb, Daf Balio! Eatm geflesdet uas auf einem ungefatte!ten pfecoe entfieben mais?, sim fein Leben su retteu. EB war bod 23 istigfeit, fith two mogltid feiner Derfon zu benáchigen, uns er l:urse bebhalb rafh verfolgt, von einen tapfeen rit: tes normánsicher $\mathfrak{A}$ bunft, beffe: Familie fich foron lange in biefem Lande niebergelc "sat hatte. Shr nor mannifher Rann mar fiz... ne ber Ritter batte aber von ber grošen Rieberlage, bie er unter bea Siblanbern angerichtet batte, uns bon reinein $23:$ berwiflen, irgend jemanoen Parbon zu geben, ben ex wabcent der frubern Siriege Diefer blutigen periode g:zoigt batte, ben Namea Rioganntlet (Rothband:

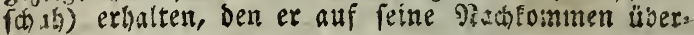
trug

"Rebaantlet!" wiebergolte ith utiviufusarlic. "Ja "Noggauntlet," fagte mein aingeblicher 20 ormans, tino fah mids forarf an; "medét biefer Marie irgens Erinnerungen in (E:ach auf?"

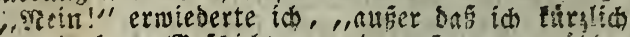

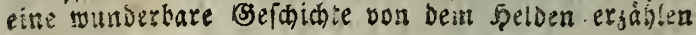
borte."

"Biele ber Art fins ifber bie framilie in unla:f," antwortete er, and fubr Dom in ieister Erzablats fort: , Ulberid Rebsuntlet, ber erîte feines $\bar{\jmath} a u$ fes,

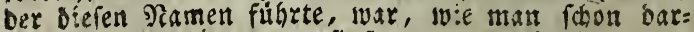
aub follieffen fánn, von finfterer, unverfósulicher (3): mitgourt, welde burch familieaswifte nod báter ges morven wax. Sin einziger Soha, faum 18 Sabre alt, 
batte fo febr feineb Baterb froljen Seift geerbt, das er ben häuglichen stwang nicht mebr ertrug, fich bem váterlichen Anfebn witerfekte, endlich ron feines $\mathfrak{i}_{a}=$ ters feare flok, den politictien seinungen beffelen entfagte, uns burch feine serbincung mit ben $2 u=$ hänern Raliols ben fortdaternden tunwillen feines Sater's rege madite. Der Bater foll in feinem Sorn ien entarteten Sobn verfucht uno gefchworen haben, ibn mit eigener feand zu tobten, no er inn trafe. Unterbeffen fohien eB, alb follte er fur biefen grojen Serluft einen Erfak erbalten. Die Labo alberide Red= gauntlet befano fith nach vielen Salyren wieber in einem 3̧uftande, ber ibrem (S) mabl, oie Jerfitung auf einen gethorfamen erben ersffnete. Dow der bedentliche 31s: ftanb feiner (3attin und ter tiefe 2 n'beil, ben er cat cn nabin, verbinderten a!berid nicht. an bem unter, nelinen vou Domalaz uno moras Mntbeil zu nebmen. er war ber vorberfe gemejen tei bent angriff zuf bab Salori, uni mar nun auch ber erfte in ber siers folgung Rialiole, eifrig bemuht, bie menige fubmen alnbánger de lufurpators, welche Deffen Flucht s: Dedent verfucten, z!t zerfteuen ober niebcruhauen." "IIlz biefe nact und naw yeriagt ober exichlagen maren, max ber furchtbare Rebgauntlet, ber Tob= feino bes fraules Balio!, nux now zmei Panbenlons

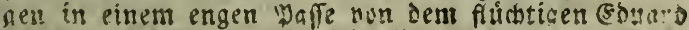
Buliol entfernt, alb pin Jângling, einer ber lebrten. bie ben ujurpator auf ieiner flucht begleiteten, fich

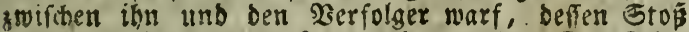
emping, ater rom Rop geworfen wurbe. Der Jelm entfiel feinem Saaupte, und Die Strahlen ber Sonne, bie gerabe úber d:n Solway aufgieng, geigten Fie gatntlet bie sugefeines ungeboriamen Sohnes in ben Farben und 2lbjeiden bes Hiurpators.

Rebgauntlet fah feinen Sobn vor ben Gúfen

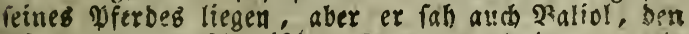
ufurpator ber fanttifcen srone, nod inner, nie es foien, inmerhalb feines Bereígs, und nut b:ord 
Den nebergeftrecten Forper feines libermaltigten $\mathscr{2}$ bángers oon ifm getrennt. Done anguhaltert, usz ou unterfuchen, ob ber iunge Esuaro verroubet feb. brudite er reinem Pferbe die Sporen ein, im siber sen forper binfuresen, was aber unalidlidherwite mí̄lang. Dab Pferd madte zwar einen Eprung vorwártb, war aber unfábig, ưber ben ficrver bes Junglings wegzufeken, uno traf Deniclsen mit bein Sinterfüe an ber Stirne, als ex eben fín erheben

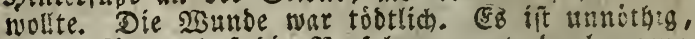

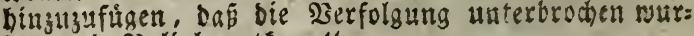
be, und balid entfam."

„Eo wils Siedgauntlet auth geidibert rarde, To ullernaltigte ín boser der (jebante an das beganzene

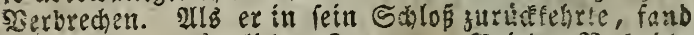

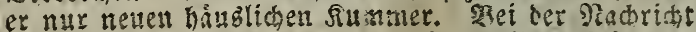

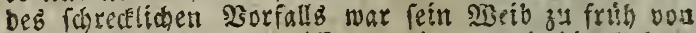
Seburtsionnerjen ergrifen worben, und bie Geburt eines Jinaben loftete int bng Rebon. Rảnzer alb 24 Stunden fá sedogantlet bei inren fiorper, ofme weser feine sige, not ieine Sselung g" berántern, fo- meit des feine erforedten Diener beneren fonn=

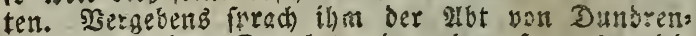
nan sroft ein. Doug? as, ber einen fo ausgezeicos neten Saterlandsfreuns in feinem thalue zu beiss wen fam, war glidélicher, reine 2tufinerflanteit 3 a erregen. Er lie puf Dem Sólosbofe eine englifo Schlachtmelosie blafen, ba ergriff Oedgauntlet mit

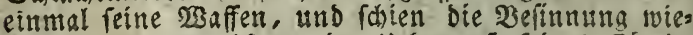
ber su exhalten, bie er in Hebermás feines हlends verloren batte."

, $23 a b$ er auch innerlich fublen mochte, von bem gugentic an war feine áugere Bewegung mehr zu erfennen. Douglas liés das fino herbei bringen, aber felbit bie eifenlarten firiger warden von Entfehen ers griffen, alb fie bemerften, bab burch ein aebeimnis:

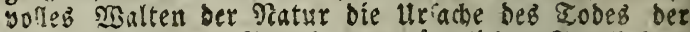
Matter und ber Beweis ber váterlichen S\$uld bem 
(selichte des fchulslofen sinuben anfigedricht war, alit

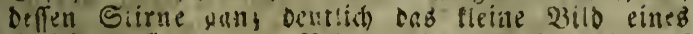

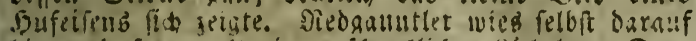

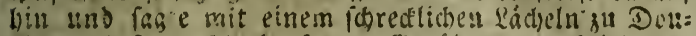
glas: cs fodte blutig fenn. (Serubst you s)itlecsen gezen feinen 2Bafenbruber und burcí) bie (Gemib: tumt an burgerliden firieg segen alle fanftere (ल)efuble

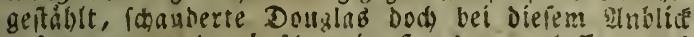

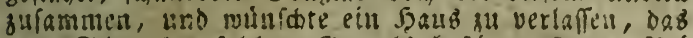

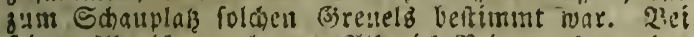

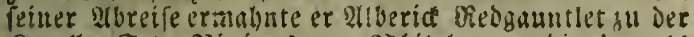
Sapelle Sct. Piminmb von 23hiteherme, bie Damals in groperm sinfelsen ftand, zu malfabrten, und reifte mit einer Eilfertigleit ab, meldae den troftlofen $3 \mathrm{at}=$

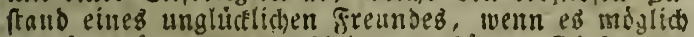

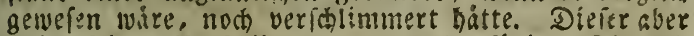
íhicu feinter Beriçlimmerung melor fábig. Sir gl= berice lies ben feidnam feines erichlagenen Solyns uns Den ber 5 mutter neben einanoer in Der alten rapeife

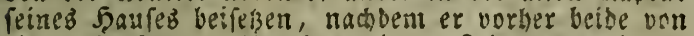
eitten beribmtell 2 gandarst jener Seit hatte einbal= famiren luffen, uno viele $200 d$ en lang foll er in jeder

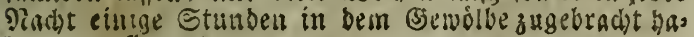
ben, wo fie rubten."

,(Enolia) unternahm er bie vorgerdhlagene Dilger: fabre nart sishiteberne, wo er zum erftenmal feit fei nem Ingltad beichtete, und von einem alten spionde abfolvirt warde, ber nachber im (seruch ber Seeilig= Feit ftarb. Daunals foll Nebyauntlet geweifagt wors

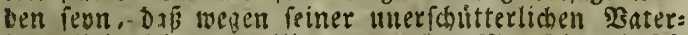

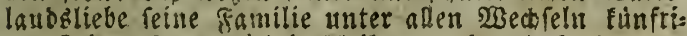
ger Seiten frets mábtig bleiben werbe; Daś aber zlie Strafe fur feime unnadifintige Graufament gegen fets nen égenen Sobn ber Seimmel befólofien babe, ba

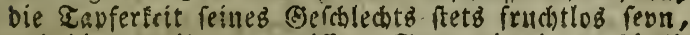
tno bie von ibnen erariffene Sache tie einen glúcelí, chen slugsana batien folle."

"Sir alberia unterwarffich ben ibm Daiellft aufs 
erlegten Bม่ glaubt, entweder rais Rom ober su bem heiligen (s)abe felbit. Allgemein w"rse er fur tost gehalter, "no erit 13 Jabre nachber erfoten in der grop̈en 5 blacht von Durham, die zwifhen Davib Bruce uno oer fros nigin philipya von Enaland geralagen murbe, in

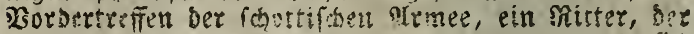

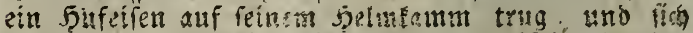

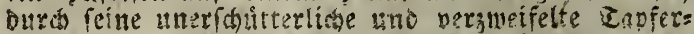

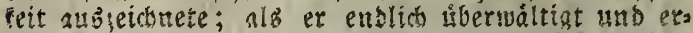
fálagen wirbe, entsecte man erft, Daṕeb ber tapfere uno ungludelide Sir wlberice gemefen war."

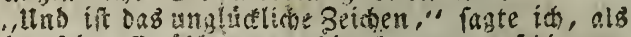

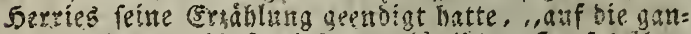

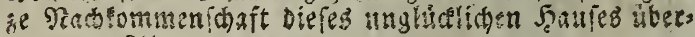
gezathen? ?̧"

So bat sas atterthum es uns úbertiefert," fas, t? Serries, ,uno now alanbt man es. Orber vie!ne tht ift in bieler 20lszalatuen etroa non iener Mhantas fie, weldo felbft exfóste, suas lie feben mill. waie andere Familien ibre Siantbimlisbeiten baben, woz

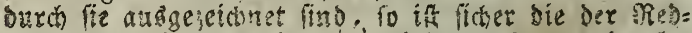
gauntletz bei sen miften Givbividaen bura eine be= fonbere Bilbung ber istirne beteldnet, me!ce nad

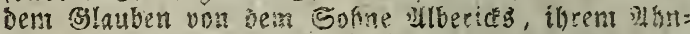

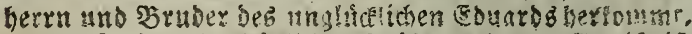

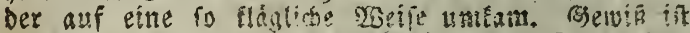

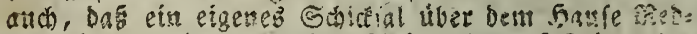
gauntlet gerualtet gu baben forint, benn fait in allea burgerlichen Fehben, welwe bon ben Beiten Btrib

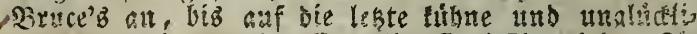

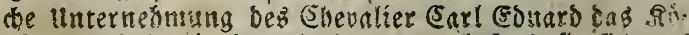
ninreid Schottiand cetheilt baben, befand fie fith guf Der verlierenden Seite."

Er folos mit einem tiefen Senfzer, wie einet ben her sjegerfand in einen Strom peinlicher sos:

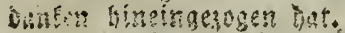

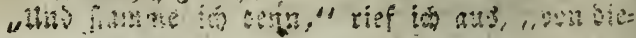




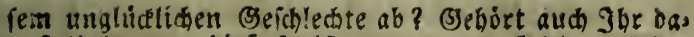
8u? Uno wenu bié fo ift, warum mus id vont ser S.ano eines SBerwanden âwang uno barte Bebano. lung exfatien?"

i, fragt jeht niat weiter," fagte er, ,mein Bes traben gegen' (Elich ift nicht Sache meiner sibuhl, fons bern ber glothwerdigfeit. Shr murtet bem. Sctoofe Eurer fanilie um ber Sorge Elires gefeslichen Dits: munss surch die furcht uno bie unwiffenheit einer allyusártlidsan mutter entriffen: welde nicht im Stans

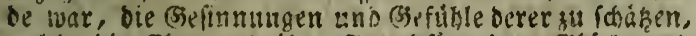

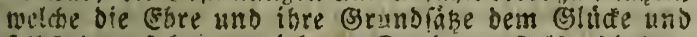
felbit dem feben voraieken. Der junge Falie, bloz an

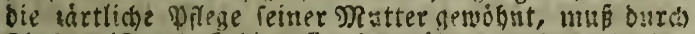
finfternis uns Soglaflofigfeit gesabm! wersen, else ibn ber Falfner feinen Bweden gemäB auffitegen ldşt."

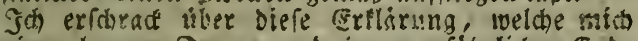
mit einer !angen Dauer, unb einem gefónrliten Ende

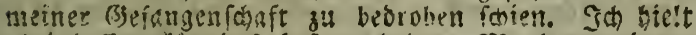
ez ingerten fitr bis befte, einigen Diuth zu zeigen, nno zu sleider Beit einen verfónenten Con anz:

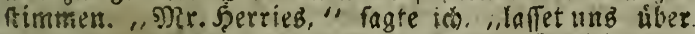

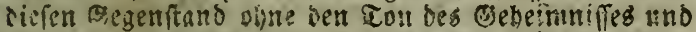

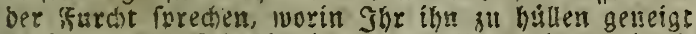

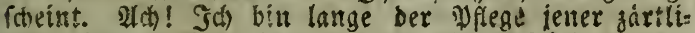
den Nitter berasbt, morauf Thr anfpielt, lainze unter frember Peitung uns aezwangen, meine Ents

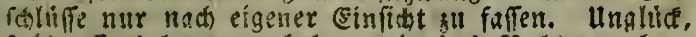
fruhe Entbelsungen baben mir bas Nect gesebsu, für mico felbit zul bandeln, uno sivang foll mid bes exften Biectio eines (Eng!ánbers nicht berauben."

"Der rechte sioseton," fagte feerrieb verchat:

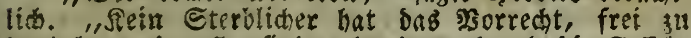
bindeln, wir alle find gebunden, durch bie Feffeln

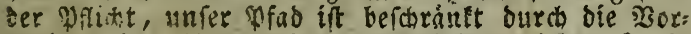
fóriften ber Egre, und unire unbebentenditen frand:

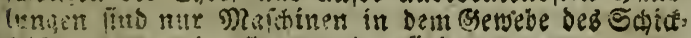

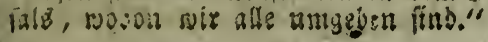


Siafd) Durchidritt er oab 3immer, wnd fubr in einem To!e ber Degeifterung fort, oer in Nerbin, bung mit einigen andern Eetren (eines Renebmeng

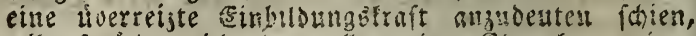
widerfurabe nidi cer allgeneine Eharafter leiller Seor unis reines Benelymens.

Sichts, ‘ fagte er in eruftem, fait melando: lifwent Zone, nichts ift bas sisort bes 3ufalls, nicts ip bie folge des freven 5 illens, die freilyeit, bereu ber englánder fich rubmt, giebt ibrem 3ैfiner fo

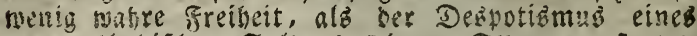
morgenlábifon Sultanb feimem Stiaben geftartet. Der Ulursator Willye!m con ?afiau gieng auf bie

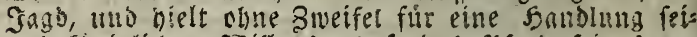
ties foniglishen millen morbeten Dpfers fur fein fónigliches sergutgen gea fattelt mar. Mber der ḩimmel woilte eह anders, mo elie bie Sonne both fand, foftete sab Etraubein bes nemlioben Thiets at einem (s)gentsns, ber fo un hebeutend war, alb ein giaulwurfbigl, feinem folsell Sizuter bas seben, und feitue angeniante

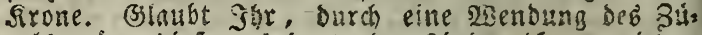
gelb måre dieb unbedentende sindernif ve"trieden

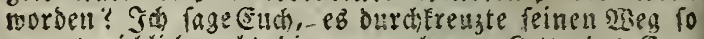
tuausmeiditich, als bie ganze linge fiette sis (saus cafub utr inmer baitte thun fonnen. Ja, junger Rasn, im Ebun und Reiden fpielen wir nur bie uns boin Beidid, bem Reiter biefes foltfanien Drames, giserbeilte frolle, vermogen nicht mehr suth thu, als แns borgefarieben, nicist mehr zu fagen, alb uns aufregeben ift; uno bod falmajer wir viel beut freiest Sillen uno freibeit beb Geoanfens und ber Şand= lung, alb of gichars nicht fterben, ober nichonons fiegen muete, gerabe fo wie ber Dichter eb angeords uet hat.

9cach diefer sieve fubr er fort mit vorfolungs:

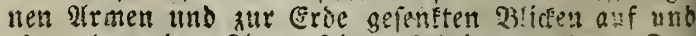
abjugeben; ber Sllang feiner Sartte, und Der Ion 
feiner Etimme erinuerten midh, bus ít biefen fon:

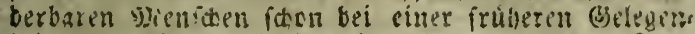
beit iolthe Ellortgeipradye in feinct einjamen frans mer batte balten lovell. Id bemertte, baś or gletch ancern Jacobiten in reineaz veriábrten Sang gezen

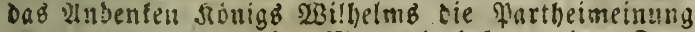
altgenommen batte, ber Mionard habe an bem Xage

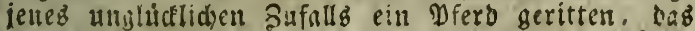

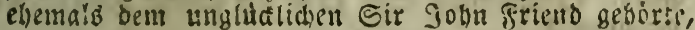
ber im Jabr 1696 wegen J̧odbuerrath hingeridhtet warte.

Tob burfte benienigen, in beffen Biewalt ich auf eine fo fonderbare $23 e i f e$ gelommen war, nidit erbit, tern, fondern wo moglich belänftigen. 21 ls id bes merfte, bas die Jeftigfeit feiner (Befüble fït.cin mes nig gelegt batte, antwortete idy ím folgenbermabea:

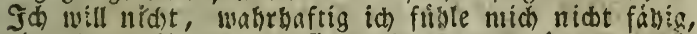
eine fo fubtile metapusfiche frage zu erórtern, wie bie, welche von ben (s) renzen fes freien 23 illens unb ber 2orierleftimmung banbelt. Eap̈t nug heffen, bas wir mit Ebre leben, und mit gatcr feffunng fterben, ohne gendringt su fewn, uber einen Dintt eine entichebene s)evinung zu bilten, ber fo wsit

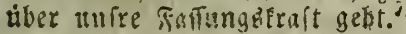

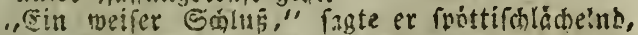
"Dablang la mie ein Stud a!s einer (Senferprediat." , Ilber, fube ida fort, ich ridate (5ure 24 imers

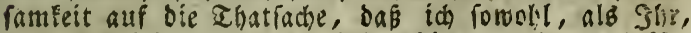
nad antrieben gelianbelt habe, bie entweber bag Me: fultat meines freien 28 illeng ober bie fiolgen ber mix von bem Schitifal beitummen siolle find. Dieie fon: nen uno im senentwärigen falle find fie nirflich im geraben $23 i b e r p r u b e$ mit benienigen, burch-swelche She benegt morben fend; und wie follen wir nun he. fitmmen, welde ben 2 sorrand baien foll? $g$ br fablt Eud bielfeict beftumt, mein Rerlermeifter su fenn,

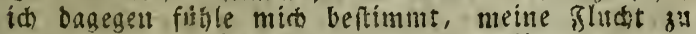

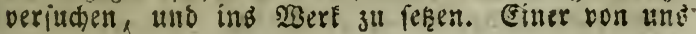




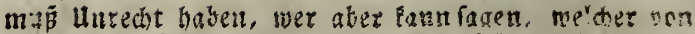

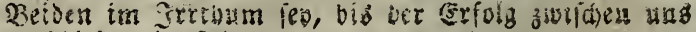
entidieśen hat?"

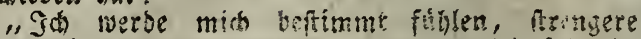

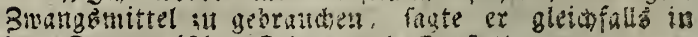
oem sone zwífien Stors und ermit."

"In bieren Falle," antrortite in, "nito $\mathrm{es}$ meine Gefinmung fent, alles firt meine greigeit zo perizchen."

"Und bie meinige, iunger SRann," ervistarte er in einem tiefen and firmien Bone, i, Sorge in tha

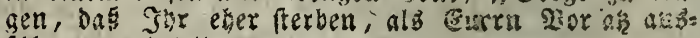
fübren werbet."

Dief war beatfic gefprowen, und in worte ing leinesivegg ofine Mutwort latien.

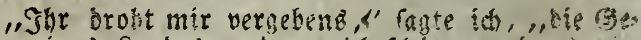

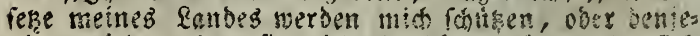

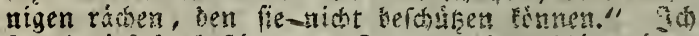

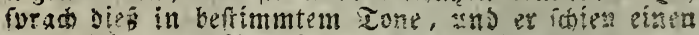

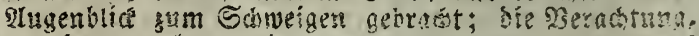
womit es aitést mir geantwortet batte, tru:g erwas offectirtes a

"Die Gefése!" iagte ex; ,nut nab wiet tema

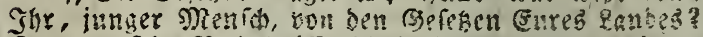
Ronntet Sar Siedtsoniffenithaft lernen unter pines nieorig gebornen Deroantentffecter, nie Saumerz

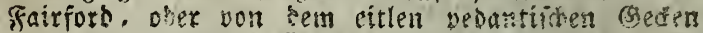
feinert Solne. ber fid jest ia aud einen mbonfaten nennt? MlB Echottland now fich angeriote, nut ret= nen cigenen hosidg uno Bsefechebung batte, würben fo gemeitie \$robeicr, anitatt $3 !$ lien Schrantern ses

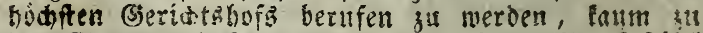
bet Ebre zugetuffen worben fern, einen altenfaficiel gu tratert."

Wlan, bien fonste ib nidt ertragen, fondern ant=

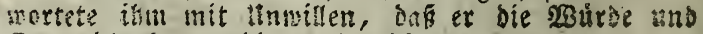

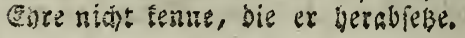


"Ih) meif fo viel von biefen fairforb's, alb vou (Each", eriviederte er."

"So viel, fagte id, und fo menig. Denn ihr lonnt weber ihren, noch meinem wabren 2 erth fod: Ben.- Th weis. Thr habt fie sefehen, bei Earersm lek̨ten 2 (I) fenthalt in Edoinlurgh.

gens att.

"fra! " rief er aub, uns blickte mich burdborin,

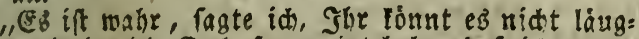
nen, unb oto ín Eud fo ge eigt habe, baf ico etmas bon Enern Umtrieben fente, fo will ich Ench warnen, Denr id bube Nittheilungswege, bie Euc nnbefannt fino. Syingt mid nidt, fie zu Eurem Pactheil za gebrauchen."

,3a mei nem Rachtheill! "erwieberte ex. "Inn:

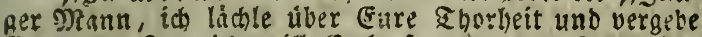

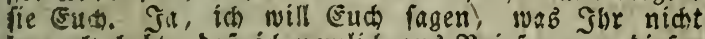

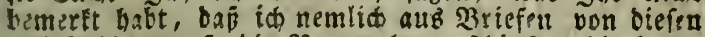

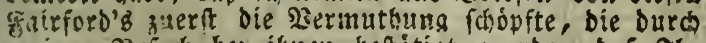
meinen Beluh bet ilnen beftatigt wurbe, Dás Jhr Die Derion fend, bie id feit Jabren gerudt hatte."

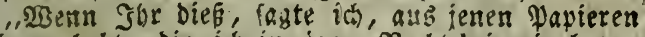
erfalyen habt, die ich in jener Racht bei mir hatte, a!g ith mich in ber Pothwendigfeit befans, Euer Baft s'l Brodenburn zu werben, fo bomeide ich Eud niat

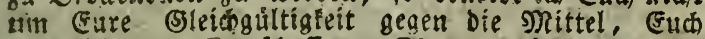

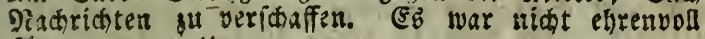
fưr - - - -"

"Stille, iunger Mann," fagte Jotrres rubiger, alb îs erwartet batte; "bab 2 Bort Unelire barf nidt in Berbindung mit meinem Ramen ermábut merden. Eure Brieftaiche war in ber Tarbe Eures Nodz, uno

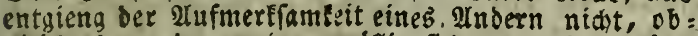
gleid) eg vor ber meinen völig fider gewefin twäre. Nein Diener Sbriftal Niron bracte mir die Fad: riche, nadbem Jhr weg waret. Ja mar maufrieben mit ber $\mathfrak{A} r t$, wie er fíd bie Rachridt veridafft batte, aber es war nidt weniger meine Pflidt, mict von ber 
Matbrbeit zu verfithern, und barum ging ith nath Eoinburgh. ICh boffte Rr. Fairford zu itberreben, in meine sfnficten einjugehen; id fans ibn aber 3 u

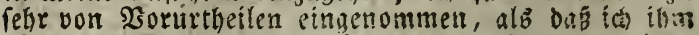
bàtte Butrauen forenten fonmen. Er ift ein erhórm= lider und furdatiamer Sclave ber gegenwartizen Ries

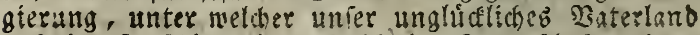

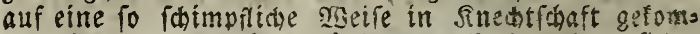

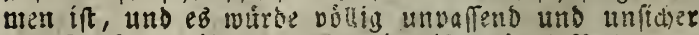

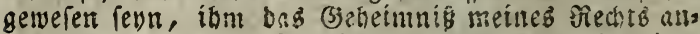
guvertraten, Eure 5anolungen bu lenen, ober ibm bie IIt, wie idh eb̉ zu gebraudhen gebente, zu enthúl= len."

Sh war entidlofen, biefe mittheilende Stinmang ou benuken, unb wo móglich mebr ?idit uber rein Sorbaben zu erhalten. Er fíten im Dunfte ber Eire

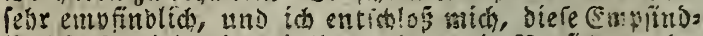
lideit fo viel mie maglich, aber mit sorficht zu bes nasen. "Ibr fagt, erwederte id, baf́ She hinters

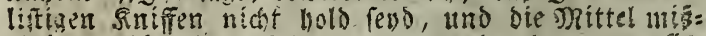
billiget, bie Eaner Diener angeivanot bat, um fich

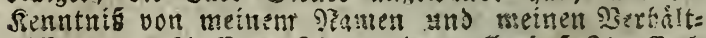

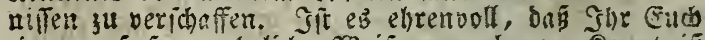
einer auf fo unehrliche weife erworbenen Reuntnif bedient?"

"siųn gefragt;" erwieberte er, "aber in ben

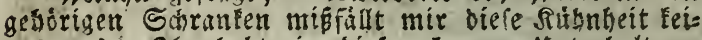
neswegb. Shr habt in bieier Iurgen Itnterhaltung mére Sharafter und Energie entwiçelt, als tố von End erwartete. Soth hoffe, Thr gleicht eiuer walb=

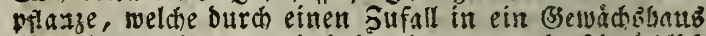
aebrabt worben, und baburd zart und fawishlids warbe, bie aber ibre naturliche fraft und Starte miebererbält, wenn fie eine Beitlang ber 2 interluft auggereg̨t wirb. Sक will Eure Franen gernbegu beant: worten. In Eseithiften, wie im Ariege, fint Enios nen und Runbidiafter nothwendige Hebel, ote von allen redtidaffenen Mewidsen verabideut, aber von allen filu= 


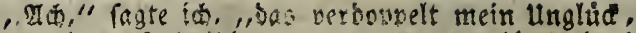

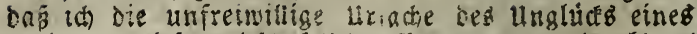
redlicheat uno freundichaftlichen Siantia gemorben bin."

"IRad) (5uch Dartiber feinen furmmer," fagte Jers

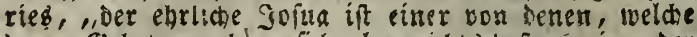

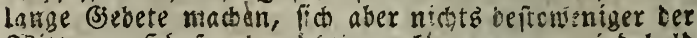
sittwen fráufer temátigen fónnen, er nito bald feimen Serluft erfeßsen. Wenn er irgene einen seer: lut erleidet, ex und die andern frommen, fo faret= hen fie eb bem frimral alb eime Emulban, und üben obne (s) wiffenbiffe úbertunchte Soturtereven nus, bib

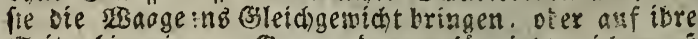

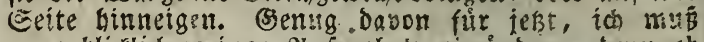
augenblicklich soizen 2ufenthalt veratbern, benn $\mathrm{bb}$ id) gleich von bem tubermáfigen Eifer bes Jerrn frie:

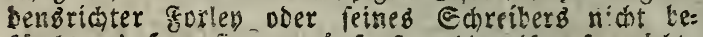
furcte, bafi or fie zum auferiten hinreift, fo móchte

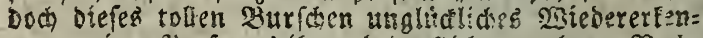
nen meiner werfon es ifnen bedenflicher machen, Nadr.

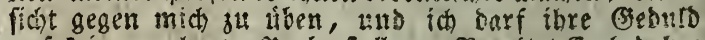
auf teime zu harte arobe fiellen. Beritet Euch bahpr atich als (sefangettet voer als çefährte zu tegleiten; wern alb bas Lestere, fo migt Shr Euer Ebrenwort geben, Eeinen \$erfuch zur filucht zu macten. Eolh tet Shy ben falimmen Einfall betommen, Euer ein: mal verpfáubetez 2 ort zu brechan, fo feno verficert, Dafs ich (5uch olne bas geringfte Bebenfen auf ber Etelle toot nieberftrede."

"Sक Eenne (Eure Plane und gibficten nicht, uno Eann "ịe nur fư gefábrlích halten. Эo bin niçt ge:

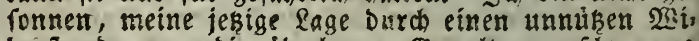
beritano gegen bie uberlegene Bema!t a erfoweren;

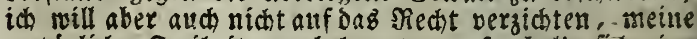
naturliche freibeit zu kebaupten; fo bald fich eine gunftige (Selegenbeit offnet. Ith will baber lieber Guer Gefangener, ald Euer Bundeggenofe fenn."

"Dab ift frevmutthig gefprochest," fagte er, uno

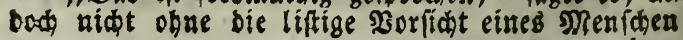


Itbrte mur einmal zuruำ, um gu fagen, baj wir mit Tage $=$ Inbrud) längftens unfre Reife antreten wurben; vielleide nod fruber, fagte er, was nichts auf fich has

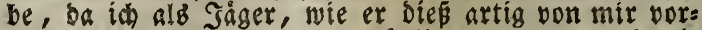
ausferste, ftets zu einem sloblichen 2 ufbruds bereit regn nuiffe.

ED baben wit unz benn verftandigt, biefer felt: fame Diann uns ids; feite perfonlichen 2ubficten bat ex biz zu einem gevifien Puntte enthillt. Er bat ei= ne veraltete und vergweifelte Politif gewálth, tus er

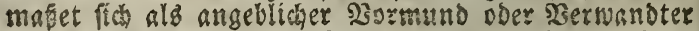
ein SRect an, meine Fandungen zu leiten

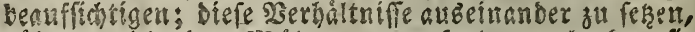
ball er richt ber sintihe soerth, fombern glaubte fie nut oor einem albernen Griebenbridter auf Dem Lans

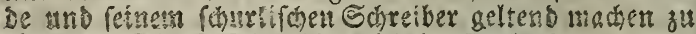
foumen. Die esejals, Die min in England ersartete,

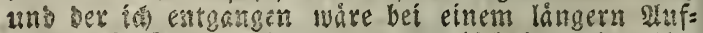

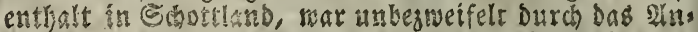

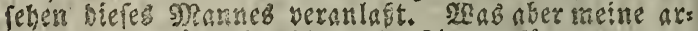

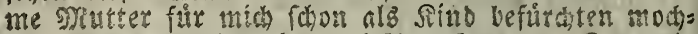
te, suggégen mish mein engliforer fremd, Enmul,

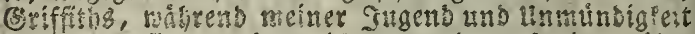

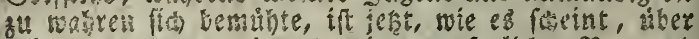

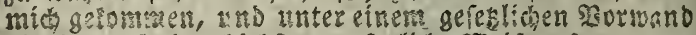

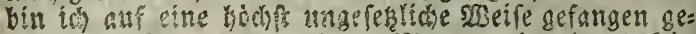
halten, zno sutar non entent sanne, der burch fein sDenehmen feture eigene politifche freineit vermirt hat.

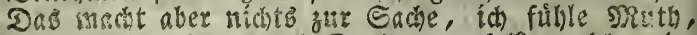
wester lieberredung now Drokungen folfen mich gwin= gen, in Die vergmeifelten Plane Diefes Mannes eins zugehen. Neg ich nam mirtlich der ubebeutende Nenfoh fenn, - mie mein Reben bigker anzubeuten foien, ober

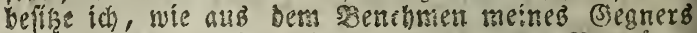
bervorzugeben fheint, furch (Beburt ober 2 semoben

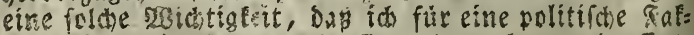
tion eine muthfenenerthe Ermerbung bin, mein Ent=

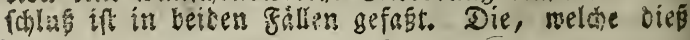




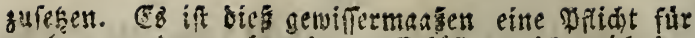
mich geworben, obne lecen Erfitüng ich mich ber Wfichten bes Tages nicht entlebigt zu habea glaube.

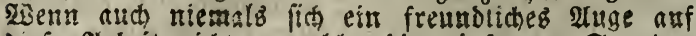
Diefe \&rbeit rictet, welche die einfamen Srunben pincg unglictlichen (sefongenen erheitert bat, fo tibt roch ber Getrantch ber Feder eine berabigende firaft ther atcite aiffacregten (3) faten Leisenfoaften ans. Ft:emals lege ich bie feber nteder, obue rait fepterg Entídilffen uno fearigern Boffnas? Defurchtungen, unrahige Ermartmugen uns unver

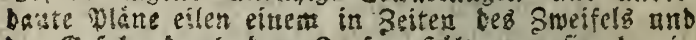
ber Giefalis burch ben fopf. Salt man lie aber in ibrem frtuge feft, uns wirf fie oufz Wapier, fo zmingt

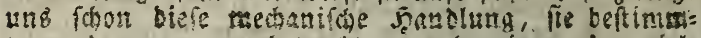
ter ind genater gn betraditen, und wir werdat viels

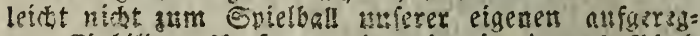
tell Einbilonaghtsft; gevase wie ein iungeb piero

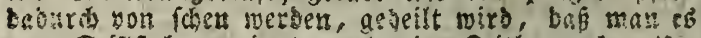

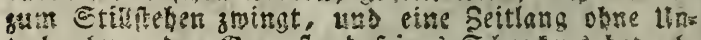

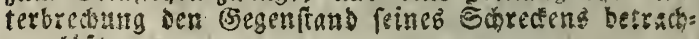
ten! !h⿻一𠃋十

Shat bie cefoldr ber Entedung bleibt, aber ans

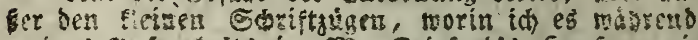
meineg Maferthalts in Mir. Foirford'b 5̧aufe za ei= net grofien Bolloxmenteit brade trm mebrere grope Eftenficle auf cinen હtempelsogen zu brimgan, ict alth wit id foron ancermar:b aubeutete, mich an bie troftliche Betradtung gebalten, baf́, went anth

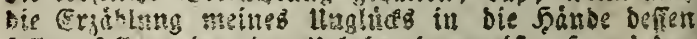
farten folte, ber ber llrheber bavon ift, fo mutrout

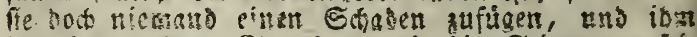
bing hen wabren (Eharafrer und bie Stimmuag feis

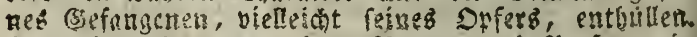
gebt aber, ba rod ansere ?amen uns perfonen in

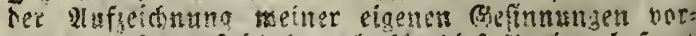

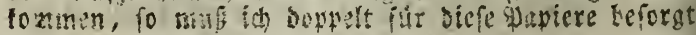




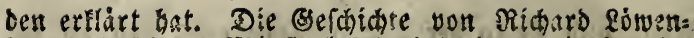
her, und feinem Minftrel 2 londel gieng mir im $\mathfrak{A} u=$ genblice Durch ben Sopf, obg!eid ich ein Sächeln nicht unterdruden fonste, wenn ich iene auf einen blinden Geiger und mich felbit antwante.

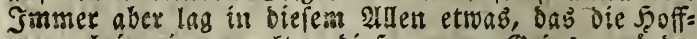
nung bei mir erwecte, biefer arme Geiger múrbe,

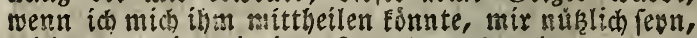
mid) aus meiner jek̨igen Lage beraugjuwinien.

Gein Eenerbe gab mix Jeffinung, die geminf dite Nittheilung su Stande su bringen, Demn ez ift wohl befinnt, Daf in Edottland, wo fo viel Piationals mufie ift, Die 230 te und Fielodien allgemein betannt fino, uns êne \&it freimaurerei unter sen Spielent

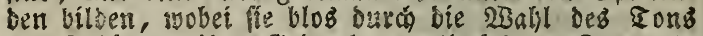

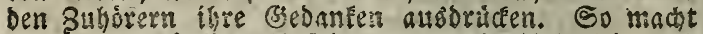

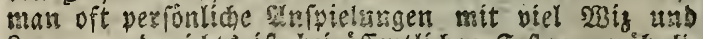
gaune, uns nichts if bei offentlichen geften gewohntis der, als sab bie sjelobie, bie zat einer belonbern Gerunsheit ober su einem conft geipielt wirb, ein

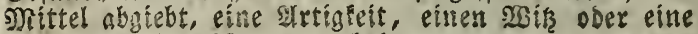
fatorifo sinsueifung assubringet.

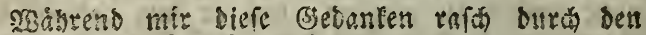

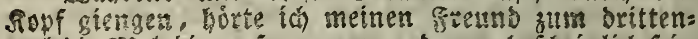
mal die sjeldote anfongen, von ber wabrdieinlich fein

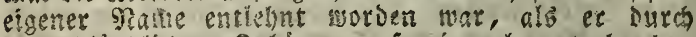
feine lantioben Subbre: auf cismal unterbromen murse.

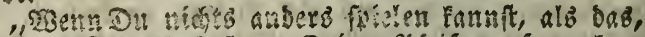
fo thateit Dit ait beften, Deine Pfeife aufzupuden,

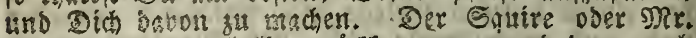
Rirou wies mun bars zuricelommen, tus Dann wols len wir fogen, - yeer ben spfeifer besabltt."

Dgo! Dacte idj, wenn ich feine fobarfern Dbren gu befircoten bate, arb bie meirer freunbe Jon und Dorias, to fonn ic ben serfu, f

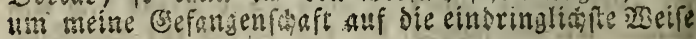


gu bezeiduen, fang id swei ober brei sinien von bem I3zfien Yralm:

"3ei Babers Etrömen rafen wir unb veintea,"

Die Ranbleute horten aufmerkfam zu, und alb id

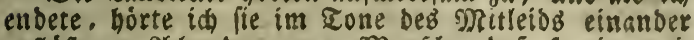

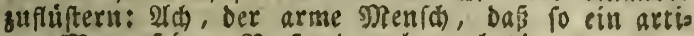
ger STann feinen Berftand verloren bat!

$\mathfrak{B}_{\text {enn }}$ Dab ift, fagte Der mandernbe 2 Billin mit eillem Ion, ber berechttet war, mein Dhr ga errei:

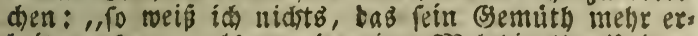
beitern fant als gerabe eine gRelodie." Ulu er

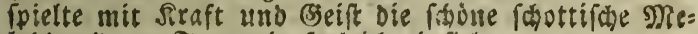
lobie, beren Eert mir fogleió einfiel:

श)eff, und if fonznte su Dir, mein Sinab,

Wfeif, unt id fomme zu Dir, mtein אnab,

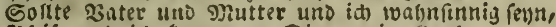

Y)eif, uns th tonme zu Dir, mein Sinn.

Balb vernabm id ein Slappern von Fuftritten

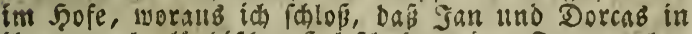

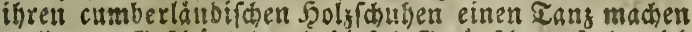

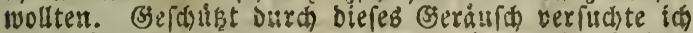
auf 2 itlin's seichen su antworten, indem id fo laut als moglicis die sidelodie pfiff:

\section{D, foum suriice, und rette mid),}

ฌsenn afles von nir weidset.

Er brachte fogleich bie zinser aus bem zaft, incent er in bie Nelodie uber ging:

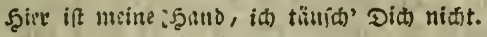

Sch stweifelte nidit linger, Daf cine Nittbeilumg glưcelid unter unz angetnupft fev, und baf ber arme glufiter, falls fích eine Eselegenbeit fánbe, mit ithm zu fwrewen, fï willig zeigen wirbe, meinen Drief cuf bie poit zu beinzell, um den Zeiftand einiger tóátigen Friebengridbter oder beb commandirenden Dfficiers in Earlizle - Eaftle altyur!f?n, ober ubers baupt alleb fu thun uns zu meiner Befreiung angu, wenben, waz in feincm sermógen ftand. Hhein: 


\section{8}

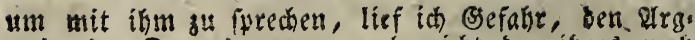
nohn ber Dorcas, wenn anch nicht ben ibreb noch einfiltigern Eornobn rege zu machen. Die Blinbs beit meitez serbundeten verbinderte mich, inm irgend eiti zeichen boin zenfter aus zu geben, wenn es and mit ber SIlugheit liberein Eav, Dieb su wagen; fo umianolit uto to unterworfen eisem Míporftand: niffe bie vou uns angenommene unterreoungstoelfe fenn modite, fo mute id fie boch als gangel einer beffern fortiesen, inber ic meinem eigenen unb meis

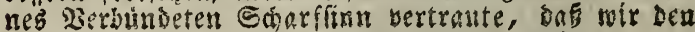
Mtelobieen ben pafenten Sirn beilegen wirben.

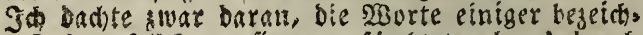

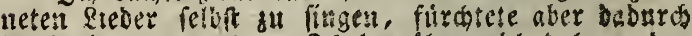
Sertadit ju erweden. So bemubte raid baber, dea

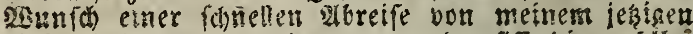
arfentbaltiorte anjubenten, und ofiff bie moblbe: Enute Melobie, nomit in Ebottland bei feflichen Gelegenbeiten ter Taub beidsloffen-wirb:

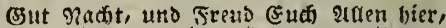

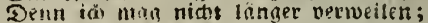

Da if tein Freund oser Feino von nit,

Der nidit gertle (äb' mid) enteilen.

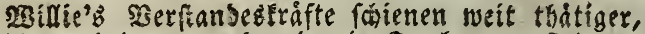
a!b bie meinigen, und wie ein santer an Beictets frache gersobut, verfiand er bei bell erften sinen gleich sen gangen Sinn, Den íd Damit verbans, und

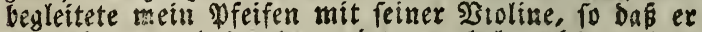
mir nicht nur baburd anzeigte, er babe mich verfan. ben, fonbern aаd verhinberte, bas̆ man mein Dféfet borte.

Seine 2untwort erfolgte fait unmittelbar, und war in bie alte siriegsmelobie eingelleibet: , Se! Solnnie Sinabe, fer auf beinen Jelm!" Scb burchlief funed ten rext, unb blieb bei der folgenden Stropbe feben, bie auf meine llmitande am meiften paste: "Eek auf teinen Şelm, ren furchtbaren Selm, wir

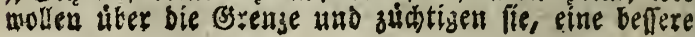


Sitte wollen wir lelfren fie, f̧ey! Snabe Johnnie,

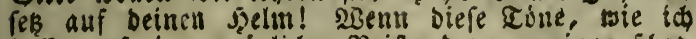

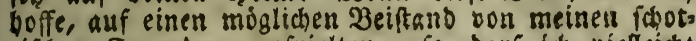
tifasen freunden anfpielten, fo barf ich vielleidt

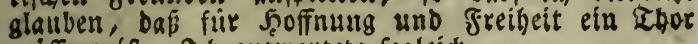
geoffuet ift. Id) antwortete fogleids.

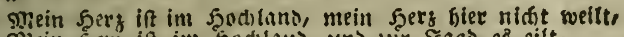

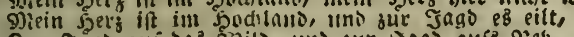

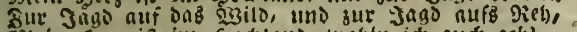

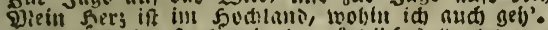

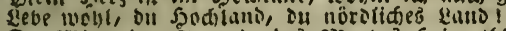

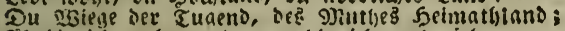

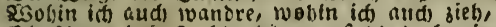

Die serge Des Sod)ln

Sogleid fpielte $33 i$ ile mit einer Rebhaftígleit, bie in ber 2 ersweiflung felbit Şoffunng erregt bätte. well nàmlids ote Sergweiflung fotottíche situlit vers ftande, bie fabue, alte Jacobitifhe Irte.

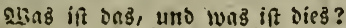 \\ Uno nod sweimnt fo viel, als bies?}

Эd) verfudite nun meinen 28 unid aubsubrúc(en, meine Sreunbe von meiner Lage in תenntni feken, und da id vergiveifelte, eine Melobie su fin

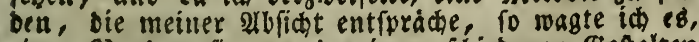
etmen sers zu fingen, ber in verfóbiebenen Befralten ta alten Sallaben vortonmt:
giso wers' id finden einen auten Mann,
Der gewitnten will Soien uno Edalub,
Der binafgeb'n mua mad) Durrişeer,
DNoine Sieben ntir führen $3 \mu_{\text {. }}$

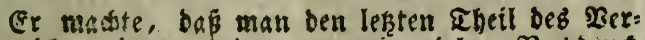
fer nidit porte, inbem ex mit vielem भुa ipielte:

Der gute givbin lieft mid) ja!

2lus biefem lonnte íd gar nidts maden, ob. gleid th Die Sierfe im (sebadtnis tiberlief, und ebe

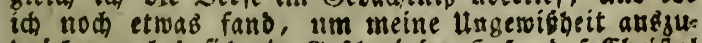
Druder, exbob fí eln sefidrei im Sofe, bab Ebrital Riron automme. Diein setreuer Sidie mufte fid 


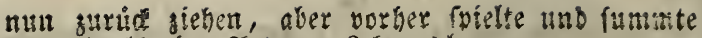
er noć) als éne IItt von Reberobl:

(Did) vertafien, Dith verlafirt, Smas,

gite mift id vertaff: $n$ Did !

(s)er wird verlöfdien oft Eternelidit,

(E)' id) twerte veriafien Did)!

So glaube id boch in meinem unglie eines

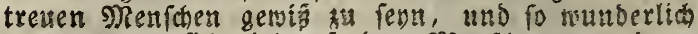
es feun mag, fic viel aif eitren menichen yon einem fo niebrigen Getwerbe zu verlaffen, Der noch itber bies bes (sefiats beraubt itit, fo freht es sosh lebhaft vor - meiner Sele, daf feine Diente mir múplín und

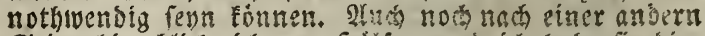
Seite hin blice ich um Sillfe, ung id babe fie bir, Ulan, an mefr als ciner Stelle meines Eagebuh

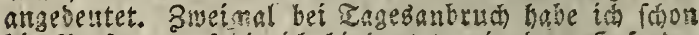
bie \$erína, auf bie id bindestete, in be!m 50 fe ber Pabtrobung gefehen, und grweimal gab fie mir burd Seichen zu veritehen, Daf fie bie Eeberden zu beuten viffe, woburd id ifir meine \&age bezreifich gu madien bemút wa?, aber beibemale legte fie die finger auf

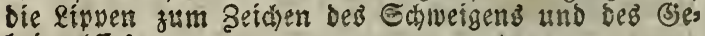
beimatifez.

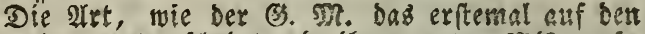
Schauplah trat, focint mir then guten milnen, fo,

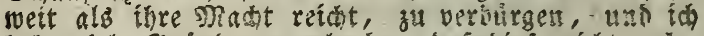

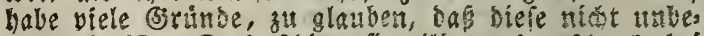

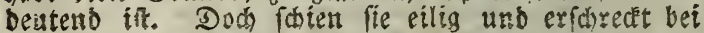
ben fluobtígen Antgenblicken unerer Interbaltung, uno bas Rebtemal warbe fie, wie id glaube, surd Den Eintritt yon Semand in ben 50 f aufgefdrecét, gerade als fie im 2 egriff war, midh Gnzureden.

Du mait nidit fragen, bo ich fruthe aufitelie, ox fo lieblithe (5rideinumgen nur bey Iagesanbrud za fehen fins; uns obgleich ids fie reit dem nicht melir fah, fo habe i entfernt gu balten. Sor Drei Tagen batte i in, ermú: bet Dur. die Einformigleit meiner (3efongenfüaft, 
mebre seiden von Mntbloffgleit, als fonit, gegeben; Dief nag bie 2lufaerffamfeit der Dienfreste rege ge. madht haben, Durn die bana die Sache befannt wurbe. IIm nád) nem rifore, wie fie aber lierber tamen, tann ich nicht fasen. Die Semb forift war fobnt, und nach italienifder Manier gebilbet:

STsie serren ifren gofin irbeitern oft berfbieben,

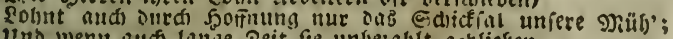
lunb went and tanise Seit fie unvejablt gebtiefien,

2ieraltet bod Daz ভduulnbefenntnifi nie.

OJus auds auf ferme 3eit tas Datum iweifen,

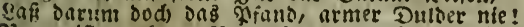

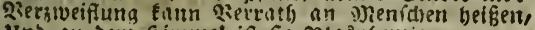

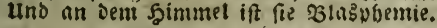

Dasi biefe seilen in der freunolichen, ber mebr

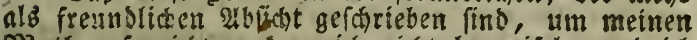
g) ath aufzuridten. fann id nicht bezweifeln, uns ich boffe, die art meines Berechnens fou zeigen, das das pfano angenommen wuroe.

Das Sleis ift angelommen, in meldem in ma. meines felbitervablten $\mathfrak{B}$ ormanob 235 illen, wie es forint, die Reife machen foll; uns worin beftelst eb? In einem Dberrod von Siamelot wie Ranbfrauen von mittlerem Bange fie su Pferde tragen, nebit einer seitmaste, wie fie fich ibrer hàfig bedenen, um

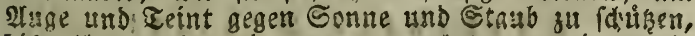
bistveilen auch, wie man vermutbet, 4m ein wentg

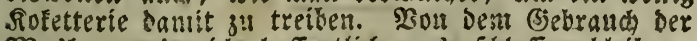
Dable merde id boffentlid auggefolofien bleiben; benn ftett saj fie conft von geprestem Papier uno mit fowarzem Sammt iberzogen-ift, bemertte id mit Sdireder, das sie meinige mit einer Stablolatte bebed ift, moourd fie benn mie Don Dutrote's $\mathfrak{D} i=$ fier, weit fefter und ontergafter wirs.

Diefer 2lpparat, wozu now ein Stablhacen fam,

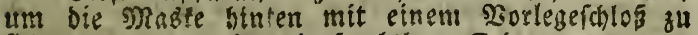
fichers, erwedte in mir fuxchtbare Erinnerungen an

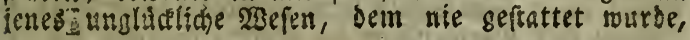


feine Mable abzulegen, und weldeb daber ben wobl beiannten hiftorífden Beinamen erbielt, Der Manu

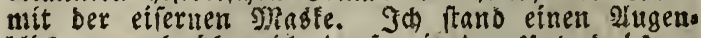
blice all, ob ich midis in roweit ber Hnteroruidung fügen folle, baf̈ thi die פertleibung anlegte, welde offenbar bie Plane meines Begners su unterftuken beftimmt war. Dann erinerte ich mid aber wieber an ) 2 . Sherrieg Drohungen, bof man midh in einen

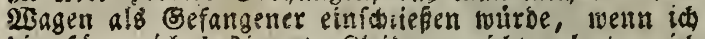
Die für miln beftinnte fileioung nidbt anlegte; i申 betrachtete ben verbàltmigmábisen Bras von Jreibeit Durch Dab Eragen Der gnable und ber weiblicben Rlei Dang alg leldt uno vortbeilliaft extauft. foier aber muE (id) fitr ben sylugenblice abbrechen, und erwarten, wes ber sjitorgen bringen wird.

(llub bie Er ághlung, aub ben vorliegenden artew ftucen fortzufezen, balten wir es fưr paffend, bier bab ₹agebtich tę gefaugenen Darfie Qatimer zu vers Laffen, unb fratt befien bie Maabregeln zu ergáblen, bie alla fairford keim tufiuden feines freundes ers griff, uno bie eine anbere glbtbellung in biejer ses istidite billoetl.)

\section{Stebentes Rapitet.}

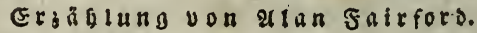

Der lefer wirb fith bereits eine Goee von bem Eharafter Alan Fairforb's gebilbet baber. Er befaE

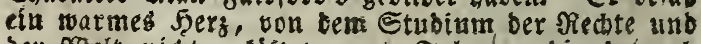
Der witert niat erfaitet, uno Ealente, bie baourd ungewohnlich erhibt wurben. Dhme verfonliche Droe teftion, beren die meiften feires alterg genosen,

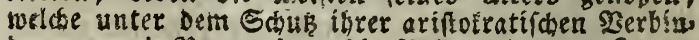

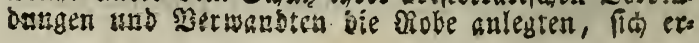




\section{3}

freaten, fab et bald, Dafi ex Dard Infitrengung Das

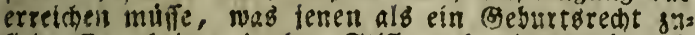
fiel. Er arbeitete in ber Stille und Einfamfeit $m$ it groper 2Inftrengung, und feine 2 rebeiten wurben $m$ it Erfolg gefront. Aber 2 lan liebte feimen Jreund Dars fie nods mebr, als fein Sewerbe, und warf, wie wir gefehn haben, alles auf bie Seite, wenn er Eatimern

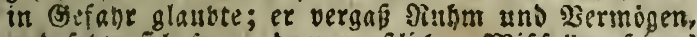

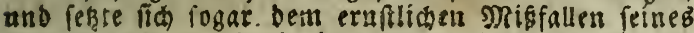

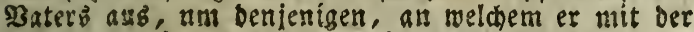
Qiebe eineb átterm Bruberg hiens, Der Befahr zu ents reisen. Dobleich Darfies Nolle lebendiger uno g!änzenter war, a!s die feines frembea, fo erfichien es Dem lesfesu boø nur immer a!d ein fein!r befonbern Borforge empfohtenes wefen, baz er in allen fálien, wo seg Singling eigene Erfabrung nicht subreiste,

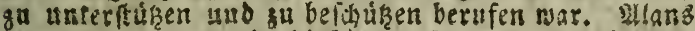
ganse Silugueit wurbe biestial exfordert, und ein IBas gertuce, Dab ben meiften Junglingeit feines anters gejubrlich geidienen bátte, haste leimen Strzecken fur ibn. Er mar wobl belannt tait ben Befeken feines

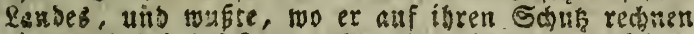
Póne; Dabei befas er neben Dem Bertratren feiner

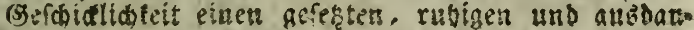
renben unb nuerforodenen Ebarafter. Mrit Dfefen

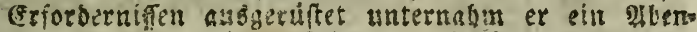

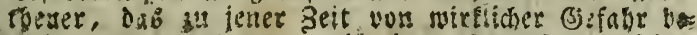
giteitet nar, uns gar wohl einen furdtiomen Einn

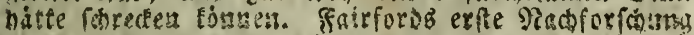
in Betreff feines frembes gefmah, vei been poniplis hen Dirnter von Dumfries, MR. Crosbie, Der Dhe Radridit yon Darfiez Berichwinden ertheilt batse.

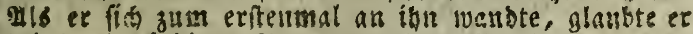

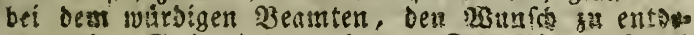

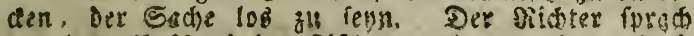

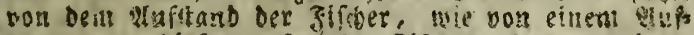
rubr minter defen gefollofen fifchervolf, der, mie er faybe, mehr dea sijerif angehe, als bie armen setate 
ratle, - bie gensg zu than bitten, um im Jnnern ben

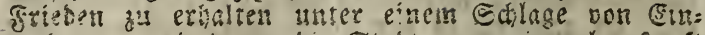
gyobnern, mit benan bie Ctabt nut eimal geftraft fey."

"Bif ift aber nictst alleb, Nidter, Eragbie, fagte INx. Mlan Fairford; ein junger Edelmenn von frang

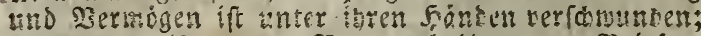

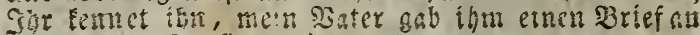

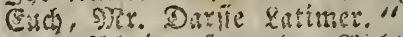

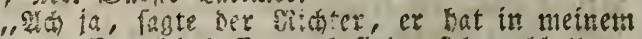
Senufe gegeffen, id haffe, er befinot fić mobl." "Id boffe es gletofalb, fagie slan ziemlich an= wirlig, aber ich muinfore meir esemifheit riber diefers Dinte. Jat felbit habt meinem suter gefdrieben,

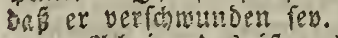

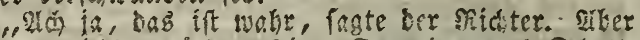

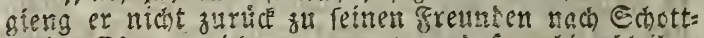
lanb? CEg war nist za erwarten, Dấ er hier bleiban wititoe."

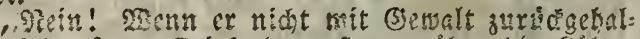
tom iuts, fagte foirforo, erfaunt liber bie ciatte,

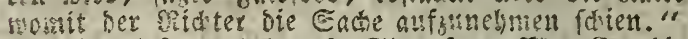
"Sirlast Euth Brauf, Str, fante sjix. Erosbie,

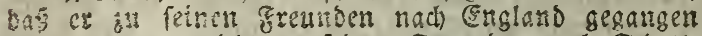
ifi, tuen er nicht bu feinen frenden nach Edsott=

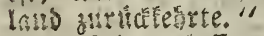

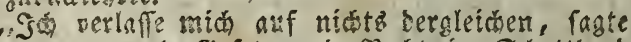

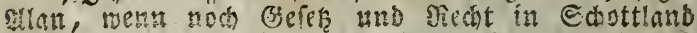

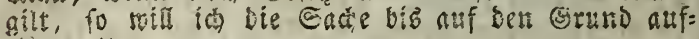

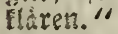

"(5)ans recht, gant rectit, ganz recht, fagte ber

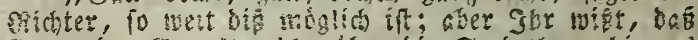
fich meine oemalt nitht aber bie હ peritecet."

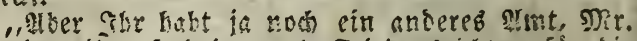

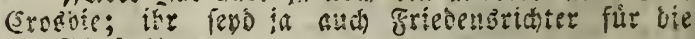
Eraffitaft."

"Soator, febr mabr, D. 5., fogte oer rorfichtige 


\section{5}

Naun, mein Pame mag auf ber fifte ber friebens. ricaster mit fteben, aber id fann nich nidst eriunern, Daß in mich ie bafur ausgegeben bátte."

"Tisn in oiterm finlle, fagte ber junge Fairford, tonnten úbelgefinnte feute eure 2 rnbänglicheit an bie proteftantifare Qinie bezweifeln, gar. Erosbie.

"(Sott belytite; Dir. Jairford, wab hab ich nidst gethan und gelitten im Jabi 1745 . Joh rechne, bas Die Soch!änber mir einen Schasen vout wenigftens

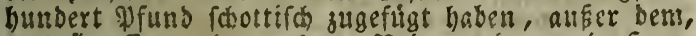
wab lie affen uno tranten, Fein, nein, mein fert, (di) bin uber ben 2ierbacht erbaben; was aber bie B3rafidaftegefdidate angeht, banit will ids mich nidt

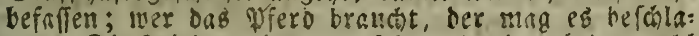
gen. Die friedenbrichter auf Dem fande butiten woh!

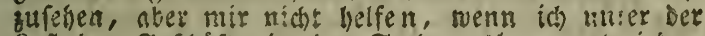

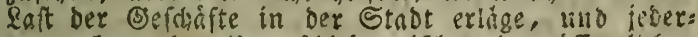

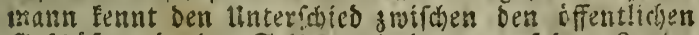
eseftháften in ber Stadt uno benen ast dem Eande.

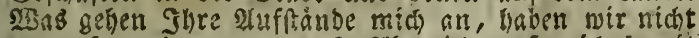
an unfern eigenen gents? maden, bern ber fiath verfammelt fich rach biefen Dormittag. Sob bin felir exfreut (snreb saters Eokn

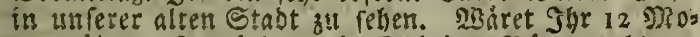
nate álter, fo wuroen bir Eud bas 2aurgerrect exs theilen, me. Allan facirford, if boffe Ghr wertet tommen und bep mir fpeisen, elie Jhe neieber abreist.

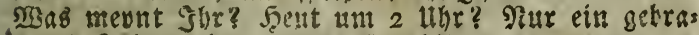
"tenes 5hash uns gefottene Ener!"

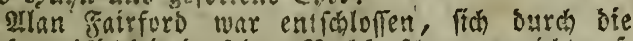

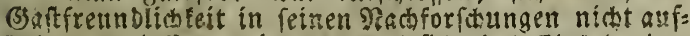
balten su lafien, wie es bie abfitit beg Einlabenden

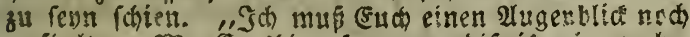
aufbaltin. Mir. Srobbie, fagte er, bif ift eine wals: asfte (E) (n)iote; ein junger Ebelmann von groben Soffnungen, mein eigener twenterfter freund, if ver:

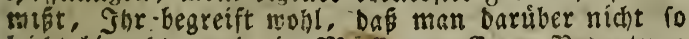
leicht hingeht, uno eill Raln von (surer Bebestung 
unb Earem befannten Eifer fur bie Regienne, nitb nid): unterlnffen, thattige linteriudumg angufillen. Mr. Erobbie, She feyd meines Saters Gremb, und ich adte Eud besbalb, andere aber whirben bara:1b fditimme Folgerungen gieben.

Die (Sefficter, bie ber f̧err shiditer finnitt, hats ten ibren guten (5)rund; felge beunrubigt lief er in Simmer anf und $a b$, indem er ofterd wiederholte: ther was fann id thun, Mr. Fairford? Iक wette, 3he Freund wirb fich swieter zeigen, er commt gntide, wie ein follechter Sataing, - das ift leine Waare, bie fich verliert, ein verbammter Junge, ter mit eis nem blinben Seiger fin \&anb umber rennt, uns an Seftielagen bem lieberlíden Solpe aufinielt, wer fann fagen, wo fo ein פiench hintomint?"

"Mon bat Reute im Stabtgefánguí feftgefebt,

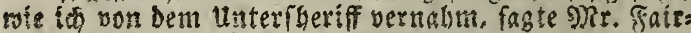
ford; Shr múf fie bor Eug bernfen und alsfragen, mas fie won bent jungen snanne wiffer."

"Sa, ta, ber unterfueriff hat einige arme Reute wersaftes laffen, ich slaube, elendez unwiffendes fro forvole, wolthe mit bem Duáfer Besbeg und feinen Stefteben 5indel gehabt haben, bie mit gychturs gegen Eure 2tatsfleidung feg's gefagt, $\mathfrak{M r}$. Fafrforo. niche gans und gar geferlich find und ber Stabtictreb bor ratint, fie ronaten gan aeferlich obne weiteres

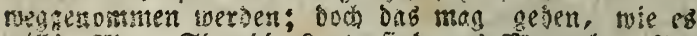

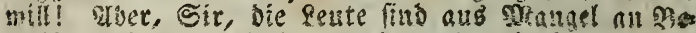
metfon wieser entlaffen worden; ser Sudcter wolite niche foworat gegen fie, thn was connte bann bes Eseriff und ich anders thun, ald fie lesinfen?

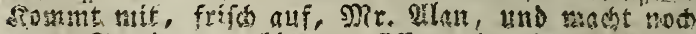

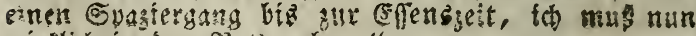
wirtlich in ben siati) gerseti,"

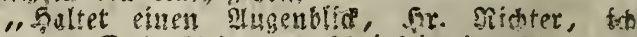

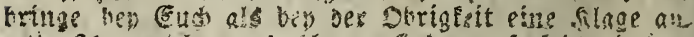

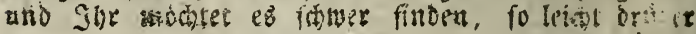
bin: 


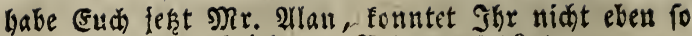
wobl fagen, Der Lairo von fiebgauntlet?"

Fartorb mar zu befonmen, um úber diefe, sbrobl unerwartete, Hebereinftimming der Namen irgend ein Erftaunen zu bezengen; ich glauble, fagte $\mathrm{pr}$, er (ev) unter bem Ramen Jjerrieb allgemeiner belannt; fo viel id meís, babe id ihm unter biefen Piamen gefelgen, uth bin mit ihm in Beferfortaft getwejen."

"2lch ia, in Ebindburgh wahriaheinlich. Sllr wiEt, Reogauntlet ift geraume seit unglủdich gewefen; uno wenn er fdout nidht tiefer in ber Sache verivit:

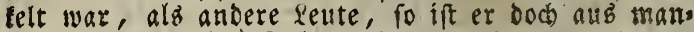
den Hrfachen nicht fo leidt davon geiommen.

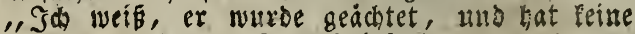
Serzeibung erbalten," fagte Fairforb.

Der vorfichtige ఇichter nickte nur, und fagte: "Shr fontt baraub fobliefen, marum er es fúr "afs feno bålt, feiner Mutter Namen anumehmen, menn er in ber (ssegend von Edinburgh ift. Seinen etae=

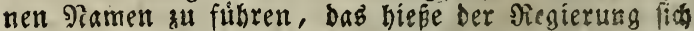
úberliefern, Jlur verfteht. Man hat indef faron lange

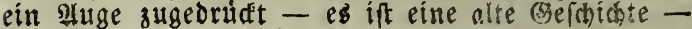
und ber Serr hat viele auggeseicinete Eigenichaften, und ift von einem fehr alten und angejefenen haufe - bat כerwandte unter ben sirop̣ett - er nennt ben Beneralanwalt und ben Gheriff; Nুettern

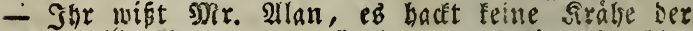

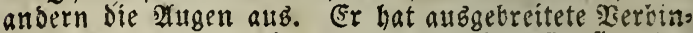
bungen - anch meine fraul if eine Soufine der Diedgauntlet'b im vierten \$rrabe."

Hincillae lacrymae! Dad)te 2!lan fairford Fey (iid) feltit, aber ber wint befimmte ifn boch, vor ber Jand fanftere Mittel zu gebranchen, und mit-Bor:

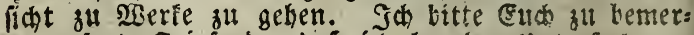
fen, fagte Fairford, Das ich bey ber unterfuctung,

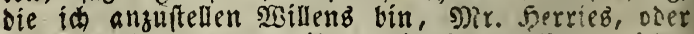
Reogauntlet - nennt ihn, wie slor molit - nidb!

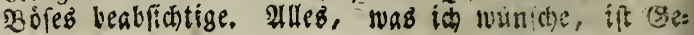


wibheit, bas mein freuno in Sicherbeit ift. Iक weis, bas er tbórict gentig roar. etnmal verfappt auf ein luftige (S)las in Der Paábe ber 380 bunng Diejes feerm glt gel)en. Unter diefen llmitanden mag Nor. Desgauntlet feine 23eweggrinde mib̄eutet, uno Darfie fatimer fúr cinen Spionen angefeben baben. Seta Einfus ift, glaube id, gropi unter diefem ges feklofen solfe, moson she fo eben gefproden habe? Der Piditer autwortete mit einern gweiten bedestfa=

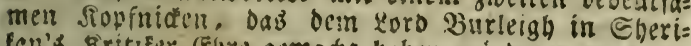
fon's Siritlfer Elyre gemad baben wurde.

"Ift es nun uidut móglic," fulyr allau fort,

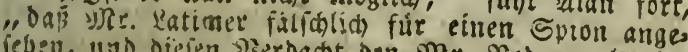

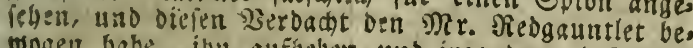
wogen babe, ith aufigeber und irgenswo einiperren za laffen?- - Solde Dinge gefdehen-bey goblen unt bel weit minser oringevoen (s)elegenbeiten, als

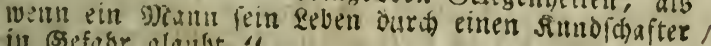
iil Sefatye glaubt."

"Mrt. Futriors," fagte ber Sichter felle ernft, in blte fold cinen sitigriff taum fur moglich, uns weitr darch einen augerorbentlichen Bufall etwas

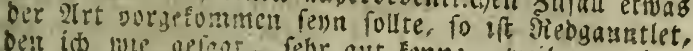
dest its lvte gelagt, fehr gut tenne, meil er meiner Jran exfer ober eigentlis vierter Better ifi, burchs

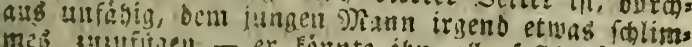

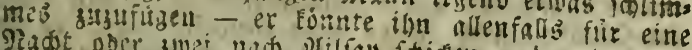

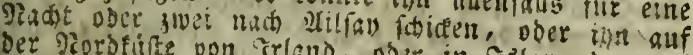
Det Prordfifte oon Jrland, ober in Sglay oder auf

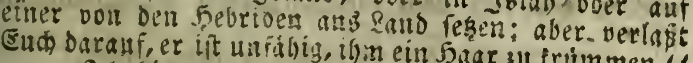

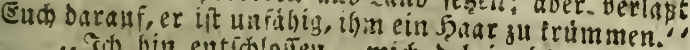

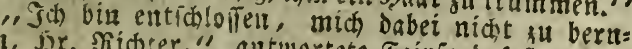

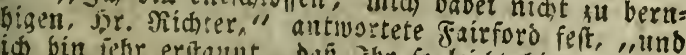
id bin iehr eritaunt, bä̈ ine fo leicht hin von bem IIngriff forcht, ber anf bie Freibeit einer Wering ges macht worben ift. Shre mist bebenfen, und bie Freunbe dez Mir. Sperries oder Mr. Siédgantlet's 
rollten ebenfalls moh! bebenten, wie es in ben Dhren eines englif́cen Staatżecretairs flingen muB, Das ein geád)teter $\mathfrak{B e r a ́ t b e r , ~ ( D e n u ~ b a b ~ i f t ~ b i e f e r ~ f ̧ e r r ) ~}$ es nidt nur gewagt hat, feinen 2 ufentbalt in biefem Ronigreide zu nehmea, gegen befien sónig er oie

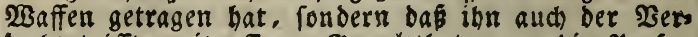
bact trifft, mit offener Bsewaltthat gegen bie perfon eines untershanen des Sonigz verfabren zu fevn, gegen einen jungen Niann, Dem eb weber an freuns ben, now an $\mathfrak{s e r m o g e n ~ f e g l t , ~ u m ~ f e i n ~ J i e \omega t ~ g e l t e n d ~}$ fu macen."

Der nichter blicte auf den jungen arsosaten

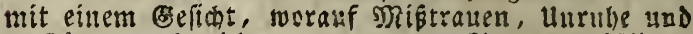
Befturzung bezeichnet waren. "Ein vertrúblid,er Sondel " Fagte er zulest, "ein verdráelicher frandel, und eg wirb gefábrlid feyn, fich barein zu mifhen.

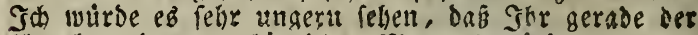
2lngeber eines unglúa"ichen smanneb intirbet."

"Diés bin ich nicht geionnen," antwortete Mlan, , voraugefergt, biefer ungltickliche Mann und feine

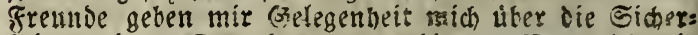
heit meines freindeg zu berubigen. Wenn id mit Nr. Fedgauntlat forechen fónnte, uno feine eigene Erflarung verrelimen, fo watre ich vermathlict a frieben geitent. STenn id gezwanaen werde, inn beg Dér fiegicrung anzugeben, to geichieht dies in einer

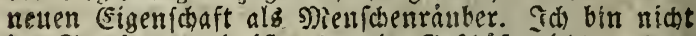

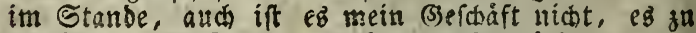
verhittbern, bas er elb geáchteter Berráthre erfannt nerbe, ber von dem Seneralyardon ausgenommen ift."

"Nr. Fairford," Fagte der Nidter, , wolltet ghr ben armen uniculdigen $\mathfrak{R} a n n$ auf einen eitlen $\mathfrak{B} e r$ bact bin ungludelich machen?"

"Nichts mebr bavon, Mr. Erosbie: mein Pre: nelimen ift fet beftimmt, wena nidt biefer 2 serdadt entfernt wirs."

" Boblan Demu," fagte- Der গichter, "weil bem 
Nichter, "ein fo fawarger Sacobite, als ber alte Sawertaig nur immer einen machen Eann, aber fonit ein waderer Inftiger (5efellifofter, mit weldem leí ner von uns brechen will, trok aller feiner Prable. reien. Iar modatet wohl benten, wenn ez bei Derby wohl auf ihn angefommen ware, er whirbe Earl Etuart fo gut burch alles hindurch gefúbrt haben, wie ein Faden burch ein Nabelobr geht, und nưbe ihn in St. Sames niebergerest baben, ebe She báttet

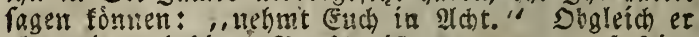
aber ein winsiger 3 urfae ift, wenr er auf reine clten weltlichen (seichichten Pommt, fo bat er bod

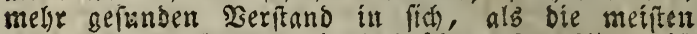

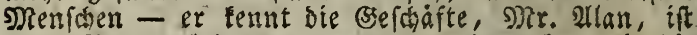
zum Niechtzgelebrten ergogen, nabm aber nie bie

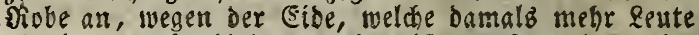

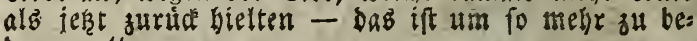
bauern.

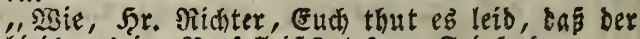
Jacobitismub im $\mathfrak{s e r f a l l}$ ift?" fagte Fairford.

" Piein, nein." antwortete Der Nichter, "eg bes

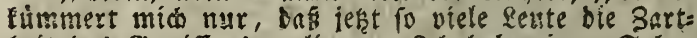
beit beg (5)eniffeng verlieren. Iक habe eimen હobn, Der zum Slectbgelehrten gebildet uurbe, Nir. Fairs ford, und für ben ich wegen meiner Dienfte und Eeiben wohl-auf einen húbichen Poften bătte redinen fỏnen; aber wenn diefe gropen Familien heranfom: men, - id menne even biefe Naarwell's: siefe Join: fincs und andere grope Latrob, bie vorleer ber (Fib lange entfernt bielt - ba muffen wohl die lleinen lente, wie mein Sohn wns bielleicit auch Eureb $2 a=$

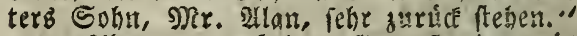

" $\mathscr{2 l b e r}$ um auf ben (Segenitand zurtic zu fom: men, פMr. Srobbie, " pagte Fairford, "Galtet Jhe

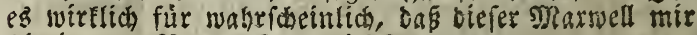
bierim von Paken feya wirb?"

"Sa wohl tamn er bab fekn, benn er ifí bie Erompete bes ganzen Eefíwaderb," fagte ber Nich= 
ber eben fo, wie der Richter, ein alter Eorreipondent feines $\mathfrak{s a t e r z}$ sar. Alan eroffuete diefem Beanten feinen $\mathfrak{B}$ orfak 2 rofenburn zu befuchen, erbielt aber die Berficherung, Dás biefer Echritt nicht nur vou vieler sefabr fúr inn begleitet, fonbern auch vollig

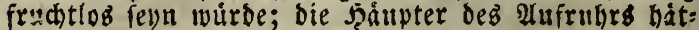
ten lăngit Shuk gefunden in ibren Salupfwinleln auf ber Jurel SRan, Eumberland uno anbern Drten, uns bie zurúdgebliebenen würben obne zweifel an Sebem Gemalttbàtigleit begehen, ber ibre gieberlaf: fungen befuchte, um liber die vorgefallenen Unruben Unterfuchungen anguifellen.

Nidut bie nemlichen Einwurfe liefien fich gegen efnen Bejuch zu Nount Sharon maden, wo er die lekten ?achrichten bon feinem fresnde su finden boffte; baju war cuch vor ber zu hr. (Srosbies Nablyeit bes ftimmten Stunbe Beit genug. Auf bem 2 bege wuinfthe

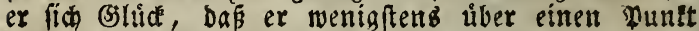
fidsere $\mathfrak{A}$ blunft erbalten babe. Der - Nann, Jvelder

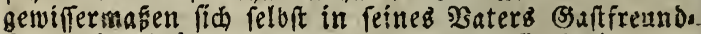
fofaft eingebrangt hatte, und ben Darfie Satimer zu einem Bejuche in England verleiten su wuinicheu fhien, gegen den er noch bastl eine Art von war, uung erbalten hatte, burd eille mit feiner eigenen familie verbunbenen \erion, fcien ber Anftifter bes Ulifitandeb zu feyn, in welchem Darfie verfobum: ben war.

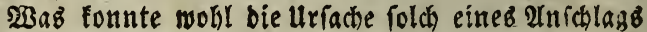
auf bie greibeit eineb harmlofen und liebentwirbis gen Dannes fenn? Unmóglich waltete bier blos ein

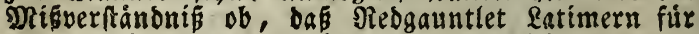
einen Spion gebalten batte; bent obgleid fairforb

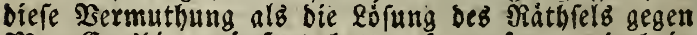
Mir. (Srobbie geaubert batte, fo wuste er bod in ber sbat wohl, baś ex von feinem fonberbaren $\mathfrak{B}_{e}=$ (udh wegen einer (sefabr gewarnt worben (ey, in ber (id fein freund befinde. Ehe ex nod felbit einen ábuliaben Sierbaht begen lonnte; Die Ermabnungen, 
welde Latimer von Sern. Sriffith in Lonbon erhielt, ber fein Sormuno war, ober fid fo benabin, fúbr= ten zu bemfelben Puntre. Eg madte inm inder leis aen Siummer, bas er ten Ridter Erosbie nidt weiter in Das (B) beimnis eingeweibt hatte, als unumganglica notbivendig war, benn es prang in bie 2ugen, baß bie Sermanbraft feiner frall mit ber verbádatigen Parthei auf reme Unpartheilidecit alb Beamter Ein

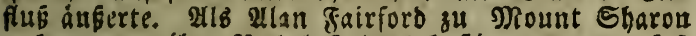
anlom, trat ím giadiel sseboeb baftig entgegen, faik ebe ber Diener die Ehrire offnen Fonnte. Berlegen welibete fie fidh $a b$, alb fie eitnen fremben erblidete, ano fagte su ibrer Entfoulbigung, fie hàtte geglaubt, ibr 3ruber Jofua fey von Eumberland surtadge= tebrt."

" Mir. Ssedbes ift alfo abwerend," fagte fair= forb, nidt weniger verlegen. . Er ift feit geftern binweg: gesangen, freullo," antwortete Rachel, weldhe die ruhige Faffung, die ibre Sefte begeidnet, fo ziems lid wieber erbalten hatte, aber ihre bleide Mange

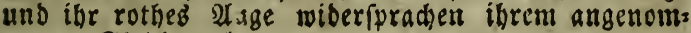
menen (s)leichuth."

"Idh bin," fagte fairford baftig, "ber nabe freuno eines iungen Manues, ber Eud nidht uabe=

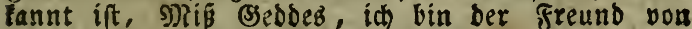
Darfie Qatimer, uno tomime bieher in ber auseritea Beángftigung, da id von bem Nichter Erosbie vers nommen babe, bas er in ber siacht verichunden fev, wo ein zerfturender alngriff auf bie fifderei i 2uftals ten bes Nir. (3) obes gemaht murbe."

"Du betrúbft Inic, Freund, Durd Deirte Fras gen," fagte Badiel nod bewegter, alb vorber, ,Denn wenn aud ber Sungling gleíd ben anbern weltliden Renfalen nur in feiner Einbiloung weife war, und fich leidst Durch ben 2 them ber Eitelfeit bemegen lief, fo liebte inn Solua bod, und fein foers neigte fich zu îm, als ware er fein eigener Sobm. Unb als ex felbit ber Saliuge ber Söbme Beliods entlases 
was nidht eber gefhah, als bib fie mide waren, ilin ou tabeln, zu veripotten und zu verbobnen, fehrte jo= fua, mein Bruber, noch einmal zu il)nen zurưd, um ihnen fưr ben Jungling, genannt Darfie Latis

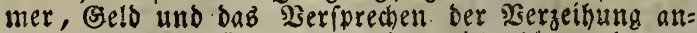
subieten, aber fie- wollten ihn nicht boren, Darum gieng er vor Den Dberrichter, ben bie Neníhen Den Sheriff nenten, und vưroe ibm von Des Júngling (S)efabr erzăblt haben, aber fie wolten ihn durchants nidht horen, weml or nidt auf oie 23 abrheit feiner Wisorte fchworen wolle, wab er obue Cunde nidht thoun fonnte, denn $\mathrm{eb}$ fteht gefdrieben: ihr follt aller Dinge nider idusiren, benn eure siese foll renn, ia, ia, nein, nein. Darum lebrte Sofua troftles zu mir gurúck, unb fagte: Schivefter Siachel, bieler Sing= ling bat fich meinetwegen in (sefalle begeben; ficher. lich werbe id nidtet fouldlog reyn, wenn ein haar feiues Saupteb gefrummt werben follte, benn liebe, id) babe gefinoigt, als id ihm geffattete, mit mix gu ber zifheret: 2luftalt zu gehen, als foldes thebel zu befurdten war, barum will ich mein plerd netmen, relbit ben Salomon, und will fathell nach Sambers land reiten, mir freunde machen mit dem unges rechten SRamon unter Den Dbrigfeiten ber Jeiben und unter igren madtigen 5pentaren, unto es foll $b a=$ bin Eommen, Dấ Darfie Latiner in Freikeit ge:

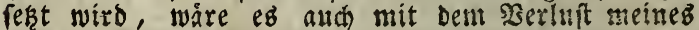
halben Sermogens." Und id fagte nein; mein Biru= ber gehe nicht, Denn fie werden Dich verfpotten uno verhobnen, fondern binge mit Dimem Silber einen won ben Sdreibern, welde ungeftumer alb Sảger binter ibrer Beute her fino, $\mathrm{eB}^{\mathrm{B}}$ wiro frei fenn ourch feime Sunft Darfie Rntimer von ben Menfden ber Servalt, und Deine Seele wird fouldos feon gegen ben Jüngling. Alber er antwortete und fagte: man foll mir nicht barein furechen in biefer ऽache. Ind ex ift fortgegangen, und nidat zuridégefegrt, uno ich

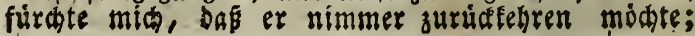


Denn ob ex gleid friebfertig ift, wie es bem gesiemt, ber iebe Sewaltthat fur eine Beleidigung feiner eis genen Seele vilt, fo werden boch weder $\mathfrak{F}_{\text {afferflu: }}$ then, nod) Die fardst vor Sdlingen, noch bas gesogene Schwert, bas ber Begner auf bem Pfabe iohwingt, ibn von feinem $\mathfrak{s o r b a b e n ~ a b b a l t e n . ~ N a g ~ i b n ~ a l f o ~}$ auch ber Solway hinabfalingen, ober bas Sawert des Feinbes ihn zu todten brohen, bennoch fteht meine foffunt nur auf $\mathrm{g} g \mathrm{~m}$, ber alle Dinge leitet, ber bie $\mathfrak{B}$ ellen ber See lenft, uno liberwáltigt bie Arnidhláge ber 20obhaften, and ber uns erlofen tann, wie ben

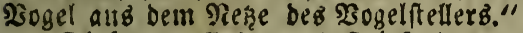

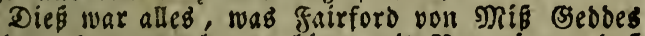
exfabren fonnte, aber er horte mit $\mathfrak{B e r g n u} g e n$, baß ber gute Duafer, ikr Bruber, viele freunde habe un: ter feinen glaubendgenoffen in Sumberland, unb ex bielt ibn für fähig, einige Spuren von Darfie Latis mer zu entsecken, obne fich einer fo groben bjefabr auss. sufesen, als feine Sdowefter su befüroten faíen. (Er felbit ritt zurick nach Dumfriez, nadbem er ber Mi (S)eboes feine Dortige aboreffe surúdigelaffen, uno fie infandig sebeten batte, inm iebe Naddricht mitsu= theilen, die fie von ibrem $\mathfrak{B}$ ruber erfialten finnte.

AlB Fairforb tad Dumfrieb zurúc'gefommen mar, wante er bie lurge Seit, bie îm nod vor bem Es. fen tibris blieb, bazu an, einen Beridht von Patimers Annfalle und von ber iekigen ungewínheit feiner Rage an Mir. Samuel (3riffitl) zu machen, bura beffen Sand bie Beldenbungen fur feinen Freunb regelmábig ges gangen warea, uno er ferste ben NGanfá hinga, DaÉ er fogleich mit bemienigen Eheile feinter Befachide befannt gemadit werden móste, die ign bei ben Fachs forichungen leiten lonnten, welche ex in ben srenss grafichaften anzuitellen $2 B i d l e n z$ war, uno die er burds=

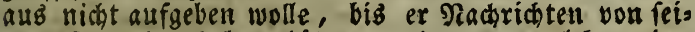
nem Freuno erbalten bátte, mochte er nun leben ober toot feon. Der junge Jiedtiggelebrte fúblte fich leidh, ter, alb ex biefera Drief abgeichickt batte. Er lonnte 
fid leinen (5rund benfen, marum man feinem freund nad Dem Reben trachten follte; er wǘte, Barfie batte nid)ts gethan, wodurch feine Sreibeit gefek̨lid gefährbet werben fónnte, und wenn and in ben leks. ten Sabren fonberbare Befdichten von Mannern-unb Fseibern in umlauf gefonmen waren, welde auf

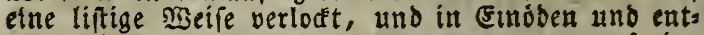
fernte Infeln verborgen worben waren, um auf eine Beitlang einem gewifín Bwecke zu bienen, fo waren bow folde Bservalttbátigfeiten meiftens von Feichern gegen arme, vou Starfen gegen ๔ worben, oa aber im gegenuártigen Falle biefer Dit.

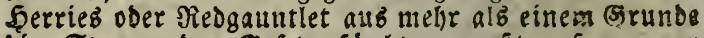
bie Strenge ber sefekze furchten muste, fo mar ex notbwendig in jebem Streite, morin er verwidelt werben fonnte, - ber fatwidgere íbeil. Freilid flufterte ibm oie Beforgnis um feinen Treund zu, Dá bie netro

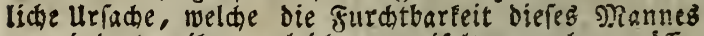
verminderte, ibn zugleidh verzmeifelter maden muife. 283enn er aber an feine 2 en Berungen lich erinterte, bie fo rebr ben Ebelmann, und felbft ben IRann von Eóre

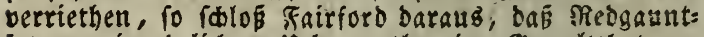
let smar in abelichen Uebermuthe eine (semalttiat ivas

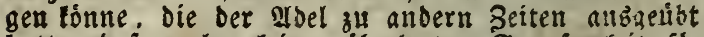
batte, baj er aber leiner úberlegten Eraufamfeit fás big fev. In biefer Hebergeugung gieng er besn in einer weit ruhigern Stimmung, als man bătte er= warten fönnen, su bem J̧errm siinter Srobbie, um ba= felbit zu fpeifen.

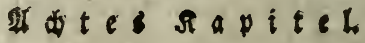

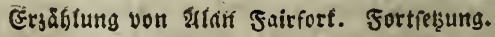

Fünf Minuten nad bem Sdlage 3wey erreidte Illan Fairforb, Der einen Eleinen Huweg gemadt bat 
te, um feinen Brief auf der Moit abzrgeten, sie MBoh: nung beg 5 rn. Ridter (Erosbie, und nurbe zu gleis wer Beit burd Die Stimme diefes Stabtbeamten und bes Lanobeamten feines Bsalts, begruist, welche Beide nngeduldig auf baв Eífen warteten.

,Rommt, fommt, Mr. Jairford, Die Edinburgs ber ulbe gebt fpàter, als bie unfrige, fagte ber ßich: ter."

„Nommt, fommt, funger Mann, fagte Der Sairo,

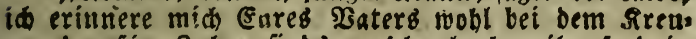
se, orengig Jabre finds - id glaube, ibr rend in Ebinlurgh fo fpát bardn als in Sonton; um 4 thbr nidbt wabr?"

"So felir find wir niat aub ber 2rrt gefalagen, erwieberte frairford, aber gewíb gibt es viele leate in Esinburgb, die fo tibel beridtet finb, da fie the Mittaggmahl big 3 uhr ginasíctieben, um volle seit su baben, thren Lononer Eorrespondenten zu antwor. ten."

"Rononer Eorrefpondenten! faate Mr. Marmell; was ber ₹eufel hat oenn Dab Boll von alt = Redin mit Sondner = Sorre:pondenten zu thun?"

"Die Rauffute múffen bod ibre saaren baben, fagte "Fairford."

, Nodunten fie nicht unfre fonttifien Mannfac turwaren faufen, und ihren Runsen Dab (seld auf

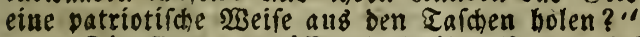

"Die Damen muifen Dod ibre Moben baben, fagt fairford."

Sơnnen biefe nidt ihren forottifien Mantel uber den Jopf nebmen, wie ibre Mutter? Ein Man tel vou buntem 3eug unb einmal im Tabre ein 5 jäbs den aus Parib, bas fỏnnte einer Ssrảin genúgen; ibe aber habt nidat viel ro!che mebr, ic glaube -

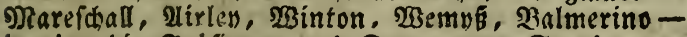
ia, ta, bie Sráfinnen und Damen von Etande mers ben jesiger seit mit ihren Staatblleibern nidht viel Plą̧ in eurem $\mathfrak{B a l l}$ faal einnehmeu." 
¿Es feblt indeffen bod nidat an Reuten, fagte Fairforb, man fpridt faon bon eimem neuen Befell: f(d)aftzlaal."

(Ein newer sefellfwaftbafal! fagte ber alte jato= bitifase. Lairb - ub! - ich håtte Imollen 300 शRen, (d)en in Furem Sefelrichaftbiaal unterbingen, aber fommt, lommt - id will nicht weiter fragen, oie Antworten fameden alle naф mewen sorbs, mad netten (suters, fie verberben mir nur ben áppetit,

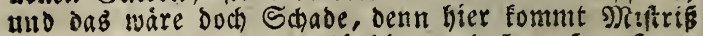
Erobbie, um-uns anzutúnigen, Das unfere \$am, melbfeule gar ift."

EB war fo; Sniftrifs Srogbie mar nidst zugegen ges weien, wie Eva "obliegend wirflichen Sorgen"; eine Pflidst, wovon fie fich nidht fur loggezahit adstete, we:

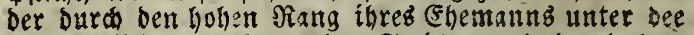
obrigfeitlidien Derfonen ber Stabt, now Darch ben

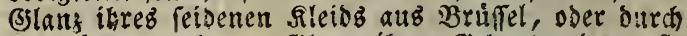
Den lober geadteten Glan ibres (S)bart, denn fie wat eine geborn: Narwell, und wie ibr (5)entan oft feinen freunden funb, that, mit mehrecen ber exs ften Familien in ber (s)affhaft vermant. Sie war foon geweien, und iah nod iegt fur inre Salye rests gut aus, uno obgleid inre anwerentheit in oer Sithe ibren Eeint in etwas erboht battei, to wat ez ;ooth nicht mebr, alb eit befacidenes 2 uffegen vour fioth auts getijan haben wurbe. Fir ben Serrn jitidter. wat reine Daas gemis ein (S)yenitand des Stolges, la Finfige faaen, fogar dzb Schredens, denn von den meiblichen mitgliesern ber Fanilie Reogauntlet giena

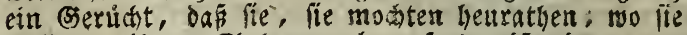
wolten, ibrem Ebehersn cben io gervif eine grate Stute in Den Stall brachten *) als fich auf 230 onver: mann'b Semalben eit weifles Dferd befindet. Die gute Dame brachte aut, wie man glaubt, eine poli:

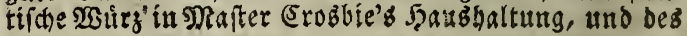

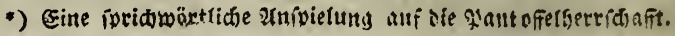


Meines (sarts Tamen witt id) lieben und efjen,

şenn itn siple aud) baffen felir,

Si)! fäb id ilun ood juructe fel)ren,

lino treiben sie $23 i b a^{\prime}$ y nor fid her.

ueber das şafier uno flter die Eec,

ueter saz ऊ̧arfer bin ju (5arl!

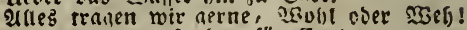

und leben und fterben fiir cart.

Diftrif (Srobbie ládelte verftoblen bem fairb zu, inbem fie fith zugleid bab \&neben tiefer Intermer fung $g a b$, wihrend ber 5err Ricister, ber Den (seiang feinebे Baftes nicht boren wollte, im Sinmer umber gieng mit einem anfeben bon ungweifelbafter 23 urbe und Itnabhångígét.

„2Bobl, mohl, meir lieber," fagte sie Dame, mit Dem ruhigen lächeln berllnterwerfung, "Shr verfteht oas am beften, und werbet thun, waG Sbr fir gut finset, orele Segenfande find weit uber meinen Forisont, ids sueifle nur, ob bie Statube ie fo ridstig geben und Eure Mablyeit fo richtig anf ben Tiff fommen wirb, als

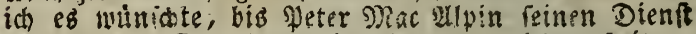
wieber bat. Der )Rann ift alt, fann nicht arbeiten, und leibet begbalb grangel, bennow ift er ber einsige, Der eine Slocie zu richten berftebt."

Ran fann bier im Rorbedgeben bemerfen, deb trok biefer Weifiagung zu beren Erfullung die foone Eallato

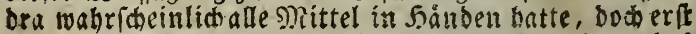

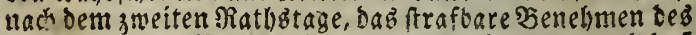

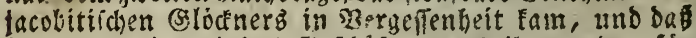
ibm noch einmal sab (s)erdaft zugetheilt wurbe, fire bie Stabt die Beit, uno für ben Serrn sichter bie (EE fenzifunbe zu beftimmen. Dibmal gina die Nabb seit angenehm voriber. Summertrees fomazte und idserkte mit ber leidhten linbefangenbeit eines Manues, ber fich úber reine Gefellichaft erbaben fiblt. Er war wirlich eine wiotige Perfon, wie fich aus feinem frots lidben $\mathfrak{A}$ eubern ergab; fein Şut war mit peins d'Es.

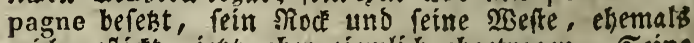
reich gefíct, jekst aber ziemlidi abgetragen. Seine slåns 
glånzenben STalb : und fenblranfen waren nur, bie erfte etwas ftart verfrungelt, uno die andere etmas be= fommazt; aud Darf rein langer Stpidegen mit lilber, nem Esefáfe bier nid)t vergeffen werden. Sein 2Biks oder vielmebr feine Laune grenzte ans beisende, uno geigte ein unjufriedenes (semith; und obgleid) er fein

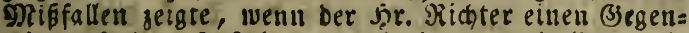
wis verfudste, fo fden ex eb bod nur an Dulden, wie ein Fechtmeifter, Der feinem ségling zuweilen geituts tet, ilgm eitren Sto bebzubringen, nue um il)n za ermuthigen. Des Lairos eigene Sd)erze waren itl= beffen ausnehmend erfolgreids, nidht nur bei bem Fern. Sichter uno feituer Frau Bsemallin, fontern aud bei ber rothbackigten uno rotbbebanderten Mago, weldhe am xich nufwartete, uno taum gebórig su beiorgen vermochte, twab ibr' oblag; weil die 2usbrúche ber Laune des g)r. Summertrees äuserft wirffam fich bes wiéren. 2llan fairford allein blieb bei aller biefer euftigleit ungerúhrt, was um fo wentiger zu verwuns bern war. Da nidht nur feine sebanfen mit einem wirke. tigeren Begenflanbe berhaftigt waren, iond:rn au由 bie

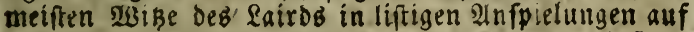
unbedeutende Stabt = ober Familten = liorialle beftan. ben; mit welchen ber (Saft aus Edinburgh vollig un= belannt war. So fallite bab (s)eläd)ter der (s)efell:

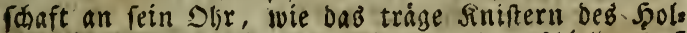
ges um einen Topf, nux mit bem Itnterfdhiere, Das baburs teine to nuizlidse operation unterlyalten ober begleitet warbe, wie daz stochen.

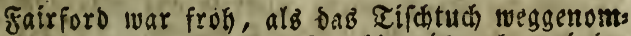
men twurbe, und als $\mathfrak{N r}$. (Erosbie nicht obne einige

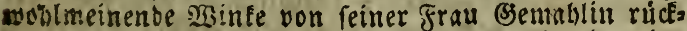

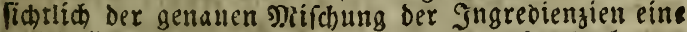
aniebnliche Siolule Punich zu Stanbe gehractit hatte, wortiber die \$lugen deg alten Jacobiten zu glänjen aufin. gen, wurben die (s)láfer vorwärts gefchoben, gefült, uno lesez von feitem (Eigenthumer sieber an fich sejogen,

Es. Ecott’s merte. XVII. 


\section{4}

worauf ber fer. Nidter mit grofer Emphafe ben Ioaft ausbrachte: "Der fơnig. "Daber richtete er einen bedeutenden Blic auf fairforb, ber zu fagen fdien: Shr tonnt nidht zweifeln, wen id merne, unb barum ift es-nicht notbig, bie perfon náber zu be: zeidinen.

Eommertreez wieberholte ben Ioaft mit einem falauen Minte gegen bie Feausfrau, während Fait: ford fidweigend feill (5)

Edon, mein junger aboofat, lagte, ber Lanbs edelmann; mit freuben fele iđ, bas bei der faful= tả $D o($ ) nod) S(haam ubrig geblieken ift, wenn gleid wenig (El)re. Einige von Euch Schwargroden wollen heut su $\mathfrak{T a g e}$ weter von bem einen, now Dem andern bóren."

"Id menigftens Sir, habe fo viel von einem Fechtögelobrten, Da i id mid nid)t gerne in einen Streit einlaffe, ben idh zu fubren teinen 2 uftrag has be - dab biese seit und gahbe verínwenden. (seht, gebt, fagte bie qaby, wir wollen bier nicht uber bie Whigs und Toris freiten - mein Mann weí, was er fagen foll, und id meis, was er benlen folls te, und atı bem zu ldlief́en, was gefommen und vergangen ift, fo mochte wohl eine seit erfocinen, wo redoríchaffene sianner fagen, wab fie benten, fie mógen Ridter fenn ober nict." "

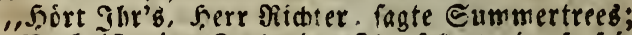
Euer 2 etb ift pine Bauberin, Shr folltet ein 5ufei fen an ibre fiammertbúr nageln. Sia ba, ba - "

Diefer Spás murve nicht fo gut alfgenommen, als bie frúberen $\mathfrak{B e r f u d e ~ b e z ~ f a i r t z . ~ 2 e i ~ n e r ~ f a b y ~}$ begann ein Bonnermetter aufunieben, und ber frere Riduter fagte halb bei Eeite. e!n ernfter Ecterg ift lein Sher; mrtir; Shr werset das Şufetfen glubeno bets finsen, Eummertreeb."

"Shr tonnt obne Sncifel ans Erfabrung sprecten, Nix. Erodbie" antwortete ber Enirb; nom ib bitte nm Bergebung; Mir. Erodrie, ich habe nicht nithig 
8u fagen, bab id alle 2lditung babe vor bem alten unb ehrwurbigen Shaufe Der Nedgauntlet."

"Ilnd daju babt Shr gute urjade. Denn ghe fend mit ibnen verwanot, und fennet fowohl oie nod fe: benden, als die bereite Serftorbenen recht gut."

"In ber Ebat, She babe Redt, Rabame, ant. wortete ber \&airo, beun id uno ber arme 5arry Nied. gauntlet, ber su Earlible aubgerungen hat, waren ein fers und eine Seele, und Dod trennten wir unb nach furzem झlsfdied."

"ID, Sommertrees, fagte Nr. Erobbie, bie巨

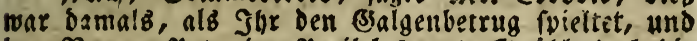
ben Famen Pate = imt = Peril betamet. Ergühlt Doc Dic Befdichte meinem iungen frelnde hier. Fr hät eis uen folden PIfiff gern, wie bie meiften aboolaten."

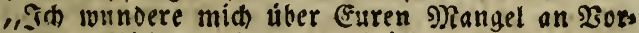
ficht, here Riditer, fagte ber Eairo. Bam mach Hrt bee Sanger, die fich weigern, hu fingen, wenn ibnen

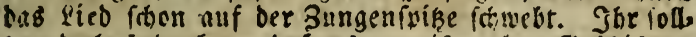
tet bod bebentin, bas ez gewiše alte (se giebt, bie man niat mit wóliger Eiderbeit aller bors jenigen auftt dien fann, bie bakei betheiligt find."

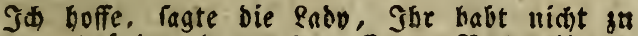

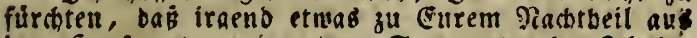
bem feaure getragen worden, Gummertrees. I be bie (s) fhidite zmat fmon gebort, le ofter id fie aber bore, defito nunderbarer fómmt fie mir por."

. Ia, shaname, aber man hat fich lebt foon lans ge genug hariber gewundert, lind eb ift Beit, Damit alliabiren" antwortese Miarwell.

fraixford hielt eg der Giontioleit gemá su fagen, ex babe ofr non ber manbervoleat filiedt Biarells gehort, und nintb founte ibm angenelsirer fenu, als einmal bas mathe an ber હadre kแ vernebmen.

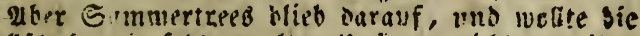
sefellidesir mit foldeen alten linfinise nicit im ibre Beit brittyen. 
"(ङ)ut, gut," Pagte Mr. Crosbie, ,ein freier Matm mus feinen $23 i l l e n$ baben. - 2 ab bentt Shr Reute in Der Graffchaft benn von ben Unruben, welde in bea Solonien aubzzubrewen anfangen?"

Seerrlich, Sir, Gerrlid! wenn bie Dinge aufa

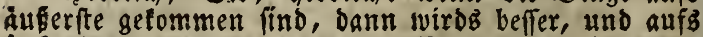
áußerfte ift eb̉ gefommen. - $\mathfrak{W a} a \mathfrak{b}$ aber meinen tols len Streid anbetrifft, wenn 3 he barauf beftebt, bie efnzelnen $l 1 m$ mitände anjulboren, fagte ber \&airb, wels wer zu merfen begann, dá bie seit, wo er feine (s)es fobithte mit 2luftand erjáblen fơnne, allmáblig vors iber gethe.

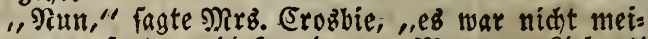
netwegen, fondern biefem jungen Mann zu Riebe."

, (8) at, warum folte id nidit biefem iungen

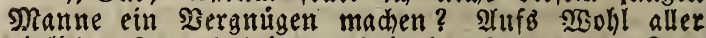
elurlichen Rente baheim, und in ber Ferne! zum rent

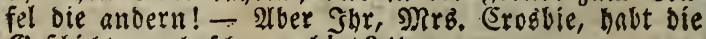
(sefchichte altw fachon gebourt?" -

" Rimt fo oft, um fie langmeilig za finden," fagte bie Raby, - und ber gairb wendete fíd oljue weitere Einleitung an $\mathfrak{A}$ lan Fairford.

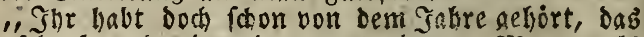
mant fünf uno vierzig nennt, iunger siann, alb

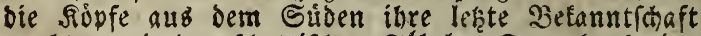
madten mit ben fohottifáen Sábeln. Da sab es eine Not berumfaneifender Burche im Lande, Die man Nebellen nonte - ión lounte nie ergranien, aus

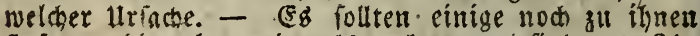
frofen, die aber niemalb getoinnen find, - She

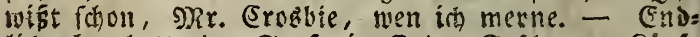

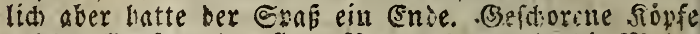
gabs yollonf, uno rafierte Macens foment in Zie Miode.

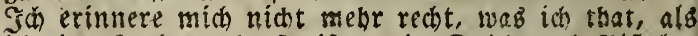

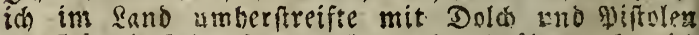
im (suxtel, fech monate lang oter briber; aber id erwadte fówer aus einem ntrubigen Trarme, sem

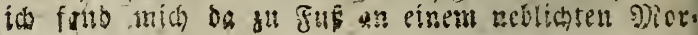


getr, meine Şanb, wahrideinlia, bamit fie nidht $b a=$ von laufe, in eitter Şandichelle, wie fie bas Ding nennen. mit bem armen 5arry Rebgauntlet zufan= mengefchloffen; fo geben wir bes $23 e g s$ mit now einem Sthod anderer, bie fid ebenfalls zu tief in ben Sumpf gewagt hatten, einen Sergeaniten von ben Siotbroden mit zwei Sieiben Dragoner zur Seite, um uns in Siube zu balten, uns uns शruth gum शRarich zu madien. Wुetut bie 2lrt zut reifen nidat fehr angenehm war, fo war ber 3wed ber Reife aud nidst febr lodend, benn 3 br verfiebt, junger

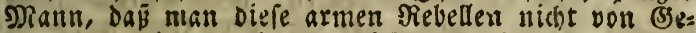
fdnorneu ibrer eigenen lieben Sanbsleute richten laffen wollte, ob man gleich batte denfen follen, fie bátten genug sibigb in Sthottland finden Poumea, un unb alle baingen zu laffen; fie bielten eb aver fúr paffenter, ung in Carlible Dab 18 rtbeil precten zu laffen, two bie Seute fo eingeiduditert waren, ba weun ibr einen ganzen bochlanbifiten 2 llan auf ein=

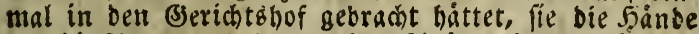
vor bie Alugen gebalten und geíchrieen baben wurden: J̧ängt fie alle, nur un fie loz zu werden."

"Ja, ia," ragte ber J̧r. Sichter, "Das war

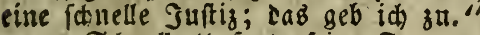

"Sdinell," lagte feine Frau; "id móchte nur, bie, rolde Sie angsordnet, ftúnoen vor ben (5)es fdwornen, id wollte fie innen empfeblen!"

In vermuthe, der junge Nechtggelehrte hålt bief "fur gant recht, " fagte Summertrees altf Fairs forb blideno, - "ein alter Nechtalundiger totirie anders gebacht baben. Inte ein Snitter mule ge= funden werben, um ben 5 und nieberzuidlagen und man mablte einen red)t faiveren. Stun id bielt mén uen Sopf beffer beyfamen, ald mein Befálinte, Ier arme Rerl; Denn id batte glúdictorweife weber an $23 e i b$ now Sind a benfen, und 5arry Redgauntlet hatte bevoes, - Shr babt 5 arry gefelyen 9Rrs. (Eros= bie?" 
"Wabrhaftig ia," fagte fie mit einem Seufzer, ¿ben wir fruberen Erinnerungen su fornten pfles gen, deren Begenftand nidht mebr ift. Er war nidat io gros, als fein 2 ruber und úberbaupt ein feinerer

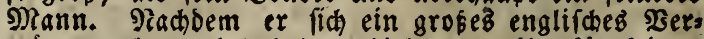
mogen erbeuratbet batte, bielt man ihn fur teimen fo guten Sdotten melir, als Ebuarb."

"Da batten die Reute unredt, " fagte Summer.

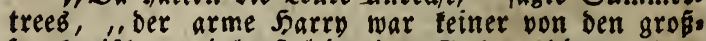
fprederifden, einberftolgirenben Geden, die von bem reben, was fie geftern tbaten, ober morgen thus wollen; wenn irgend etwab gerabe zu thun war, oa battet Sor ben Sarry Jiebgauntlet feben follen. Id fab ibn bed (sulloben, als alles verloren war mebs thun, als swanzis jener aufgeblarenen Prabler, bis bie Soldaten, die ibn gefangen uabmen, farieen, man folle inm nidis zu leis thun, fo babe es jemand aubbrúclich befoblen; Denn er war ber tapferfte von

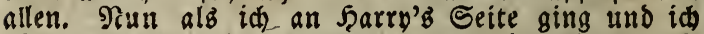
fưitte, Dafi er im Morgennebel meite Şand mit emporbob, um fí, bie Alugen albzuwifden, benn me: gen ber feffeln fonnte er nicht anders, ba mennte id), mein Scerz miffe um ihn breden. Unterdeffen probierte uns probierte ich, meine f̧and fo llein, alb eine Damentgand, zu machen, ob ids nidht allenfalls aub meiner eifernen f̧andfbelle beraubidlupfen fon: ute. Sor fount benten," fagte er, indem er feine breite Enodichte feand auf ben sifa ilegte, ,.Daś ids genug stl thun hatte, mit meiner feand fo groś als eine fomelsidulter, aber Ghr fehi, die fauftinod)en fitto rebr grop̈, und fo musten fie mir die Saandidselle ziemlión weit lafien; endlidh falipfte ids mit meiner Szand beraus und wieber binein. ber arme fiarry nar

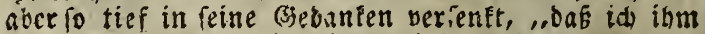
bas, wab ich that, nidht bemertlich madnen fontute." "Warum nicht," fagte 2l!an Fairfors, "fur ben bie Exjåblung intoreflant zu werben anfing." "Weil piue ungeidsladte Befte von einem Dras 


\section{9}

soner batt an ber andern Seite ritt, unb id ibn eben fo gut ins Sebeimnis gezogen bátte, als Sarry, und bann wirbe es nidt lange angeftanden baben, bís eine piftolentugel birch meine 9) bátte. - Эa muste alfo fo gut wie móglia fur mid felber forgen, uno, bei meiner Seele, $e$ b war Beit, Denn ber S3algen ftand mir ftoon vor dem (se: fidte. Wir madten su Mpffat balt, um su frủ, ftuden. Die Moore, tiber Die wir maridirten, tannte id redst glit, oa id in febr verfdiebenen Bei= ten auf jebem grorgen Lanob in biefer (5)egend ge= lagt batte. 'Sebt, fo wartete id, bis id an bem Siande bes Zeichs von Erriditane war. Sor fennt ben Wlaz, man nennt ibu gewólnnlid Des g) Rarquib Dufenftand, weil die 2uriche Innandale ilir geftoble: nes 2 ieb bort hin su treiben pflegen?"

Fairford beseugte feine Unwiffenbeit.

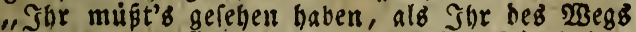
baber famt; $e^{b}$ fielit $a$ ub alb ob vier filigel ibre sipfe zurammen ftecten, um alles Tageslidit von bem bunfeln tiefen Raume zwifhen ihnen auвzus fdiefien. Fine tiefe fdwarse, gráulid aublehende Soble ift da und gebt io faroff wie moglid gerabe vom $\mathfrak{3} 2 g$ binab. 2 uf bem srunbe finoet fid ein Hleiner $\mathfrak{B} a \bar{b}$, bas man ez faum für miglich balten follte, bas er feinen $2 \mathrm{seg}$ aus sen bart aneinanders liegenben Şugeln heraugfinben fonme."

"Seine gute Paffage, in ber $\mathfrak{E} b a t, "$ fagte arlan. "Sor fonnt wobl fo fprechen, fo falimm ber alct

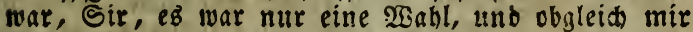
bie saut faruberte, went if an ben rumpler bachte, ben id madien follte, fo fafite ict mir doch

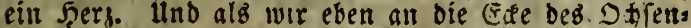
ftandes von Sobnftones famen, faliufte ich mit meis ner 5 and aus ber f̧andfhelle beraub, und rief bem Jarry Siebsauntlet 3 : : folge mir! banu oritute id midh unter bem Baucbe bes Dragoner Dferbs hin,

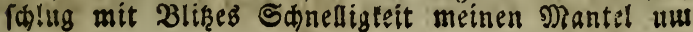


mid, warf mich allf bie Seite, benn ich fonnte bier teinen fü auffellen und fugelte nun hinab úber Şaidefraut, 3rombzerftráuche und হannenwurzeln, gerade wie ein Tá hinabrollen wúrde. Bei \&ott, Sir, ich muí nod lachen, wenn ich Daran benie, wie bie Sd)urfen von Rothroden (Se)fidter geidnitten haben mógen, benn ber siebel war wie geragt, febr biá, barum merften fie niđt, bas̄ lie an einer fo Galburechenden Stelle waren. Fealb war ich binunter; benn bas sugetn geht faneller, als bas Silettern, ehe fie ihre $26 a f f e n$ ergreifen tonnten, oann gingz aver piff! paff! puff! auf ber Strafie. aber ber Siopf war mir fo toll, Daś ich nicht Daran benlen lonnte, ober auch nur an bie harten puiffe, die ich, von ben Eteinen erbielt. Sih behielt indeffen meine Sinnen beifammen, was jeber fúr lounberbar halten wirb, Der ie deal plak gefehen hat, is half mir mit rell Sianben fo gut $i$ h fonnte und fam endich auf ben Brrund. STier lag id einen Alugenblict, aber ver (5es

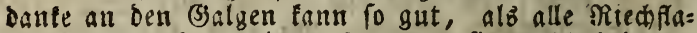
fichen in ber 2 selt, einen Jiann zu fich felbit bringen.

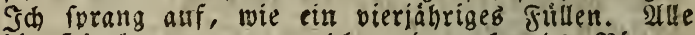
Die frigel tanten um mich, wie grobe oide Bienen, fowarme. To hatte aber feine Seit baran th ben= ten, befonderb, ba ber Peebel fich burch bab Jeuera aerfitreut hatte. Ia fonnte isie Sdurfen fehen, wie ite an ber Sinte bes Mioorbrubes berum frochen, und id glaube fie faken muda, auth, benn einige bes gannen an Dem Şligel binab zu flettern, aber mebr, wie alte weiter in isten rotben Dtänteln, wenn fie von einer Felepresigt nach Saute fommen, alb whe ein gewanbrer 3uriche, gleich mir, Darum bieftea fíe bald, und luben ibre serwebre; (s)ott befoblen, ibr

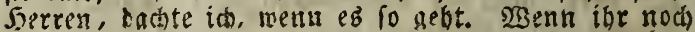
ein Nort mit mir fut reben habt, fo mogt ibr aur $\mathfrak{n a d}$ Sarrizfraw = gauns fommen. und fo madte

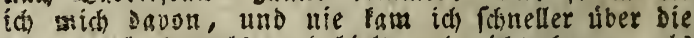
Dicore, ale samalb, unb hiclt aud nidt eher an, alb 
bis id brei (s)ewaiffer von ziemlider Tiefe; benn es batte turs vorber ger:gnet, ein halbes Dukeno Berge, uno eiil paar taufeno Hader Faide uno Sumpf zwi fhen mie und meinen Freunben, Den Olothrodé, batte."

"Diefer Streid lwar es, ber Eud) den शamen Pate - in - Deril erwarb," fagte grr. Erosbie, füllte die (5)lifer, uno rief mitbrend rein (S)aft, aufo. seregt Durch Die Erinmertmg, welche bie That in ifm

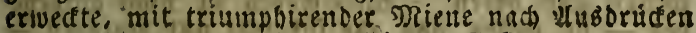
bes 2 eifalls und eitler gleichen-Befinnung umber

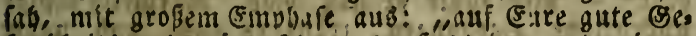
funbbeit! und moget Jas euren $5_{2, \alpha l s}$ immer in einem folden albentbeuer wagen.

" Soum! It weis nid), " antwortete Summer. treeb. "S

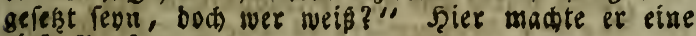
tiefe Patre.

Durf id fragen, was aus Eurem freund wur. De?" Sagte Hlan Fairford. "H(th), ber arme 5ar= ro." erroieberte Summertrees; . ich fage Ettw, es toftet imiter jeit, fich su cincm folden arbentbeuer 3u entichliesen, wie es mein Frewno Erosbie nennt; greil geaclean, Der gerabe binter uns ging, aber bas (5)luck batte, bem Balgen ebenfalls burd einen lifti. gen Streich su entgehen, hat mir nadber erjablt,

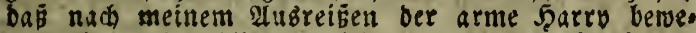
gungaloz ftelen blieb, obgleid alle unfere mitgefanges nen Bruber einen fármen maditen, fo ftarf́ fie nue

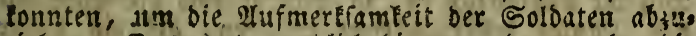
siefren. Er rarute, enolida hinwey, oa er aber bie Eegeno nicht fannte floh er entweber aus Berwirrung ooer weil er ben 2(jh)ang fuir gar zu fteil bielt, ben Shugel link binauf, anfatt fid mit einemmal hinabs gunagen; 10 murbe er leidat verfolgt und gefangen. 25are er meinem Beifpiel gefolgt, fo wirbe er alth gensg birten gefunben baba. die ifn verboraen unb

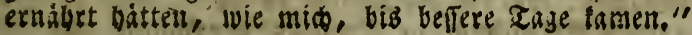




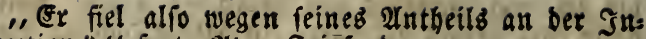
furrection?" fagte alan fairford.

"Allerbings," fagte Summertrees, , fein Blut war zu rotb, als dấ man eb zu einer Beit bàtte faonen follen, wo diefe farte fo gefuht war. Es wurde hingerichtet, Sir, wie Shr eb nennt, o. \%. es warde mit faltem Blute ermordet, wie fo mande an: bere wadkere Befellen. - $\mathfrak{W} 0 \mathrm{bl}$, aud wir werben unfern $\mathfrak{Z} a g$ baben - aufgeichoben ift nidht aufgebo: ben - fie balten uns alle fur tobt unb begraben aber" - bier fúlte er feit (3) lab̉, murnelte einige undeutliche Drobungen, trant $e^{B}$ aนB , Hno nabm bann wieber feinen gewóbnliden $ז$ gen das Ende feiner Ersáblung ein wenig geftort worben war."

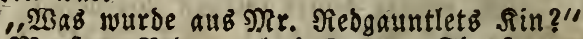

Mafter Reogauntlet! EB war Sir Jenry Reb: gasntlet, und fein Sobn, wenn $D a b$ Sind noch lebt, beist Sir $\mathfrak{A r t h u r}$ - id nannte f̧arry wegen unferer genauen Befanntia)aft, und Rebgauntlet alb bab Dbers baupt feiner familie - fein eigentlider Name was Sir Jenry Reogauntlet."

"Sein Sobn ift allo toot?" fragte Irlan faits forb. (5B ift bod Saade, wenn ein tapferer Stamm aubiterben follte."

"Er bat einen Bruber binterlaffen," fagte Sum, mertrees, weld ber jekzt der. Sievráfentant ber. Samilie ift. Und $e b$ ift auch gut fo, oenn ob er gleid in vieles Sinlíbt ungluatich ift, fo wirb er boch bie Ebre feis neb Şaufes beffer aufredt erbalten, alb ein unter bieien erbitterten $\mathfrak{W}$ bigs, ben Derwandten der (3es mablin Sir Shenen's erzogenter Snabe; Denn fie fteben mit ber Famílie Rebgauntlet auf leinem guten Fuß̈e; erbitterte $\mathfrak{B h}$ !gb find fie it jeber f̧infint. Es war eine tolle Seurath swifhen Sir Senry mo feiner Gernablit. Das arme Ding, fie wollten ibr nisbt gefattell, ibu im (Befángnî́ zul feben, und ba fein ganjes E:gentbum in Befwlag genommen nuto ges 
plůnbert war, fo batte es ihm an ben gemeinften शrotbmendigfeiten gefeglt, obne bie 2Anbänglichteit eines weit befannten blinden Eeigers. Sth habe ibn felbit bei Sir Jenry gefehen, vor und wáneend ber (Be) (dachte. Id) borte, er babe in Den Strafent vors Earlible die Sseige gépielt, und bab (S)elo, was et belam, feinem Jjerrn gebracht, wábreno er in bean Sdloffe eingefperrt war:"

"Id glaube fein MOort bavon," Pagte Mirb. (Erob= bie, glibend vor tnwillen. "Ein Redgauntlet wäre gwantigmal geftorben, elge ex von einem Beiger et: Wab genommen bátte."

" 50 ho! nicht oben hinaub , bab ift alleb tunfma und Hebermuth," lagte ber \&aird von Summertrees. Die leckeriten Şunbe effen aud folect)te Brocken, Baafe Erosbie, 'Jhe wišt nidht, wab einige Eurer freunde in iener seit thun musten, um ein Rapfs den voll Suype ober un ein Stúc 'Brod. Th babe

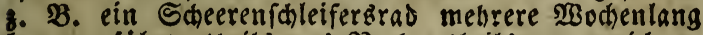
berumgefúhrt, theilb aub ?oth, theilb um mid za verbergen, oa habe id an jedeb alten 3 seibebthitr higg, bigg, wigg, wigg, gemadit, uno wenn Jhe einmal Elite Stheeren gefdiliffen baben wolt, id tann eb furr (E) thun, wenn mein Rab in Dronung ift."

"Sgr litúbt mirt) erft um Erlaubnis bitten," fagte Mr. Erobbie, benn id babe mir ergablen laf fen, bas Shr bie fonderbare Node habt, emen Sub ftatt bes Pैennings zu nel)men, weแn (5ud) ber Sunde gefiel.

"Sommt, lomnt, mein berr," fagte bie fabo astffeheno, wenn ber Punfd bei Euch uber bab Effen Die Dberhand befommt, Dann ift eb seit, midh ats,

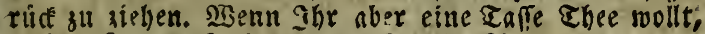
meine ferrn, fo fonmet a!!f mein Simmer."

allai Fairfort war nid) fehr betrubt iber bie Entfernung ber Dame. Sie fichen, obgleids nur im vierten (5rade vermand, Dods z"l viel auf bie Ehre bes şaufes jiçsauntlet zu balten, um nicht burch bie 


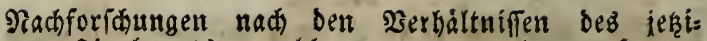
gen Dberlyauptis, welche ex zu maden gefonnen war, in Innrube gebradt zn werden. Eonderbare verwirrte Bermuthungen ftiegen in feiner Seele anf aub ber unoollfommenen Erinnerung all bie Ergath.

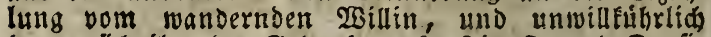
brang lich ihu ber (5ebanfe auf, fein Frellnd Darfie

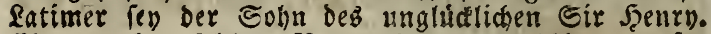
Ege ex aber folchen sermuthungen nachsing, muste ex zu entbecken fuchen, wab gegenwártig aub ibm ges worben war. SBenn er in ben ñanden jeines obeims

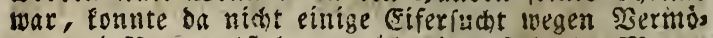
gen ano sarig entitehen, selche einen fo harten gland, wie Niedgauntlet, zu falimmen Manbregeln gegeu efuen Itingling verleiten mochte, ben er nimt naw feinen 2lbfichten ful medeln im Stande war? Schwei.

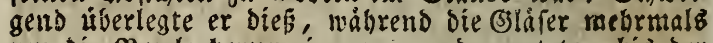
im oie Bowle berumgiengen, uno wartete, big des Sor. Ridter gemå feinem eigenen 3orichlag ber Endje erwahten warte, weșwegen er then aubortatid met Dir. Piartozll von Eummertreeb befannt gemadt batte. Echeinbar hatte bet Sir. Ricter fein iserípres dell vergeften, ober war wenigftens nicht febre eilig, eb gu erfüllen. Fr fprad mit grofiem Ernite von der Stempelafte, welcte gerade tamals den amerifanis fchen Eolonien Drohte, und uber andere (Segentiande

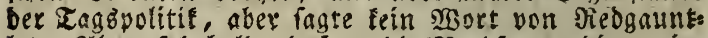

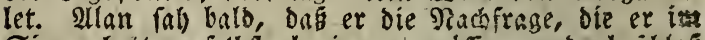
Sinne batte, felbit beginnen múffe; und beidlob dem aemós zu verfahres.

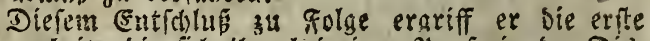
Belegenteit, bie lid inm bei einer Yaure in ber Dib: cuffion ber Eolonialyolitif barbot, uno ragte: "Ich

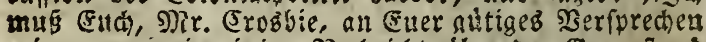
exinnern, mir einige Siaci)ridst úber Den (seaenftans gu verfiaffen, wegen beffen id fo beforgt tiu.".

"Maghrinftig!" fagte MRr. (5rosbie nach augen:

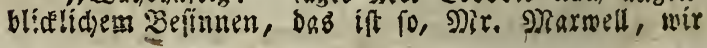


Path su ertheilen, uno nidht (sud ron armen einfál= tigen yanbetelleuten Niaths zu.erbolen.

"Wenn nicht gernde Rath, fo ift es bod bismeis lea un're Pritht, fragin vorgulegen, פRr. MRarwell."

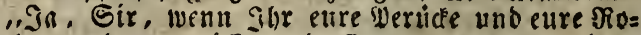
be anhät, bann miffen nir (Eud) fcron has gewobns lide Privileginm ber 2 lonotaten und ter 2 geiler zu= gefteben, zu fagen, web (5udh beliebt. Wrenn She aber Enern 2umtsiammid nidt anhabt, fo ift bie $\bigodot_{a=}$ de anderba, wie fommt Shr bann Dazu, allzhuebmen, ba bung fiete, ober melir tarou wiffen foll, wie Shr, was Dort voraieng? Die Jrage geht von einer reht unpaffenden Sorausepkug ant.

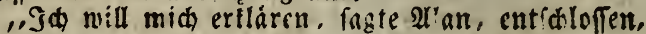
bem Mir. Marwell feine Belegenbeit zu geben, die tuterrebung abjubredien; Shr fens ein genauer freund von Mir. Nieoganntlet, ex ift fasslo:g, an Diefem ges maltfamen 2 lngriff Theil genommen, und mit (3ewalt fí ber Perfon meines fretuntes Darfie eatimer ke= madtigt an haben, eineg jungen Mauneb pon Ber= mogen und Einfus, nad beffen Ecoidial su forfaen it gans feft entídoloffen bin. Dif ift ber flare Stand ber Sache, und alle dabei interébirten Partheien, Ener fremnd insbefondere, werben urfacte baben, mix

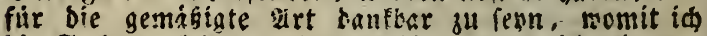
bie Sadhe zulleiten aeforsen bin, wenn id mit vers baltnibmásiger offentheit besanselt wer\$e."

"Ihr brot mich miB̈verftanten," finte-marivell in einem it on weit miloeren Tone; id fagte (E)th, id fey der greunb bez lebten Sir fherry Nedgauntlet gervelen, der im Jabr 1745 zu feairibie, nabe bei Earlib!e, bingeridtet wurbe, aber itb tenne nieman, ben, ber jest Jen Mamen Resquuntlet fübrt."

"Ylor fennt rod) Mr. Serries von Birrengwort," fante allan !hdolns, Den ber Name Redgatinlet zulftelt?"

Miarmell fais bea Mr. Eroabie mit einem fare 
felte mit bem 5Trn. Nidter einige Blice, bie nidt febr troftlicher 2 rt twaren. Fairford ftand auf, unb gieng in Simmer umber, um ibnen (selegenbeit zu etner linterrebung zu geben, benn er hoffte, Das ber fictbare Eindrud, den er auf Simmertrees gemadt batte, feinem sorbaben gebeiblich werben wurbe. Sie ergriffen die Belegenbeit, uno wifperten einans ber in bie Dhren, Der Lairb auf eine ziemlich heftige

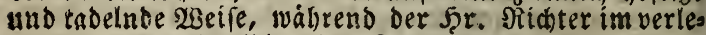
genen und entichuldigenden Eone antwortete. Einige abgebrochene $W_{0}$ orte bernahm Fairforb, beffen Begens wart fie zu vergeffen fálenes, da er im 5intergrund bez Simmers ftand, f(l)einbar befcháftigt, die śigu ren auf einem fwónen indifchen Schrante zu betrachs

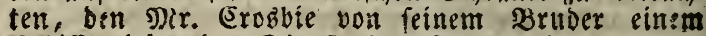
Erhiffrayitàn in Dienit ber Eompagnie sum (B)e: foient erbalten hatte, toeb er horte, tibergengte ilyn, Dap fein 20 ortaben und die 5 artnádigleit, womit ex eb verfolgte zwifhen Den Serren Streit erregt hatte. Dem orr. SHarme!l entfubren entlich bie Worte:

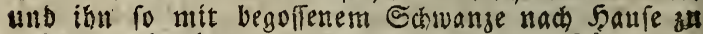

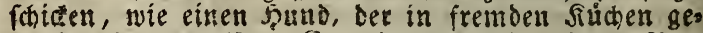

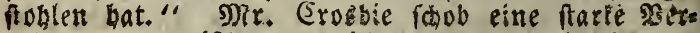
neinung Dasnifden "nicht baran zu Denfen madt die Sadhe nur falimmer - meine Lage -

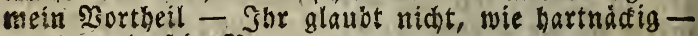
Berebe, wie rein sater.

Sie wifoerten unn nod) enger zurammen, enblid aber erbob SRr. Erogbie Das̆ fintende STaupt; ex furac in einem freundicten sone; fommt fert Eud nieber zu Eurem (S)Lab, Mir. Fairford, wir tabea uafre Siopfe zufammen geftect, und Jar folt feben,

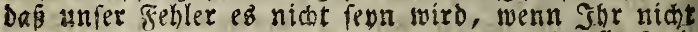
gan: sufrieben geftelt werdet, unb sir. Darfie Lati

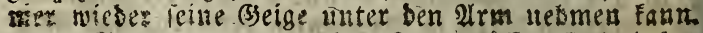

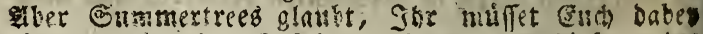

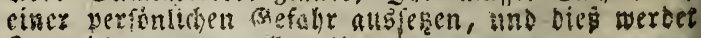
Stz nicht ungen mo!en." 
Meicie Serrn," faste gairford, "id merbe

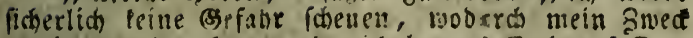
crreidt merden fann; alier ith lege eb (s:a) auf (Euer (Bewiffen, auf (Fures Mr. Narwed, als eineb Mans neb bou çbre uno cines Eselt: nnç, und auf $\$ 28$ Eurige, গxr. Erosbie. als einer ririgleitliduen Merfon ano eines treuen llntertbanen, Dabi $\$$ br midh in oies fer Ingelesenheit nicht irre leitet. "

"Piein. was mich betrifft." Faste Summertries, id will हैuत mit einem Ma! b e Mabrbeit fagen, und offen geftehen, Das ich SRittel wein, den armen Siedgauntlet an fehem; mo deés will icn tbun, wenn Sor es verlangt, ind inn befonworen, Fuct fo gll be= banbelu, wie Euer Beftáft Po erforkert; aber bet arme Diebgauntlet ift fehr veranbert, ia bie mabrbeit gu fagen, fein Zeriperament war nie bas hefte, inbef fen will id Eud vor jeser grópersu Gisiabr fíther ftellen."

"Davor werbe ich mid relbit fduigen, "f fagte fairford, "indem id eine binreidande Bes atung mit nebrae."

"In ber Ibat," fagte Summertrees, "Ins werbet Slir nicht thun. benut firb erîe, glaubt otr, bas wir ben armen Sisnn in tie sanbe ber phis? fter liefern wirden, sa in Bearntheil mein eititeo: 3wed mar, die Sace in jeser şinfint suf eine feierliche Wreife "abjuthun, sund ich nur barsul ben

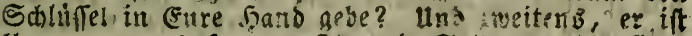
fluy genug, Def wenn Sor mit Solseten ober Ech= ftablern noer ctwas bergletchen ifit n-se fommt, id (5ud) bafur fteben lann, Das Jijr ibn sie erwifden werbet.

Gairford behadite fich einen 2 usgenblid, und tiber: legte, Dab ber Bortbeil, biefen ') iann :n isben, um Renntni von ber lage réneğ freanbess su erbalten, mit feiner ferfonlichen sefabir zu theuer erfauft feD:

จ3. Ecott'̧ æ3etfe. XVII. 
went et aber ben für fich felbit ficherften - sseg cin. fchlug, und oie seferze ju fiulfe nabm, fo fab er wobl, märbe er Der nötbigen Szndrichten beraubt feyn, Die ifn leiten musten, oder Sieogatuntlet würbe ron Der (3efabr benashridtigt, wabrf(beinlich Das Land ver. laffen, uno feinin Befangenen mit fich fübren. Fr mieberbolte Daber: icis berlaffe mich auf Euer Ehren. mort, פRr. IRnewell uns merde allein Euern Freuno

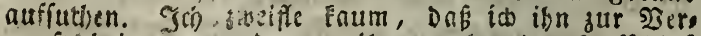
nunft bringen, sul bon ibm genugenden 2uffchlus Über פRr. Satim: erbalten werbe."

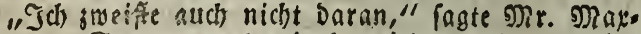
mell von Euimertrees, Doch mird es immer eine Zeitlang Daturn, uno Ifor merdet 23 erjug und unbe. quemlichet aben baben. Dreine 2 serficherung gebt nicht meite?."

"Jut riblite, wie fie gegeben marbe," fagte alan Fairfort; aber lábt mici fragen, wäre es nicht befier,

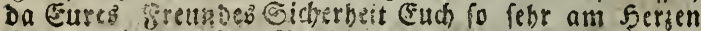
liegt, tits She ficherlich Dic meinige mit Fsillen nidht

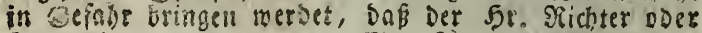

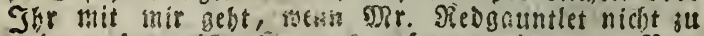
weit entferal iff, in sto verfuden, ibn our 2 ser. nunft zด bingen?"

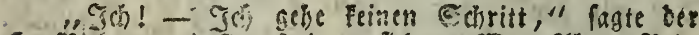

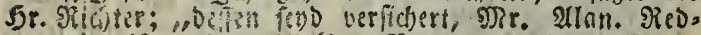
gauntlet if meines SiBeibes Detter im vierten. (5) bas if nicht $z$ u lä:egnen, wåre et aber auch Der leţte oon ibren us meinen germanoten, fo würde eš

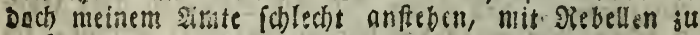
ocrEebren."

"Sa, ober mit ciomeigercrn su trinfen," fagte Maxrsell, und fültte fein (Slab, id) mürbe eben fo.

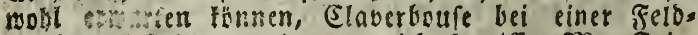
predigt it finden, uno wns mich betrifft; Mir. Sair, forb, fo. Fonn ich gerabe aus bem entgegengefepten Grunde nicht mitgeben. Eg mübe unter ber 230 ütbe 
Deb Nichter biefer blühenden und loyalen Etadt fenn mit Rebgauntlet zu verfebren, uno bei nir wurde eg heisen: Sag nit, mit wem Dut gebft u. r. m. Da murbe eine Poft nacl) fondon abgethen mit / ber Seituns, swei folche Jacobiten, wie Siejgauntlet uno ich bătten auf dor Jaide eine Bufammenlunft gebabt bie habeas Corpuzafte murbe fuspendirt werden Die Jama mirde von Sarligle biz an bes Landes Enbe in bie Trompete frosen, und wer weis, ber 28 indito founte mein ganzes $\mathfrak{B e r m o g e n ~ m i r ~ u n t e r ~ d e n ~ J i n : ~}$ gern wegblafen, und meinem forper nod einmal in

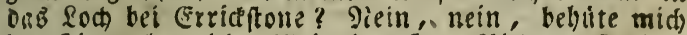
Der f̧immel - id) will in bes frurn. Siliderter Eabinet geben, und einen Brief an siedgauntset fareiben, und Endh anweifen, wie Shr ibn uberliefern follt." "Da ift Dinte uns Geder in den Binmer." fagte

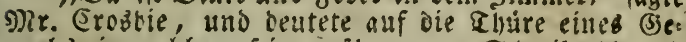
madbs, in weldem fein nubbaumener Echreititio und feit Ditindirder SchranE fith befanden. Eine feber, bie fatreiben fanth, boffe ich? fagte ber alte Raird.

"Sie fann farciben, und ortbogranbifh, beibes in oer rechten Sano," antmortete 5 j)ir. Erosbie, indem ier \&nird fich) jurüdjog, und Die Ehureibinter fich ju= madite.

Ende Des Dritten פ̇andhens. 



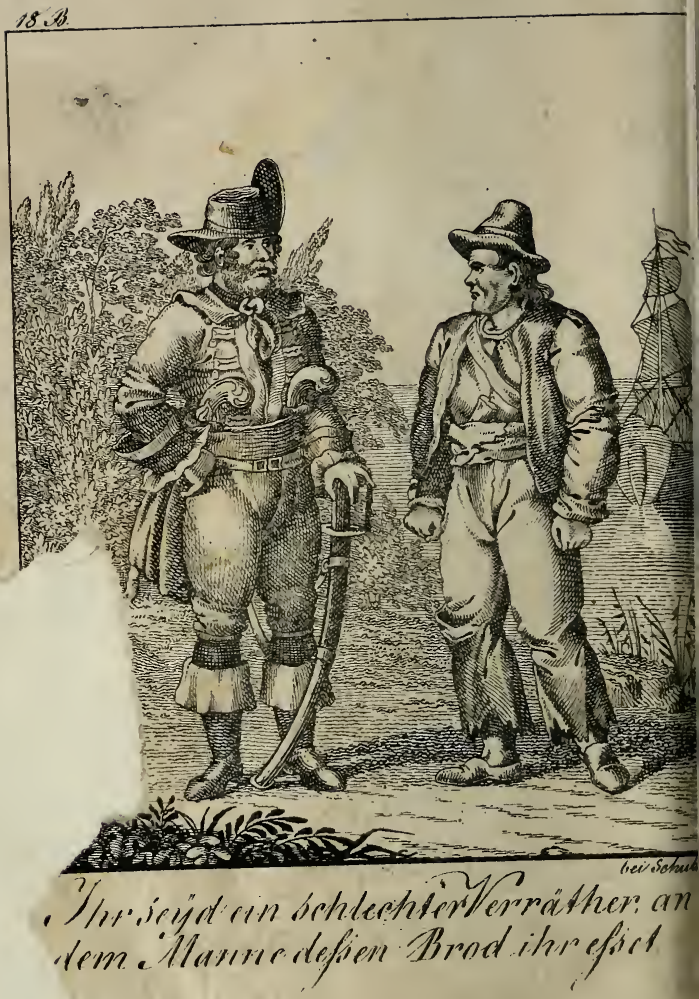





\section{$\mathfrak{l} \mathfrak{e} \mathfrak{d} \mathfrak{a} \mathfrak{u} \mathfrak{t} \mathfrak{l} \mathfrak{e t .}$}

Ex ftes sapitel.

Eefálung von alan gairford. (Sort ţung.)

Mr. Mactwell von Summertreeb batte nicht fobals bав simmer verlaffen, als गRr. Srosbie ägftlid nad allen Seiten binbliate, feinen Stubr didt an ben fel=

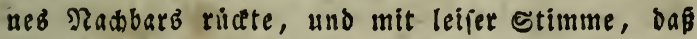

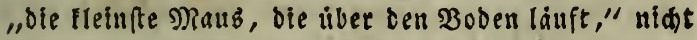
erfaredit worben waire, igm in's Dhe su wifpern bes gann.

" Rr. Fairford," pagte er, "Sgre fend ein guter Juluge, uno was now meir ift, SGr feys meineb alten

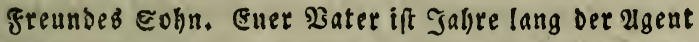
biefer stabt geweren, und bat etwab in unirem Nathe zu fagen; fo find 2ierbindidefeiten zwiftien unz ento ftanden, bald auf ber einen, bald anf ber andern Sel-

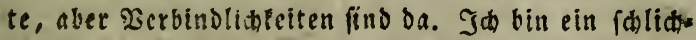
ter maun, me. Jairford, bod id boffe, Igr verftegt mid." 
"Id) glaube, Ghr meinet $\mathfrak{e b}$ gut mit mir, Nr. Erobbie," erwiederte gairforo; "uno fiderlich rountghe Eure (s) bite bei feiner vefiern (selegenlyeit geigen."

"Dra if? is bas ift elen ocr plunft, wobin idis wollte, Nir. Alan; Denn anperiem, bấ ich, wie eb meiner Stellung sufommt, cin fronobafter greund ber

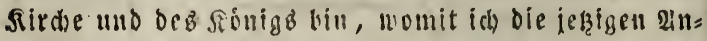
oromungen in ber Sirche uno bem etante meine, fo fonnt Sgr, wie ich fagte, immer rect)nen aif meinen beften - Rath."

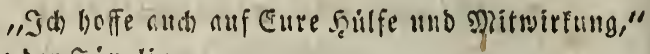
fagte ber Juingling.

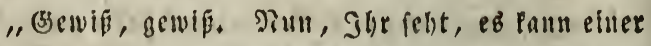
die Sirdhe lieben, ofue eben alf igren duferliden

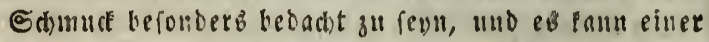

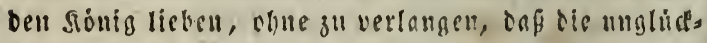

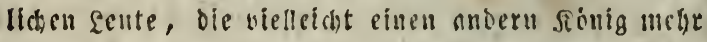

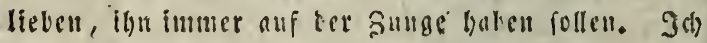
habe frembe und sertindungen unter fruen, Nir. Fairford, wie Encr Sater Elienten balen mag, fie find gleifa) und 3 lut, wie wir, biefe armen Jacobis tell, Gíhe gloamb uni Eunt boch immer, Inio bars um - ich boffe, gibverfteit mich - ich bin efa offe. ner, (d)lidlter sisam."

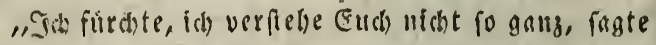
gairford; "1no wenn Shr mir irgend etwab im Gebeim 3" fagen halit, meln thenerer פir. Erosbie, fo wurbet

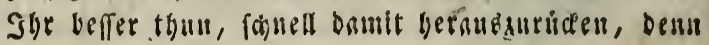


Der sairb muß feinen 3 rief in wenigen Minuten fertig. baber:."

"Bebt nidit fo fonnell, oet spate ift zwar gleich im Siopfe fertis, aber feine geber lauit nicht fo fajell liber bas Papier, ald rein Jagblund riber bie Ebene von Iintwald. Iक gab ihm vorbin eine Stidelrede, wenn Ibre es bemerti gabt; id Eann mandes zu \$ate - im speril ragen, indés ex if meitrer grau nabez 3erwander."

"2iber Euer Ratb; Mr. Erosble," fagte 2Alan, welder begriff, oaf der warbige Ridter, wie ein fdeues Pfero, vor feinem eigenen מorfar zurúcbebte, gerade wenner fï ibm nabern zu wollen foien.

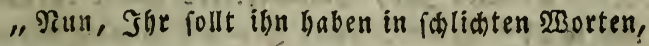
Denu id bin ein folichter Nann. - Seft, id will annebmen, irgend ein freund, wie ghe relbît, wire

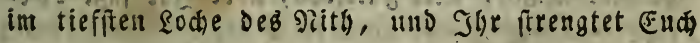

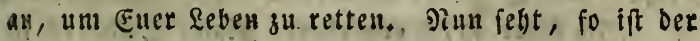
Fall; id kann Eud nidt wohl helfen, id bin ein di. - der, fursarnigter Mann, und fein Gawimmer, was

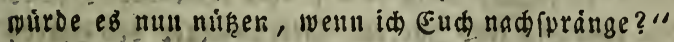

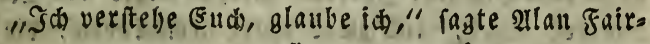
forb. "Ibr glaubt, Darfie Latimer feg in Lebengges fabr.".

"Iक, id lage gar nidatz sarúber, Mr. Allan; aber went ex es wåre, wab id burdaub uidht glaube, ro fliest ia Eein Iropfen $\mathfrak{B l u t}$ von ibm in Euern arbern, Mit. Alan." 
"Sber bier bietet mir Euer Freunb Summertrees einen Brief an an biefen sebgauntlet, wab fagt IGr baju?"

"Ih, sir. Alan, id fage gang und gar nichto

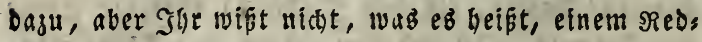
bauntlet in's ঔefidt zu feben; verfut es nur einmal mit meiner grau, bie nur eine von ignen im vierteu

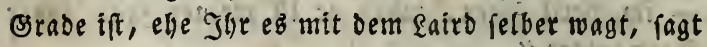
nur einmal etwaz von ber Revolution, und febt, wie fie Euth anblickt."

"Die Schuffe von diejer Batterie úberlaffe id Eud alle, Nix. Srosbie, aber fpredt (Eud) aub, wie efa Dann, glaubt $\Im$ br , Summertreeb meine es ebrliđ mit mir?"

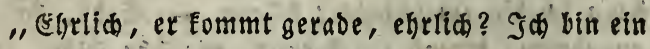

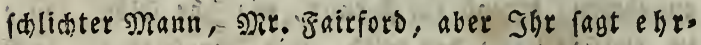
li $i$ ! ! "

"I由 fagte fo," erwieberte 2Alan, " und eb ift

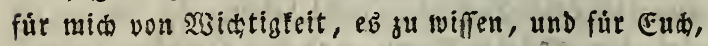
es mir zu lagen, wenn dem fo ift, denn wenn $\$$ be eg nirdt thut, fo feyd Shijein Mitichuldiger bes Mierds vor ber ghat, und swat unter ltmitanden, bie bie Sache einem boebebaciten Niorbe nabe bringen."

"Norb! פBer furicht Denn yon Noro, fagte ber Riçter, dab ift nicht zu fúrdten, Mr. 2Han, nur wenu ich an Eurer Etelle wore, um gang offen gu ipre. wen," hier naberte er feinen Nund bem shre bes jungen Niectrgelebrten, und nac einent rochmaligen 
"Iक) leifte (E) (s) gen, suf einige Unhequemlidfeiten aber múpt $\$$ gr (Eud) gefát machetr."

"Diefen will id midt) untersieben und ber (3efabe mutbig entgegentreten."

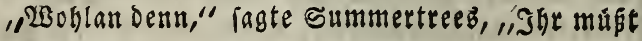
nach - - "

"Эक will (E) allein laffen, meine ferern," pagte Mr. Erosbie aufftebend, "wenn Sbe mit Eurer Sache fertig fend, fo findet Sbe mids ain Ilyeetifd meiner Frant."

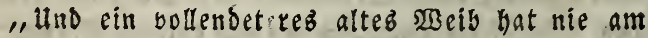
Ibertich gefeffen," fagte Marwell, als jener bie shure zumachte; "Oableste 23 ort trifft ign, fprect)e es wer eb will, uno Dod, weil ex ein idlangenglatter Serl.ift, weil er auf eine gute weife von fich felber zu fpreden verifegt, gute sierbindungen bat, und befouderg weil man nie no d) aukfitiden founte, ob er wois ober Tory ifi, bat man ifn fohon zum britten $\mathrm{mal}$ zum gichter gemadit! Doch zut ङade. Diefer Brief, Mr. Jair, ford (bier úbergab er illm benfelben verfiegelt), ift,

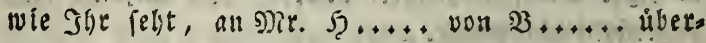
fdriebra, und enthált Eure כeglaubigung bei bierem Jgern, ber auth unter feinem gamiliennamen গeds gauntlet befannt ift man abrefilit aber fe!ten bie Briefe an ign unter diefem ?amen, weil er in einer

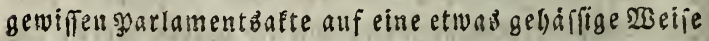
erwágnt ift; id sweifle nicht, bas er Euch wegen Des 
Der Annahme biefer Bebingung móglider $\mathfrak{W}$ eife $a b=$

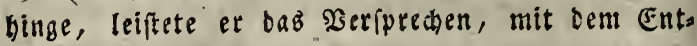
fđluffe, ez zu balten.

"llno nun, Sir," fagte er, "wobin foll id mit Diefem Briefe gelgen? Sit DR. Şerrieg zu Brofens burn?"

"sein, und id slaube, ex wirb audi nidat wies Der borthin Fommen, bis die Sade mit ben Etec"s

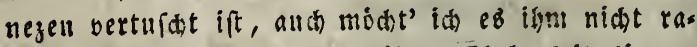
then; Die Duafer nit aller ibrer EGrbarfeit fonmen ibren sroll fo lange belalten, alb andere Leute; und ob id gleid niat die STlugheit bes Mr. Erobs, bie belige, ber nidit wiffen will, wo fich feine Freunde im llnglüce aufbalten, bamit man ign nidbt vielleidt aufforbern módte, zu ifrer ஒefreiung mits

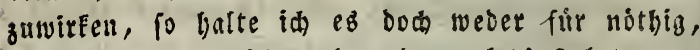
now fúr Flug, mid) nad Reogauntlets Fahrten zu erfunbigen, fonbern id wuinfste, mir bolfommene

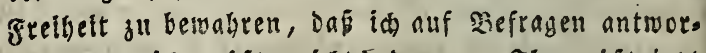

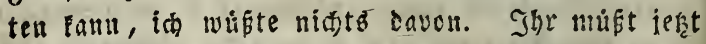
nac) dunan zu bem alten Rom Trumbull gelsen, Den bie Rente Tom Iumpenny nentu, nub biefer welp entweber wo Redgauntlet if, ober fann (E) einell flugen sath geben. Shr mùt aler wiffen, Dap ber alte Iurmpenng (Ead) auf leine Frage ber art slutwort giebt, wenu $\mathfrak{J}$ hr nidt bas Erfenmungz. wort allsipredt, inoem 3 br igl: naw bem Etande bes Monder fragt; wenn er antwortet: nidit sidst 
gentig, um eine Labung an's Sand fu bringen; Dann fagt Jur: Sum Senfer benn alle Salender von 2lberbeen! Dann wiro er frei mit Euch fprechen. Nun aber modt' id End ratben, feitte 3eit zu verlies ren, senn bie sparole wird oft gewectielt, und nebmt Euch unter Diejen Niondidipuriden in 2 at, benn rechte und siechtrgelebrte feben nidit bod in igres (s)unft."

"Э由) will im 2Augenblid" abreifen," fagte ber iunge grovofat, "fid will nure erft bef Mr. Erobble und feiner semablin mid verabidieden, und bann io balo binwegreiten, alb ber Şausfmedt in Beorgb 3)afthof fatteln fann; was bie Ed)muggler betrifft, io bin id weber sollanfieber, nod alccifebeamter, and wie ber saun, ber dem Ienfel begegnete, babe. id) ifnen nidis zu fagen, wenn fie mir nichts, fas zen wollen."

"She feyd ein wackerer junger Nann," pagte Summertrees, altgenfdeinlich mit wachiende: $\mathfrak{B o r}$, iebe, sa er an 2llan eine গanfdheit und retactung. ser (sefabr bemerfte, die er vielleidst von jeinem dubieblen uno Esewerbe nidat erwartet batte; ",ein. edbt wackerer, junger Mann in ber gbat! Ino es.

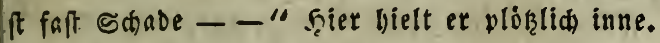

"28ab ift Sdabe?" fragte Fairford.

"Es ift foft ๔anabe, Dap id nidit felbft mit. ₹ud gehen, oder (E) wenigfteng einen'vertrauten jübrer geben Eamu." 
Sie gingen nun mit einander in $\delta a b$ @alaf: Simmer bez Nr. Erobbie, benn in biejem sufluchts. orte fervirten in jener zeit bie Damen ben ithee, wenn baz (s)efellihaftz̧simmer von ber sounidbowle eingenommen war.

"Ilye feyo ja rect mäpig gewefen, meine f̧ern,"

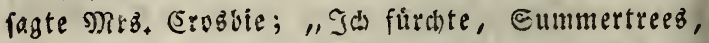

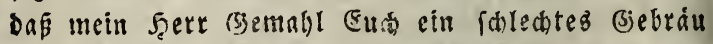
yorgefest bat; ghr feno fonft nidht gewobut, bie Yunidbowle fo balo im stich fu laffen. (E) fage i.) nittz, Nir. Fairforb, benn Slir fend now zn jung, um lange fort zu zeten; boch id boffe, She werbet ber feinen welt in Evinburgh nitt fagen,

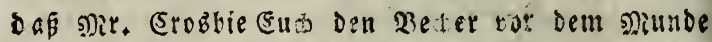
wegnalm, wie es in bem Riede heipt."

"Ih bin Jhrem J̧errn Bemabl und Shnen, Mabame, fehr verbunden fur Shre Brite," erwies berte Ilan; "Die 2 babrbeit ater ift, it) babe no

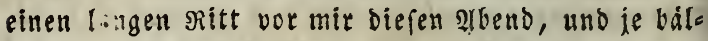
Der ith zu Pferde bin, befto beffer."

"Diefen abend?" fragte Mr. Erosbie angfts (id); "ware es nicht beffer, NRorgen frúl, bei sage seg zu reiten?"

"Nr. Fairford wird eben fo gut in ber abends lủble reiten", fagte Summertreeb, inbem ex Alan Das. Wort aus bem Munde nabm.

Mr. Srosbie fagte nidhts melle, und aud feine fran that feine frage, und beseugte fein Frfau.

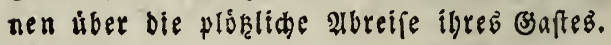


trabtungen wábreno Deb Ritts waren niabt bie ans genelimiten. (Ex fonnte fid nidt verbeblen, dáp ex ein wellig gar zu Feck fit in bie (sewalt geadteter und verzweifelter 刃ienfhen gebe, benn mit folden nue Fonnte vermuthlider $\mathfrak{2}$ eife ein Niann in Nebgaunt. lets sage verbundet feyn. Auch an andern urfacten zu Befurdtungen feblte. es nickt. Silanz fharfer Beobadtung waren verfaiedene Beictien von Einver.

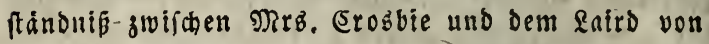
Summertrees nicht entgangen, und es war offenbar,

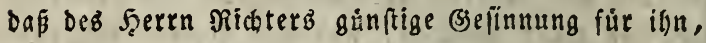
Die er fitr aufridtig und gut gemeint bielt, 'nidt feit genug war, um bem Einflus ber Seebindung swifden feiner Frau und feinem Freunde Saiderftatd zu leiften. Mr. (5rozbie's Lebewohl war wie Mac.

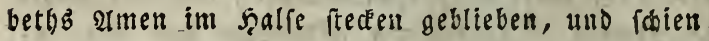
anjugetgen, daß er mebr befurdte, als er zu áusern (iid) erEủignte.

Diés alles zufammengenommen, dacte alan mit siemlider atengftidafeit an હbafespeare berabmte seilen

\section{- 1) Sin Trovien}

Im Dcean fudt einzn ansern Trubier,"

Bebarrlid Eeit war aber ein ftarter 3 ug in bez jun. gen Nedtggelehrten (sharafter, Etetz uno aud ję̧t war er einem hizigen şferbe ganz unábnlid, weldes vor Nittag burch -zu grofe 2uftrengung am Norgen ermuibet. Im Segentrieil fdienen feine erften $\mathfrak{B}$ es míbungen, gur Erreidung feines 20 orhabens nidt.

binee. 
bet ait bet Eee war. EB ftand in eiller fleimen

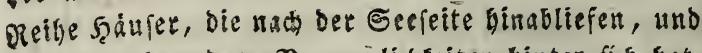
(3) drten uns andere Bequenticheiten binter fic bat.

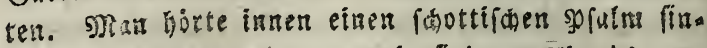
gen, wab Der Ronbe fegte: Sie find an arbertojegen, and gab zu verfteben, dás man fie por Enbigung Deb (5ebets nicht cinaflen waitoe.

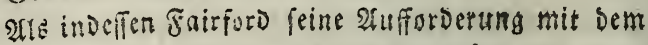

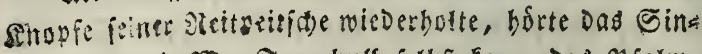

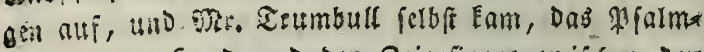
but in Der SamD und ben Seigefinget zroifder Den

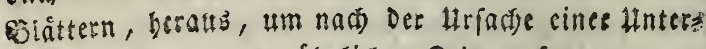
bredung jt fo ungemdinlidyer Beit fu fragen.

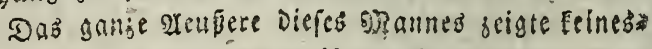
wegs Den Sijertrauten berjweifelter Dienf foen und Den

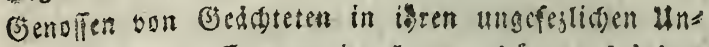
terne:munjen. Es war cine lange, idnut, beingte (5) effalt nit scifiem Jaare, Das auf allen Eritert

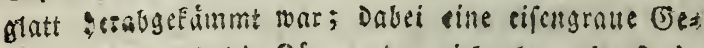

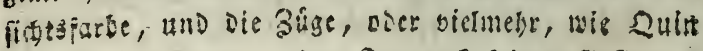

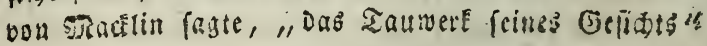

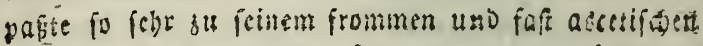

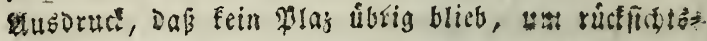
lofe Recésit oder follaue Nerftellung su bejeichnen;

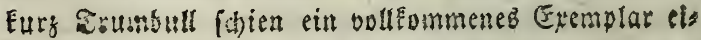
neỏ farcen altent Eonvenauters, Der aur bas fagte,

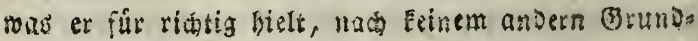
fas, als nach Dem der siflicht bandelte, uno winn ex 
irrte, fo gefdonh es mit ber bollen Heberjeltgung, Daß er Bott mehr Diente, nlz Den snenfor)en.

" Sicrlangt Jhr etwas von mir, Serr?" fagte Se Jll Fnirford, Deffen fübrer bercits Den gilicfiug arigetreten batte, gleidffam um Dcm Tadel bes ftrert. gen alten Mannes zu entgehen: "SGir maren beidoffo tigt, und es ift Samfrag atbend."

Slan Jairfords vorgefopte gheinangen Fnmen Durci) Das steufere uno bns Stenehmen dicfes man

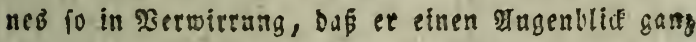
versukzt ba ftanb, und einem esciftiden, der elies von ber sanjel ftieg, eben forebl ein fonderfaces Erfenmunzenost zugeraunt bátte, als betr natungts. merthen familienoatel, bes gerase in feinem bebet fure und mit ber Gegenftúber feinet Ecrge unters

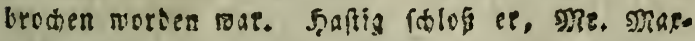
well babe einer diel angebradten sors angefpro dett, oie? vielleit? fey et an bie unedite perfor getwiefen roorben; er fragte baber, ob et mit me. Rrumbull fprede.

" Nit Rhomas Erumbna," misortete sel alte Mann; "gुas ift Euer Begebren, Şer??" nno

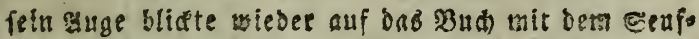

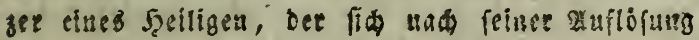
pebut.

"Tenut Thr MR. Marwel voa Summertre? ?" fagte sairforb.

"Iक babe von einem folben colman anf ber

$$
\text { - } 2 . .
$$




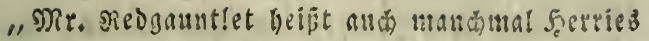

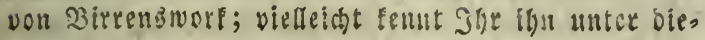
fem Man:en."

"freuno, gir feud mabifich," antwortete Ir. Trumlutl; "ebrliche sente baben genng zu thun, eis nen गamen unbefect zu crbalten. Ja) Feme uies

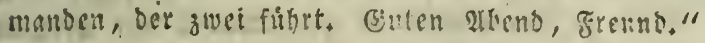

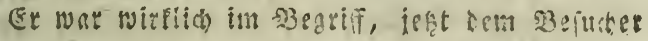

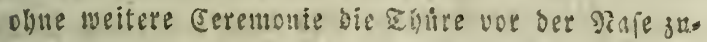

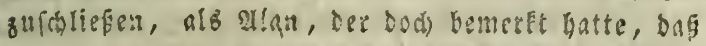

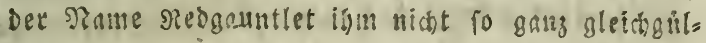
tig fey, ibu einen atugenblide sufbelt, uns mit leis

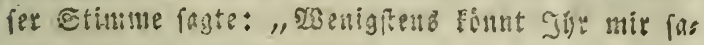
gen, wie Der Mrond Ptegt."

Der alte giann erichrak, als mate et verjucket, und elge er antwortete, fable er Den zrager mit eis nem foraren Dutboringensen'Blice an, Der zu fos

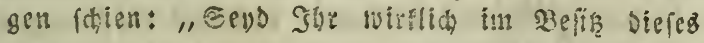

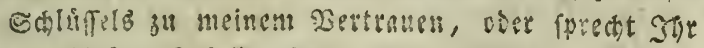
a!s blopem Ratrall po?"

Diefem fonten forfidenden Bride antwortete Fuivford ourch cin Eistoln seb Cirverfandniffer.

Die eifenhaten Mnbeln in bes alten manneb

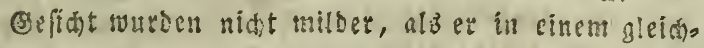

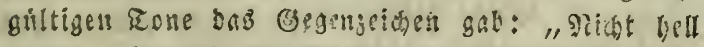
genug, eine Rabung a!n'b Lanb zu britgen."

"Sum fenter cenn alle Silender von gloes. Deen!" 
1) Und fum henfer venn alle शarren, bie ihre Seit verbersen," fagte Thomas Trumbull, "Sionn: tet shr mit bas nidt gleiti anfangs iagen? Ino wit freben auf oer offenen Strafe on, fommt berein."

Fe zrg den Fremben in oen ouneln Eingang bes Salifes, und fhlof die Thure forgfóltig, Dann fedite et feitra sopf in ein Simmer, aub weldem

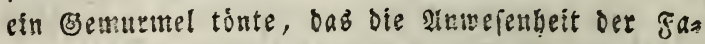
milie sarin verfundigte, und fagte laut: ein $\mathbb{B}$ erE

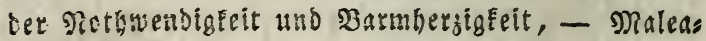

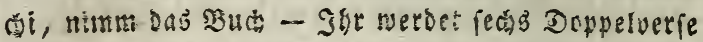

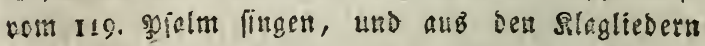
leien. Has Du, Malescol," fagte er in einem reis fern $\mathbb{x}$ cue, , Du wirf ibuen faon etwas borpres bigen, defí es bouert, bis ión wieder fomme, fonif geben mit die unborfichtigen Rurice aus dem Şaus ie, und in ten Cibenten umber, verlieren ifre

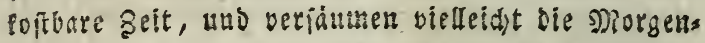
futf."

Eire unverfandito Intwort von innen seigte Mareadis Bereitwinigfeit an, iem Befeble fu ges borten, uns ga:. Teumbull murmelte fo etroas vor fich bin, als cr bis Eblice folof: "feft gebunben,

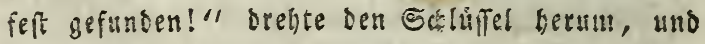
fecte ifan in die Taiche; sann bat et feimen (B)afi

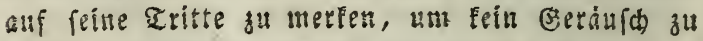
matien, fubrte ign outa ons gaus und su einer Sinterbure binnus in einen Eleinen लsarten, Şlet 


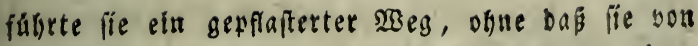
einem sachbar gefeben werben fonnten, zu einex

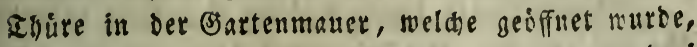
und ein geheimer Eingang in einen Etall von bret 2atbeilungen war ; in eiter berielben ftand ein Dferd,

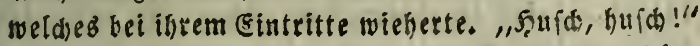
rief bet alte Mann, und unterftų̧̨te jogleid) feine

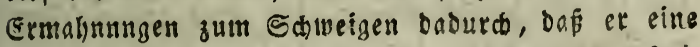
Şandvoll 5afer in bie Srippe warf, und Dab yierb verwandelte bald ben Erfennungblaut iffer segeno wart in ben sewobnliden deb sermalments feites - gutters.

Da eb faft ganz ounfel getworden mat, folofi ber alte Mann mit weit mekr Bebendigfeit, als man bon feiller ftarten figur batte ermattea follen, bie feniterlaben in einem sugenblia, bradte phospbos,

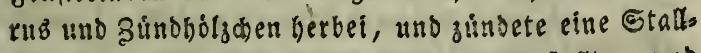
laterne au, Dic er auf ben Futterfaften ftellte, uno wandte fid Dann zu gairford. "2Bir find hiet alleil, und on faron einige seit verftricten ift, fo feyd is gutig, mir Eure Botidaft zu fagen. Sft ez ein

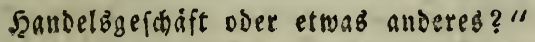

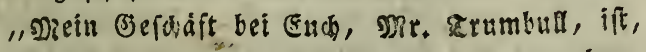
von. Euc fu verlangen, mir bie פittel smjugetien, wie id biefen $\mathfrak{B r i e f}$ bon Mir. Mraxivell von G:!nmers trees an ben faird von Эiebgauntlet úberliefern finn."

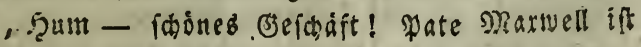
Dod nod immer bet alte - immer prate in soeril, 


\section{4}

Eraig - in - speril, fo weit id ibn fenne. faft midh feinen Brief fehen."

(er unterfuble ijn mit vfeles Eorbfalt, wanote ifin bin uno ber, uns betrachtere bejonvers sas Eies gel febs alfinertian. "Hlles ift ribtig, wie id res

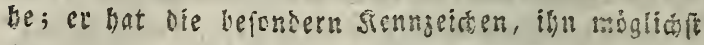

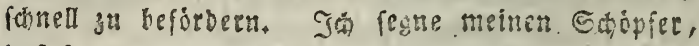
Dafich feil grofier mana oder eimes gropen sians nes Benoffe bia, und fo bente ín bei biefen seilen

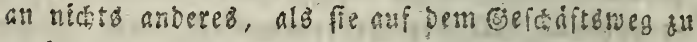
befortern. Shr reyd woht in Diefec cjegend gans fremo, vermutbe ich!"

Faitford antwartete bejabers. Ia, ib bate fie

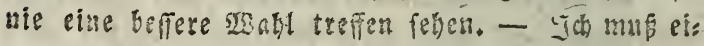
uet rtifen, Det Eud Irnleitung gibt, was She thun

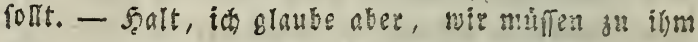
seben. Shr feyd mit fehr weht empfoblen, fremb, uno olye sweifel ans guten ertinden: Sor follt

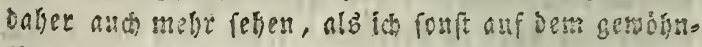

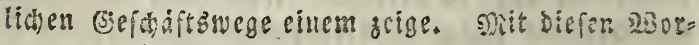

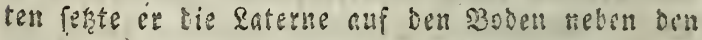

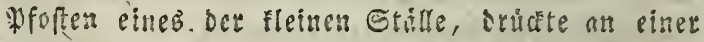
Eleinen feder, die benfelben ouf bem Doien fefriclt, und. forob nun Den sofolten auf bie eine Geite, uns entigidte eine fleise galltyire. "Folgt mix," fagte

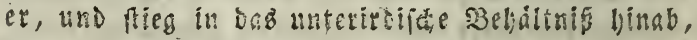
wobia diefe gelineme Definumg fügrte.

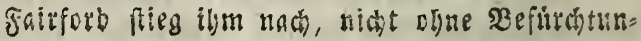


nidit jum Bebet gefommen, Şiob, unb es ift Dod Eamitag attent?"

"Swanston befractete die Jeuny, Sir, uno

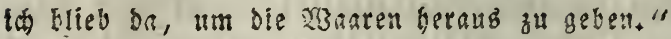

"Nithtig, - ein Where Der Netotyensigfeit auf bem (Beichafturge. Segelt die tanzenbe Jenny mil Der fluth?"

"Ia, ia, sir; fie pegelt nac - - -"

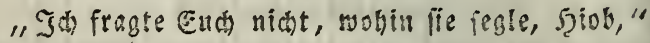

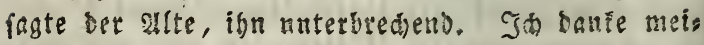

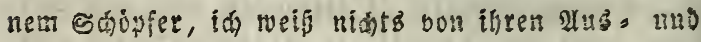

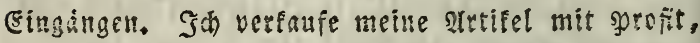

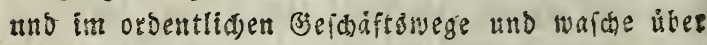

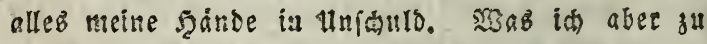
wiffen winicte, ift, ob bet frert, ber ber saito ver Solvay = Geen beift, eben jest auf ber andern Seite beb liferz ift?"

"Ia, ia," fegte Şiob, "ber zairo ift fo ets

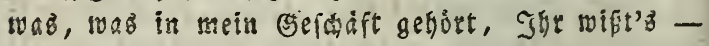
efn werig Eontrebano, oder fo; eb sibt eil Ftatut fiber iga - aber dab macht uicts; nad det (je.

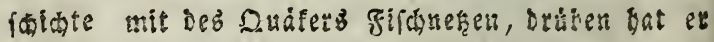
fic aub sem Staube gemacht; bean er bat ein rebo

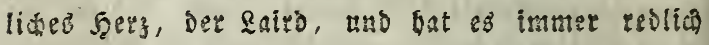
writ dem sande gemeint. Hber wie! ift bern anch

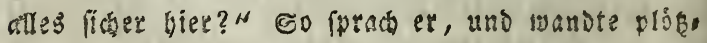
Itd) bie Richtfeite ber Raterne gegen Han fairfors,

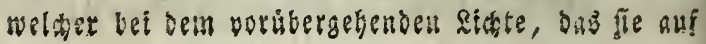




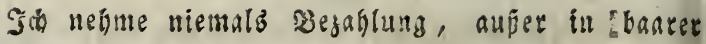
D?uue."

"In, ix," murmelte oer mit ber Saterne; "Euet

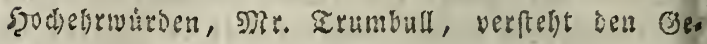
chif tif biveg."

" Noun, ich boffe, Shr follt noch eines Tagb eto fahren., Şiob," antwortete Nr. Srumbull, "mas ber Sroft eines reinen esewiffens ift, und niwt nothis gu baben, 2lufpaffer uns Eontrolleute, a citz uns 30 d

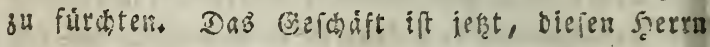
wegen enes ermiten (S)efdaftb nad (Emberland zu briagen, uno ifu eine unterrebung mit bem fairb

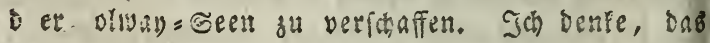

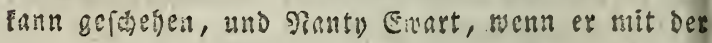
Brigg bei ber Rorgeniuth abfált, ift ber Narn, ber ijn glit fortbringt."

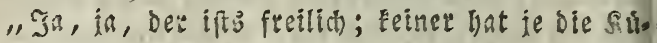

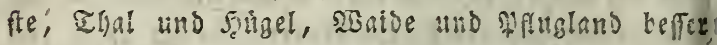
- gefonnt, als santy; umb ber fann ign imster zum Rairs bringen, wemu She fióner feys, dafi eb mit tem

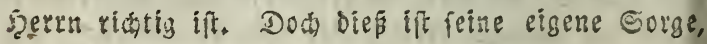

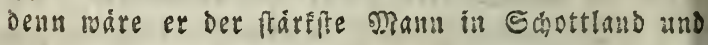

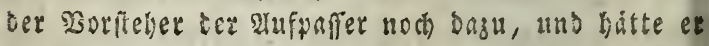

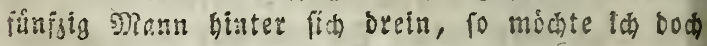
sidet tutben, ben fairs anders, alb in outem, eis

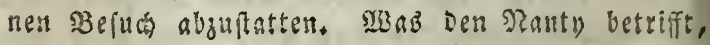

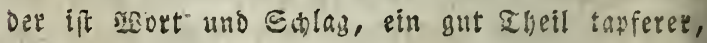
alo shrific sityon, oon bem fie sinen fo gropien fär 
ruhis fhlafen fonnt, bis er (E) ruft. Die wenigen Sachen, bie She beburft, will id Euth beingen, benn bie, bie auf foldge Botfonften augeben, durfen mide

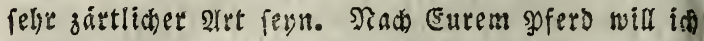
felbft reken, benu ein mitleibiger Renich ift ouch mit, leitig gegen fein $\mathfrak{x i e h}$ - bas wirb auf unferem (s)e foditsweg alljuft vergeffen."

" ST3ie, SDeifer Trmmbun," erwieberte Şiob, 5, Igr wift, wenn wit gejagt werben, bann ift nide Seit, die Segel eingujiegen, uno bann reiten bie

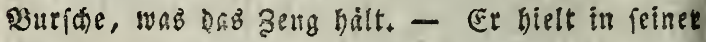
Siebe an, of er fah, Dap ser alte Jann bur. bie

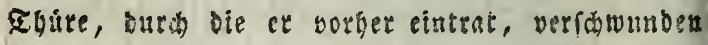
nat, - fo matro der alte Eutnpenny imster, fagte et zu faitford; vom ganget f̧andel frimmert et-fich une un ben grofit, - uns jum zeufel, bas ift ime

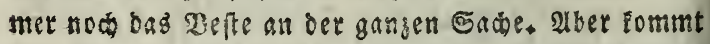

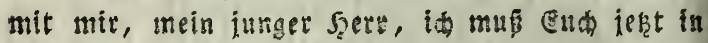
Giderbeit bringen, bis es zeit ift, an 20ob za geben."

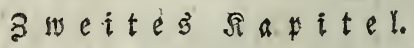

Ergablung vor atan gatroto. (T):tresung.)

gairfors folgte ieinen murrifden Fubrer surd cir fabveinth won fiffern und $\mathfrak{B}$ allen, an welden er 


\section{2}

In biefer sage wat eb allanb erfteb Giefdidf, Den Drt, wo ex fich befato, mit einiget senanispeit su unterfuchen; er purtete aljo sie Lithter, uno gims bann langfam in bem (s)emadye unfer, indem or sab Aeupere und die Anbol)ung gemau betractete. (8) faiten fo ein fleineb Speifezimmer zu fevu, mie $\mathrm{cb}$ gewolgnlic in oen feruiern ber beffert slaffe bon sand werfern, Sileingándern mo bergl. fin befindet, Gatte am obern Ende eine pleine qlbtheilnus, worin fith Die

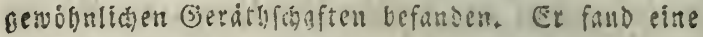

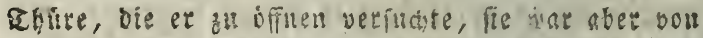

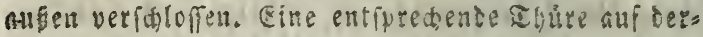

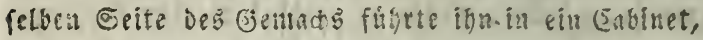

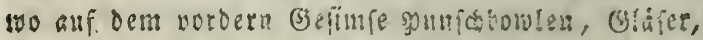
Ebeetafiet nut Dergl. fich befanten, wabrens ouf des

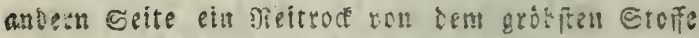
bing, zuei grope Beiterpifrolet fásen aus der-Th=

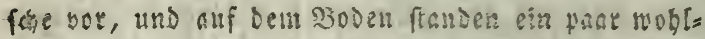

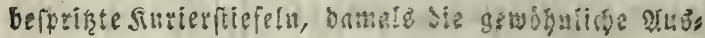

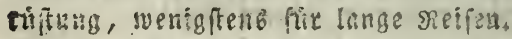

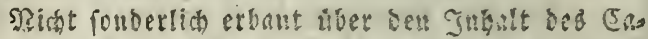

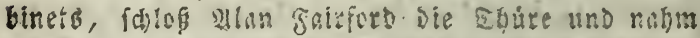

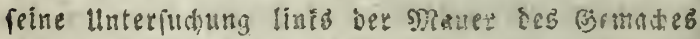
mieder vor, um gh entdelten, arf mel Siob Dutleoge entferrs batte. Dat geteime 2urd

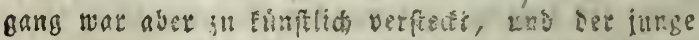

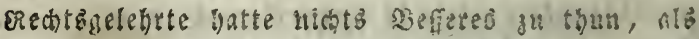
aber feine fonberbare sage matsusenfen. Er batse 


\section{4}

einem Singling von einer fo frommen Ergiehung be, fonders unangetegm cuffofen mupte), onf der graus

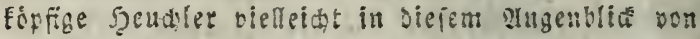

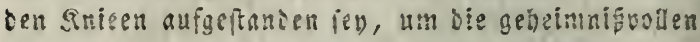

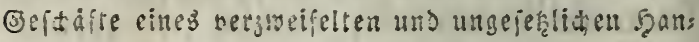
bels jut betrellett.

Det alte Mrann, gersobut, mit fdarfem Bifid die Phyliognomie berer zu keuttheilen, mit denen er

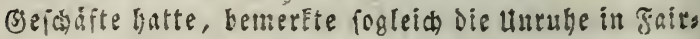
forb's Benehmen. "Feut es euch," pagte et. "sisnlt She ong gierd wieder abjattein, und das şagitica" aufgeten?"

" Primmer," Fagte Fairford feit, gereigt fowost

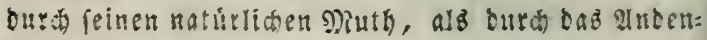
Eelt an feimen frelud; "nimmer, fo lange id lete uno Seaft habe, es binassufibren!"

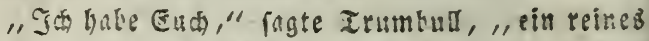

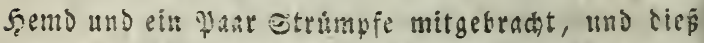
ift alles Gs?ad fornt; aut wia id's einem yon ben 3 urider fagen, Daser Eud einen Dieitrod leigt, denn olgne einen icls den fommt man ju Sdiff und zu sperse nitit mit fort; uno was Euern Mantelface anfelangt, io if et in meinem armen jaure, auФ wenn er mit (sold ans Dphir gefuit ware, fo lïter, alz in ser Eiefe einez ङ̦atts."

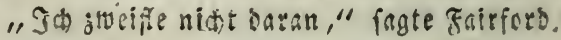

"Hno mat" iagte Irumbut wiedernm, "litte 


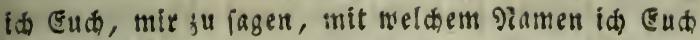
oem S?anty (2utonis) Ewart nennen foll."

"Alan sairforb beíze id :"

"Oas ift aber," fagte Erumkulf, "Euer wirflis der నot = uno Sumame."

"ltus welden anoern folle id getien," fagte ter junge Rann, "glaubt Sgr, id bitte llriace, einen an: bern zu wảhlen? Und Dabei, gRt. Itumbull," iek̨te भlan birzu, indem ex olaubte, oaß ein wentg Epott

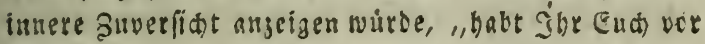

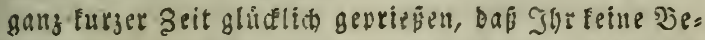
Eanntimaft mit benen battet, deren s?ame fo berrufen rey, dap fie genothigt waten, citen andern zu waten."

"Drabr, feitr wafie," pagte sir. Trumbul, "bennow, junger snanu, trage id meine grausn

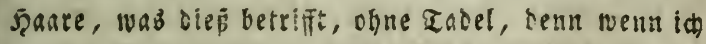
in meinen (seidadten unter meinem sorinjoce uno meinem geigenbaum fiçe, unb bie ftarfen 2 affer bes Porden gegell das (5jols, Das oafü bezablt wird,

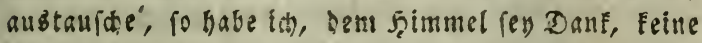
פerfappung notbig, unb trage meinen eigenen $2 i a=$ men, Igomas Trumbull, obne cefabr, deafellen zu beffeder. Du aber, Dèr Du alf fullammigen sigegen gebit, Du witroft wobl thus, zwei Jiamen sa bas ben, wie Du swet fremben baft, am ong eine outch Dab andere rein zu balten."

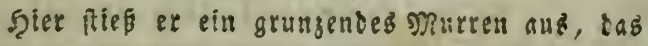
genau zwei sondeliawingungen bauerte, und bie eins 
jige stundberung am Eseldater war, Das firb ie ber alte Eurnpenuy, benn bié war feil Epintame, ges fiatete.

"silr feyd wisis, Mat. Erumbull, fagte gait:

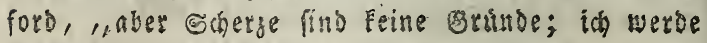
meinen eigeren Tamen belalten."

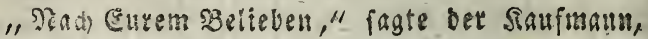

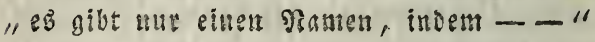

$23 i t$ wollen bem seuchler nist buth bie ungeilige

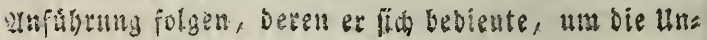
terredunz ou ristiefien.

Qular folgte istu in finmem, forwaigenoem aiba

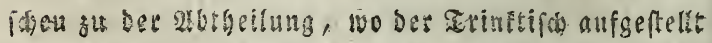

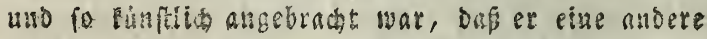

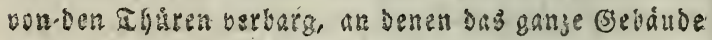

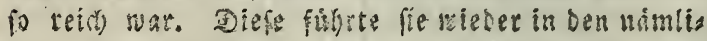

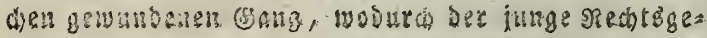

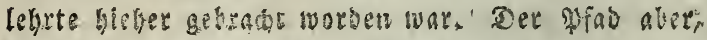

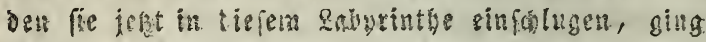

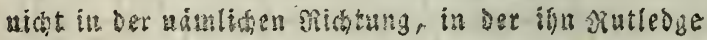
gefinte Gatte; or fibrte aufwirtb, who endigte an einent Dacifenfter. Erambull sfifnete $c 8$, แno mit

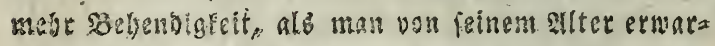

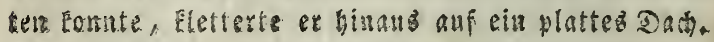

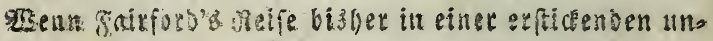
texirofiten sumofigite fortgebangen mat, fo wat lie

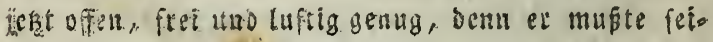

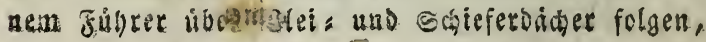


freut, fo nafie vor bem Elatritt bes Eabbaths folden

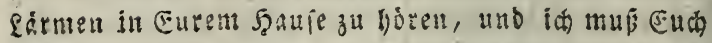

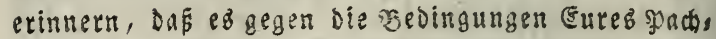
teb ift, welwer verlaugt, Dafi She am Gamptag fpats

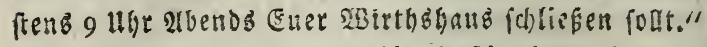

"Sa, Jgert," ragte Jiobin Şafitie, Durch Den hefs tigen Tarel feineswegs beuntuhgt, "aler ght mápt bedenten, bafich feit 9 ubr Paintanden mebr Gerein, gelaifen babe, aufer Eut, ber fid relbft eingefubrt bat; Denn die meiften fino fosen reit mebreren Etun. Den lier, um bie 2 rigg su laden, u. f. w. Es ift

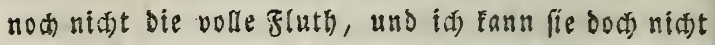

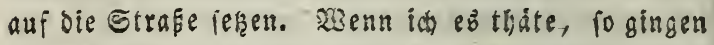
iie zu eimem andern wirthbisas, und um ibre Geelen whirbe es bephalb nid)t beffer fiegen, un meinen Deu=

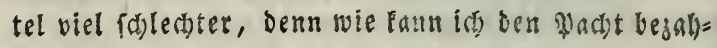
(eir, wern

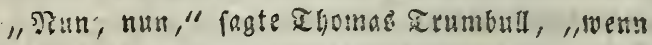
ez ein Wert ber Nothwendigect if und auf bem eh: :

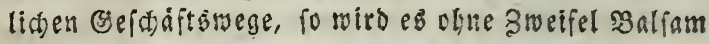

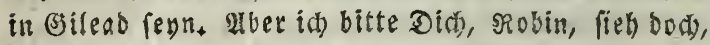

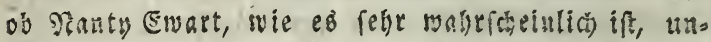
te: biejear unjeligen Irmeenbolten fid befinoet, uno wemu et da ift, fo fag igin, ex foll rorfictis bersufs fonmen, und mit mit und biefem sinnn da iprecter. Und ba es nicht gut ift, sobin, beim Gpreden fo tres

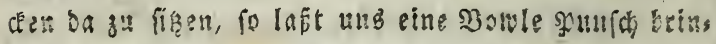
sen, Sgr wift eg, wie icis's liebe." 


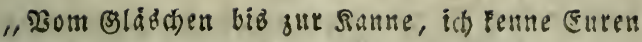
(Sefdmade, Mr. Tlomas Erumbull, " pagte der Sairth,

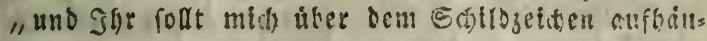
ben, wenn ein Eropfen mehr Sitrone ober ein Siorms d)en weniger suder oriunen i ik, als 9 br es gerabe liebt. She feyd Eurer Drey, da werdet 396 woht oab

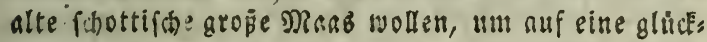
liche Relie z" trinfen."

"Beffer Dafit beten, alb trinfen, Robin," fagte Nr. Trumbull. "Ener (s)ewerb ift gefátrliá, Rebin,

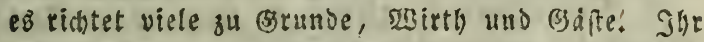
werdet abee die blate sowle ulgmen, bie blate 30 sts le, die wirb ftom allen Durft vertreiben, und ole fund.

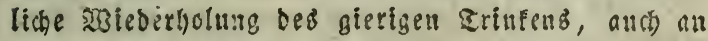
einem Samfragabeno, vethinbern. Sa, Nobin, ebift Ediabe un Ranty Ewart - Panty liebt bod auch, feinen fleinen finger maf zu maden, unb vir mollen ifu nidit hindern, sechis, fo lang et noch suth steuer, mann serftano betalt."

"Pianty Ewart feuert Euch bur ben gुentland.

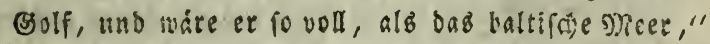
fagte Robin fraftic ; fo trippelte ex im sugenblice bie Ereppe hinab, Eebrte aber foglein's guride mit oen

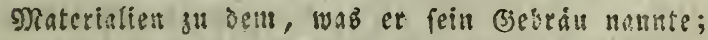
Diefe beftanden aus zwei englifhen Duart: Bramm:

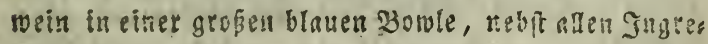

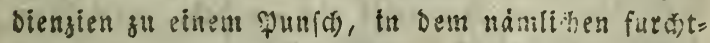

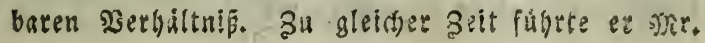


Intony oder গanty Ewart ein, Deffen goerfon, obgleids ex fdon ziemlid vom Brantmein betumEen war, gaits fors's Erwattungen Denno betrog. Eefne Sileibung sont, wab man fo ármlich anitändig nenat, ein Track mit verblichenen Ireffen, ein fleiner fed aufgefę̧te:

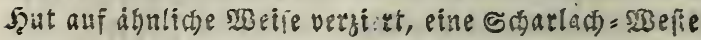
mit veridjabter હticferei, bergleidjer F̧ofen mit fils bernen sniebandern, und dabei trug er einen guten

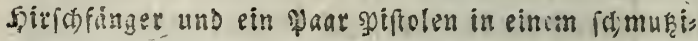
gen s3e

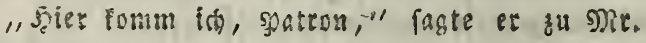

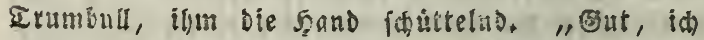
fabe, She babt fơ on etuab es:og an Bord genommen."

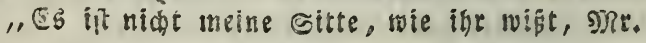
Enaro," fagte ber sutte, "fo fpat am samitag

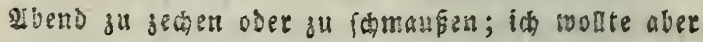
Eurer elufmertiamett nur einen jungen greunb ems Pejlen, ber auf einer befondern Reife begriffen ift, mit eirem griefe an unfern greuno, ben faitd von Yate - in - Ylesil, wie man inn nennt."

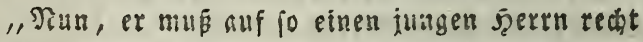

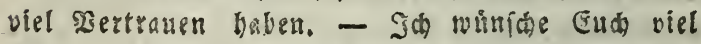
Blưce, Sir," fagte er, fin gegen fairford berveus gens. "Bei unfrer Frau, wir Elatebpeare fagt:

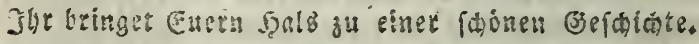
somm, syatron, wit molien eing trimen auf peine

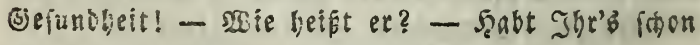
gejagt, uno hab ich's vergeffen?" 
miglta etwas von inger lintergaltung zu sernebmen.

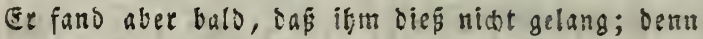
was auch wirflid feine sbren erreicte, wai fo fefir

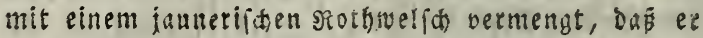
Eeinea Ginn binein brathte. Enblid folief er cin.

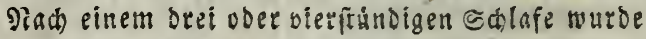
er burd Stimmen aufoeweckt, welde itu baten, aufuftehen und fic zur wbfabet bereit zu maden. Et iprang alio cuf, uno bejand fith not in berfels ben Inftigen Bejelffiaft, die getade mit isker unges beuren Punfobowle fertig gewordea rar. Zu alans Erftaunen batte bab (s)trản nut renig wirfung auf Dab Gebirn von spenflien gehabt, bie gewobnt waren, zu jeber Etunde zu trinfen und in ben un= gewoinnlichiten Duantitaten. Der 2 sirth fprach zwat ein wenig fकwer, unb auch mit ber annge Des nir. Ehomab Erumbull wolle es nimt recht fort, Tanty aber war einer von ben ธálufern, bie frike bas wars Dea, was mat Bonvivants nent, und Eag und

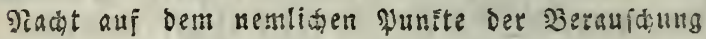
bleiten; Da fie aber felten gans nucbern find, find fie ald eben fo felten gans betrunfen. Itnd in bet Iyat hitte fairfors nidt gersust, womit Enart

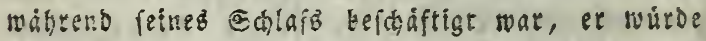

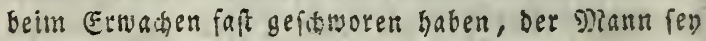
แน์ต

Eer warbe in biefer Reinung beftánt, als fie in bas untere simmer Gimazinata, wo zwei ober 


\section{3}

Drei Matroien und Epizbubengeficter auf ibre $\mathfrak{B} e$ felgle warteten. Ewart nahm bie ganje Leitung auf fit), gab felue Befelle mit Siurge und Beftimmtbeit, und fab Dorauf, ons fie mit ber Etille und Edinal. ligleit vollgogen wurben, wie eg bie befonderen $4 \mathrm{~m}$. fránde exforderten. 2llle wurden jeß̧t auf die Brigg gefchicet, welche, wie man fairford zu verficbell sab,

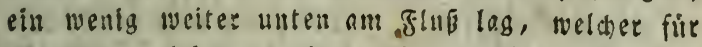
Shiffe vou leidter fabung bis faft eine Mieile oon ber stabt foiffuar ift. 2alb fie aub bem sisiths= baus gingen, ninfdte ibnen ber Wsitth shlü auf ben $\mathfrak{B}_{\text {eg. Der alte }}$ rumbull ging ein wentg mit,

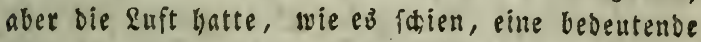
Wirfung auf Den sutitand relues Eelirns geiupert, Denn nad)bem er Han fairford erimert hatte, baß ber nadefte Iag ein Gabbatf fey, crmahute er ifn duserft weitläufig, ja benfelben heillig zu balten. Enb:

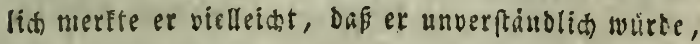

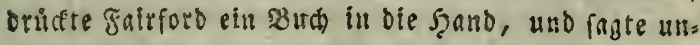

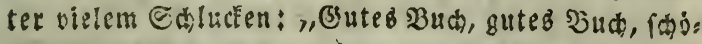
nes eciangbud, paffend für ben morgenden હabbath."

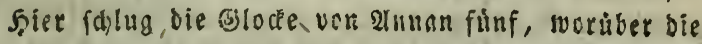

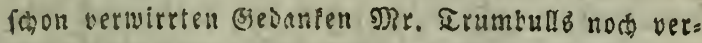
wirter wurden. "Ei ? Sf ber Conatag falon gelom= men und vergangen? Der Simmel (ev) geprieben! Pat ifts erfaunlich, bas ber શactmittas fü bieje Jajirs zeit zu butrel ift. - Der Sabbath ift rabig boriffer

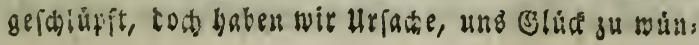


44

faen, das et nicht gans filect angewendet worben ift. Ioth borte wenig von bet şredigt - ein fulter Dororalift ifts, glaube id, geweren, aber- Dab (5es bet, i市 erimere mich, alb batte id die sBorte felbft gejagr." Sier wiesergoite et eir paar @itlen, ber.

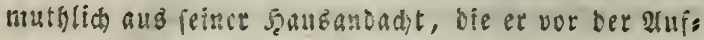
forderung zit dem, twas ex feituen (Sefchaftsweg nann. te, abgebalten batte. "S(i) erimere mid nidht, dab mir je ein aabrath fo gut vorubergegangen vare."

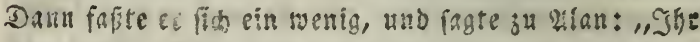
fonnt diefs Duth lefer, mer. Fairford, morgen, es

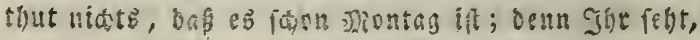

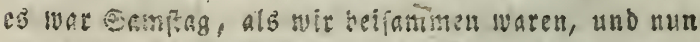
ifts Eonutag unt es if tumfle ?iadt, - fo ift uns ber Eabbath rain surib) die finget gefolupf, wie

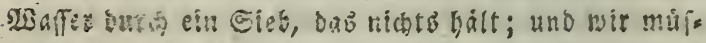
fen mu norgen fruth weder anfangen, in sen mub.

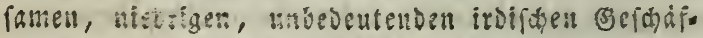

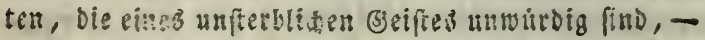

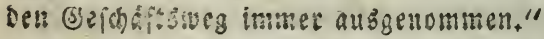

Drei vou Den Senten. Febrten jest nach der stadt

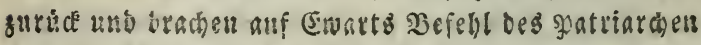
Etmalgnunger furz $a b$, inbem fie ign zurtic maîl feis ner Bebaufung fubrten, Die ubrige Jefell waft ging vormvirts zu ser Bitgg, die mut auf igre anfunft wars tete, um die sufer zu lidten und Den flup bingb zu

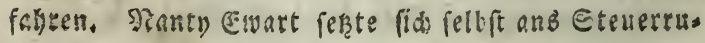
ber, und bie blope Sethihrung baron fotien bie now 


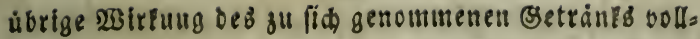
end s" zerftrenen, denn er wuste fein Eleineb Scifif mit ber grópten senaugfeit und Sidsergeit burch einen engen uno gefábrlichen sinnal zu leuten.

2lan Fairford bemulzte eime 3eitlang den bellen Sommermorgen, um bie nod siemlich cunfelu siuften, sutichen benen fie bingleiteten, zu vetradten; als fie aber endid megr und mebr feinen sliden entichwams Den, machte ex' fein fleines গündel zum silfen, wis delte fict in ben Duerrodf, womit ign ber alte Irums

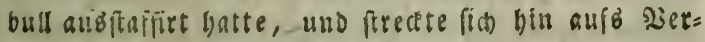

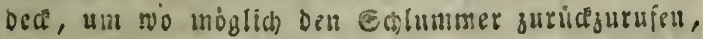
allo bem er exiocd worden war. Saum baite fid ber S๙

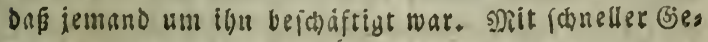

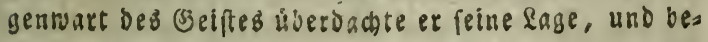

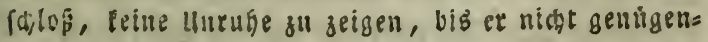
Den (3ruid Daju hatte; er wurde aber bald von frimer. 2usft bejreit, alb ex bemerfte, bapi ber um ibu bes porgte Panty fo fauft wie moglich einen gropen ङdifs fermantel um ign fisluy, Damit er gegen die slorgen= Init seforizt fey.

"Ou bift faum aub bem Ei geichlipft," murmelte ex, "eb wáre aver søade, menn Du wieder abfabren múpteft, olgue eir wenig mebr vou leis uno freub" diefer welt gefeben ju baben. Dugleid eb, meiner Trea, weun Da Das gewónnlidse Edidefal baft, Dab

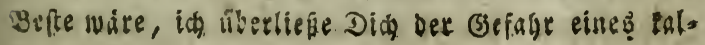




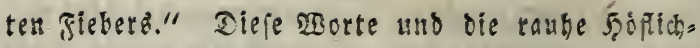
Eeit, mit ber ber spatron ber fleinen Brigg den હdif: fermantel um gairfors zu fithgen fich bemigte, gaben

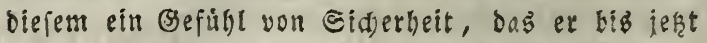
now uicht gebabt batte. Eorglofer firecite er fith auf ole harten Bretter, uno verfiel balo in einen ed?af, oer aber fieberiftit und niwt erquickento war. Es itit fdon anderwarts bemerEt worden, daf Mlan Fairford von feiner Mutter eine zarte Sonftitution mit einer 2tnlage zur s(ubzegrung geertt batte, und da er auper Diefen Brunbe zur Befurdtung das eingige Sind war, fo ftieg die Eorge, ign vor feudten Better, nafien Supen uns ben manderlei lnbequemlidfeiten zu be. mabren, moran Sinder in ๔attland all vor weit biberer (seburt meiften gewibut find, bis zur হoets weisitionng. Bei oem Renichen balt oer Beifit die

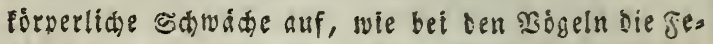
bern ben Siorper tragen. aber biefe siraft hat ihre srenze, und wie bie ङ. forwer werben muffer, fo bricht bei fortgefergter an= Arengung auch bie geipige straft bes Menfwen endith zufammen. als der ßeifende ourch die strablen der bereits bodifelgenden sonne erwedt wurbe, fublte ex fait unertrágliche sopficmersen, netif sike, Durî,

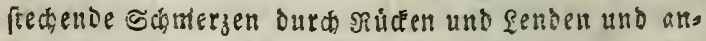
bere Inzeigen einebे beftigen, mit fieber verbunde. แen ระofts.

bie Irt, wie ex sen vergangenen $T a$ und $^{2}$ sie 
S?adt gugebradt batte, welche firr bie meiften jungen Nenichen von gexingen Folgen gewejen wáre, war fü thn bei feiner zärtlichen Eonftitution und Ergiebung bou falimmen, uno fogar gefábrliden solgen begleis tet. Er füblte bief, doch wollte er bie Eymptome der unpapliáfeit befámpfen, weil er fie vorguglid det Eeefraulbeit fufchrieb. Er feg̨te fich auf Das Berded und fhaute auf bie Scene ringsinmber, wie bab lleine Swif, bas ben solway hinabgefabren war, mit gün= ftigem soromino fábwartb zu ftellern begann, die

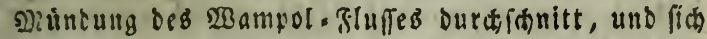
tiffete, bie norblidite Spize non Sumberland zu um= regein.

Fairforb füblte (if aber im bidiften (srabe unpas: lit, reitle $\varsigma$ thimergen waren von einer entmuthigenden und niederorudenden art uno weber Der Eriffel, Der fich auf ber einen seite majeftátifa exbob, nod auf ber andern Eeite die entfernten, jetod nod maleris fdern umrife ven Sficoaw und STaramara, fonns tell feine dufmerlfampeit in rem Nanfe feffeln, wie Diep fonit bei foinen Gcenen ber gall war, und bes fonders, went fie etwas s?eues und Exgreifendes lat: ten. Dod) lag es nidt in Alan Gairforb's Sharafter, (i. Der Nutilofigleit ingugeben, aum wenn fie son E. feiner Tnjace, aber anftatt Des fleinen Salluft b, ben er mitgensmmen batte, um burd bas \&efen eines diets: lingslaiffers fich eine bofe stunde zu vertreiluen, 


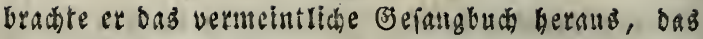
ibm wenige Stunden vorker der mápige uno gesviffen= bafte s)ir. Sbomab Erumbula, fonft aud ฐurnpenn

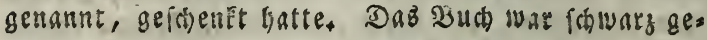
- bunber, uno feir 2reusereb papte ganz fúr ein sofalm=

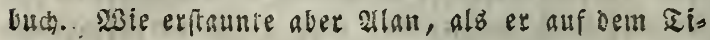
teiblatt folgende Siorte las: Luftige (s)oanten fü luptige lewte, ober Mutter Mitternach to mib̌cellas nee: sum zeitvertreib; alb er abet die Dlátter um= fकlug, wurde er Durd) fittenlofe (sersiblungen emiport und burch nod fittenlopere fiever, welthe mit figuren

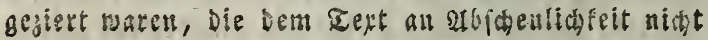
nawifauber. Suler efort, oadte er, uno diefer ver. worfene Graubart ruft feune Samille sufammen, uno

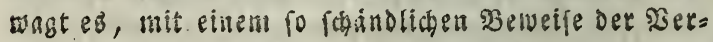

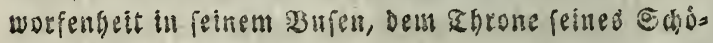

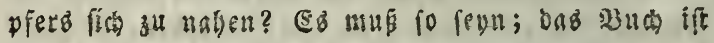
wie biefenigen gebutiden, weldye frommen andad digen Segenitanden gewiomet fiub, uno ofme siveifel ver:

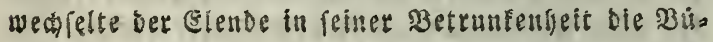

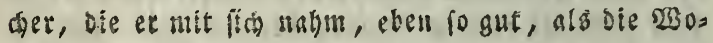
dentage. - Ergriffen von Unwillen, momit ebelmú

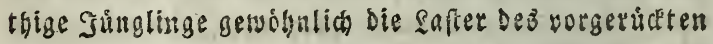
glterb betracten, warf allan, alb ex bie 3 latter mit unwilliger feaft ungewendet batte, Dab $\mathfrak{B} แ 4$, fo weit et Eonnte, in bie See biuaus. ce mabm bann reine zuflucit zu beri Salluft, den et anfangz vergeblich

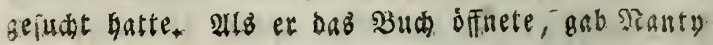


pus; Deine Moeal ift fo firenge nuo fallettipifion, alb Dein Styl; bie eine fent fo wetig Erbarmen,

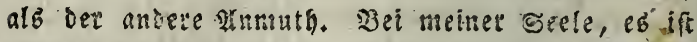
nidht artig, perionliche stmmerfungen su machen uber einen alten Befarnten, ber nán ciner fâf zwansig= jábrigen Trenumg eine furge, freundiche unterce

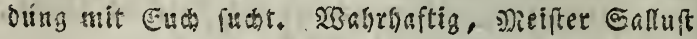
verbien not metis auf bem Eolrsay gu fdimimmen, sib Mutter mitternact felbit."

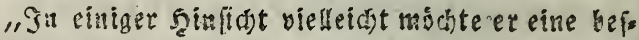
fere Behanofung vou Euren feinben verbienen," fagte alan fairfors, "Acan wenn er bas saftet offen be. icheribt, fo fobeitit ex es nut gu thyn, um raffelbe alfgemein verablatur gu maten."

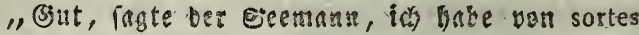
Virgilianae *) getiort, unb if glaube, bie sortes Sallustianae verbea viatg eben fo wativ revn. Tol have den ebrliten suffous meinethatber. befragt, uno eine

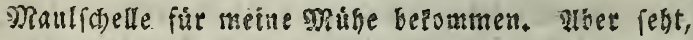

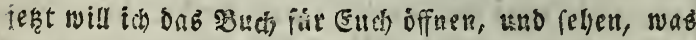
fith Dem 2 luge zuetf Darftellt! Sebt bier! Catilina... omnium flagitiorum atque facinorum circum se babebat. UnD bam wieder: Etiam si quis a culpa vactus in amicitiam ejus inciderat, quotidiano usu par simi-

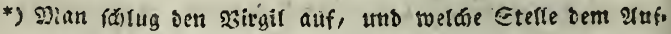

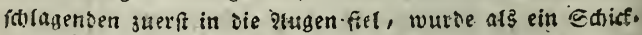

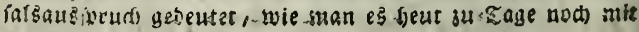
ber 3ibet madt. = 
wer Red)t hat, Dber nid)t. - Shr feht aber úbel aus;

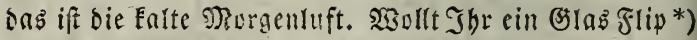
ober eine Tlafide beifen Siumbo**)? Sber wullt Ibr eins rom ádyten (hier zeigte er cine פranntrueinfafd)e), wollt Sbr cinen Mund voll TabaE, - oder cine Pfets fe, - ober eine Cigarre? - eine Prife; das madyt

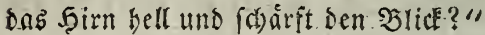

Fairfors wies alle: biefe: freunolia)en anerbietun= gen $a b$.

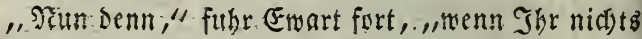
fur ben freien Saabel thun wollt, fo mus idi ibn in Sduts netmen:"

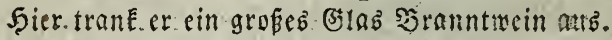

"Ein Saar von dem Sunde, der mich bis, fubr er

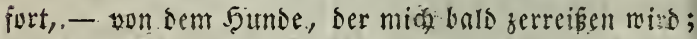
und ora mun in Dummepf inn immer in ser feble baben. Siber dos alte Irinélieb fagt : bier fang cr und 3war gut::

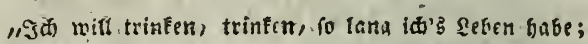

"Sair firten mur. falten, fatten Trant in (5rabe."

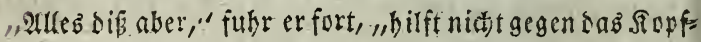

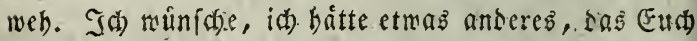
gut thate; toch wir boben ia Sbee uns Eaffee an bord;

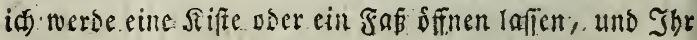

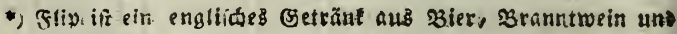
-Sitronerifait.

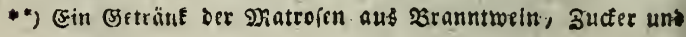
23affer. 
foltt im $\mathfrak{2}$ ugenblick ctwas baben. $\Im$ br feyd in bem 2 t ter, wo man fo fowad)es oeug mebrlicbt, als bie ftar= Een ฮౌetrainté."

Sairford banEte ifm und nabm ben Sbee an.

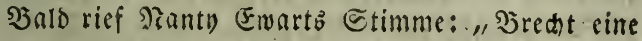
Sifte auf, Ibr গুaifarb von cinem ๔diffinungen; wir brauchen fdjon mieoer - Eein Stteker mebr? Alles -zu

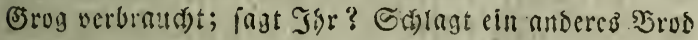

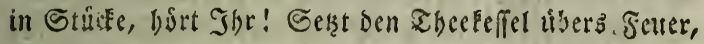

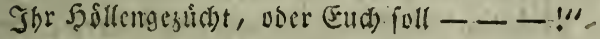

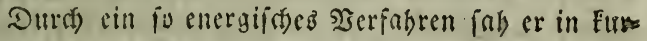
zer zeit fich im Siande, zubcm Plak̨e, nu fein Paffa gier frant uno eridjopft lag, mit ciner Iaffe ober vicl=

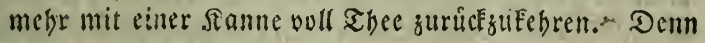
auf ber fpringenden Serny mriat man alles nadi) einem

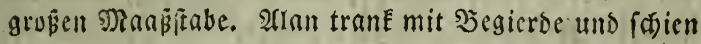

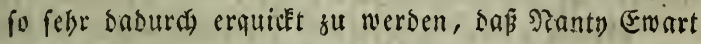
(d) wor, er molle aud bavon trinken, aber mur, wis

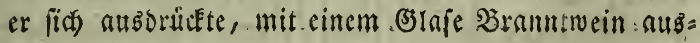
ftafint.

\section{Drittes $\mathfrak{s} a$ piter.}

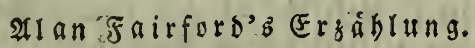

( Fortiekgung.)

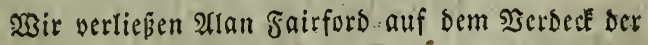
Eleinen ๔a)muggler $=.3$ rigg in sem troftlofen auftande, 


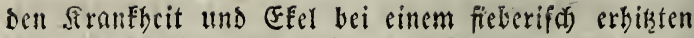
Nenfisen ton aingfyidem Gemithe berborbringen. Die

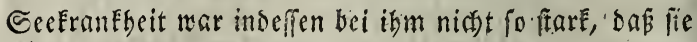
ith volfig ocr Empfindung beraubt noer feine 2ufmer fameeit ganglich son dem abgewand batte, was um ibn

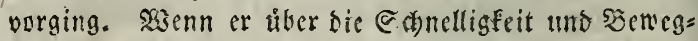
lich Ecit, womit "bic Eleine đregatte" bie 2 Sogen surci)=

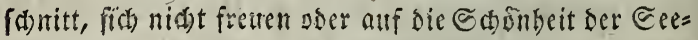

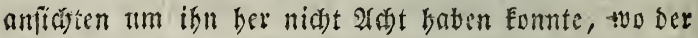
entfernte Sfiofan fein Sjutpt erfob, glciafan ber in

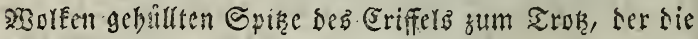

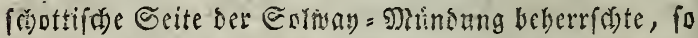
brtte er bod) Siraft und פejonnenbeit gem!g, um bem

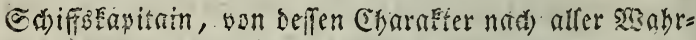
(f) fondere 2ufmerffamecit zu erweifen.

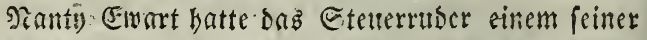
Eeute gegeben, - cincm Eabléppigen alten Miann mit

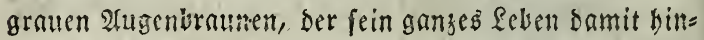
gebracht hatte, bie Brflgejez̧e zu umgchen, und bie und

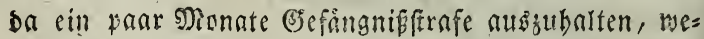

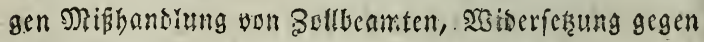
গ̧efaragnabme von sisanen und bergleid)en.

2anty ferzte fich bei fairfors nieser, bradjte ifm noch) zu feinem shee nndere (Erfrifdungen, sie er fit paffeno bielt, und fober in foiner 2 (rt aufridtig bentibt, Deffen sage fo angenebm zul madjen, ars sie ttmftantse

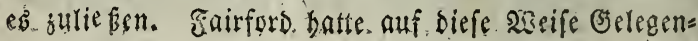




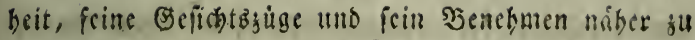
betratiten. Offenbar war Eisart, obgleid) ciit guter Scemann, bod) nibt für biefes Element erzugen. Er mar ziemtid gut unterricijtet; uno (d)ien ç aud gern šll

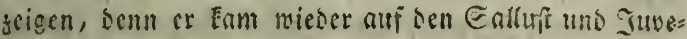

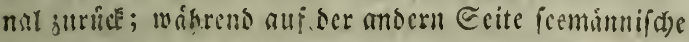

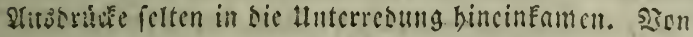
Perfoin war er cin Fleiner, artiber Miann, aler sic tro=

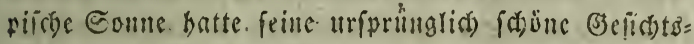
farbe in cin Dunferroth vermandilt, und dic Ealle, sie

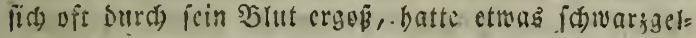
bes bincingemifot, befonterb tare ber meipe abcir ses \{atugcs fo dunEer, ars cin.sopas. Er war febr blime,

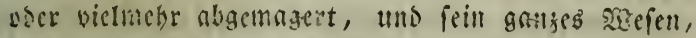

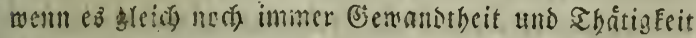
zciste, beries doch wegen fes tibertriebenen G̈ebrattds

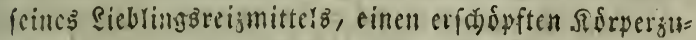
ftant?

"Ibr fehet mich fofari an," fagte er zu Fairfors.

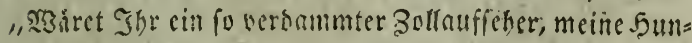
sc wartsen (Fud) bard genug gepacte baben." Er fdylug

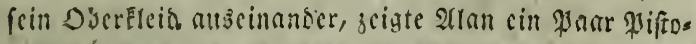

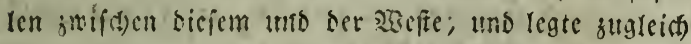
feimen Singer auf ben 5abn ser cinen. "Ifber laffen mir bab, Jar foro cill ebrlider Jert, obgleid) ziemlid

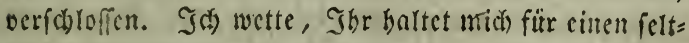

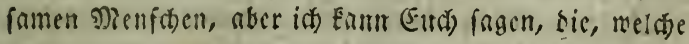

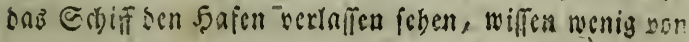




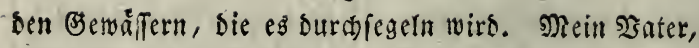
ein redttfdaffener alter Serr, Gätte wobl nie baran ges bad)t, mid) als befeblababer ber fpringenden Jenny zu feren."

Fairford áuferte, Mr. Emarts Ersiehung iđcine

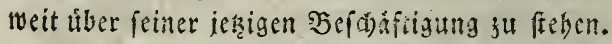

"Die mid nur vom Grifier nad' ben Solway = Mos

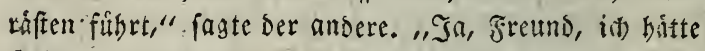

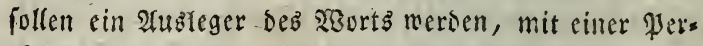

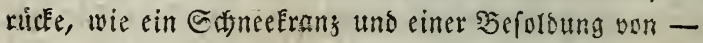

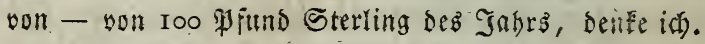
Jd) Ea:m aber, obgleidy in meiner ielzigen Etellung, oreintal fo viel nusgeben." Shier fang er cinen \$ers aus einem alten nortkumbriffen fiebe, indem er babei bie $\mathfrak{b e w}$ igungen ber $\mathcal{E} a n b e b=$ Einnobner nad)madte:

"\$3ifty) Tofter ging auf die Cee,

Eilberne Eduatten an firtem Sinie,

Er fonmt jurïit, uno freipt mid,

Der efrlicfe MBifry Fofter."

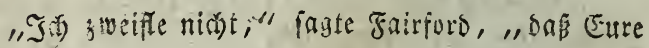

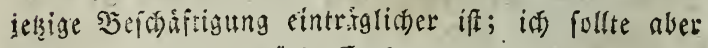

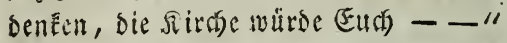

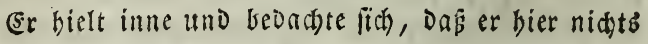
unangenebmes fagen Dúrfe.

"Eine efrrentullere veridafft baben, meint Shr?"

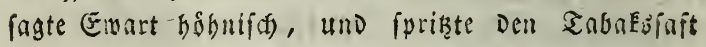

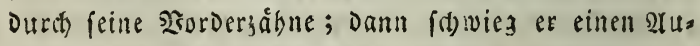

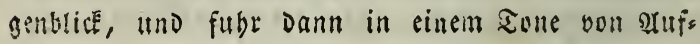


rid)tige eit, Die alls ciner innern Bewiffensregung bers vorging, fort: "in wabrbaftig, und cine talliend. mal gliffiliciere Daju, ob id) gleid) nud fo meine

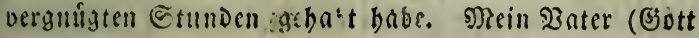
fegne Den alten 5gann!) war cin àcter Eproffe von Dem alten fresbuterianiften Gtamm, ging in feis ner affarre umbir, wie ein Sinpitain allf feinem Sin.

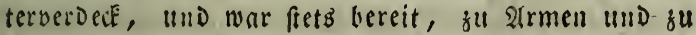
গeciden zul geben. Der fairo zog feinen Sut fo rafa nor bem geiftlidyen 5yerrn ab, alb Der atme Mann

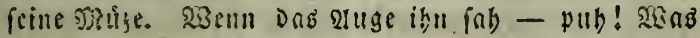
bab id iegt Damit jul forffen? - Er mar in Der

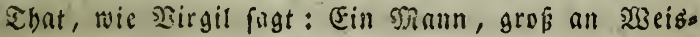
beit uno frommigfect. alber er ware wobl nod) weifer gewcien, menn er midh zul Şauje brbalten batte, ftatt midh in meinem I gten Jabre auf Die Inniberfitat zull fchicken, um Die Boottebgelabrtheit zll ftudiren. Das war cin veroammter Mifgriff son Dem alten

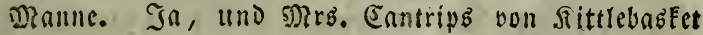
(Denn anders forieb fie fid) gar niøt) war unfre

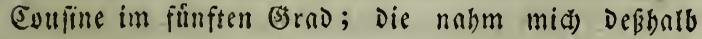
in Soft und sisobnung um 6 Gdillinge Die 200 che, anftatt um 7 ; Das war eiue folled)te ErfparniB, wis

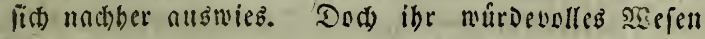
batte mich in Droutung erbalten Esnnen, Denn fie las nie ein sinpitel in Der $\mathfrak{b}$ blel, aufer in Der Eamo brisger 2usgnabe bei Ianiel gesnutst, und in geftickten Samnt gebunden. Nit ifts, als febe in fie nod)! 
Ind Somntags, ivens wir fatt

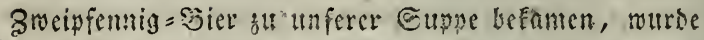

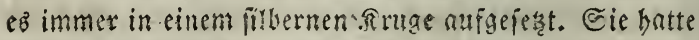
auth eine in Eifber gefapte Szrille, waibend bie meines Dater nur in Sorn gefapt mar. Diefe Dinge mad)ten anfangs ifren Einoruck, bod) gemobnten wir uns baro

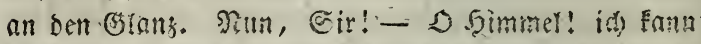

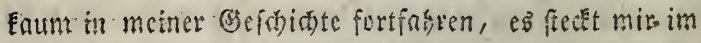
Sarfe, i biefe Dante batte cine Znoter - Tep Cantrips, cin

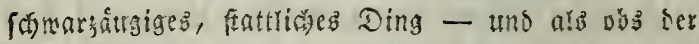
Teufer batte fo baiell wolien, ba war fie verbammtc Sreppe zum finften Stout uns ibr Fus fom nic daud weg, id mobte nun anz ben Eollegitum Ermnten, der sobin gehen. Soin ware its gern ausgemidsen, Eir, gern bei meiner Geele! Demn ióf mar ein io unifurs: ger Singe, alb ie ciner bet Sammerumir Fam; sa war

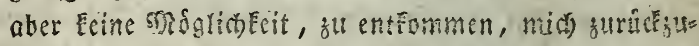

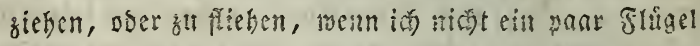
beEm, oder cine Seiter crbielt, fieben Ctock bod), um

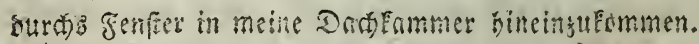

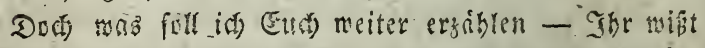

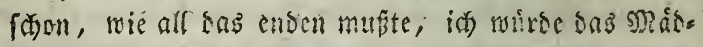
d)en gebeutathet uno mein Scil beritht baben, bein Simmey! bas wirte id, benn fie war cin artiges uns

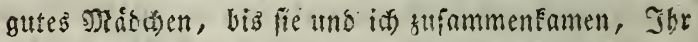
Eennt in aber sas alte Sics: Die Sitch' wirb' uns nidt lafien feyn. Ein woblbabenoer Mann an meiner @telle 
witrbe sic Sache mit sem গirthenfanmeifter un ein

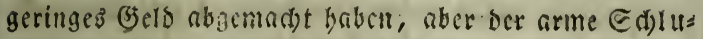
cfer, der nicgt ciacn Pfentig. Daran fu menten batte, uns feine Coufine von Sittlebabet gehentrathet batte,

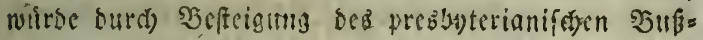

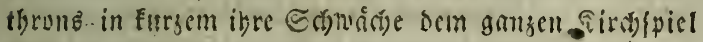
baben verkintigen, und nie Dibello fagt, int 2tnge=

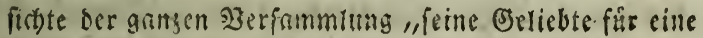
5. . e erEtâren miffen."

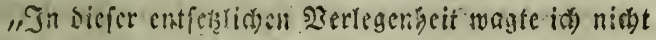
zubleiben; wo in war, und gedacte, heim zu meinem Sater ju geben. Norber nber trug id) Jau Sabaray,

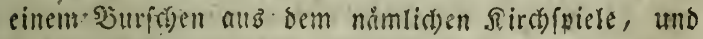

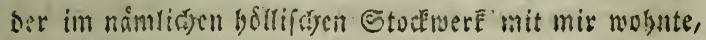
auf, ein werig nad)zufurfós, wie ber alte ferr bie

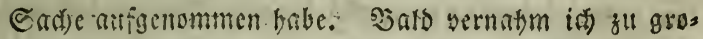

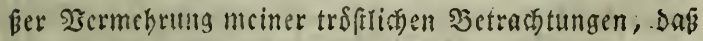
ocr gute alte giann cinch (of(t)en Birmen gemad)t, batte,

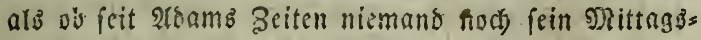
mahl ohne Danfgebet zu fid genommen bnle. Eeds

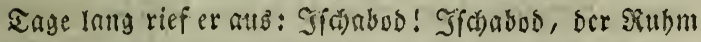
ift gervichen won meinem Sante; und sim fiebenten bielt

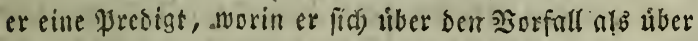
eime ver grofen 2rufforderungen zur Demithigung vor

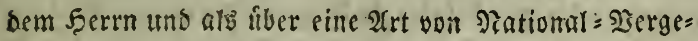
ben ansbreitete. Th boffe, Dip trug gu feinem eigenen

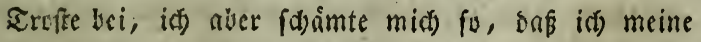

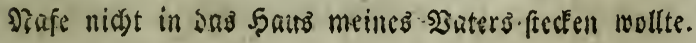


Id) ging befibalb nad) Seith, vertatif(t) meinen groben

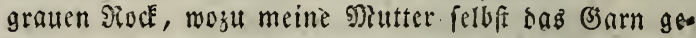
fponnen batte, gegen eine Sacke mie biefe, liek meinen Pramen ins: Sd)iffregifter einfdreiben, uns fegelte nad Prymouth, wo fie gerabe cine Escabre nad) 2isctindien

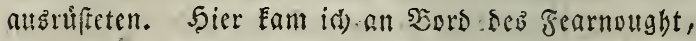
Eapitain Daredevil, unter Deffen SRamidant is bald ben Deufil, sas Edbreüen mciner frubern Sugens, fo

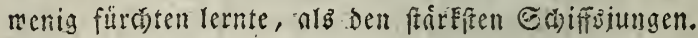

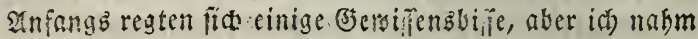
sas Cecgenmitter (bier zeigte er auf feine flafde), mels

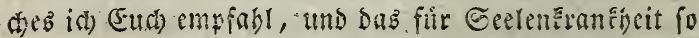
gut ift, als fitr MagenEranEbeit. Waas? Ibr wollt niç) ? STun benn, fo muf id); auf (Eure (5) efunsheit."

"Ihr meroet, furchte ich), Eure Erzichung in Eus rer neuen lage pon geringem stuken befunsen; baben," fagte שairford.

"Sergeint, Cir," ermicberte der Eapitain ser

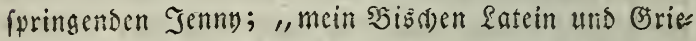

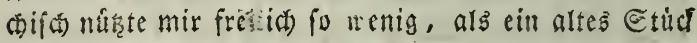

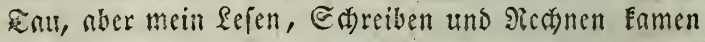

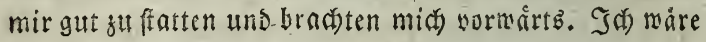

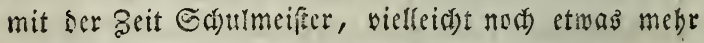
geworben, aber biefer mảatige ₹ranE, ber Sium, beo fiegte mich zus sit, uno fo Eam ich, medte id aud Ees gel auffeken, fo viel id wolfte, bodis nie redft von ber Etelle. siser Jabre braditen wir in bem glibenden Simmelsftrid fu, und id Eam endrid zurtid mit cin 
wenig Prifen=ङeld, unb batte nod) ben (J)banken, meine alte Univerfitátỏgeftid)te in Dronung zu bringen unb mid) mit meincm $\mathfrak{B a t e r}$ zu verföhnen. Id) fand Iad Sabaway, ber mit einem Duzend erbarmlider Ed)us iungen sie grichifoxen Eonittgationen ableicrte uno cine.

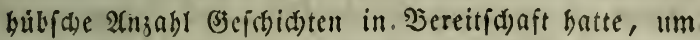

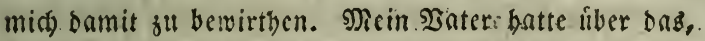
was er meinen $\mathfrak{A} b$ farr nannte; fieben, Sonntage ges prebigt, uns eben, alb. feine pfarrfinter zu hoffen bes gannen, onß̧ ber Etrom mun zu Enbe fenn merbe, murbe er am sten Sonntag Fiorgens. toot in feinem SBett gee

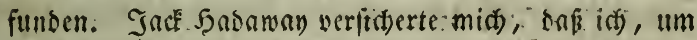

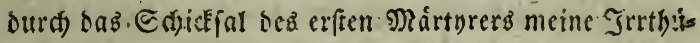
mer abubúken, nur:in meinen ङeburtbort geben burfe, mo sie Eteine in ben Etmpen fich gegen mid), als ben

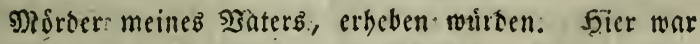
aber aul cin bibfact, - nun bie sunge blicb mir cine ๔tunbe im Siunbe ftille; und war am Enbe nur fábig, Mirz: Eantrips. bernub̧ubringen: Diß̧ war mieter neter: O5:

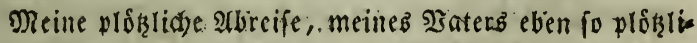

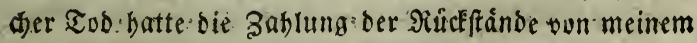
Softgelbe verbinbert; Der.Sirth war ein Srámer, unb fein. Serz fo verfault, alb sie-banmivollenwaare; wo

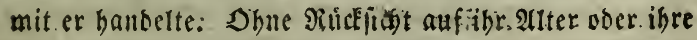

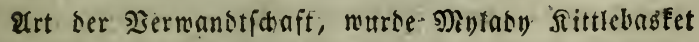

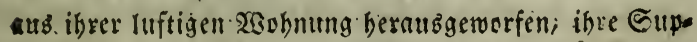

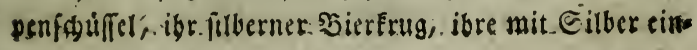




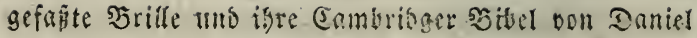

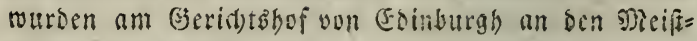

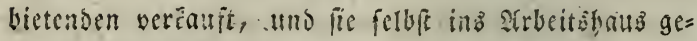

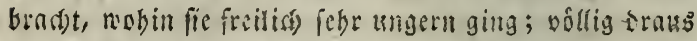
erlofit, wie es ibre Freunde Mur winifgen Eonnten,

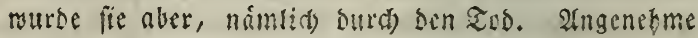
Beinugen firt mid), ber id ber verbanmte (ct hielt eis nen 2ilgenbrick an) Origo mali gemefen war. Der beffe

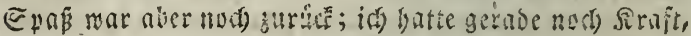

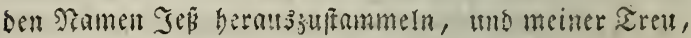
er batte aud o a f u

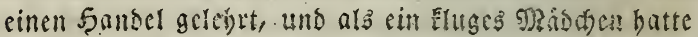

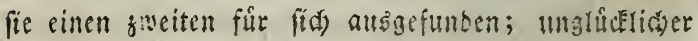

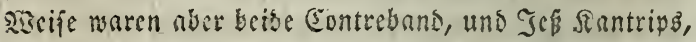
Fod)ter ber \&adi Sittelbabet, Gatto bie Ehre, wegen

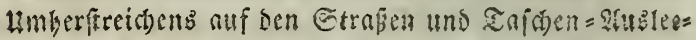
ren ungefibr 6 jounate, ebe ids das lliel betrat, nad oen Colonien transportirt fu werden."

Er änderte ben bittern Tu bes afieftirten Gder

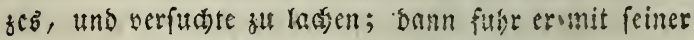
braunen Siand ûber feine traunen frugen uno fagte in

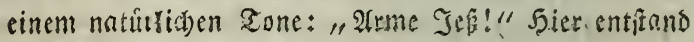
eine Paufe, bis frairfurb in Mitreiben user des armen Mannes Ceelenjuftand, und in ber liebergengung, saf 'etwas in ifm iey, wae ohne sen frithan Jerthum und

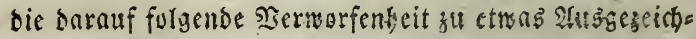
netem und Eorem bitte bernawadben fónnen, die uns terresung burd) bie im Tone bes mitteios ausgefpro= 


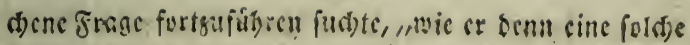
Eaft wen Elent babe crtagen Eomen."

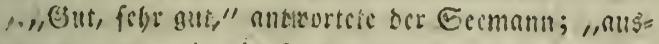

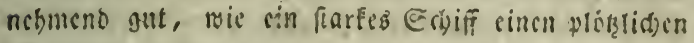

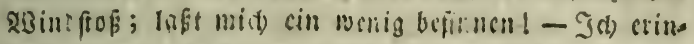
nete mid), saß idl) Dem Jack fin feine interefianten uno angenebmen Piadjrid)ten febs gefaßst Bnnfte, zog Dann.

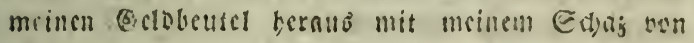

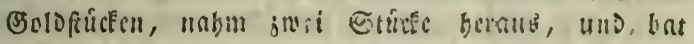

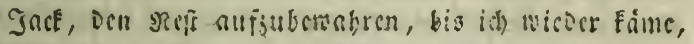
Denu ids molle nad) NIt = Pieclic fatren; Det arme

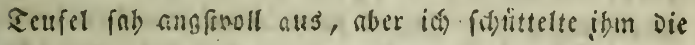
Fand, und ramite dic Srephe binab in fold)er wirrung, Dab id trots Dent, nab i(t) gefort batte,

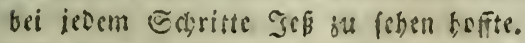

"Es mar Dharftnß, und Dir Eenobntiche Menge [andfreicler uno s?arren satte fich ben Dem (seridjts. bebsube "-fammelt. Jch fab, oab federnann vers mundert auf mich fab, und ich glautte, einige bats ten gelacht. $\Im(6)$ mag wobl auch fonderbare Be ejichter senus gefinittan, und viefleicht mit mir felbft gefpros

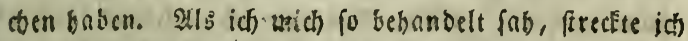
Die geballten Feinfte gerade bor mid bin, ten Sopf norwártz, tmo rannte nun wie ein Bodk, menn er eis nen Joung machen wi2?, gerab: Dic Strape binab, ftiek

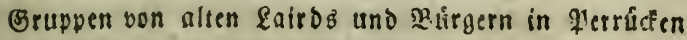
auseinander, und frectite alles yor mir nieber. Ieth borte Den Sanf: "baltat Den Rafenden!" und Die Stabt= 
wache wiederfolte inn, aber $\mathfrak{S e r f o l n u n g}$ und $\mathfrak{W}$ ider: ftano maren bergebens. Jah verfigigte meinem lauf, Der Seesuft, glaube idh, f fuhrte mich nach Seith, wo ich nich bals nachber wieder fano, ganj rubig ant llet auf und abipaziereno, um baz ftraffe Saưert ber Cchiffe zat bewundern, wobei ich- Daran bachte, wie eine Echlinge mit einem, Der Darin bănge, wie eime Quafte fid) ausinebmen murbe.

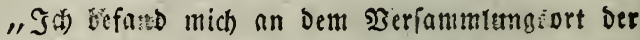
Matrofess: fruber foton mein sufuchtart, ich fturiste binein, fand eine oder zwei alte כefanntfoften, machte ein balósez Dujend neue, tran amei $\mathfrak{E} a g e$ lang, ging Dann an Sord eines Eleiren @ichiffes, - bin aach Sortsmouth, uno wurbe bann in einem artigen,

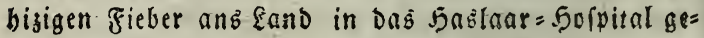
bracht. $233 a$ thut 3 ? - Sch wurbe beffer - nichts Earn mich umbringen - ich Fam abermals nach 2 Seftindien und ba idb in ber andern sselt noch nicht ongin Frim, wohin ich Ja Eommen serdiente, fo fam ich faton in Diefer in ein Duntier, Das fobmarge Teufel ju Ein wobnern, flammen und Erobeben u. f. w. sut unter baltung batte. Nun, Bruber, ich that oder fagte et was, ich) fann nicht fagen, wab - wie Ieufells: follte ich auch, Denn ich war betrunfen, wie Dabios @au* ${ }^{*}$, Sbr

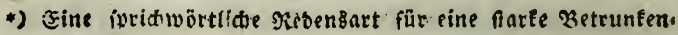
beit. Die Frau einez gewifinen David Elond, weldher eine

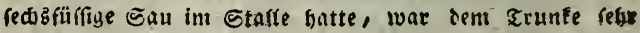
ergeben, wefbalb fie oft bon ibrem Mianne gesüdtigt wum 


\section{6}

befangen als moglid), "ob ei nls Rảuber gltictidi Beriefell fer?"

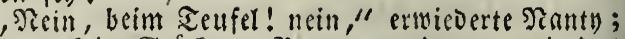
(i) Eonnte Ecin Stúkfben Sutter gewinnen, mir Das Šrod ztl fomicren. (5z toar Eeine Dronung unter unb, Der, welder beute Eapitain mar, mubte mor gen Das Erijiff frgen, uno waz Die Seute betrifft, fie fagen, Der alte stuery und ein pant andere Ers: Fniler báten jich (5) clo gemact) ; ju meiner żeit ging aber nlles wieder fort, tho zmar aus gutem Grunde,

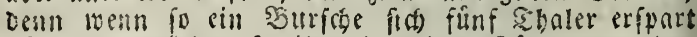
bitte, fo murben fie ibm in feiner Saingematte ien sals abgerdynitten baben. Lino dann war cs immer ein gratifames, blutiges Sanomerk. - \$lab! ich mill

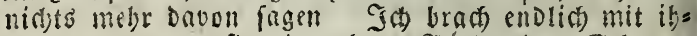
nen, denn was fie cinmal an Sord einer Echnalle thaten, - nun id will nid)ts fagen - folled)t gee

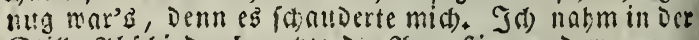

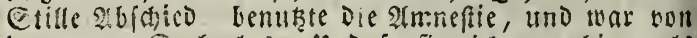
ber ganjen eada los. Uno io fize ia nun bier, als Eteuermann Der fpringenden Senny, einer Jiuffanale oon eincm Ediffe, alier fie geht Durch Das senffer,

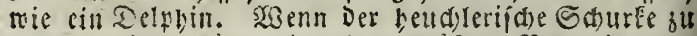
Einnan nidit wire, Der Den gripten Dortheil und feime efefubr Dabei bat, fo frúnde es um mint fo gut,

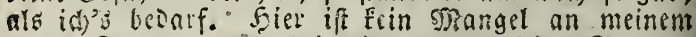
beften Treunde," Dabei mies er alif feine Srannte meinflafase; "aber id will Euch cin Ëebeimnis fas gen, et uno id) fino fo gut mit cinander befannt mors

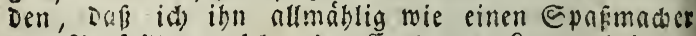
Don profeflion nnfebe, Der Euth zum facten brinat, Dof Enci) Die Eeite fomergt, wenn Ihr ikn nur bie and in fert; mobnt Ghr aber in cinem Galle mit ihn fufammen, fo mad)t er (5ud) mur ben fiopf Dumm. Sa

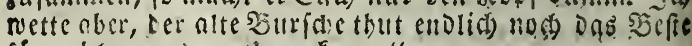
fúr midi), mas cr thum Eamn."

"IInD mas ift Dicfes?" fagte Fairford.

"Er tod det mids, und es thut mir nur rio, Das "s fo lumge Dauert." 
So (prad) er, fprang auf peine Sinße, lief nuff Dem sardecte bin uno ber, und gab feine ?̧efeble mit Der gemóbnliden Deutlicheseit uni) Şefrimmtbeit,

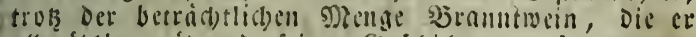

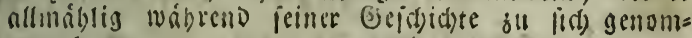
men batte.

Obgleiti) Fairford fict) nicts weniger als wobl fúblte, berfudste er Dodi), aufófufteben und nad) Dem 23ordertheil Der Djrigg fith. zu begeben, fowohl um Des

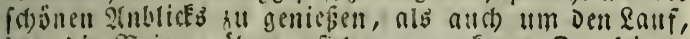

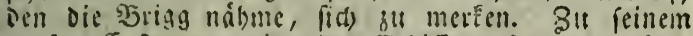
grobien Erftaunen ging ons ENd)iff, anftatt quer tiber

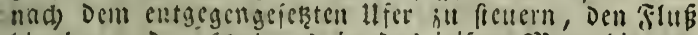
binnb, und anfdscinend in Das irif(t)e ojeer binaus. Er rief Pinnty Enart berbei, Dritite fein Erftaunen Daríber allo, und fragte, warum fie nicbt gerade binuber nad) cinem Safen in Emmberlano ftenerten?

"Tỉarmm, Das if einmal cine vermünftige Trage," ermicoerte P2anty; "als ob cin Ed)iff fo gerade in feinen Safen cinlaufen Esonnte, wie cin Whero in Den Etall; ooer als wenn cin Ed)leidbánoler Den Sol=

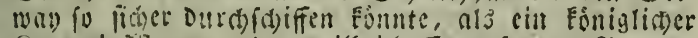

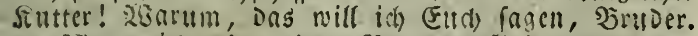
- 233 enn id nidt cinen Rianti aufficigen fehe won פonneßs, Das ift Das Dorf Dort an Dem Sorgebirge, mun i(t) 24 Erunden wenigftens in Ece bleiben, denn wir miffen das 23 etter oanach mefien, ob die (d) latten Sitdfe fort lind."

"llno wem Gir das Gignal Der Giderbeit fes bet, "פeeifter Ewart, was ift Dann zut thun?"

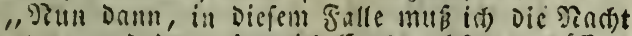
abwarten, und Dann fefe id) (Eud) nebst Den Siuffern und Dem andern ëerumpel ans Land bei GEtns burnefi.

"lind werde (d) Dann Den Raird treften, fúr Den (i⿱i) Den Dricf bier babe?" fubr Fairforo fort.

"Dns," fagte (Evart, "wiro fira) bernad) auds meifén; Daś Gaiff bat feinen \&auf, Der Ed)leidbaand. 5 .. 


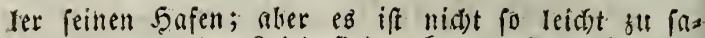
gen, wo man Den Eaird finden Ennn; aber meiter ats 20 Dilen auf oder ab, Eann er nidat son bier fern,

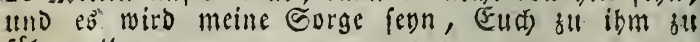
fî̉nent.".

Fairford fonnte Dem Sanulder nidjt widerfeken, Der ihn Durdizudite, wenn er fid erinnerte, Dás es

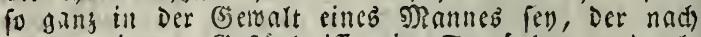
feinem eigenen Befrindnilfe cin Eecriatuer, und nls ler $53 a b r i d) e i n l i d) E c i t$ nad ein Ëeñd)teter uno ein Ed)leidhánoler mar. SRanty Emart bermutbete Die

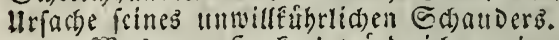

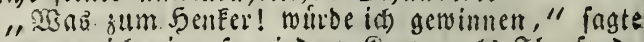
er, "wenn ifis eine fo niedere Jiarte, als Shr feyo,

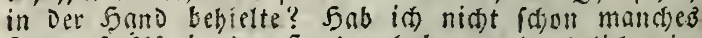
Trumpf $=2$ (f in Der frano gebabt; uno chilids wies Der alsugefulelt. Ia, Dic fpringende Jenni) Eamn aud etwas anoeres tragen, als sáffer. Ëeket nur nor

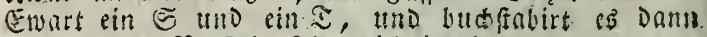
jHfammen. Serfteht Shr midh ieţt?".

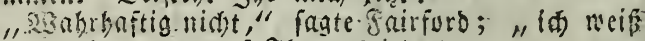
Durdaus nid)t, iworaur She anficit.."

Nun, beim Supiter, Du biff entweder Der un ergrúnditofte doer ber diummfe Surride, Den ich ie ges fithen babe, - ooer es iff mit Dir nidt ridtig. Iot mundere mich, roe Gummertrees fo: ein ;irtlides Sing lafigg Dem. Ufer altfgabeln. Fonnte. N3ollt Jhe mich) feinen brief feben laffen?"

Fairforo nabm Émen stnfand, feinem sisunf sil erfúllen, Dem er, wie er nubl. merEte, nicht flig= lich miderfeken Eonnte. Ser Befehlshaber Der furins.

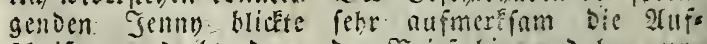
farrift nn, Drebte Dunn Den Sorief fin uno ker, un terfucite gennu itden foberjut als ob er cine ges zierte 5andithrift beurtheilen: nollte; Dann tindigte er Den Srief Fairfurd wieder cin, okne che cinjge Semetkung:

"Nun, iff co jeţt ristig mit.mir?" frogte ber: iunge Refitagilegite. 


\section{0}

erft verliés id Den armen Sack. Id) glnube, Shr ferd in Io Ialyen Dic jucite Je!ron, für Die Jianty Emart etwns mebr gegulten but, nis cin Talnés= forpfer."

"2ie cicjt, Sir. Emart, lebt Ibr bauptiácblid mit SPenfdien, bic zu febr lur ibre cigene ummittel=

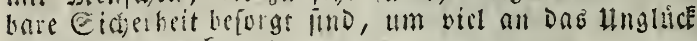
stnocter zu BenEen."

"Lno mit mem lebt Ghr Benn," erwieberte Nanty

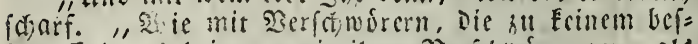
fern Ende es bringen mit ibren \$ierfütroungen, nls jum Salgen; nits raneffiftern, nerche vie Junfen mit

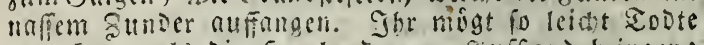
crmeden, nls Die 50 lonte sum saffiand bringen;

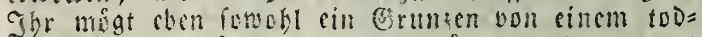

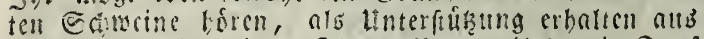
2Sales uder (Eheibite. Jar tent, neil on ein Soyf fievet, miffe nut Euer Edatm ohen auf fommen.

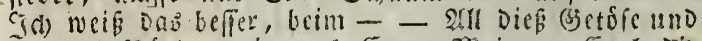
Viefe 2huffínde, cie nadh (Etrer gieinung (Eud) Die sabn breaten follen, raben auf (Fure 2tngelegenbeit gar Eeine Serichtung, who Das befte Mitter, Dem gouls zen Feid) auf cimmol zur Einigeit $x$ ut verbelfen, ware ons estint eimes folden Unternehmens, motein fich Die fitten, tolien Befellen cimlaffen wollen."

I(i) bin in ier That nidot in foldien (Seheims niffen, morauf chr aniuip clen focint," fogte Fair= ford; tho mit cinen fád)eln lekte or, entidolofin, Santy Emarts mittheilende Etimmung su gleidser

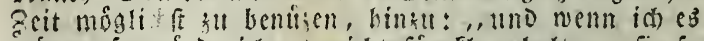
mare, fo mitroe ide es nidt fưr flug barten, fie fo

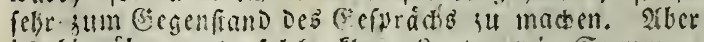
id) lin tiberieugt, foldte Eltige Eeute, mie Eummers trees tno oer Sairo merden wobl Briefe toecheln obne Eefahr fiur ien Gtaat."

"Id) berfiche, Freund, ifi berfehe," fnate Seanty" (smart, bei meldem endid dod die genofiene Gruflig"eit uno ber Inbafsoampf eine besentende sien 
tie ansern Figenthumer mollen. Sisenn id aber ganjer Eigentbimer deîjelben ware, id) múrbe diefe sbrigg nidgt

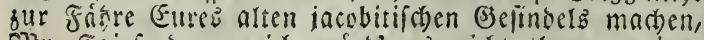

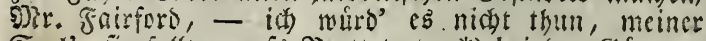
Gecl'; fie follten aufs jotett treten *) bei hen (3) fttern. roie id) es von befferm feuten gefeben babe, als id) nod) unter ciner gewillen farbe fegelte. Da es aber Euntres band ifit, und an bioro meines edjiffes, und ids ben serebl, mie ids legeln foll, in ser sand babe, fo mus (t) fie bahin bringen, wohin fie beftimmt finb. - Niun, Sobn Robertb, bebt ein wenig sas ङteuer! - tho po,

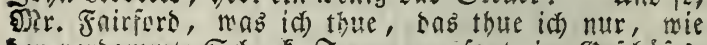

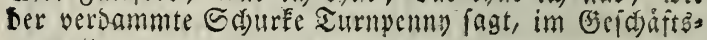
mege."

Er batte bie lethten finf Minuten mur mit Edmies rigEcit gefprodien, uns fiel jeţt ber fänge nad) aufs sibrbec bill, burt) sie Miclige der eingenommenen gei= frigen Setrunke endidi zum Edweigen gebradbt, obne

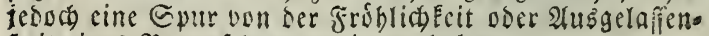

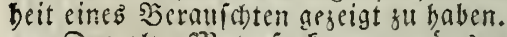

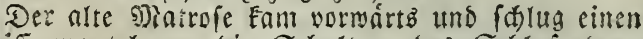
Ed)iffermanter um sie Edultern bes Ed)lafenoen,

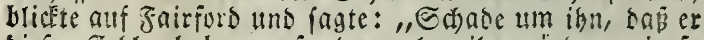
siefen fehter haben mus; Denn obne ibn würse er cin fo

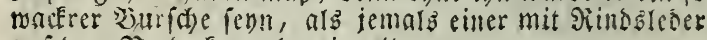
auf bem \$iserbecke umberging."

Gairford.

"Und was miffen wir benn thun," fagte siran

"Saviren, um fieter zu geten, bis wir bas zeiden feben, unb Dann bcm meitern $\mathfrak{Z}$ cfehle gehord)en."

So fprad) Der alte Mann, Eehrte zu feimem (b)

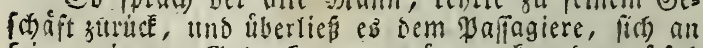
feimen eigenen G̈edanEen ju ergóken, Eurj Darauf fah

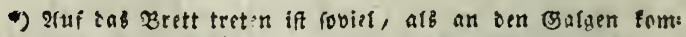
men, weil ser Berurtbeilte auf ein Brett treten muf, bas natgher unter four weagejogen wirc. 


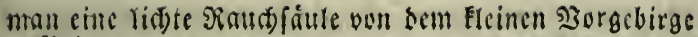
auffeciacu.

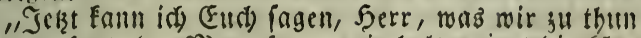
baben," fagte ber Diatrufe, "wir balten iebt bie Ece

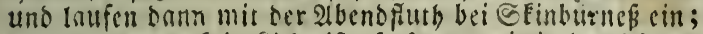
oder menn bort fein sidet iff, fo fegeln wir in sen seams

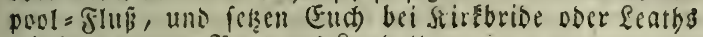
mit bem langen $\mathfrak{g o u t}$ ans Eand."

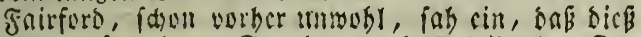
Ifn nod) alf mebrere Etunsen fü sem leitenben 34 .

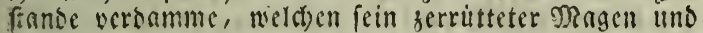

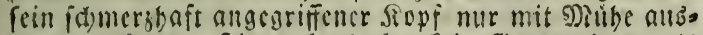

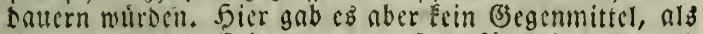
(3ebuld uno bie Erinncrung, bap er fur feinen Freund leibe. Alb bic Eomne hober fticg, wurbe itm idslimmer

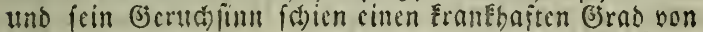
Ed) irfe zu crbalten, nur um sic verichiedenen (berúche, son benen er ungeben mar, won bem Weragerud an bis

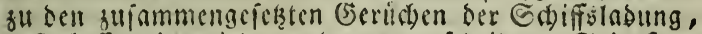

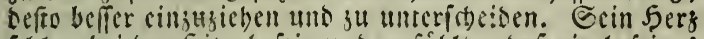
fdilug bei ber Jike beftig uno er fúblie, ba ein befriges Fieber in vollem 2lnsug fey.

Dic Ecelcute, die, io meit es ibr Ђeruf erlaubte, fehr boflid) und aufmerfiam waren, bemereten fein Eeis ben, uno ber cine war bemulbt, ibm einen Sonnens forirm aub cinem nIten Eegel fu machen, wábrend ein nnberer ith Eimonade bereitete, Das einjige JetránE, zu befien osemus man ithn bewegen fonnte. Nadsoem es biefe getmufen batte, fief er in cinen, obnobl nidt ers quickenden Ed)lummer.

\section{Sitertes a d a t}

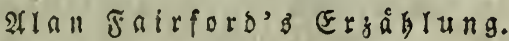

(Fortienung.)

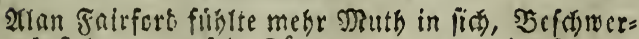
sen fu befteben, als fein sorper zu ertragen im Stande 


\section{4}

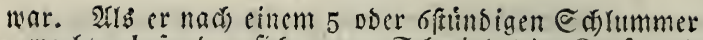
ermadite, befand er fict wegen Sobroindel im Supfe und

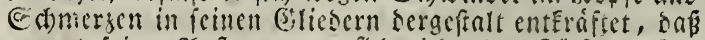

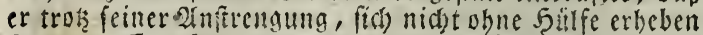
Eonnte. Er borte mit cinigem Soergnugen, dof fie ges

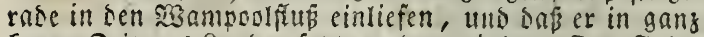
Eurger seit ans Lanb gefeçt werben wurbe. Dả Jabr= zetts legte alfo bei, anderte feine flagge und bief nutbe wom llfor aus bura Eignale foglcid benutrodrtet. Nian

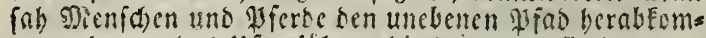
men, ber an bas Ufer führt, bie letętern pafend aus̉ge= riffet, un iste Lasung fortbringen fu Evnnen. Burne zia fif

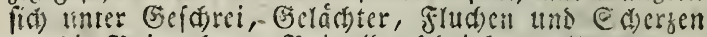

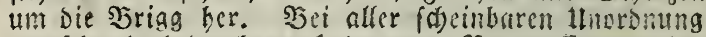

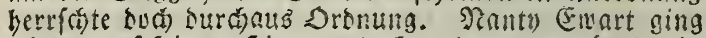
wieber alf feinem Sinterverbec trmber, als baste er in feinem feben fcine geiftigen Getrâné zull fict) genommen; er. gab sie nothigen Şeferle mit Escnaulgfeit, und fah fie mit Punftricheit ausaefúbrt. In ciner halben Etunde war die fabung ber Srigs gróftentbeils in sie Socte

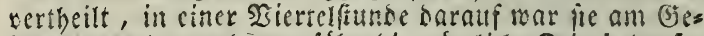
fase geranbet unb ungefábr fie nómlide zeit bedurite

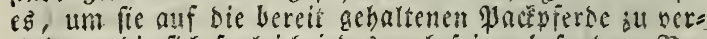

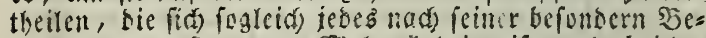
fimmung, ferfireuten. Dgethr steheimnis wurbe bei ser

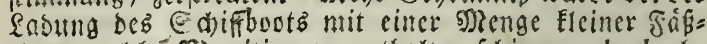
c)en, werd)e metuition bu entbalten fdrienen, beobads= tet. Diế gefdah erft, als bie Sandhungstunden bes

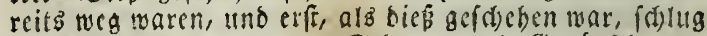

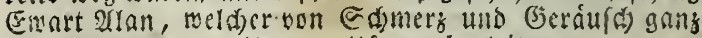
betutubt mar, yor, ifn ang ltfer zu begleiten.

Siur mit EduterigEcit Ennte Fnirford fir über

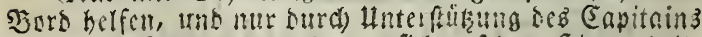
uns feiner fente, vermodiste or, fid) auf bom Sintertheile bes Eoots ju erbalten. Sianty Enart, meld)er Dara:

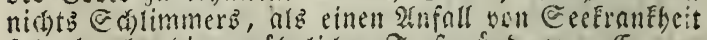
fab, brable die gewógntionen aroftgrunde an. Er vers 


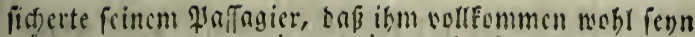
murte, wenn er nur cinmal cinc balbe e tumbe am Eand gewefen wáte, unb or toffe, mit ibm bei sinter Ernctens

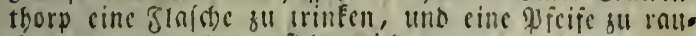
den, sam werte er fids gleid) bon ser unbequemrids) Ecit erbolen, sic ihm DดB ungenebnte Sictiten anf bem bof sernen pferse zugezogen babe.

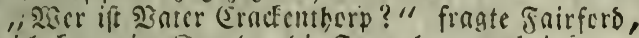
obglcid) Enum in Etanbe, sis frage berwarzubringen.

"Ein chrlicher Dinnn, wie fum cincr unter tnllfeneen," antwortete sinnty); "nd), wie siele Slafden Sirantmein boben er unb id) jull unfrer Scit mit cinan=

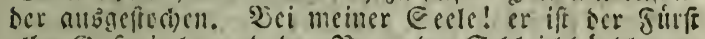

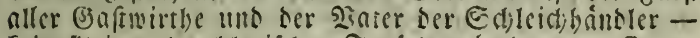

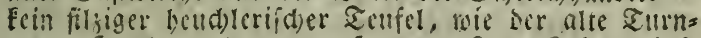
fenny) Jear:baut, Ser mur nuf anderer feute Soffen trinet und ca für Eunoc bált, menn cr Eafin zablen foll, ncin, cin alter chrlider (3)birgshabn; - sie Samfirtbe find fdon minudien ₹ag um uns neben itm ber gewes fen, aber saner (Eraffenthorp meip feine Eecoci ju ridis ten; in wiro Ecin sierbaftobefell anbacfortigt, ofer or

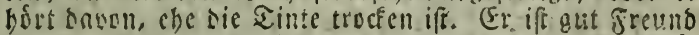

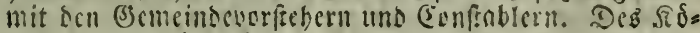

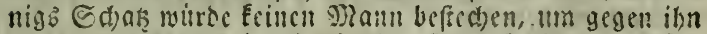
zu zengen; nem in cin fold)er Edyute fo ctmab fid) pornebmen murse, fo murbe er am nidafen gjourgen feine Ohren vermi jen, ooer fie ferbft im Colman fucten mus=

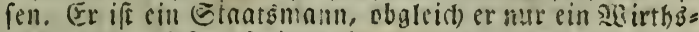
bnus bat, sick gefdricht aber unt ocr sjeqtiemlid)Ecit regen, und um cine Entfruldigung 3 haben, baj er grofie Sieller und viele fente bat; feine fratt ift cine fatilide Yerfon, uns eben fo feine ₹uchter Doll. Sianbr= hafrig, Ghe weriet sa im Sajen fenn, bis Jar wieber (Ellf) allf sie Jabrt begebt, id) aber mill mein $280 \mathrm{rt}$

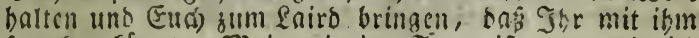

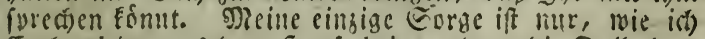

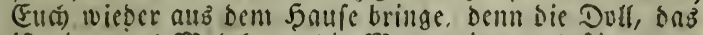
ift ein reres Mlubden, bie Douter immer luftig, uno 
Sinter Cractenthorp ber befte Befellid)after! Er trintt (Eud) cine Frafde Sium oser Sranntwein, obne zut mugien, nber nie mad)t or feine sippen mit dem elento

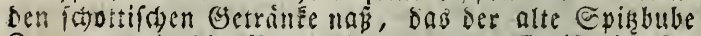

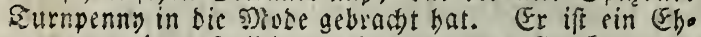
renmann, icter 30 ll *) voll ibm, ber alte (Erackenthorp, auf feine siseife beift bief; sabei bat er Intbeil an Der

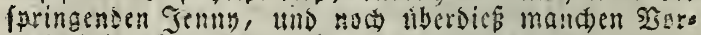
theil beim Jiondidat. Er fann Der Doll fajun einen buticten yennig geben, menn ibm ser bubfothe Surf(t)e anfeht, ber lie auf fein leben lang nehmen mill."

刃itten unter biefer langen Sobrebe alt $\mathfrak{T}$ ater Era.

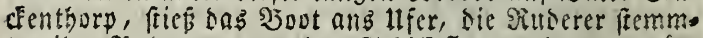
ten ibre ?uber an, um bas ๔e) iff fott zu balten, wabo reno bie altoeren Surfate gerndeju in șajer fprangen,

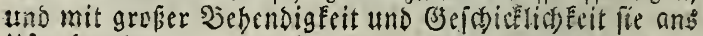
Ufer bracten.

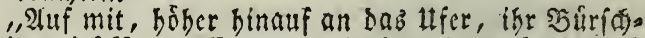
(ben!" rief Nanty (Ewart, "bod) uno trocken, hod und troden; Diefe signare vertrágt Feine Jeudjtigfeit. sitn aud fur unfern Jranfen bier geforgt, bod und

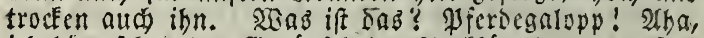

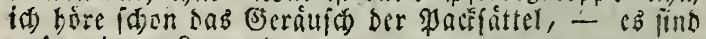
unje eignen feute."

Ilnterbelien war sie ganse Ladung bes Foots, fie

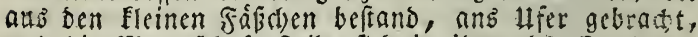

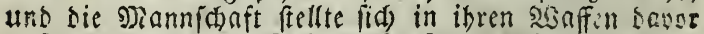
auf́, unb wartete auf bie ankunft ber Pferbe, welche

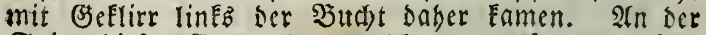
Epitze biefer Enunlcade, weld)e aus zufammengefoys welten unb mit \$adefátteln verfebenen partien beftans, crichien Eeudend unter feimer anfrengung, cin fo uns

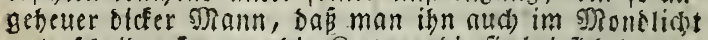
unterfociben lonnte; bie Setten, bie fie bei fich batten, um die 53 allen bu befeffigen, Efierten furchibar.

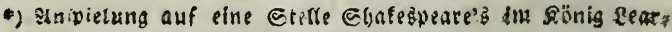

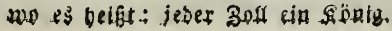




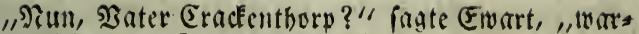
IIm fo cilig mit Euren Pforben? 28 ir gebenEen cine गiacht bei (End) jublciben, Euren alten Sranutwein su Eoften, und Eurer Frnut cigencB Bsctráu. Dab Sig= nal if aufgefteclit, uno alles gebt gut."

"Iflcs geht faled)t, Capitain গanty," foric bet Dann, ju sem er iprads, "und She werbet es fo fin. ben, menn Sbr Euds nid)t aus sent Etaube madot; es fino geftern neute Scien jul (Enrlible gefnuft morben,

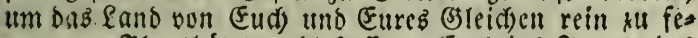
gen; - Ihr thatat moht befer, Euds ins Innere bes. landes binein zu mad)en."

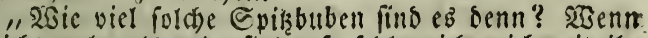
co nicht mekr als zebn find, fo fdilag ids mists mit ihs. uen.".

"Sum Tufel aud)!" antwortete Crackentborb. "fie haben bic rotbrodeigten Dragoner von Carlible bei. (iid)."

"Siun bann," fagte Nanty; "fo miffen wir wies: fir unter 巨egef, fonmt Mr. Fairforo. Shr múbt auffitsen und rcuten. - Er bort mid nidst, - id

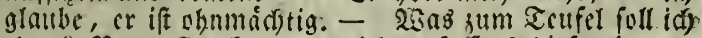
thun? SBater. Eradeentborp, id) mus. (Eud) sicfen iungen Jiann Inffem, bis ber: Eturm aubgeblafen bat, - bort Shr? cr hat eine Sotfdajt an ben fairb von einent ans Dern Alten; ex Eann weber reuten nadg geben, id mus:

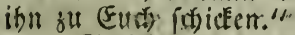

"Sd)ickt ibn fum Garnen hin," fagte Crackenthorp;

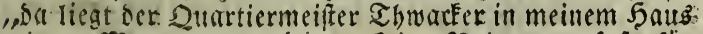

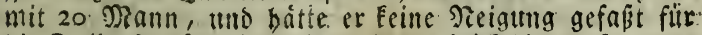
bie Doll, io batte id Ecinen Afugenblid bieber Eommen

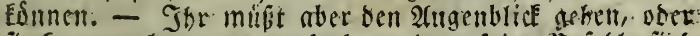

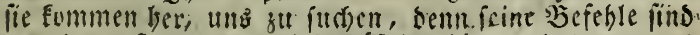

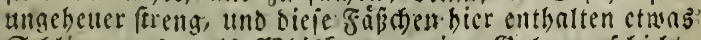

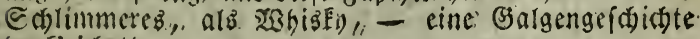
ben E' id).".

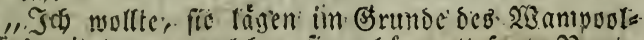

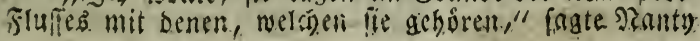


ewart. ,260er fie fins cin Sheil ber fabung, uno mas

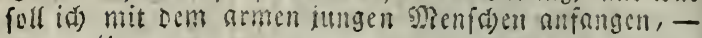
"1"

"Ei mas; foron mander befere Sumráce bat fir nuf ben Soden legen mulpen, mit eimem Meantel fibcr

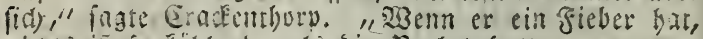
ni(b)ts if is Fithlens, als. bie Nendilufi."

"Ia, ex mirse morgen fribe als genug fenn obne 3weifel, nober es if einc aute Eeele, er foll nicht fobald Ealt werden, menn id) helfen Eann," antwortete Der ("a= pitain ber fpriugensen Jenny.

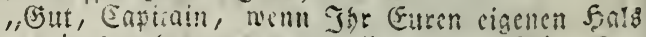
firr ben cines nobern magen wollt, warum bringt ghe ibn nitht $z$ ben alten Friulein zu Fairlabics? "

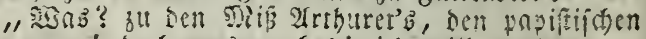

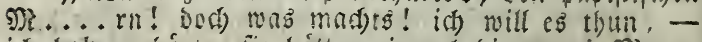
ic) babe gchort, fie hatten einmal bie ganze Mann= (i) aft einer Sorigg nufjenommen, bie an Hfer forane site."

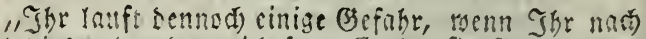

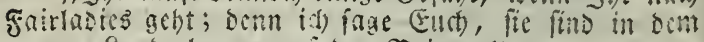
ganjen Rante hertm auf Den Scinen."

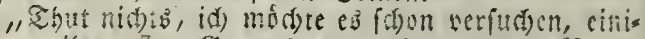

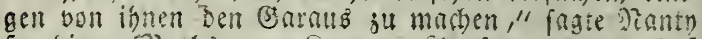

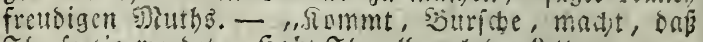
Igo fertig metbet. Sabt Thr alle gelasen?"

In, ja, Eapitain, wir nerben in einem Stugens bitu fertig fern," fagte bie ₹ruppe.

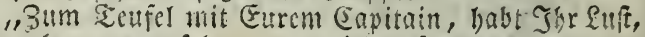
nich) gehangen zu fehen, wein id) gefangen gernumen merse? ग2tn ङีlick zu."

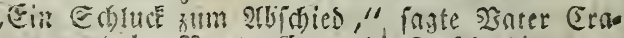
denthary, tho kat Pinatis Emart bie Flaid) bin.

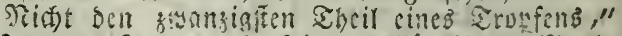

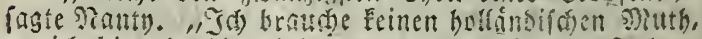
- id bin chnebin bisis geriag, wenn's ans gect)ten

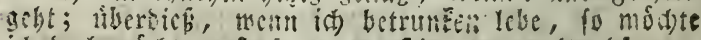

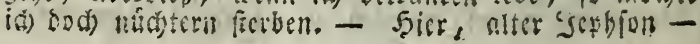


Ifr fend das gutartigfte Dhicr unter ifnen, fetzet sen Suritaen zwifden uns auf ein rubiges Pferd und wir wollen its bann fickerlich aufred)t balten."

2tls lie fairfurd vom Suven aufboben, fribnte or (d) mer, und fragte mit matter Etimme, wo fie ith bins fúbiten?

"2tn cinen Drt, wo Shr fo perborgen und fo rubig feyn Eonnt, als eine פT?atts in ibrem Ruch," fagte Sianty, "wenu wir (Ench nur erfit gliteflich binbrins gen. - Eebt wohl, Sater Eraffentborp, uns vergif= tet ben Quarticrmeifter, wenn Jhr Eünut."

Die beladenen pferde iprangen vortoerts in einem barten Srabe, inbem fie eimanber in einer finie folg= ten, und allf icoem zmeiten pierde faj cin farker

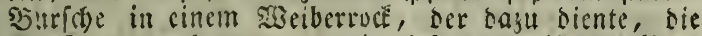
28affen zu verbergen, nomit biefe verzmeifelten glens

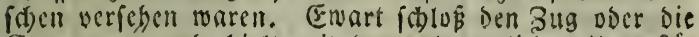
Earavane, ttho bielt mit Der gelegentlichen unterftüs

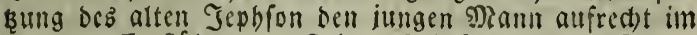

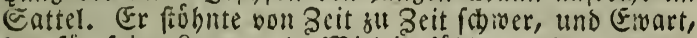
ber für feine fage mebr Ditleid fúblte, als man von feiner febensmeife batte erwarten follen, bemuihte fid, ifll zll erbeitern, und z"l troffen, indem er ibm einige siadsid)t von Dcm Orte gab, wo fie ibn binfubrten; feine Sroffezmorte aber wurben báufig unterbro(ben burd) bie NatbionsigEeit, feine Leute zu rufen, und viele von ibnen berloren fich unter bem sieraffel ber Fáfer und unter bem Jilirren ber fleinen Jetten, womit fie bei

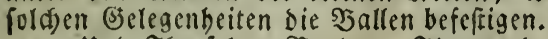

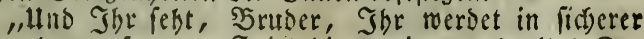
șerwabrung ieyn zu đairlabiez, ein gutes alteb $3 u=$

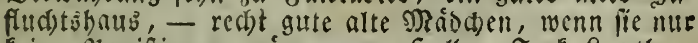
feine Mapiftinnen waien. - Sallo, Inal Sowtber, ba!tet bie Sinie, fonnt Ihr nict)?"

"ltub es fint red)t orbentliche feute, baben gemug su leben, die altell Midod)en, fino fo cine 2 rt Seilige, Sionuen u. f. w. semoesen. Der Dott, nerin fie reben,

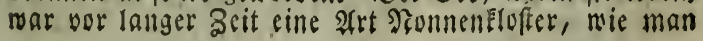


iie nod) iefst in Flanbern hat, manche feute mennen

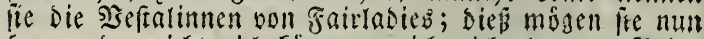
fenn, ober nicht, id) Eümmre ntid) niobt dorum. Şlin= Einfop, baltet bas giaul doer es foll (Eud) - - ! Eo unter grúpen 2IImafen und bei gutem Efien, fino fie bei

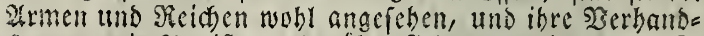
sungen mit plapifen, bariber fiebt man binweg. (53

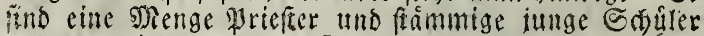
und Dergleiden um bas 5 aus ber, es if mie ein š̉ez

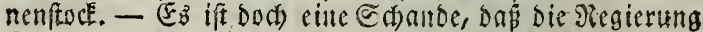
Dragoner nad) cin plant ehrlidien Eenten aubrentoct,

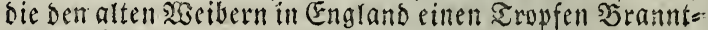
mein bringen, und diefe fumpenterls fo obne weiters. ben \$apismus cinfawarzen lápt, uns - Sourm? was-war bas fúr cin Dffeifen? - Nicin, $\mathfrak{e B}$ war nue ein Jibia. Shr Jem Eollier, feht Euch ein wenig um, wir muifen ibnen auf ber Sobe von şains ober im Grumbe von פ̧rottbole begegnen, fonft nirgends.

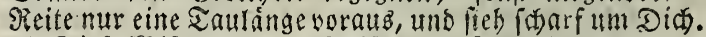

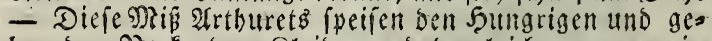
ben ben sinceenden filcider und dergleifjen, - mein Sater nannte fie zmar nur elente Sumpen, Eleibete fia.

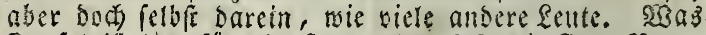

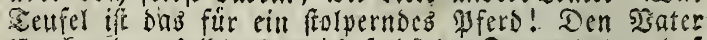
(Erackenthurp foll bod gleid) ferbft ber $\cong$ - I holen, bas et eimen ebrlidgen Jerl auf fo eimen etulperer febt! "

Durd folche uns ábntiche (seipráche, fo wie ourds feine woblgemeinte Bubringlide Eeit, vermebrte Nants ben Yeibenden. Buffand Sairforb's, ber von quálenden

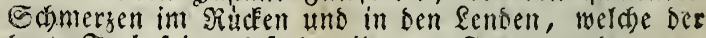
barte Irab feines Pferbes inm fur Folter mad)te, ges peinigt wurbe, uno bie rnube Etimme bes Eecmanns, melde bart all feinem Sobre tonte, batte foun fruber feinen Sopf, roie mit fdarfen siefiern terfidnitten.

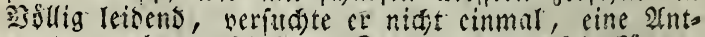
wort fu geben; und in ber Ihat war aud fein Esroers

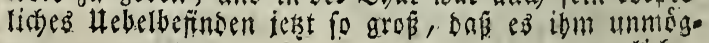

lifi): 
Maíc)en orin; reitet benn aus ber Sinie, und wartet bier bei mir; und Ihr, Eolfier, führt ben Sgaujen hins uber nad) sisalEinford, Dann wentet Shr (Eud) Dem 50a

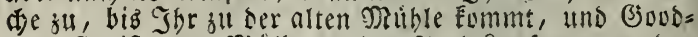
man Chrift, Der siuller, woer Peel fautemag werden (Euth fagen, wo Shr balten follt, aber ids werse (Eud) vorber nod einbulen."

Die Seibe ocr foftpferse benegte fid in ifrem frus

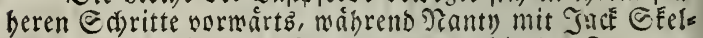
ton an ber Scite deb soega wartete, bis ber zug vor= áber und Sephion mit grairford bei ibuen rar; zur groben Erleidhterung Des Lekstern ging es nun in cinem

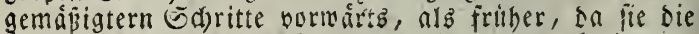
Erupve vorausgeben liçen, worauf senn allmáblid) Daß Jlappern und sas Gerafel in ber Entfernung erfitarb. Eie waren nod) Eeine Piftolemidusteite von dem Platie entfernt, no lie fich getrennt hatten, als eine Eurze פjie= gung jie vor einen alten verfallenen Thormeg bradte, befien plumpes fronton im Etyle bes I

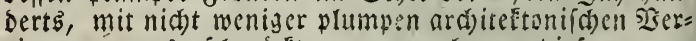
sierungén ausgejdmutckt war; mandse von biejen waren berabgefallen und logen zerfircut am פ̧esen, tum sie

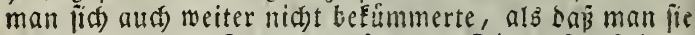
aus bem gerasen zugang entfernte. Die gropen fteiner.

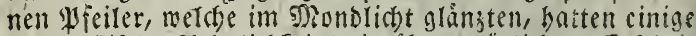

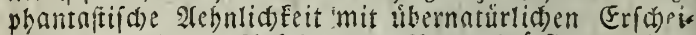

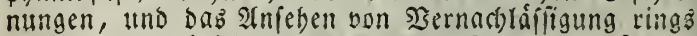
umber erregte bei denen, welde Den Bugang ipaifirten, Eeine vortheilhafte Ioee von Der 230 bumng.

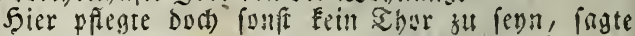

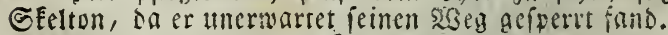

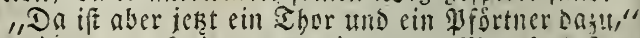
fagte eine raube Etimme von innen. "\$23er fend Sha, uno mas verlang! Ifr in biefer Etunde Der STad)t?" "\$Bir wollen mit ben Damen iprecten, - mit ben

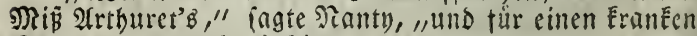
Mann um linterEunft bitten."

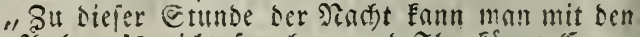

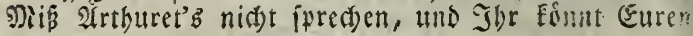


Era!nen Mann sum Doftur fibren," antwortete ver=

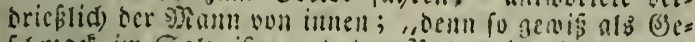

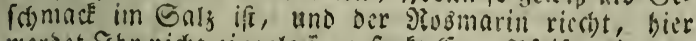

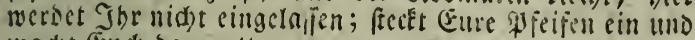
Mad)t End) Davon."

"2ilic, Ditt Banener;" fagte Efeltun, "bift Du Demn "Pforrite: aepurden?"

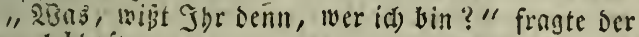
Dicuer lebbaft.

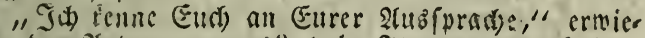
Derte ber 2lnicie; "waz? babt Sbe Denn Den Eleinen

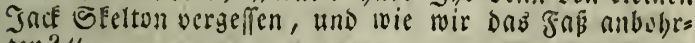
ten?"

"Isein, id) babe (Euch nid)t vergeffen," fagte JadE SEeltan's '̉eEannter; "aber meine Sefeble lino bee frimmt, niemant in biefer siad)t berein zu Jafifen, uno barum - - "

"Soir find aber bewafinet, uno laffen uns nitibt zus

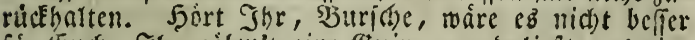
fir (Eucis), Ibr nihm't eine (3)uince, und liç̧t uns ein, als dak wir zuerit bic Shure einbred)en und Deinen Siopf nadber, benn id will meinen Sameraben bier nicht vor Eurer Soüre fterben feben, - das fend verfi= (d)ert."

"Non, id) weiß nid)t," - fagte Der Surfine. " was mar bem aber bas fir \$ieb, bas ill.foliter Eile voriberzeg?

"Niun, einige von unfern Leuten ven Şomues, Gtonincultrum uns ber Gegend unber;" antwortete

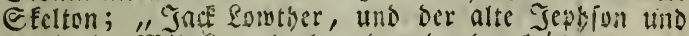
ber becite $23 i$ il Lampligh uno nnore bergleid)en."

"Niun gut," fagte Dick barbener, "fo gevio als

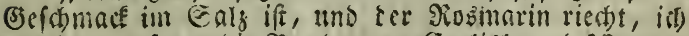
glaubte, ez feyen bie Sjanden ron Carlisle uno sistgton, und Der Ton brad)te mein 5erz auf bie Eumge."

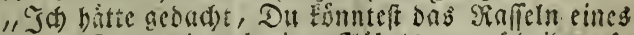
Faffes wom Silang cinco brciten Sábels unteríasiden, fo gut als cin Eálfer in Eumberland," fagte SElton.

" Solm, Şrtber, weniger mit Eurer Sinnlade, 
und mebr mit Euren \$einen, menn's gefált," fagte Sianty) "jeser sugenblid, ben mir bier fachen, ift ver= Juren. Uetht zu sen Danien, und fagt ihnen, eas soanty Enart bon ber fpringenden Senny cinen jungen 5errn mitgebradjt bat, ser Siriefe von ङd)ottland an cinen gewifler widstigen Sorrn in Eumberlano mit fien fubst,Das bie Eolsaten neg fino, und ber Serr febr Eranf ift, atlo menn ex nidht fu sairlasies aufgenommen wits, fo firbt er entweder bier am Shore, ober wirb yon Den Siothr: $:$ en mit allen fcinca payieren gefangen."

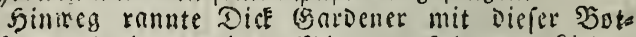
(d)aft, tho in wenigen sjoinuten fab man fichter f(b) immern, was Fnirford, Der in Folge Des Saltens zu fich fe!bft gefommen mar, üherzeugte, ons man Die fronte eines jiemlid) groben 230 hnhalifes Durdulief.

"Silie nun, Menn Dein freund Dice Bardener nidot wicoeriommt?" fagte Sepbion su GFelton.

"Sua Daun," ermiederte Der 2!ngeredete, "bin id) ibm eit phen folder Zraftament fouldig, wie Du, alter Jepbron; on Dan Eode erbalten baft, und i(b) werue nid)t wenizer chation und redićs znblen."

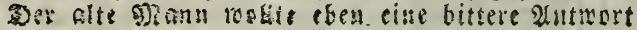
geben, als frine Breifel zum Gomeigen gebradt

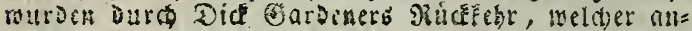

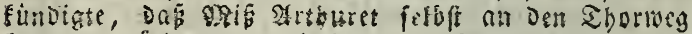
Eonmen rofrede, un mit itnen su fprewen.

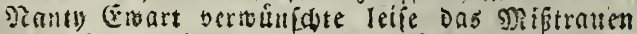

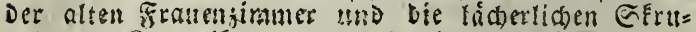
ye!n Der Satbolifen, welde fo viele $l l m$ fínde mad)=

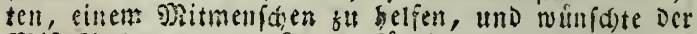

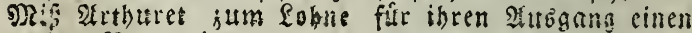
Derúli Reomatismus ober 3ahnmeb all Den Sals; nuer fo eben jeigte lid Die Dame, IInd fonitt alles meiterc Sortummen Eurs ab. Gie war on eittem Dienfinioben mit einer gaterne hegleitct, bei beien Sibit fie Dic antentelender io genaul letrastete, alo Die geringe Salle uno Die Gitterfube bes ncuen I bo= res eq geffatteten.

15: thut mir reid, פrasame grthuret, baf? 
wir Euth fo fpat gefroirt baben," fagte Santy ; "aber oer Foll ift Der - - "

"Seilige Jungfral! " fagte fie, "roarum fprecht Shr fo lant? Wisie? fend Sbr nidbt s'er Jiapitain Der Deiligen Eseroncba?"

"In, in, NRadame," crmicde:te Frwa:t, , fo neno nen fie wahrbafrig Die \$origg ju Dinkirch: :n, aber lángs Dens $4 l$ fer bier nent man lie die fpringenoe Jenny." "Shr braditet den beiligen 2 ater S5uvnabentura beruber, nidjt nabr?"

"In, in, Mrndame, id babe genug uon Dcm

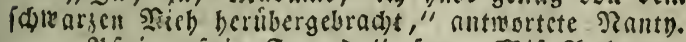
"Plfui, मfui, Freuno," ingte MRis Trthuret,

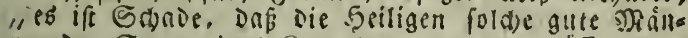
ner Der Eorge einco Seţers anvertraucu mülien."

"Das nutroen fie auth nist thun, Foadame, wenn fie cinen Edlingel pan einem sapifien finden fonnten, Der Die Silfife io gut Eennt, als ich; für oie (Eigenthumer bin idi) io feft, mis Etafil, uno fehe immer nads Det Ladung - mag es nun leben=

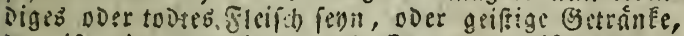
Das if mir alfes cins; uno Eure siatbolifen baben

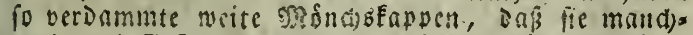
mal gnei Eefichter Darunter verbergen Ermen. S5ier Der Serr aber ift nin Eterben, uno bat Briefe bei lic) bon Dem Eniro bon Enmmetrees an Den Enird oer Eecen am Golman, wie lie ifn nennen; und iede Brinute, Die er bier liegt, ift ein szagel bull fei= nem Earge."

"Scilige 5g?aria! mab foffen wir thun?" fagte Mis sirtburet, "wir máfen ign aufnebmen auf ieoe Befalyr. - Jbr, Sicharo Bardener, belft cinem von

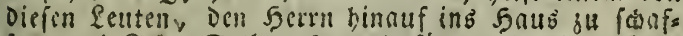
fen, und Shr, Eelbn, forbt Dafí, Daß er am Ende Der Inngen Gallerie fein simmer befómmt. - Ibr fend ein Siejer, Enpitnin, aber idj ocnfe, Shr fend red=

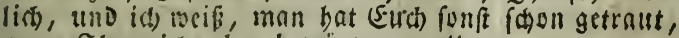
wenn She mid nber betrigt - - " 
von Eurer Erfohrung zu tálfichen, meine Praxis hat fid) allf oie jungen bef(itranft; nun auf, Mr. Fairs ford, 'gluth grlabt, Shr werdet bier gut aufgenom= men (evn); - verfuct ju geben."

2lian that es, und erfrifdit burd) Diefen 2 lufent= balt erÉlarte er, er Eưnne mit alleiniger Şúlfe Deg

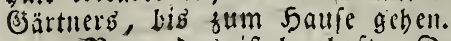

"Siln, Das if bershaft; DanE Dir Dide, Dab

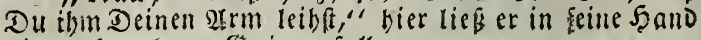
Die veriprodicne E゙uince fallen. -

"felt wobl Denn, Mr. Fairforo, und aud Shr, Thaome Artburet, Denn id) bin fdon zu lange bier gewejer."

Diez fagend warf or fid, fo wie feine beiden begleiter aufo pferd, und fprengte im Ealopp Da= oon. Doch trot DeB Eseráufd) Der STuje ibret giferde, borte man Den unverbefferlichen 2ianty Die alte Sallade fingen:

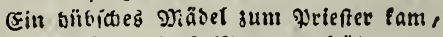

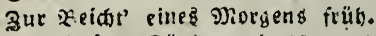

Bon Deiner Sünor, wie th Der sam'?

fiomm, iag' aufridtis mir fie!

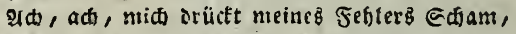

gretn Ëeliebter mid) licbte, wie nie.

"Scilige Sungfran!" rief Mißs Eerałkina aus, als oie unbeiligen Sone ibr Obr erretizten; "mag fúr

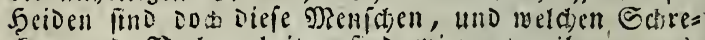
fen uno Sistlegenbeiten fino wir' unter innen aus = gejert! Die Seiligen mógen uns gneivig fegn, mas

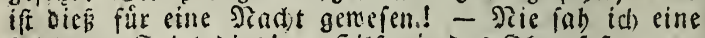

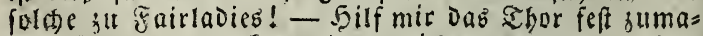
ben, Gidiaro, uno Fonm onnn mieder berab, um alifzu= paffen, Daf Eeine unmillfommacren Defudbe Éommen; - nicht Dïß Shr unwillfommen tåaret, junger Niann, benn es iff genua, infi Shr foldger Sulfe beourft, wie

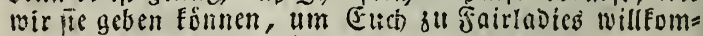
meil zu madsell, - id) mollte nur jagen, su einer anvern Zeit - Dod) es ift ia aud alles recht gut fo. Der (Bang nad) Dem Saaufe ift nidst Der anjenebmfte, 
Eir, feht ror Eud) auf Dell Boden, Der Bartner

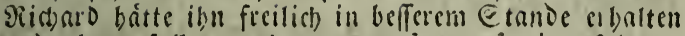
und ebnen follen, aber er muste auf eine spilgers fabrt nad) (Et. 23infredobrunnen in 23 allig geben." - Bier butfete Didét troden, was er in ein frilles Sancta Winifreda, ora pro nohis vermandelte, Da er merfte, Daj er ein innres (B) efúbl verriethe, Das mit

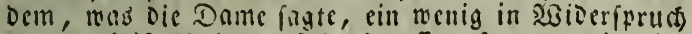

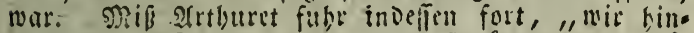

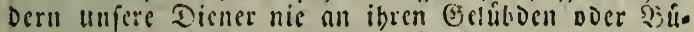
fungen, sjer. Jairford, - id) Eenue cinen febr murs

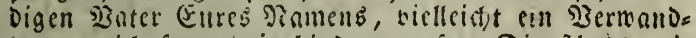
ter, - id) fage, roir bindern unicre Dienfiboten nie an Erfulltung ibrer Golüboe. Sorbute unjere Frall,

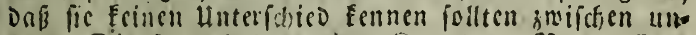
ferem Dienfte und Dem cines Siejel's. - Sichmt Euch in 2lcht, Eir, Shr merdet fallen, menn Sht nithos

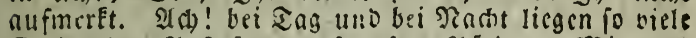
Eteine Des anfrufens auf-unfern Pl faben. Dit no(b) mandem ojercoe glcider art, Das ein june mitleidiges, afuer ausis einfáltigez fraucusimmer, mit ciner

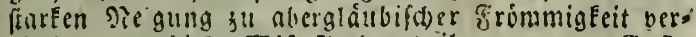
rieth, untertielt MRis 2lrthuret ibren neuen Baft, welder, ftulfernt an isDem Şindernib, Dab̉ die Tróm. migfeit frities Jubrers Ridgard batte im $23 \mathrm{eg}$ liegen lapten, enolid) cine feancrne. Treppe binallf ftieg, melde nuf Der Geite mit Esreifen doer andern berals Difhen Eonderlarfeiten gejicrt uar, uno cine $\mathfrak{Z} e r s$

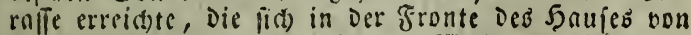
Fairlnoirs hilliog; es glito Der 2630 hnung cines nlts vaterifa)en (EDelmann bon einiger 3yedeutung mit feinen Siciben ron cingcferbten Jibein tind engen fens fern, bic und $I_{\Omega}$ noch mit eincm niten Thúrmden in

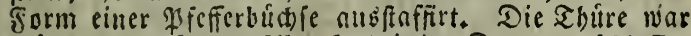

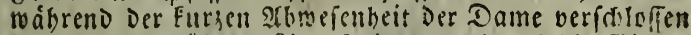
morDen, ein Differcs fidt t foinmerte Dutrd) Die (s) itter. thutre De: 5alle, wold be allf einen grofien gepflafterten Finum fribrte, Der mit Tasmin uno nudern Bjewád) fen bedeckt mar. alle senfter waren finfter, wie sid). 


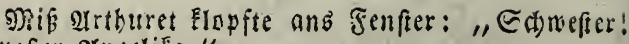

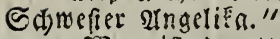

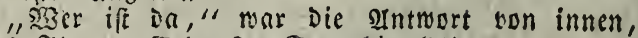
" feno Shres, Edinefrer Cerapbina?"

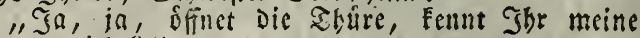
Etimme niøt?"?

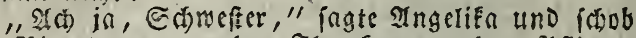
alle "Firgel toeg, "aber Sbr Eennt uniere glficht, uno Der Geino iff natham uns stl uberfallen - incedit sicut lec vorans, (er geht umber, wie ein brúl= lender Eome), fagt Das sibreniarium. - 2 en babt $\$$ br biebergcbracht? D Eamefier, mas babt Sor getban?"

"Fe ift ein junger 5jann," fogte Eernpbina, eilig" ibrer Echwefter sibiderrede unterbrecteno, "cin Nermander, glanbe idi), oon tinfrem wuroigen giater Fairforo; er tourse nm Stor zurudgelafien ona bem Eapitain Des gefegneten Ectifes "Die beilige Eends beva" - faft toot - uns mit briefon nerjeben an - -"

Dicfe lesten scorte murmelte fie nur mit leifer Stimme.

"शrun, Dn ift freilid nicht zu berfen," fogte Ingelifa, "nber-es iff ein ung!uctictior Zufnil."

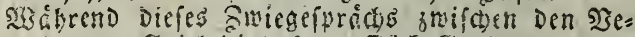

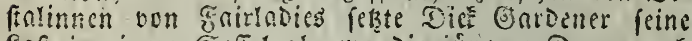
Eaft in einem Esffel ab, mo Die júngcre Dame nach

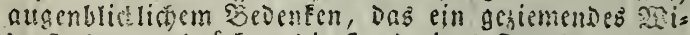
Derfieben ausdrickte, sic 5and eines fremien zube rubren, ibren seigefinger uno Daumen an Jairforos Sand legte, uno feinen gu!s befublte.

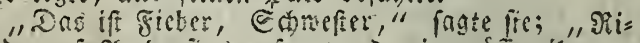
saro muß simbrofus rufen, und wir muffen ifm et mas gegen ons fieber fenoen."

Simbrofius fam fog!eid an, cin febr ordentlid und nditbar attefebender, alter Diener, in oer $5 a=$ milie nufgemachlen, tmo oon Etufe zu Stufe in Der Ertbutets Dienfte geftiegen, bis er endicid Salbarjt, Salbalmofenier, Salbellermeifter und ganjer Saus= bogt geworden war, D. b. menn Der grater Seistiger,

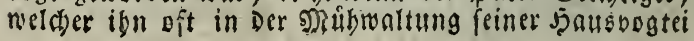


gropem Eraat $z u \mathrm{ibm}, u \mathrm{~m}$ ibm ibre 2rufroartung ju

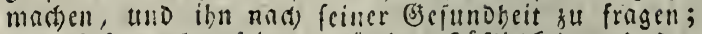
Damin holen galan jeine natürliđje Sofflid) Écit uno Der Danfe, oen er für ibre fdtellnige und miloe schulfe

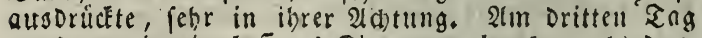
wutoe cr in ein befieres simmer gebrad)t, als Dass jenige war, Dab man suerft fúr ibn in פereitid)aft

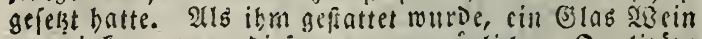
su trinen, war Diefer von vorzulifider Qunlitát; eine bon ienen ionderbaren, altoaterifhen, mit epinn, gerweben bifierjogenen Jlaiken wurden bei Diefer Eee= legenbeit vorgibradt, meld)e nur nod) in sen (s)eworts ben alter fanditze u finden find, two fie jeit mebr als einim balben Sabrhundert in ungeftorter Serbors genbeit gelegen baben mogen.

Eo angenchm indeflen Der arufenthalt fu fair= Indieg fúr eintell Sranfen fenn modate, fo mar er es Dof), wie fein ieghiger Intoobner balo bemerte, nicht in eben Don Grade firt einen Gellefenden. 2Als er Daś erftemal, fo wie er nur aus Dem bette fried)en Eonnte, an Das Fenfer trat, fo mar Diefeb eng vergit=

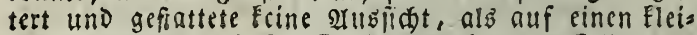

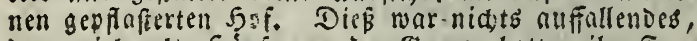
Denn viele alte Seáujer an Der Bsrenje hatten ihre Fen= fier auf Dieferbe sirt gefduchtit. Dann aber benierfte Fairford, Dá ieder, Der ins Simmer trat, ooer es verlief, Die Thure mit groper હorgfalt jedesmal vers

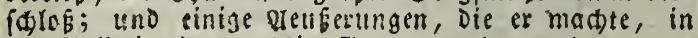
Der (3allerie oder aud) im Garten umberjugeben, wur= Den oon Den Damen forvobl, als son ibrem premier= minifter, De. Simbrufitu, fo falt aufgenommen, Daß ef nohl fab, eine folde stuboebnung feiner Sorred)te

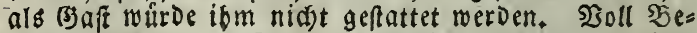
gierde, fich but oerfidern, ob Diefe auserordentlide

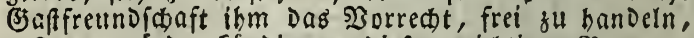
geftatten mübe, Eündigte er Dieferm widutigen פeamten nebft berdlidsem Danfe fúr Die Eorgfalt, momit er bebandelt roorden war, feinen Sorfak an, am nách= fen Forgen Enirladies zu verlafien, uno verlangts 


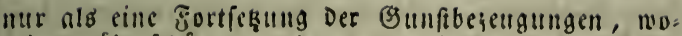
mit er liberfetiftet worden war, ein Tfero bis in Die nád)fte Etnot, IIID verficierte 5ir. Ambrofius (bier

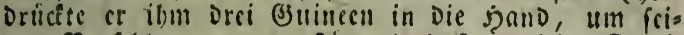
nen Torfding sul unterfrition) Dafi er feine DanEs barfeit nidit nuf cille folde sileininfeit bcjoranfen nerbe. Dic Jinger Des wirbigen Dieners f́dolofen fit) mafdinenmábig uber Dem honorarium, als ob ein Srrad in Der gelebrten foncultát ibin ein Recht gezes ben batte, bie şallft suzumaden; feine elnesrort

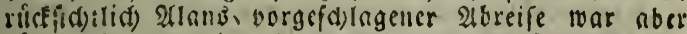
fúrs erfte altsireidjend, uns ald ct gedrägt mutrde, fieg fie sul oer peremptorifden serfitherung, onf ifm morgen nod) nidit gefinttet werben finne, nbsureifen; fein Leben babe in Den 2 ugen Der Damen allsuviel sisertb, uno fic founten eb nicht jugeben.

"S(t) wcif an beften, was mein rigenes feben

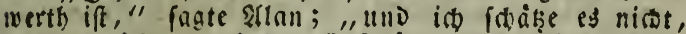
in Niergleirfung mit Dem (3)efd)áfte, Das meine auben. blictlicae Ibeitigieit erfordert."

Da er von Mr. Ámbrofitts noá feine genígende Quntuort erbielt, fo bielt er eg fur Das bicfte, Den Damen fellifi fcinen (Entidilub in Den gemáfigtiten,

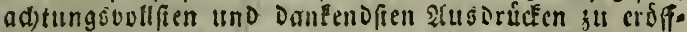
nen; Dod nber in Der art, oaf er feinen feften Ent= (d)lub ausoriclete, am Morgen, oder fpátefiens beu

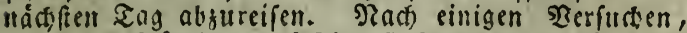

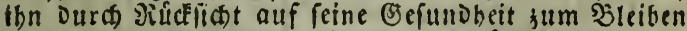

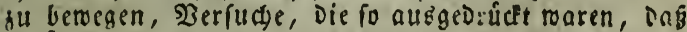
er uberzellgt wurbe, man rolle nur auf Dicfe vecife feine gibreife auffolten, erflárte innen fiairford gera=

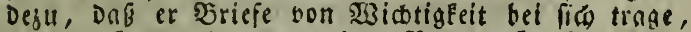
an ien Ferrn, Der unter bem Namen Gerries, Ficd. gatmilet uns Der fairo bon Den Geen befannt ( $P$; ;

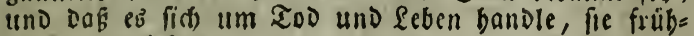
seitig absuliefern.

(⿹) mage es, zu fagen, G(j)efter Ingelifa," fogle Die iltere Mifs 2trthuret, "Daßs Dick ein chren=

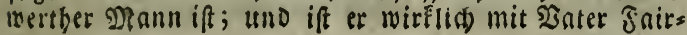


furd "serwandt, fo Esnnen wir Feine Befahr laus fen."

"Seftis Maria!" rief Die iungere aus; "YFfu Dowh, Eshmefter Eeraphina, pimi Dod! ! vade retro, - begio Did binter mit."

"(5) glt, glit; aber Ed)wefter - Edirefter alnges

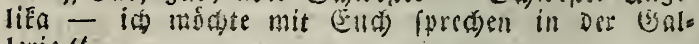
lerie."

Nun rauichter die Damen in ibren feidenen

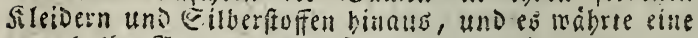
sute balbe Etunoe, ebe fie rocoer berein rauidten,

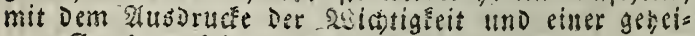
men Furcht auf ihren Eefidtern.

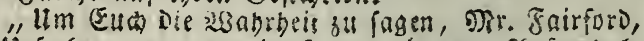
bie Urfade. marum mir seltion lángern sufenthalt

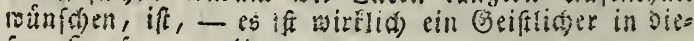
iem 5aufe - - "1

"Ein ganj ausgejeidneter Dann in Der Ibat, -" fagte Die Eatuefer Mngelifa.

"Fin Befnlbter Des Serm!" frimnte Gerapbinn ein, "und mir muden uns tmeres Oeroiffens megen freuen, menn Sho bot Eurer glbreife ein wenig mit ism iprecten mistet."

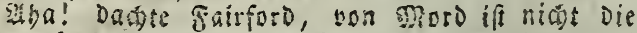
æiede, pondert auf cine Sjekebrung ift es abgejoben! Jib Daif oie guten, aiten Damen witat roi Den Jiopf

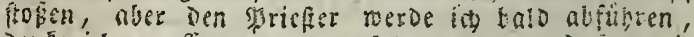

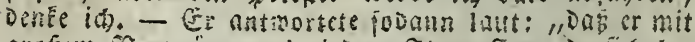

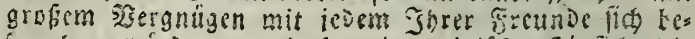

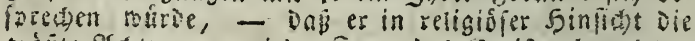

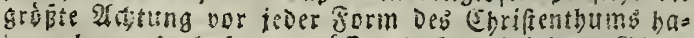

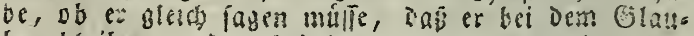
ben blriben werde, bei dem er ergogen morten fey;

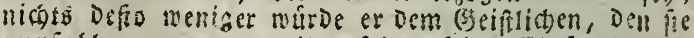
empiablen, ment er ibn febe, feime Ebrfurat lice feigen - -

"Es ift nimt gerade Das," ingte Shmefter Ees

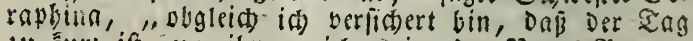

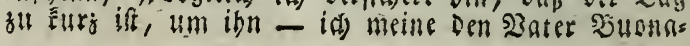




\section{4}

voller nuf ben Ton borden finnen, batte er nud) bers fündigt, Daß fid) Das fraupt ber saird)e in eigener pers fon nabe. Sie ffellten fich g!eid) Echildwadten, an beide Seiten Der Shure, Durrd weldse fids bie lange Jaallerie in Fairfords simmer endigte; hier franden fie

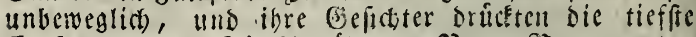

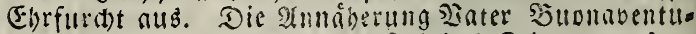

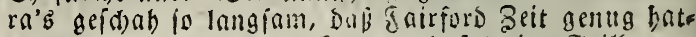
te, alles bies zu bemerien, und fid) im Etillen ju vermunsern, wic ein fdblauer, ehrgeisiger griffer es dabin gebiadot habe, feine múrbigen, aber etwab einfäls tigen SBirtbinnen folden aberglábifa)en Eeremonien jul unterwerfen. Soater SHonnocnturab Eintritt und

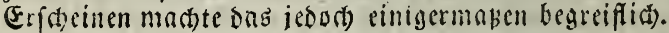

Er war eill Mann von mittlerem Alter, ungeo fábr viersig oder briuber; aber Eorgen oder sinftren. gunngen, ober ein Had)láfiges sibejen batten ibm einen sinid)ein von frubjeitigem 2llter und peinen sigen einen gewifien Ernft, man modte faft fagen, כrate. rigkeit gegeben. (Esle Zlige blieben aber nod) immer,

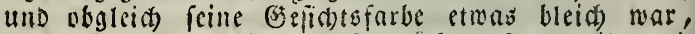
und bie feiner Ëtime nufgebruteten falten ibm eis nen melandsolifolien anftrich gaben, fo zeigte boch bis bobe Stirne, das grope mohl geformte aluge und bie

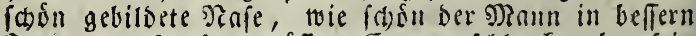
zagen gerwejen fenn maile. Er war íhlantê, aber fein gebickter Gang entjog ibm Den 30 ortheil feineb boben

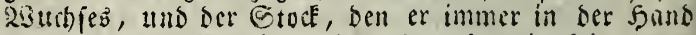
trug, und gelegentlid gebrattiote, fo wie fein lange

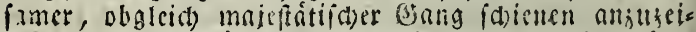

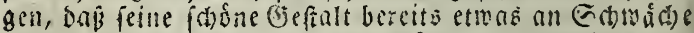
leite. Die Jarbe feines 5 gars Eunte man nidgt ents bedien, weil er, wie es Mode war, sine Ferricfe trug. Seine weltlide Jileisung war fadn, obwobl feierlid), und er batte sine Jofarde auf fistem Sout, ein Itmftand, Der Fairford nid)t in Erfaumen fethte,

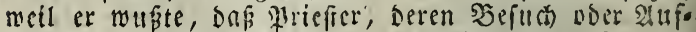
enthalt in England lie ben geferliditen Strafen un.

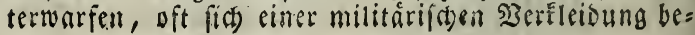


dienten. Als bicfer ftattlid) Mann ins Simmer trat, mad)ten bie beiocn Damen, sie einander bas (beflid)t sufesten, wie Eolsaten auf ibrem thoften, menn lie cinen Oberofificier fallutiren wollen, alif ieser Seits

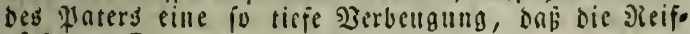

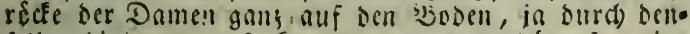
felben binburd) sull fuE Eu f(bienen, als bátte fich cine

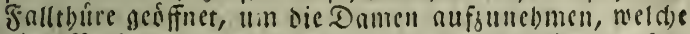
biefe sirrbeugung madten. Der ithater ideisn an fols d)e Ebrenbesengungen, fo tief fie and nuren, gewobnt, or mande lich ein wenig juerft gegen bie cine, Dann gegen bie andere Éd)nefter, "wabrend or mit cintr

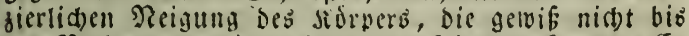

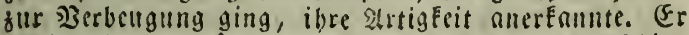
fodritt aber vorwáts, obue fie anzurcben, und foleten Daburd) anzmseigen, Dap ibre Gegenwart im zimmer nid)t notbrendig icy.

Eie entiernten fird aljo, inbom fie rucflings mit

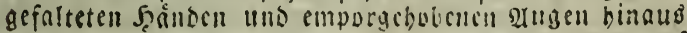

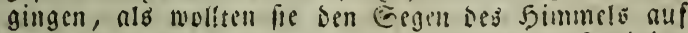
sen von ibnen fo hod) ucrebrten Disner ber Disligion berabfeben. Die Shute bes Bimmers wurbe hiates

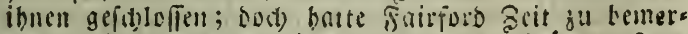

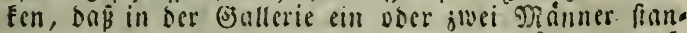
Den, ulid dafi diebmal nid)t, mie er fruber bemerlt

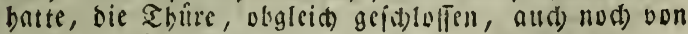
nuben verriegelt wurbe.

Sionnen die Buten Eeclen, Indste fairforb, bon

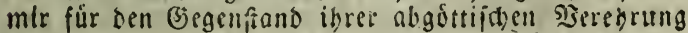
(3ifabr befúr(b)ten? alber er batte nici)t aeit, fernere Semerkungen zu madjen, Deinl Der Frembe war beo reits bis in die 9)itte bes Bimmers worgenten.

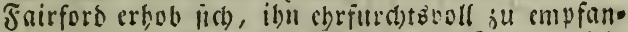
gen, nls er aber bie alngen allf feinen jefud rich. tete, glaubte er ful bemerken, dóp der plater feine Stlicfe vermicd. Seine Grande, unbefnnat zuble

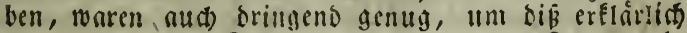
su mad)en, uns fairfors eilte, ifm ben stwang abs zunebmen, indem er feine Sjlicke zu şoben fd)lug; 
alb er fie aber mieder ethob, fallo er bas grofie, helle

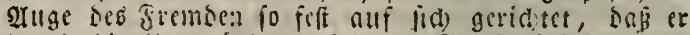

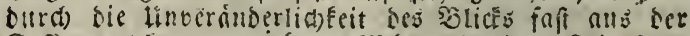
zonfiung getommen ráre. Sลábrend Dicjer seit fran. oen bitise.

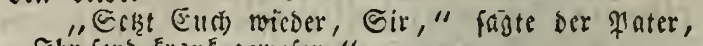
"IbE fend Erane gemefen."

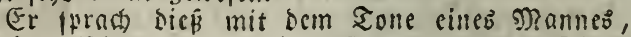

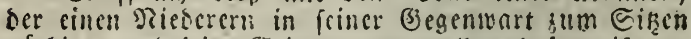
ndtbigt, tho feine Etimme mar voll und fotiorifid).

Foirforb mar etmas erfaunt, baß er lid) impeni. ren laffe burd sab sufcien oon Euperioritit, sas fod sigentlico nur gegen folde alsgentht metson fonn. te, liber meldye bie Ferligion sem Spredensen sine

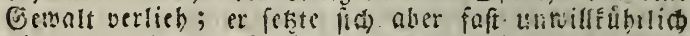
niescr, uns war in sorlegenbeit, mie er sen fur

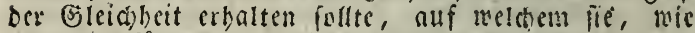
er wobl fiblte, eigenthas fieben follten. Der fremse besicnte fid) bes siortheils, Den er liebalten hatte.

" SNan bat mir gejagt, Eucr Shame ien frnim foro," fagte ser sinter.

Ann antwortete sur(t) eine Serbeugung.

"Ein forsttifd)er grovofot," fubi iener fort; "in Den weftlidien (s)egensen, glaube id), lebt cine fomitie roan (5)eburt und Siang, genannt fanirford von finirs ford."

Silan bielt się fúr eine fonderbare פemerfung son einem fremben Bjeifrlisten, senn bafür mufté cr ben ginater 3 nonasentura regen feines szameng bato ten, er antirortete alio nur, ar glaube, es fer fo eine familie ia.

"Eevo Shr vernanst mit ibnen," fubr ser Fro. ger fort.

"In) Darf allf bicfe Ehre Feinen 2 (nfwrud) mas

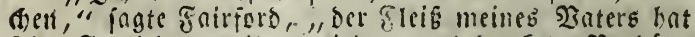
feime Eamilie aus ibren nicbern uno sunfeln Nierhálts niflen beraugagehoben, id bobe Eeine crbliden Aniprúdse altf Sftrjeidnung irgend ciner strt. Darf id mid nech ben urfacen hiefer frragen ertunsigen?" 
"Shr werbet es fogleid) erfahren," fagte 3̈lronas ventura, ber bei bes iungeh stannes Anerfennung jei=

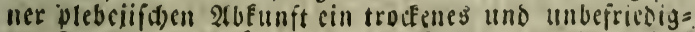
tes 5em! batte ertonen Inffen. Er bedeutete ibm biers auf, fig zu berubigen, unb fubr baun mit femen Fragen fort.

"23enn aud nidat von Stande, fo fend Jgr sod, 3meifels obne burd) (Stejunnung und Ergitbung cin शrann non (Ebre?"

"Ich) buffe, Gir," fagte gllan, bor llnwillen er=

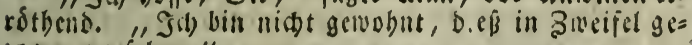
gogen z"l feben."

"ड̉ebulb, iunger Mann," Fagte ber uneribults

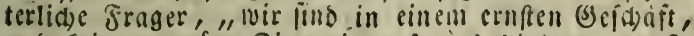
und Eeine unnukze Bicrerei mus lins bindern, ernfts baft dorriber 3 ll fpredsen. Thr wist wabridgeinlida,

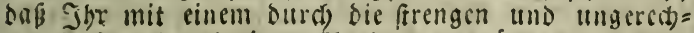

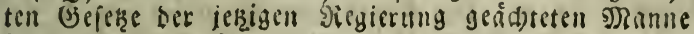
fpredst.

I(6) Fenne Das Gtatut tom Inbre 1700, weld)es

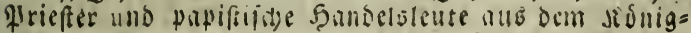
reidue verbannt, und in betretungsfate auf fumma= rifhe Heberfübrung bin zum Iose verdammut. Das

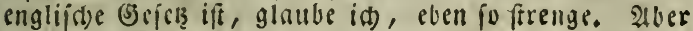

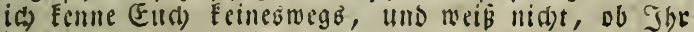

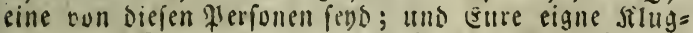

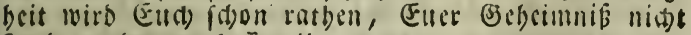
Eund werden zu lalien,"

"Sellug, Gir," pagte ber Priefter;", id be= für(b)te Eeine unangenehmen Jolgen, weil Ibs mid) in biefem Saufe gejeben babt."

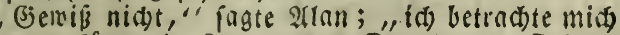
felbft, nls fü mein feben, Den Damen von Faitla

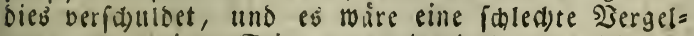
tung bon meiner Esite, wenn ida toss, was id) un= ter biefan goffrembliaten Dadje gejeben und ge= bort babe, náber ju erforfobell fudjen, ober bifannt madien mollte. In, menn id bem Wrátendenten fellof in foldder \&age begegnete, er murbe, weill auti) meine 
Loyalitat etmas sarunter litte, vor aller (3) fabr surc eine Snoiscretion von meiner Seite gefidert fernn." is- "Der \$rátentent," fagte De" givefter mit einem

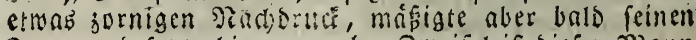

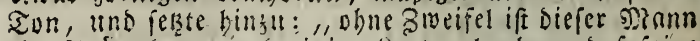
ein Prótendent, uns cinige Ecute glauben, Daß feine

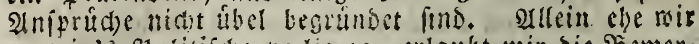
Ins in's 90 itifide verrieren, erlaubt mir bie Bemers Fung, Dus ici) erfisunt bia, einen Manm bon Euren Dreinungen mit sfir. פRanwell bon Summertrees uns ont. Siesgauntlet in vertrauten grierbaltniffen zu finsen,

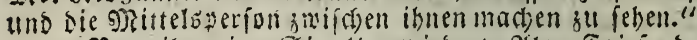
"Derzeibt mir, Eir," ermieberte quan Fnirfurs, "ia) frrebe nidt nadj ber Ehre, ibs sjertrauter ober

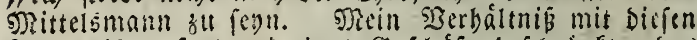
Reuten ift nuf ein eingiges (sefdofft befarankt, sas mich febr nabe ninget, weil eb bie Sidjerbet, viel= leicht sas Eeben me ues thenerfen Freundes betrifit."

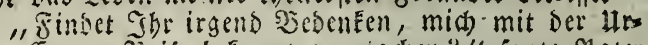

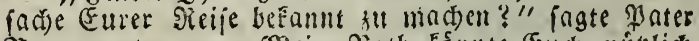

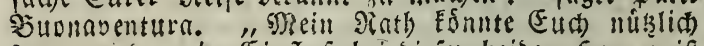
feyn, tho mein Einflub bei biejen beiben Serren ift bedittend. "i

Tairford formanfte cinen arugenblice, ermog in ber Eile die Umfanse, "ns fam ju Dem Ealuffe, bas

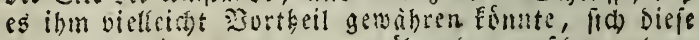
Sijerion geneigt ju matien, weibrent er nuf ber nne ern Eeite nichts wagte, wenn er ibr Den Gegenftand feines Reife mitrbeilte. פRadibem er Daber Eurglid die Soffs mung ausge(prod)en batte, Ne. Stronabentura wurbe bas nemlid)e 2 ertrauten gegen ifn beweifen, ons es son ibm verlange, gab er ibm Eurz giandricht von Darfie Latimer, - von Dem Bjebeimní̄, Das úber feimer (3)e burt walte, - uns von sem linglúc, bas ibn betrofs fen batte; enslich non feinem eigenen (Entfolub, feis

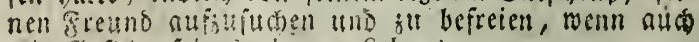
mit Gejabe feinevo. cigeren zebens.

Der Eatsolifá Priefer, beffen Gitte es gu febn

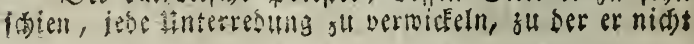


felbft sen 2lnfró gegeben batte, madite feine :emer= Eungen filier bas, was er borte, fonsern tbat nur cin Want nbgeriffene Fragen, mo nid)t red)t flar (b)ien; Dann crlob er fid son feinem Sitze, ging zmeimal im Bimmer auf und ab, und murmelte nit sadsornd juifden ben Sabnen bas nisort: ", Iollfoyf!" glugenf(d)cinlid aber war or ge= nisbut, alle beftigen Sewegungen zu beherrfden, benn

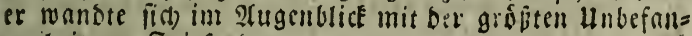
genibeit an Fairfors.

" $\mathfrak{W} \mathrm{cmn}$ Tbr glaubt," fagte er, "obne Euter 2 gort

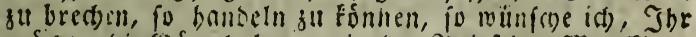
modetet bie stute haben, mir ben Jrief bes gRr. Fiax. nell voln Summertrees zuzcigen. S(t) modjte bcjon= Der bie aufid)rift fehen."

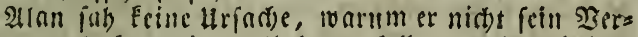
trauen aud) fo neit nusbchnen follte, tuld gnb ibm obne weiteres sen Srief in bie 5and. গRadjoem er ben Sriff, wie fruber SRanty Evart und ber alte Drumbull berumgetwendet, unb, wie lie, bie arsoreffe mit sieler (Senauigfeit unterfud)t batte, frogte or $21 a n$, ob er biefe 230 rte bemerft batte, und niej juglerid nut cinige an ber untern Geite des Sriefo mit bibleiffift grmadte

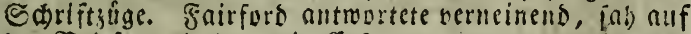
Den Vrief, uno las mit Erftnunen: cave, ne interas Bellerophontis adferres (búte Did), \$jellerophons כirief 3u úberbringen); biefe 28 arnung traf mit Der (Ermab= nung ses. Fr. Erosbie, er murbe wobl thun, in sen Jirief binein zu feben, deffen lleberbringer er fey, ro genau zufammen, Daß́ er im SEegriff war, aufzuiprin= gen, unb cinen $\mathfrak{z} e r f u d)$ zur Studt zu maden, obne zu miffen, wohin und mefseregen.

"Sleibt fiken, junger Mann," fagte ber Pater

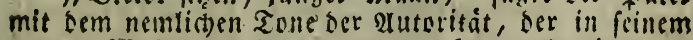

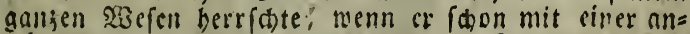

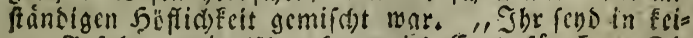

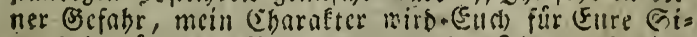

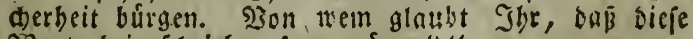
230 rte beigefíricben fern mogen?" 
Saitforb biette antworten Eśnnen: "yon Fanty

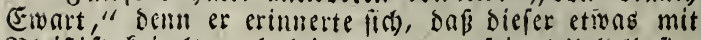
Bleiffift Erizelte, obgleid er wegen feines Hebelbefin= Dens nidt) gennat barauf. gemerEt batte, too und auf was. Da er aber nidjt twuste, welden ग̃erbadjt ober welde folimmen Folgen ber/arntheil! bes Eeemanns an feinen 2 ngelegenbeiten auf ibn bringen Esmnte, io bielt ex für's befte, $\dot{\gamma} \| l$ antworten, er fenne bie 5 sand nid)t.

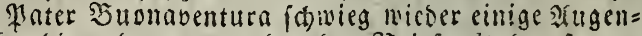
blicke, sic er sajull anwanste, den sorief mit ber ftreng= fell 2UfmerEfamEeit z"l betrad)ten; bann trat er an ein Fenfer, gleidjiam um bie 2tufichrift, ttho sas, was auf Dem umfdhlage ftand, bei fitirferem Sid)te genau fu unterfuden, und 2 tan Fnirford fab init eben foviel Erfraunen, als Míbergnugen, wie er Enlt uns befonnen, das Eieget erbrad, Den Sorief dffnete und las. ,5alt, Sir, balt!" rief er aus, fobald ibm fein Erftaunen erlaubte, feinem llnwillen sisorte jul geben; mit wels

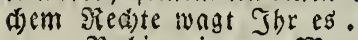

" Rubig, iunger Mann," fagte Der Fater und

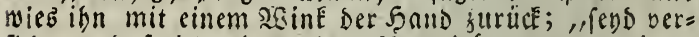

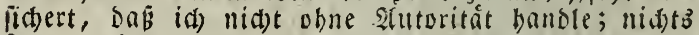
Eann zwild)en $\mathfrak{M r}$. Maxwell und Mr. Fedgauntlet yorgehen, sas idi nidft zu wiffen nollfommen bered)= tigt wáre."

"Das Eann feyn," pagte $\mathfrak{A l a n}$ bod fof aufgebracht;

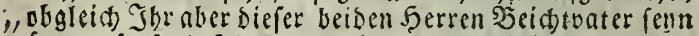
moget, fo fend Jbr dod) nitit ber meinige, und da Jhe sas Siegel eineỏ briefs erbecht, ber meiner Sorge anbertraut wurbe, fo thut Slyr mir - - "

"Jein Unred)t, id) verfid)re (EuG)," antwortete ber

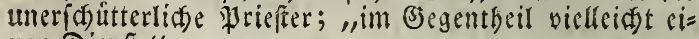
nen Dienft."

"Id) verrange Eeinen 2rortheil um foldhen Preis, oder ber auf foldhe siseife erbalten miro," antwortete

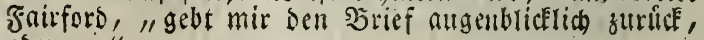
oder - "

"Go lieb (Eud) Eure Cicherbeit ifit," fagte Der \$rie=

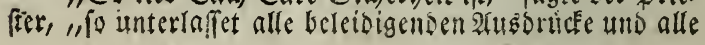


Drobemben (beberben, id) bilt nid)t ber Mann, ber fid ungefraft broben ober belcidigen lást, und eß̉ find genug

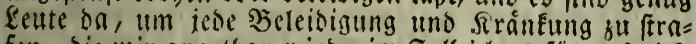
fen, bie mir angetban wiro, im fall icl) $\mathfrak{C B}$ für unf(d)ick

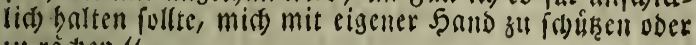
su raitben."

2lls er bief fagte, nabm ber pater ein fo furdftlofes श्Befen uno cill fo rubigez atrichen an, bais ber iunge

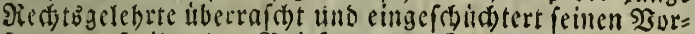

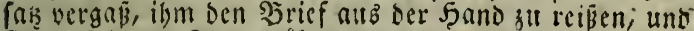

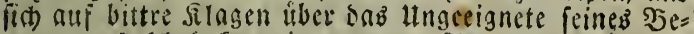

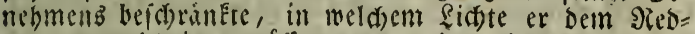

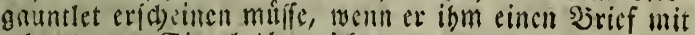
erbevai)enem Siegel tiberreidse.

"Dafin:" fagte gisater 5itunaventura, "foll binrei= dent geforgt merben. I(t) mill fribft an Sledgaintlet

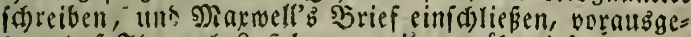

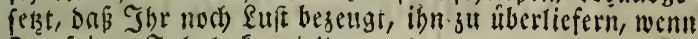
Ior feincit Jubant Eennt."

Er gab fosam ben \$rief an Fairford surúd, uns to er bemertête, dẩ biefer zauscrte, ifn zulefen, fagte. cr mit siadoruck : "febt mur, Denn es betriffi (Eud)."

Diefe afnmabnung, verbunben mit ber friberen bes

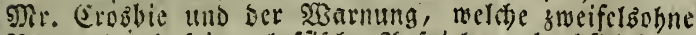

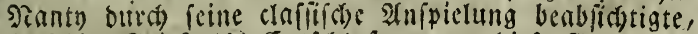

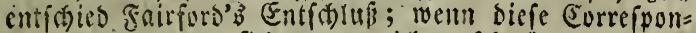
senten, badste er, fid) gegen mich verfactioten, fo babe

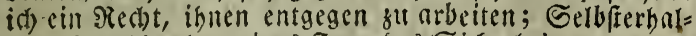
tung fowphl, ars meinç freundez Giđferbeit verlangen,

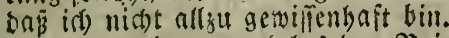

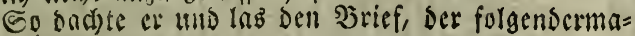
Gen Initete:

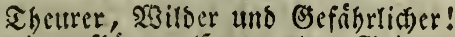

Sisollt Thr nie auffioren, Euern alten Epiknainen zu verbienen? Shr babt endia Euer 23 ild aufgeftsbert,

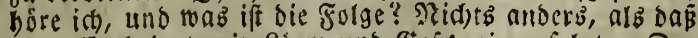
mant (Eud) ieķt mit firm uno Befóthei verfolgt. Der Heberbringer biefé if ein junger nafentweifer 2lovo Eat, weldier eine formliche serage gegen (Eud angebradt bat, 


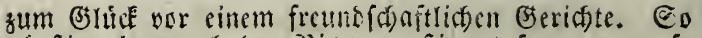
gunftig aber auts ber siditer geftimmt feyn mag, fo fonnten dod Eouline. Sennis uno id isn nur mit Mrithe

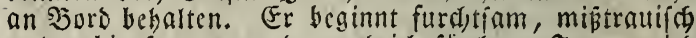
und unbiegfam zu weroen und ich) fürdete, Jenny wird bald ihre Stirne vergebens gegen ibn farten. I

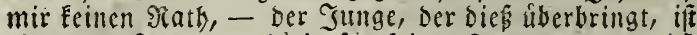
eiin guter Junge - thatig fur feinen Frettnd, - und iक babe incine (Egre verpfindet, bafi er Eeinen yerionliden Unannehmlicheeiten auşgejeb̧t fegn foll, - meine Ehre

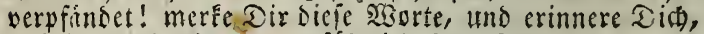
Das id auch mild und gefábrfidh feyn fann, io gut als meine s?ad)barn. Fot babe ibn aber nicht gegent eine Eurge (sefangenifaft gefichert, und ba er ein regfamer,

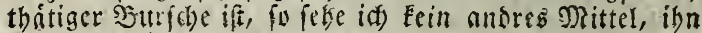
fo lange aus Dem ş⿻

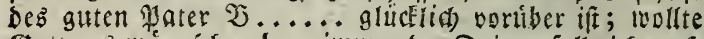

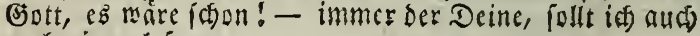
noc) eirmal fern

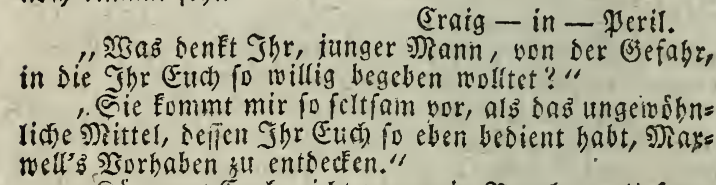

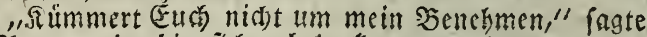
Ser Yater, ,id) bin ficter bei aftem, was idy thue, und

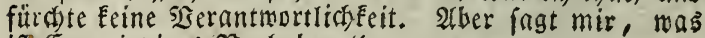
iff Euer iekiges গ̧orbaben."

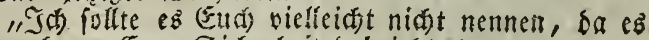
(ich auch un (Eure Eidberlecit babei bandelt."

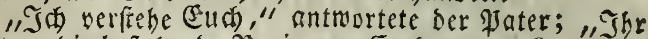
wollt an bie beftehende Siegierung Eub menden? - Das Eann auf Ecinen fall geftattet mersen. - Eber baltch

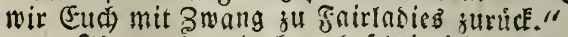

"Ihr werbet boch mahrifheinlich," fagte Fairforb,

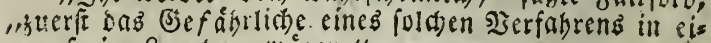
\#cm freien san be crnigen."

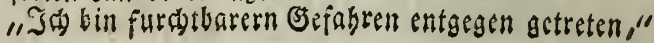




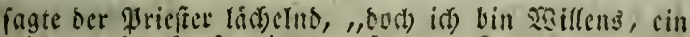
milberes 2tuBEunftemittel ju fut)en. Sommt, lapt unz bie Endye zu cinem 23 ergleid) bringen."

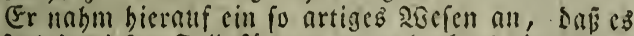

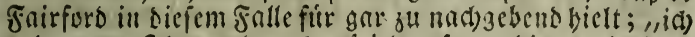
nebme nu, Shr wetset cä zufricoen fenn, bier nod) cinen Eng oder simei in siermabrung zu bleiben, porausgejekt," Dab id) (Eud) mein feierlió) Diann, ben Shr fudbet, treffen, - ifn in volliger $\bigodot_{i=}$ d)erbeit treffen, und boffentliob aud) ganz gefund, unb

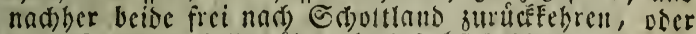
nad) Eurem (B)efallen úber (Euc) ferbit beftimmen."

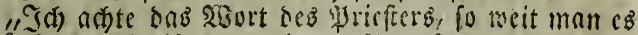
oerniuffiger siseife von cinem Preteftanten ermarten Eann," ermiederte Fair ford; , aber mir fobeint, Ibr Eonnt faum son mir ermatten, ba

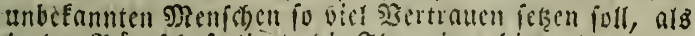

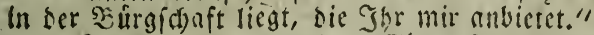

"Id) bin nidgt gecwobnt, Eir," fagte ber gater in

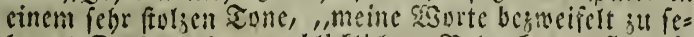
ben." Dod nad) augenblidtidsem bebenEen verflug bie

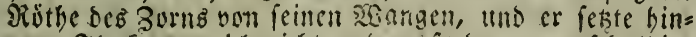

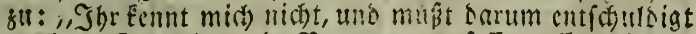
wersen. Td) will mebr Bertraten auf Eure Ebre ferzen, als Ibr sistlens foteint, ju ber meinigen zu faffen; und ba wir cimmal fo acfielt fino, sa bez andern verlajen mus, fo roill id) (Eut) fogleid) in Freibeit feken, und mit ben Mitteln verferen Infen,

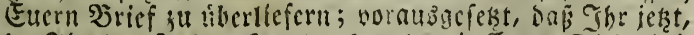
ba Sbr ben Inbalt Eeunt, es nod) mit (Euter E iberbeit

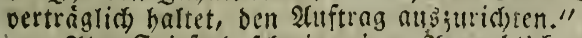

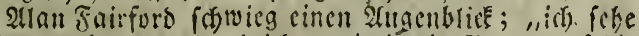

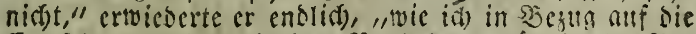

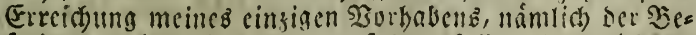
freiung meinas forcunes verfabren foll, whe mids an

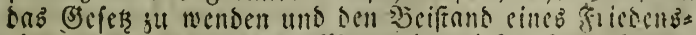
risters z" verlangen. Saenn ici) Dieien fonselbaren Brief bes Mr. D?armell, mit beffen Inbalt ind auf eine 
fo unermartete sieife be Ennnt nurbe, überliefere, fo theile id) nur feine Ëefangenf(h)aft."

"llno wenn Shr (Etid) an cinen Friebensrideter wen=

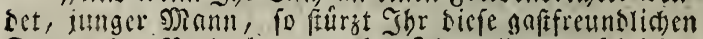
Damen ins Jerberben, wereben Shr, aller menfd)lidjen

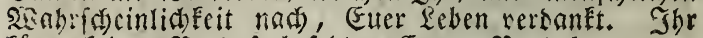
finnt Eeinen Serbaftebefebl zu Eurem 2̧orbaben erIan= gen, ohne rine genaute singabe alles befien, was Shr in fen lesten ₹ngen erlebt babt, zu maden. (Fin Friedens $=$ richter mirbe Eved vertitidten, eine bollftandige siand)=

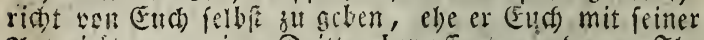
2!uturitit gegen cinch Dritten betwaffnete; und wenn She riefe Sindriditen gebi, fo if bie Eidjerbeit biefer Da men nets mensig gefóbriset. Shundert Epione baben fabn ibre astrgen auf siefen sufentbaltert gerid)tet, und rid = ten fie nod), aber (Sott wird sie Eeinen befdithen." Syicr Enctijigte er fich ondict, tig, und fubr sann fort "Ib: finnt nun cine Etwnoe uber ben beften glan nad)=

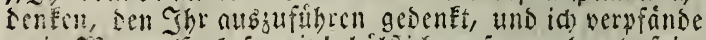

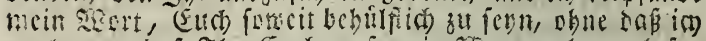

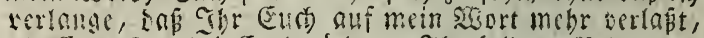

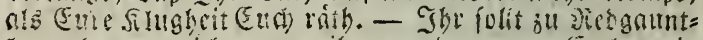
Iet echen, - ich ncunc ibn gerabeju, um Evd) mein

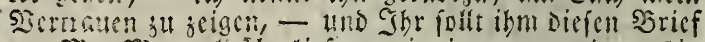
yon Nir. Niakwell uiberliefern mit einem bon mir, morin

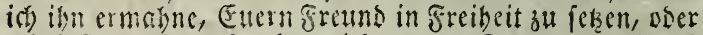
minigftens Eure \$erfon nidgt angttaften, weder Durd Eefongenbaltung, ned) auf eine ansere giseife. 2ijenn Tht mir io weit traucn esennt", fagte or mit einem frolzen

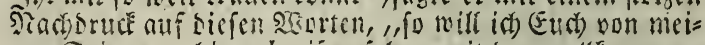
ner Eeite ron bicr abreifon fehen mit bem sulfemmen=

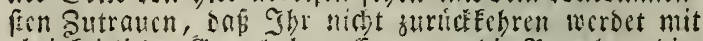
obriafeitlid)er Cerrali bewafinet, um sie S̈ewohner bie= fes 5 alles zum serbetben binmegjufdeleppen. Shr jeyd jung und uneriabren, crzegen zu einem Eemerbe, sas den

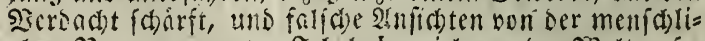
d)en sintur ergettat. Tab babe viel von ber siselt geie= ben, und beffer, als sie meiften Sienfden erEannt, wie 
fehr gegenfeitigeß $\mathfrak{S e r t r a u e n ~ i n ~ § e b a n d l u n g ~ w i d j t i g e r ~}$ Begenftande erforberlich ift."

Er (prad) bieß mit cinem 2 Anfehen son lleberlegen= beit, ia von 2Autoritat, woourch Jairford, trok feines in= nern (3)genfrebens, fo febr zum Ed) weigen gebrad)t unb

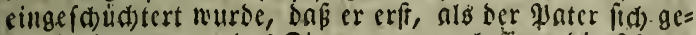
wanst batte, um bab Bimmer bu verlalfen, bie suorte fans, ibll zu fragen, "nab die Jolge fenn wübe, menn er

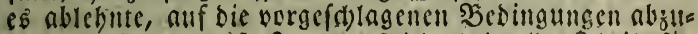

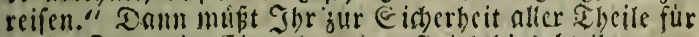
cinige ₹age ein Eimwobnci unn gairlabies bleiben, wo rir sie Sittel baben, (Eud) zurlidizubalten, und die Eelbferbnltung wiro แas in siefem falle fivingen, Bes=

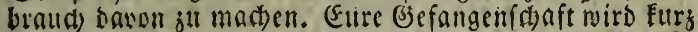
fenn; Die Ead)en Esmen nicht lange fo bleiben, wie fie fins. - Die sidolfe mû̉ bald anffitcigen, ober fish für inmer liber uns nieberlalien - henedieite! "

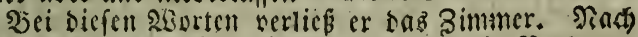
feiner (Entfermung fuiblte fich) fairford fehr in $\mathfrak{X}$ erfenen= beit, mas er nun thun folle. Eeine Ergichung fomohl,

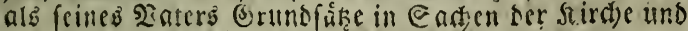

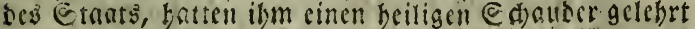
vor silapifen, fo mie cincn feften (S) lauben an olles, mab ibm son Der wunifden Treut ber Sefuten unt oon bem 2uรี worben mar, nosurdi bie Fatholifshen griefter, wie man allgemein giaubte, ber $\mathfrak{X}$ crpflidtung zu entgeben fuds= ten, gegen $\mathfrak{s e b}$ er ₹reue und (B) nuben zu balten; bod war in Dem 2infants und ben Sasorten bes Pater buona=

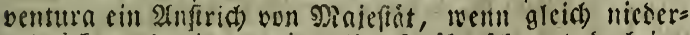

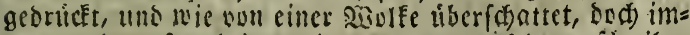
mer nod) grof und imponireno; $e^{3}$ mar (d) neer für inn, dieß sic feinem Drben uns feiner Sieligionsparthei fift und

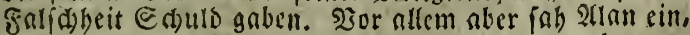
wenn er nid)t feine Sreikeit nad ben ihm angebotenen besingungen annchime, fo merbe er mabrfdeinlid) mit Eemalt zurlickbehriten werben; in ieber Sinfíg)t gewann cr aljo burd Afnnabme ocrfelben. Eine Denngftigung 


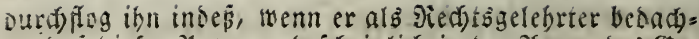
te, Das ciefer Plater wahridgeinlid) in Den 2lugen bes (J) =

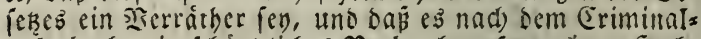

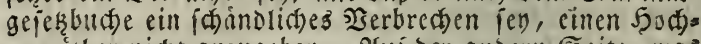
verráther nid)t anz̧ugibsu. 2At ter ansern Ecite, mas er aud) Senfen oder argaghnet modite, fo funtte er es bod) nicht auf fids nebmen, ju jagen, ber siann fey ein

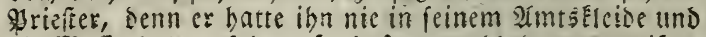

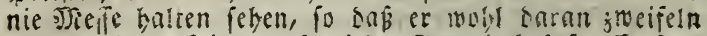

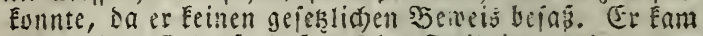
alio ju sem £

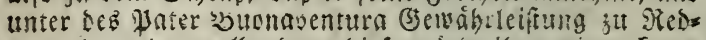
gauntlet geben wolle, benn bicfe-mutre ifn, wie er Faum

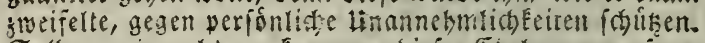
Gollte er einmar saju Esmmen, bicfen Eselmann zu jures Gen, io fúble er nech das nímlid)e Butrauen zut fitg, twie

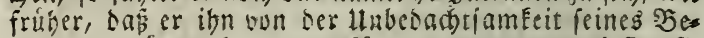
nebmens muroe vibergeugen fonnen, menn er aud) Darie

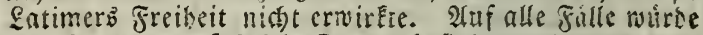
er erfabren, no lid fein greund befinse, uno unter tols Gen $l$ imitanden.

Da Sran nun entidjoffen wor, fo martete er mit

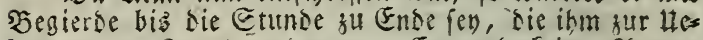
berlcgung geitattet norsen wa. Er wurbe feimen 2 fuget blick linger auf bie folter ber Hngebulo geipant, als bis sie beftimmte zeit verfiolfen nar, Demn fo trie tie

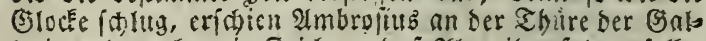
lerie uno madte ein zetiden, Dap atan ibm folgen folle.

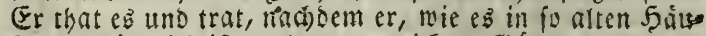
fern geroibnlid ift, mebrere vernickelte (s)ánge surdmanto belt hatte, in ein Eleines Bimmer, Das bequem eingeridis tet war, und morimne er ben Pater Suunaventura auf énem Oiuhebette liegen fand, in Der @tellung eines son

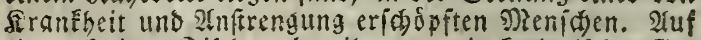
einem Eleinen Sif

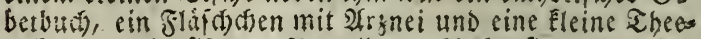
tafie son dinelifacm Porcellan. 2(mbeulus trat nid)t

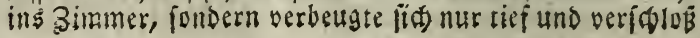


bie Thure fo reife wie moglid), fobalo fairforo cingetrex ten war.

"Eekzt (Eud) nieder, iunger Mann," fagte der Pas

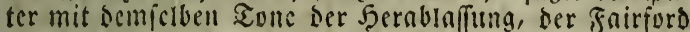
(c) on vorber in Nertounderung gefert, in beleisigt batte.

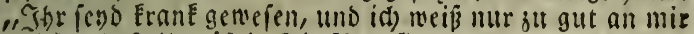

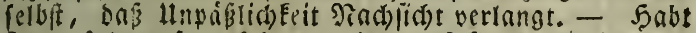
Shr," fube cr furt, fubaro er fab, Dafs lid) 2llan nieberge: feßst batte, "babt Sbr Eud entidlofien zu bleiben ober abjurciferil?"

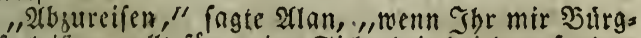
(d)aft leiften wullt firr meine Eidherbeit bei sem fonderbaren Mienfa)en, ber fíd) auf eine fo ungefeblid)e 28 eife gigen meinen Freuns Darfie fatimer benumnen bat."

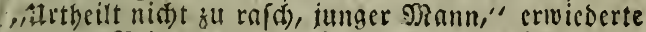
ber syater. "sedogauntlet bat in Sesiebung alt ben jun

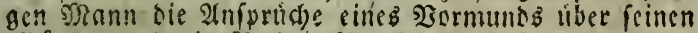

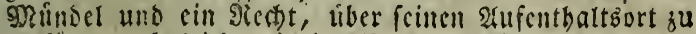

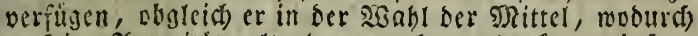

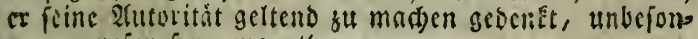
nen gewejen fern mag."

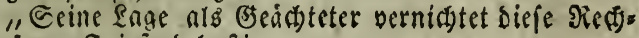
te," fagte sairford baftig.

"Eicherlid)," erwicberte ber Rriefter, lädelno uiber

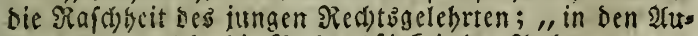

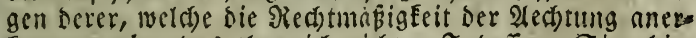
Eennen, aber sas thue id nidgt. Indeffen, Sir, bier ift meine Stirgidsoft, le pet den Subalt, und nebmt nidgt wicser einen llriasbrief mit (Fud)."

Fairfurd laz fulgendi sosorte:

\section{(s)uter Fruns!}

SBir (enden (Eud) hicr einen jungen Nann, ber bie

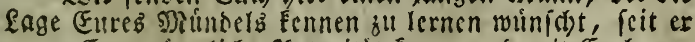
unter Eure viterliche 2aturität Eam, und mit (E)d un

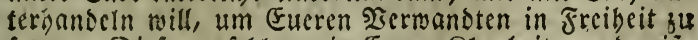

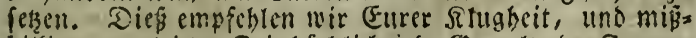

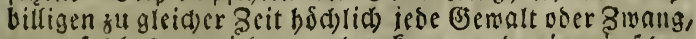
wenn folches bermieden werten Ennn, und wir munfoben.

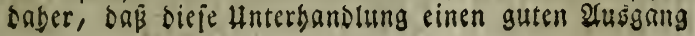


baben moge. Suf alle falle indeffen bat ser Heberbrin= ger unfer verpfándetes 230 rt fir feine Eiđjerbeit und

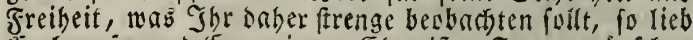
(5td) unire tho (5ure eigene Ebre iff. Ferner munfolen wir uns mit (Eud) zu befpredten, fobalo als moglids, sa

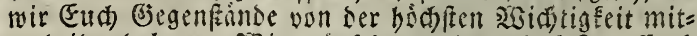
gutbeilen baben. SBgir wunfshen Daber, Daj Jgr Eud in aller (Eile hieher begclet, uno fagen (Eua) biemit ein berzlioges sebenugl

$$
\mathfrak{P . ~} \mathfrak{~}
$$

"Ist werset einfehen, Gir," fagte ber Pater, als

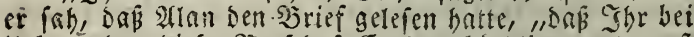

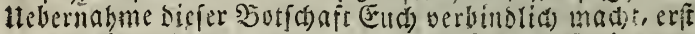

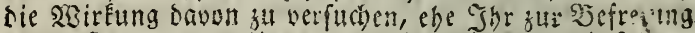

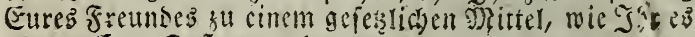
neunt, (Eure Bufucht nebmet."

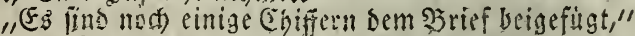
fagte Gairfort, als er den şrîf allfuncrefom gelejen bane, "sarf id fingen, wab lie bebeuten?"

"Eie betreffin mcine eigenen sangelegenteiten," antwortete be: Mater Eury, "und baben gar Eeine be= githang auf die Eurigen."

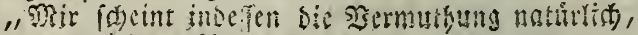
- - erivieserte sisn.

1" Shid)tร Darî vermubut werden, was mit meiner

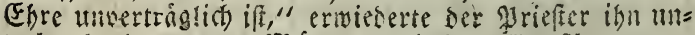

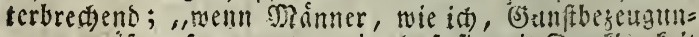
gen crmeifen, fo er:barten wir, baj fie mit Danebareet angenummen, nber mit banEberer 2 destung abgelebnt, nid)t lange unterfuci)t uns befittelt wersen."

(Id) nebme Euern sbrief alfo an," fingte Tairford nac) פRinutenlangem Heberlegen, "tno ber DanÊ, Den

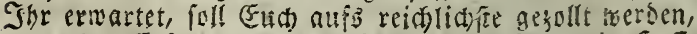
wenn ber Erfoig dem entfpridgt, wozu Igr mir Soff= nung gemadjt habt."

"(5)ott allcin gebietet liber ben 2lisgang," fagte

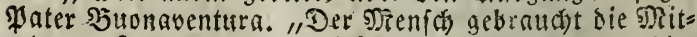

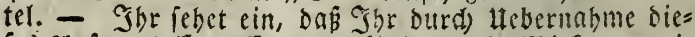
fes guftrags Eute Ehre verptimbet, bie soirEung mei= 


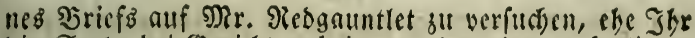

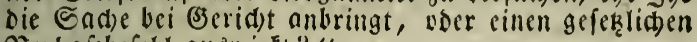
כerbaftbefobl ausivirEt?"

(I) balte mid) fur verbunden, to zu banbeln, als cin Siann von stort und Ebre," fagte Fairfurs.

"(3)t, id) traue (Elld), fagte ber \$ater. "Id will

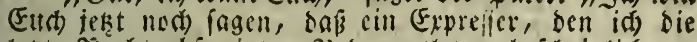

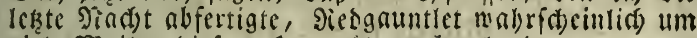
viele Deilen biejem Srte nuber gebrad)t hat, wo er eb nicts fict)er finsen wiro, irgend cine Eewnitthat gegen (Eucren Jretlito zu verjudien, follte cr aud) unbejomen genug fenn, Den Fatb Des Sir. Siakwell won Summer= treeb eber zu befulgen, alB meine befeble. Woir verftes ben ię̧t cinander."

Er fredfte feine 5and gegen allan auz, weld)er

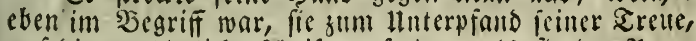
allf sie gewobnlidye siseife zu faifen, als lie ber pater

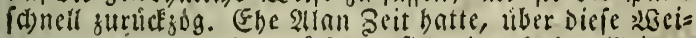
gerung nad)zubenein, offinete fid) eine fleine Éciten= thure, bie mit ciner $\mathfrak{x} a p e t e$ versedt n'ar, Die \$iorbange nurben bei Eeite gezugen, und eine same trat, wie

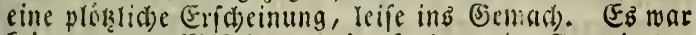
Eeine vun Den MRis Atrtburet's, fondern eine Frau in Des Sjltitbe ocs lebens uno ber vóllig entfalteten weiblichen @d)onbeit; artig, fd)lanÉ uno von imponirendem 2 Anfe= ben. Itre guldenen Lodfen fielen uber Die Etirne, Die ncbft dem herrlichen Blanze ber gropen, offenen, blaten

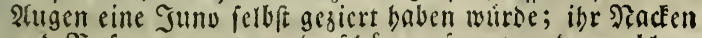
und Sufen waren wunberiden geformt und von blen= sender siscipe. Sie war eit wenig zur fülle geneigt,

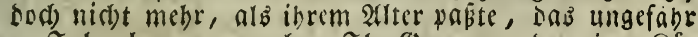

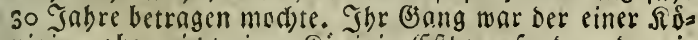
nigin, aber nidte ciner sionigin (Eftber, fondern der ei= ner $\mathfrak{Y}$ afthi, einer fubnen und befeblenden, niate einer [dulidternen Ediunbeit.

Pater 5 monaventura erbob fid unmillig von feinem fager, als ob ibm taB raf(d) E Eintreten misfalle. "Tiun, Diabame," fagte er mir ciniger Strenge, "marum ba= ben wir jek̨t bie Ebre Euter Esefellid)aft?" 
" Siseil es mir fo beliebt," ermieberte bie Dame ganj rutig.

"Beliebr? Masame!" wieberbolte er in sem náms lid)ell unwilligen $\mathfrak{D}_{\text {bite. }}$

"In, beliebt, Ěir," fubr fie fort, ,tind sies mein Velieben halt immer genauen Sd)ritt mit meiner $\mathfrak{D}$ fididt.

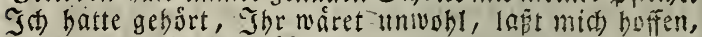

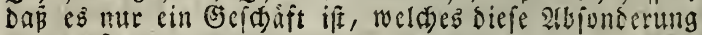
veranla st."

"Ich bin mohl," ermieberte er, "solfeummen wohl, und idi) DanEe Euth für Eure Sorgfalt, aber wir lind nicht allein, und biefer iunge Diann - - "

"Diefer iunge spann." fajte fie uno beftete tho

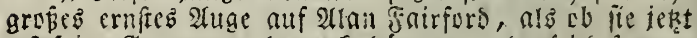

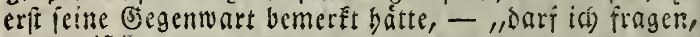
wer eE ift?"

"Ein andermar Masam, Shr follt feine (5efrididse exfabren, menn er weg iff. Eeine (3) egenwart mad)t ez mir unmoglid), midj meiter ơu crefláren."

"sienn er gegangen ift, mag es mobl zu fpát fern," [agte sie Dame, "und mas ift feine Eegenwart fưr mid, menn Eure Eimerbeit auf dem Expicle frebt? (Es if ber

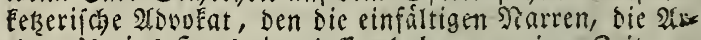
tburet'B, ins 5 aus eingelafen baben, zul einer seit, no

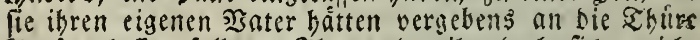
topfen lajen follen. Shr werbet isn obds fidjer nidgt oqn Eud) Iafien?"

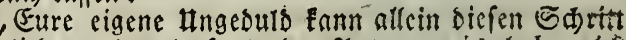
gefábrlich mad')en," fagte der Pater, "id) babe mirt) emichlofen, ibn zu thun, - labt nidist Euren unberdseis benen (Eifer, fo gut aud feine Quelle fenn mag, sie Sacte umnothigermeife gefábrlic) matien."

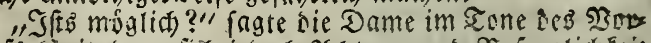

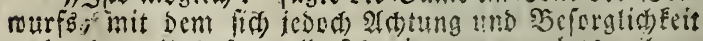
verband. "llnd fo mollt ghr immer yormarts gehen,

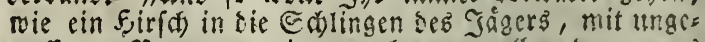

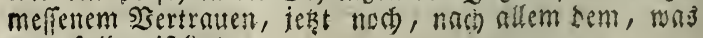

" porgefallen ift?"

"Etille, Dabame," fagte ser pater Junnayen= 
ciumen Eommen, wo Ibr erfabren werbet, was es beipt, einen Jann, wic mid), fu verbinden. 2 Sas die Dame betrifft, fo ift lie eine hodgl mitrsige perfon, und man Eaun Durd)aus nichts von igr fagen, das nid)t ihr lob verfündigte. SRid)tsbeftomeniger - Eurz, Eir, wir wandern in biejem Augenblick in einem Morgennebel bie Sonne witb, wie id boffe, bald fteigen, und ibn

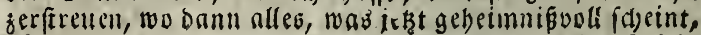
vollig entidaleiert werden wirb; - oder er wird fid in Shegen aufïfen," fethte er in einem feierlichen ₹one bin=

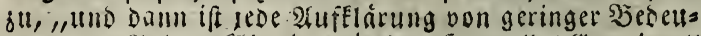

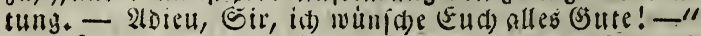

(Er mad)te eille artige 2ierbeugung und veridumand burd) Diejelbe Cententbure, Durd) welci)e bie Dame ein= getreten war, und grlan glanbte ifre stimmen in bef= tigem Streit aus dém anfiobenben Simmer zu borell.

Im 2lugenblick darau trat 2rmbrofius cin und fage te, ein Pferd und ein Jubrer rarteten auf ibn unten an ber Ierralte.

"Der gute Plater Duonaventura," fekgte ber Sel= lermeifter billzu, ,ift fo guadig, Eure Eage sub beruck

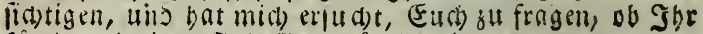
für irgend einen sall (3) eld nótbig bátet."

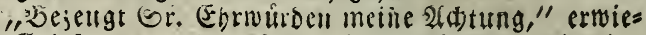
derte Fairford, "und verficbert ibn, Dẩ id Damit bin= lànglid) verieben bin. (Jd) bitte (Eud) gleid) fallb, ben פRiß̈ 2(rtburet?

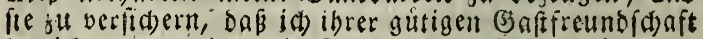
Der id) vermutblid) mein Eeben banke, fo lange id lebe,

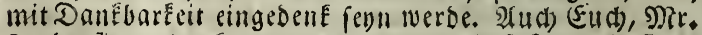

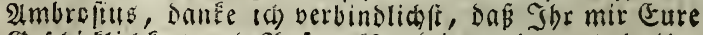

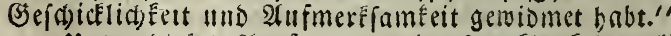

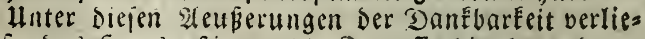
Ben fie Das $5 a 4 s$, fitegen die ₹erraffe binab, und ges langten an Den Drt, wo Der ङ3ártner, Fairforbo alter Setannter, auf ibn wartete, jįeno auf dem einen Pferde, und das andere an ber f̧and fubrend.

Hnfer tunger Sied)tógelebrter fagte Dem ) 2 r. 2fms brofius Leberobl, befticg Dav wferd, und ritt ben. (S)ng 
"Eoucit als es an ser sgaferfeite fortgebt," fagte

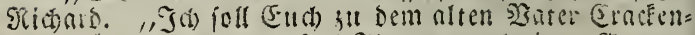

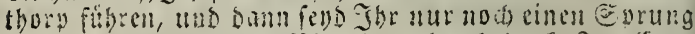

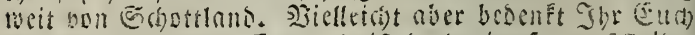

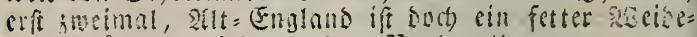
grund fir bas sieb aus ism Jivach."

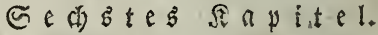

(E) toblung bon Dorfif fatimer.

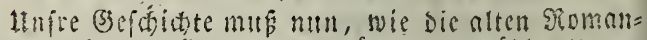

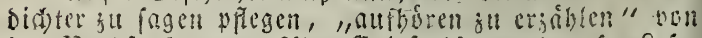

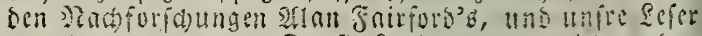
son son grbenthellern Davfie Eatimers tntertichten, fen

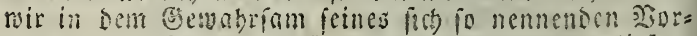

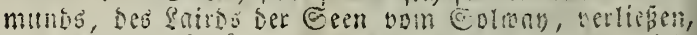

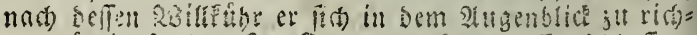

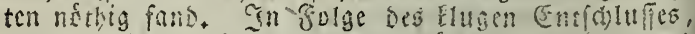

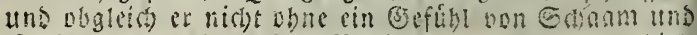

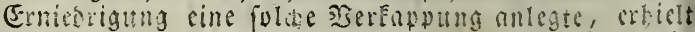

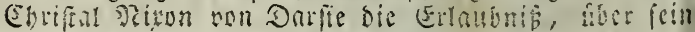

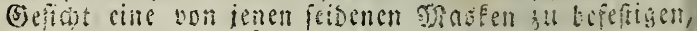

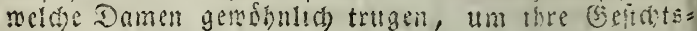

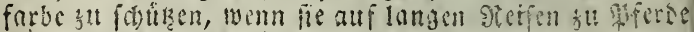

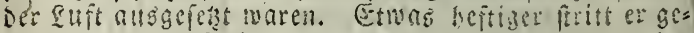

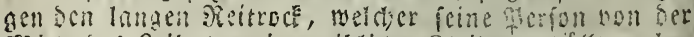

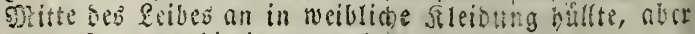
ct mutre aud) bierin nadgebeh.

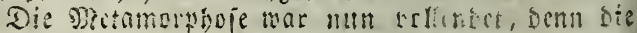

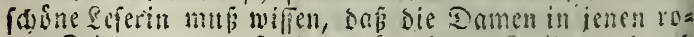

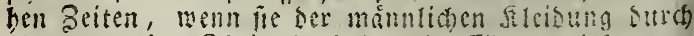
śnlegung eineg Theils serfelben eine Ebre etwiejen, ge= rase fiefelben sitte, gidofe und siseften trugen, alb sie

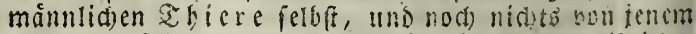

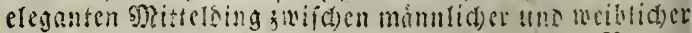
Jicisung เoustcn, sas icht par excellence, ien siancn

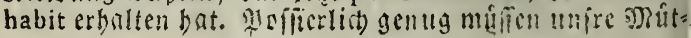


tet ausgefebei baben in sen langen, viereceig gefchnitte= nen $2 \delta$ cEen ofne Siragen mit sioften, beren ungcheure

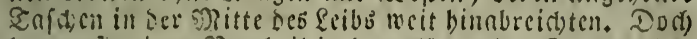
battul fie cinen Sortbeil in ben giänsenden jarben, den

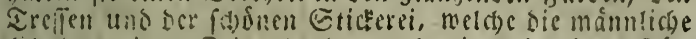
silerisung ience 3eit erlaubte, tmo wie es in victen fóls

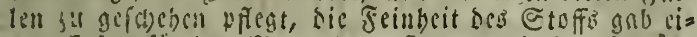
nen Erfak fitr ben Diangel an EDmmetrie lunb Echodn= beit ser form in sell steidungen felbft. Dods sick ift cine s(bfit) meifung.

Im 5ofe des niten Gebaubez, das balb Escifiz,

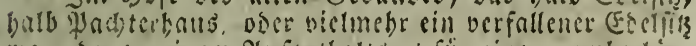
mar, ser all cincm Aufentbaltsort fü einen cumberlasi=

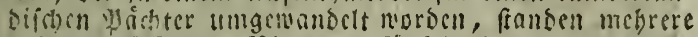

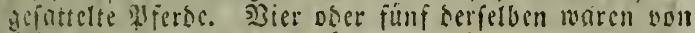
5iencrit des nieserern giad)tern befiegen, melde alle nit હcblvert, Piftolen uns Sarabialers nobl bewafinet maren. Buse sason maren aber fur Frallenjimmer ge= fattelt; Sas cine savos trun einen Duerfattel, Sas an= bie blus cin Siffen binter bem'sattel.

Darje's Sers idslug lebbnfter, senn er begriff Icia)t, safis cincs won sicfen für ibn beftimmt fey, uns

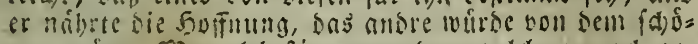

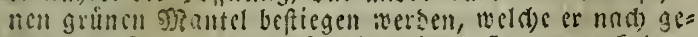

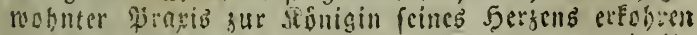
batte, menn gleica die Éselegenbeiten, mo er mit ibr batte zufammen (enn Esnnen, fid) Das eine D)?al auf ein frillew arbenterien, bas nusienal auf einen lendiden Sans beforinften. Dick war insefien bei Darlie zati=

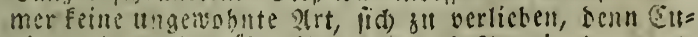
piso tritumbirte fiber ibn nur nad) 2itt cines nrarat=

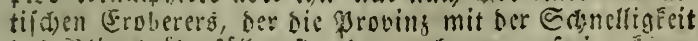

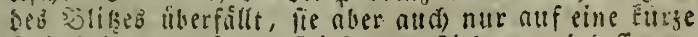
Seit behausten Eann. Diefe nelte eicbe ront inbeffen ct:

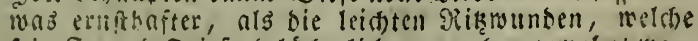

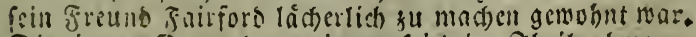
Die junge i) ame hatte eille autfridtige Sheilnabme an ibm bejeugt, uns bas gebcimuibodle 2isefen, toomit Diefer Antbeil serfoleiert war, gablsibr bei feimer leb: 
baften (Finbiloungstraft Den Eharaiter eines wobl.nol= lenden und fohtikenden sseiftes, eben fo mobl ials. Den eines fohonen 23 eibes.

In frúberen Beiten war Der Ruman feiner furjen Neigitirgen fets fein eigenes 23 erE gewefell, und war verfabuanoen, ie náber er Der Perion fam, Die Der Ge=

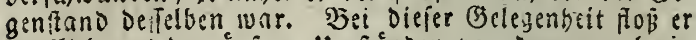

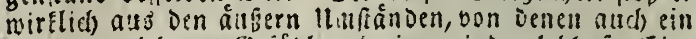
weniger reijbares Eerúbl und eine minder lebhafte (Ein=

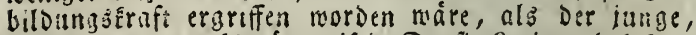
unerfabrene uno fojmármerif́the Darfie Eatimer befas.

(Er wartete Daher angftlich), ztt weiten Dienft Der Belter mit Dem Dameniattel beftimmt ist). (Ehe aber eine Jrau erichien, Denfelben einjunebuten-, wurve er felbit aufgefurbert, auf Dem Jiffen binter Ehriftal DRikon

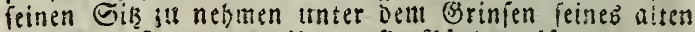

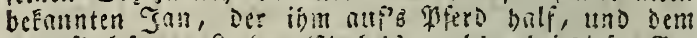

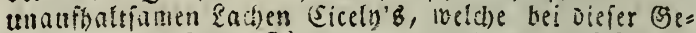

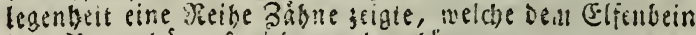
oen Jang bestte ftrcitig machen tönnen.

Eatinter war in einem 2!lter, wurin es ibm nicht gleistgut!tiz war, Der Bjegenftand eines allzemeinen. (3):= léthters ju iegn, menn atteb nut fire Baucrn und yjilch=

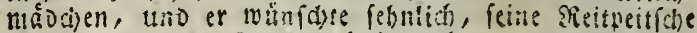

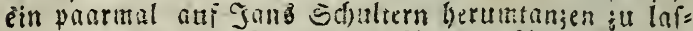

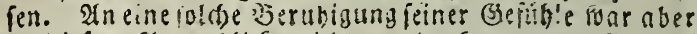

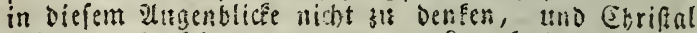

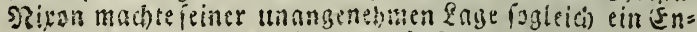
De, inben er Den Reitern aufsubredien befahl. (5r

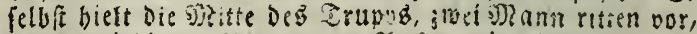

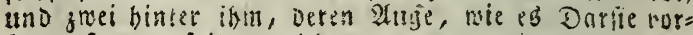

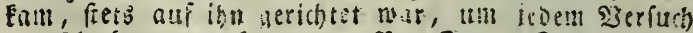

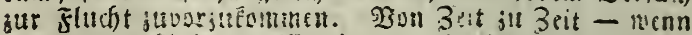

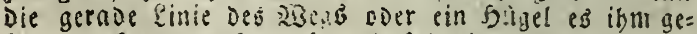

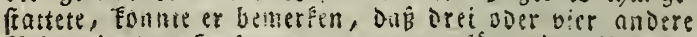
ßeiter in our Entfernung bou ungefást einer 23iestel= meile ibnen foigien; unter Dieien fonnte er Die fohionfe Beftalt Reogantlets untericheiden, fo wie ond mith)

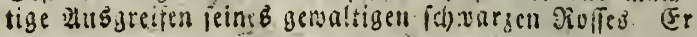


3weifelte Faum, Daß ber Brtinmantel mit Dabei fen, abs. gleich er inre (B)effalt ren Den andern nicht unterichei-

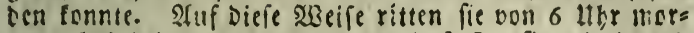
gens-bis beinabe ro $l 1 h r$, ohne onf Darfie mit irsend icmano ein sisort gemedjeft taitte, benn ihum miderte oer blofie Geonnfe, fid) in eine Unterreitung mit Ebri= fal siren einjulaffen, gegen ien er cine inftinftartige abncigung fithle; nuch wat bie biffere mo unfrcur:o= licke (3)

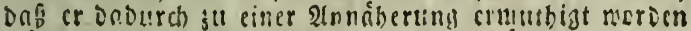
n'äre, menn cr altch Suft injll gehnbt haitle.

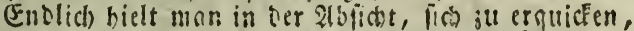
uno altojurubin; wis man aber biober alle E Erfer uno renolinte Derter auf bem sisege vermieden batte, fo mabte man anch jeţt bei eincr iener grofen serfollenen bollandifoen Sdheunen 5 alt, bie man mandjmal auf

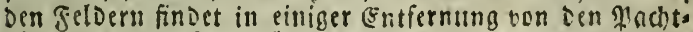
bistlern, woju fie aetören. Dod waren on biefem ein=

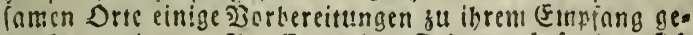
macht rorben. 2um (Enoe Der Edieume bifonden fich goufen mit futter fir Die PFerbe, uro eine M?enge \&es bcremittel fur bic Nenichen murben unter Etrobbuns Deln berborgejogen, unter melehen bie Sidrbe uerfectit anaren, welche die febersmittel enthielten. Die beften

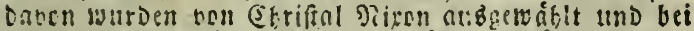
Eeite geftellt, wibleno die fette iber bie fubrigen bers

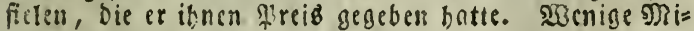
nutcu nacherer traf auch ocr Ninditrab ein, ftieg ab,

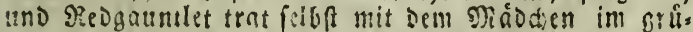
nen Frantel an Der Eeite in bie Echeume. Er ficllie

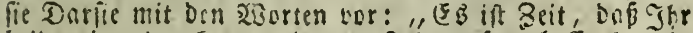
heide einnnder Eennen lernt. S(b) berfarach (Fuch mein Dertranen, Darlie, und die Żeit if geEntmon, mein

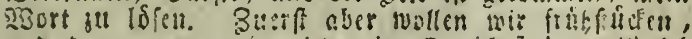
und Donn renn wir wiejer im Esttel find, will ich

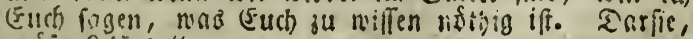
arüt filin: "

Der Sefehl war fochell, und liberrafdlte Entimer, deffen sisermirrung Durcí Die dolfe Unbefangenbeit und 
Seidntighit frieg, momit Siling inn ifre 20 ange und ibre sano bot, uno bie feinige brâtite, welche fie mehy ergriff, als Die itrige gab; Dann fagte fie freimuthig:

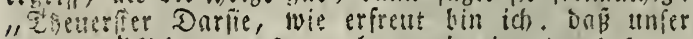
Sheim eiblici) ung gefrattet hat, mit cinanoer befannt ju merosn!"

- Darfie sepf farminbelte, und es war vieflecibt gut, sab seogantentlet ign auforderte, fich nieberjuferent, Derm gerade Dieie Benegung diente ism basts, feine Derwirtung zut verbergen. (Fs gibt ein alteb fied:

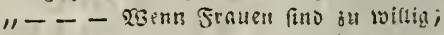

Eo fiefit zer Jiann nux wie cin shor."

Eime gute Darfrellung tno Darfie Entmers Blicke bei

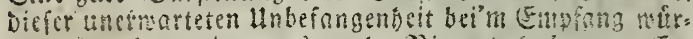

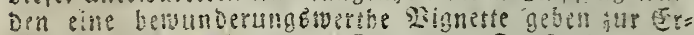
lautertug befer Erelle. "Dthutrifer Darfe, "tmo fo

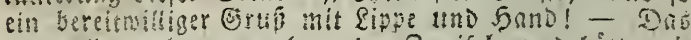

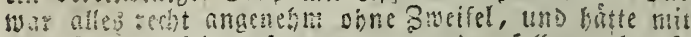
aller Danfogrfelt augenoumen werden follen; seber fo

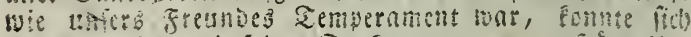
nicisto meniger mit feiner Denfart veriragers. Faitte ifm

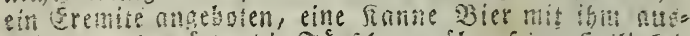

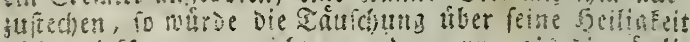

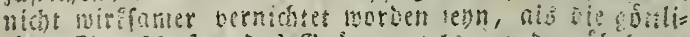

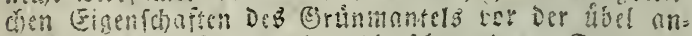

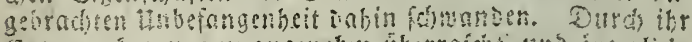

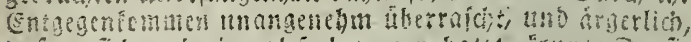

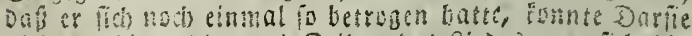
nith tmbin, wie joe Beilen des liever not fich hin

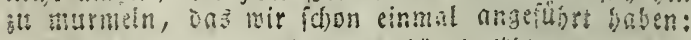

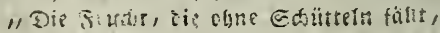

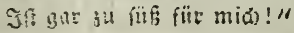

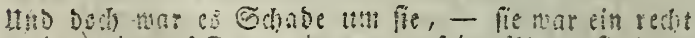

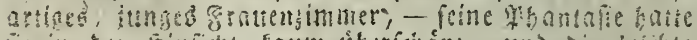

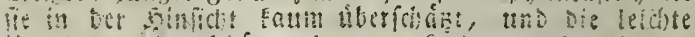

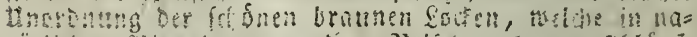

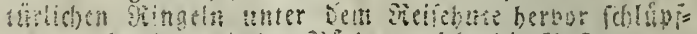

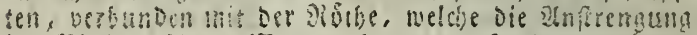

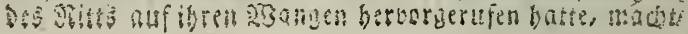


fie noch reisenser, als fonft. Sebgnuntlet felbft mits

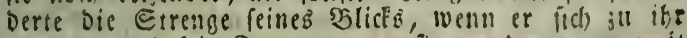
mande, tund fein $20 n$, nenn er fie anredete, mor meit

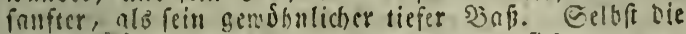
ftorren Guze Ehriftal Niron'B erheiterten fich, wenn er

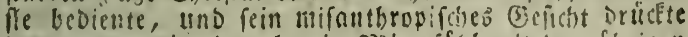
Dann, rucnn ie einmal, ein O)Ritacfínhl mit Der fitrigen

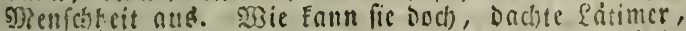

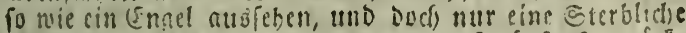
fonn? Eo viel Entgegenfommen, wenn fie ánferft ?trutite. baltend fenn follte? Disie lát lid) Shr Destagen mit

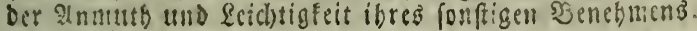
wereinen?

Diefe berworrenen Eedanfen, meicle Darlie's Ein= biloungafraft beicáấtigten, gaben feinen ?jličen cin

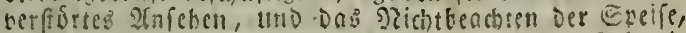
bie ifm norgerest wurbe, berbunden mit feisent Edmecis

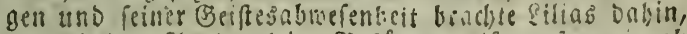

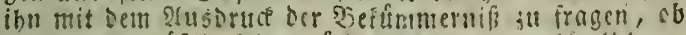

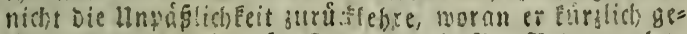
litten batte. Bei Dieier Firnge erbob SDr. Feogatuntet, weldjer cbenfalis in ferine Serrachtungen terloren folien,

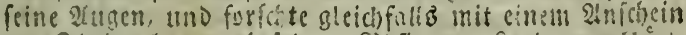
yon Theinabitre nach feinem SS. finden. Satimer ertlarte beiden, ong ibin bollfommen mabl fer.

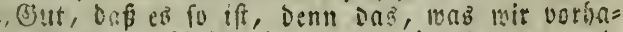

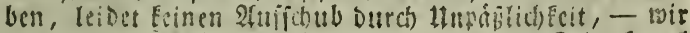
baben, dy ie Setpur ju fagen fllegte, feine Seit, from tu ferin."

filizs ifter Geits bemingte fids, Darfie stt bemegen,

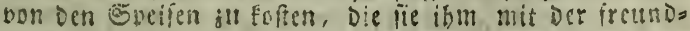

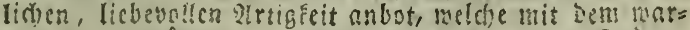

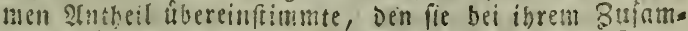
mentrefien gejeigt batte; Dicje girtig?eit nar aber fo $n n=$

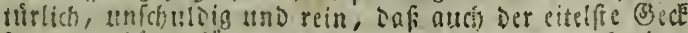
fie niabt bitte fitr Jofetterie mebmen, oder als ben

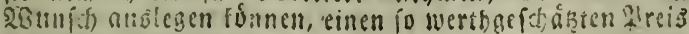
alo feine Bumeigung ju geninuen. Darlie, welcher nut

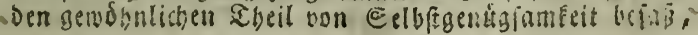


melchen 'innae feute gemobnlich baben, sie fich sem cin und jmanisgten Fabre nábern, wubte fich ibr šes nehuen nicht zu críñen.

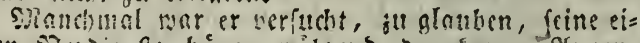
gutin seroienfte fiaten nubrens Der furjen 2ubin= blicke, in benen fie cinander gefoben batten, inm fo lihe

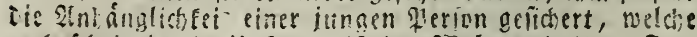

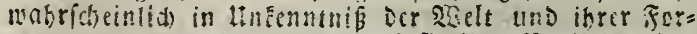
men erjogen wredon war, Def fie ibre Sorliebe nicht

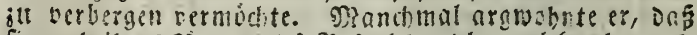

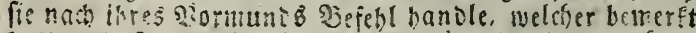

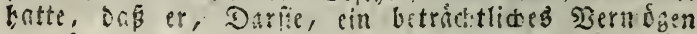

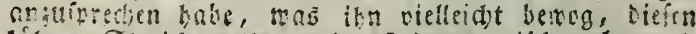

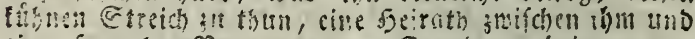

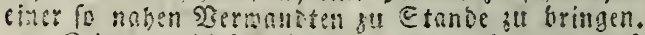
fieine ton bicien zirermuthtngen aber war auf ben Eharatter Der letterienoen Werfonen antrenobar. Mi Silias venelumen, buglete fanft uno natúrlich, entfal=

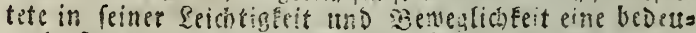

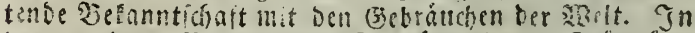

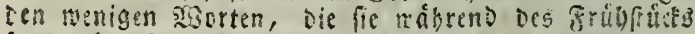

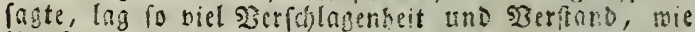
inn Eatm ein fromengimmer baben fonte, bus cie zin

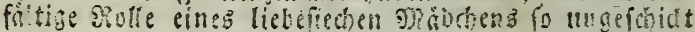

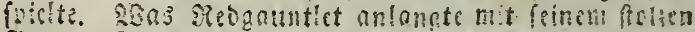
Gange, feincr Duffern atirne, uno feinem brotenden uno befelb!enden Blicke, fo fonnte itn Dorite unmolich

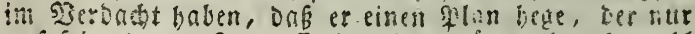
auf fein eigenes Sntereffe bereshnet nare; eten fo moht réte er glauben fonnen, (safitus babe Eajars- Safú en nusleeren mollen, fentt ben Doid) gegen ben Diftater ou jicher.

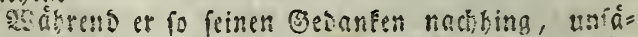

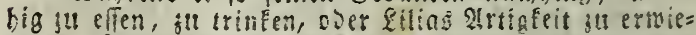

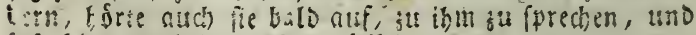
rap formeizend ta, wie er fetbfr.

Eie waren faft eine Etmnde an ibrem subseplaţe gebliehes, als Reogauntlet laut fagte, "fiel, hinat!?

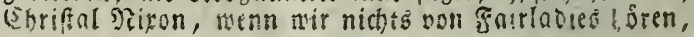


to mitien mir uniere Sieife fortfetsen." Chrifol begnb (ich) tor bie ituie, Febrte nber fogleid) zurtick, und ingte in feinem ferrn mit einer Etinume fo ramb, nie feine Btine: i, (silbert Bregion fommt, fein wero ift Ban? neif nom estaume, als wenll es icr boje Jeind geritten létte."

Siengammiles warf Ien Teller bon fidh, ton Dem er eben Berefien hatte, uno eilte nach) Der Fhive Der Echelts ne, Durci) meldie Der jore im nemlichen augenblicte eintrat: ein menterer 23 urfche mit einer fchnars fomm tenen Ingonüüse und einem breiten sürtel mu feinen Seib, waran leine Rootentniche bing. Sor seth, womit

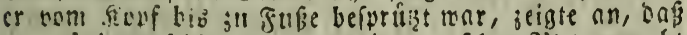

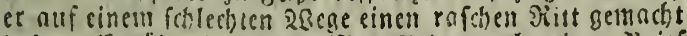

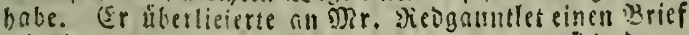

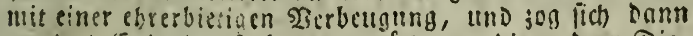
an Das (Enie ter Ëcheune zurutit, wo die nndern Die. ner auf bell હtrob fofien oder lagen, um einige Erfri= f(h)ungen ;u fich bu nebmen. Reogauntlet erbrad) ba:

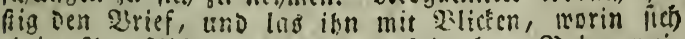

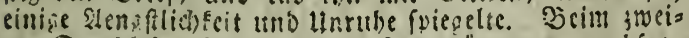
tell Durd)lefen fobien fein Difievergntigen fu nachien, feine Etime berfinfterte fich, tuis Deatlich war Das

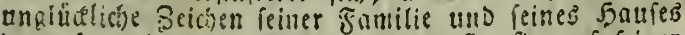
Darant fejeichate. Noeb nie batte Darfie anf feiner Eitirne ein io trefiendes bild jenes aeidjens bemertst, Das Die Saze Derfelben beilegte.

Reognumilct bislt Den vifenen $\mathfrak{x}$ rief in ber cinen Santo, lino frefé mit Dem Beigefinger Der andern Dars auf bin, indem ct fu Ebriftal Riton bulb laut, nber unnillig fagte: "Segentefehl! - खBir follen abermals

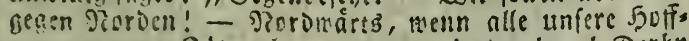
nungen gegen étoen liegen, jutu fweitenmal nad) Derby

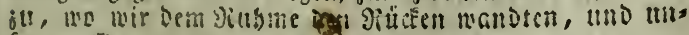
ferem Eur: entgegen gingen!"

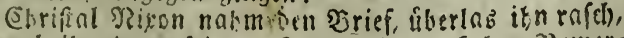
und ent ihn Donn feinem ferrn nit Ber Enlten Bemers fung iltrute: "2leivlicher Einflub herricht vor."

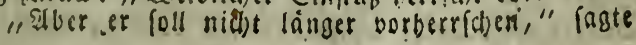




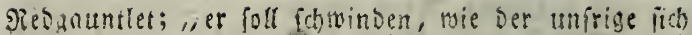

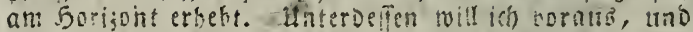

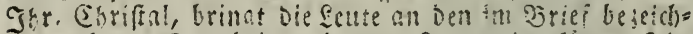
neten Drt. Dell beiden iunsen Seuten ba fontut Ghe ulan geftatten, Daf fie fich ungehinoert linterbolten;

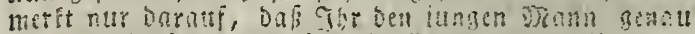

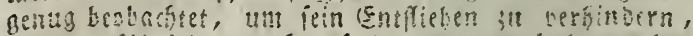

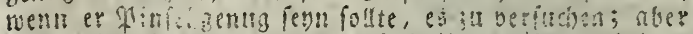

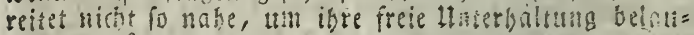

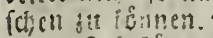

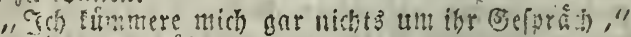
fagte șinon verbrafifich.

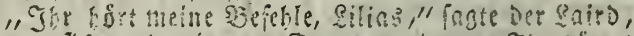

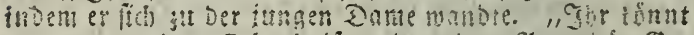

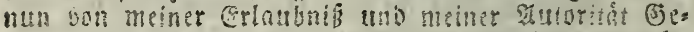
brattch maden, tum ibn bon tufern fommlen = singeles

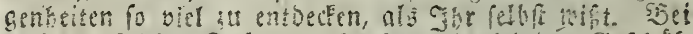

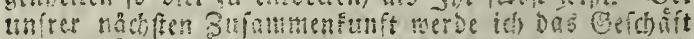
Der Entbullung oflender, uno ith hofe. ich meroe nech

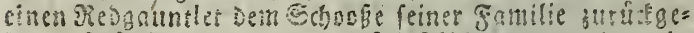
ben. Eafe Entmern, we er fich fe!bfin ncint. nlleen ein

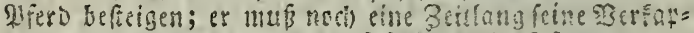

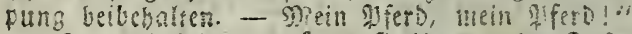

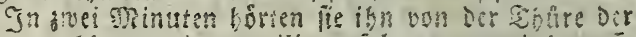
entune binmegreiten, eilig gefolgt ron amei bernati=

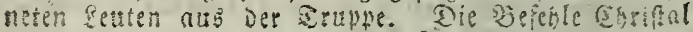
szirous braciten unterbeffen alle tilurigen in sostwentme,

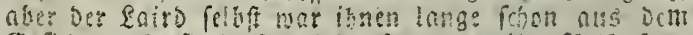

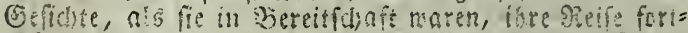

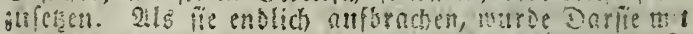

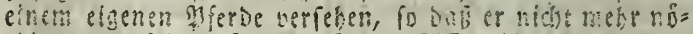

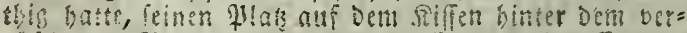
abdotmen arign einjumehmen. Er war invefen ge=

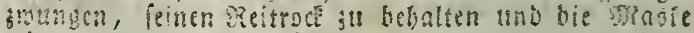

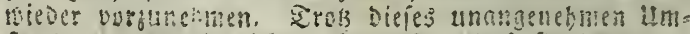
ffances, amo obglcich et bemerEte, Eẩ lit ibu Das

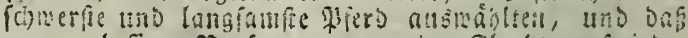

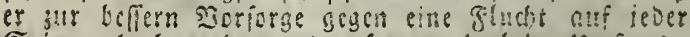
Eeite nabe bersacht twarde, fo wat boch ber dimfand, 
Da muB noch Gotwierigkeit fenn; uns wenn, wie Der Dichter fagt, ber Strom ber glúhenven leidenfitint

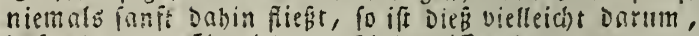
Dab́ obue Den Eintritt bon Sindernilfen Das, was man Das roananafte in Der Eiebe nennt, in leinen boch yne. tifhen Ebarater uno Blange fió oorfinien Entm; eben fo wenig, $a ! z$ it einem flt: $\beta$ eine heftige Etrdmung (e)n Eann, wena er nicht Durch fteile 1 ire eingecngt oder Durd) entgeisen ftebende Felien jurticgefic fen wiro. Gndeffen búten dicjenigen, welche cine bas feben eingeben obue diefe finderniffe, melese eis

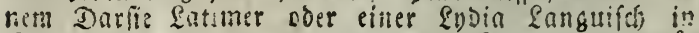
Echeriban's " Pefsenbublern" Mergnúgen berciten nio =

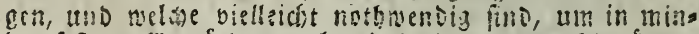
Der fiftern Gemúthern, als lie inrigen, eine fomarme=

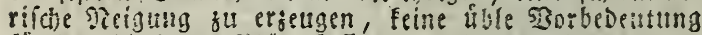
fur ibe flinftiges (b)ltie faflen, weil itre Betbinoung anf eine rubigere siseife gefdilofien murbe. Segcrifeitige sqeigung, eine genaue fenntnis des beiderieitigen 5 bas rafters, ban man in ibrem falle unoctialt bon ben

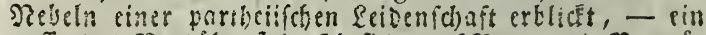

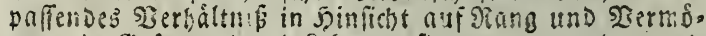
sen, in Geftumas und Lebenanficteri, - werden weit bittifizer in einer jerfandesebe geftnoen, als Dn, mo bis is irbinbing nuf eine romantifie zuneigung ficl

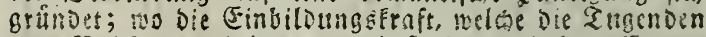
und Solfommenbeiten, momit fie den geliebien B?gen=

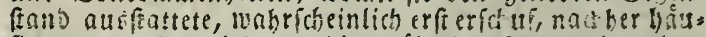
fig angatuelibet wirs, um bie qualenden folgen ber cige=

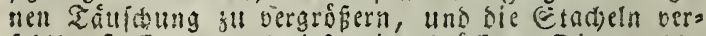

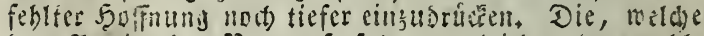

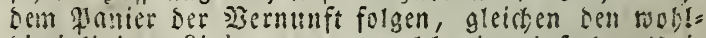
cisciplinirten einientuppen, welde eine einfagere Iniz

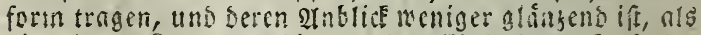
Die leidten Srupyen, Die von Der Einbilsungeroft be= fibligt, riner groferm Gidert, it, in nud) ciner beffern Eaure in fon Simpien Des menid)lidyen Lebens genippen.

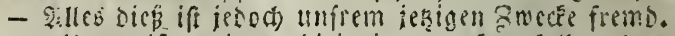
lingemie, wie or fickenige antescit folle, beren 


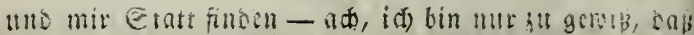

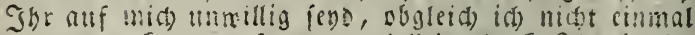

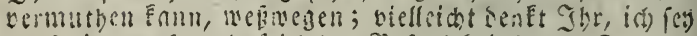

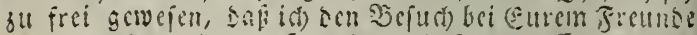

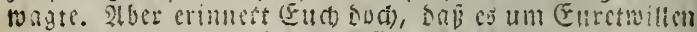

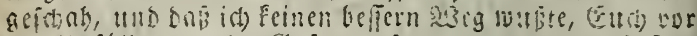

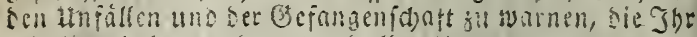
ersulfet habt, mo modi) crsulbet."

"Ibeure Easo" - Fagt: Darjie, feine Erinncumg

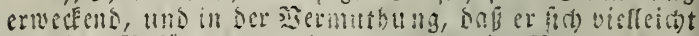

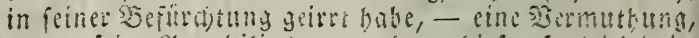
mel ic jeine 2trt, Eiths anjuresen, sicjer foglest) mit=

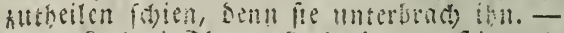

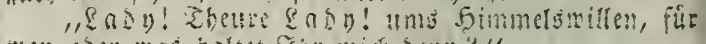

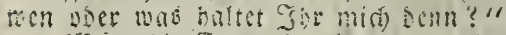

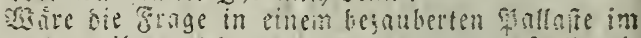

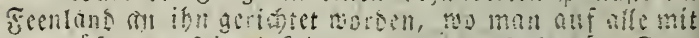

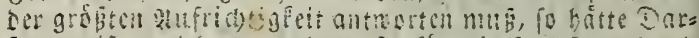

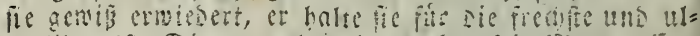

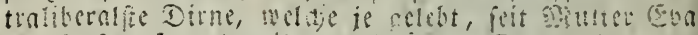

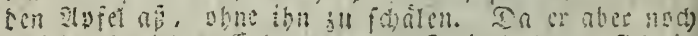

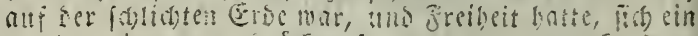

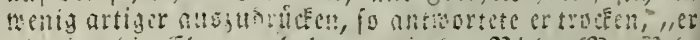

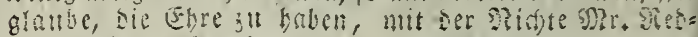
gaunllet's ju forechen.". -

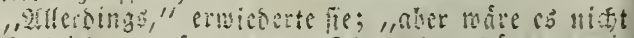

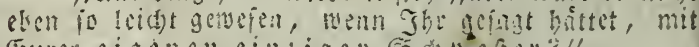

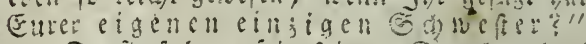

Darlic fubl anf in peinem entel, als baits ion cine atlact getroffen.

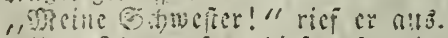

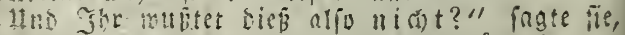

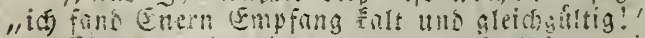

Fine wot berglibe Hmanmang fant jet3t imistien

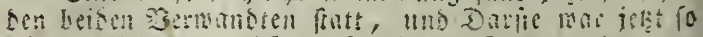

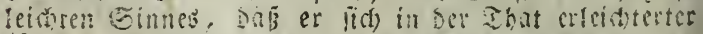
fithlte, Der Derlegutheit ser lebten halfon Etunde los

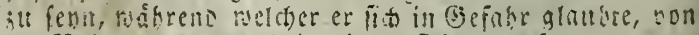

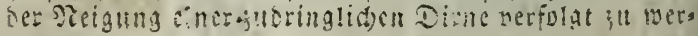




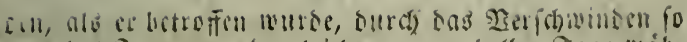

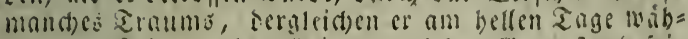

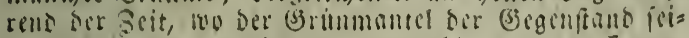

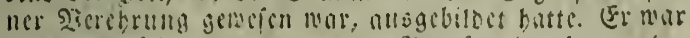

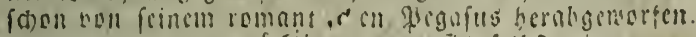

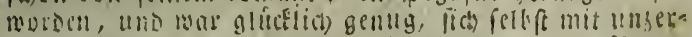

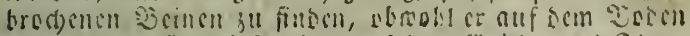

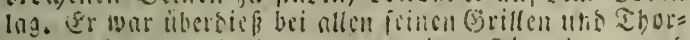
beitell cin coelmuthiacr, guthergige: Gingling, und

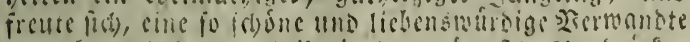

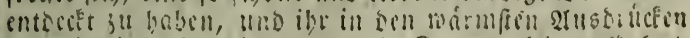

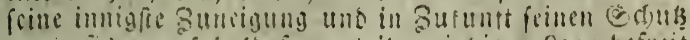

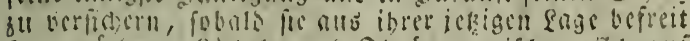

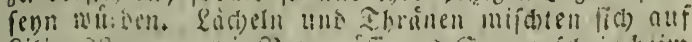

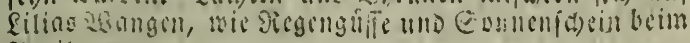
Stpriltwetter.

"T)

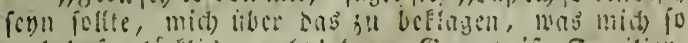

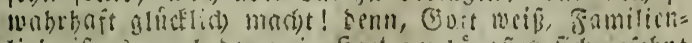

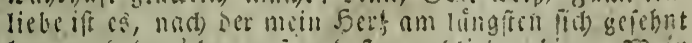
bat, uns ber id) am fremseften geblieben bin. Tgein

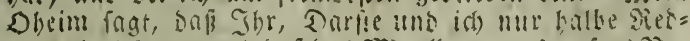

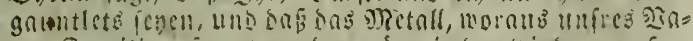

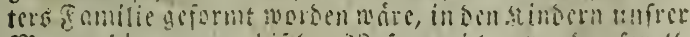

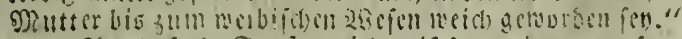

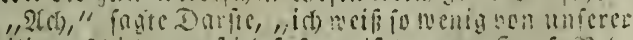

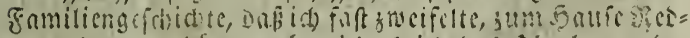

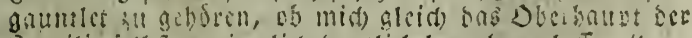

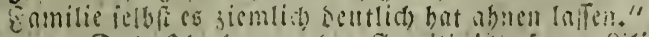

"Dos Dberhallat set Familie!" fogte Pilins,

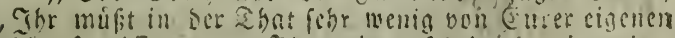

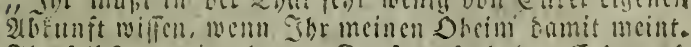

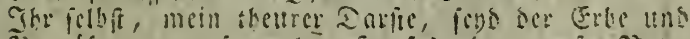
Seplifentant unites alten 5ुnuf's, senn umfer grater

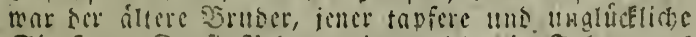
Gir Sentr) inalie Siengnuntlet, welder in Sahre $17+6$ ou Earlite hiligeridftet nutse. Et verbans sen sin= men Inrfie mit sem feingen ron unerer s) Juter, ser

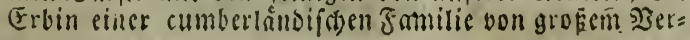




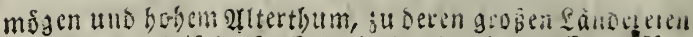

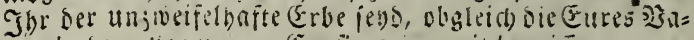
ters in for allgemetnen sonfiocation mit beyrifien maren.

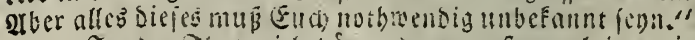

"In Der Shat, idi) hír: ej jum eiftemmal in mei= nem "Ében," aitwortete Darfie.

"Hno Sor wuftet nicht, Dafi id Eure (d)mefter

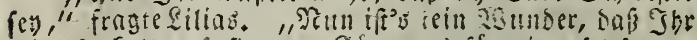
mich fo Ealt cnipfingt. Sitt was fif eine fellone, wilbe uns fredide Dirne mitit Shr midi gef)alten baben,

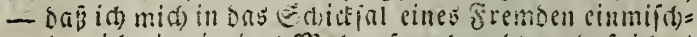

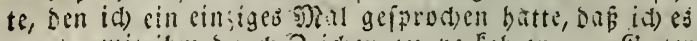

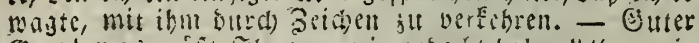
Eott! Was mist She bon mir gadoht baben?"

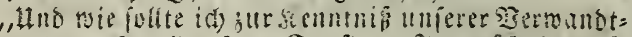

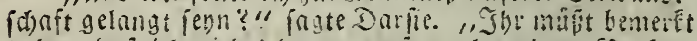

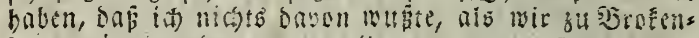
burn mit einanto tanjten."

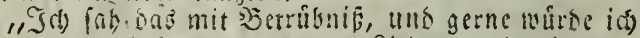

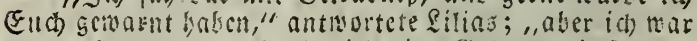
genall berdadt, ltno ebe id cine (B) ober herbci fibren Esante, um unit Eudi) ju einer vol= len Erelárung uber Dent beunruhigenben (sigenfand ; gelaingen, muste ia) bas simmer verlaffen. SBas in fagte, war, wena Shr Euth erinmert, the Marnitng,

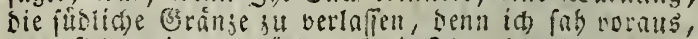
was pich ereignen wittoe. Ecit Sht aber in ter (ses=

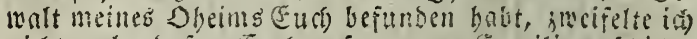
nid)t mebr, bas er (Eub) unjere ganje samilienbeldyithte mitgetheilt balic."

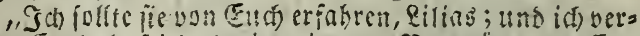

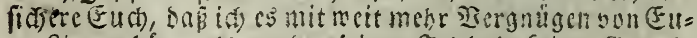

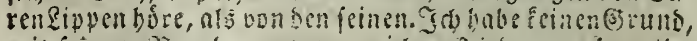

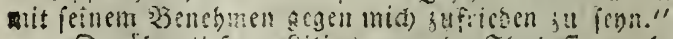

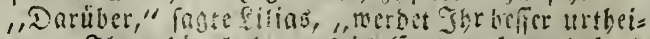

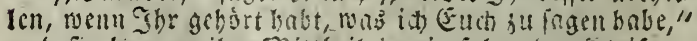
und fie begann ibresonttheilung in folsenter ibeife.

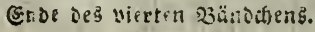



17.23

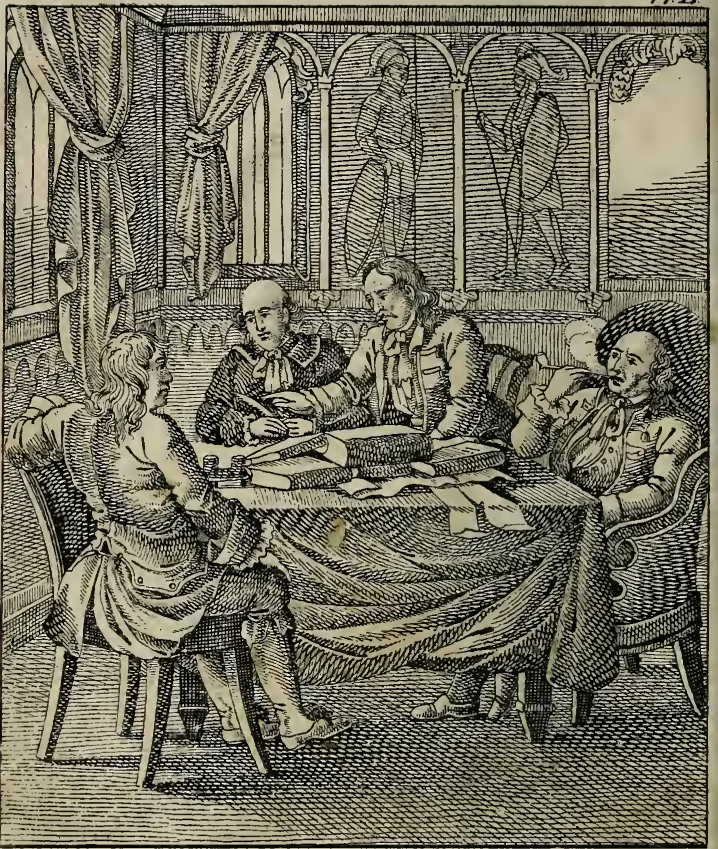

fres Schuek

Wollt 'thi Las feschurien? 


\section{Watter Scutt's}

fammtlidje

\section{$\mathfrak{W}$}

$\mathfrak{e}$

$\mathfrak{l}$

f

e.

Feu uberfegt.

Reunzebnter $\mathfrak{B}$ and.

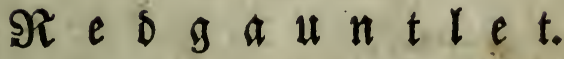

હine Erzáblung aนs bem adtzeg̨aten Jabrbunbert.

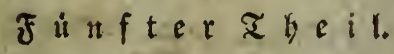

\section{S $t \mathfrak{u t} t g a r$}

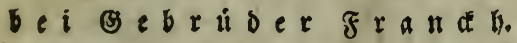

$$
\because 1826
$$





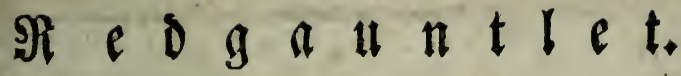

$$
\text { Eine E } \mathfrak{x} \mathfrak{z} \mathfrak{a} \mathfrak{h} \mathfrak{l} \mathfrak{u} \mathfrak{g}
$$

aน จеm a

\section{Bom}

\section{Derfaffer des 23 a oerled.}

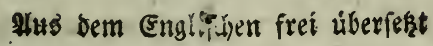

$$
\text { oon }=
$$

- Earl 23 eit.

Jch folge Dir, Sheifter, nur uoran, Dir bin ich bioz zum Tus getreufich jugethan:

(

\section{Finftes Bándtyen.}

\section{St $u t t g a r t ;$}

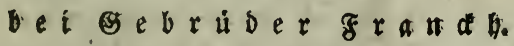

$$
1826
$$





\section{ge g gantlet.}

\section{E $r$ it $e^{3}$ sapitel.}

Er\}dilung von Darfie Intimer. Fortięultg.

"Das รุans Niebganutlet," fagte bie junge Da: me, "lag feit Jahrbunberten, wie main glaubt, -unter einesn Fludhe, welder feinen Minth), feine Ialente,

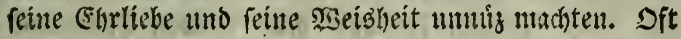

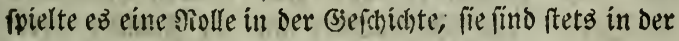
Lage von s)ienfhen gewefen, bie mit verzweifelter Siraft= 2rnftrengung und beharrlichem Ersulben alleş tutge=

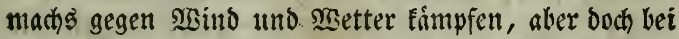
aller Siraft und Entifchloffenheit nidbt in Etande find, il)ren Sauf weiter fortzufezen. Mian bellauptet, biefes unglidelidse Berdsick grinde jich allf eine Sage, bie id

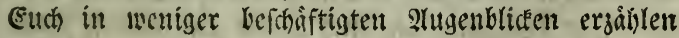
will."

- Darfie fagte, er balle bie trajifhe G̈sfiftidste Sir artheride Siegauntlets bereits gehort.

"Id brandse alfo nur su fagen," futhr gilias fort, "Dar unfer sater umo Sheim b:

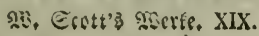




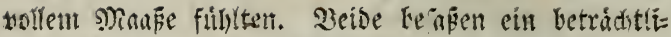
dyes siermogen, bas surdh unfers sinters seurath noch betrachtlich vermurt wmbe, mo beibe hatten

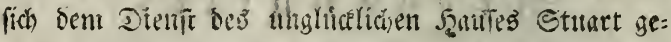
wibntet; aber Fatilien = Fitulithten witroen, wie unfie Siltter nentigiteng glaukte, ibren (Satten zurickgebal= ten lubet, an beu Gcenen Des Jabros 1745. offenett Intlycil zunebmen, båtte ifu nicht der grofie Einflus,

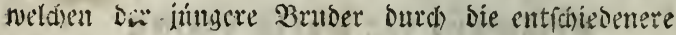

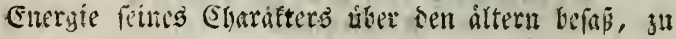
diefem linternebmen fortgeriffen."

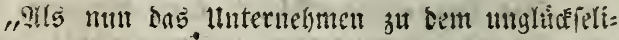
gon Insyang fani, ber unferm Sater feines Rebens leraubte uno feitew 3irnder zum Eril vernetheilte, fiol Enou giedgantlet ans sem gorben Englanos,

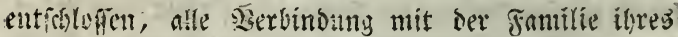
(5emalyls, hefonbers aber mit feinem zruber, alsut= brechen, ba fie biefelten negen ibes unïnnigen poli= tifchen fanatismus als die liriache fétnes frufliseitigen

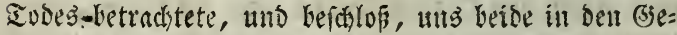

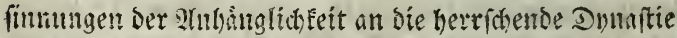

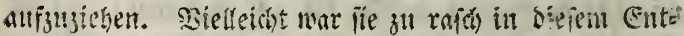

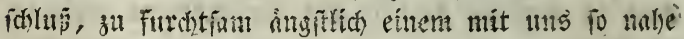
werbundenen Beruanden, als แnfers Baters einziger Britider war, wo moglid muth ben srt zu verbergen,

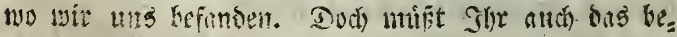

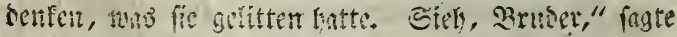

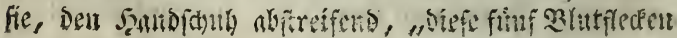




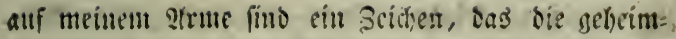

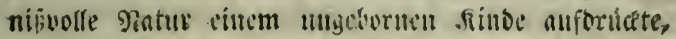
als eine Erinnerung an feithes saters gewaltimen Eod uno feiner g)iutter linglite."

"Ih) waret alfo noch nidht geboren, als incin Siaz

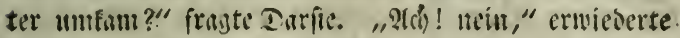
fie, "mudi) waret Slyr noch nicht ein Jahr alt. Es war aucl) nidst zu verwumbern, bapi meine s?iutter, bie po erfatitternbe Ecenen erlebt hatte, cine unkefiegbure. Ingit segen. iller Sinter enwfano, uno befonbers

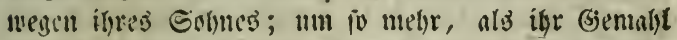

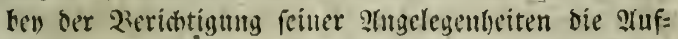

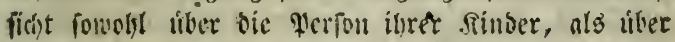
ilice (3)titer, muabhingia non benen, welche in ber Cont= fiscation begriffen maren, feinem Bruber J̦ingo ant= sertrinte, anf welden ir ein unbegrentes Sertraner Feg̨te."

"Itber meine Siutter lyatte finten Brumb, die

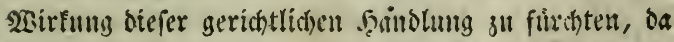
fie z" Gumiten einter geácitteten Plerjon aligefä̈t war," Figte Darife.

"Plichtig," erwidoerte Sillias, aber unferes Dheitto

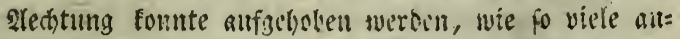
Dere; unive s)iutter, bie igu firchtete unb hafie, leb= te buram in emiger 2hitgit, lie michte den, welden

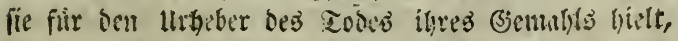

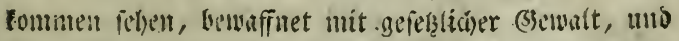

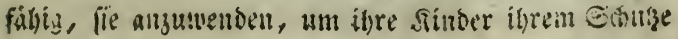




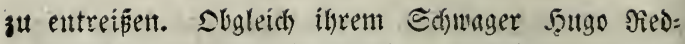
gauntlet immer noch die geferliche (seemalt abgieng, fo

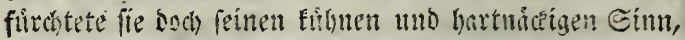

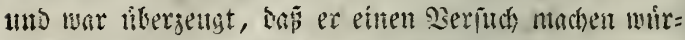
be, fich ter Merfon ilyrer Sinoer zu bemáchtigen. Ituf ber andern Seite iwurde unfer Dheim, beffen frolse

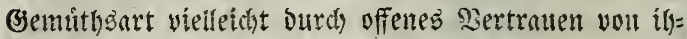
rer Ceite lefinftigt worben ware, gegen son mis=.

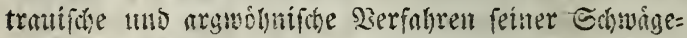

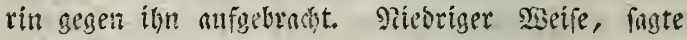
or, miphrauthen fie feitue unglitcliche sage, um inn von bem Sduze und der Ergielung biefer finder aus=

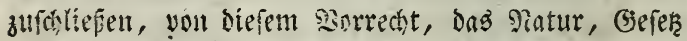
und ber saifle ifires Saters ínm tibertragen bobe, und er frswor, fich eittem foldyen unrecht nicht su unter= werfen. Rosu Sieoganutlet exfuhr diefe Drobungen, unid ilje furcht fieg, bie nur alljuwohl begruntet war. Sablurend wir beide it einem alter von zwei bis brei Salyen mit einander in étlem ummanerten

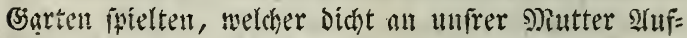

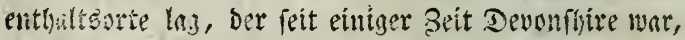
crftieg mein Dheim ploblich bie sintuer nit megreren Dinnern, ith mutbe croriffen, uto in ein $300 t$ ge= Eracht, weldies ilyer wartete. Neine siutter flog indeffen zu Eurer פiettunz berbei, und da fie Euch feft uthifbromg, fo founte mein sleim, wie er mir

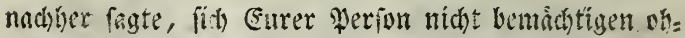

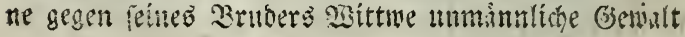


bu liten. Deffen war er nidt fóbig, unb ba nuf mei=

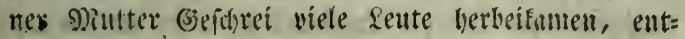

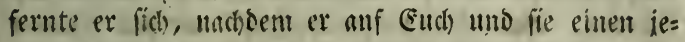
ner forredlidyen Blide semorfen batte, meldye, wie nan fast, ein unghiceliches Erbtheil unirer samilie vou unfrem 2(bul)ertm હir atbericé finto."

"Ith crimure nich einigernupent bes 2 uffritts," fagte Darfie, "thno id) glautse, es war-mein Dheint felbit, ber ben umftano mir bev einer nenern Gjelegent=

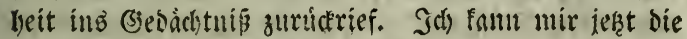
ängftliche aligefdyloffenheit erfliren, unter weldher mei= ne arme gintter lebte, ilne vielen Ihrinen, ibre framyflaften Infille und inre fortoanernoe tiefe sie= landyolie. Mrme Mutter, was war Dein Soos, uno

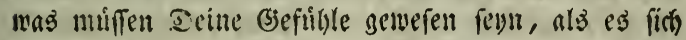
reinem Ende milte!"

"Damal's ergriff fie," fagte Sillins, ,iebe Sorfichts: maafiegel, meldye ibre Erfinolamfeit ibr eingeben foum= te, um aud) (etter Dafeyn vor bem gefürchteten Dian= ne, ja vor Endy felbft, z!t verbergen, bem lie firds)= tete, wie fie fich ofters mageorrickt haben foll, bas feurig wilse Blut ber Nebyauntlets wirde Euch an= treiben, Ener Bjechice mit bem Eures Dheims zแt ver= einigen, ber nod) immer mit politif(hen Sntriguen fich befdiftigte, welche bie meifen andern \$ienflyen als

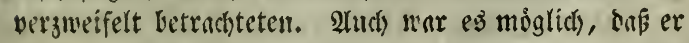
fo gut, als andere, Sierzeibutth erljielt, ba bie Nie:

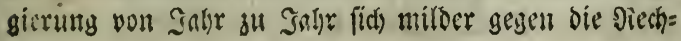


te der Sacobiten benvies, and bamn fontte er als ge=

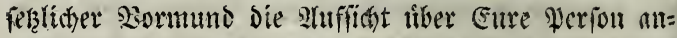
furedien. Sueide Fälle betrachtete fie als den geraben Weg zu Eurem Rerberben."

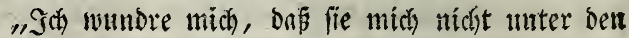
Sdhus ber Ehancery ftelfte," fagte Darfie, "oder midh Der Snrge eines måchtigen Srentubes aitwertrante."

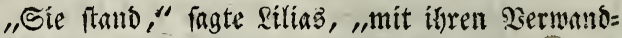
ten wegen ber Seenrath mit umerm Sater nicht auf

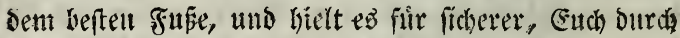
serborgentheit gegen unTers Dheins serituche zu be= waikren, als burch irgend einen Schus, ben bie Ge= ferge gemaiben founten. Siefleicht bandelte fie unflug, aher ficher war ifge serfaben febr begreiffich, ba fie Durch fo manthes tunglice uno fo viele liurube anperft reijbar geworben war. Sammel (sriffitis, ein ausge= geiduteter Banquier, uno ein würoiger Geifflticher, ber jefit toot iit, waren, glaube idh, bie einzigen Perro=

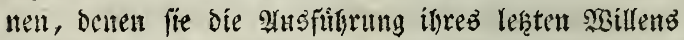
anvertraute, uno mein sheim glaubt, dafi fie beibe

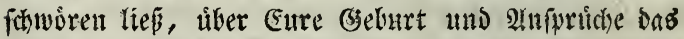
tieffe Stillfoweigen zu beobahten bis zu Eurer (5rop̈= jóbrigfeit, uns Eud unterbefien auf bas verborbenfte zu ergiehen, baunit $\mathfrak{g h r}$ ber Beubathtumg meines Dheims um fo eber entzogen wirbet."

"thto ich zweifle nicht," fagte Darile, "boa fie

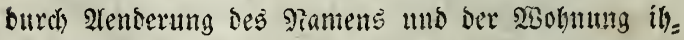
ren Sweck volfitandig erreidyt hatteu, obne ben glickli= 


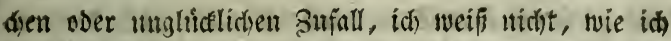
inn itenten foll, welder mich madh 3rofenburn uns:

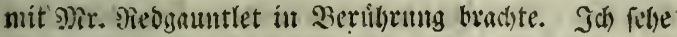
mutr and), warum man midh vor Englano genarnt bat, Denu in Eughus - - ."

"In Englund allein, wein ich recht verîtand,"

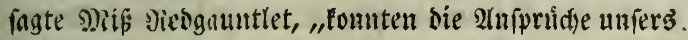
Dheims mif bie \$ewabrung Ener Perfon nit Sewalt bebauptet werden, falls er in feine gewỏlynliden bur=

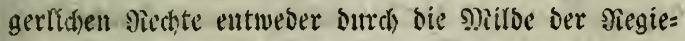
rung noer burch cite Serinterming berfelten wieber

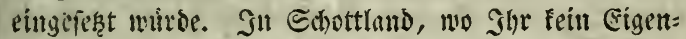

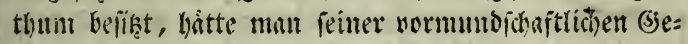

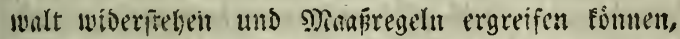

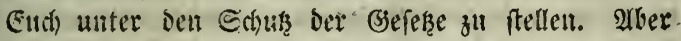

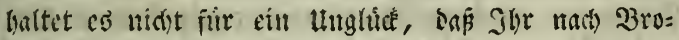

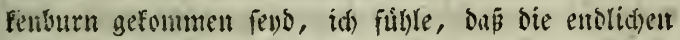

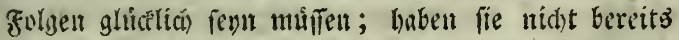

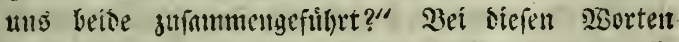

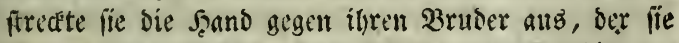

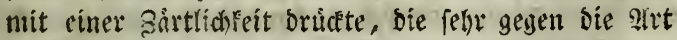

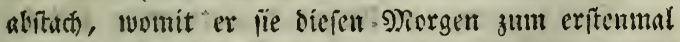
ergriffen batte. (es entitund eime augenticliclye Hau=

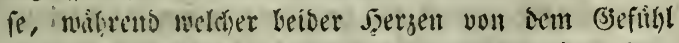

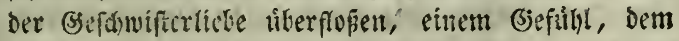
bie Ituritinte fic bisher entfrembet batten.

Endict) Erach Darfie bus Stillichweigen, uno fags

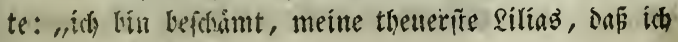




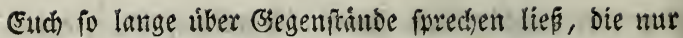
mich betrafen, wailyento ich in volliger ltugeníb)eit uber Cure (seichichte uno gegenvartige Lage blieb." "Die exitere if nidht fonderlid) intereffant, uno.

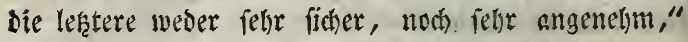
antwortete Siliaġ; "jest aber, mein theneriter Bruber, werde ich eine unichą̧bare હtifice haben an Enrem

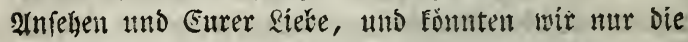

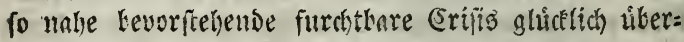
ftelsen, fo babe ith fur bie sufunft wenig Furdot."

"seaft mich wiffen," fagte Darfie, "was unfre ge=

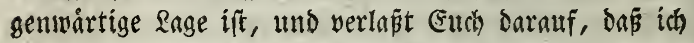

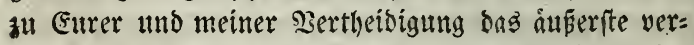
fuchen werbe. IIts wēlchem Grunbe fant nein Dheim sưnftien, mich als (sefangenen zuridezulialten? Wenn aus bloṕem meiner Mutter, biefe ift foron lange ticht melyr, und ich fehe nicht ein warum er winidien follte, nut fo viel Beftwwerden und (befaibr den freien Millen eines Menichen zu befdrainten, Der nad) wenigen Mionaten Das Piecht erfint, furr fich su banteln."

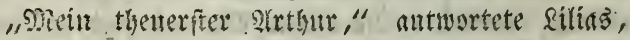

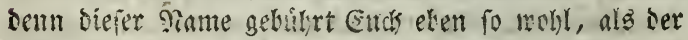

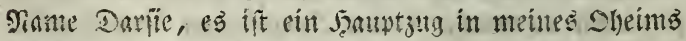

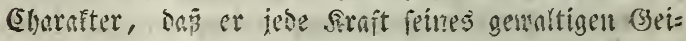
fies ben Dienfice der verbannten Famillie Etnart ge= wionet but. Dir Tod feines 3rutbers, bie Sicridileu= Dering feines eigenen Sernigen habu foinem at: 
seerbten Cifer für bas Şans Stuart cinen tiefen unb

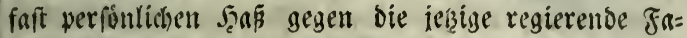
milie beigemifat. 2)it einem SSort, er ift ein poli= tifcher Echuirmer von bockft gefäbrlicher 2 art, uno gelst bei feiten unternebmungen mit ciner suverficht fu Siserfe, als bàtte er bas (Sefúlyl, er fey ber attlab, ber allein im Stande fey, eille pinfente Sadje aufrecht sll exhalten."

"Itno wo oder wie, meine Rilins, babt benu She, on Shr gewié unter feiner Leitutig ersogen vourdet,

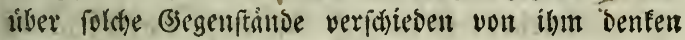
lernen?"

"Durd) einen fonberbaren Batfall," erwieberte \&i= lias, "ill bent Ponmenflofter, "wo mich mein Dheim bintradite. Dbgleidh die Hebtifiin ganz eine Dame nach feinem Szerzen war, fo fiel bod meine Ergielutug als einer Sioftgängerin einer vortrefflichen alten zu, weldhe bie Brunbfäse ber Sanfeniften angentomnten

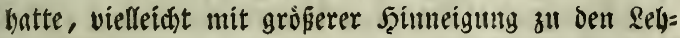
ren ber Sieformirten, alb ber Siatbolifen. Die ge= beimuifvolle Saseife, mit ber fie mir biefe sebre bei= brachte, gaben ibuen bey meiner Sugend einen noch groferen Vieiz, uno iit ergriff fie um fo lieber, ie

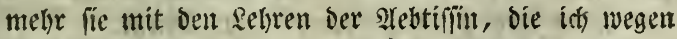
ibrer Etrenge baste, il gerabem Midoerfarudse ftan=

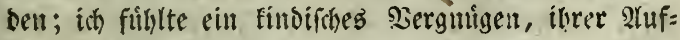
merffamfeit zu fpotten, und in meinem Innern felbit allem. Dem z"l wiberfuredsen, was id offentlid) mit 
Erntribly

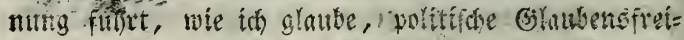
heit mit jich, bein id batte nidat fo forlo bie linfelde

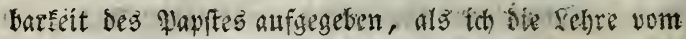
erblichen und anantantharen Fechte an besweifeln be=

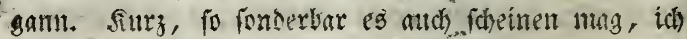
trat aus einem Warifer filofter nicht gatane alz vol= lendete sabig und Westeftantin, boch mit po groper sit guting bau, als ware in in den protefrartifiten Echu= len in-Ebinburgly erzogen worben."

"Sielleidit nich mebr," erwiederte Darfie; "senn je nakger our Rirche - - bas Epridimort ift fchon etmas abgenusç. Slber wie vertrugen fich cure frei= finnigen sheinungen mit den garabe entigegenfebur= ben sorurtheilen meines Dyeims ?":

"Eie wimben fich vertragen taken wie Feuer uno Tsaffer," antwortete eikias", "batte id die meinigen bliden laffen; ba fie midh aber fortwibrentem Tndel and Borwurfen ober nod) etwas forlimmerem ausges fect listten, fo bielt ich fie miglioht geheint, fo sab gelegentlifier Tabel megen Sillte ober Miangel an Ei= fer fir bie sute Sache dats forlimmite niar, was id zu befaliren hatte, soch bis nar forlimm genng."

"Sich lobe Eure Borlicht," Fagte Darife.

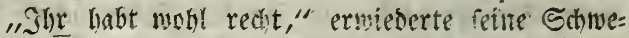

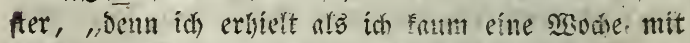

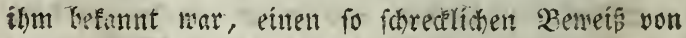

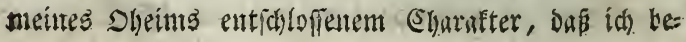




\section{5}

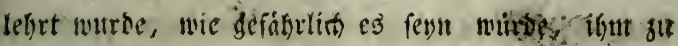

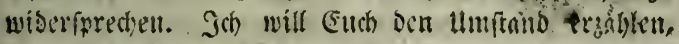
benu Jar werdet baraus befier, alb aแs irgeno etmas antorem, was id) von feiner fiedgeit uno Sd)uirne: rei alififiren foumte, feinen rounantighen uno ent= fa)loffenten Sharafter fennen lernen."

"Id) batte nich manches lange Jabr im silloiter befutben, ba wurte ich ful eituer bagerli, alten, fdyot= tifden Dame von bubeun siang, ber Tochtex eines: Antglicelidjen gebracht, beffen Sçaupt in Sarir 1715. int Semple $=3 a r$ aufgerted worbent mar. Sie lebte von einer fleinen senfion vom franzoffifhen f̧ofe und ges

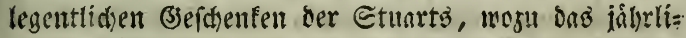
we softgélo, bas fuir midh bezablt muroe, einen win= fethensurthen. Beitrag billote. Cie war weber tibel= Iaunifd now geizig, fie follug mich nidst, uno ließs mich nickt faften, aber fie mar fo vollfommen von siang: farcit und Sorurtbeiten eingenommen, fo furditbar grinslid in ber Bienealogie, und fo fdneidend bitter itt Endyen ber luittifrion Woltiti, sas id oft Dachte;

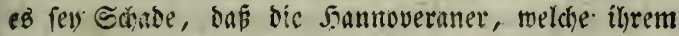

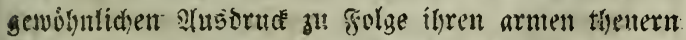
Sater ermoriet batten, feime theure Doditer im Lantse ber efbenbigen fief̂en. Desplalb war ich erfreut, als meit Dlyeill erjaien, ano mir pliblich fein saor:

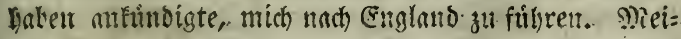

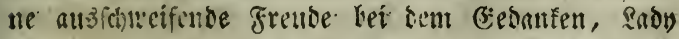
siachel siongebragon zu verlefien, nutbe etmas gema: $=$ 
figt, als ich ben bifitern Blick, bas frolge Benthmen und den befeblenden Ton meittes nahen Serwandten bemerfte. (Er unterbielt jids indocfien auf ber sieife

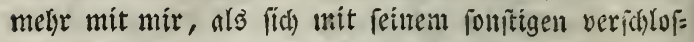
fenen sibfen vertrug, und folent fels begierig, fich von meinem Eharafter, beịonders in Simlicht bes 刃)

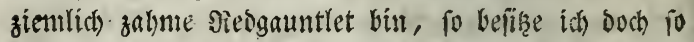
viel vou unferm Samiliengeifte, um nich in Befah)= ren to gefapit, als bie.meiften meities (jeichlechtes, zu- benthunem, uno bei zwei Belegenbeiten in Raufe unfrer Sieife, einem orobenden viăberangriff unto ei: nem Umfturg แmfers sigagens, war meill Benebmen Der 2lut, meinem Dheim eine feldr vortbeilfafte Soee

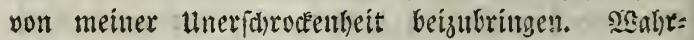
fheitrlich) munterte ilyn dif auf, ben fonderbren Plan, mit bem er ungieng, in 2ltbitbung zu bringen."

"Elye wir Ronoon arreichten, anderten wir bie 2irt mifers fortfonmens, fo wie ben sieg, allf wel= d)em wir uns ber Etabt nilserten, meler als einmal; Dum madsten wír gleich cinten șofen, ber wieberfolt in eimiser Entfernung von bem Siłe, den er einzu=

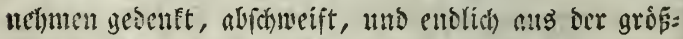

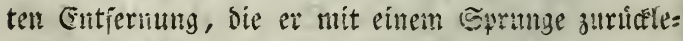
gen faum, in denfelben bineinichlipft, eine angeftrengte Tagreife, unt langten in einer fiflfen uno sumfelen

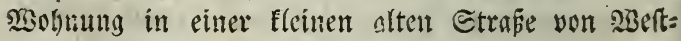
uínifer, nicht weit vout ber 21btei ant." 
.Diefe refweftable Perinn mar vermuttlich Mr. Elrifal siren?" frozte Sarife.

"Ser nemlide," nritwortete Siling, "macht feine 2atregung, bie than verratben founte, dap wir inon ilkm furechen."

Ierfle gub duth seichen zu erfenten, bas at fie verfancen babe, uno fie fathr in ihrer Ergablung fort.

"Sie waren beise in voller Gleioung; mein Dreim nalim eintu Buindel aus Nirong Sand, und Pagte j:! mir: deilins, idt fonme, bich an einen Drt z"l fulbren,

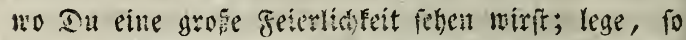
fdinet Du fannt bie flleibung an, bie Du in bie= fsm Payet fribeft, mo kereite bich, mir zu folgen. It) Fand alte prothtige mo gerchmackvolle meiblidhe filetsung, die aber ettros an bie antife form granzte,

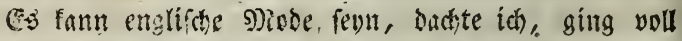
Neugierde nuf mein Simmer, wo idh midt in (5ile ant fleidet:."

"Nein Shein betractitete mich mit 2lufmerffam= feit: Cie faum fuir eines von ben Rlumenmảbden gel= ten," fagte er ju sitron, ber blos nit einem Sopf= nifen onturetere.

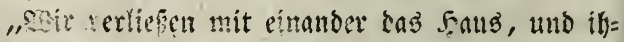
re Semtuis ber Basen, ficfe mo sebentege war fo

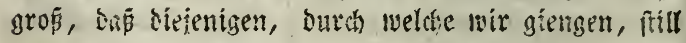
and verloffen waren, objgleid in ben Souptifrafen bas

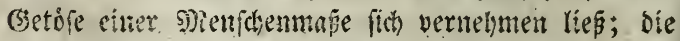
๔trnpenläufer, benen wir begegneten, wardigten uns, 
ernutbet burch Das 2 mishamen fobinerer Bieitalten, faum

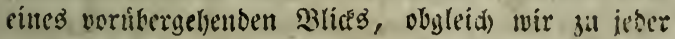
andern Seit unter biefent Sorftabt = Dobel eine betit= ruhigende 2 hufmerkfamfeit erregt babon witroen. Endo lid) giengen wir ifber eine breite Ștraje, wo viele Solbaten siache bielten, withrenb andre erichipft burdh foron gethane Diente afien, tranfen, rauditen wno ne: ben ibren zufammengeftellten 'Şaffen faliefen."

"Eines Tngs, PRirn, fprach leife mein Dheim, mollen wir folon bie Siotjride lelyen, Iuadjanter bei

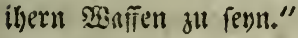

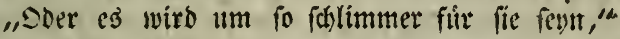
entgegute fein Gefólyrte mit eitter Etimme, fo wib= rig, wie feill (Sejidi)t.

"Itubefragt und unaufgelyalten giengen wir surds bie Siachen binourch, und Piron flopfte beeinal ant eine fleine Scinterpforte in einem ungcheuern altet Brehånde, meldhes gerabe vor ums ftand. Die Thare ging auf, uno wir traten eill, oljue bap id bemerfte, wer uns cingelaffen batte. Durch ein Plan enge unb. ounfle Biange gelmgten wir endid) in einen unge=

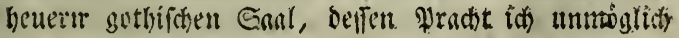
bejhreiben fann."

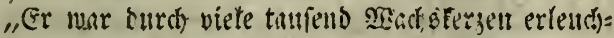
tet, beren Gjlanz anfangs meine 2lusen bendete, da wir gerabe aus dem bunfeln wnd gebeimell Eingmy

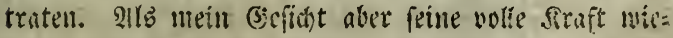

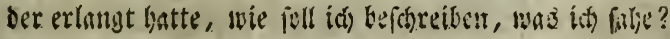


linten fenton mugheure ₹ifde, an betten Prinzen

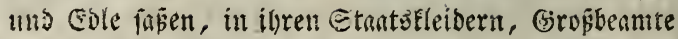

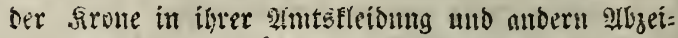

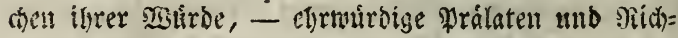

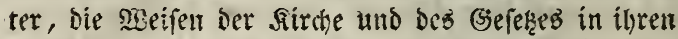

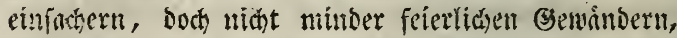
- nebit mandsen andera, beren altertbunlides mo anffallendes Softume ibre 3ebentfamfeit antundigte, oligleidy id nidht errathen fonute, wer fie feun modytetr. Iluf einmal aber wurbe mir alles flar, - es Nar Das Sromungsfeit, wie mir auch das (s)murmel um midh ber beftatigte. IIn einer Tafel, bie bouber Mari, als bie thbrigen, und fich ủber bas gäme obere

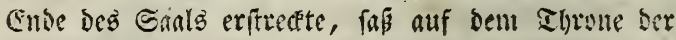

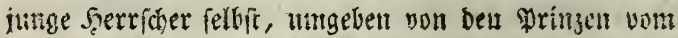

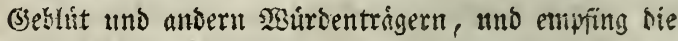
fruldigung und Serekrung feimer thiterthanat. E.e

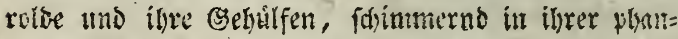

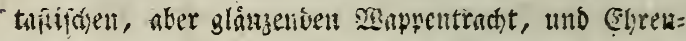
phen wanderlich ausjeliento in ber Tradt alter sei=

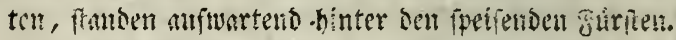
Sn best Gallerie:t, wonte ter gerüumige Eaal mance ben war, glanzte alles, je methr, alb meine arme siu:

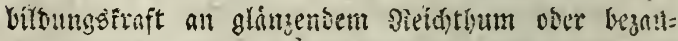

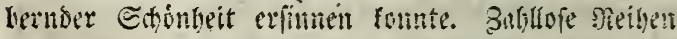
von Damen, beren Dinnmten, Sunelen utio glwi=

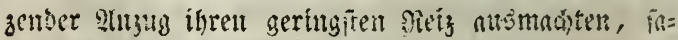

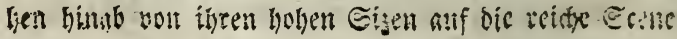


unten, unb boten feloft wieder einen alublide sor, fo

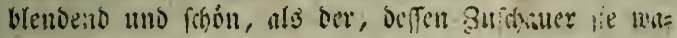
ren. Inter biefen Gaberisn mo binte: ien ziffien

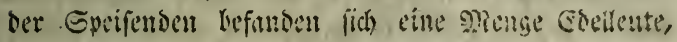
gefleibet, als went fie am seofe aufwarteten, beteu

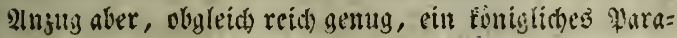
bezimmer zu fommiden, lie bei einter Sien, wie bie= fe, nicht anszeidgnen fonnte. Huter bie in nam nan=

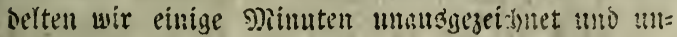
bemertst umber. Da ich melnere junge verionin wie

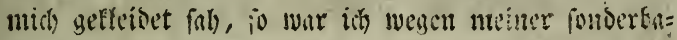
ren fileioung uidst verlegen, uno fient: midi mur sut

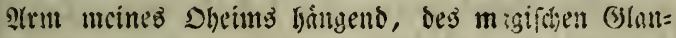
zes eittex foldyen Geene, uno tiber feine cstite bas er mir sieß siergmigen vería aft babe.

Sad) utto nad) betmerfte idy, bap̈ mein Díeim ei= nige Pefinnte unter benen batte, sie fid unter ben Ballerien befanben, und wie wir felbit, mur sufobsuer der feicrlichfeit zul fenn fotienen. Sie irfninten eill= ander an eittem einjigen sionte, oft mix an eintm

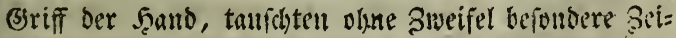
dell aแb, unb bilbeten alimálblig eine Eleine B̧rutpe, in seren Mittelpunt wir uns felbit fejanden.

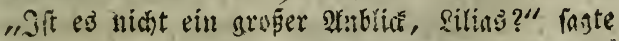

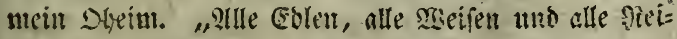

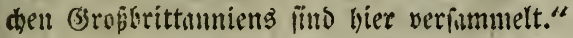

"Eg ift in ber That alles," ingte idh, "luas bicis- 


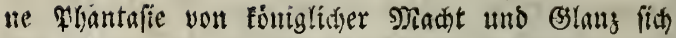
Denfen fonnte."

"Inabdien," lifpelte er, uno mein obeim faun

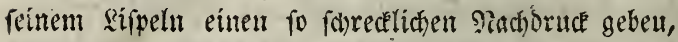
- als feitrer Donnerftimme, "alle Edeln uno sisurbigen in biejem fojonen sande find bier verfammelt, aber nur um gleich Eclaven und Sammarozern vor bem Ebron eines neuen llfirpators zu friechen."

Sch) blickte ifin an, wto bas finftere Erbzeichen

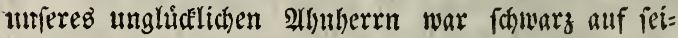
ner Etirne.

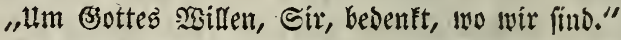

"Iturchte nichts," fagte er, "wir find son freln= ben umgeben." Sals er vorwoirts sdjritt, fótitterte reine frarke, nervigte Gejalt zufammen burcis bie un= teroruacte (Semuthosbewegung. "Siebe," fagte er, "Sort bickt fich Sorfolf Der 2lbtritnnige vom Eatholi=

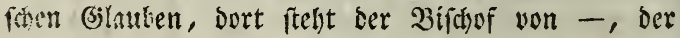
Serrither Der Sirche von England, und - o Ectin= De ber Edinte! bort bengt ber riefenbafte Errol bas Siaut vor bem Enfel beffer, ber feinen 2 ater ermor= Dete! \$ter ein Scichen foll gefehen werden biefe siacht unter íneli, - Miene, Mene, Tafel, thboriu, foll auf biejen Mauern gelejen werben, wie es einft bie

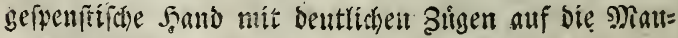
ern Belfazers farteb!"

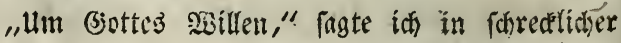




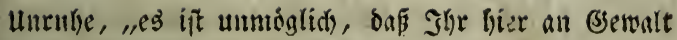
benlen fonnt in biefer Bsegenwart."

"siser bente baum buran, Párrin," ervieberte er, "and) nidst ber ntindefte llnfall fann uns begegnen, wenn Du nur Deinen gerilgmten 9uth z!rammen= nebmen unb meiner seitutitg folgen willit. saber thue es mit faltem 3lute uno finnell, benn humbert Reben find auf oent Epicle."

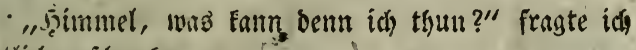
tootrida) exficrocent.

"Pin rafih meinen Bejegl vollzielsen," fagte er;

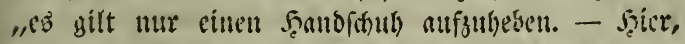
nimm biefen in bie șanto, bebecé iln mit beinem Silcibe, fer) feit befoumen uno fonnell - oder, idi trete anf jeben gall pelbit lerbor."

"NGenn bier feime Sewaltthatizfeit bealfiditigt

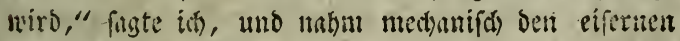

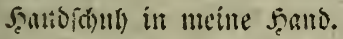

Sa) Eounte mir feine Ilbitht nid)t voriteflen, bei

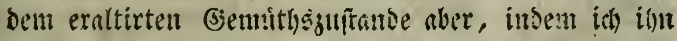
fah, war id tifergengt, sap Itngeborfan z"l cinem wit=

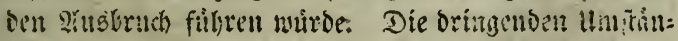

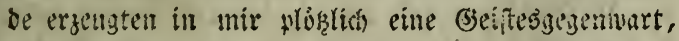

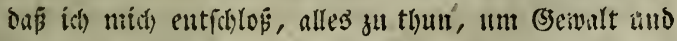

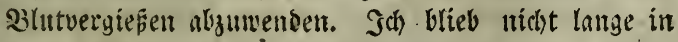
Ungeníp̧yeit. Ein laiter Trompetenitón uno die Stint=

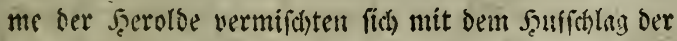
Sinfe, uns cin Sitimpfer, volfommen wic bie bewat: 


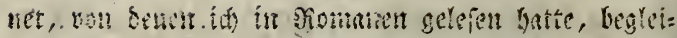

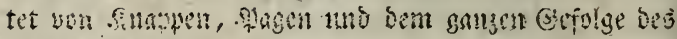

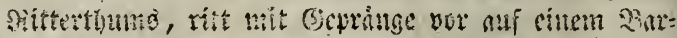

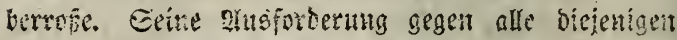

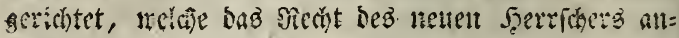

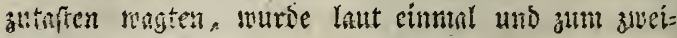
tommal norielefer.

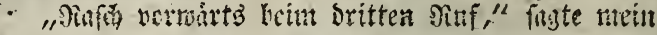

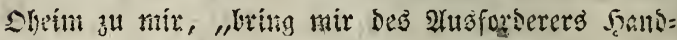
f(hub), und lapi ben mcinigen bafur zuride."

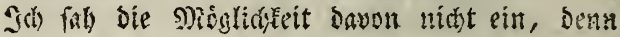

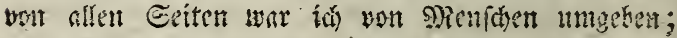
aber beim oritten Sllang bir Trommaten offnete

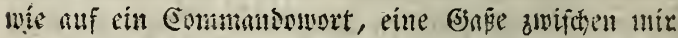
und bon finmpfer, anto id borte mcines Dhemb Gtimme: "ifezt, filias, iezs!"

- Mit rafkem, aber feftem Edritt, uno mit cintr

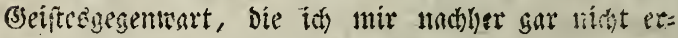
Whiren fonte, entledigte id mich meines sefingrtichen

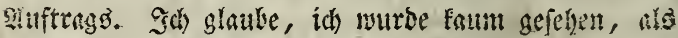

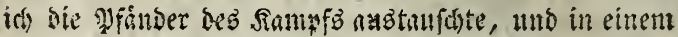

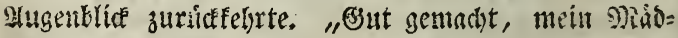
di)en," fagte mein Dbein, an beffen Seite idi mids wister fano, ungeben, wie zuvor, burch bie Piense

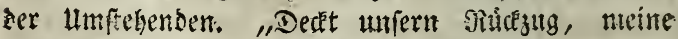
şerrn," fagte ex leife zu den lunftehenden.

Noum marbe bor uns ggelafen, bís wir der Nianer

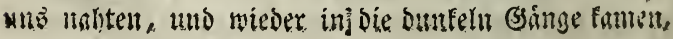


burit) bie wir eingetreten waren. In cincm fleinen Sorzinmer bielten wir an, unt boîtig huiflte mich mein Dheim in einen A)iantel, weldser ba lay; - wir

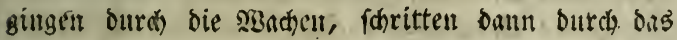

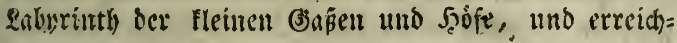

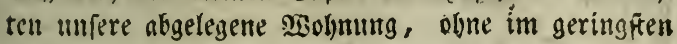
2lufmerffamfeit zut erregent.

"Id babe oft gergort," fagte Durie, "bais cin

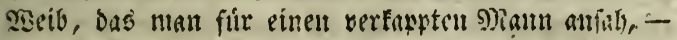

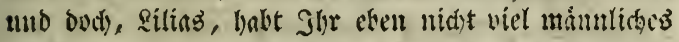

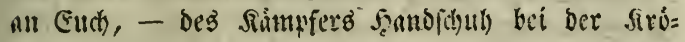

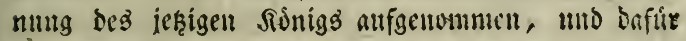
ein Sampfzeichen zurlidgelaffut babe, mit eilutm set= tel, worin ber Sannf angetomment wurbe, voralls:

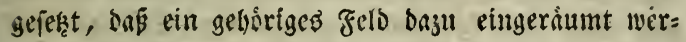

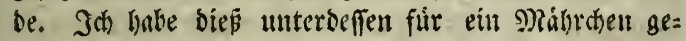
balten, und bachte nitht baran, wie mabe mich bie an=

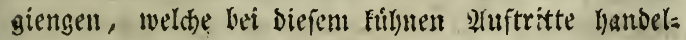
ten. Siso unlont Shr ben 9iutly bazu ber?"

"Finitte id Seit zum ?indsoenfen gebabt," antwor= tete feine Sdywefter, "fo wurbe idh es tyeilb ans

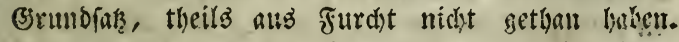

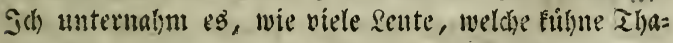
ten thun, weil idy nidyt 3eit batte, zurvidizutrite!n. Die Eacte muroe twentig befaunt, uno ber fioutig forl

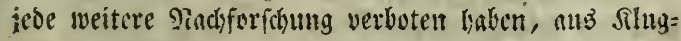

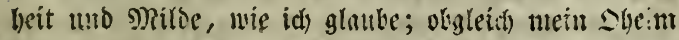

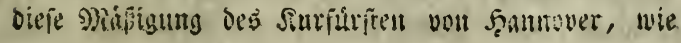


ex thn nennt, theils bem Sileinututh, theils citer fibermithigen Berachtung ber Purthei, welde feilt Nedst nibht anerfent, zufdreiben will."

"Sind Eure fratern F̧andungen bei biefem un= finnigen Sdwámer eben fo gefăbrlich gewefen?" frag= te Darfite.

"Tein, auch niat fo wichtig," fagte Rilins, ,ob id gleidh oft seuge von ben fonoerbaren und verzwei= felten umtrieben gevejen bin, woburch er troks aller Şinternipe, uto mit Seraditung aller (sefahren ben

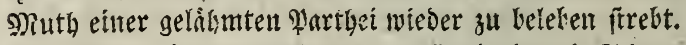
Idh hale in reiner Siefellichaft ganz England mind Schott: lanto ourchreipt, und ben fonberbariten und wideripre:

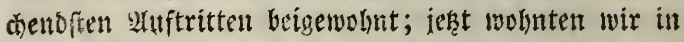
sen Echloffern bes frolzen atelo von Eherbire uno

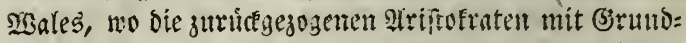
fäken, fo alt, als ilyre \$odnumgen uno ifyre Sitten, noch immer jatobitifde Neinumgen begen; die nidoite

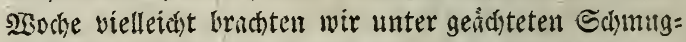

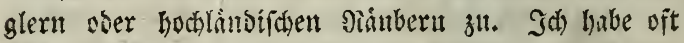
meinen Sheim als cinen wahren f̧elden, oft als ei= nen gemeinen Derfbiworer bandeln, uns mit ber er=

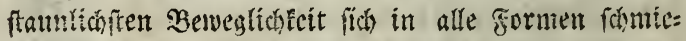
gen feben, um feiner Sacte Anhinger zu erwerben."

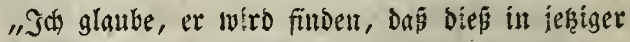
aeit Eein leid)tes unternebmen iit," fagte Darfie.

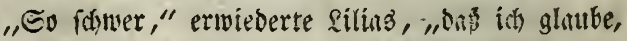

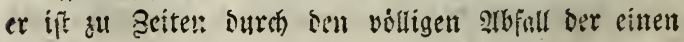


und die salte ninberer fo verbrieflid) gesworden, ba or auf bem ginnt ftano, fein 'llnternelsmen mirzuge:

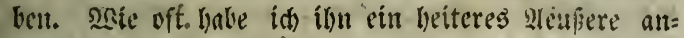

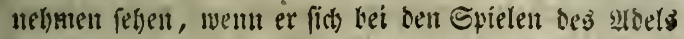
ober den Beluftigungen bes gemeituen 20 offz befand, um eitue voribergebende Popularität su erwerben, wilyrend illm bas feers bredsen wollte uilber ber (Ent= artung ber Beiten wie er es nannte, úber bie atbual)=. ne ber Thdtigfeit unter ben alten uno ben sinngel an Gifer unter ber beranmach fenten (Seneration. WBenn mun ber $\mathfrak{T}$ ag in ben hàrteften $2 \mathfrak{n}$ /trengungen voriber: gegantien war, brachte er bie siacht bantit zil, in fei= ttem cinfamen Bimmer auf und ab zu gehen, ben serfall ber Cache beweinemo, ober wumfdent, bus ibn Peodens fugel oder Belmerimo's atrt getroffen ha= ben modite."

"Sonberbare Tánfang," fagte Darfie: "ift es

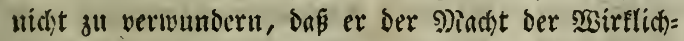
feit nidht nad)giebt?"

"IIda!" erwiederte Rilias, "Die Şirfliafeiten ber leztern seit fojienen feinen foffunngen zu fameidseln.

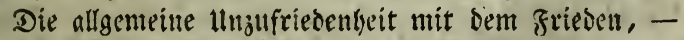

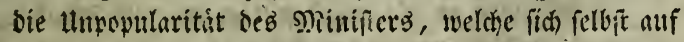

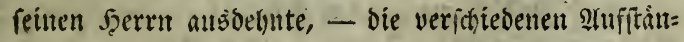
De, welche ben Srieden ber Seatutitabt fiorten, uno

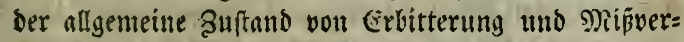
gmigen, melcher bie siation ergriffen zu baben fcheint, baben bie crlóphenden seoffinuthen ber Gaforiten anf 
eime ungemobnlidbe Seife ermuthigt, unb forsolst an rimifach sofe, als an bem bes \$lratendenten, wenn man biefen fo nennen Eaun, mande verleitet, Den Cinfitifrungen berienigen; welde wie nein Dheim, noth boffen, wem alle andere bie Seoffining lảngit ver: loren baben, ein geneigteres Dhe zu reiben. Sch glau= he andi in ber That, bus fie in biejem Singentidic auf einen verzweifelten $3 e r f u c h$ bebadst find. Nein Dheim bat in ser lek̨ten seit alles gethan, um bie sumei= gints jener willen Escnteinden zal geminnen, bie ant Eolmay wohnell, ufer welche unfere Jamilie oberher: liche Siccte befas vor ber Beit ber Hedtung, unter weldien auki im Jabr 1745. bie 2 (nbanglidfeit an un= feren unghiterlichen Sater, fo wie an ibn felbit, eine

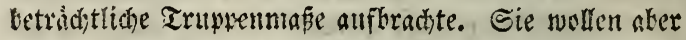
feimen Suforderungen nidht lánger Giebor geben, uno fultren wuter anserem zil incer Entfouldigutg Eure Slbucienbeit, als ilgres uatirlichen sberbaupts uns

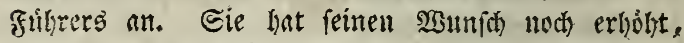
(iic) Eurer zu kemádtigen, uno wo mỏglich Ench Ju

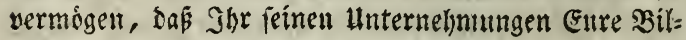
ligum!g ertheilt."

"Diefe wirb er nie ergalten;" antwortete Darfie;

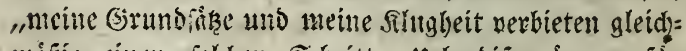

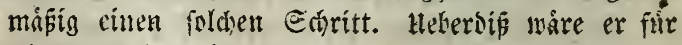

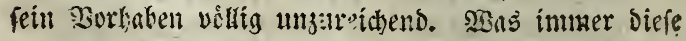
Reute vormenden mogen, um Eures Dheims 3ubring=

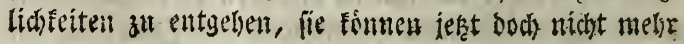


f̧e:z brechen, ober illu zu cilter verzweifungsvollen Tljat treiben.".

"Sa, Rilias, Slur vergest aber, bap̈ bie Jolgen

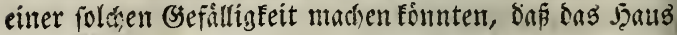
Reogauntlet uno idh mit einem Sallage ing Şaupt verloren."

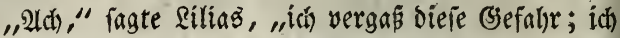
bin mit gefălirlidien umtrieben fo vertraut geworsen, wie nan von ben sairterinnen in Peithiufern jagt, onf fie an bie Suft nm fie her fo gewointt wirsen, bis fie fogar bas gefalyruolle berfelken vergäien."

"Itno bod," fagte Darfie, "wenn ith mich in Freis heit fescen folnte, obne es zu einem offenen $\mathfrak{B}$ rud lommen zu lafien - fage mír, Rillias, biltit Du

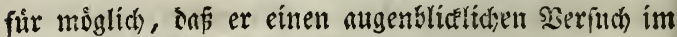
Simme baben fam ?"

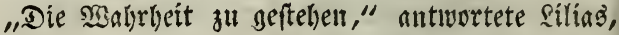
"iid fann daran nidht zueifeln. Sine ungewoinnliche Bemegung ift unter ben Iafobiten biefes Sandes ge= wejen. Cie bauen froffnungen, wie idh (Euch gefagt babe, all ltmptinde, welche mit ífere eigenen Etárfe

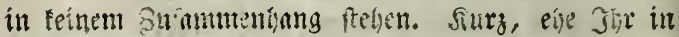
biefe Gegents famt, lurbe meines sheims 2 sumfd,

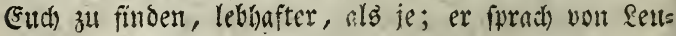
ten, bie in 2 hugenblick zusamntengebradst werben foll= ten, von Euerm Pamen uno Cherm Einfuś, um fie

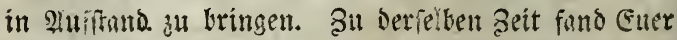
erfter כefud zu 2rofenburn ftatt. Eine sermuthung, 


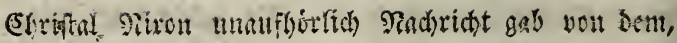
"Mas Sigr vornalunt."

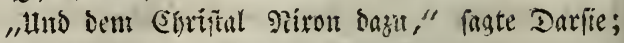

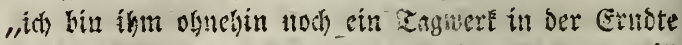

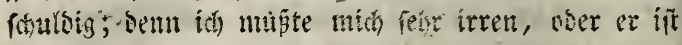

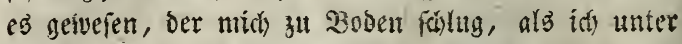

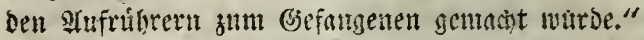

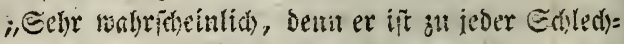
tigkeit bereit und sollig. Sieit Dheim. war ferst un= gebalten doruber, bem obgleich ber 2luffumb erregt war, um eime Gelcgenheit fu buben, Eart it ber \$er= wirrung hinwegznfithren, fo wie atd um bie Jicher in 3wiefpalt mit ben biejehen zu bringen, io wate ca buch fein lester (sedonfe gemejen, Euch audh mur ein

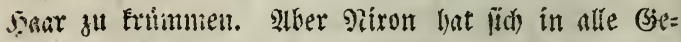

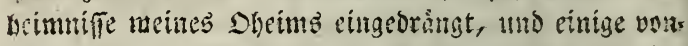

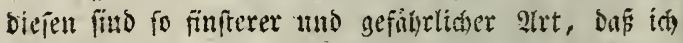
aneifle, of er es magt mit ilgm in Streit all fommell, ohgleid es wenig Dinge gibt, bie er nidht wast.

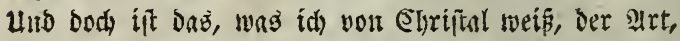
ắ es meinen sheim benegen finte, ifim den De= getl burch Dell Reíb zu ingen."

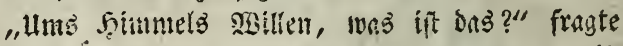
Darfie, ,ich bin gatm befonders begierig, bas zul wif fen."

"Ser alte brutale Todfoye, beffen (sefidit und

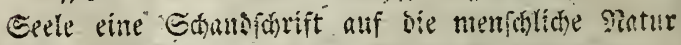

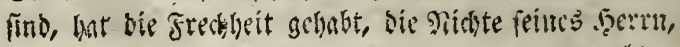




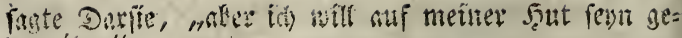
Gill it?

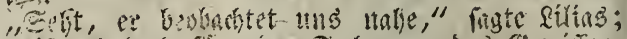

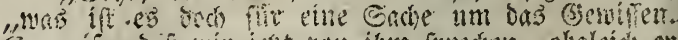

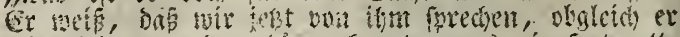

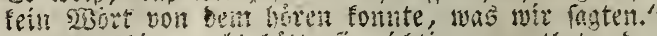

(5. foterh, als hatte lie richtig vermuthet; dent

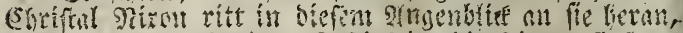

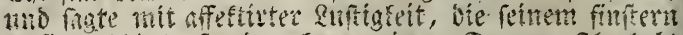

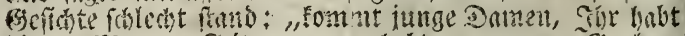

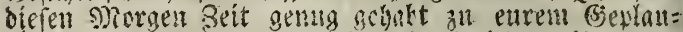
ber, mo (sure sumgen mifen, denfe ids, move fenn.

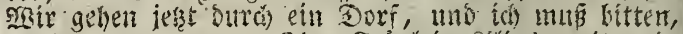

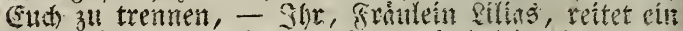

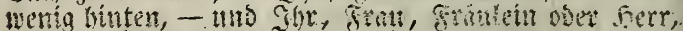

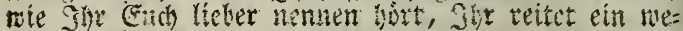
nig vorivånts."

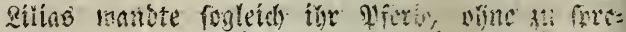

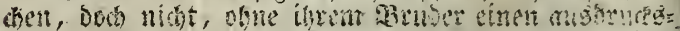

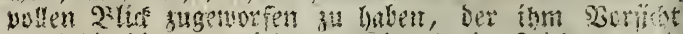

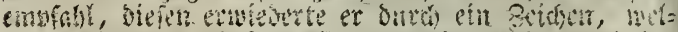

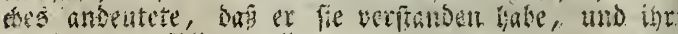
gerlangen exfüllen wolle.

\title{
รูพ
}

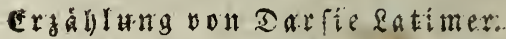

\author{
Fortegung.
}

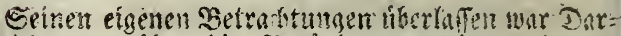

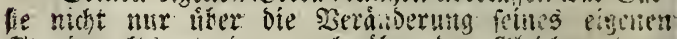

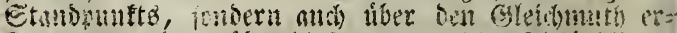

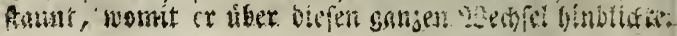




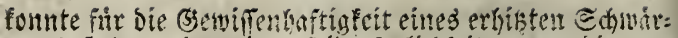

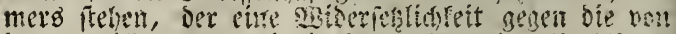

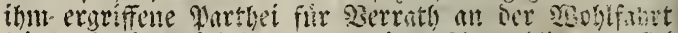

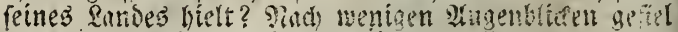

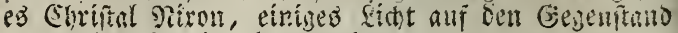
gu werien, ber ifn bemmengigte.

2lls bicfer fimitere Trabant obne weitere Eiremo: nien biht an Darfes Seite ritt, fliblte biejer aus 2lbfheu eine 2(rt Fteberichauter, fo wentg war or in

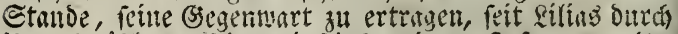

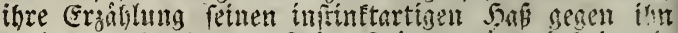
nod vernebrt hutte. Eeine Stimmte tontte Babei, mie

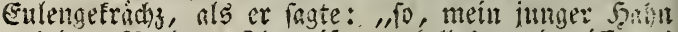
aus tem Torben, Ghr wipt man alles, who wifit is

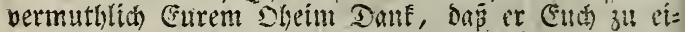
ter to elirenvolfen That infporute."

"Id werse meinen Oleim mit meinen Geitnurnt: gen riber biefen Gegenfand befant mathen, beocr ids

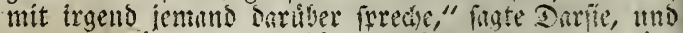
mar foum in Etande, biefe wenigen sisote suf eine

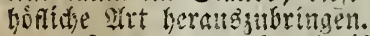

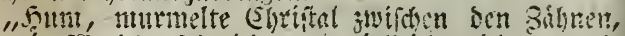

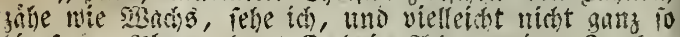

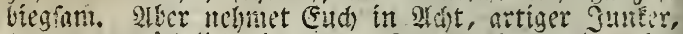

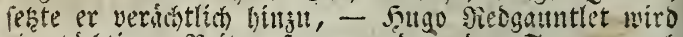

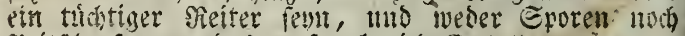
Sertfche fparea, bas verfpredie ich Eat:"

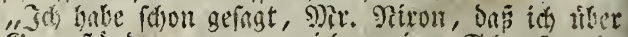
ote "Eegeniftinde, nowon mich meine Editveffer in

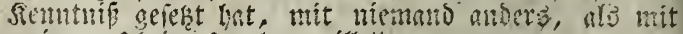

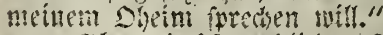

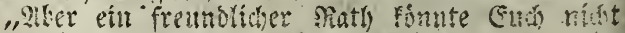
ichaien, junger Serr," erwieserte ?irou. "Ser alte

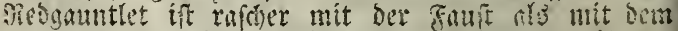

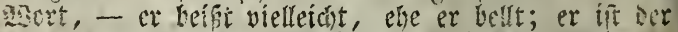

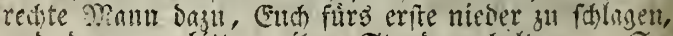
und bann zu bitten, ism Etmo zu bartin - હo, 
Dinft mikh, cine fleine gutgemeinte sisarmuna begen ben Tolgen fintute nidit) fainben, bunte biefe nidht un= verbereitet viber (E)d fontuien.'

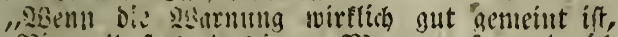
Nir. "Pitrun," fagte der junge Niann, "fo werde ín fic mit Dant anboren; ifi fie es nicit, fo mus id foch darmit horen, ici) mag wollen ober iticht, weil id

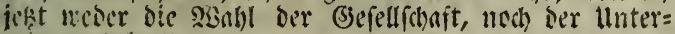
ricumb bake."

"s? int, id habe nur wenig zu fazen," fonte Piron, imberi er feinent suffern uno lomirnoen sgefen ben

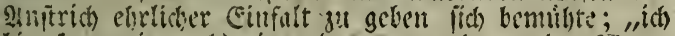

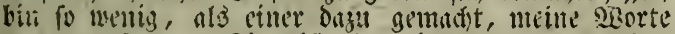
meyzmwerfen. - Stier ifit aber bie frage, wollt \$igr

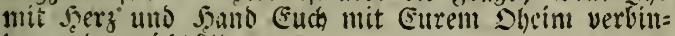
deti, door nitoit?"

"Ilno snem ith mun ia fane?" fragte Darlie, ent=

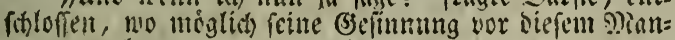
tte z"l vertergen.

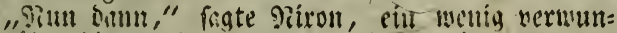
fict "utser bie rafche 2uttwort, "bann miro altes gut netien, - Shr merdet an biefer edefn Unternebmung Igeil nebmen, tmo wenn fie gelingt, - verrancht Slir

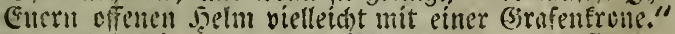
"Ilno wie, wenn $\mathfrak{e}^{\mathfrak{g}}$ miölingt", fagte Darfie.

"In anu geluts'; wie es schen mag." - frgte

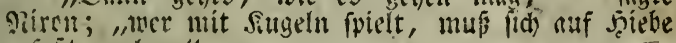
gefait machent."

"P?un, nelum't aber eimmal an, idis bitte sine

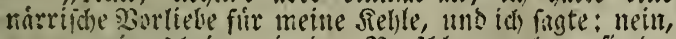

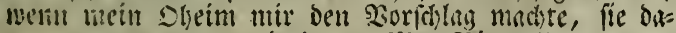
ran zu. wagen, L wie batm, sir. sirun."

"ioun ban mogt Ghr fúr cud felbft forgen, jum=

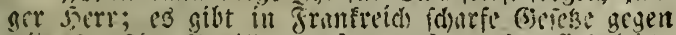
wincripenifige qutwillen, - letires de cachet fint leicht

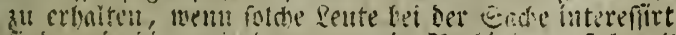

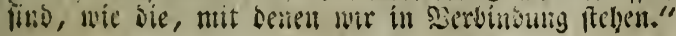


"Tुir fino abu nicht in Frantreich," fagte ber

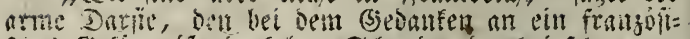
fones (S)

Eit foncl pigelnoer Eugger bringt Euch bals

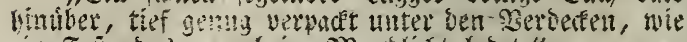

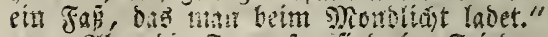

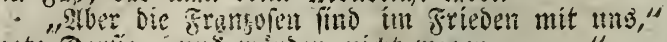
fagte Darile, ,lits wurben nicht wagen

"Bstr wurse bent je von Endi boren " unterbrath

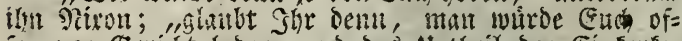
fen vor Gericht lroent, uno tia Urtheil Der cinferfe= rung in Den Courier de l' Lurope fekell, wie man es

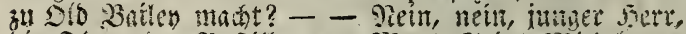

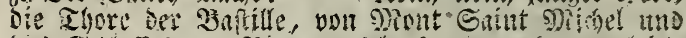

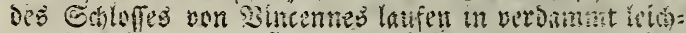

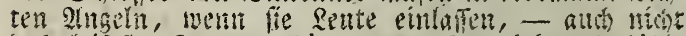
oto leifsite finacen bort man. Da giebt es fible

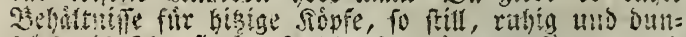

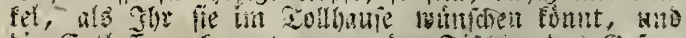

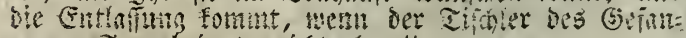
gentes Eurg britgt, utht cher."

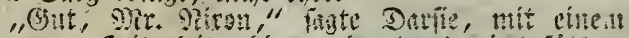
Tone voir satereit, sie er ourbats nidit fibite;

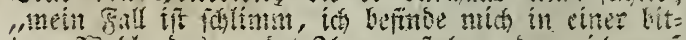

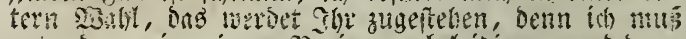

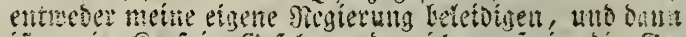

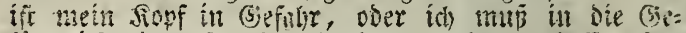

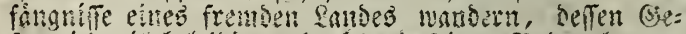

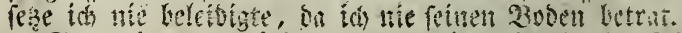

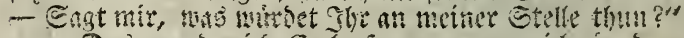

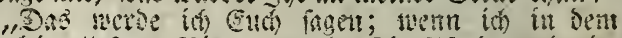

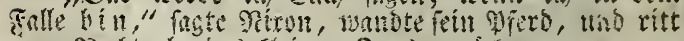

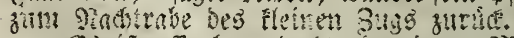

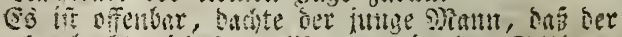

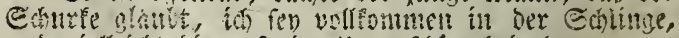

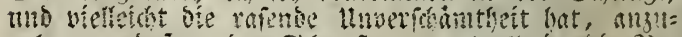

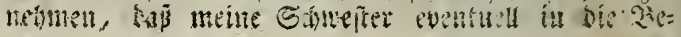




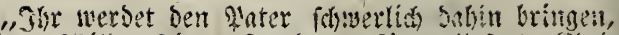

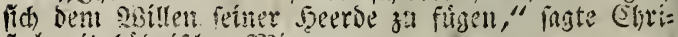
fal mit sofntider sniene.

"Er mü uns wirb!" antwortete siebgamitlet furz. "sleite einnal vor, Eqriftal, - ids mobte mit meinem Seffen ipredyen. - Sch bofie, હir sirtbur Feggauntlet, Gir werdet zufrieben fesn mit ber gret, mie ith mich oer Pfidit gegen Eure Sibnefter entle: oigt babe?"

"Ghre Gitten und ibre Dentart find untubellait," fagte Barfie; "ich bin glicklich), cine fo liebenswairoi ge gerwante fentien gelernt in sisent."

"Das freut inids," antwortete eisogauntlet; "idl) verfebe mish nidt fonsorlith anf bie Ciginfichaften ber

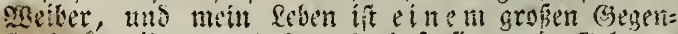
fento getwiomet getocfen, fo daf lie mentg Belegen:= heit hatte, fich weiter anszibiloen, feit fie frantreich rerlieg. In babe fie indes fo wenia als miglid oen timannebmlidgetten Imb Entbefrumgen meines ivan=

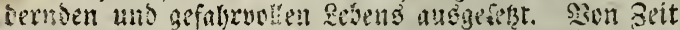
fa Beit if fie Sogdyst uns sponate lang bei angefi=

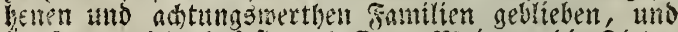
(d) freme midh, ons fie math Eurer Pietum, die Sitten und bus Benchmen bat, bie ibren Stmos geziemen."

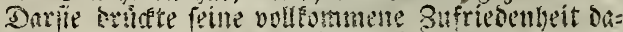

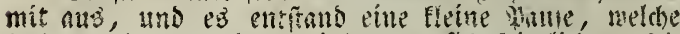

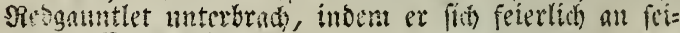
ner sefich wande.

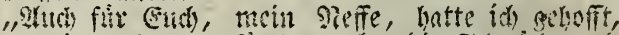

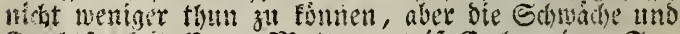

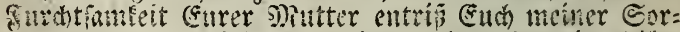

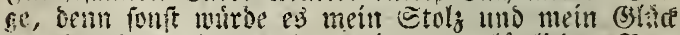
genelen feba, ben Sobn neines unglualidien B̧ra= bers anf benl Wiato Der Eire geleitet zu baben, anf

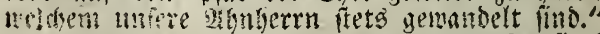

ginn Fommt oer Eturm, butite Darlie Ge! fith

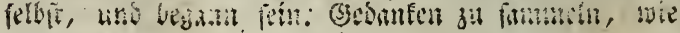


bitutosos Moor ectrieten fenn, ment sentt nitt im

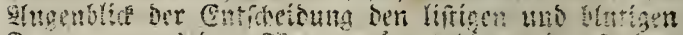

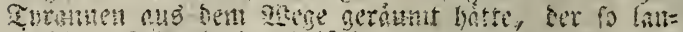

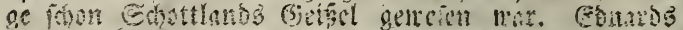

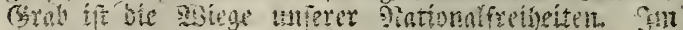

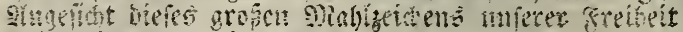

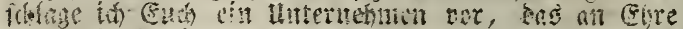

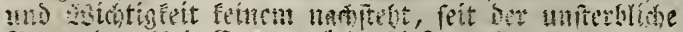

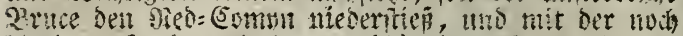
b!ttigen sand nad ber unablingigen frone Edstt= latiss griff."

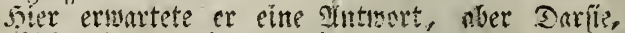

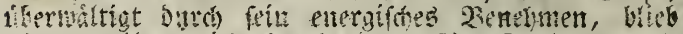

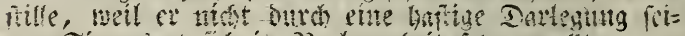
ster Emmesat fich in 23 erlegentit feisen trollte.

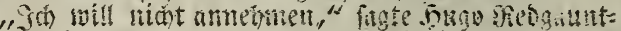

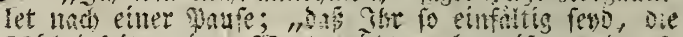

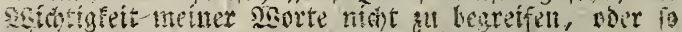

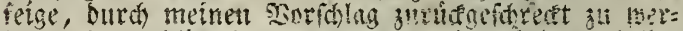

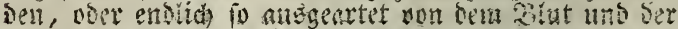

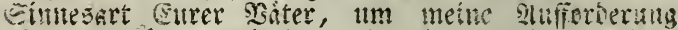

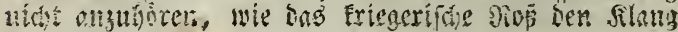
Fer atumpte."

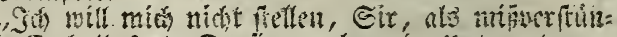

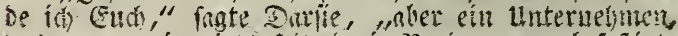
Das gegen cine jest feit sret hegienungen befeitigte

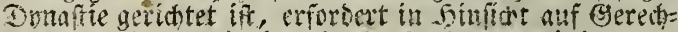

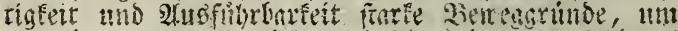

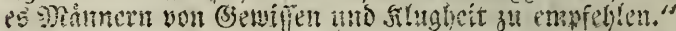

shit zhgen, bie vor llnwiflen giubten, frgte siev=

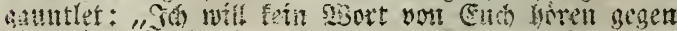

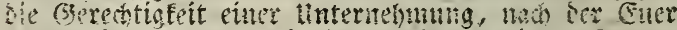

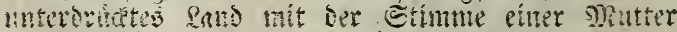

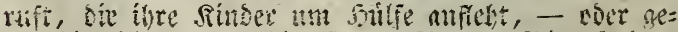

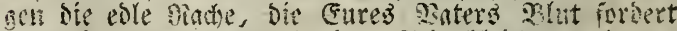

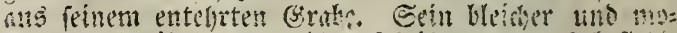

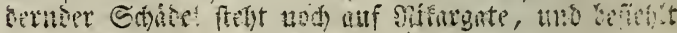


Siampf entgegen, und Shr allein focint Saillens, ein to verzweifeltes unternelymell zul wagen."

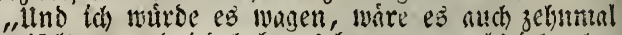
verzmeifelter, uno ín babe es tegunnen, als fich jetti= mal grôfere Scinderniffe entgegentbuirmten. - STate ich meitles Bribers Blut vergoflen? - Sann id burf id bas Soter Unjer beten, ba id meinen fiein= ben uno ben Morbern nidht vergeber habe? - Bsibt eo einen sumftgriff, ben ich nisit angenanot, - cine

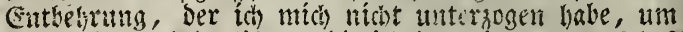

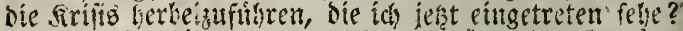

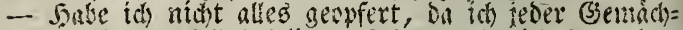

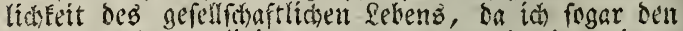
llbungen ser Feligion entfigte, wenn id in meitiem (sebet meinen Furiten mo mein ?aterlano nicht neat= ticn burfte, und bieş alles nur, um der edlen Eache Shithanget zat erwerben? - Sate ish nlies bief gethan, wur um jest auf eimmal alles aufangeben?"

Darfie mar int Zegriffe, ithn zu unterbredsen,

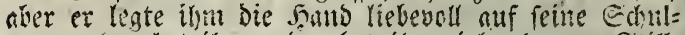
tit, uno gebot ibn, ober fat ilgn vielmelgr un Etill=

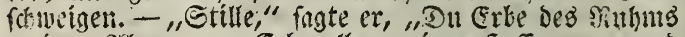
meiner Mhnen, - Erbe aller meiner froffnungen und

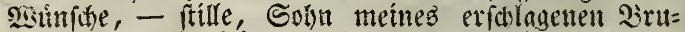
Ders. Id) habe Didn gefucht, uns um Dich getrotert, wie eine oiutter um ibr émziges fillto. Raj mich Dich nicht in bem 2angenblice pieser verlieren, wo

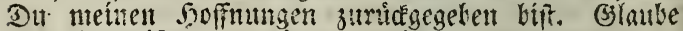
mir, iti mistrane nteinem beftigen Temperamente fo

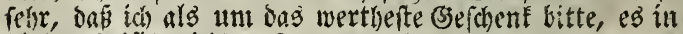
biefer sirilis nidat aufzuweden."

Darfie ermiederte mit Frende, saf die Ehrintrdyt vor feinem Dheim ín beftinmen merbe, alles anzu=

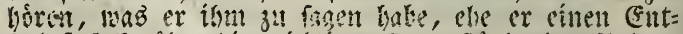
fdhlup foffe user die mishtigen (siegenfinde bes 3eden=

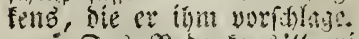

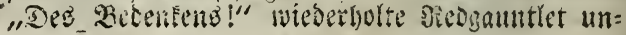




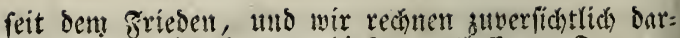

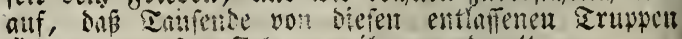
(iid) unter unfere finnent reiten lictsin."

"note!" faste Darlie, "nno anf folde utbefímm:

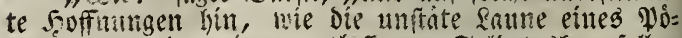
herrinufens ober einer entlafienen Erliatesfo, follen

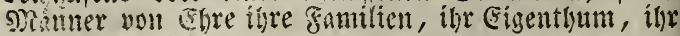
felen majen!"

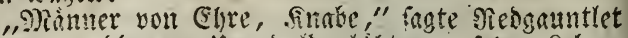
mit "singen, oie von llngesulo glabten, , feren selien, Eigentlum, frumilie uno mlles anfs Eviel, nenm biefé Eire es befieblt. Sair find jest nidht fotwicher, a!s onmals, wo fieben SRm in den SEiloniffen von spoidart lanbeten, ben Thron von bes thiurpators zun \$ianfen

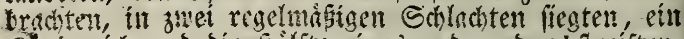
Sonigreich und bie Seiffte eines anbern burdhitreiften,

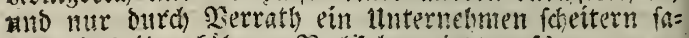

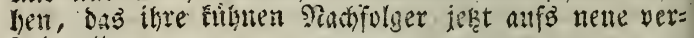
fuchen."

"itho ein folther Serfuch mird ermflich gemadt wersen?" fragte Darfie. "Entifunisiot mitc, mein

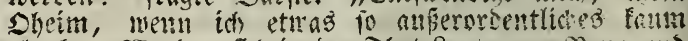
glaube. Wervent fith it ber That feute non vinn mo

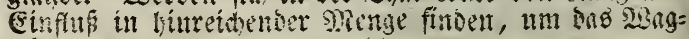
fitide von 174\%. "Hernetient"

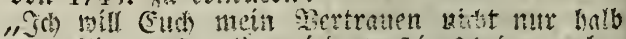

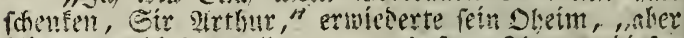

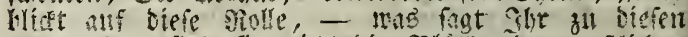
gianter? - find fie micht bie Bhthe Ber meftlichen

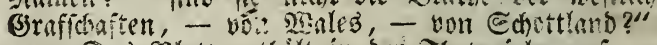

,Das Blatt entbitt in ter rhat viele grope uno

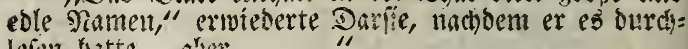
bejen hitte, ener.

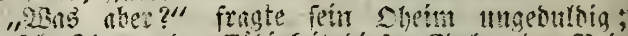

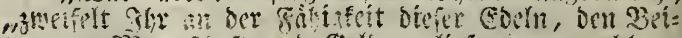

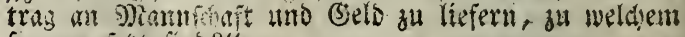
fie angefiąt fono?" 
Gatten, als' er an ber Spije einer fiegreiden $\mathfrak{A}$ rmee it (snglano einbrad), feime Eanoung unter weit niti= ber günfigen unftainoen begimfigen folften. Er figlof

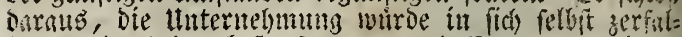
len, und es bas beite fern, unterdeffen su forweigen,

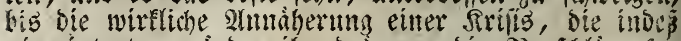
tie eintreten mitroe, iljn brange, die Sorichlige fei=

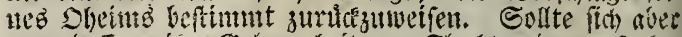
unterdefien eine Belegentheit zur. Flutht zeigen, fo be=

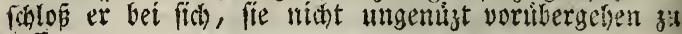
Inflen.

Sุugo Peogauntlet beobachtete eine Beitlang die Blicke feines Neffen, unto fagte fobann, gleid als ob er. Durrs einen andern Soeengang auf bent nehmlichen

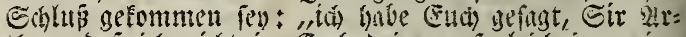
thur, Dur id nint in Eun oringe, fogleth in méne sorichlage eurjugelden; nud whroen bie folgen eimer

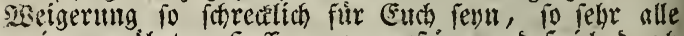
meine genábren Soffmungen serfitoren, bn id sura bie the

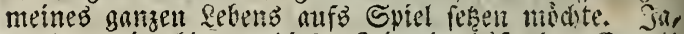
Artbur, ich bin za biefer seit ein bifipenver Eremit gevefen, zu einer andern ber fdyeinbare Bsenope von (Sjencisteten uno $\mathfrak{S e r}$ meifelten, mand)mal endich oer untergeorbute Pigent von Menichen, Denten id mich

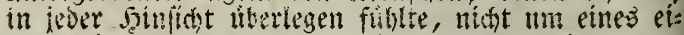

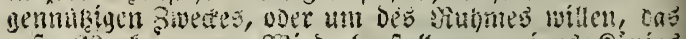

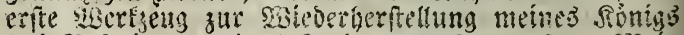

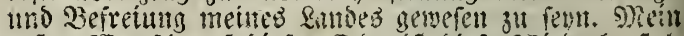

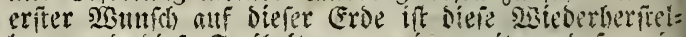
lung uno diefe greibeit, - mein zweiter, bap nein Refie, der sienrafentant meines soules uno neines seliebten Prubers dic sgortheile aller meiner afnfreti= gutngen fir bie gute Eadhe eritoten folle. 2iber, ferte er binzu, inden er einen feinter vernidtemen

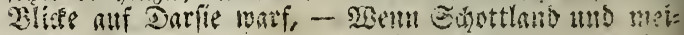




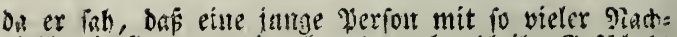
gichigfeit fich gegen ibn benalgn, obwohl ifyr (sefblecht

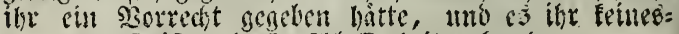
wergo alt Geift uno (entichlofienlieit georach.

Die Fleine steitergefelfichaft tråberte firh num bem

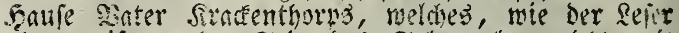

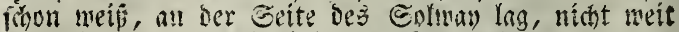
non einem rols'n Etcindamm, lan methem meirere Fifcherbovte lagen, bie hälfig in verichiebener Eiaen=

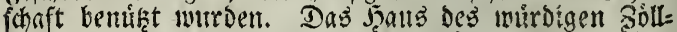
nerb war zu ben verichiedenen! Geidsiften, die er trieb, eingerid)tet, benn $e^{3}$ beftand aus mebreren, an cin

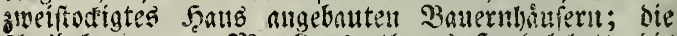

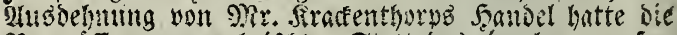
Dergrofferungen exheifdt. Statt bes éiljolnen grosen

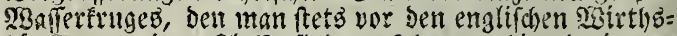

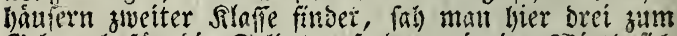
Gebrallá) fin bie Eoldatenterbe, wie ber abirtl fich

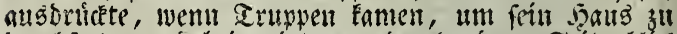

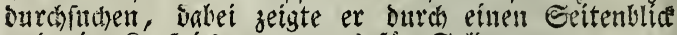
und ein Sopfniceen an, was für Solbaten er ntone.

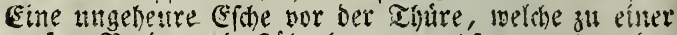
aropen Zreite und F̧obe Gerangemadben war tros oer

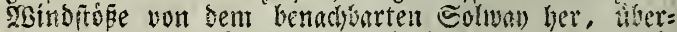

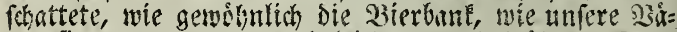
ter fie nomenten, wo, obgle:ch es noch fruh am rage war, mebrece Burbate, welthe Diener bon Ebclleuten zu fern fohienen, Bíer tronEen uno rauditen. EEtuer

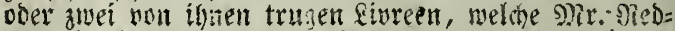
gountlet befant fólenen, bemt er murnelte zmichen

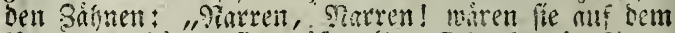
sisege ztic solle, fis nuisen ínte Shurfen in Rivree

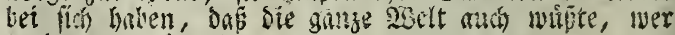
versomsit mire."

2lls er fo mumelte, bielt er nor ber Tuire bes

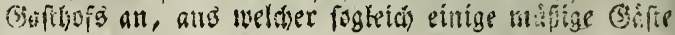


" "Iक wollte mich nidht auforingen, Sit," etwie: berte Irlan; ,oie Lage ber Dame fdien Şulfe su for:

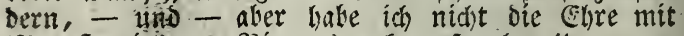
S.?. Serries von Dirrentwork zu iprechen."

"Slir irrt Fuch, Sir " fagte giedgauntlet, wand= te fich ichnell ab, machte eiu Beidsen mit bet Şand ge: gen Shriftal, ber ben wiberitrebenden Darfie raich in

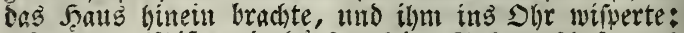

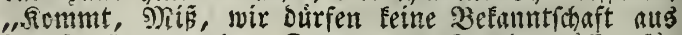
oen Fenitern machen; Damen von Stanbe muffen fü (iic) bleiben. - Beigt uns ein Simmer, Nater Sirat: Eenthorp!"

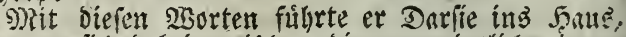
inden er fich dabei zwifden bie vermeintliche junge Same uno beit verbahtigen fremben itellte, um eine 9)ittheilung Durch Beichen fu verhindern. arls lie ein= traten, liorten fie eine Sieige in ber gepflaitertin uno

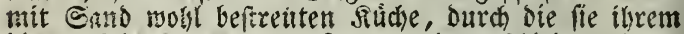
biden Mirtlye fo.gen musten, nno veridiedene seute beluifigten fich, nach ilsen Tonen zu tanzen.

"3uni Teufel noch!" fagte Piron su firadentborp; "waram foll bcun bie Dame ourah den pobel bes gan=

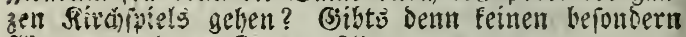
Weg z"i unierem Stmmer?"

"Sieinen, Der frir mích paste," antwortete ber (sintivirth, uns legte feine foand auf cen anfelnliden Srineerbath. "Sol bin tricht Tom Turapenun, um wic eime Fibechie burd Sd)luffellober zu friedsen."

grit biefen soorten fuibrte er fie ourch oie latige

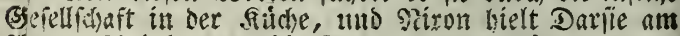

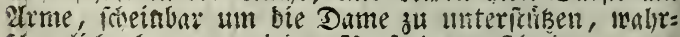
fdemlich aber, un ieben Sieritud) zur filudit ou ver= finsern; fo crbeitete er fich Durd die sienge, die ein

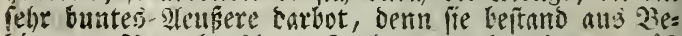
ijenten, 23uerburiden, Seeleuten mo anberem mufi

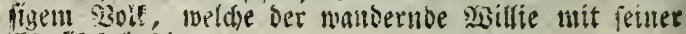
gimit falmintste. 


\section{3}

Todb an eincm antern Treunb olne ein seiden fet: ner (3)genwart bortiberzugeben, ware wirflitbe Sllein= nutbigfeit gewefen, uns als fie an bent erbihten Gike Des Blinien vortiber gitugen, fragte í)n Darfie mit

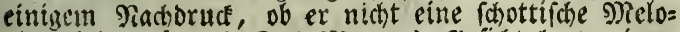
bie fpielen foume? Des Manmes Befidt batte einen Alugenblid vorber gar feinen 2lusornde, als er aber Dariies Stimme borte, wurbe fein (Sefitht mit einem= male glánsento, uno bewiés den Irrthum berer, wel: de ben Sauptausbruce piner Phofionomie in ben 2 Lu= gen finden wollett. Er wariste fein (Sefícht nads ber (3)gento, nober ber Toul fam, feine obere sippe bog fith eit wenig, und behte vor innerer Berwegung, in= be F́ Erftanten und Frende ein blúbendes Sioth anf feime bleidhen Bangen brachte. - Er vertaurate bie ge= meinen Etrice bes Dubelfad's, die er mit wiberitre= bendem nub nadiläigem Bonen hergebudelt hatte, mit ber fdionen fisottifdsen Melodie:

\section{"Een wilffummen, Sart Etuart!"}

Mie mit 2egeifterung ertonte fie von ben Sai= ten, und nach einer Paufe ber hodhiten Bewunderung, wirbe fie burch cin Reifallg̈geidirei aufgentommen, welches zut zeigen foien, bns ber Rame fowohl, als bie Ansfilyrtng allen Berfanmuelten bichit angenebn war.

Indeffen bielt Elriftal Tiron Darfie feft am $21 \mathrm{r}=$ me, folgte bent $\mathfrak{B i r t b e}$, halbnte fich mit einiger Sdmies rigfeit ourch bie georangtuolle sithe einen 2 seg, und trat nun in ein Eleines Binmer an ber andern Sei= te derfelben, wo lie filing gedganntlet bereits fíbend

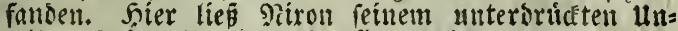
willen freien sauf, wandte fick beftig zu Sirafenthorp, bebrobte ihn mit bem beftigiten llnwillen feines Be= bieters, dab̆ die Sachen in fo fdlediter Drommg ma= ren, imm feine familie zu empfangen, ba er bod fo ausoruaclich ibn batte siffen laften, er wintche allein zu fenn. 2aber Sater Sirafentyorp war nidt vor ben Siopf geinlagen. 
"Tile! Bruber Pixon, Du bift unwillig diefen Morgen," erwieberte er; ,bift mit bem unredten Fufie beralls, glanbe ids. Da weist fo gut, wie ich, bấ bie meiften Re!te Da unten von des Squires eige=

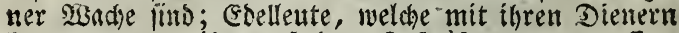
fommen, um ifin auf Dem (Seid)iftsweg zu treffen, wie der alte Turapenny fagt; Der lekte, weldher fam,

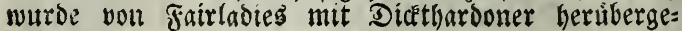
ichicett."

"Zlber ber Blinde Frazeltoe Sdurke bort," fagte Siron, "tvie babt She es getwagt, fold' einen Spich=

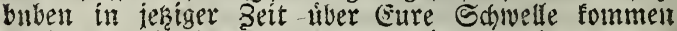
3u laffen? - Sibun eg bem Squire nur im Sraum

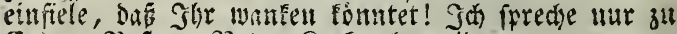
Euren Zeften, Sater Arafenthors."

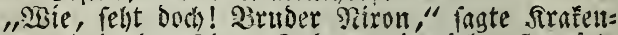
thorp, uno brehte feinen Eabad nit vieler (jemids)=

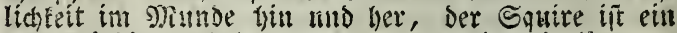
felgr wirbiger Edelmann, bas werbe ich nie lätgnet, aber idh bin weber fein Diener, nod fein 2 afoll, tutb

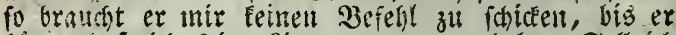
bort, Dafi ich feille fivree angezogen babe. Soll id aber geute yon meiner Ighure wesweifen, fo fomte ich elen fowohl ben Bierzapfen ausitopen, und ben Echild herunter nehmen, - was aber bas soanten be= trifft, fo virto ber Squire hier fo ebrliche Reute firt= ben, als er nur immer mitgebrad)t bat."

"Tiun, Shr unverfhainter Talgflumpen," pagte Pitron ; "was wollt Shr Damit fagen?"

"Pichts," fagte firafentborp, "als bas ich bas rathe fo gut herausfelgren Eann, wie ein anoerer, Gir veriteht midh - b' i if hell genug in mecitem obern

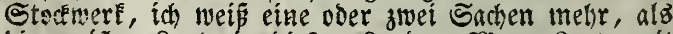
bie meiten Reute in biefem Rande. SBent Rente mit gefäbrlitsen Dotichaften in mein Seats fommen, fo werben fie an Son Srafenthory Eeine Sintsenpfote filt=

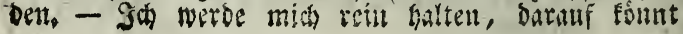


te Pilias zu ibrem Brutber, ,hat mir einen grosen Sortheil uber ilgn segeben. Denn ba er meis, da mein Obeim ian mit eben to wenig Bsewiffensbifien niebcrichieffen whirbe, als eituen Aluerbaln, wetn ex feime Frechlyeit gegen mich audh nur abuete, fo wagt er es feit ofefer seit nicht mehr, jenes ungeziemende

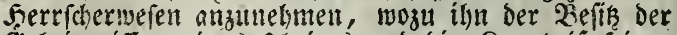
(S) beinnitle meintes Dheints und die Renntnî́ feiner geheinften plate gegen die librigen (3lieber feiner Fa=

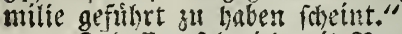

"Inverien fere idh mit sergungen," fagte Darfie, "Bape ber sisirth des Soutes ibm nicht to ergeben focint, als ich befurchtete, und bies unterftuht die

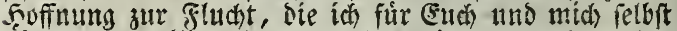
nógrte. D Rillas, ber treuefte nteiner frtembe, allan Fairfors, ift mir gefolgt, uns in biefem slugentilice bier. Ein anderer, zwar nieberer, aber ich glwube, sbenfalls getrener greund, ift auch ímerbalb biefer gefärtiduen sianern."

Silias legte ben finger auf bie sippen, und wies

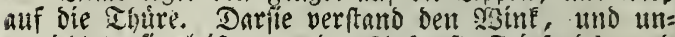
terriditete fie leife von ber 2infunft Jairfords, uno

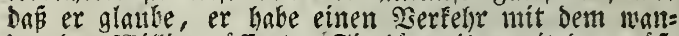
Dernoen asillie eroffuet. Sie borte ihm mit ber grós. ten Ifumerffamfeit fu, und hatte eben ifre 2lntwort begontten, als ein lauter Sârm fión in ser fitche er= bob, verurfont durdi melyrere ftreitente Etinmen, unter bentell Darile aud bie Etimme Allan Fairfords unterichetoen zu Eonnen glaubte.

sergeffend, wie wenig feine eigene sage ínm erlaubte, ber 5 elfer anderer zu werden, flog Darfie all bie Slyure; und ba er lie von aufen verichloffen und verriegelt fant, ftemmte er fid mit aller (Ssewalt entgegen, und machte bie vergweifertiten atnftengun= - gen, lie allfabrechen, trok Den $\mathfrak{B i t t e n}$ feiner Ecline= fer, baş er fíth berulbigen uno feine Eage bebetten

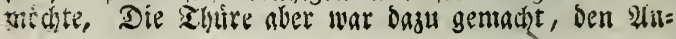


griffen von 2lecifern, Sonftabeln und anderen Perfonen ju niberftehen, bie man als wurbig betrad)tet, oen sonigofhluffel" zu gebrauchen, um fhloffefte srte offell und zugainglia zu machen, und trokte ba= ber allen feinen Bemuibungen. Unterbeffen Duserte Der Lårn auben fort, uno wir wollen im utáchiten Sas= pitel unfern defern bie Urjache beffelben anjeigen.

\section{Drittes sapitel.}

Eróblung von Darfíe Latimer. Fortęung.

Son Fradenthorng (safthof war nod niemals, reit fich feine Echorniteine an ben hlferll dis Eolmab erboben, von fo verfatedenartigen Senten befudit wor= ben, als biejen Morgen. Mebrere von itmen waren Pente, beren Nang weit hóher-fdien, als ihre Slei= oung und 2 rat zu reífen andentete. Die begleitenden Diener niderlegten fohon bie Shlúffe, bie man aแb

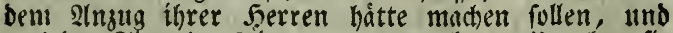
nach ber Sitte ber sitter vom siegenbogen *) gaben fie manche Sointe, fie, maren nicht bie Rente irgento je= mand zu besienen, alö ginnner vom erften Fang. Diefe Serren, weldhe bauntiachlidh bielger.gefonmen waren, um mit $97 \mathrm{r}$. Fiedgauntlet zufammenzutreffen, f(c)ient verorúglich und angitlich, giengen mit ein= anter auf unt $a b$, fcheinbar in tiefe sefuridhe ver=

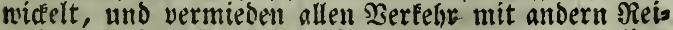
fenten, welde ber 3ufall biefen 2 Rorgen an benfelbet Erbolungșlak gefuibrt batte.

*) Der sibreebedienten, fo genannt wegen ifrer oft febr bunten sileioung. 
IIt ob bis Schicfal e3 fich vorgenommen hitte, sie Wlane ber jafobitichen Serichwore: in Berwirtung ou bringen, waren bie zuftromeriden gieifenten unge:

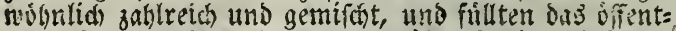
lide simmer bes (safithofs, wahrent bie politifien Gifife bereits die meiften intern Bimmer des Fenafes eingenommen battent.

Unter andern war alth ber ebtlide Solta (5) bes angefommen, der - wie er fagte, umberreifete in ber Detribuís feines ferzent, und tratrents um bas Echicfal Darfie Ratimerb, alba. Wäre diejer fein erftgebornes Sind. Er war an ber ganzen sutite des Eolivai) hingezogen, batte balei noch mebrexe

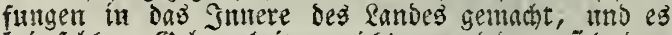
bei folden (S)elegenheiten aidht vermieden, lich dem

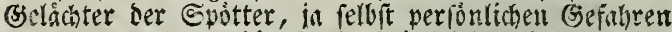
auszuferen, Da er bie Eshluwfwitifel ber Echmuggler, giojtamither und anderer Reute biefes Bseliditers be=

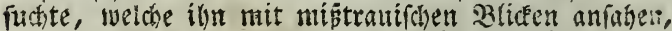

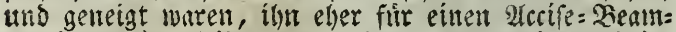

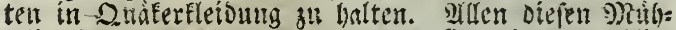
Feligfeiten unb (sejaluren hatte er fid aber vergeblia

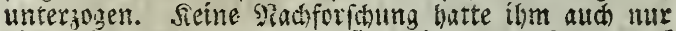
bie geringite Sptit von Darfie Rarimern gezeigt, io das er zu firdoten begann, ser arme Stingling móchte weggefúbrt worden feon, dem ber Menfaemrab war

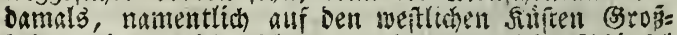
brittantiens nidht felten; aud founte fein Sdiffal wohl noch farger und blutiger geweín fenn.

Nit fdyeren f̧erzen gab er jein Dfero, feinen

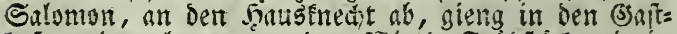
bof, und verlangte von bem sisirthe Fribitude und eit

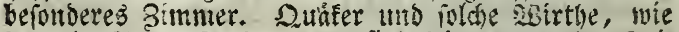

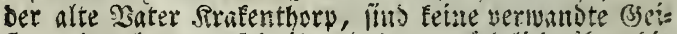

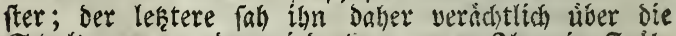
Shilter an, und erwiederte: "nucun Slye ein Friths

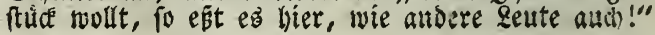


"Itus warum funn ich nidst," fagte ber Duiflet,

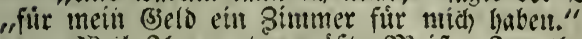

"iseil Shr warten múst, Neifter Sonathau, bis beflere Reute bebient fino, oder mit Eurez gleidjen entell mollen."

Soltu (B)edbes frach nicht weiter liber bieien Puntt, fondern feste fich rubig uieber nuf ben Stubl, Den ibm Sirafenthory anmies, verlangte éne Diaa

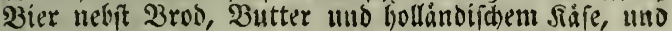
begann feinen Şunger zu ftillen, den bie Morgenluft ungewointich rege gemacht batte.

Wuathend ber ebrlide Duafer fo bejchaftigt war, trat ein anberer Frentber ins 3inmer, und feste fit nalie an ben Tiich, nuf welchem Deînen Rebensmittel ftnoen. Ex fibly brufis nads Sofua lin, leate fict bie trocfenen uts aufgefprungenen Qippen, als ex ben gu= ten Quafer fein Ziroo uno Sáfe verarbeiten fah), uno machte die 2enegung bes Trinfens, wenn Mir. (Jied=

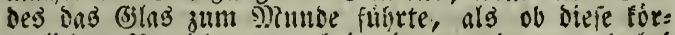
perlichen serrichtungen bei eimem anbern and bet

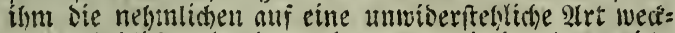
ten. Endliá), als ob er feinem 21 petit burchaub nicht megr wioeriteben foume, frngte or in einem unithern

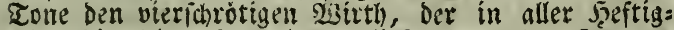
feit, bie feine Eorpulenz zuließs, ourch das Bimmer fidritt, of ex nidit eine Plad" = lie habent fomte?"

"Jgerr, vun einem rolden Ding babe ith nie ge= hort," fagte ber 2isirth, und wolite fich weiter inhies

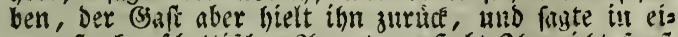

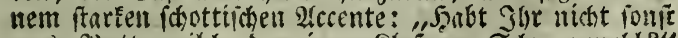

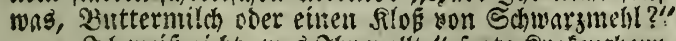

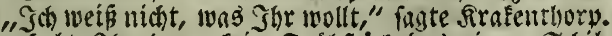

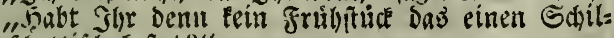
ling ichottio foptet?"

"Das ift eill Dfennig Sterling," fagte Srafen: thorp mit poittifichem \&achen. "Sietil, ভawnev*), fo

4) (5in Squttname, ien matt oen Gaptten gibt. 
tann idh leixs geben, aber id will Euch fatt machen aนs Mittleiben - ".

"Ein orbentliches atmerbieten fahlage idh niemals aus," fagte Der arme Teufel von Gaft, "lnto wenn aud die Engländer Teufel find, fo tant man fie bow bojfliđ heisen gegen Edelleute, bie unter 2 erfappung reifen."

"Ebellente! - f̧um! - Fagte Sirafenthorp bow feine 3laufapue unter ínnen, bie tídit allf bie= fem Tup̃e hinft." Damm nahm or eine Shutffel, bie nod einen bebeutenden sieft uon einen Ding enthielt,

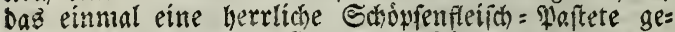
wejen war, und ftellte lie auf ben Tirah vor ben Frem= ben mit ben Siorten: "Wier, sheifrer Edolmanm, bier ift etwas, bas alle Plack = Pies, wie She fie nennt, werth iit, welche jemals aus einem Echanfunfe ge= macit murben."

"Plun, ein Edhanfouf ift immer ein gut Ding,"

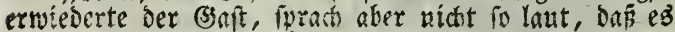

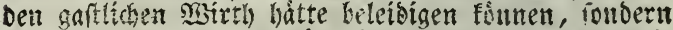

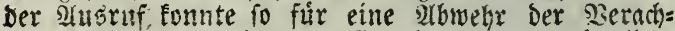
tung gelten, nomit man fich diter bieß gewohntide Sericht ber Schotten łu sufern pfleate.

Shterauf begatn er fogleich bas Shonfenfleich und Die Wnitetenrinde von Der Grhiffel an Den Mund zu bringen, aber in fo ungebeuern Etucéen, als erlabte er fich nach Dreitágigem fraften, uro nutle fich noch fur eine ganze formmende Faitengeit veriergen.

Sofua Bjebdes betrachtete ín ongezen mit Erftau= nen, ba er tie einen folchen 2 lusoruce von freiftun= ger feim sffent bemerft z"t raben glaubte. "Freund," fagte er, nachoem er inn cinige slninuten beoliachtet hatte, "manil Du fo it Dich himeinitonfit, fo wirit Du ficterlich noch eriticken. BBillit Dul nitht einen Sug aus meinem firuge thun, um Deitter trodenen Epeife hinabublitfen ?"

"Mieiner Ireu!" fagte der frembe, invem er im 
Effen anbielt, und ben freundlidien cinlaber betradis tete, "\$as ift leine fohlechte Eroffnung, wie man in ber (S)eneralverfammlang zu fagen pfegt; id habe (d)led)tere 9)iotionen von weiferen siáthen gehórt."

gir. (S)ebdeg liés ein Dutart Bier fur unfern fremin Peter Pleetes fommen, benn ber Lefer bat

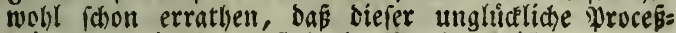
trämer ber in frage ftehende $3 a n d e r e r$ ift.

Das opfer ber Ehemis hatte nidht fobaro ben Nirug erblict, als er ithn mit berfelben Emergie er= griff, bie ex bei ber sierarbeitung ber Paitete entfal= tet batte, - er blies den Sthaum mit folcher (semalt oon fich, Dafie ein Theil bovon an 9)ir. (S)eboes Ropf fog, wno bamn fagte er, alg erinnere er fids, was die

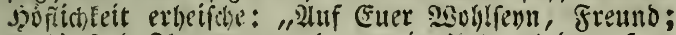
was! fend Jls zu vorneshn, mir wintwort darauf zu geben, ober bort Jhr micht gut?"

"Isch bitte Dich, trint Dein Bier, Freund!" Fag= te ber gute Duafer; Du willît bofich gegen miah feun,

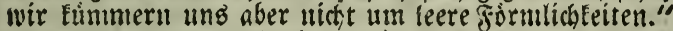
"Sias? Shr fend ein Suifer, feno Jur?" fragte Peter, und fuhlyte bann ohte weitere Eeremonie ben firug an ben glino, von bem er thn audh nicht éger wieser wegsog, als bis tein Tropfen von biefem Ger=

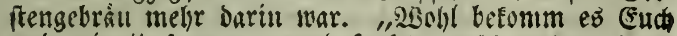
uno mir," fagte er, uno felifate, als er den situg

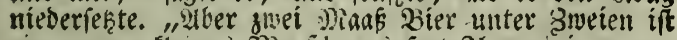
- ein gar zu fleines soiaá̃! was fagt She ju eillevis an= bern Siruge? oier mollen wir uns eine berbe fohotti= ide Whinte allf cinmal geben laffen? Ints ware io un: recht nicht!"

(D) mazit fo viel fommen herfer, als̀ Du willit, nuf Deine eigene siednung, Treitnt," frote (3sedoes"; "ich habe svillig beigetragen, Deinent naturlichen Durft

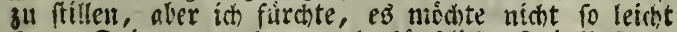
fem, Deine ermorbete und funftlide Drintlerft su beiriedigen." 
1Das lieist mit bentlichen 2 sorten, Shr nelint Elire 2urgichaft bei ben \&euten deg Sianfes zurtice?

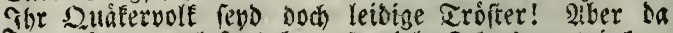
ज̆br mich veranlast havt, to viel Sinltes zu trinfen, was ich am Sormittag gae nicht getvohnt bith, fo ben= fe id, - Shr finntet mir plent fo gat ein Bslas Brauntwein. oder Eeft mbieten; ich bin efen nidst

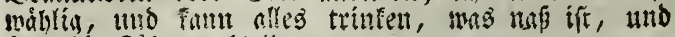
Lilter bie Bảhne gelit."

"situt cinen Trowen auf meine fioften, greund,".

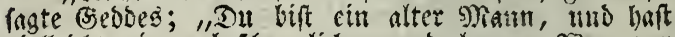
vielleicht einen bejdwerlichen unt langen saeg vor Dir; Dut bift tiberdem inein \&andsmann, fo viel ich ous Deiner Sprache fatlieffe, uno id will Dir nicht Die Mittel geben, Deine grauen Scare in einem frem= Dent Rante z"ll enteliren."

"(s) bie Innirekenden, welche die Hnterredung sul interef:

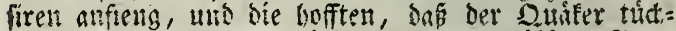
Itg verfwottet werben wirbe von bem ichádigen bett=

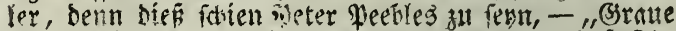

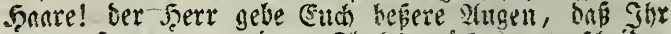

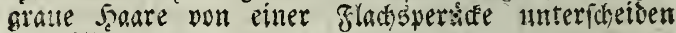
lernt!"

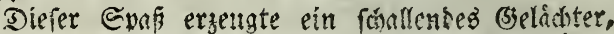
uns, nas nod beffer wa:, ala ein trocétuer ?aeifoll, pin Manm, ber battelen funs, riff: "Mater Frafen= thorp, bringt ein folfowchen Branntwein. Sd) will bem Burften on ein Ech!tickenen reichen, wäe es

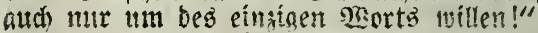

Der כranntmein muroe annenblidfid gebradit von einer Mingo, welde als 2 urfwirterin biente, uno Pe $^{2}$

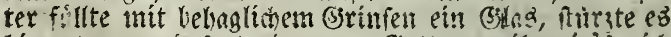
bímuter, unto fagte boun: "Sott verieib mir's, ich

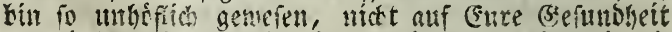
zu trinfen. Sob glaube, ber Sligker bat mich nit fei= nem ungesogenen \$̧efen angefteft; er war im Begriff, 
iptelt bat, als man einen nur in einem Nechtşftreit ipielen fann," fagte Peter.

"Einen Hovofaten, Menich!" antwortete ber Ra= pitain ber fpringenden Jenny, benn ber mar es, und fein anderer, der Mittleio mit Peters Trinfluit ge= labt hatte, mun, Bjott helfe Dir, Du bift auf ber unrediten Seite deg Solway, wenn Du Mlovofaten

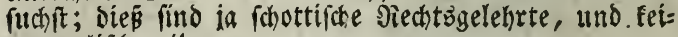
ne englifchen."

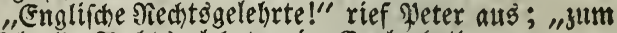
Teufel alle Siechtoggelebrten in Englanto."

"Id) winfthe von ganzer Seele, es móchte wabr fent, aber wie Tellfel, fonmt Euth das jek̨t zu Sinne?" "Piun, leí (jott, nir hat eitter igrer Dttorueys fosin an ben Beutel gegriffen, und mir gefagt, da es anper inm feinen fiechtsgelebrten in England ge= be, der bie Platur eines vernickelten Prozeseses fenne. Inno alo ia illm fagte, wie ber Saluft, der झllan fair= ford, mir es gemacist bake, antivortete er nir, id fonne eine Silage úber oen fall anftellen, gerade als

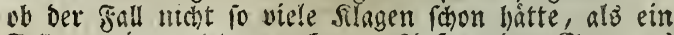

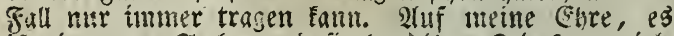
ift eitue gute Eache, uno fie bat; ibrer zeit falon viele

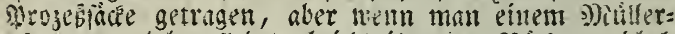

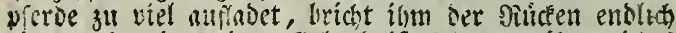

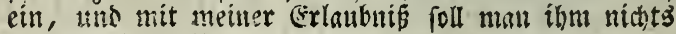
melgr auplezen."

"Ther dieler allan Fairford?" fragte Fanty, „Eommt, trinft ben Tropfen Branntwein vollends aus, fagt nir mehr von ihn, uto ob Shr ilgn in Gsus tem soer Bovem alffutst."

"3u meinm Beften, uns niat su feinem Ectas den, bas verfichere id) (Euci)," ingte pleter; "Dentt ein=

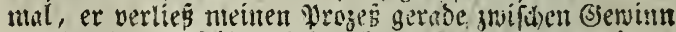
und Serluft, und if nat) Eustheriand zezogen, unt einem wilden Buridyen, Pamens Darlie Satimer, nadjunpus rell."

"Darfie 
"Darfie Satiuter," [agte Mir. Badocs haitig;

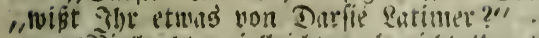

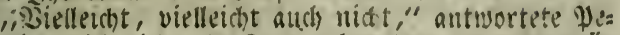
ter; "ich will nitht alle Frogen beantmorten, menu lie

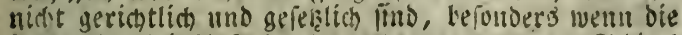
feute io viel arufbebens nuthen un etmen Salut

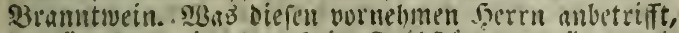

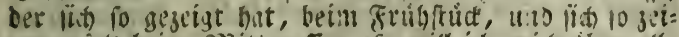
get wiro beim g) Rittaseffen, fo will id mith ther alle Dunfte anslaffen, Die Die. Sande zu Endi lringen Eintten."

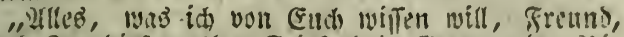
ift, ob Sor biefen עlan Fairford in (5)utem ober 230:

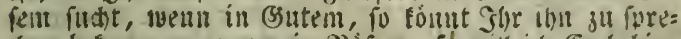

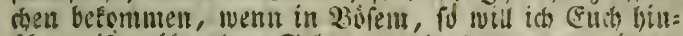
toberweifen úber ben Solwan, mit oer gutgemeinten

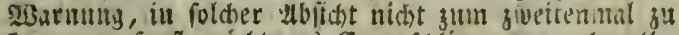
Fonmen, fonit modte es Eut falimmer ergelen."

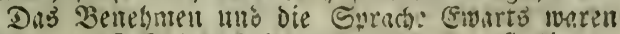

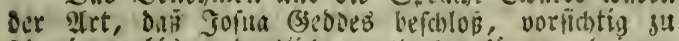
fdimeigen, bis er beutlitber entbeden fonme, do jenter ifm in feinen gacbforidumsen mach Darlie Patimer bebulfitc) ober binderlict) ienn werde. (Er beftylos da= her, aufmerffam Darauf su horen, was guilden De: ter und bent Seemann vorgebe, und auf eille Giele= getheit su warten, bell ecitern zu frazen, folalo als er vou feiner neuten Betanntfiaft getrent fent mitos. "El," hagte ferer Weebleys, ,th) wulte iem ar=

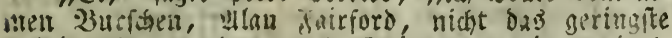
Lebel antian, er bat manthe (Stumee von mir verbient,

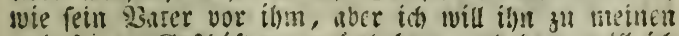

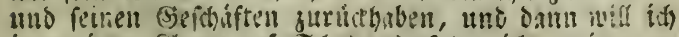
it meiner Silage auf Saboensurfás nitbt meiter ge:

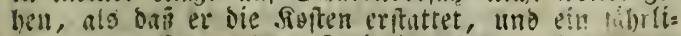
ches Snterffe vou dem fapint gublt, von! bent Babe

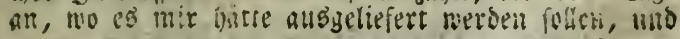

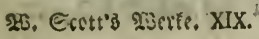


gwar bei Jaeller und Pfennig; Shr feht, bab dief bas wentigfte ift, was ict nomine damni verlangen fann;

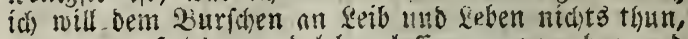
- man nú leben uno leben lafien, - vergeben uno vergefien."

"Der Teufer hole mich, Sreund 2reitframpe," fagte" Sismty Entart gu bem Quifer, wenn íd heraus

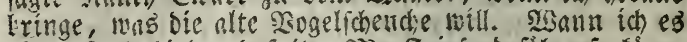

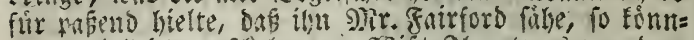
te es vieflectht geichelgen. - Xsibt Shre etwas von bem alten Parichen ba? Shr ideint Doch eben Euch rémer anzullebmen."

"s?idgt melir, als ich jebent im itnglices gethan bitte" " fagte Geosses, bem es nicht unangenehm war,

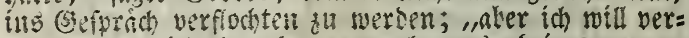
fucten, was ich thun fann, um heraubsubringen, wer er iti, tho warun et in diefer (segeno fich befindet? wher fins wir nidht au felgt bobachtet in biefem offe= nen simuer?"

"ricdtig," fagte Nanty, uno auf reinest $\mathfrak{B e f e h l}$ wieps Lie Anfwárterin sen Sprechenden ein Seiten= zimmer, weter aber folgte ibnen, in ber inftinftarti= gen sofinung, bas or bei ifnen noch etnas zu trits= fen befommen wirbe. Sism batten fie fich nieberge fest, s!'s fie in bem elen verlapenen simmer eine Bei ge borren.

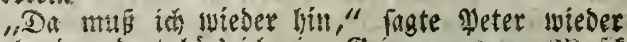
auffetenes, "bort bor' ich eine Beige, uno wo s)iufit ift, gibt es etwas gu effen oder za trinfen."

"Iक mill gleid etwas hieker bringen laffen," fag= te ser Sudfer; "aber unterdeffen labt Jhe irgend el= nen Suftano, uns Cuern samien gu fagen?"

"Durdhats feinen, menn Shr ihn braucht, um midg" beim 3utrinfen mit bem sors = uno Bunamen zu tennen; bent fomit mothte ich leber Euern Fragen

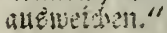

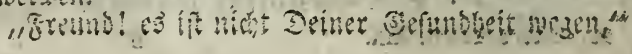


"er, Mr. Teebles, " fagte Tanty, insem ex Die Ituteresung loblich abbrach, ,waret Sbr nicht ein= nial Burger in Edinburgh?"

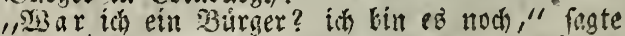
Seter unvillig, "id babe nichts legangen, woourds ich mein giesht vermirft bàtte, ich bente, cinmal sida: ter, tho inmer s) inloro."

"Sitt, Feerr Butger, fagt mir ferner, habt She einiges Eigentium in ber griten Staot?" fubr, Evart fort.

12as labe ith, - netmlich vor meinem thalice gebabt; ich batte zwei ober orei fleine Feaufer in ei=

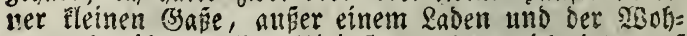

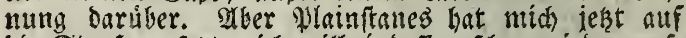

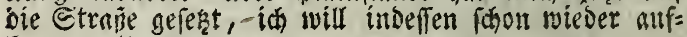
fommen."

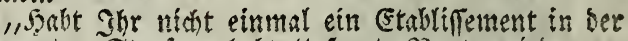
Eovenanter Strafie gebabt," fragte ?anty wicoerm. "Shr habts getroffen, wenn Shr gleidy nidht wie ein "Evonanter ausiebt," fagte leter, - "woir follen auf fein anbenfen trinfen! (ons jerr ift auf

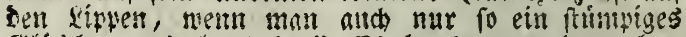
(s)läben angigeleert bat!) (Es bradte von bem ober: ften Boden bis stir Şausfur ungefäbr vierzebu Dfund lobrlich, auffer oem bubínen sieller, ber an lúdéte Sirtlenorib iermte bet war."

"Erimert Sbr Euth nidht, bafs Shr eine alte Same it ber siletbe buttet, smirs. Eantriug von Rittlebasiet?" fragte santy, mit Shuge feine bewe: gung unterorudeno.

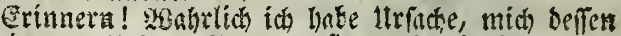
gn erimern," fagte Deter; "fie madte ia Bunferott bet mir, ber alte Beien, mo wich allem, mas bas Sefer that fonnte, um mich besablt zut machen, in: bem man ibre Eacien im Huffreich berfunfe, a. f. 11. wie bas (siefer will; fo rannte fie ine ins grterits:

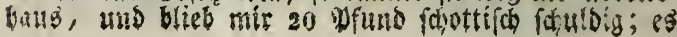




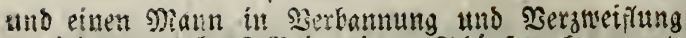
getcielith zu baben? Wei meinem Schóper, faum ent= balte ich mich, Sants an Ench ju legen!"

"Sin nich? - ich troge Euch!" iagte Peter. "So

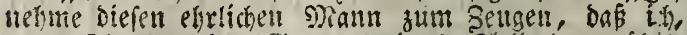
wenn She mur ben Gaum meines Sleibes aurúbit, pine Silage gegen Euch einteichen werbe wegen 2 be

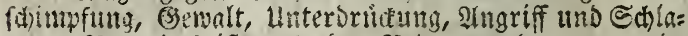
gen. Siun bas ifi altá ber siebe-werth, went ein olte' siseib zum (s)rnbe gelgt, eine junge Dirne in bie

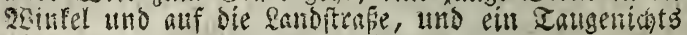
Likers. Mieer ftatt on ben Balgen!"

"siun, bei meimer Seele!" fagte 9ianty; "D28 ift

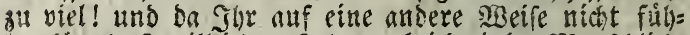

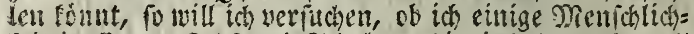

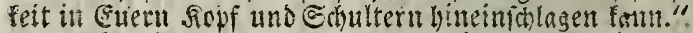

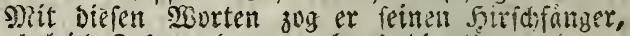
und okgleid Iofus, ber vergebent die Litterrebung, beren getsaltfamen 2luğgang er vorberiah, ;u tuter=

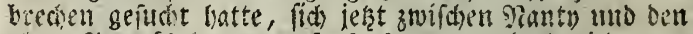
aiten prozeffrimer swarf, fo fonnte er bod nidht vers= hitndern, Dá nidht ber Reketere zwei ooer orei berbe Ed)läe mit ber flachen Jlinge liber bie Schultern befont.

Der arme Peter peebles, fo feck er Den Etreit herbef gefithrt hatte, fo untibmlich benabm er fict, alb eg anfö ätíserite gefommen war; er fohrie last allf, rante umber, und fiturte zu ber Eghre fis sim= mers uno felbif zum Sante hinals, verfolgt vou Pian=

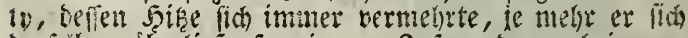
Derferten tiberlié, fo mie von Soju, der nod immer

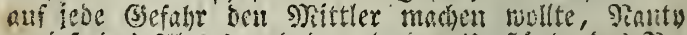

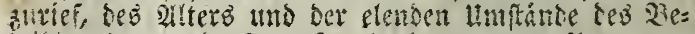
leidrers zu gebenten, fo we bem armen peter, er

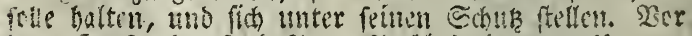

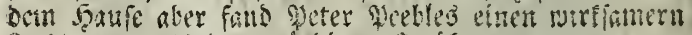

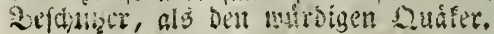


Siertes a a pitel.

Erzáblung von alan Fairforo.

Hufere Sefer uerden lich erimnerm, dof Jairford

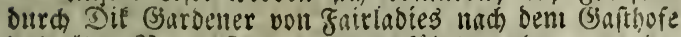
Des alten, Sater Arafenthorp geführt worden war, ba= mit er hier, wie ihm ber geheimmipuolle peter 'Buto= naventura gefagt hatte, feimem szunfahe gemás mit 9r. Picogauntlet zufammentreffer, und wegen Der,

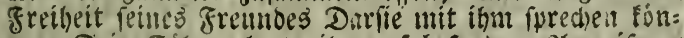

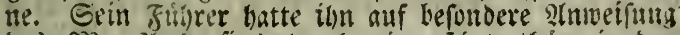

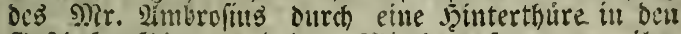
(5)afthof gefurbrt, und bem sisirthe allfgetragen; ibnt ein befonoeres simmer énsmriumen, uno ilyn mit als

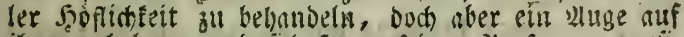

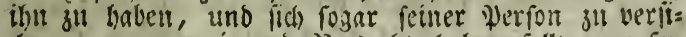
dera, wenn er ligento serdant haben follte, er fen ein Spion. Er war indelfen Éinen eigentliden Buan= ge unterworfen, fontern uttroe in ein siminer gefuilert, wo er auf bie 2(nfunft Des Edelmamis, mit Dem er élie 3ufammentunft wuinjote, warten folle; oiefer wirbe, wie Sirafenthorp ibn mit einem bedentenden

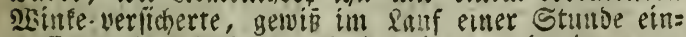
treffen. Unterdeffen emprithl er ibu, mit einem ans

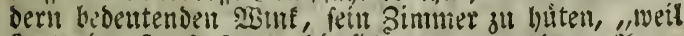
Reute im frame fenen, bie fia) gern un anderer 2luge fegenbeiten befimmerten."

2ulan Fairford befolgte die Alnweifung, fo lange er es fúr gut fand; als er aber unter melyeren s)ier=

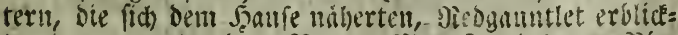
te, cen er unter bem ?amen Jir. Sitriez you 23ir= fensmorf aejeben batte, uno ozr fid buich feime bohe,

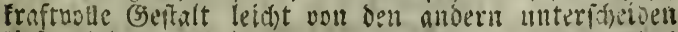
lies, litelt er es für angemffen, fich binuster bor bas 


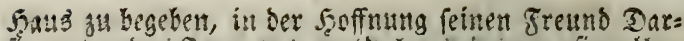
lie unter ber Trupe bu entrecten, nern er fie náber betrachtere.

Der Seper crinnert liti, baj er badurch Darfies Fsll won finem suerfattel bernb verbinderte, of er

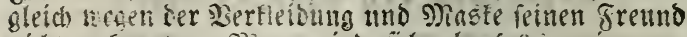
nickt erfannte. 9)ian miro fich ebenfalis erinnern,

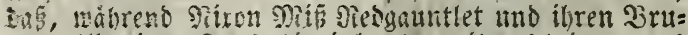

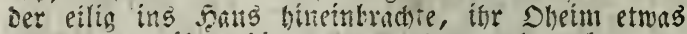
sufgevrat tifer sie tumermutbete uno unlequeme Jinterbrectinng mit Jairford im Gefträ blieb, ber

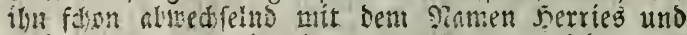
Siesgaumtlet anhereset latte, von denen er feinen, fo wentg als bie Befmuttchait mit bem innegen Miechtös gelehrten, in siefem siugenblice nutuerfenten seillens

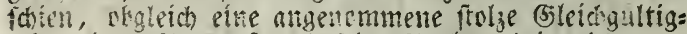

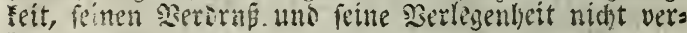
vergen Enmte.

, 9ienn mir curdans mit einander befannt wer= ten follen, Eir," fagte er endlin, .,mourn ich bie

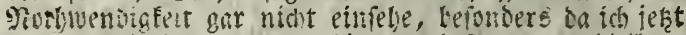
gand worjuglid grionmen bin, uniefunnt zu Eleiben, fo mus id Ench bitten, nir foull ju fazen, whe Jhe all fagen babt, who mir zu erlauben, wichtigern Dits= gen mid zol miomen."

"S) ieine glngelegenteit," fagte Fairfero; ,ift in Diefem Zrief enthalten; (bier tiberlieferte er ten von S) Tarmell) ith bin thergeugt, bas, unter meldem sala nien es Ench anto jest gefillen mas, mafatreten, in Eure Ginde, uno in Eure allein biefer Bhrief liter= liefert tuersen foll."

Neoganntlet monde ben Brief in Der Fand bin

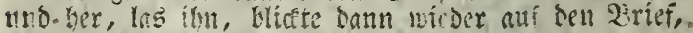
und bemerfte finfter: "ons Eiead ift erbrósn, war

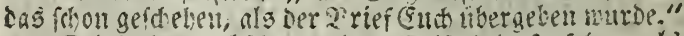

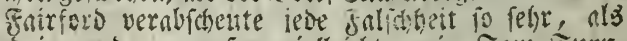
ingut jemano, - anper vielletdt, nie Tom surit= 
gauntlet, indem er sie Sorte allans mit Erftatmen

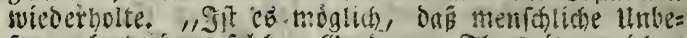

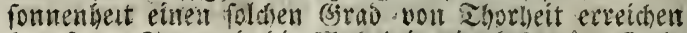
fana? - Eagt mit bie sgabutheit, ich beftwote End,

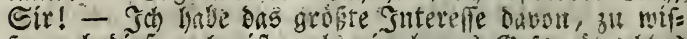

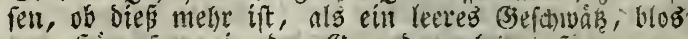
vom frorentagen in Der ssegent unther dufarmmenge= foppett. Sly rend ein giedstşglefirter, unto temt bie (jefaltr, oie ein fatholifcher priefter länt, den feitue Qficht-an biefe blutigen ufer fútirt:"

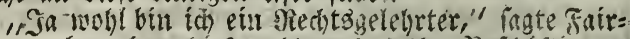
ford, "aber eben diefe aditungaverthe befchiftisung

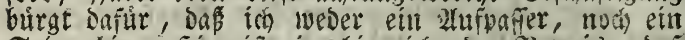
Spton bin. Feier ift ein hinteichender beweis, bas̈ ich den Pater Bubnuentura gefeben babe."

Er tibergab Rieogantlet Bitonaventuras Brief, und beondtete ign wahrens bco Relens geran. "Iolle \$ethơrung!" murmelte er fitr lich mit ss!dfen in be=

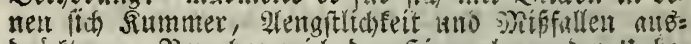
orcideten. "2iemalue mich ber frimmel var ber unbe= fontentheit ménar Frennde," figte Der Evanter, "ge=

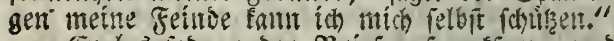

(5r lab fodmm oen Brief aufmerffam, uno blieb

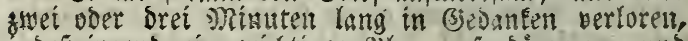

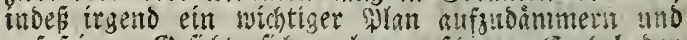

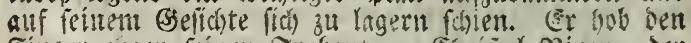

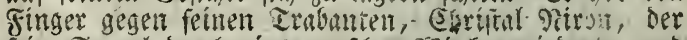

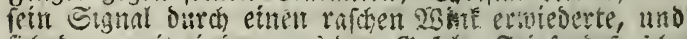

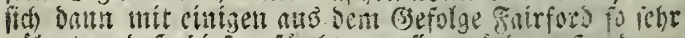
náberte, bafs biefer furrdtete, fie warben şand an ilgn legen.

In oiefern 2fugentide hơrte man einen sairn aus

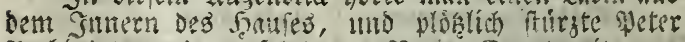

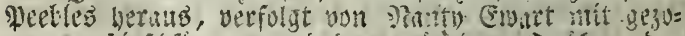
genent sirfofinger, tino tem waroigen Juber, oer mit eigener (Sefabr frembes itabell gu verbiten lathte. Eine fonderturere und sugleich Eomifonere bisitalt 


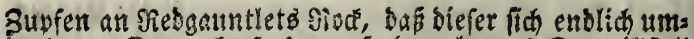
brekte: "Dummifopf, fag auf eínmal, sas Du millft." "Ssut, gut! auf eimmal benn," Pagte peter pieeb=

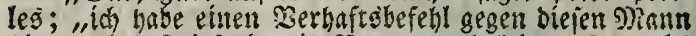

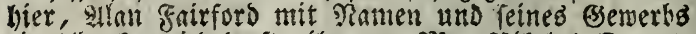

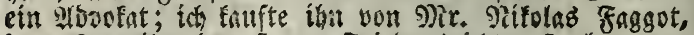

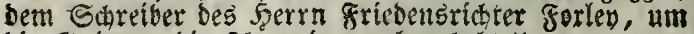
Die Gninee, bie Jir mir gegebent habt."

"S5a!" Pagte sreoganutlet, ,haft Du mirflich einen roldhen Methaftsbefegl? la mich isn fehen. - Eieg genau

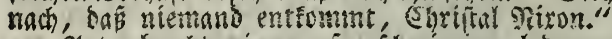

Peter brante eine grop̧e, fomierige, lederne Brief=

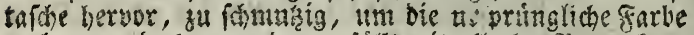
roch fu entoeden, unb angefullt mit aluerlen Bemerfun= gen, Erimuerungsblå'tern ano ber frimmel weís, was fonit noch. 2lus biefer foptbaren shape bratbte er ein

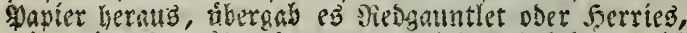
wie er isa fortwongrens nantte, uno fagte babei: "es ift

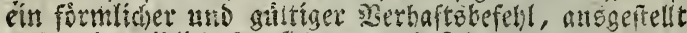

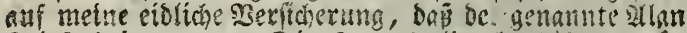
Fnirford in memem Dientre geief̧ich beichoftagt wath, aber bavon gegangen, uni ther die Branze geftohen it, and wu ba uto bert beramichweifr, un feiter gegen mich ubernonmenen pflicht zu entgehen; saber wito Den Sonftabeln uno antoern aufgetragen, nachzuiuthen, und ilsn zu ergreifen, bantit or vor ben elrenwertheu griebensicidter forley zar luteriuchung, uno, went

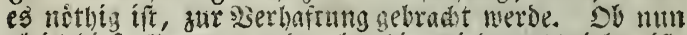
gleich dié alles gan, broenti wier niederge chreben ift,

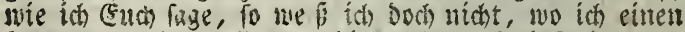

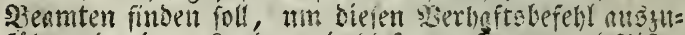

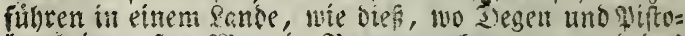
len kein erfen silort in Binegung fonmen, unb sas solf fich unt ben sriesen sionig Beorgs fo menig fims nert, alo um ben oes alten Sionigo Eont? Da it ber betrunfere Eemann who nape Duåter, die haben

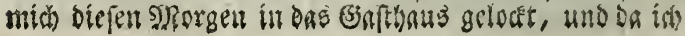




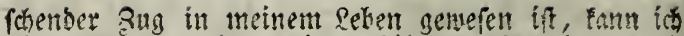

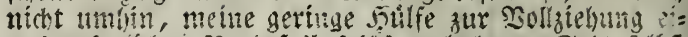

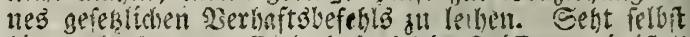

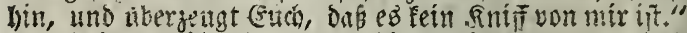

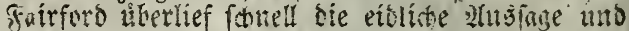

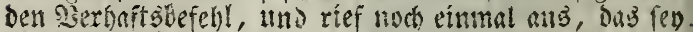
ein unverfdionter Betrua, uno or inolle gegen bie, wel= the auf einen folchen Derbaftgbefehl bin bandilten, anf hodffen Edhodenserfas flagen. "Jdh errathe Eure Bes

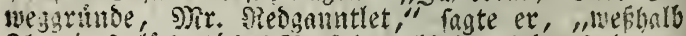
Glr ein ro läcberlidies gerfabren hilligt. 2uber fens ver=

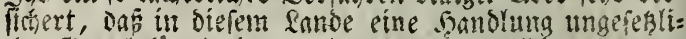

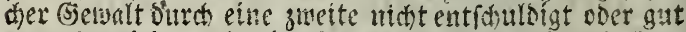

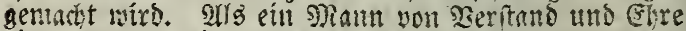

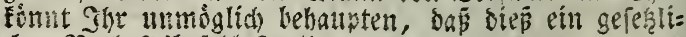
wer Merhaftäbefekl fer.".

"Sh) bín fein Frecritagelebrter, Sir," fagte Nies= gauntlet, ,unto mase mit nicht an zu wifien, was Gejés ift, nub mas nicht, - Diejer 2 efehl íf mads ber form riatig, uno bas ift gentlg fưr mich."

"What jemals irgend ein menich gehort," fagte

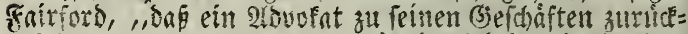
zufebren gejmungen muroe, mie ein sifrbetier in foblen= oser Sarzwerfen, Der feinem Meifter entlanfon ift?"

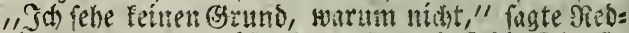
gauntlet troden; es mifipte denn fern, Dấ die Dienfie

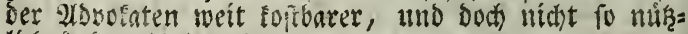
lích finte, alä jente."

"Sos fonnt Ghr nicht in Erufte menen;" forte

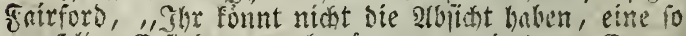

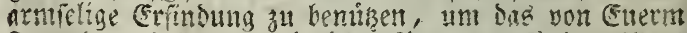

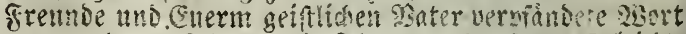

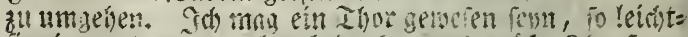
fimig zu traten, aber bedenet, was mitht Ghe fonn,

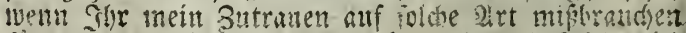

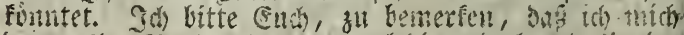

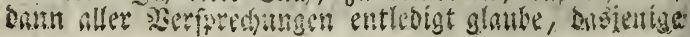


bolaten, noch bie Eี infalt sines alten Feud)lers wer:

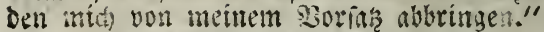

"ilieiner Eren," ragte der Savitain, der mun feis nerfeits worwarts fam; "sas if nicht lobtich, (s)eneral; unt ich jweifle, ob es ber 2 Sille meiner Sdbiffaberru ift, an einem joldsen Barfahren Theil ju nehmen. - 9utu,

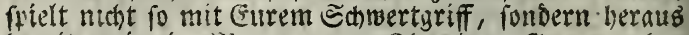
Damit, wie ein D)tann, went Jgr einen (Sang mathen mollt." Er zog den Jeirichfärger, uno fubr fort: ,ith will weder metnen Gimeraben sairforo, now bell alten Suafer beleibigt fehen: Zum Ieufel mit allen Sierbafts= befehlest, falich oder wajur, jum Jienfer mit ben Jries benstidtern, uno nieber mit allen fonitabeln! bier fitht Der fletne Santy Ewart, um zu vertieten, was er gejagt hat, trok allen yoliden uno Burgerliden; uno trok allen fenfeifen in ber 233 elt."

Der Juf ,zum Teufel mit allen Serhaftabefehlen"!

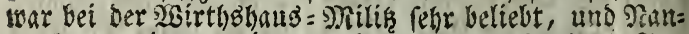

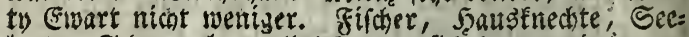
leute, Samuggler, alles begann fio herumbubrittgen. Frafentbory bemígte fid vergebens, ben gitittler ju machen. Die Begleiter Neogauntleto begaumen ihre

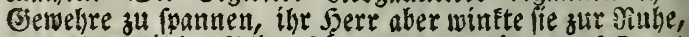
gog rafd, wie ber Bliks, fein Sd)wert, ftúrgte auf Enart

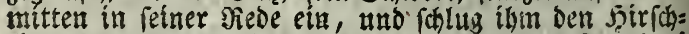
fồnger mit foldher Ssewalt aus ber Jand, bấ er brei edhritte weit wegflog. In Demelben slugenblite fries er inn nit feeftigfeit zu Bodea, ichnang das Schnert

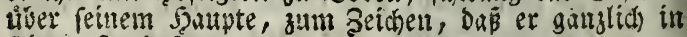
feiner 5aitb rey.

"गiua, Shr Erunfenbols, Shr פagabunde," fags

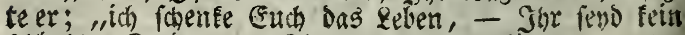
fa)ledter Serl, wenn Shr es mur lafien fontutet, unter

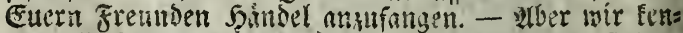
neit alle Manty Enart," fagte er sll ber umberfiehen=

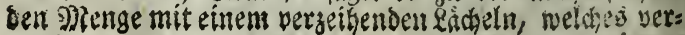
pitit 
Diefen trunfenen Burfhen ermuthigt, fein Berwebr is jekgen, und hait Du nicht felbif Deinen Etoce gefdum gen in ber Eathe? Denffi: Du, Dáp die Eide bes teleidig: ten sieter Peebles und bes gewiffenhaftent Elyriftal Rtio:t neben benen ber Gerren ba, die biefe fondertare Esene nit anfahen, die nicht unt einen (Fid fowworen, wite fie cin fileit antithen, fondern Denen Eibe in Bollangele: onleiten bas redte Effen und Irinfen fins, - g!aubit

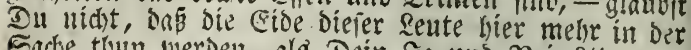
Eache thun werben, als Dein Ia uno Tein?"

"Id) f(b)wore auf arles," fingte Peter; "alles ift

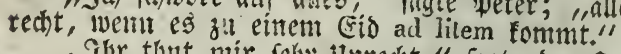

"Ily thut mir fehr unrecht," fagte ber Duafer, unerfichuttert von bem allgemeinen (Belachter; ,idh bake nidgt aufgemuntert, die wasfen zu crgreifen, ob idi

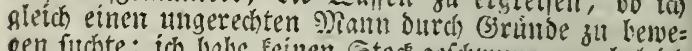
gen fuchte; ich labe feinen Etode geformungen, obgleids

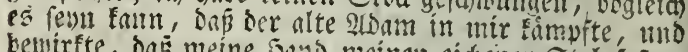
bewirfte, das meine sand meinen eicheinen Etob fefter,

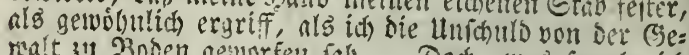
ralt 3 Boden geworfen fal). - Soct, was furedie id son SGalyrleit und Newt ju Dir, der Du vout Jugend

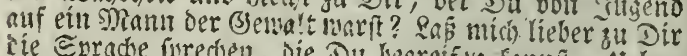
rie @urade furedhen, Die Dut keareffin fintut. Hebit= gieb biefen jungen s) ann mir," fagte er, als er fied= ganntlet ein wenig aus bar DRenge fiuneggefúrt batte, , und ich luill Dids nicht nur befreien von ber foweren

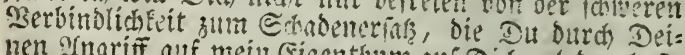
nen Ingriff a!tf mein eigenthum auf Dich geiaben haî,

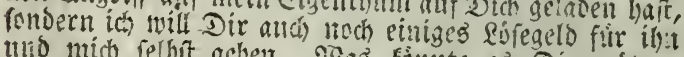
mid mích relbit gebent. $29 t^{3}$ fónnte $e^{3}$ Dir miken,

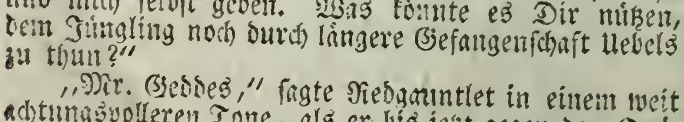

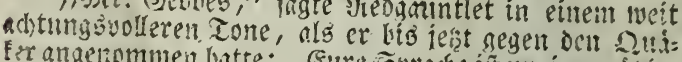
Er angenommen hatte; "Sure Sprache ift uileigenmisisig,

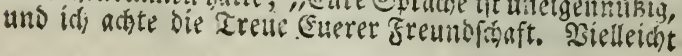


liaben nir beibe uns misverfianten liber unfore (s) runs =

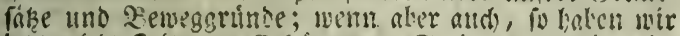

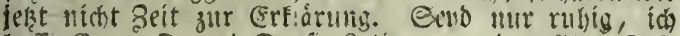
boffe Euern fremto Iarfie Ratimer zu einut Ëbrenfufe emporbubehen, wranf Shr ifn mit Sergmigen fohen follt, - nein, verfusht ess nidit mir zu nntworton. Der

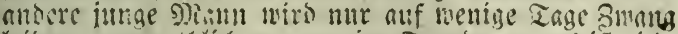
Yeiden, vermmtblidy nur wenige Etanden, - es ift nidht

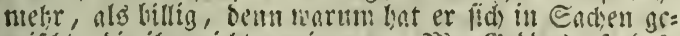

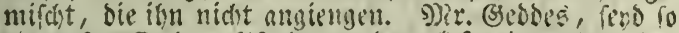
llug, fezt Cha) zu Nierbe, uns verlapt eimen sor, ber je longer, ie weniger zum alufontlyaltsorte für einen

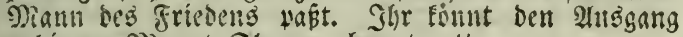
rubis ju Siount Elbaron alwarten."

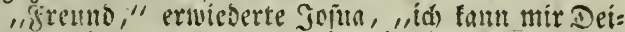

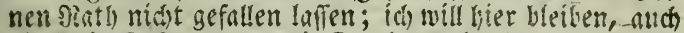

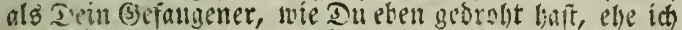
Den Jüngling, ber ourdi mich und meine linfalle fo viel gelitten hat, in einer noch zweifelbaften enge vertaffe, burtum will ich mein Pifers Enlomen nicht befteigen, noch mill ich mein fraut menden nach s)isunt Eha= rom, lis ía das Ende diefer Eade erblide."

"Eill G:efangener mifft Ghr bann fenn," fagte Sieb= gainntlet. "Iidh bake feime 3̌eit, bie Eache weiter mit (Eud) zuberwredben; sber fagt ntir, warm beftet Shr (Eu= re 2 Iticen io alfmerfon anf meitte Lente bert briben?"

"Die 23 alyryeit ju lagen," antmortete der Duafer,

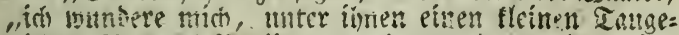

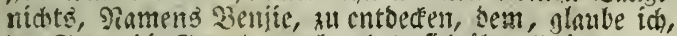
der Satan bie Bsemalt geveluen hat, fiest hoorall biul zu ver=

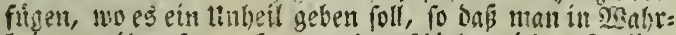

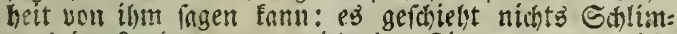
mes im falide, wo er niaft ben finger, wenn nidyt Die ganze Eand Darin hat."

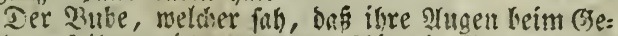
ifradje auf ibn geriotet waren, fohien in Berlegentit 
unb beithbe begierig, fich bovon zu moken, ober nuf ein Seichen vout Reugguntlet naberte er fich, insem er ben

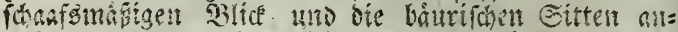
rahm, mornnter bọ Eleine Sdurfe feite sififigleit mo Swligbtiteré vertarg.

„asie linge bift Du benn bei son Reuten bier, Burfóne?" fragte mebununtlet.

"Seit bet Gefhichte mit Den Ctecrnezen!" fagte

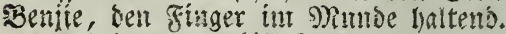

"llno marum bift Iu uns gefolgt?"

"Ith wagte nicht, barjeim zu bleitben megen ber Sonitabelu," erwieberte Der 23 he.

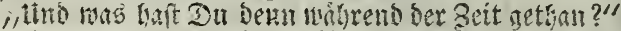

"(sethnn, Sir? - id) weî́ tiicht, mas Sfyr witer "Thun" werfteht; id liabe nuthts gethan," fagte Denite;

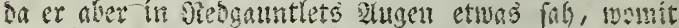

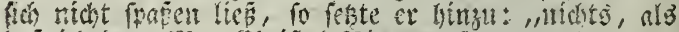

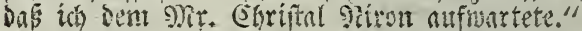

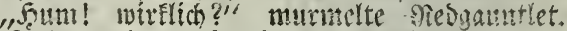

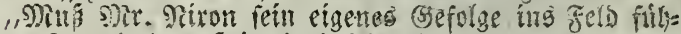
ren? - sas mis ich oocis fober."

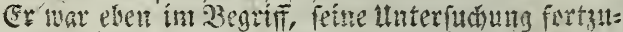

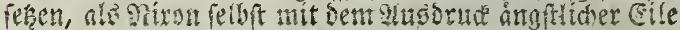
Fam - , wet Mater ift gefemmen," fagte er letie, und die Sorre: find befimmen in bem grofiten Simmer

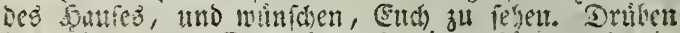
ift aud Euer geffe, uno madt énen Rorm, wie cin ภrenifh in Tolrbante."

"F(t) will gleich nad anem feiren," fagte Teosentit

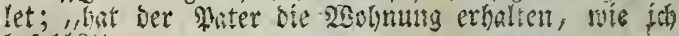
beingl?"

Ekriftal nicete bejobent.

"Pan bunn, sum enblifien Serfuche," fagte Sied= antintlet; or faltete feine 5 anse, blicte aufusits, Ereu= sigte fich, mis nach biejer frommen juntums (beinabe

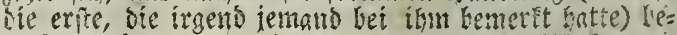

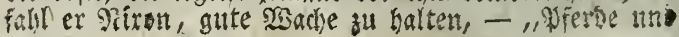


"Er kat alfo llurecht erritten von Euern fhinden?" fragte Darfie fols. "Isa, idh weis es; olser if bem fo,

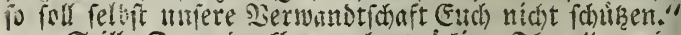

"Erill, Du unbanEbarer, hartnådéiger Thor," erwie: berte Nebgamtlet; "Doch halt - wirf Du zufriebea fesn, wenn Du dieien arlan Fairforo, Detnen wertige=

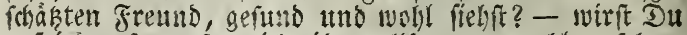
zufrieden ferst, fage ich, ihn vollfommen wobl zu fehen, obne es zu verfudien, ein sisort mit ifn zu furechen? - Эelsmt meinen grm Denn," fagte Febgauntlet, "muo Shr, Sithte Qilias, nehnt den andern; Eir 2(rthur, feno auf Eurer seuth, Euch orbentlich zu betranen!"

Darfie mubte nadigeben, volfommen uberzengt, bas feit Dhein ínta feinelluterreoung mit einem freutioe ge= itaten wiroe, beflen (Finfusgenis gegen feine ernitlid)= fren istinche bellubt werben wirde; einigermagen war

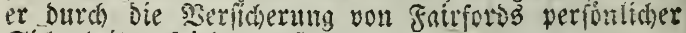
Eiduerbeit zufrieben geitellt.

Meogauntlet flibte fie burch einige (singe, (denn bas

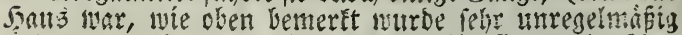
แHD z" verficicoenen seiten gebant) bís fie an ein Sini=

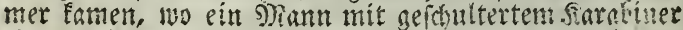

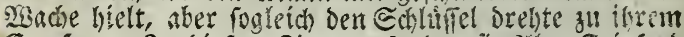
Empfang. Sn biefen Bimme: fanden jie allan Fairford tuto ben Duafer, augenfdseinlich in tiefem (sefprsche nit émaneer. Eie bliceten auf, als Sheogauntlet uno foitu Begleiter eintraten. Sllan ualm feiten sut ab, und macte cine tiefe Derbengung, welche die junge Dame,

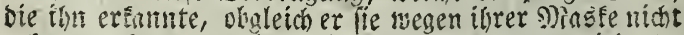
erfenuen foitnte, mit eitiger serwirrums erwieserte,

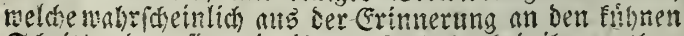
Goritt, Den fie mit ibrem Befuase bei ilsm gethan batte, entifants.

Darfie whusste zu forecheu, aber wagte es nicht. Gein Dheim allein fagte: "meitue Serru, id) weifi, Shr

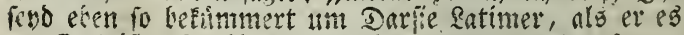

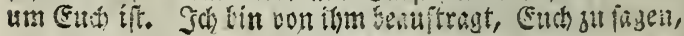


Daser fich fo mohl befindet, ald Shr. Sth hoffe, Jite werdet Euch alle bald triffer. Snteffen iolle Shr, obyleitsid) Ench nicht die Frefbeit geben faml, in Enrer einftiveili= gen (Befaugenfichaft fo gut behandelt werben als móglich."

olne bie alntworten anbuboren, weldhe ber giedit: gelebrte unto ber Duáfer zu geben fid herilten; gieng et

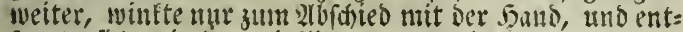
fartte fich suit ber wirflidjen and mit ber fajeinbaren

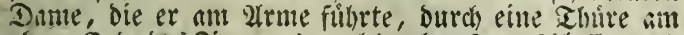
obern Ende bes 3immers, welche ebent fo verishloffen und bewacht war, wie bie, burch weldie fie eingetreten woren.

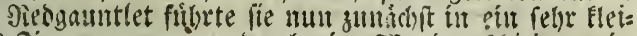

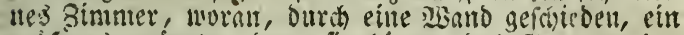
grofieres granzte; benn fie borten das csetwayte ber fistueren Etiefeln, wie malt fie bumals tritg, als ob mebrere flerfonen anf mo ab giengen, tho leffe und angfilid) einanoer juffifferten.

"Sier," fagte Fiedsmuntiet zu feinem Pieffen, indem

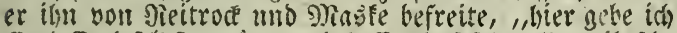
(Eud) (End) felbit zurude, tmo hoffe, bas Shr alle incibtche Geballfen mit diefer weiblictsen fleidung ablegt. Erró thet nicht, eite sierfleioung getr: gen zal baben, zu bet

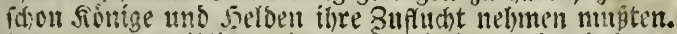

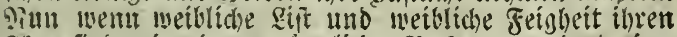

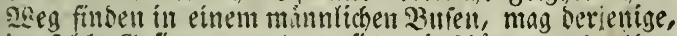

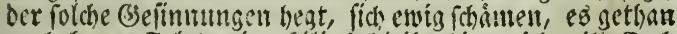
zu haben. Folgt nitr, eilliag bleibt biter; id will Euch nut bei benten einfiflerth, die id) als Eure (5)enopen in Dem rulbmodliten linteruebmen zu fehen hoffe, it bem biefe Sonnd je ein Echwert gejogen hat."

Darfie hielt an; "Ogeim," figte er, ,meine Derfon

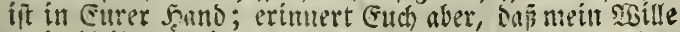

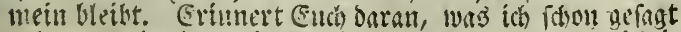

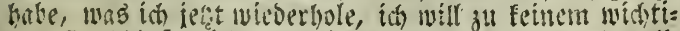

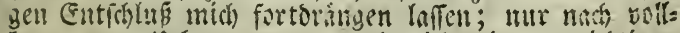

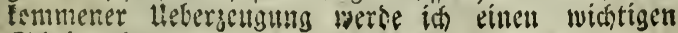
S(lititt (i)an." 


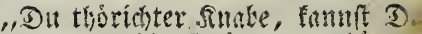

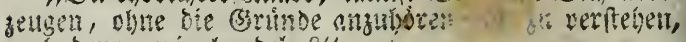
nach benen mir bandela?"

Shit diefen sgorter faste ex Darife ant grme, nits

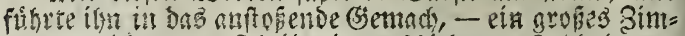

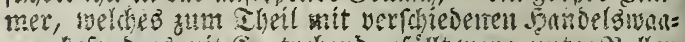
ren, Defonders mit Eontreband gefint war; unter 23 allen unb faper giengen varfdiedene Serren aut und $a b$, de:

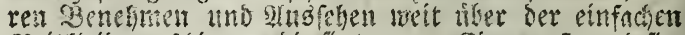

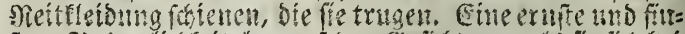

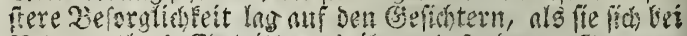

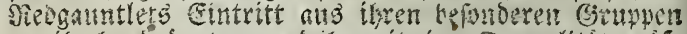

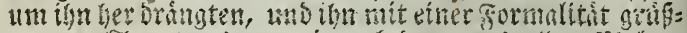

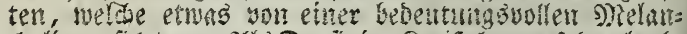

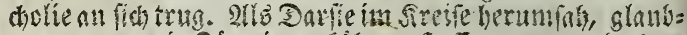

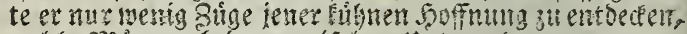
melche sRänner bet verzweifelten ltuternémmugen su er:

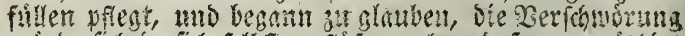

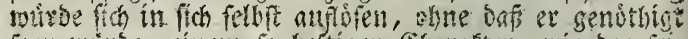
fent mirue, einem fo beftigen (Shatefer, wie ber fei=

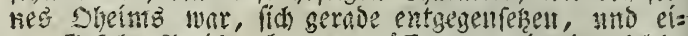

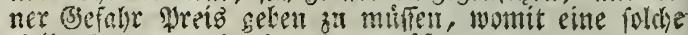
grstoerfestug verbunon feun iniste.

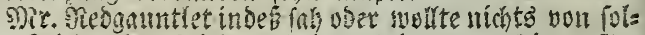

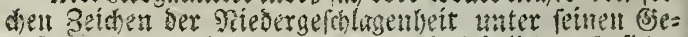
nosen felen, fandern trat ibnen mit froglident (S)fiote

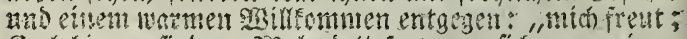

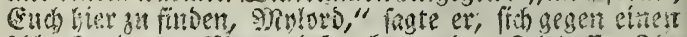
folanken iungen shant the vertengent. "gon bofie, gre

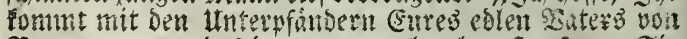
Z ..... und feinem ganzen lowalen Saufe. - Eir

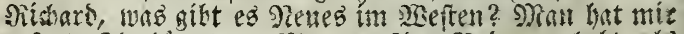
gefagt, Gru bittet 200 Mam anf den Beinen gehabt, als

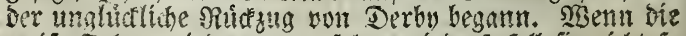
sacise Fahne wicberim entfaltet wirb, fo foll fie nicts fo

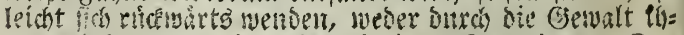

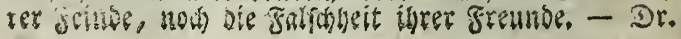


(5rumbail, ich bettge mich vor dem seprafentanten vou

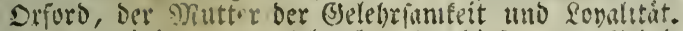

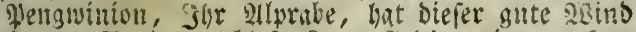

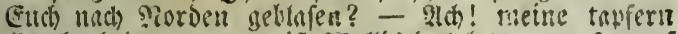
Eanibrobritten, wann ifi sallio das lekzte gewejen auf betil pfabe der Efore?"

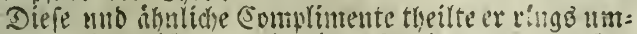
her ats. bie meift mur mit fillen Derbengumgra aufge= nomment turben, als er aber cimen feimer sondoblate, mit ben gianen giac = Jiellat, mo shiandil won Eun= mertrecs nit dem Sinmen Whate - in - Peril bogriste,

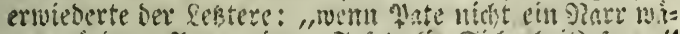

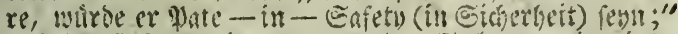
and ber Exftere, ein magerer a!ter Et plmant, in einen

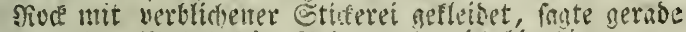

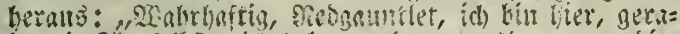
be wie Jir felbit; id) labe menily su walteren, - bia, welibe mix in oer leaten seit menue (Sititer nabmen,

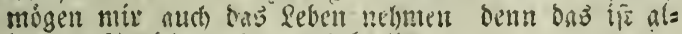
teos, nofuir ith 8 tr forgen bubr."

Die englifien EDellente, bie noch in 2iefth inres

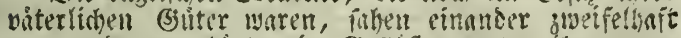
an, Into man borte ein (S) fitifet unter ibnen vou bent Fudse, Eer feinen Gotwing verloren babe.

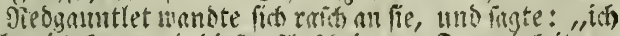

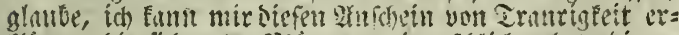

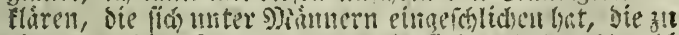
eiltem to eolen 3ned verfammelt fins. Ilnfere stmabl

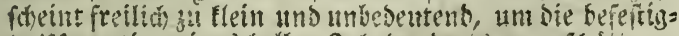
te llfurpation eines baflien Sablymberts an erfolittern.

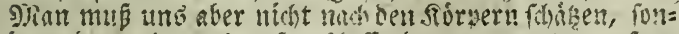
Dern barnad), was unfere

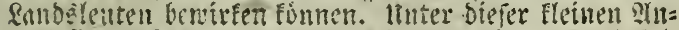

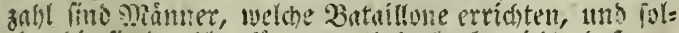

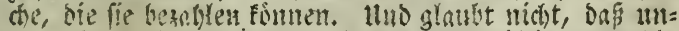

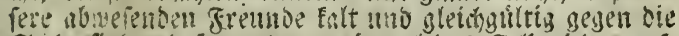

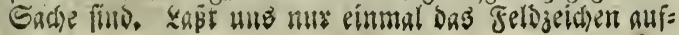


fteden, tutb es mirs kegrifit werben von allen, welche bie Stuart liebent, und vou ber diod) grobern 2 mjahl,

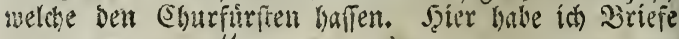
voit

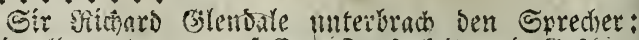
"ivir alle vertwatu-auf Eure Tapferfeit und (Se)

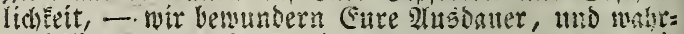

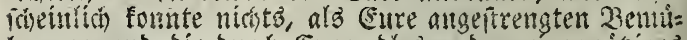

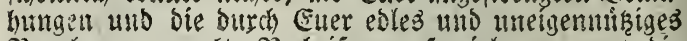
Bencimen ernedte siacheiferung fo viele vou uns, bie zerfireuten Ueberrefte einer entmuthigten warthet, bes wegen, noth simmal zu einer feierlichen Derathung hier jufommen zll fommen; Dent id negme on, meitre

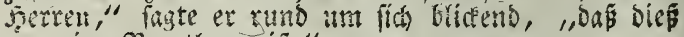
thir eine Berstrumy iti."

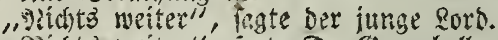

"shidsts veiter", Gagte Dr. Srumball, feime grop̃e afabemiffie Yertice fchuttelno,

Int "nur eine Jerathung" war bas Edo bor andern.

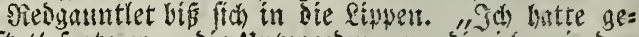
bofft, " fagte er, "ove unterredungen, bie ich mit ben meiften von (suth von Beit zu beit bielt, follten etwas beffer's zur sieffe gebracht haben, alb Eure 20 orte an= oruten, uno glaubte, wir fonnten bier eben fowohl auss= fuibren, als berathen; wir fino ja vorbereitet. Sd fam mit enten sinte funfluttoert siann aufitellen."

"foufbundert Mann!" fagte einer ber Squires

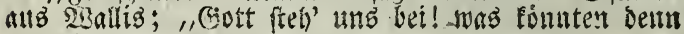
500 'Mann thun?"

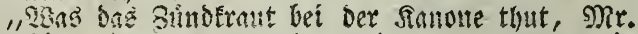
Meresth," entwortete Peognantlet; "es fest umb in Dett Etang (Sarlfele ": nehmen, und Thr wist, was unfere frembe in sifem falle veriprodyen biben."

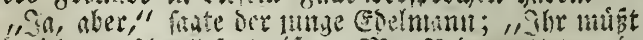

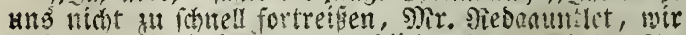

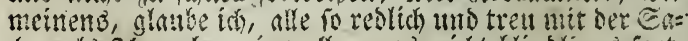

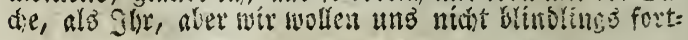


lidien Beiftes yerbammte. Drfors wird Menichen, (5)eld

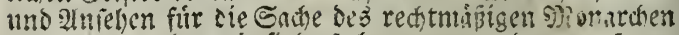
bingeben. abar wir find oft letrogen worben von frent=

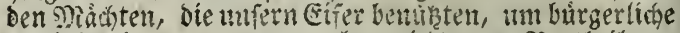
Uneinigfeiten zu erregen, aber nicist zum siortheil un=

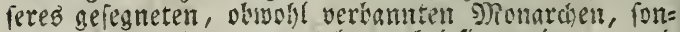
Dern um ltmuljen anzuzetteln, wobei fie gewinnen, tnts nir ju Brambe geben. Sxford iviro fich Saber nidht er= helen, menn nicht unet Soubernin folgit fommt, um

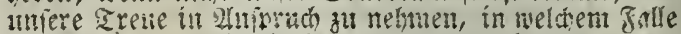

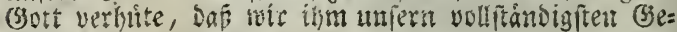
boriam veriogen follten."

"Ins ít eit guter Siath," fagte 9)ir. Mneredith.

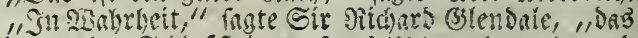
if ber mabre Edylubfin unferes Ithternelymens, und

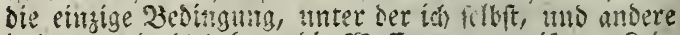

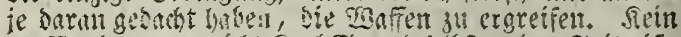

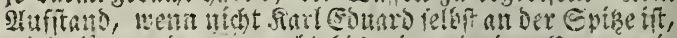

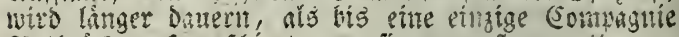
Sotsrces aufmaridiert, un fie zu itrifretich."

"Das ift auch neite sieinang unt bie meint gan= zen Fantilie," fagte ser oben eridinte innge Edelman; und ith geitelye, das id) etwas erifaum bin, zn einer to gefiblidon sufummentunft anfgeintoert worben zu

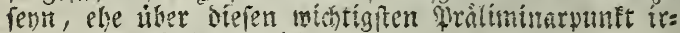
geno etras befitimat iff."

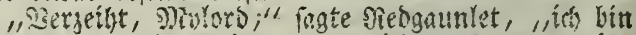

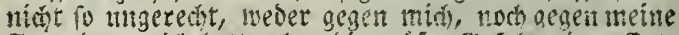
Frentub: - ich batte olgne die arofte (sefalit ciner Ent= Defuni feine soittel, unfern entferntern Serbindeten mitzutheilen, was einigen meiner elyrenwerthen freun= be befantut ift. Eo mutbis nuto entifyloffen, wie vor

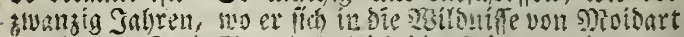

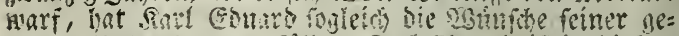

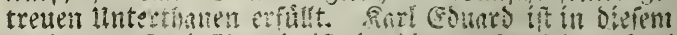

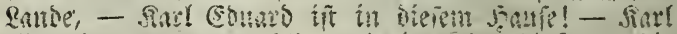

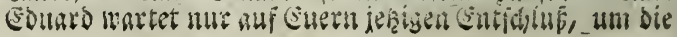




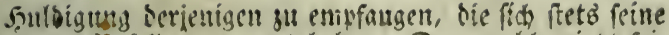

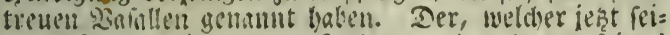

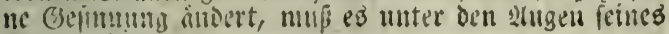
Entueruins th)แ!n.

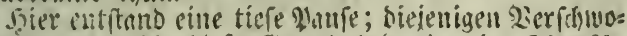

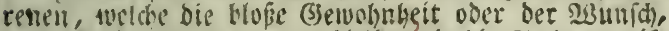

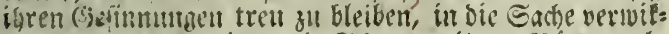

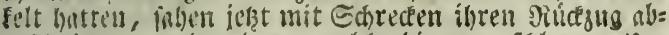
geidhnitten, und antere, weldye bie vorgefalagene tht= ternebum in ber ferne als hoffunugretch angefelsen hitten, sitterten, als der 2lugenblick", wirflid) baran Ebeil zu nelinen, fo merowartet und faft unvernicio= (iid) fie titerrafdite.

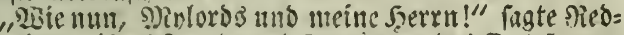

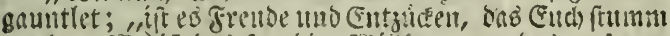

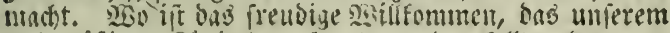

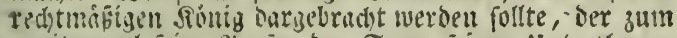
zweiteminal fente perion ber Sorge jeiner Unterthanen

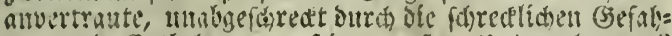
rin und Entbigrunget feiner exten untenehmang?

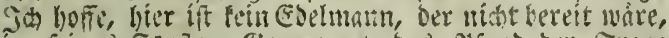
in feines Juriteit Esegenmart bas Pfand ber Erene

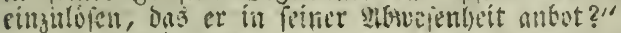

"To wenigftens," fingte ber. junge Godman ent=

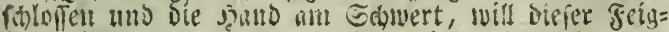
linty nicht fern. sisenn fint an biefe hift: gefommen

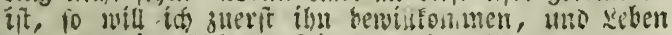
uno Berutogen femem Dienite weihen."

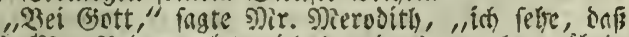

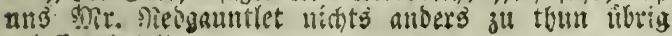
geluffen hut."

"STltt" paste Eummertrees, "ba if nod) cine ast=

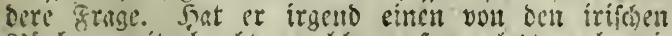

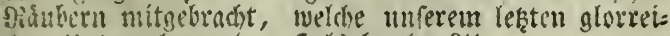
den ltuternehmen ben fealş bracben?"

"s?icit eilien sian bavon," faste siedganntlet.

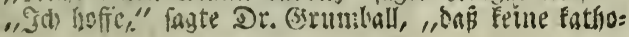


lifhen Mriefter in reiner Geferlichaft fint. Sol will'mich zwat nicit in bie Eemiffensinchent meines Eomveraints mifchin, aber als ein unwurbiger Eohn ier engli=

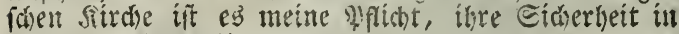
If d)t zu nehmen."

Siein sasiftifcher frunt oder Saze ift bier, welthe

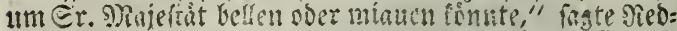
gauntlet. "Selbfe sir alte Schafteshurn fonnte fidh fei=

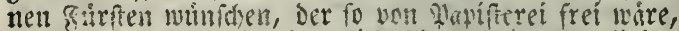

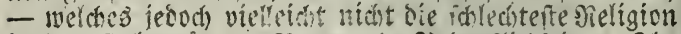

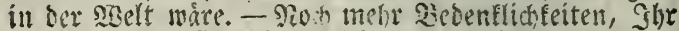
Serru? laffen fich Eeite baltboreren Grince auffinden, um ber Erfuflung unferer Wficht แno ber \$ollzichung

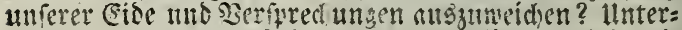
beffen martet Euer fionin auf Eure Erflärung, bei meiner Trene! er bat einen froftigen Empfang!"

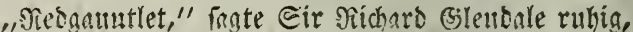
"Eure Siormurie folfen mich zal nidhts bellegen, was

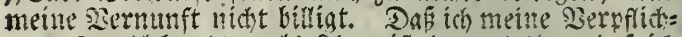

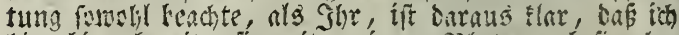
bier bin, bereit, fie mit meinem 3 hute 3 befiegeln. 2iber ift ber fionig wirflid hier ohne alle Begleitung eingetrofen?"

"Ex bat feinen Mann bei fid auper ben jungen..... als Mojutanten uno éthen einjigen Sinmmertener."

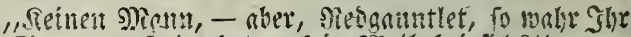
ein Ebelmann fers, hat er feill sijeib bei fich?"

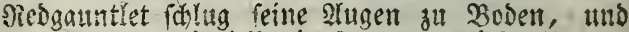
fagte: "es tijat mír léto, is fagen zn muifen."

Dic Befellychaft blicéte émander an, und blieb einen

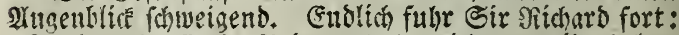

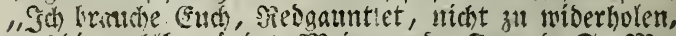

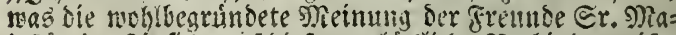

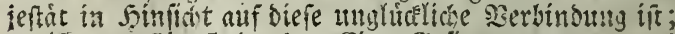
es if nur Ein Bsedanfe, Eine Belinumitg unter uns

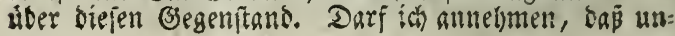


und ketroffen, als Shr fenn tonnt, saf ex fie anf biefer

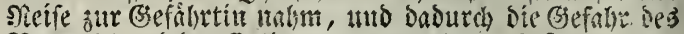

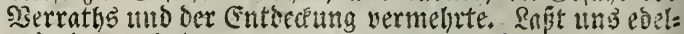
muthig hanbela gegen unfern Eowwernit, uno ment wir geseigt bolen, "nas wir fur ibn thun wollen, fo twerben mir beifer im Gtande fevit zu keftimnen, was wir yon ith als Spfer fortern follen."

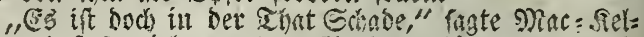
lar, "Sas fo viele wadere Eberfente bier verfanmelt

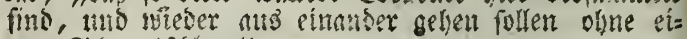
nen ङduettolag."

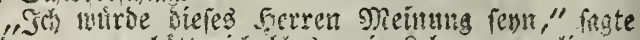

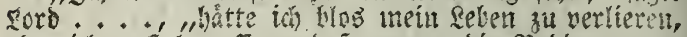

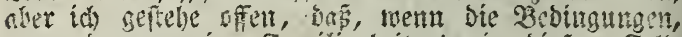
unter benen neine fontilie betrat, in biefem folle

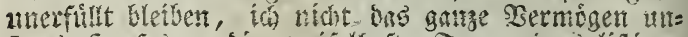

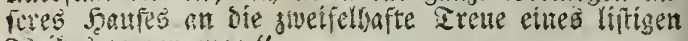
Dirives natgen mag."

"Es timut mir \&eio zut fersen," fagte Nedgauntlet, "da

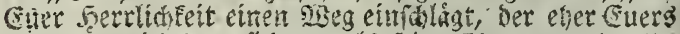

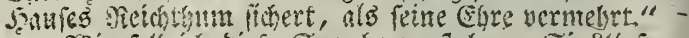

"șie foll ich bicfe Exatade veritehert, Eir?" fag= te bet funge Eoclmant frois.

"sietit, meine Sertu, lap̌ Freunde Eoinen Streit be= gitmen," fagte Dr. Cormmbali bermittelnd; nit alle

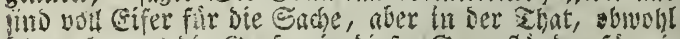

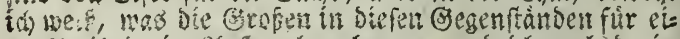

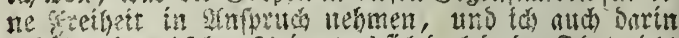

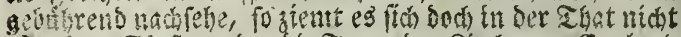
für cuten Firiten, ber Die Erene Der firche von Englond in sinfurad ntmmt, in foldyem (sefbifte in foldier $28=$ gleiturg antufonstnen, - sim non caste, eaute tamen.."

"Sth nundere mich, tyie die Sirche von England furem lustigen alten siamenovetter fo zugetyan ift," fagte siedgount!et.

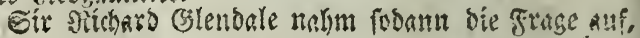
als- 


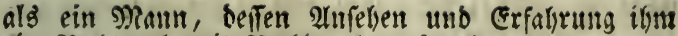
eill Piecht gab nit ?iadsoruce zu furedisen.

"Wir baben feine 3eit zu verlieren," fagte er ; , loir

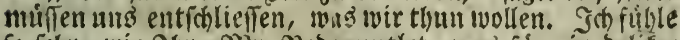
fo febr, wie Shr, NRr. Niebgauntlet, mas fur ein belitas ter puntt es ift, mit unferem Souvernin in feiner ieţi= gen Rage zn unterbandelis. 2lber ich mus eben jo an Den ganglichen Sturz ber Sadje, an ben Buterverluit mb

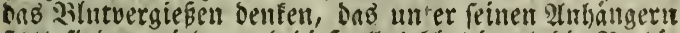

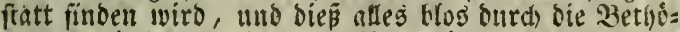
rung, mit ber er eillem siseibe antaingt, bas von dem iesigen MRiniter befoldet ift, wie fie vor Sabren in

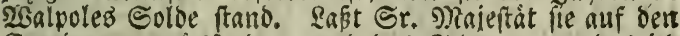

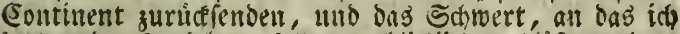

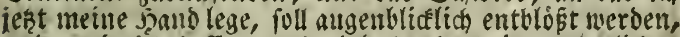
utio, wie id boffe, nodh viele bundert im nebmlidgen Atugenbliç."

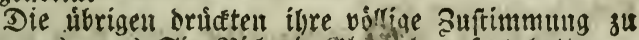

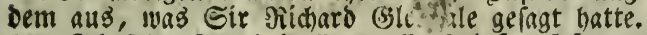

"Ih Tebe, She babt Eutern Enrfalus gefant, meine

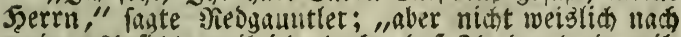
meiner 2 miicht, weil ing glaube, baf Jgr surdh ein mil= Derez und coelmithigereź Benelomen weiter bie Sathe

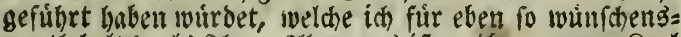
werth halte, als Jar. Sher was ift zu tfun, wenn farl

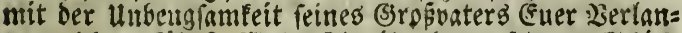

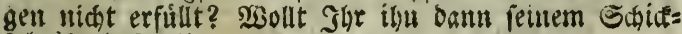
fal ùberlaffen."

"Sott verhute!" fagte Eir Ridaro hartig; "unto

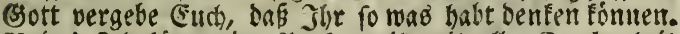
giein! Sh fur meine Derion will mit aller Ergebenleit

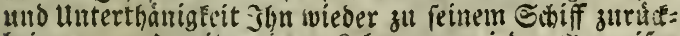
bringett, uno mit meinem \&eben gegen ieben yngreifer vertheioigen. 2lber wemn ics feine Segel nusgebreitet

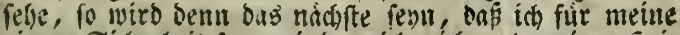
eigene Sidherbeit forge, indem id midn nach meitur f̧eis

ฌ. Ecott's werff. XIX. 


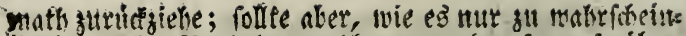
(id) ifr, unfer Sorbaben rubbar gemorden fenth, fo tiber:

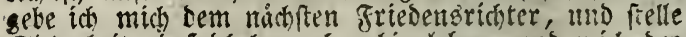
Eidyerbeit, iaf id bernach rubig leben, und nith ber berifhenden Benalt untermerfon mill."

Wieserum bezeagten bie llebrigen ibre tletereint fimmung mit ber gieinung bes Sprechers.

"शiun benn, meite Sherru," fagte ?iebgauntlet; „ich

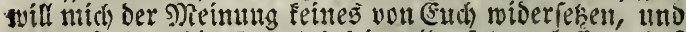
id) mus (E) Die Eseredigfigeit wiberfalsen laffen, bas oer foonig in Ditefem Falle eine Beoingung nidit erfillt

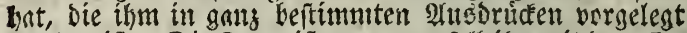
sorben ift. Die frage if nun, wer foll ín mit dem Ere gebnis unferer Bufammenfunft befant madjen? benn ich neline an, Shr werbet ilym nidst in (S) fammtheit auf =

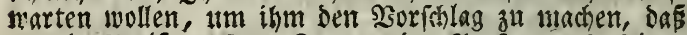

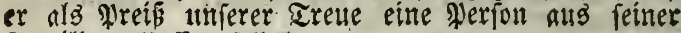
familie entlaffen forl."

"I(t) Dente, s?r. Rebgauntlet follte diefe Eroff: nung madien," fagte Rord - - ba er zweifelsoline unferit Sorftellungen (5)echtigfeit bat wiberfabren laf: fen, inbem er fie Dem fironig mittreilte, fo fann nie=

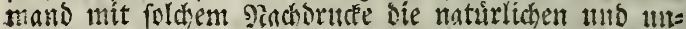
rermetslichen Folgen Daritellen, wem jene nidit bends= tet werselt."

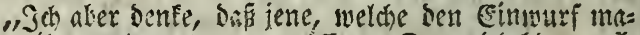
an, ibu aitd vortragen mithen. Dent ich bin verit: dert, ber fionig wirb es̀ foum glonben, went es ilum

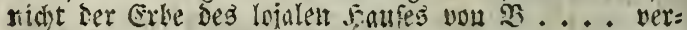
firbert, bas ur sor erite it, ier fétiem seriprechen

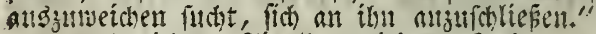

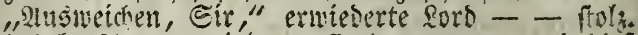

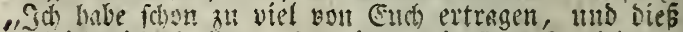
bill ich nidgt oulsen. Dergonut tuir Eure Degleitutg Dort lasey Dit Dhinen."

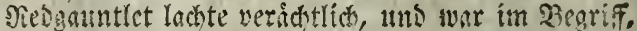

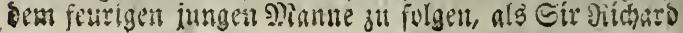


wieberum basnifach trat. "ISollen wir Dem," fagte

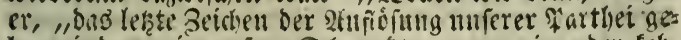

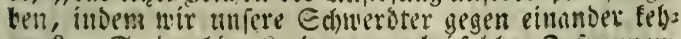
ren? - Eeno rubig, forb - - ; helolden sufammen fintien mms vieles glme Folgen voruber gelgen, mas ant=

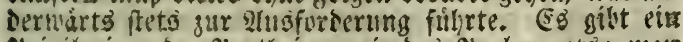

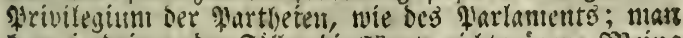

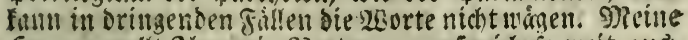

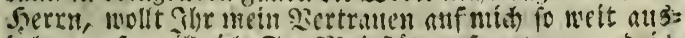

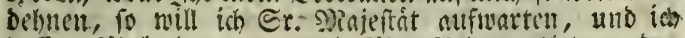

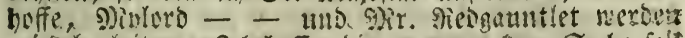

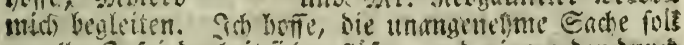

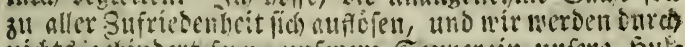

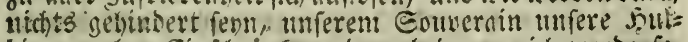

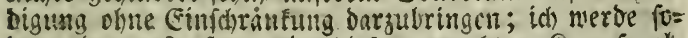
banu der erite fenn, in-defen getedtent Sampfe at: les anfò Eviel za feken."

Shesgatutlet iartit anf einmal worwarts, nno fagte: ,minloro, wenn mein (Eifer mid) ctmas fazent lies, das

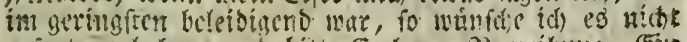

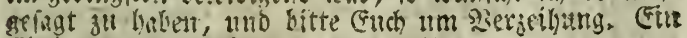
Eoelmmil fomn nídit neigr thun."

1. Sch) batte nicht einmul io biel von Mir. siefiganntret

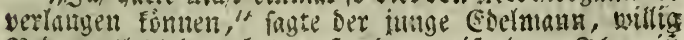

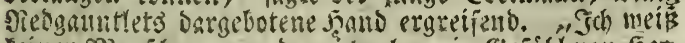

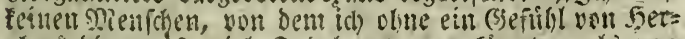
alutirbigung fo viel sadel ertragea fonte, als vor ilim."

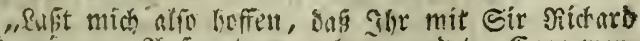
uno mir zur glufuartung geben nerbet. Cuer nar= mes gitut niro unfern Ëfer befenerm, unfere făbtere Heferlegumg Eure Sikze minfigen."

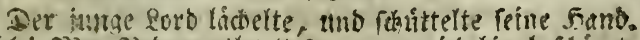

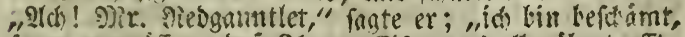

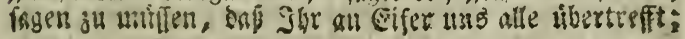


(id) will biefe Senbung nidht ableknen, wenn Jis Gir

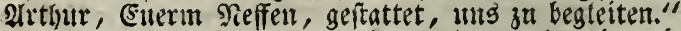
"siein Sieffe!" fagte Siedgauntlet, unto fhien ei=

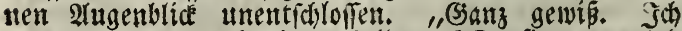
boffe," fagte er mit einem 2 lices auf Darfie, "er wiro

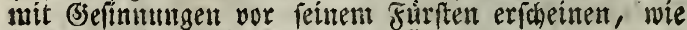
fie ber (Bjelegenlieit angemefien fims.".

ËB folen aber, er bảtte lieber Darfie zuridégelaffent, wenn ifm nicht bie Beftirchtung gefommen wäre, bie unentichlofenen Serbutnoten woirben in feineri2lbwefen= beit einen Einftus auf iln, ober er auf lie äupern. ijh will gefen," fagte. Nebgauntlet, "uno um Betior bittent."

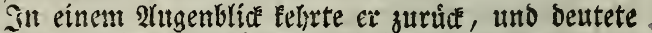
vinte za fprecí)en, bem jungen (E) tmann an, vorauszu= gehen. Shm folgten Sir Эitchard SSlendale und Darlie,

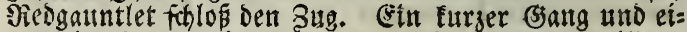
He fleine Treppe fuibten zu der Thure des einftweiligen

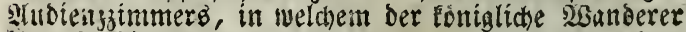
ihre Jinloigung empfangen follte. Es mar ber oivere

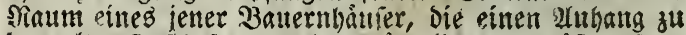
sem alte: (Sa)thof ausmachten, armlich ausgeruffet, itau= big uno in thoronutng; Denn fur fo unbebadtfam man sas unternebmen aud antehen mochte, fo hatte man bod Corge getragen, die 2lufmerfiamfeit der Fremben nicht burd befondere 2 ntordnungen für bie Bequemlids feit des

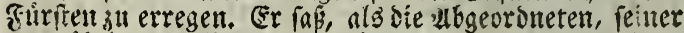
nod) thrigen gebliebenen anthänger eintraten, und als er iid) ertuos, vorwarts fam, uno fich verbeugte, am inre

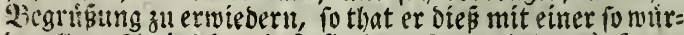
devollen 2rtigfeit, Eaß fie Den Mangel bes causeren Ponis erfeste, und sie elende $3 a u e r n t u b e$ fich in einen ber seranlafing wirbigen Salon yerwandelte.

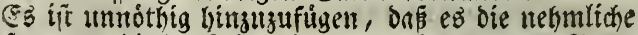
Merien toar, die ser Refer fdion unter bem Panten Water 2inctinentura Eennt. Seilie Sileibung wir bie nehmli= che, dic er Damals trug, auper einem weiten Sieitroc", 
unter bem er ftatt Deš Fleinen Degens ein zu feieb und Stos gerechtes Sdywert tritg uno ein Paar Piftolen.

Piebgauntlet ftellte ibm nach uno nach ben jungen Sord - - und feinen Serwanden Sir Artbur Dar= fie siedgauntlet vor, welcher zitterte, alo er fich vet: beugte, und des Fremben frand fifiste, benn er fah fich zu feinem Erftantur it eine Sandiung bes foodverraths bereingeriffen, bie zu vermeiben er fein soittel wüte. Sir Sithard (s)lendale ichien Sarl Ebuard werion: lich befannt, weldber ihn mit einer Miifchung vou Sirte und Rieke entpfieng, und die Shranen mit zu empfinden frien, bie bem Ebelmann in bie alugen traten, als er Sr. Najeitit in feinem angeftamniten Sieide willfommen hief.

"Ta, mein guter Sir sicharb," faate ber ungluali= dhe fourft in einem melandoliforn, bod entidolofienen Tone, , fiarl Esuard ift noth einmal bei feilten frems belt, - vielleidht nidt mit feinell frubern froblichen Soffungen, nelche bie Befabr verringerten, aber mit ber nebmlichen seraditung bes folimmiten, mas illm begegnen famn, wenn er feime mo feimes saterlants Siectite geltens macbt."

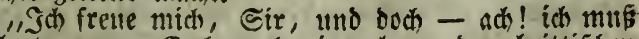
auch trawern, Fuch now einmal an ben brittifiten Sitifen su feben," fagte Sir gitaaro (s)lentale; ex bielt inte, bie wiberiprechenoften Emprinoungen bin= berten ilsu, weiter fortzufabren.

"Es ift Der Bitl meines trenen uns leibenden Solf3, ber allein mich bewenen fonnte, nod eimmal bas Gobvert

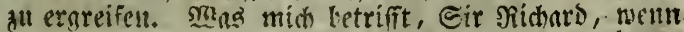
id besadite, nie viele meiter Injalen und eraekentat

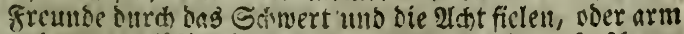
und vernactilisigt in frembem lande ftarten, fo faws

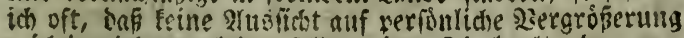
mich ie wicher wirleiten follte, pinen Titel gelteits an mas

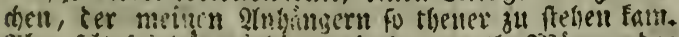
Hber ieit foipicle wirboige uno ebrenwertlie glianser ber 


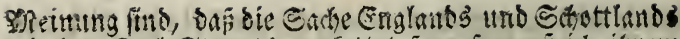
snit Det Jorl Ettarts verfettet fen, fo mus ich ifrein tapfesn 3etipiele folgen, alle altoern 3 etradbtungen zur

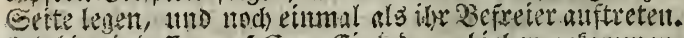
Sid) bir indeffent anf Eure Einlabung bifler gefonmen,

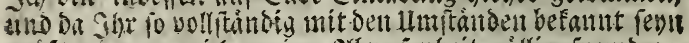
snisc, benen mich neute 2rkwefentheit vollig frento ge=

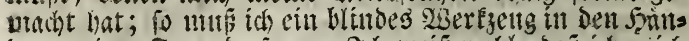

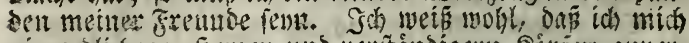

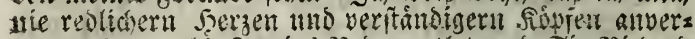

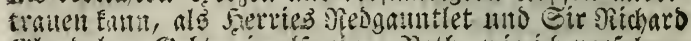

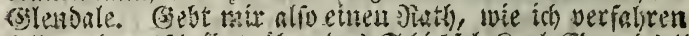

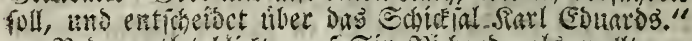
Besgantret bliçte allf Sir Sichard; als wollte er fugen: "tonut Shr in einem alngenblick, wie biefer, auf eincr unwefeatlithen und mangenelgnen Bebingtang bes

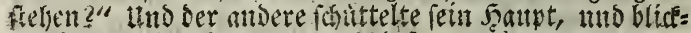

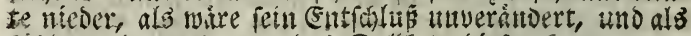

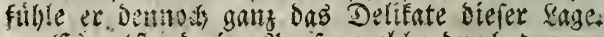

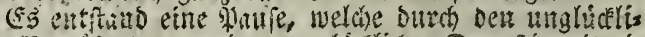

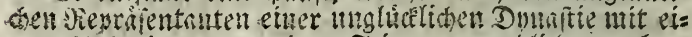

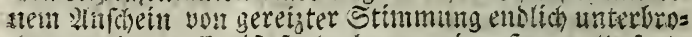

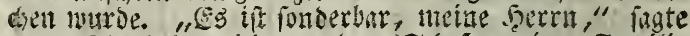

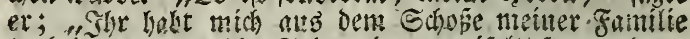
berocigerufen an bie Evike einer zueifellyaften und ges

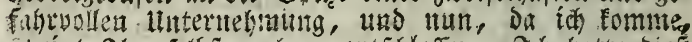

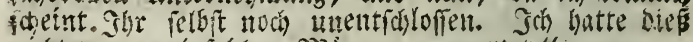
nicist von zloet folden gozintern ermartet."

"Sins mich betrifft, Ei:" fagte neogauntlet, moer Stabl meimes Schuertes ift titht zuberlápiger, als meine (seifnnung und Denét."

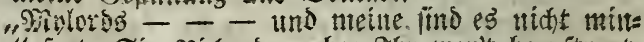

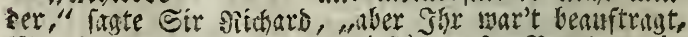
gir. Fieggantlet, Sr. Minieitat unfer Begehren in Merbinbang mit étitgen 3eotingutgen vorgutragen."

"llind id entlebigte mich mituer pitids gegen 5 r.

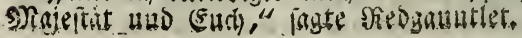


Şa nobtete auf feine 2eoingung, meine Serrur

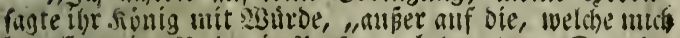
berlef, meine Jiciste in Derion zu bebautin. Die bas

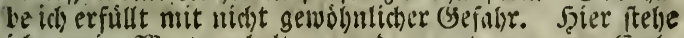
id, mein : Wort zu balten, und erwarte nun bon Eutb, Dás Sbr Dem Eurigen getrell fevs."

(Es war aber noch etwas in unferem Sorfalage, ober bitte es wenigftens fenn [ollen, wem Ew. S) iajeftat crlauben. Es war eite Deoingung Damit verfnupft." iId) fab lie nidht," antwurtete Sarl ibu unterbres

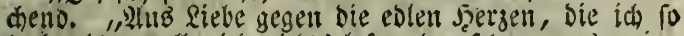
bod adte, wollte ich nidsts lefen oder felden, was meine liebe ober aldtung gegen fie batte vermindern formen. Beduguigen Fonmen nidst itatt finden swífden Furit und lutertgaitu."

Sir", fagte giedgauntlet auf ein Sinie niederfina

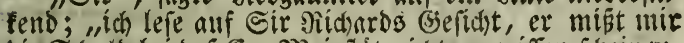

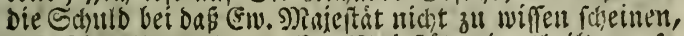
was Shre llnterthanen (Ew. S)iaieftat nitgetheilt zu fes ben Ivinidste. Itm bes f̧immels willen! um aller mei= ner friheru Dienfte und seiden willen, last nicht biefen

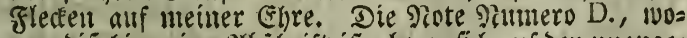
voul bif bier eine atbidurft ift, besog fich auf ben unanges nebmen Gegentand, auf weldien Sir Ridhard miebe: rum Eure Uufmerffamfeit ridjtet."

Glor orangt mir," fagte oer fritft loch errotbeno, Eximuermnget: anf, bie ich germe aus neiment Siedástmis verbant batte da ich fie Eurem Ebarafter fur fremo

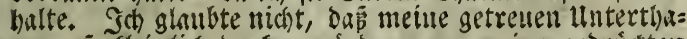
nen, io fleinlido denfen wurben, um meine georudet

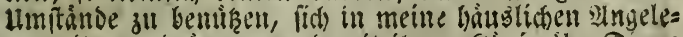
genbeiten zu orangen, nno mit ihren Sionig tiber Dinge zu unterbandeln, worin bie geringiten s)ienjchen bas jeat baben, nach eigenent Dibillen zu bandeln. Ju Gtnatsangelegenbeiten uns in offentlidien Befdaften sverbe id nicis ourch oie anfithten meiner weifeiten alathe

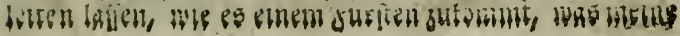




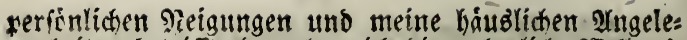

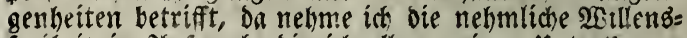
freibeit in 2 (nfpruch, bie ich allen meinen tuntert)anen geftatte, und obne weldie eine sirone weniger werth wáre, al's eine Bettlermuze."

"Ertauben Ën. S)iajeftát," lagte Cir গiichard (slent= Iale; ,ich febe, es ift mein loos, gegen meinen $\mathfrak{S}_{\text {Sillent }}$ sonlrbeiten zu fagen; aber glaubt mir, idh thue es mit elon fo grobem Bebauern, als mit tiefer (Ebrfurdt. Eg ift nabr, nir haben (Eud) an bie Evize einer mádtigen Internehmung gerufen, und Ew. Najeftat balen einge: wifligt, unfer futhrer z" nerben, bie Ehre ber Cicher: heit vorziehetts, und die Piebe zu Eurem \&ande Furer é= genen Bequemlidfeit. Wiber wir festen ebenfallè als ei= nen nothmenoigen und unatioweidslichen, vorbereitenden Echritt zu 2luefúl)rung unferes planes feft, - und ich múpes fagen, fogar als eime beftinimte Redingung unfe:

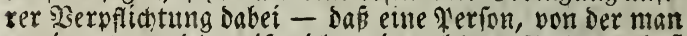
annimmt, - ich neif nidot mit melchem fiedte - ba fie (En. )Raieftat innigftes Sertrauen befike, und von

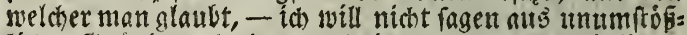
lícten Grunben, fondern aus einem febr wabricheinlichen serbacht, - bas fie fóhtg. fen, bies sertranten an beu (Sturfurften von Somnover zu verrathen, von Em. Siale= fiat Snofbaltung unb Biefellichaft entfernt werben moge."

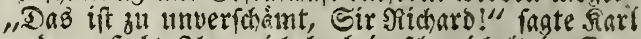

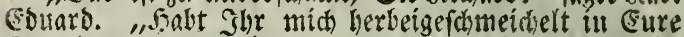
Eemalt, nur um mich auf eine fo ungesiemente 2 seífe

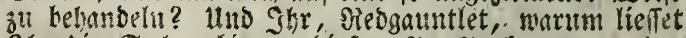
Thr die Eachen bis zu biefem Punte fonmen, ohne inish näber baranf anfmerffan z̆l maden, weldie $\mathfrak{Z}:=$ teidianngen man mir zufigen wirde?"

"soiein gnádiger f̧urft." errvieberte Nedowuntlet. "id bin hierin mur it roweet

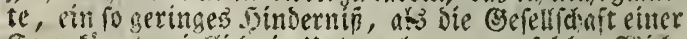

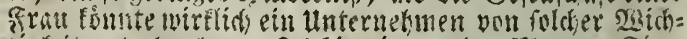

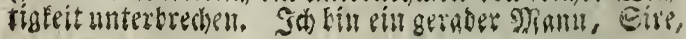




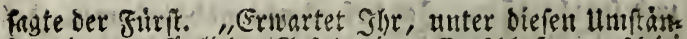

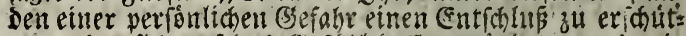
tern, ber fid) auf bas (jefúl beficn grumbet, mas mir

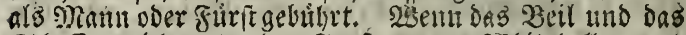
Schaffot mich unter ben Fentern von teten, id lnurbe lieber benfelben 23 eg betreten, wie metil Utgrofsvater, als in bem geringiten \$unft nact)= seben, Der meille Ebre betrifft."

Er furach biefe 9 sorte in einem entichloffenen Tone, und blicéte in ber Gefelifichaft unber, yon benen alle, (Dar= fie auszgenonmen, ber bier eit gluicliches Ente einer bo dhit gefahrwollen unternehmung zu fehen glanbte) in

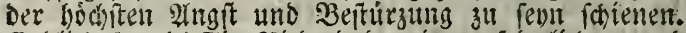
Enolid) frrad) Sir Sichard in eituem feierlichen dino melartholifhen Tone:

„Ståmbe bie Sidjerbeit bes armen Piidard Estendale allein auf bem Spiele, ith babe mein Rebent nie ro hoch ge:

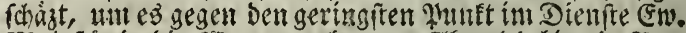

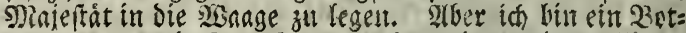
idhafter, - ein Beauftragter, bir fétue \$flicht erfüllen

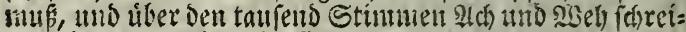
an wirben, exfillte ich fie nidgt nit Treue. 2lle Eure

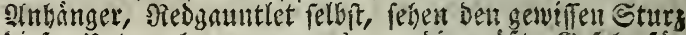

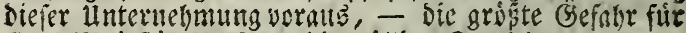
Ev. Majeftát Perfon, die vollige Sernichtung Eurer ganzen Wartlei, went fie nicht auf bem Wunte beftehen, ben unglidefeligerweife Ew. Niajeftit nidht lenilligen

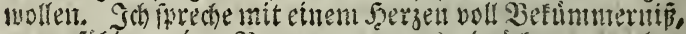

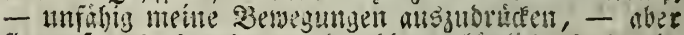

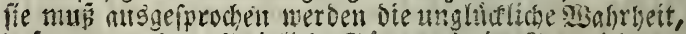

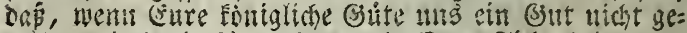

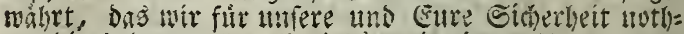

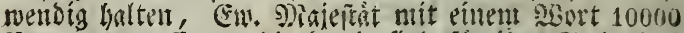
9) Zann entwafinen, bie bereit find fur iliee Sache dus Eswert zu fiebon, voer, um noch Dentliber zur reden,

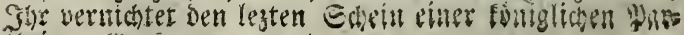
the un Siroblattanted," 


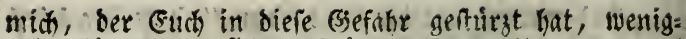
fteitb fur Etren fichern Niudsug forgen."

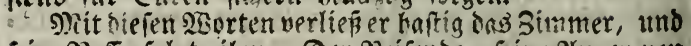
fein Peffe folate ibm. Der gieifende, reine 2rugen von Sord - - uns Sir Fidhard sslendale abmendeno, marf fich it eitten Etuk! am obern Ende bes (B)emarts, Mák: reno biefe in groffer Beroranifi in einiger Entfernung beifammen itanden, und fuifterno fich unterredeten.

\section{Sed d tes fapitel.}

\section{Fortferang.}

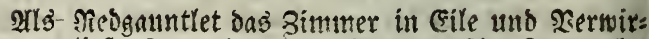
rumg verliés, fo nar ber erfte, dem er auf ber Trepne be: gegnete, und zwar fo nake bei ber Thtire ber Simmers, Daß̉ Darfie glaubte, er muffe gehordt baben, fein Diener sitron.

"פ3as zum Teufel thuft Du hier?" fragte er fdnen uno finfter.

"Эch warte anf Gure Befehle," antwortete Priron; "iid hoffe, alteg nebt ant? - verzeiht meinem Eifer." "2rues gent follectit, Sir; wo ift ser feefulyrende Burfhe - Emart - beist er nidot fo?"

"sinuty Fivart, Eir; ids swill ihm Gure Befelsle likerbringen," fagte Fírom.

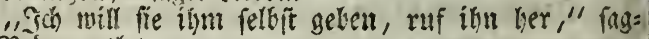
te Resgauntiet.

"IfEer molfen Ew. Binnden bie Ifubiens verlaf: fen?" fauts p?:as?, noch immer acaperno.

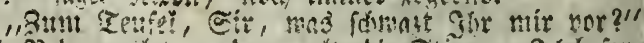

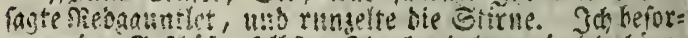

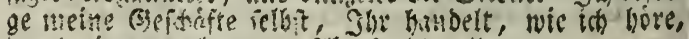

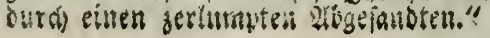




\section{0}

Cong thun fehen, - ein halties Edode an einem sMor: gett, - alb' tat die Rinte pap̃itte."

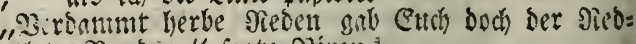

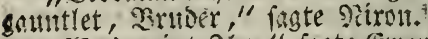

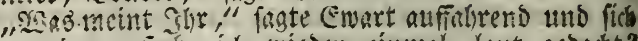
hefimments. "șiase it toieter einmal laut gebucht? nicht wabe?

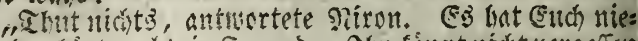
ma:s gerint, als ein frems. Shr font nidit vergefien

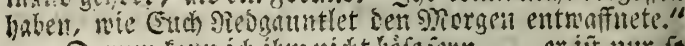

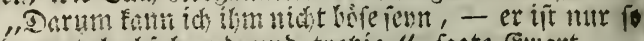

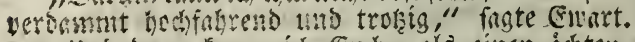

"lind ham fente (d) (End), als cinen ảchten Pros teftenten, "foute siron.

"Taśbin ich, Kei Bjott," fagte Ewart ; "Itein, bie Enenter Ka'sen mir nie meine seligion entreiffen fónten."

"1no ein frentio bes fionigs bseorg und ber han= niverichen Succefion," fagte Siron, immer fehr lang: fam gebend litts frechend.

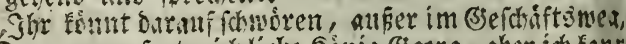

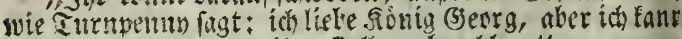

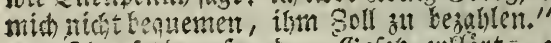

"Thr feibs aufer bem "jeferes erflart, glanbe ich, ragte sitratt.

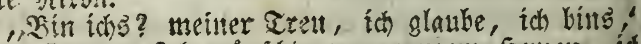
ragte (Ewart. Grit minichte von ganzem Serzen, id

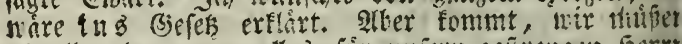

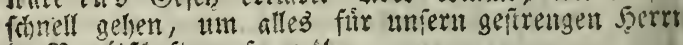
in 2ereitfouft zu fezen."

Sich will Esth cinen beffern Streid Yefren," ragt Sitron; , ida if Doch nur blutiges sebellenware bort.

"Tia, Das wiffen wir alle," fagte ser Ednungbler aber "Fer Sotneekall formityt, glaube ich."

Es it émer unter ilnect, besen. fonf - breífig-tau fert - Dfatio - Eterling - boar Bjels werth ift," faat

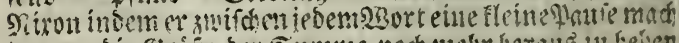

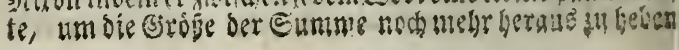


"Mein Peben if nerloren, menn ghr es thut," fagte Piron; "melmt, sूermuft an.".

Sie - waren lest in einem flemen didhten Sebuifhe an:

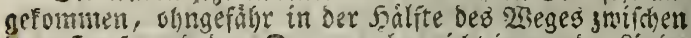
Dem Jaafe uno dem Damm, aber nidht in geraber Pinie, Denn Saron, beffen abint war, Beit zu geswinnen, batte Ewartell unvermerlich davon abgegogen. Er fal) jest die

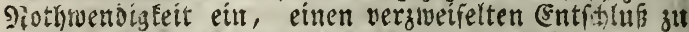

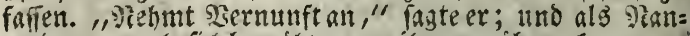
tv immer noch fich benlibte, all ism voribersufommen:

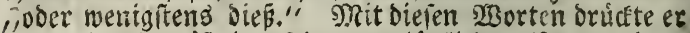

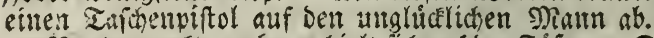

Tants wantte, aber erbielt fids anf den Fúpen. "Das traf ben stucéyrat," lagte er; "Shr babt mir ben lezten Dientit geleiftet, und id will nidat undantbar fesn."

शa diefen worten fammelte er alle ibm noch librige Sraft, ftand einen 3 lugenbliat feft Da, zog feinen Sirfid)=

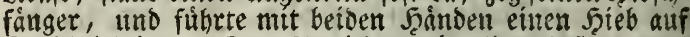
Elrifal siron. Der. Streidi, nút aller anfrengung cines vergweifelten uno ferbenden \$) annes gefibrt, zeig= te eine Sraft, die man won Ewarts alsgehagerter Sieftalt, nicht batte erwarten follen; er fpaltete Den Fut bes Glen= ben, obgleid) er ourch eine Eifenplatte gefouzt war, uno drang tief in ben Shabel ein, worin ein Stid ber $\mathfrak{X}_{3} a f$ fe ftecken blieb, weldhe bei bem wuthenden Streiche gerbract.

Siner von Der ghamintyaft ber 3 rigg, ber umber: ftreifte, wurbe ourch ben, obwohl nicht ftarten, Sinall Der fleinen Pifole birbeigezogen, uno fand Die beiben.

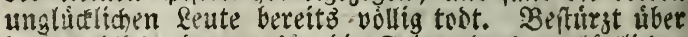

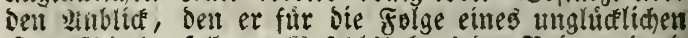
Sampfs bes gefallenen Befehlshabers ber 2 rigg mit ei= nem Bollatifeber bielt, (beitn zufülligerwéte war ibnt gitron nicht perfonlich betannt, ) eilte bet i) Ratrofe zurides zum Soot, um feinen (Sefákrten ?antys Echidfal su wertinben, unb ibuen ben siath ful geben, fich unb bas Eniff in Eiblotheit Ju biugen. 


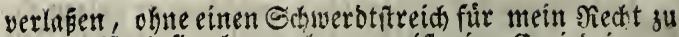
thun. Sisas fie aber verlangen, ift eine Erniebrigung, und : Rischgiebigfeit utumiglich."

- Siedgauntlet verlieś mit fétnem sieffen, der ein unfrei= milliger Suld anter oiefer auperorbentlidjen Scene war, rod einmaldas 3immer bes abenthetterliden stefenden, tino wurbe oben an ter Treppe von Son firacenthorp anf: gegalten. - "Siso finto bie andre serrn?" fragte er.

"Drituen im weitlichen Elyeile des şanfes," antwor=

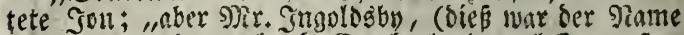
unter bem siedgaintlet in Eumberlans an belunnteften war, - ich wollte Ench unr fagen, Das ich all bas \$olf

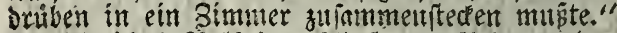
Duloig.

"siseldes' Solf benn?" fragte Niedgauntlet nnge:

Pint, bie fremben Giefangenen, liber bie Niron die

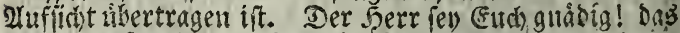
iftent greses feals, aber wir fonnen nidit abgeionderte Shatiere genug haben fur bie Reute, wie in Pangate voer in Beolan. Drutben iftein toller Bettler, der ein grofert Mant merden foll, wenn er feimen Dyrozen ges winnt; (Sott belfe igm! Dort ift ein Duafer unto ein fieditsgelebrter, die wegen cines 2luffands beichnldigt

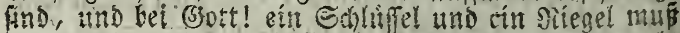
fie alle halten; bent wir find gepropit voll, wit Ghr balit ben alten 9itron weggeidifft, oer in biefer \$gerivirrung

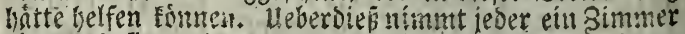

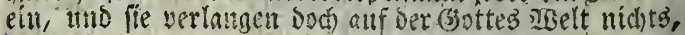
- ategenommen ber alte sikann, ber beftelft genng, bat aber feinen Wfentíg zum Dezahlen."

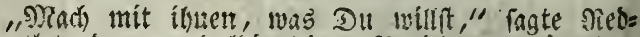
ganntlet, der ungebuldig feinen Pericht aneebort hate

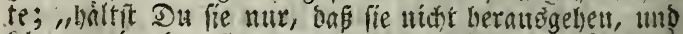
Garmen in ber Segend unber madten, fo fimmere (icly. mid. Hichts baruln."!

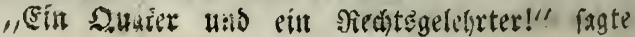




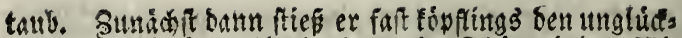

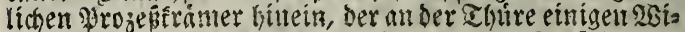
deritano leitrete, uno dep̈tals einen berben Stö́ befam,

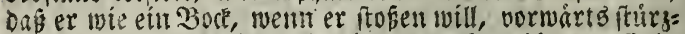
te, uno zwar mit eitur beftigfeit, ba bes Simmers gefommen, uno mit bem Shtte, ber auf

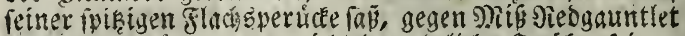
aizerannt wore, wenul nicht ber ehrliche Duáfer jeinen Eanf nufgebalten, inabeim Siragen gefapit, und zum Ste: ben gebrachshitte. "freunt," fagte er, mit bem vabe= baft guten Tonte, Der fo oft olyne (Seremontiel ftstt findet;

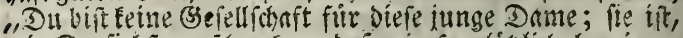
twie 2u fiebrt, erforrocfen, das wir fo ploblich hereinge=

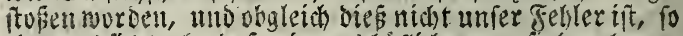

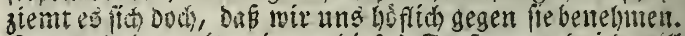
Fomm bater mit nit an biefes frenter, und id will Dir frgen, was Dir zat wiffen nothig ift."

"itno warum foll ich nidht nit ber Sady forechen, Freund?" fagte Peter, der lekst halb betrunfett war. "Sch have fornt fenon mit Domen gefprochen - warum

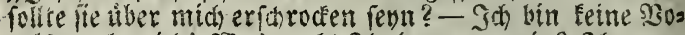

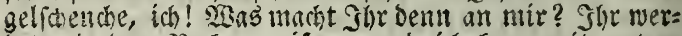
bet mir Den siod zerreisen; uno ich Eunn mit guttem (3)runo eine flage gegen (Euth anitellen, um mich suf Eure Sioftell sartum atque tectum fil machen."

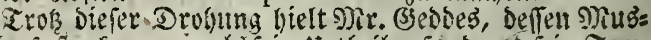
felu fo itart waren, alb fein urtheil gefund und rein Teme perantent rulgis, ben armen Meter unter einem Swange, gegen bell er nidjt anfámpfen fonnte, in einer Ecte bes

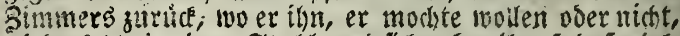
niederiste in einen Stubl, uno fid neben ibn, io da

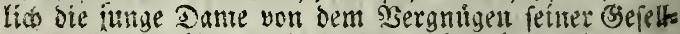
fohaft, bas er iar zugeducht hatte, befreit numbe.

Shatte Meter reinen gelelirten Álovofaten fogleich er: famt, fo hitten nud bie wohlwollenten anftrenguthgen

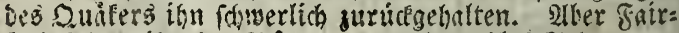

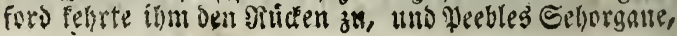


Dintelin durat Bier und 2 ranntmein etmas verduftert, noren im 2lnfdsuen einer halben Sirone eifrig beidiaf: thist, swelthe Gointa zwiften Damment und Beigefinger bielt, unt zugleids fagte. "Treund, Du chift arm und unverforgt. Diefverichafft Dir, mobl angenemoet, Deiz nes reibes ginflutung uno sicthourit auf metir, als eis

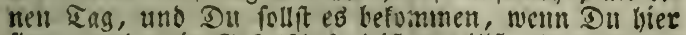
fiken, mo mir Bsefellfhaft leifen willft, denn meder Du, nod) ích, fint eine pafende (stefellifhaft firr Damelt."

"Ias mag won (Eud) gelten," fagte Deter verád)tlid); -ich mar fonft wobl gelitten bei ben Damen, unb wenn ict) im ?noen mar, lecoiente ing fie mit eiment ganzandern

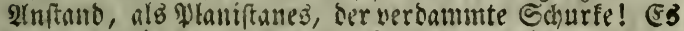
war altib ciner vou den Streityumten zwifhen uns." "Ont, Frouns," fagte ber Dudfer, welcher be:

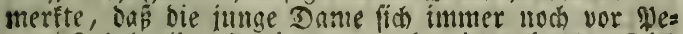

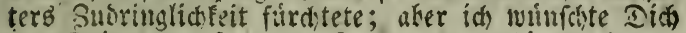
vou I cinem gropen qrogepe furedjen zu horen, ber fo beribmt gemortsen ift."

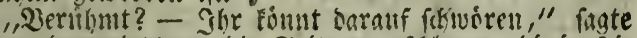
Deter, benu iefst war bie Eaite nutgerdilagen, die in rei= ner werriatten Cintirbungstraft forttonte. Ier arme g)ir. (Seibog müte mu eine lange Tiraie verndimen,

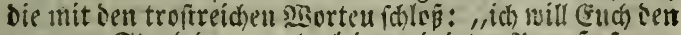
genaten Stnto der niunderlei vereinigten Prezepe figen,

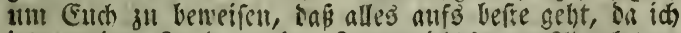

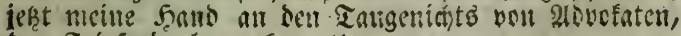
Den Fairforo, lezen Emm."

2ilan fairforo war getaie in Begriffe, sie mas̆lirte

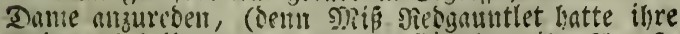

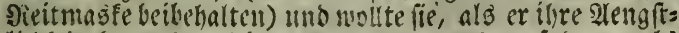
lichfeit bemerfte, feines vollen Edusces nerfictern, als

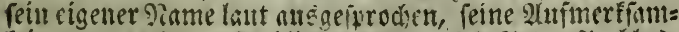
feit rege machte. Er blicite umber, fah) Peter Plecbleş,

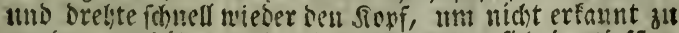
werten, was ibm auch gelang, on Weter fich im ticfifen Eefprèch mit bem chrenwertheiten auborer befand, bejfen 


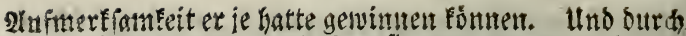
biefe fletue 3 enegung, fo furg fie mar, gemann allan ei= nen unermarteten 3 ortheil, dem wibrend er berumblids=

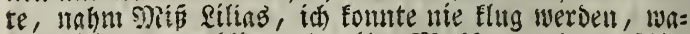

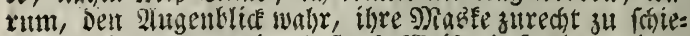

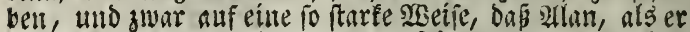

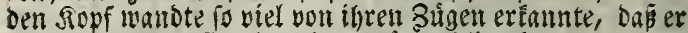
bereditigt war, fie als feine fohone Silientin anjureden,

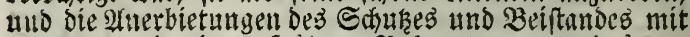

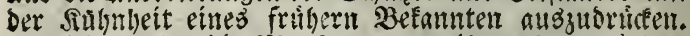
Rilias nabn die sinste ganz von ínem hodherrothen= sen (selidt. "Mir. Fairford," figte fie mit fait unloor=

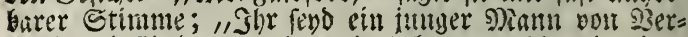

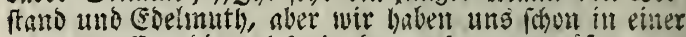
Qage getroffen, bie eud fonderbar vor fommen múfte, tho idi fonte nidt unthin, mich wegen meiltes vorid,

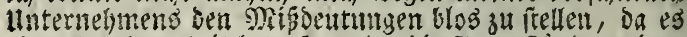
eime OHgelejenheit betraf, an ber bie Gegenftänoe meiner theuriten seigung ileil haben."

"Ein IIntgeil an meinem geliebten Frand, Darfie Ratimer, " fagte Fairfore, eit wenig zurticktretents, tut

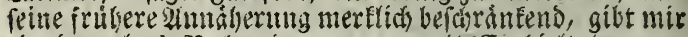
eint boppeltes fied)t, der - - - Er bielt inne.

"Seiner Ecbmener miglid su werden, wolltet She fagent," erwieberte lilias.

"Seine Ed)weiter, Mabame," erwiederte Fairford im ăberîten Eritaunen. - "Schwefter?! vermuth= lich unt feiner Peeigung nad)."

"I?ein, Eir; mein theurer Bruber Darfie und id fino Durat bie Bande ber engiten Bernandifaft verbun=

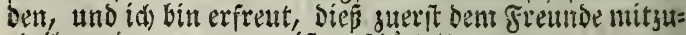
theilent, ben er ain meiften fohàzt."

Fairforis eriter Gsedante war bie heftige Reiben=

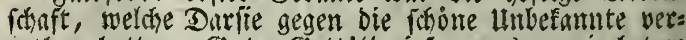
rathen batte. "Bేuter Sott!" rief er ahb, "loie liat ex Diefe Entoediutg ertragent."

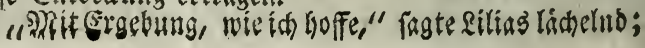


weine volfommentere Sdbuefter hitte er wohl erbalten fointen, aber uidht leidht eine gefunben, die inn mege liebt."

I(t) meinte, - ich meinte mir - - " Pagte ber

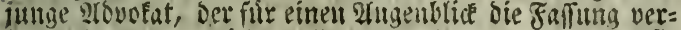
lorent hitte; - ifíl wolfte nur fragen, wo Darfie Ratimer in biefem 2 lugenblice ifit?"

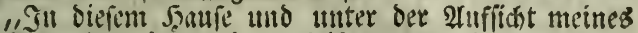

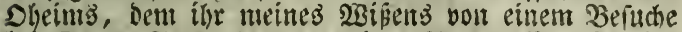
bet Eurem \$atter ber unter bem. Pamen Mir. Serries von 3irrensiwore fennt."

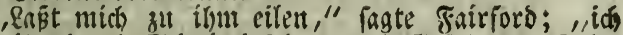

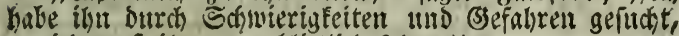
- id mus ibun autgenbliáliá) Febent."

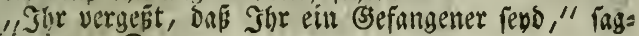
te bie junge Dame.

"Whabr, waljr, aber id) fann nidht lange gefangen ge: Galtent werden, ber angefúbrte (strunt ift zu lád)erlid)."

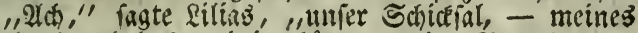
SBruberó uno Daß nteinge háttgt von den Zeratbungen

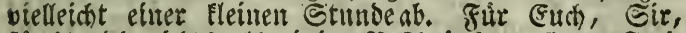

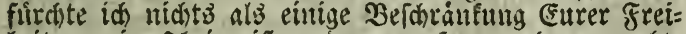
heit; mein sheim ift weder graufam now ungeredst, obgleids wenige in ber einmal ergriffenen Sadhe fo weit gelsen iverben."

"Utio Das ift bie Des Pratend - - " -

"Itm Sottes $23 i l l e n$ fpredt leifer!" fagte Rilias, die

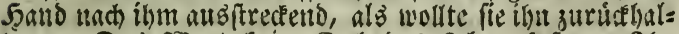

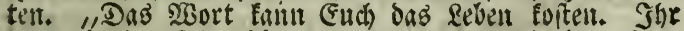
fentut in ber That bie Schreden unferer jesigen Rage

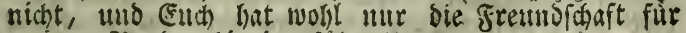
meinen Bruder liuteingefiibrt."

"Ich femte allersings die étuelne tmitande unerer Lage nidst,", fagte Fairford; , aber mag bie (jefaly feyn,

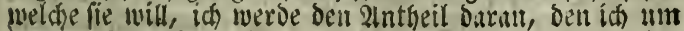
meines frentutoes willent tralsm, (midh nídht gerentent laf (eli,) ober un ber Sdjwefter meitues Freundes willen," 


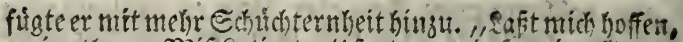

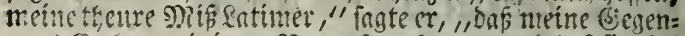

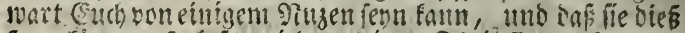
fent firme, fo loft mido um cinen Thetl Eures 3utrau=

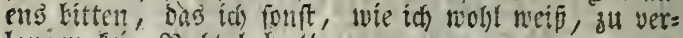
langent fein siecht babe."

Er fikgte fie mit biefen ssorten nach ser Bertiefung eitwo entlegencn fenfters, unb indem er ihr faste, bas er

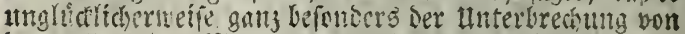
bem tollen alten giame, augagest (in), depen (Eintritt fie in 11 mrulge verfezt hatte, hángte er Iarfie Patímers Jieit= fleto, was in sem Sinmer zurtickglaflen morsen war,

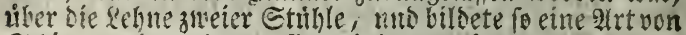
Edirm, hinter bemer fich mit bem (srtinmantel berfted":

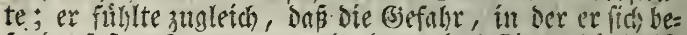

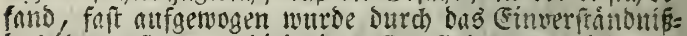
sas ibm geitattete, stejenigen Empfintunen mieder le= bendig merden zu laffen, welche er um feines frembes millen in ber sieburt erfididt hatte.

Das Perbiltuis bes Sinthenden uno Berathenen, tes Echusers uno bes Echizlings ift fo beronders gecignet fur bie gegenfeitige Lage des Drannes uno des 2zeibes,

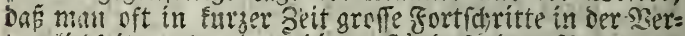
traulidfeit modst, benn die unitäbe forbern sertrauent

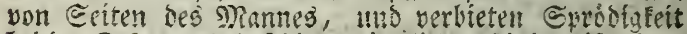

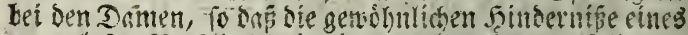
amonglofen Şerếlirs tnit einemmale zufammenfallen.

Eo meit als miglich gegen Bevkachtung gefichert, in léfem Geftráche in einer Eche figend famen fie fo mahe

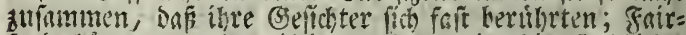

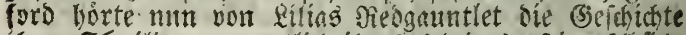
ibrer Fámilie, itomentlich íbres sheints, feine glbick= ten mit ilrem Bruber, und die singit, die lie friblte, Barfie midte in biefem 2ligentlide in ein versweifeltes Itnternebmen vermifelt merien, ins feinem sermogen, refleidit feinem Seben Gefahr krachte.

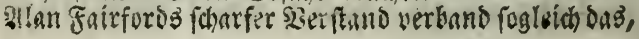


was er boxte, mit bem, wonon er in Fairladies sentge genefentuar. Sein erfter (schanfe war, anf jebe Befenlye

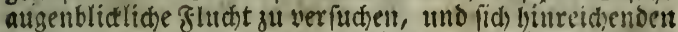

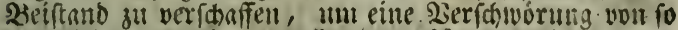

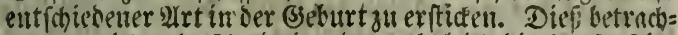
tete er uicht als famierig, bent olggleich die 2 luffenfeite ber Thite bewacht twar, fo mar boch bas genter offen, und nicht uher 10 fun vom 230oen entfernt ber Ylaz, anf den siefes gienty, shne Ulmizaunung und reidylith mit

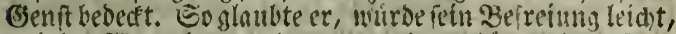

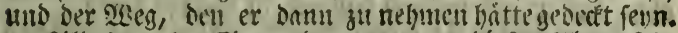
Rilias machte Cinmentoungen gegen biefar Whan. She

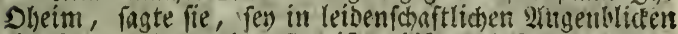

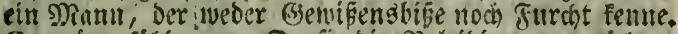
Er wáre făbig, an Dariie die Delétoigung gut rachen, bie er feiner gheimms nads von Fairiors entpangun babent

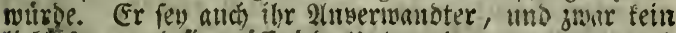
lieblofer, unb fie nuiffe jede lutternelonung, ment such

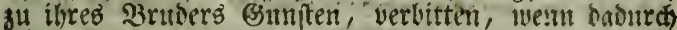
rein teben einer Befahr ansigefest wirbe. Fairford felbit erinnerte fich an ben giater 3 uonaventura, ntto zmeifelte gar nicht, tap er einer ber Sobne bes alten nitters Sft. (Seorg fen; mit (sefinmungen, Die freilich feitter Yfitht

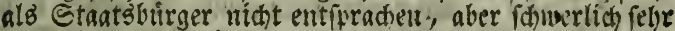
getade!t merben fonneut, fohrefte er vor dem Bebinfen

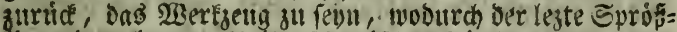

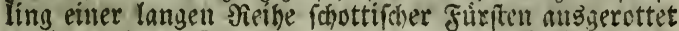
werden follte. Dam dachte er Daran, bet biefer bem lintergang serieibten Nerion so moglich eine 2litoienz

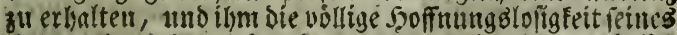

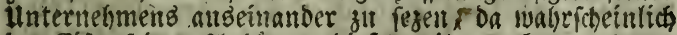
ber. Eifer feiner Alnbànger bie Er gab aber ben \$lin fogletich wieder all, fo bald er ibn

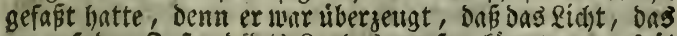
er anf ben 3!titnond sis Ranbes werfen founte, zul fpat fornment wurbe, um bemientigen zu bientell, bou dem

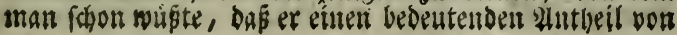


Der erbliden frartnafigfeit habe, bie feinen Borahein

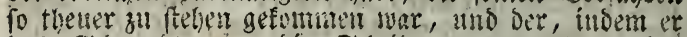

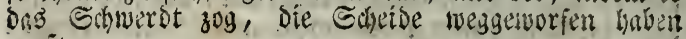
muite.

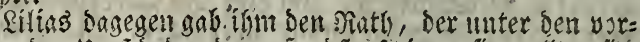

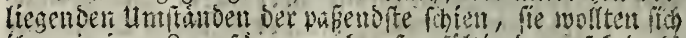

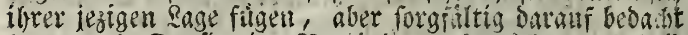
fevn, mit Darfie eine Serbinbung zu eroffinen, fo buld er einen (5rad von Freíheit erhalte, in welchen Falfe Dam

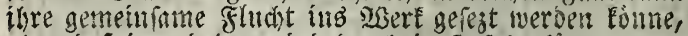
obne daf írgent jemand Daburch itt (Sefahe Éane.

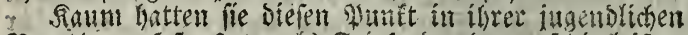
Beratgung feftgefest, als gairfors, ber anf die leifen,

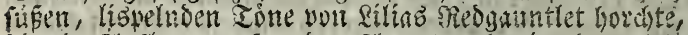

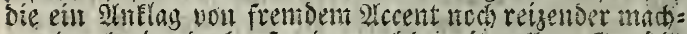

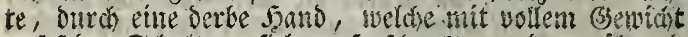

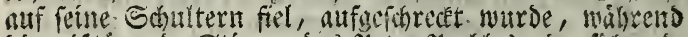

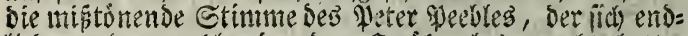
lich von Dem woblmeinenden Dubfer losgentaht hatte,

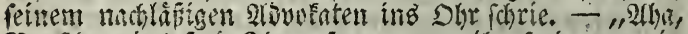

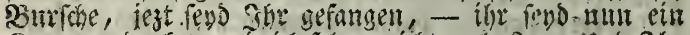

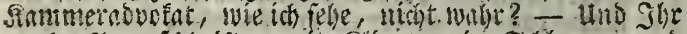

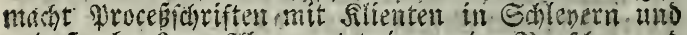

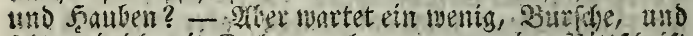
fegt, wie ich mit (sub ungele, wan neine bittiórift

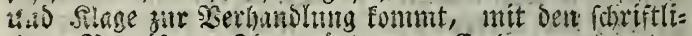
dien Besverfen, Jar mogt แun Euch verantworten ober nicht."

Es hatte Fairforoen in feinem Reben nid)t fo viel aritifrengung gefoftet, die erfte 2lufwallung zu inter= oruacen, uno fanm entrielt er fich, bell alten solpel niebersuichlagen, ber inn in einem folden 2ligenblito

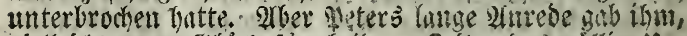
viclleidht jum (S)hick für betoe, Beit, dis volling Ath= ziemlide eineo foldhen Serfargens zu uherlegen. (5)

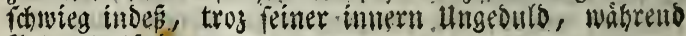
peter fortfutir: 
"Gut, meinartiger şarr, is Pebs, Shr fobant Euth

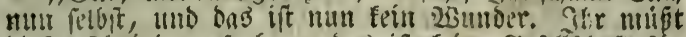

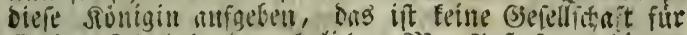

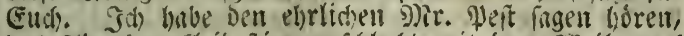

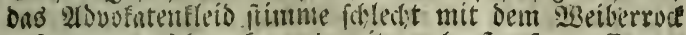

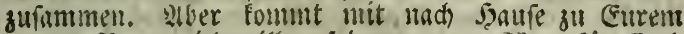

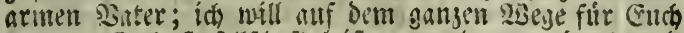

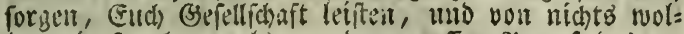
lell wir fprectien, als vou bem groffen Wrocés des ar: ment \$eeblis gegen Plaintanes."

"sibent ou es ausbalten fannft, Fremto," fayte ber

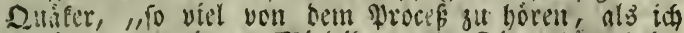
ocreits nus reinent Ritleíben mit Dir gebort babe,

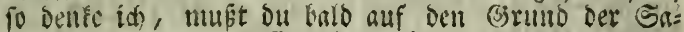
che foummity wenn fie nidat vollig grano = anto bos bentos itt."

Fritriors falttelte zientia unwillig die grop̈e fno:

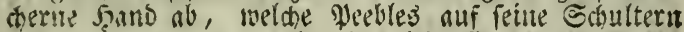
gelegt lintte, uns mar im Besriff, fids etwas unjanft

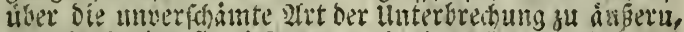

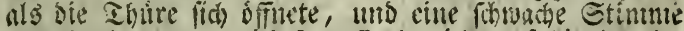

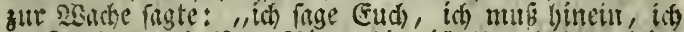

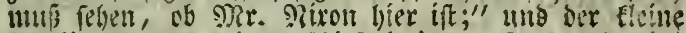
Senile freste feinen idiefgeorudetert Sopf und feine

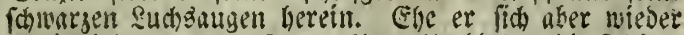

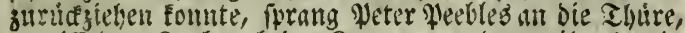
ergriff ben sinaben beim siragen, 1 mo jog ifn berein its Simmer.

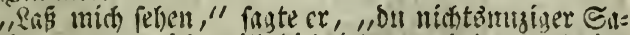

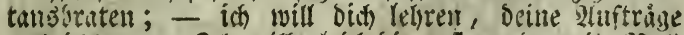
ausirident. - Sob will gleid Die erite und zweite \$or: labirily vollifiecten gegen oidh, Su. Tenfelsjunge!"

"T⿱B

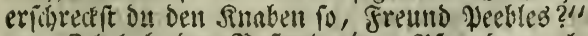

1Ith buthe Dem Baftard einen Piennis gegeben, mix Eaback zu faufen," fagte ber arme Sropf, "uns ar 
bat mir nidjt Redjunn alogelegt yon feinem 2ütrtra ge ; id wifls ifm eintranfen."

- Niit biefen $\$ 3$ orten fieng ex auch an, getwaltfam bie Taiden von Benjies zerrisenter Sacie ausjulleten,

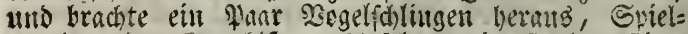
Eugeln, eiten angeviäenen mpfel, zwei geftohlene Eier, von beren Peter in der Cile bes Sithents eines zer= brach, und verfófedene andere Sleinigfeiten, die nicht

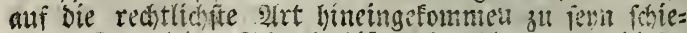
nen. Der fleine Echurfe biép uto fólug unter diejer

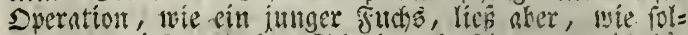
des Ungeziefer, weder Edyrei nod silage von fid ges

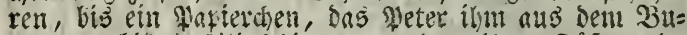

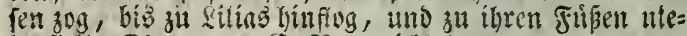
berfiel. Es twar an (E. S?. gerichtet.

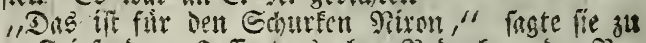

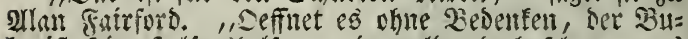
be ît fein selfershelfer, nir wallen bod felben, was ber Eduft in Echilbe fuifut."

Der fleine 2entie gab allen ferneren wiberfond auf, uno liép fict yon sleter einen ङhilling nebmen, von bent fich biefer, wie or fagte, megen Eapital und Sinfen be= zahlt machent wolte. Der Bube, Defien \&lufnerffameeit auf etwas gant anores seridtet forien, fagte nur: sine. gitron wirs nid tinthringen."

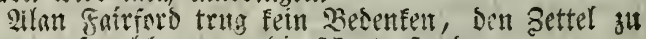
lefen, ouf welchem nur sie sionte itansen:

2alles ift vorbareitet; baltet fie nur bin, his id fomme. Sht fount auf Ence Beloinung rednen. (5. (5. "İ(h), mein Dheim, mein armer Dlyeim," fagte

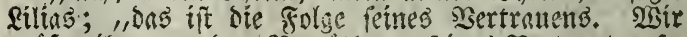
mifien ín you ber serritberen feines Bertranten fo= gleid) Pischricht geben. Das ift ber befte Dienft, ten wir allen leiten fónnen. Geben fie ibr Unternebnen anf, wie lie lezt muifen, fo ift Darfie frei."

sit cintm withen famben teibe an ber halb offenen Ihure; eifrig verfangte Sairforo mit \$ater Juonaveus 
tura sut furechet, Pilins uidht minder heftig eine gans turge ltnterrebung mit ibrem Sheim. SBailnend die Echitbwache mingewis war, was fie thun foltte, wurbe ihre Mufuerfamfeit anf ein lautes Bjeråus an ber

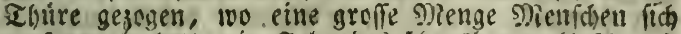
verfanmelt batte; in Folge bes idhrecbaren (sefchens,

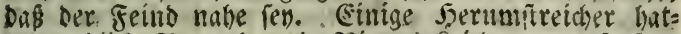
ten endlid Fantus und 9itonts Reidname aufgefun=

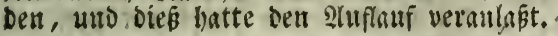

In biefer Sermirrmug gab bie Schillomadhe nidit

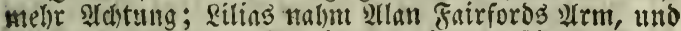
fie fimen Lnanfgelalten in bas intere Bimmer, wo bie Sauptperionen bes unternehmens, beren 3 erhand:

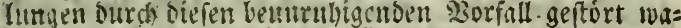
ren, it groffer Befturzung lith befanden; ber Shewa=

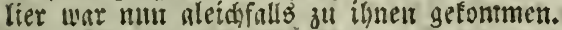

"Blö ein Wuffitand unter diefem Samugglergefin: bel," fiste Niergauntlet.

"310 3 cin-3lufitano, fagt Shr," ermiederte Sir

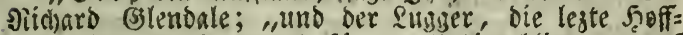
nung bes. Entfommens fưr - " hier blickte er auf Riarlu, - - "fdinebt bort mit vollen Eegetn auf Ditl Mieere!"

"Miacht Euch meinetwegen feilte Sorge," fagte ber ungluatlidge fririt; "ich) war foron in fohfimmern \&agen, ware fie aber ald bie folimmite, ich fürdite lite nidst. Sorgt fin Eud) felbit, meine Lorbs uns 5erren."

"9iein, niemals," fagte ber ittuge sord - - ; unfere einzige frofinumb berubt lest auf eiten eldren: vollen setoerifanice."

"So recht! fagte Nebsauntlet. Rast Derziveiflung Die "cintigfeit unter uns berftellen, Die cin Bufall ftor=

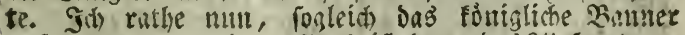
aufsupfanzen, und - Sisas ift benn das ?" fragte ex fillter, als Rilias, um fétue 2lufmerfiamfeit zu erre= ge日, ifn am sileide zubfte, den settel in feime Jano 
gab, und himsufugte, er fey fur शiton beftimmt generent.

geognuntlet las, liês es fallen, ftarrte auf bie Sotelle bin, wo eg lag, tmo hob soande uno 2angen gen frimmel. Eir Diidjard Eslendale bob bas unglude= liche Panier muf, lns es uno fogte: "siun ift nlleg

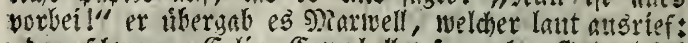
, Der fomarze Enlin Eamplell, fo wabr Giott lebt! s(b) liorte, er fey in ber lesten \$acht mit \$oft vou Sonion gefontmen."

(3) leidhfam als $\mathcal{E}$ cho zu feitten (sebanfen, horte man bie (5)eine Des alten Blinben, Der mit vielem 2uosirud einen (Elan = 9)iarít) fuielte.

"In ser That, bie Eamphells ricken an," fagte s)iac Siellar; "fie fommen tiber uns mit bem sanzen Bataillon unn "Sarliale."

Ein muthlofes Echweigen herridte, und smeí oder brei von bor Gefellichaft begammen, fich hintweg zu= fatleithetr.

Nit bem eblen (s)eift eines jungen englifaen Edol= manns rief Luro - : Sienn wir ?iarten geweien fint, mollen wir venigitens feine feiglinge fenn. - Wit ha= ben einen unter uns, ber melir merth ift, als wir

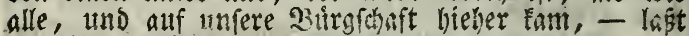
uns isn wenigfteits retten."

"Niecht, gantz redit," antwortete Eir Michard (s)!en= Dale. "faft uns zuerfit fur ben fioníg forsen."

"Ias foll mein (sefáaft fenn, "fagte Neogauntlet;

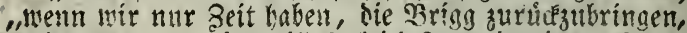

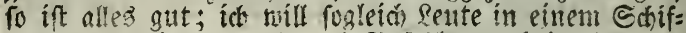
ferbont aledsiden." (5it gab Befegle an einige ber un= teritchmenoften in feinem (Bsefolge. - "Pafi ín ntte cimmal an sore fern," fagte er, "unferer fino genug,

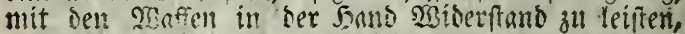

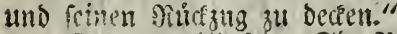

(3)tit, gutt!" fagte Eir Sitchard, ,luns ich merbe Die Đunte ansfucten, bie fich vertheidigen lapen; die 
alten Dutwerverfomirer follen Fenten versmeifeltern Sisiberftano geleiffet haben, als wir. - Siedgantutlet, fulbr er fort, ich felse, einige unferer freunde find bleid), aker Euer sieffe fdeint jejt meler Feuer in ben 2rugcn zu haben, als wo mir uns fult befirachen, tuto die (scfabr nod) ferne mar."

"Das if bie Int uneres Shaufes," antwortete

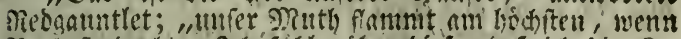

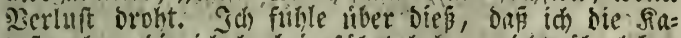
taptroplie, bie id herbeigefubert bate, nidt tiberleben barf. Last mich ntir erft," lier wandte or fich an Sarln, "Euer s]ajeftat gelseiligte Perfon fo fider mif́ fen, alè diế jegt miglich îf, bann - -"

"Start Euth alde lleberlegung meinetwegen, She serrm," fagte Sint abermals'; "der sriffelberg bort miro eher fichen, als idt."

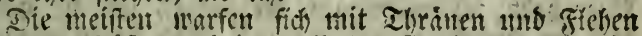

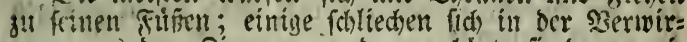
rung atts bent Simmer, uno man horte fie drnou rei= telt. Hlibemerft bei diefem ariftritt batten Darfie, fei=

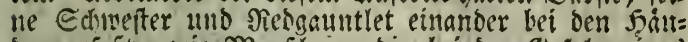
ben gefaft, wie Menichen, bie bei ber Bsefalyr eines Echiffiruchs entichloffen fino, miteinander zu leben ober" an ferben."

9)itten unter siejer verwirrten Ecene war cin Mami in einfaciem sietteleide, eine fotharze Sofarse mif betm Fint, uno nat mit einem firfofonger bennffinet, obne alle limftrinde ins simmer getretert. (Er war grofi, buger uno fein 2husfehen wie fein Venteknelt angen= fibeinlich militárifds: Er war unnufgebalten burch bie sisadcn beteingefonmen, und ftono unm faft untbewaff= net unter Remaffucten, bie nidits berto weniger auf ibu, wie auf ben Engel ber serfterm! blickter.

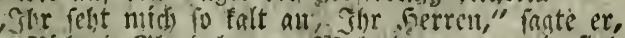

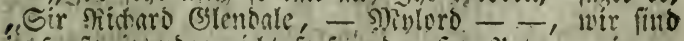

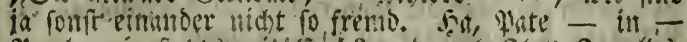
Derll, wie fteth nit' (E) 


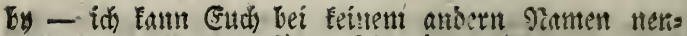

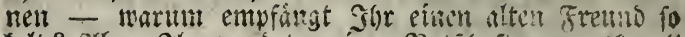

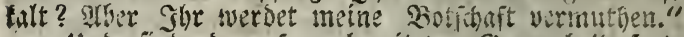
"llino firio baratif vorbereitet, sencral," pagti

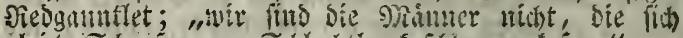
gleich Schafen zur Schlnbtbunf fohlewyen lajen."

Pab! Shr nelnnt dab viel zu ernithaft, lä́t mich nur ein Misort mit Eudo preeben."

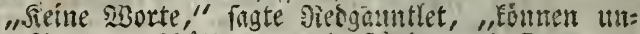

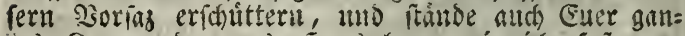

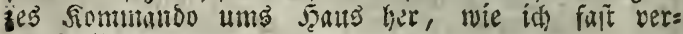
mutfie."

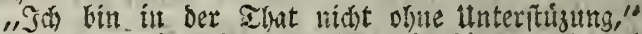
fagte ocr Gemeraf; "aber wem Shor midh horen wollt-"

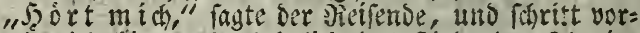

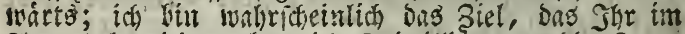
Iuge habt; ich ergebe mirth fretwillig, um die Serrit aus ber (3)efabr zu rettell, laft Eub Daran genthen zu ifrem Beiten."

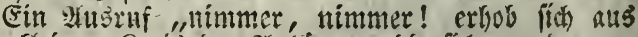

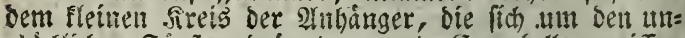
glúcéliden Shriten orángten, แno Emmpbalf ergriffen

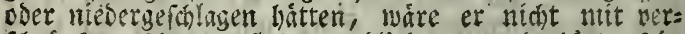

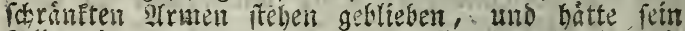

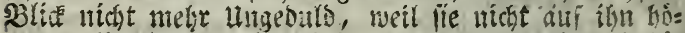
ren wolltat, als bie mintoefe furcht vor. (Semalthad=

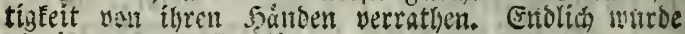
es citten Hitgenblid fíl.

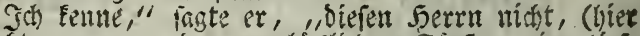
mathe or gegen Den unghickltchen Furftell ciue tiepe

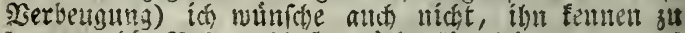

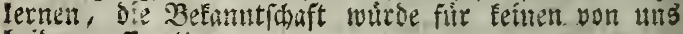
beiden pafren."

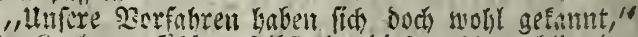

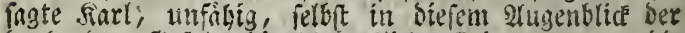
brobenoen Gefabr die fomerglide Erimterung an bie

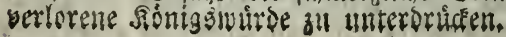


16. meine Eicherbeit enf bie Iroue ber Midionen baue, bie mein Sied)t atterfenter, - unb auf ben serfrans und die filngheit ber wenigen, nelche aus Grrtbimern ber Ergiebung fortfolbren, es̉ zul lóugnen. Er. Majeftăt will rogar nidot glatben, dop die eifrig= fren Sntobiten, die nodh tubrig find, sen Bebanten

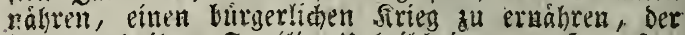

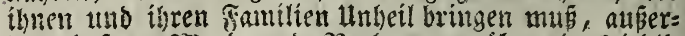

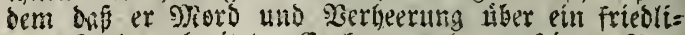

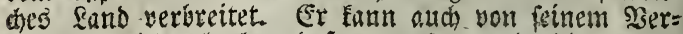
nanden nicit glauben do er tapfere und esle, wenu gleich im Srrthum befindliche s)ianner zu einer thlt= ternebumang auforbern werbe, Melde alle zu Brunde richten nüs, bie ben frúbern Infállen entgiengen;

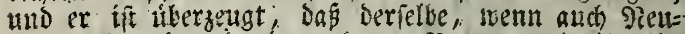
gierbe oder irgetio ein anterer Feneggrutio ilg in

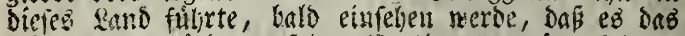
flügfte fent ruiroe, allf den Eontinent zurickgufebren. uno Er. Mialefrat betautert féme Rage allzufekr, um

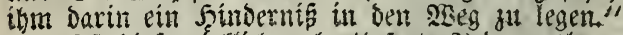

Sift bies mirflith mohr," pagte gieggauntlet. "Iit

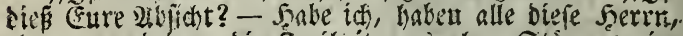

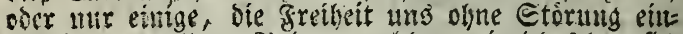
sulchiffen auf jenter Brigg, welde, wie idh febe, fith bem lifer wieder liabert?

-Ibr, Eir, fo wie alle diefe Sterren hiter," pagte oer sjentral; ,alie, bie bas Echiff faffen fatm, haben bie Freibett, fich obne Etorung von meiner Seite cint

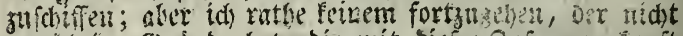

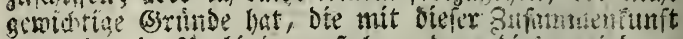
ber nide in serbinoming freben, Dem biefer nirs ge gent firmen weiter gedacht netselt."

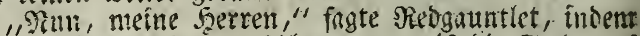

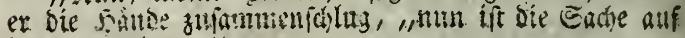
immer verlocent."

General (Emplet nanite fić) alts gentiter, ald

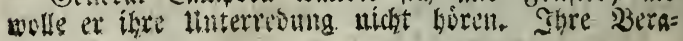




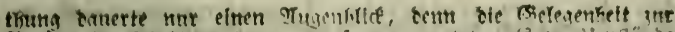

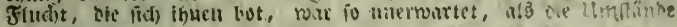
oringelis svaren.

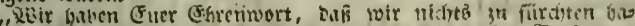

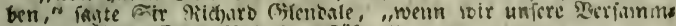

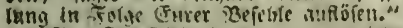

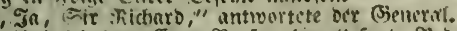

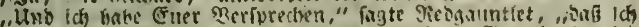
an Buts jenç \%

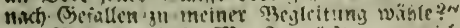

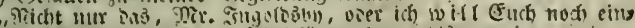
mal kebyauntlet nennen; Jor fönnt iogar biz zu eluer andern

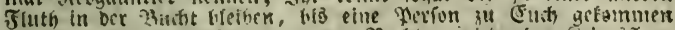

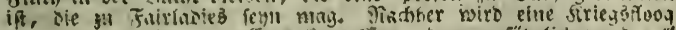

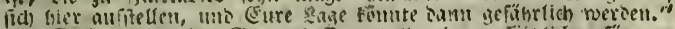

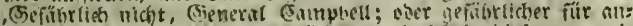

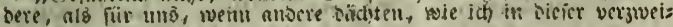
felten ßaje nod)."

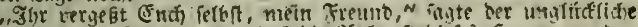

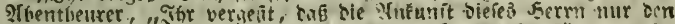

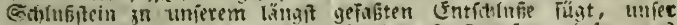

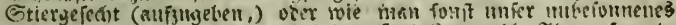

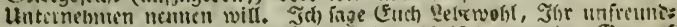

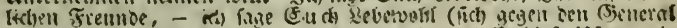

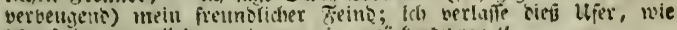
(b) cả betrat, allein, unts um nie zuriidinfebreis."

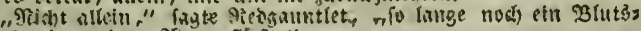
tropfen in meinen 9Foru fleçt."

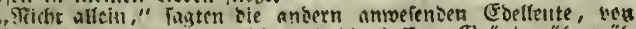

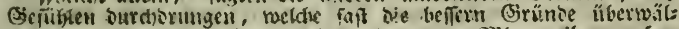

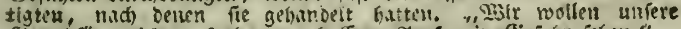

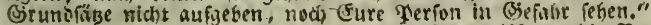

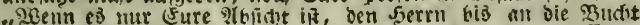

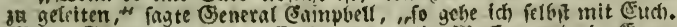

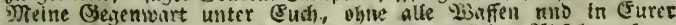

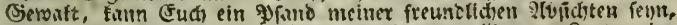
uno wiro jugleid jeter Störung borbengen, vie von. Scuten im Dienft herrühren fömte."

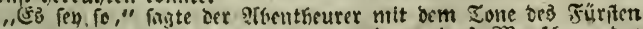
gegen. einen Unterthanes, nidit mit bent eines Menichen, eer bent Berlangen eines libermächtigen Frintes nachyibt.

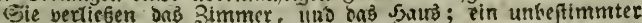

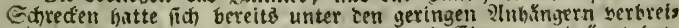
tet, ble furs vorber fich um bas Samb uno Eingang gebrängt bats

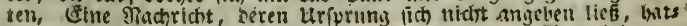

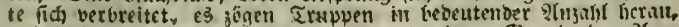

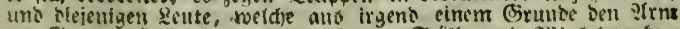
ier Sievalt fürditeten, butten ïch in Etólle uno gỉinfol verín 


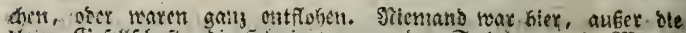
flente (sicfellichait, bie lict) -jekct gegen ien Eteindanm in श) Jarich

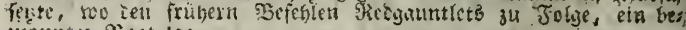
nianitis Soot. lify.

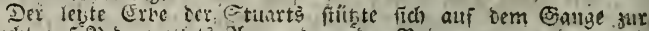

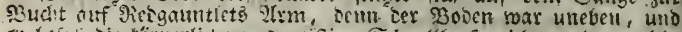

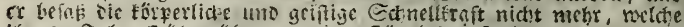

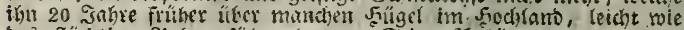

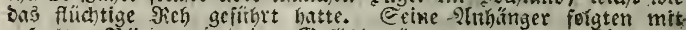

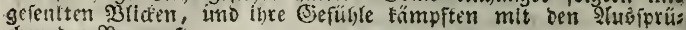
d)en Des 2 ermuitft.

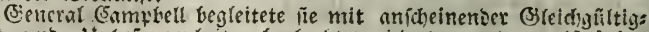
Eeit unb Unhefangenkeit, beobuditete jeouch, und jweifitgofine

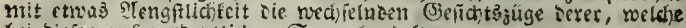
bei bieicr auferorientlichen Eecte bonbelten.

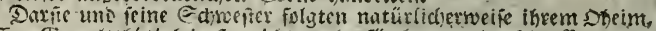
seffen (Semaltthatigfeit fie nid)t melor fürchteten, ca fein Sharater

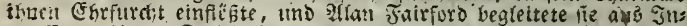

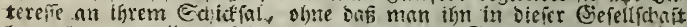

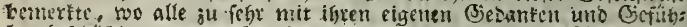
len fridiafrigt toaren, fo wie mit - sm levoritebensen 2 lugenblide

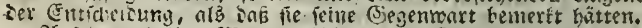

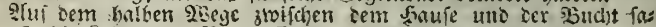

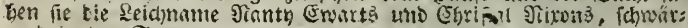
jeni it ier Eonnc.

Daह พ

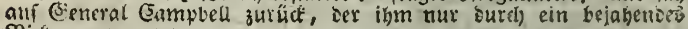
Sitifen autrovitete.

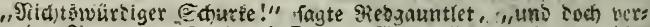

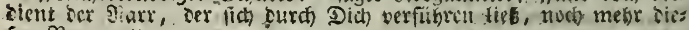
fen Shamen."

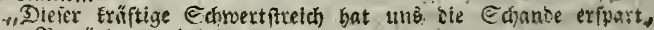
cineu Nerräther au Felohnet."

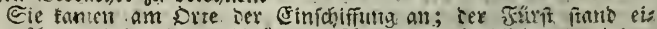

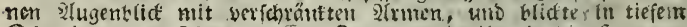

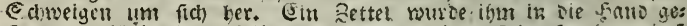

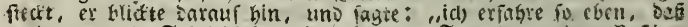

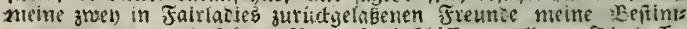

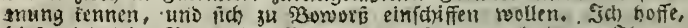

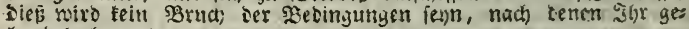
Gantelt batt."

"Sieviśn nicht," fagte Sieneral campbell; "fie follen wolle Frei: foit balen, fich mit (euch) ou bereinigen."

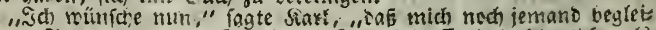

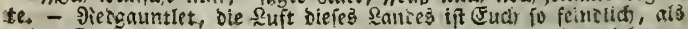
mir. Diefe f̧errn hiben ihren Frieten geidsloffen, oier vielmebr

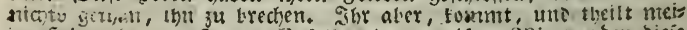

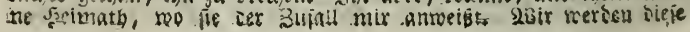




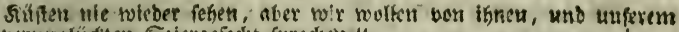

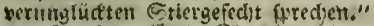

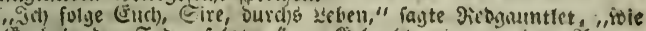

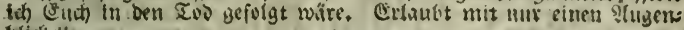
bltiơ:"

Ber Frïrit fah fm Srelfe umher, uno ats er de tem goien zus

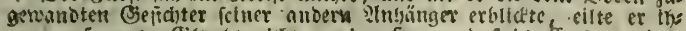

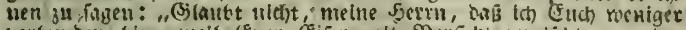
verbuniell bin, woll (Euer Eifer mit Norficht gemblicht war, eer

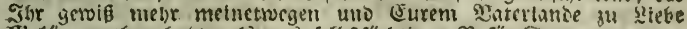

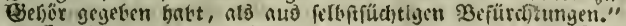

Er gleny nun boin elnetn sum anoern, ulto unter Ed)luchsen uno bervorbed

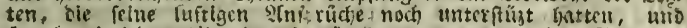

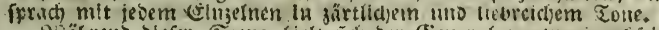

Q

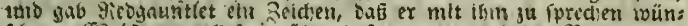

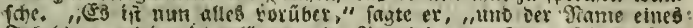

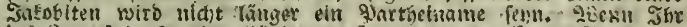

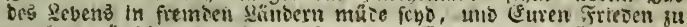

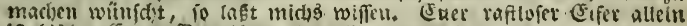

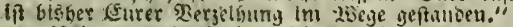

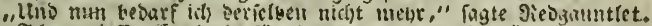

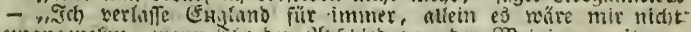

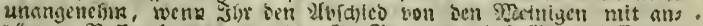
b)

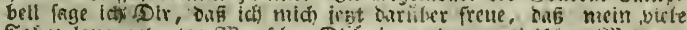

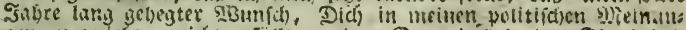
gin zal ergichen, nidit exfült nurbe. Du, trittit in ben Dieup bes

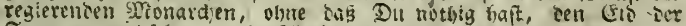

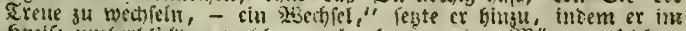

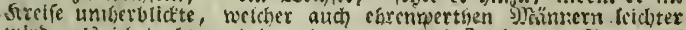
whtrb, als id) Didhte; einige ater tragen has Beldien ser Tiente nuf

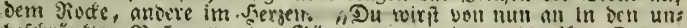

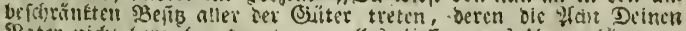
SRater nid)t heraubu funnte, - allez teifen was ifm gehirte, -

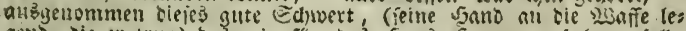

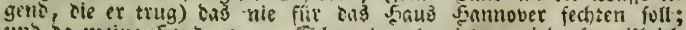

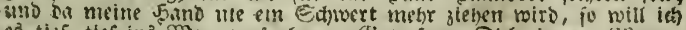

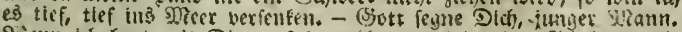

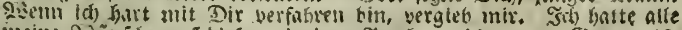

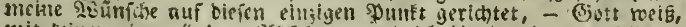

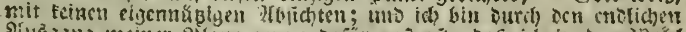

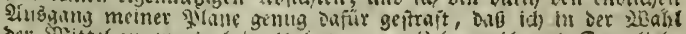

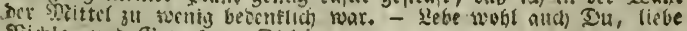
Silible, uno Bivtt fegme Dick!!"

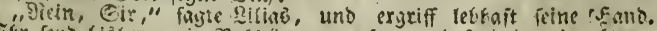

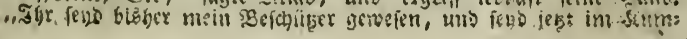




\section{1}

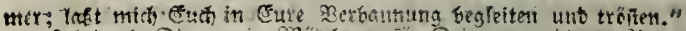

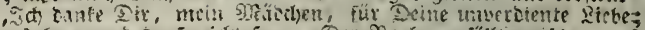

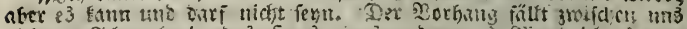

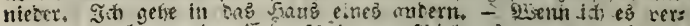

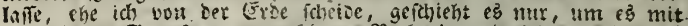

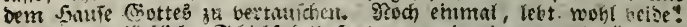

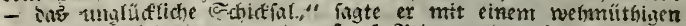

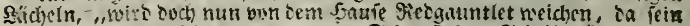

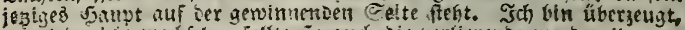

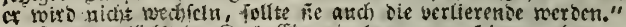

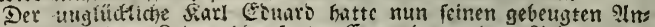

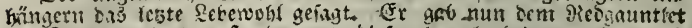
cin Zeidien mit ier Sand, tho biefer fant herbel, tim inm ins Echiff ju beffen. Stenteral Eantplell, ot ebentulls feine Dienite an, ba bic aneren won det Eccae ju fefterjriffen raren, um ibm ju: yor zu fommen.

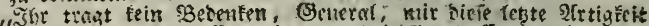

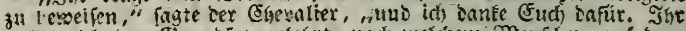

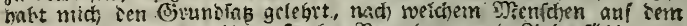

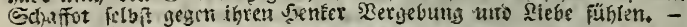
Sebt wuti!!"

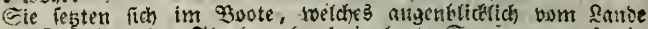

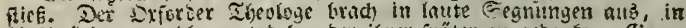

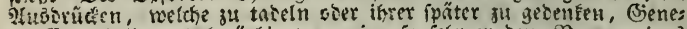

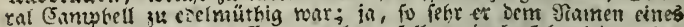
sobigy unt Eamperis (5igre midite, foll er boch fich nicht baben

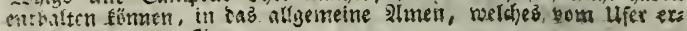
fabshe, mit einzuftimmen. 


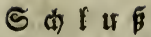

\section{bon Doftor Durrwieftatb in elitem 23 riefe all ben 2 erfaffer bed $\mathfrak{B}$ a verle\%.}

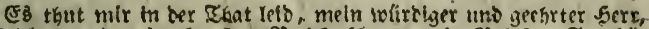

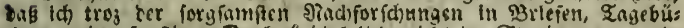

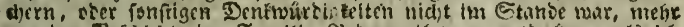

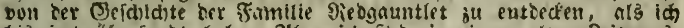

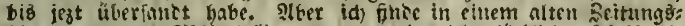
blatte, genannt 23bitebalizazctte, volt ber ta) glúdflicher Disife el:

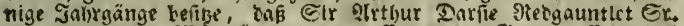

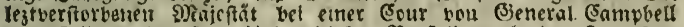
borgeftellt worben fer). Ueber bieien Borfall matht Iet Sernubge: ber in form eines Eonmentar3 bie semerkung, ras role nit vol:

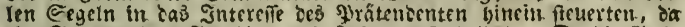
rin Edoutte einen Jafubiten bei Sgof borgeitellt babi. Da bie गुoiz: freibeit nur auf sirtefe gebt, Die elne linge rägen, fo hate id feis nen Ratm für feime weitere Bemerfungen, weld)e ble Ilbicht ba: ben 34 zelgen, baß viele wohlunterrichtete \$erfonen jencr 3cit be: fiitchteten, ter junge Sidnly möchte felbft our g)arthei Der Etuartz ubertreten; - plue Siataftrophe, bor oer tnocis ser folmmel diefe fiönigreiche kydabrt bat.

भrus einem Ehefontraft in ben Familien sIrchiben eriche ich

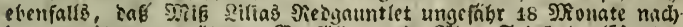

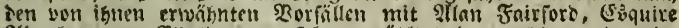
2lowofat, bou Elinforter, fich vermäblt habe, toeldjer wic wix,

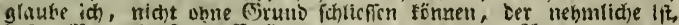

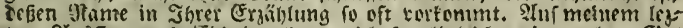

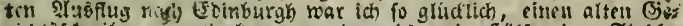

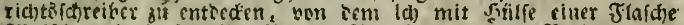

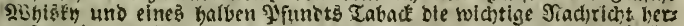

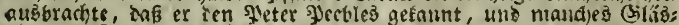
d)en zut Seit Des alten (Sierichtid)reibers Frafer nit ibm aubgetrum: fen babe. Ex fagte, ierfelbe bätte nod) jebn sabre nach fiönig (Seorgz Thronkeptelgung gelebt, feg in fteter Ermontung, feinen

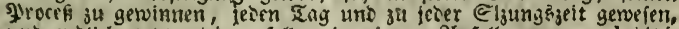
uni cnolkh toit nitiergefallen in cinem sinfall non perplenité,

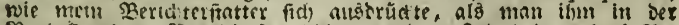

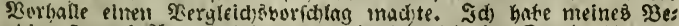
richteritatterg 9 lusigug tribebalten, ia tch nicht im Etanie bin, ge:

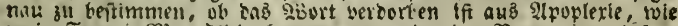
mein Freune SDir. Dloktad sermuthet, oder Der Name einer befort

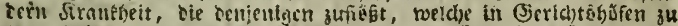

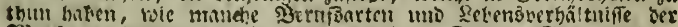

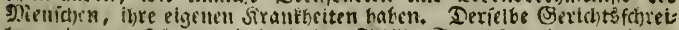

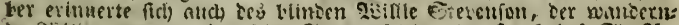

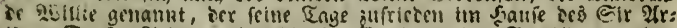
thur Darfe Sieigauntlet follos. (Ex batte icr Fumtlie mandien

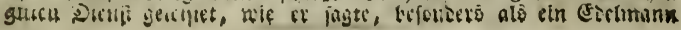




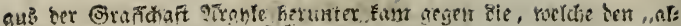

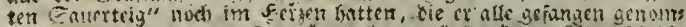

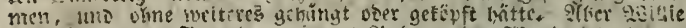

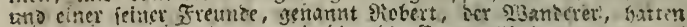

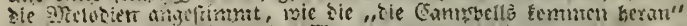

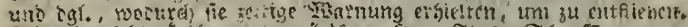

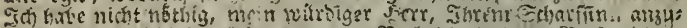

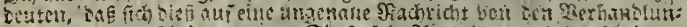

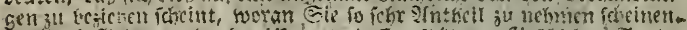

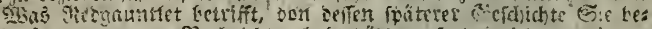

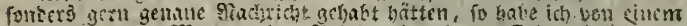

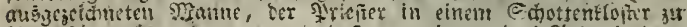

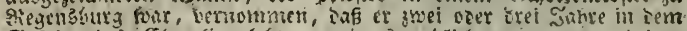

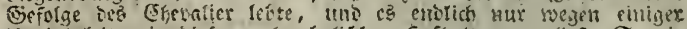

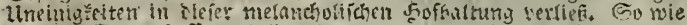

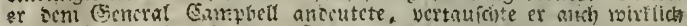
jonen Qlufenthalt nit iem filofier, uno entfaltate in sen festeu

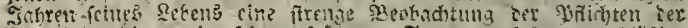

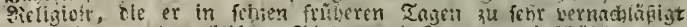

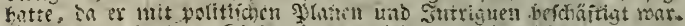

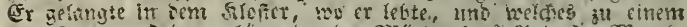

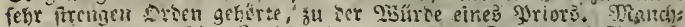

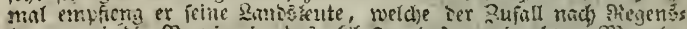
burg, uni ste Seugier fin tas firofter bes - Fradite. Nhan ba:

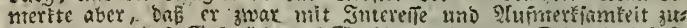

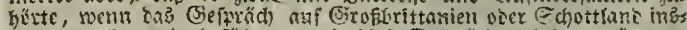

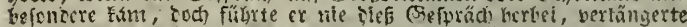
es aud thicht, besiente fich niz ser englifhen forache, fragte nie nad) englifhen singelegenheiteh, uns namentsldi) nie nach felner

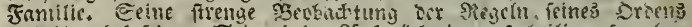
gat ibn fei feinem Tobe einige 2luiptiche turatif, beilig geforochen

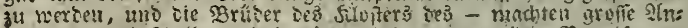

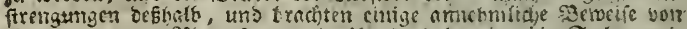

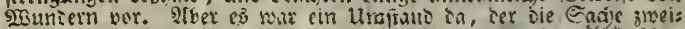

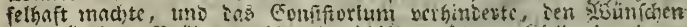

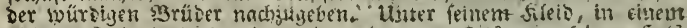

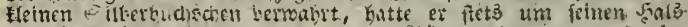

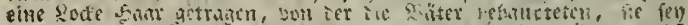

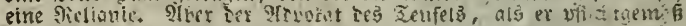

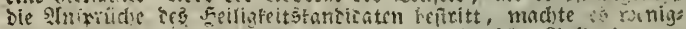

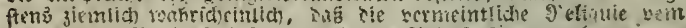

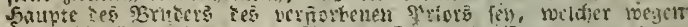

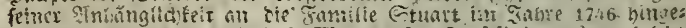
riditet norien fen: und sos glotto; haud olliviscendem (nid)t

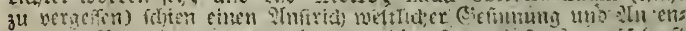

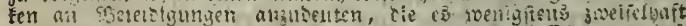
machtcit. of Siater fiugo wuib in ber. Etille uno Dlint:rheit be?

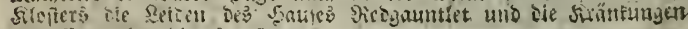

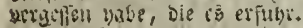






UNIVERSITY OFILLINOIS-URBANA

||

30112042024924 